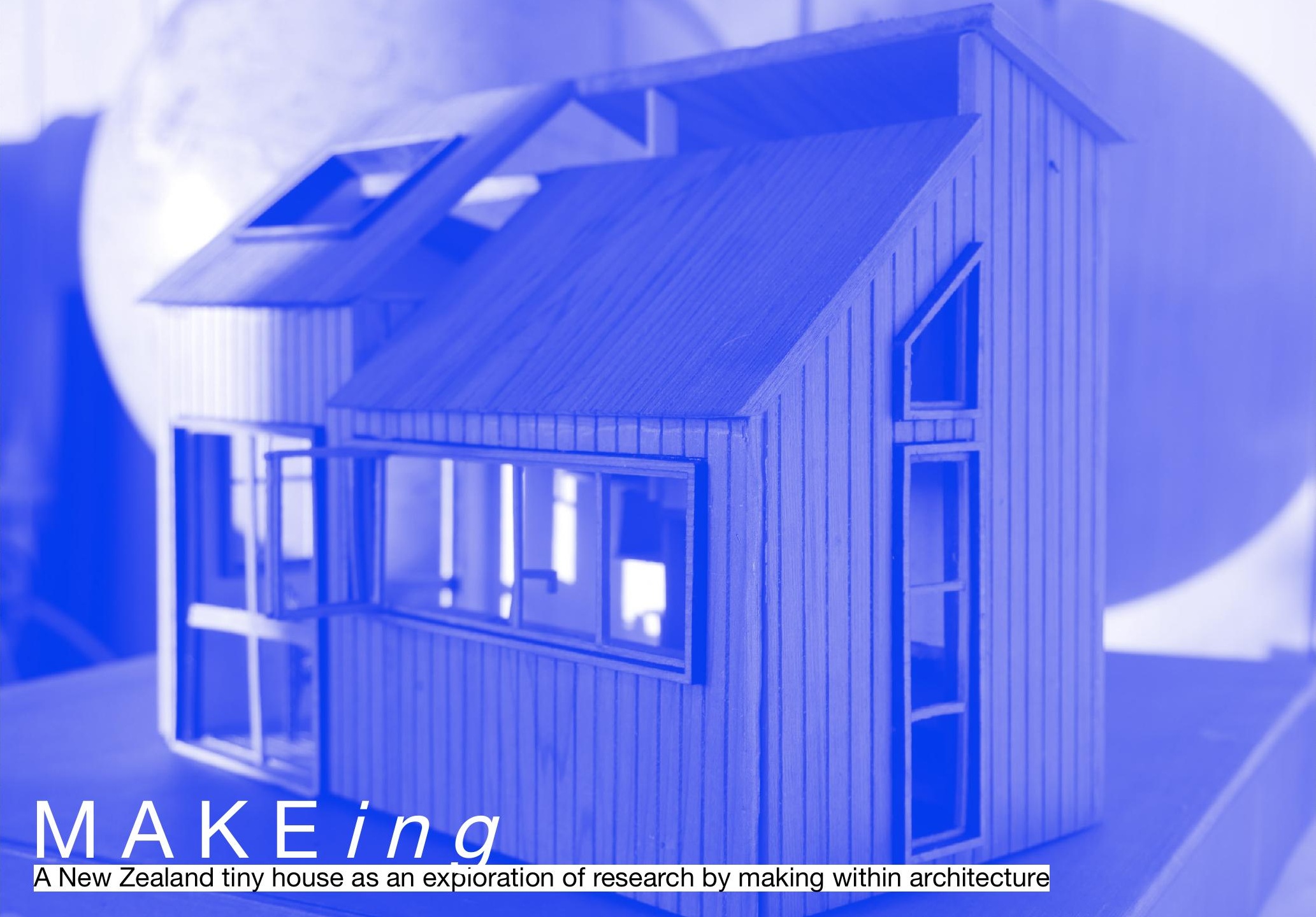


M A KE ing:

A New Zealand tint house as an exploration of research by making within Architecture

BY

\section{Kathryn Petra Parker-Price}

A thesis submitted to the Victoria University of Wellington in fulfilment of the requirements for the degree of Masters of Architecture

\section{Victoria University of Wellington}

2021 


\section{ABSTRACT}

Making within architecture encompasses many definitions and modes, but these are often at some distance from the production of buildings. IE architect's 'make' drawings and models, but a builder makes a building. This thesis explores the benefits and liabilities of bridging between imagining and enacting architectural production thought the design and build of a 'tiny house'.

Via an analysis of craft, symbol, processes and experience, the research begins with the activities of 'the hands' in architectural production. From here the mode of micro-architecture - specifically, a client driven 'tiny house' is investigated and implemented as an example of research-by-making.

A theoretical and model-based concept for the design of the 'tiny house' was developed, from which researchby-making could be conducted. The Build Phase, comprising the most significant aspect of this research, was then implemented, with commentary and reflection.

Although this approach is not without its limitations as a proxy for practice based making, it facilitates a greater range of making considerations than conventional studio-based production. In this way this project makes and advances an alternative design-research while advocating for learning by making. 


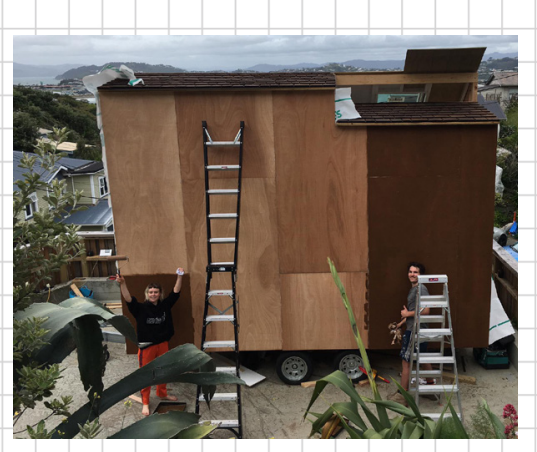

$1+1=0$

4.

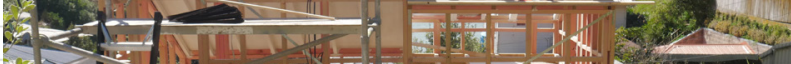

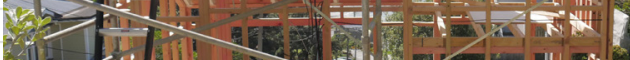

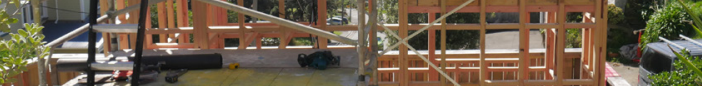

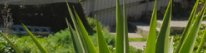

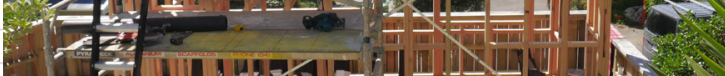

(1) 14 .
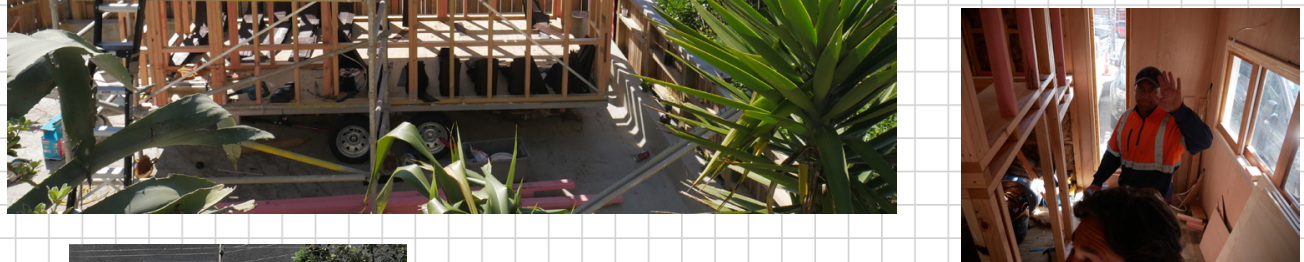

MI m
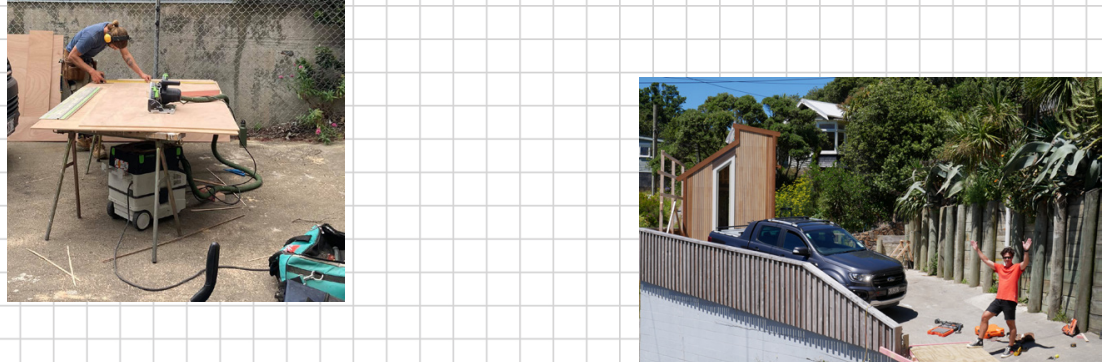

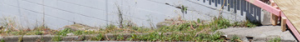

$+$

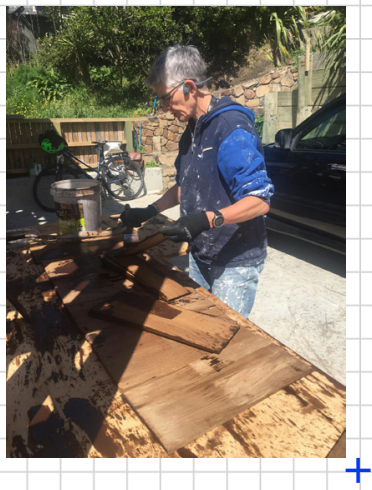




\section{ACKNOWLEDGEMENTS}

This thesis could not have come into being if it hadn't been for the unwavering faith and support I received from my supervisor Peter wood. Thanks.

Secondly, I would like to acknowledge my mum for her extremely generous financial support for this project as well as her tenacious emotional support and understanding.

A huge thank you to all my friends for everything.

To all the tradespeople who helped progress the build in so many ways; the builders (Tom, Quinn, Julian, Matt), the plumbers (Tim and Rodger), the electricians (Niall, Jamie, Josh) thank you all so much for your expertise.

Thank you Helen, for providing the best editing a girl could ask for. You truly are a special woman.

Lastly, I would like to dedicate this book to my best friend, Sol. You are my whole world on legs. Thank you so much. I promise to never bite off this much again (or at least not drag you into it!). 
TRAPITISN:

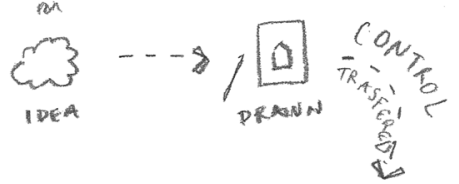

$$
\begin{aligned}
& \text { Sigy } \\
& \text { C } b^{-} \text {MADE }(B Y \text { EXTERNAL) }
\end{aligned}
$$

WHAT HAPEENS

EUILT.
WHEN THOUEHT

+ REALIED

ARE CONTROLED

BY THE
SAME TIANOS? conos be up the

cond in

CSITE.

- client

- envipigrintar conceras.

- FUnCtion

CPAN BEYONO

(TMC2sis.)

stodo??

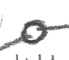

FRIOAY.

$<$

IPRAGMATIOS.

PREU DENTS. $\rightarrow$ TOPELOGHAR.

ORAW NG??

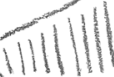

IS IT EASE"R

TO EXSPERIENENT

W ARCMITECTURE

WhEN TMERE IS TES

LESS AT STARE?

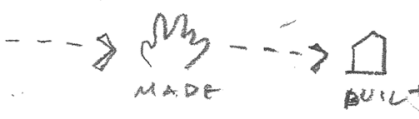$$
\text { MAINTHEREO }
$$

\section{INVITEO \\ COMPETE \\ sugut}


THE FOLLY, KIOSK,

TINYHOUSE, PAVILLION INSTALLATION SCULPTURE

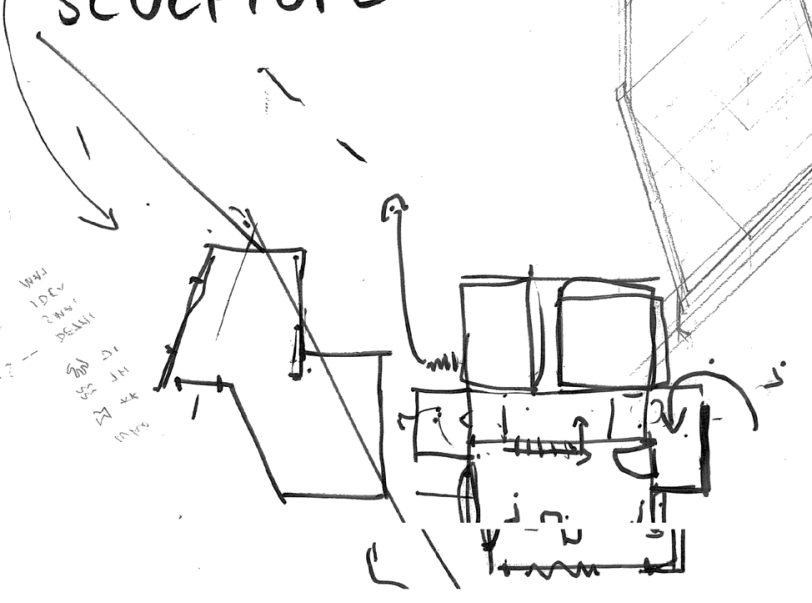

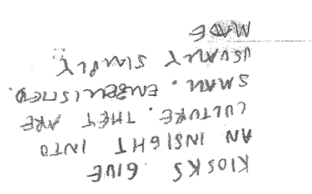

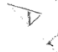

4 vosismeens $\rightarrow$ syor

SigN 1771
to 3 HWL
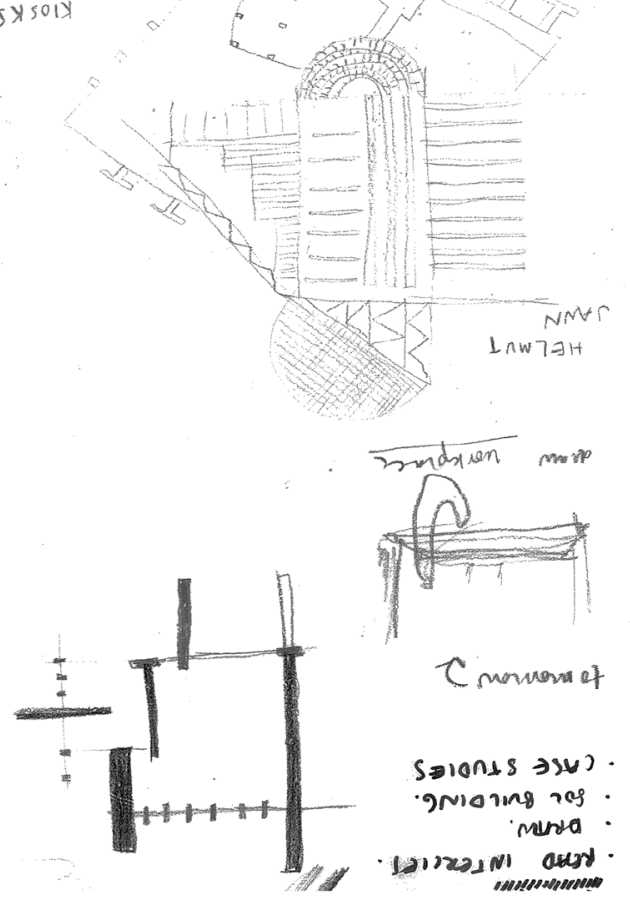


\section{WHA}

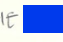

WHAT AKE WUY MAIN CONPULTS /I CONERONTATIONS WTH IT?

Wow poes architecture be $600 D$ or BAD? How ARE THERE SUCH BORING SOUM Norms SURPOU noINo IT??

IF I AM ME AND I dD ARCHitEcTURE AMI DOING ME or ARCTITELTURE?

15 the only real thing I leartot is The ONLY REAL THINODL, how to SPEL AT ARCHITELTURE
ARCHITECTURE? ARCHITECTURE?

$$
\text { I LIKE TO USE MY HINDS. }
$$$$
\text { soly } \mathrm{s}\}
$$

IF YOU SUCCEED IT BUILDING A MODEL, you visualize WHAT IS LIVING INSIDE OF You,

So That the outsipe notio chr ADAPT IT, STUPY $1 T$, DISCOVER IT, SFE IT.

\section{BODYS ISEK KINGELEZ}

Imodels are the spatial rendening of the mahers obsessions. $\sigma$ francesco Bonami invisterevicle

COGNITI.N 


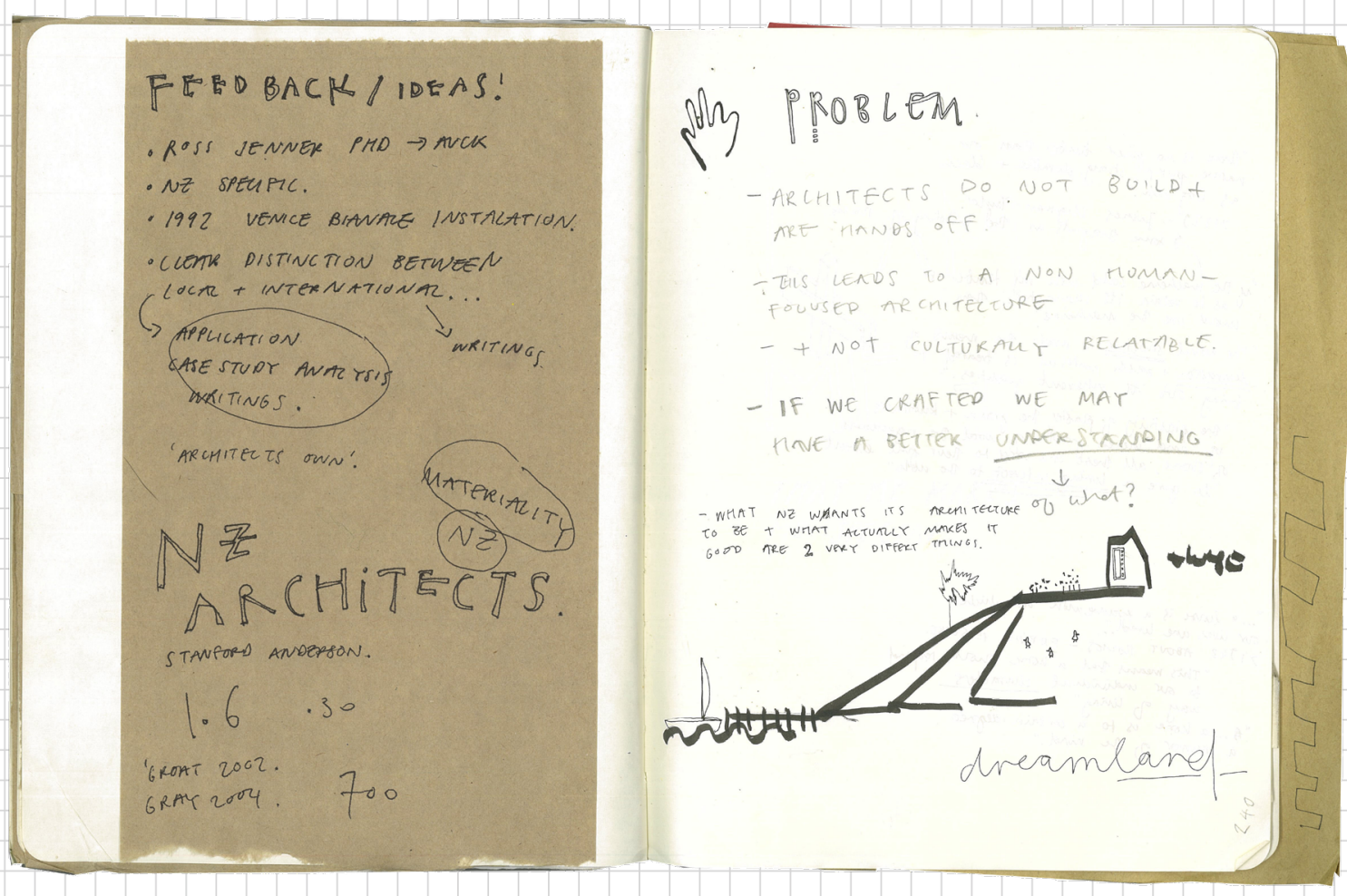




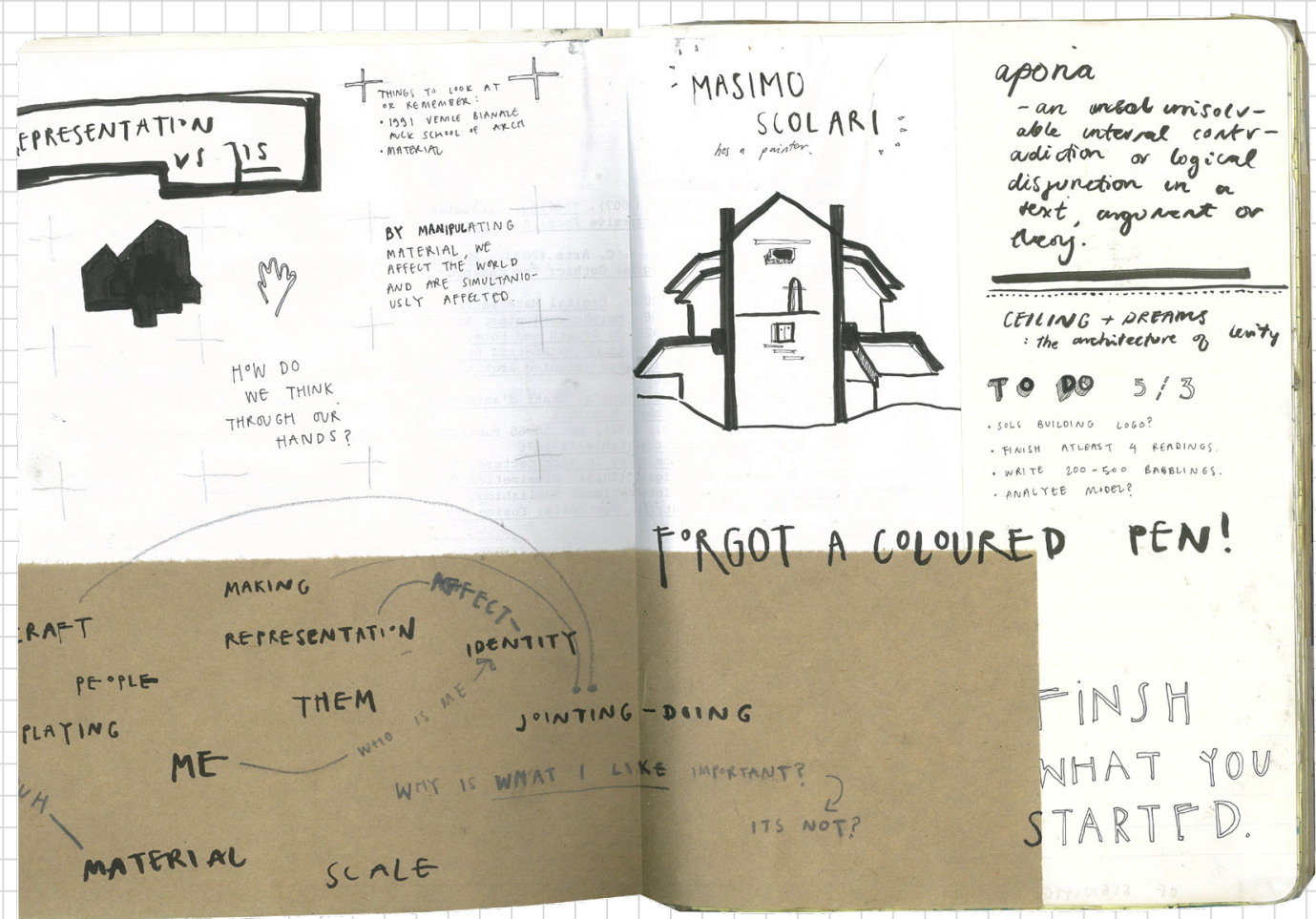




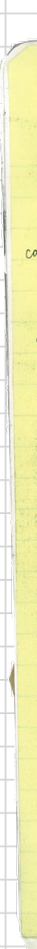

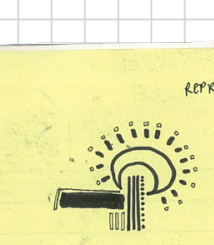

REPRESENT A

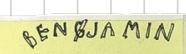

carto scarpa $\rightarrow$ relationship of to whole to its pats

detail as a generaters.

"sonctimes the bilating as a whobe is present in the sence, and go it feems a detail anrang detrils."

P 24
TME TOU-TME
TMLE DETMIL.
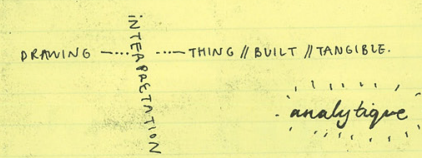

4. De detril was so longo seen as a joint

unstead it ras seen as à poductorn of draing

ARTS TCRAFTS MOVEMENT... \& PETAIC SEEN AS

MEANS OF REOEMPTIAN

"Te jount... The detail, as the

prace warea of the meeting of

tre mental constrving and of

the actual constretion "P26.

PEETL AS A MINIMAR UNIT IN THE PROCGSS of SIGNIFICATION.

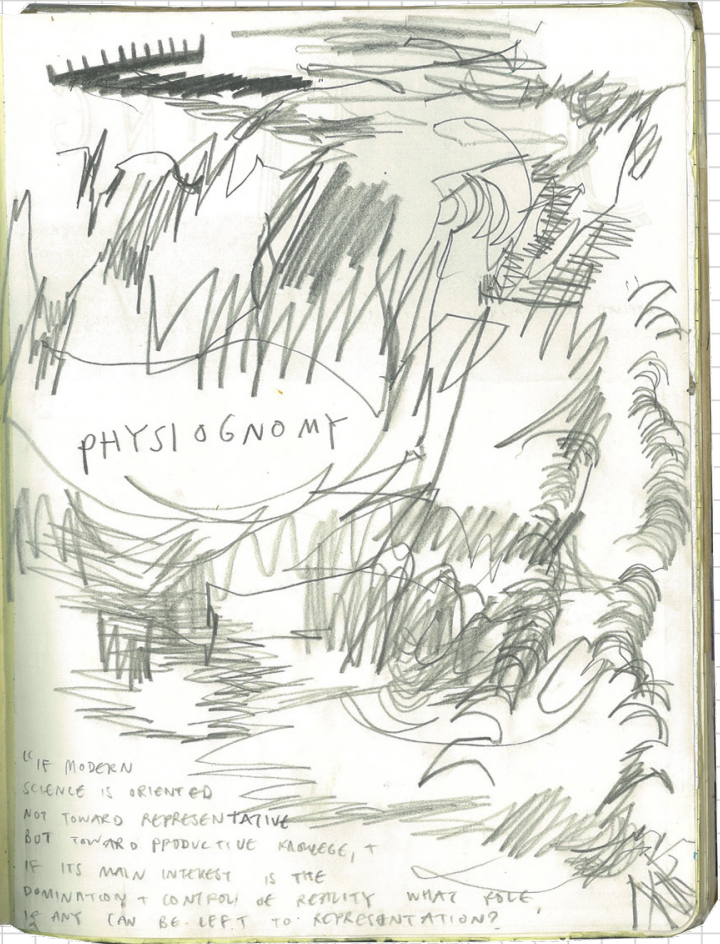




\section{$P R E F A C E$}

I have always wanted to be an architect. Since someone, somewhere suggested it as an occupation you could pursue. I have always been intrigued by people and their relationship to both one another and their contextual surroundings and the consequential ability architecture has to facilitate those relationships. I have always found the physical experience of this fascinating, and the concept that the physicality of making with the hands develops an experience. I have been told many times: "We are architects. We build things". However, I could not disagree more. As a student of architecture I often feel I have no idea what 'we' actually do. I have no practical knowledge of building; only theory. How is it possible to even begin to try to understand how space is conceived if we have no physical experience of how the elements implemented in its construction work together at a basic level?

Cynical as it sounds, I wondered if, verging on five years at tertiary education, I had any real skill or knowledge I could be proud of. I have treated this thesis as an avenue in which to explore how I may fit within architectural reality. A way of exploring the utopia of architectural conception and production I believed to be true. The utopia where I am me and that makes me special. What I create with my two hands is a direct self-actualisation of myself as an architect in the world. In a sense this thesis is something of a sole searching exercise. On reflection perhaps, a little soul destroying at times. 


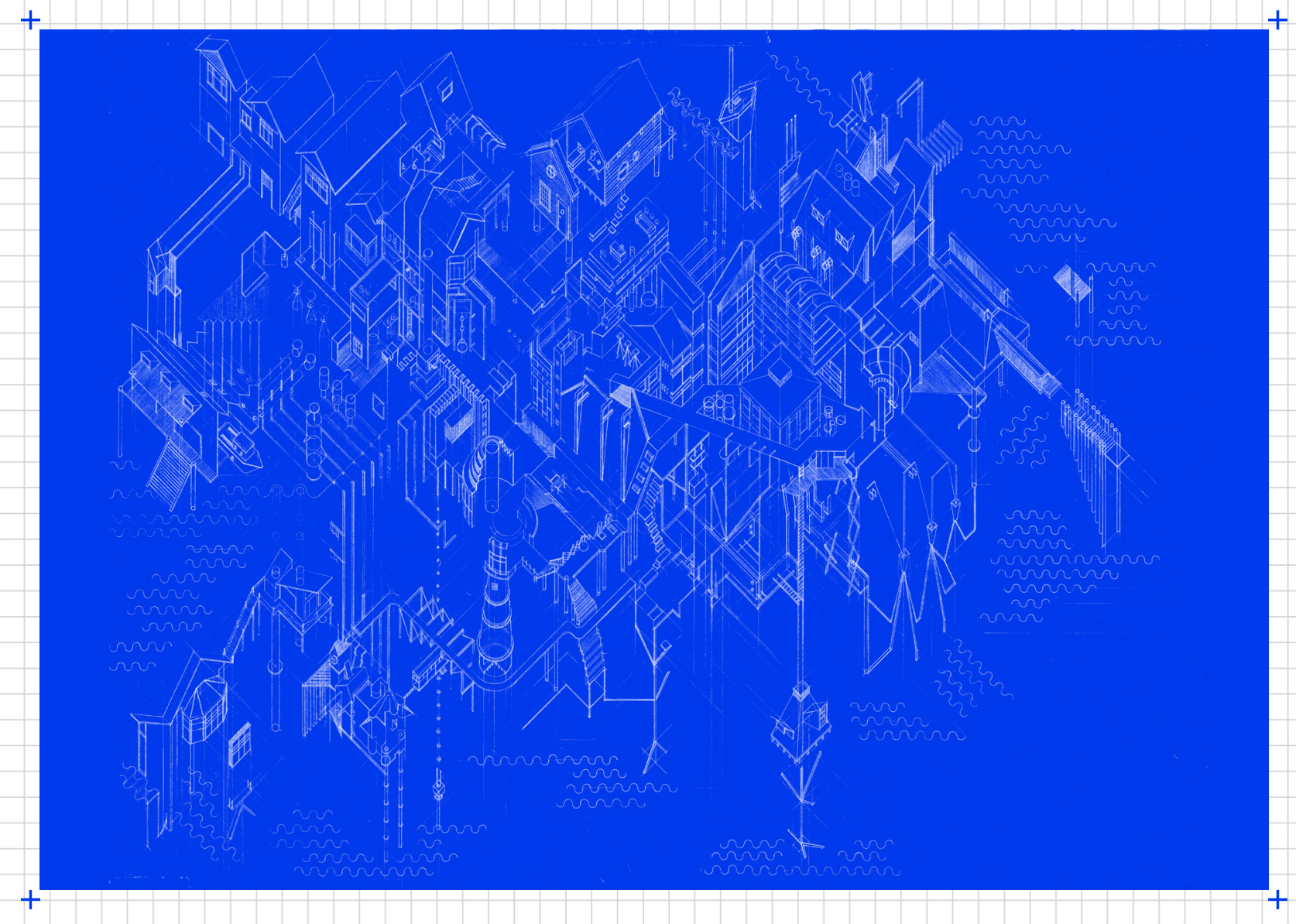

Fig//1 personal work process axonometric 


$$
\begin{gathered}
\text { WHENE TO } \\
\text { DE GNM. }
\end{gathered}
$$


How to - a guide

Introduction

Methodology

Theoretical timeline

The hand

+ a definition of make

+ representation

+ knowledge \& symbol

+ experience \& character

+ craft \& detail

+ process

Part 1.0 notes

67

PART 1.1

Typologies

Tiny

Miniature

Tiny House

Non-Tiny Tiny Houses

Tiny House Movement

+ North America

+ New Zealand

Tiny house timeline

Part 1.1 notes

PART 1.2 Design investigation \#1 104

Client

114

Site

Trailer Tenure

116

Design Investigation \#2 12

Domestic Space Framework

+ inhabiting

132

+ eat \& play

133

+ cook

+ bathe

+ sleep

149

Development

Concept

155

Part 1.2 notes

\section{PART 2.0}

Introduction

Foundations

196

Foundations

198

Site

Material \& Technical decisions

206

Material Exploration

208

Beginning Building

212

219

Changes

225

16.08.2020

235

Roofing

240

Material Conclusions

248

The Week That Followed

251

Shingles

253

Visual Progress

262

After a Break

273

Colour Dilemma

275

Electricians

277

Contingency

279

Material Arrival \& Plumbers

281

Flashings

289

Material Application \& Insulation

292

Fleshing out Weight

295

Moving Day

297

Conclusion

305

Built

307

Things I Learnt

213

Part 2.0 notes

315

Figures

317

Works Cited 


\section{HOW TO}

My personal way of working is through friction with material. Therefore, the sketchbook is my preferred method of collation. The research has thus included the ongoing and coordinate sketchbook within the thesis to attempt to allow a more holistic insight into the work. The sketchbook has been used as a more relaxed form of note taking, idea exploration etc and therefore is simply supportive of the surrounding research. Questions, suggestive statements and themes which arose predominantly throughout the initial stages of the research acknowledged as is in keeping with my research umbrella.

indicates a somewhat significant text I have come across yet may
not be directly related to within the work.
indicates 'thinkers' people who have theorised particular concepts
the research grapples with

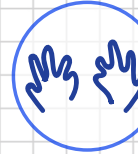

indicates 'makers' in the physical sense of the word: people who have made things with their hands

indicates the 'made' 


\section{INTRODUCTION}

"Whether in ritual, myth or architectural speculation, the primitive hut has appeared as a paradigm of building: as a standard by which other buildings must in some way be judged, since it is from such flimsy beginning that they spring"1 -Joseph Rykwert

Architectural making involves a multitude of modes, mediums and materials as the practice progresses. Fundamentally, this thesis explores the physical realm of architectural 'making' -making with the hands and material; a tactile relationship of maker and made. Conceptually split in two, this thesis offers a theoretical standpoint, before taking physical action. However, with reference to the following pages surrounding the research process, this split is predominantly for legibility.

Part One, explores the concept of 'made' with respect to character, craft and process within architecture. A development of stance is conducted, essentially outlining an assertion of sorts for the research. Real aspects of architectural practice such as client, brief and site then allow for the research to be developed in reality before design investigations are carried out.

Rykwert wrote "...paradise is a promise as well as a memory"2 in that the primitive hut must be looked upon in the promise of architecture. Part Two, the real working part of this thesis is an exploration of making with my own two hands, with the ultimate goal of constructing a variation of the primitive hut for the shelter and inhabitation of my family.

Sally Ogle reflected, "...sure there are architects that build. But they're the exception". The following pages are an attempt to consider the possibilities of that exception. 


\section{METHODOLOGY}

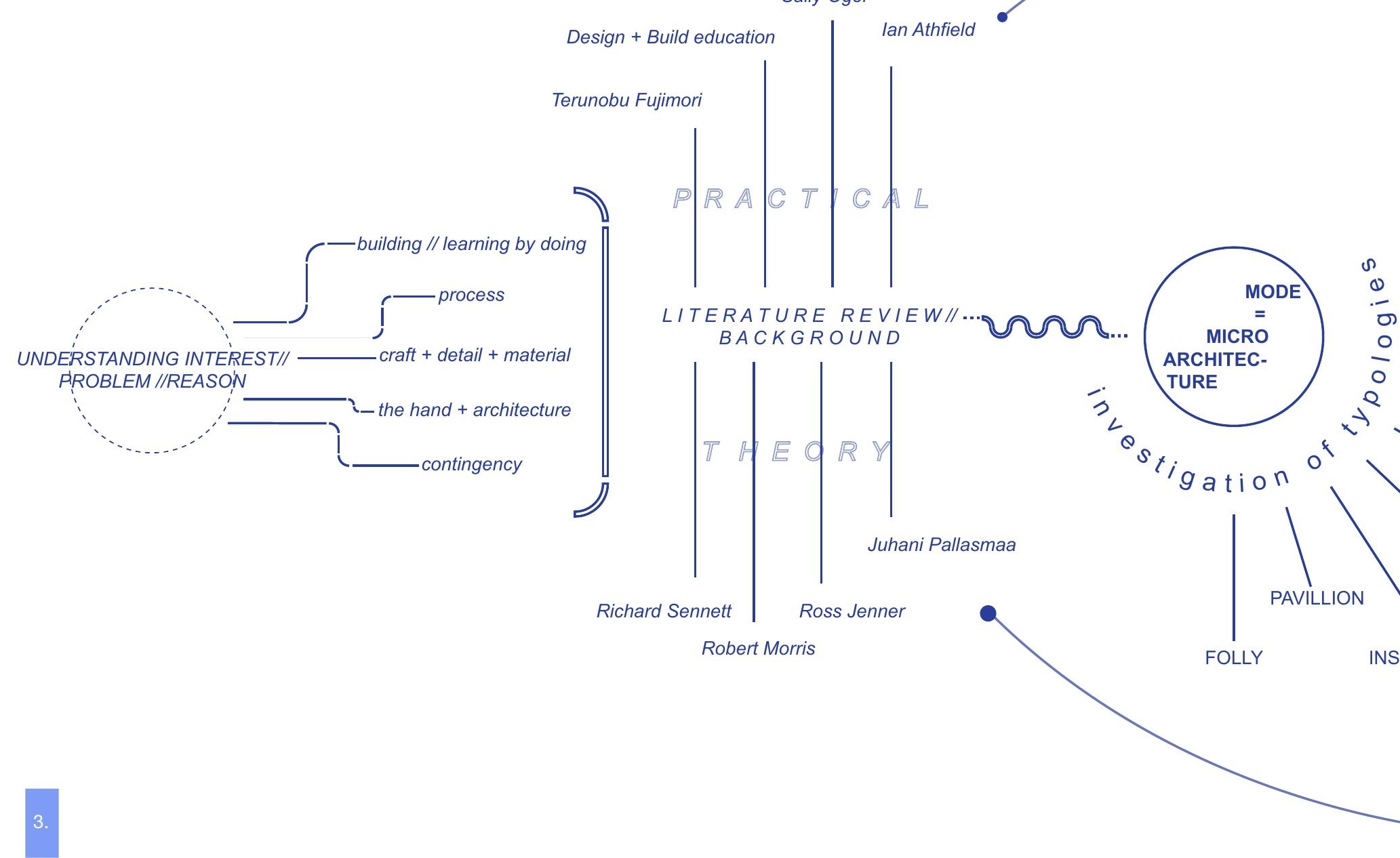




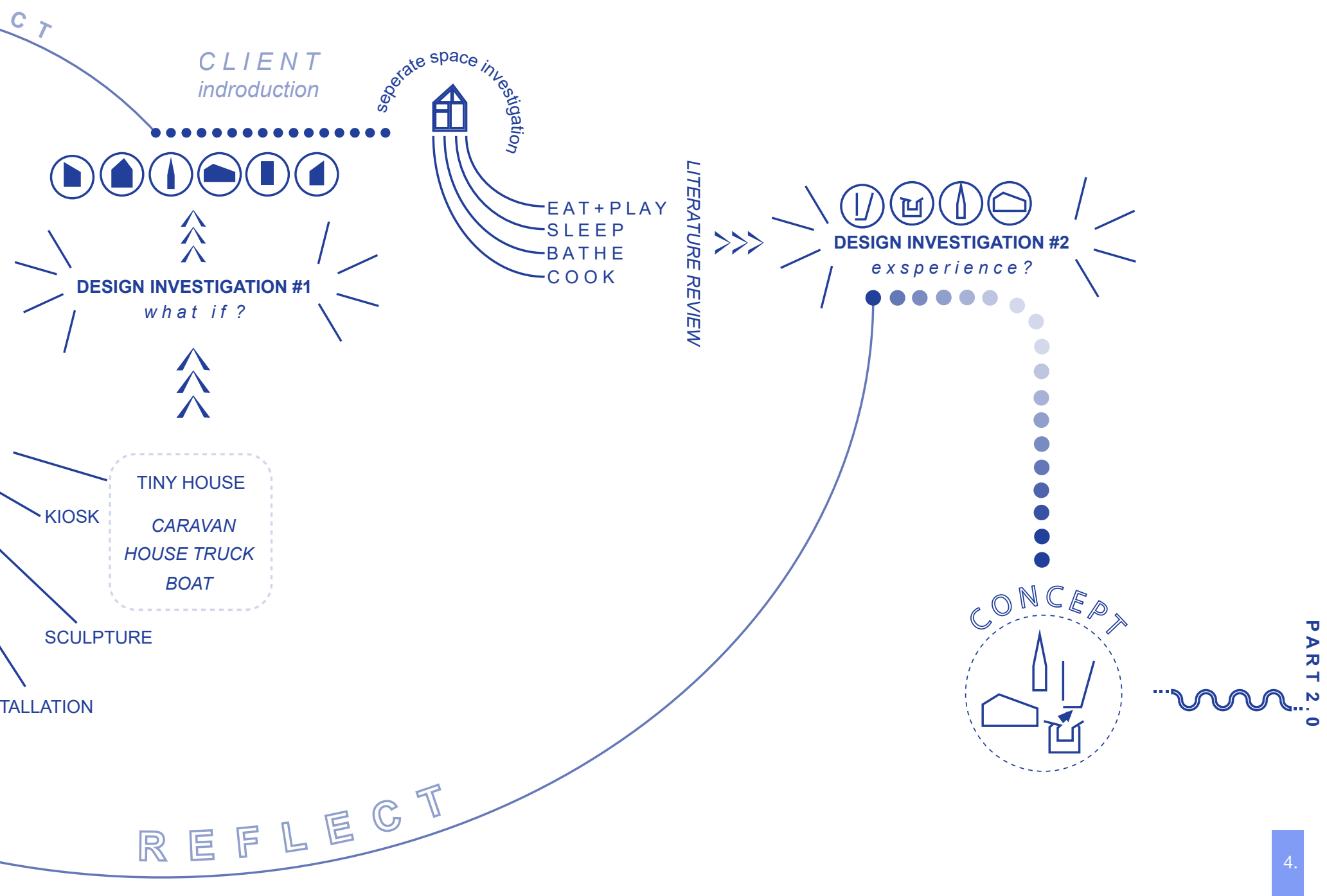




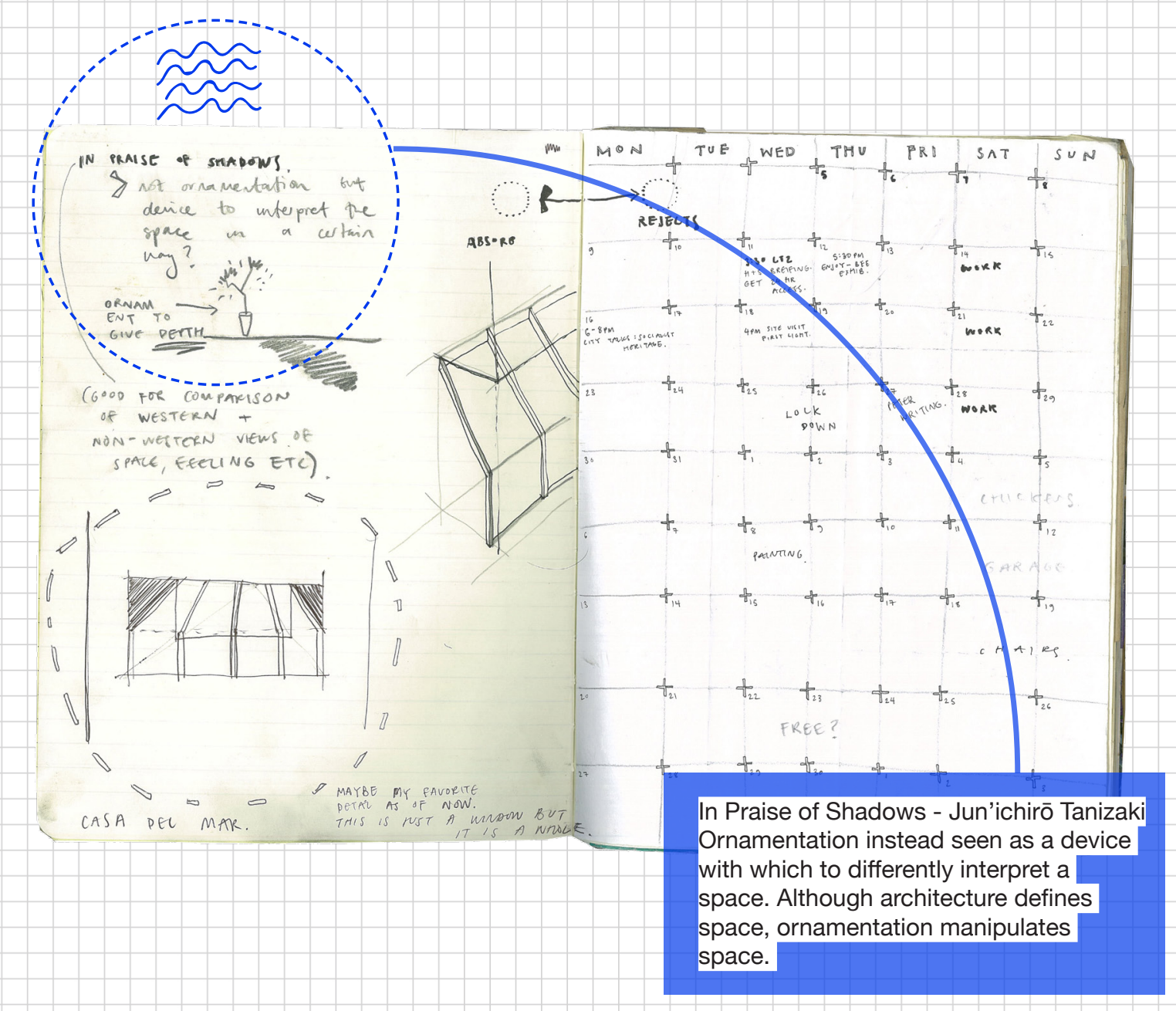


THINKERS

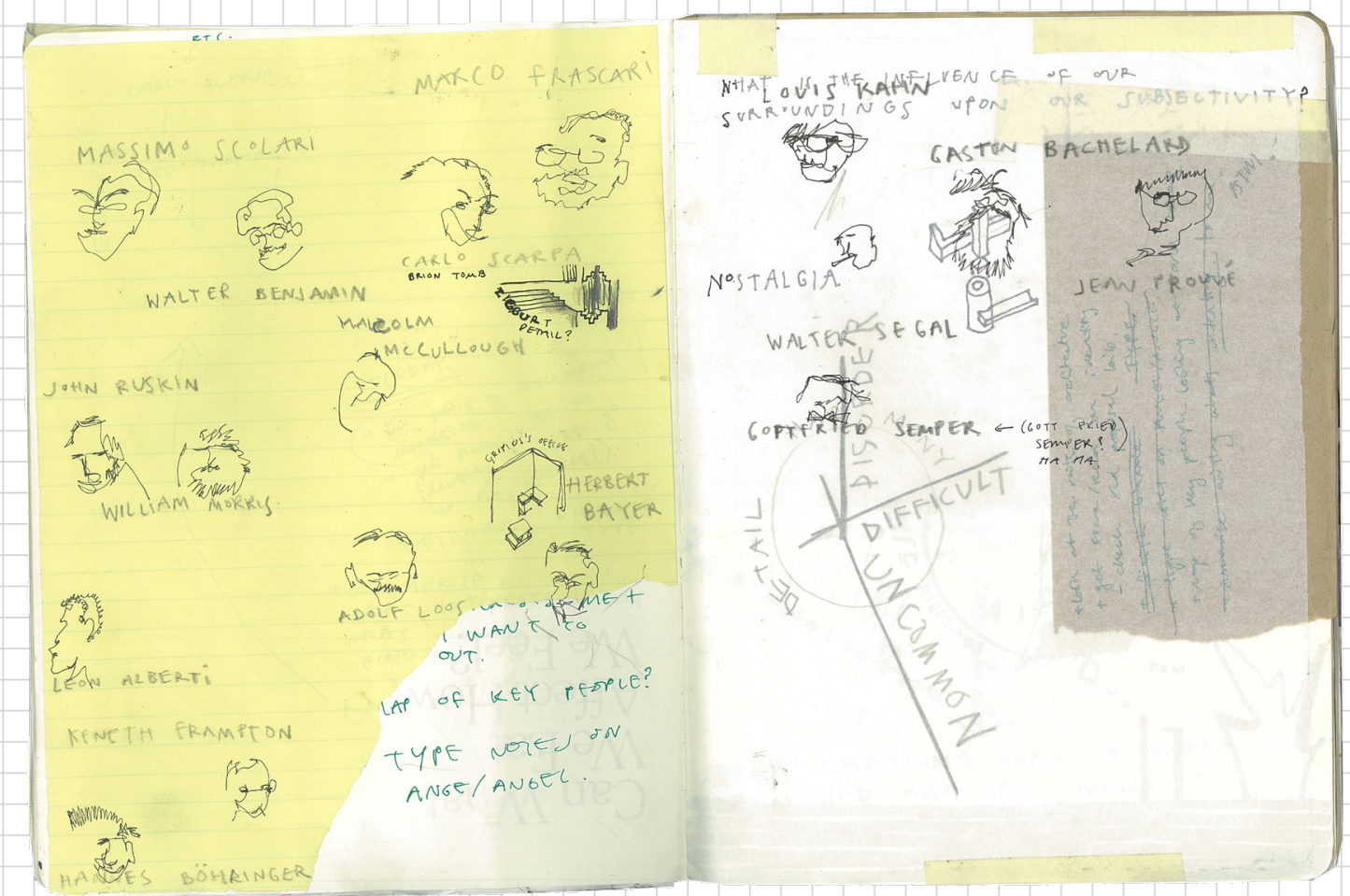




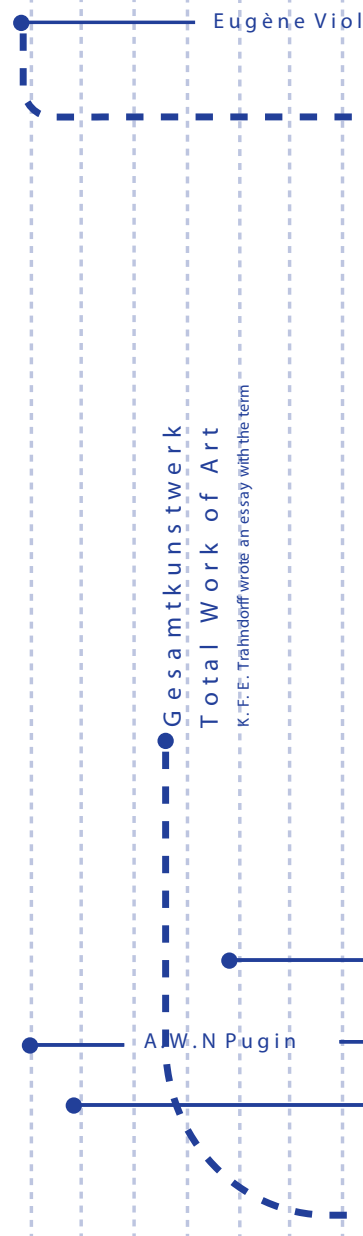



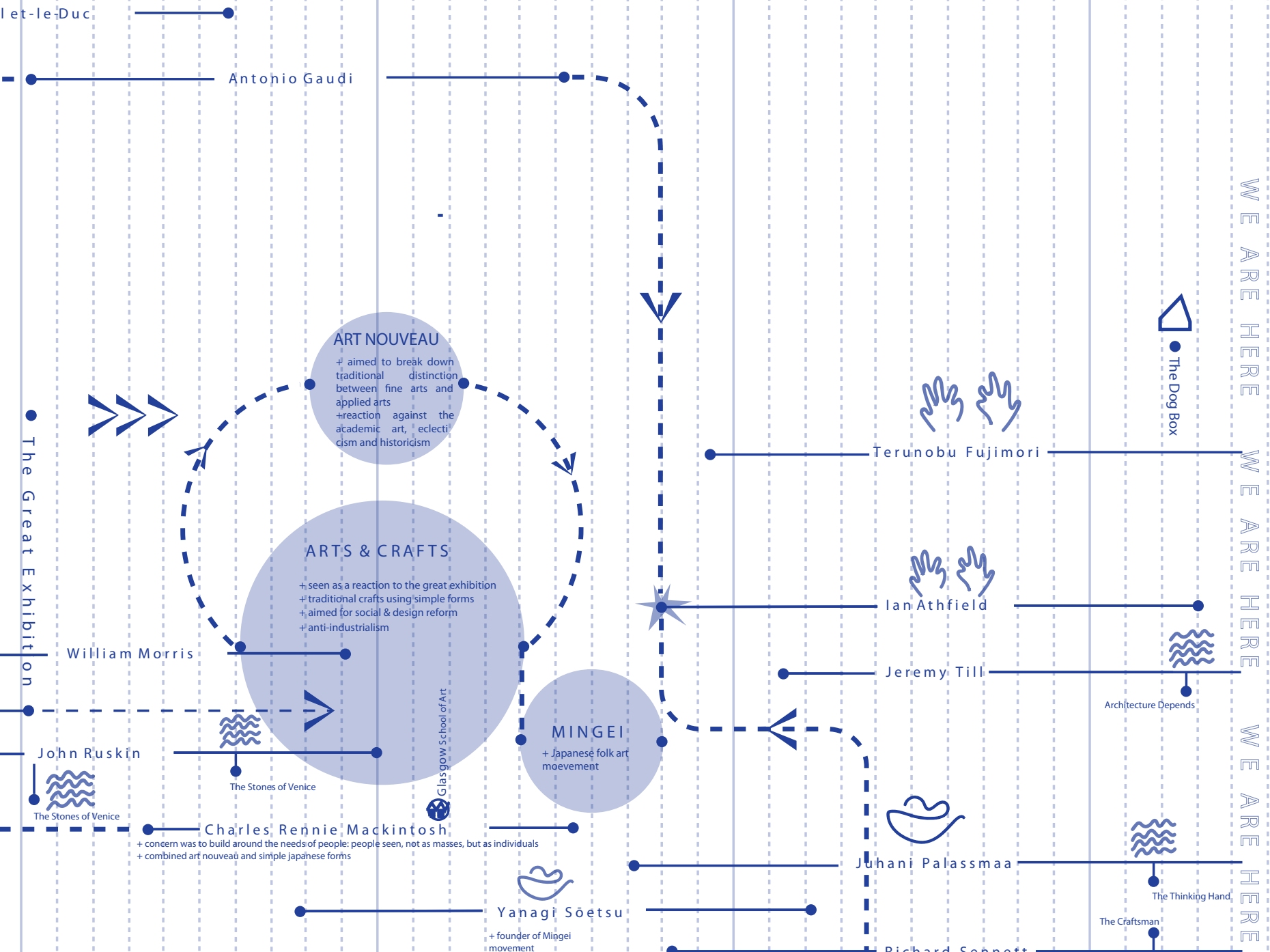

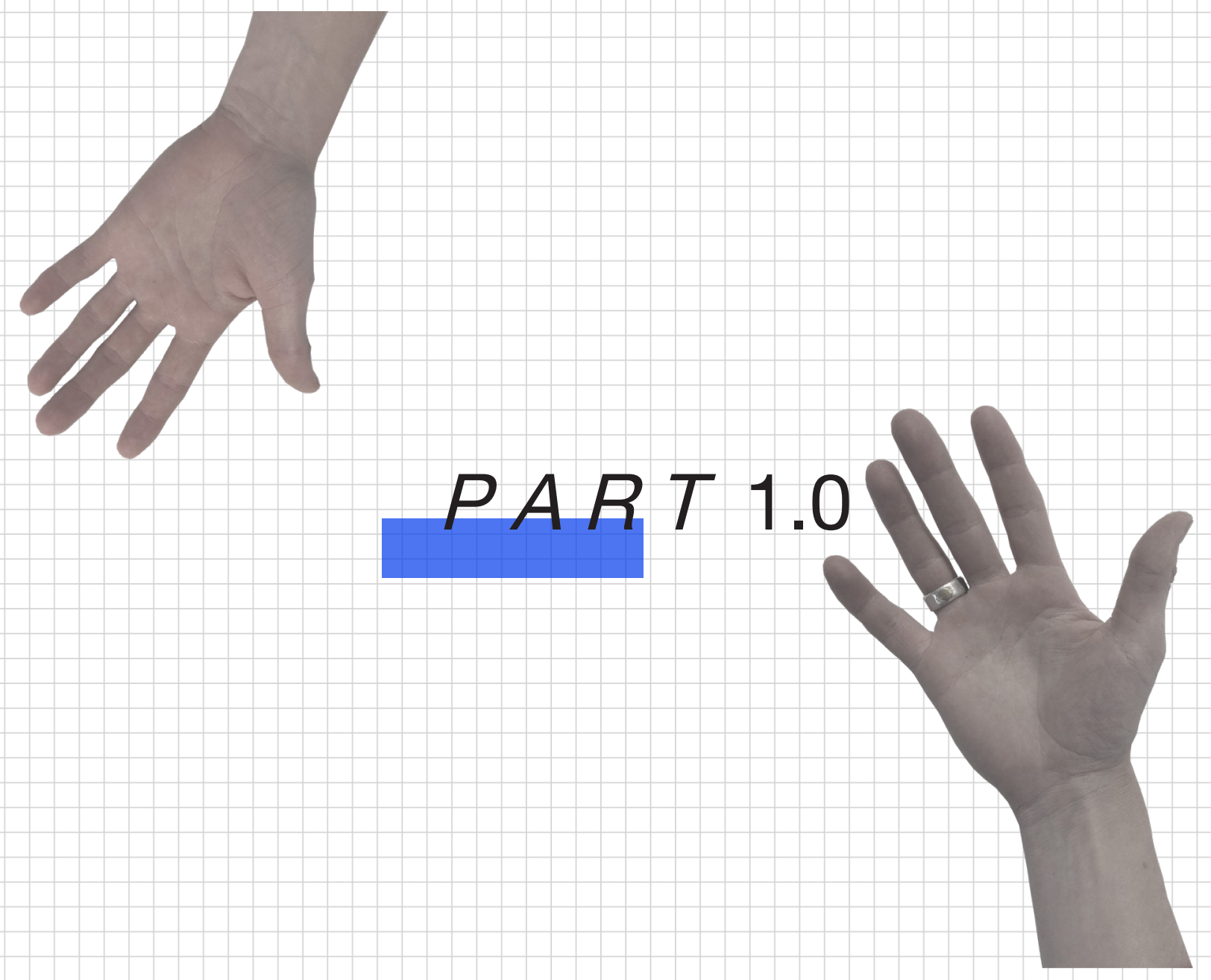

11 


\section{THEHAND}

a definition of make

I began this research with a simple question; what can my hands do? Consequently, how does that effect what I make and how it is experienced or reacted to?

Inherently, I wanted to build something, anything that was real with my own hands. The definition of real as being so reasonably vague as to incorporate post boxes, miniature dog houses and character-based shelving. I wanted to investigate, simply, what can my hands achieve that my brain cannot?

The verb 'make', is described as "to bring into existence by shaping or changing material, combining parts etc" 4 .

However, the term does not have to be so physical. One can 'make' assumptions, conclusions, statements. Or make another person do or say something. It is control. To make something is essentially to produce,

construct, create. It is to act with intent. Typically, we see the hands as those which make. The term 'make' within this research is predominantly a reflection of research by making. 
teu-tare detail.

MAHRCO FRASCARI'S DREAM HOUEE A THEORY OF IMAGINATION.

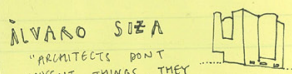

INGENT THINGS, TMEY

Trom mopers to Dencuinos -

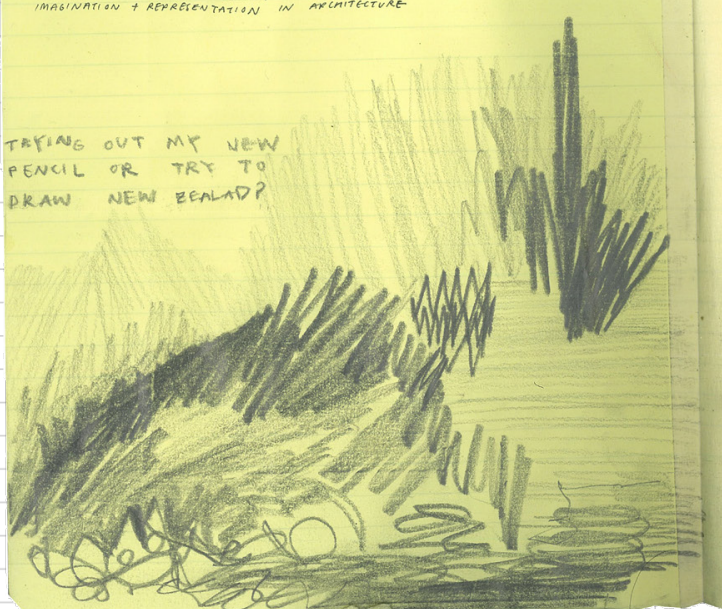

$x_{0}$

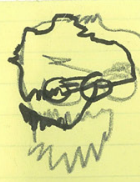
what does stonybeling:

arcliterbu?

s'eleven excercuses in the ait of ardirectral draing' stongtelling the only way to wake ino bivial archtah
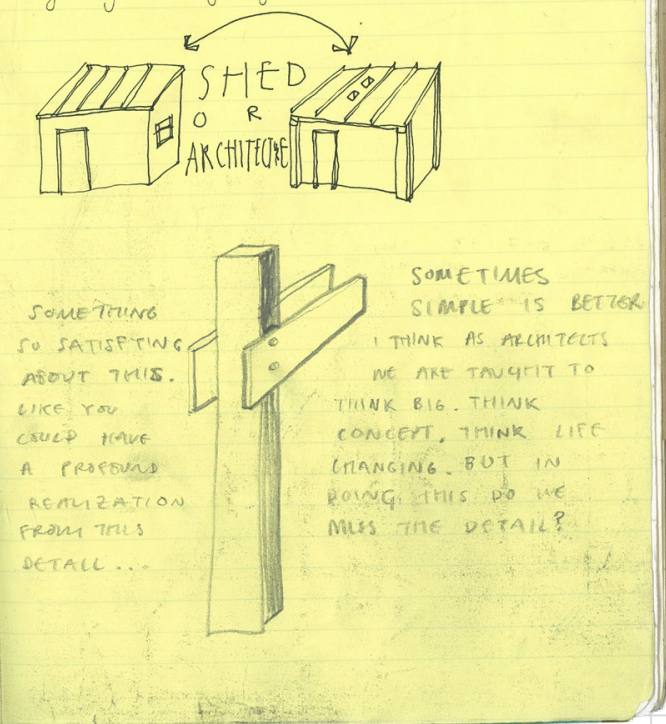
When considering the notion of making within architecture not only is there the physical and mental construing of concept but also the complex notion of representation. "What surprised me most about architecture", Aldo Rossi once recognised "is that a project has one life in its built state but another in its

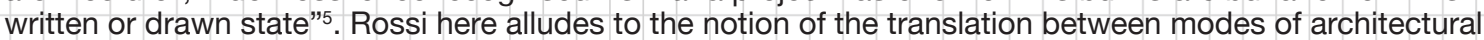
representation. Do we make representations? Within his now dated yet compelling essay 'Architecture and the Conflict of Representation, Vesely Dalibor explained a shift of representation within architecture. He allowed that architectural representation was once somewhat of an art form, vague and interpretational but has since shifted. It is now more analogous with science in the sense that conceptions are clearly defined ${ }^{6}$.

Architectural theorist Marci Frascari also maintains the separation between the drawn and the built, allowing that both separate forms of representation were perceived as architecture. The interpretation by the craftsmen from drawing to building was the condition at which details were considered, allowing invention and innovation to act out the potentially vague concept of building ${ }^{7}$. Drawings were made, and separate from buildings made. This has now been replaced by exact and potentially over specification of drawing.

Juhani Pallasmaa recognises this process as having “...fragmented the traditional entity of the architect's

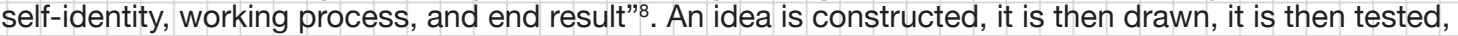
it is then specified to ensure all aspects have been thought out before being built exactly as outlined.

This stipulation is where the constraints are found. How is it possible to specify the solutions to problems you cannot see or cannot foresee? Vesely states that "the crucial element in the development of the physiognomy of representation, particularly in architecture, was a tendency toward idealization. It was through idealization that visible representation moved closer to ideal forms which thereby acquired a new tangibility". Through this newly developed, and potentially now greater shift seen within the manifestation of architectural representation came the need to specify- thus, disallowing the process of interpretation and, consequently resulting in the elimination of the ability to exploit the craftsman's creativity. This somewhat idealised move away from contingency in architecture has, in a way, also diminished the architectural making process. The process defines a point at which architecture is done, disregarding the continuation of the users influence of the built as architecture. 


\section{THEHAND knowledge + symbol}

Traditionally, we see the brain as the intelligent and creative capabilities of the body and the hands more so as a key physical tool to carry out tasks. However, this is an often-misunderstood distinction ${ }^{10}$. The notion of 'the intelligent hand', that is to suggest a hand beyond the physicality of it, was introduced as early as 1833, when Charles Bell published 'The Hand'. Bell argued for the levelling of the hand and eye with respect to knowledge and intelligence ${ }^{11}$. It could be argued that to detach the physical body from the intelligent and creative capacities of a person lessens, or rather somewhat disrespects the capabilities of both the brain and hand simultaneously yet in distinct ways ${ }^{12}$. For example, to build a chair with one's hands could be seen as the physical body acting out the instructions of the brain. However, the brains material knowledge of the task is gained through the hand. Both head and hand are in continuous consolidation.

Within his book "Process: Material and Representation" which explored the translation of architecture, Gail Peter Borden suggests "the significance of the how we make (representational method, the materiality of what we make with and the techniques of both) are the determinants of form"13. The hands knowledge has a direct effect of the made. Jeremy Till argues that the computerisation of architectural process has led architectural thinking to be governed by visual, suggesting that it "...brings the distancing of architecture from the temporality of the world right to the start of the design process"14. This reduction in temporality implicitly affects both architectural production and architectural discourse as a consequence, less importance is often accredited toward physical making within architectural practice.

For a variety of reasons, architects have become less directly engaged physically with the process from idea to realisation. I would argue this space is where architecture becomes interesting or intelligent or engaging. For this reason, it could be argued, perhaps not so much that the story that architecture divulges has changed or that its role as a form of cultural production ${ }^{15}$ is irrelevant, but that the method by which the story is constructed has shifted. Through this change of conception, inevitably comes a change in the relationship of realised architecture and the user. It should be noted here the somewhat interchangeable use of haptic and tactile. Both describe the sensation of touch. However within this research, the haptic will generally be used to describe the sensation in terms of the user/occupant, whereas the tactile will pertain 
more to the relationship of maker to material. Or rather tactile describes process whereas haptic relates to product.

The separation, or fusion of the brain and hand has been discussed in relation to architecture and craft by writers such as David Pye, ${ }^{16}$, Juhani Pallasmaa ${ }^{17}$ and Richard Sennett ${ }^{18}$. Their discussion situates itself within the notion of craft, and more so the relationship of the hand and the craftsman. Sennett suggests that "...understanding is separated from doing, the 'mind's eye' that of an observer rather than of a maker...the craftsman, engaged in a continual dialogue with materials, does not suffer this divide". Suggesting that the physicality of involvement allows a greater connection between understanding and doing, or rather, the noun and the verb. Through the process of craft, it is simply argued that the intelligence of the hand is evident. A consideration is evidenced. Yet as Pallasmaa allows, although architecture was once seen as a craft, or situated within the realm of craft, it has since become detached ${ }^{19}$. Both Sennett and Pallasmaa express the notion that architecture in which the hand is evident, haptic architecture, is in a way, more profound than structures which do not possess that quality ${ }^{20}$. Therefore, it could be argued that the haptic intelligence of architecture is ultimately obtained through the craftsman's hands and, consequently, the relationship between architect and craftsman is imperative.

Pye bluntly allows that "the quality of the concert does not depend wholly on the score, and the quality of our environment does not depend on its design"21. The translation from concept to concrete is where the architecture is determined. Sigurd Lewerentz, a famous Swedish architect was particularly known for his on-site influence and relationship with the craftsmen executing his work. For example, within his St Mark's Church in Stockholm, although Lewerentz implemented a particularly basic and cheap material, brick and mortar, his understanding and consequential attention to detail in the way each brick was laid ultimately influenced the overall architecture ${ }^{22}$. Through specifying the variation in mortar between bricks not only was Lewerentz able to create his desired forms, but also either emphasize or diminish the prominence of the brick. Such attention was taken, it is said he would even sit and point to each brick being laid and prescribe its placement to the bricklayers ${ }^{23}$.Although Lewerentz was not directly physically involved in construction, his dedication and appreciation to those executing his work enabled a dynamic relationship, 


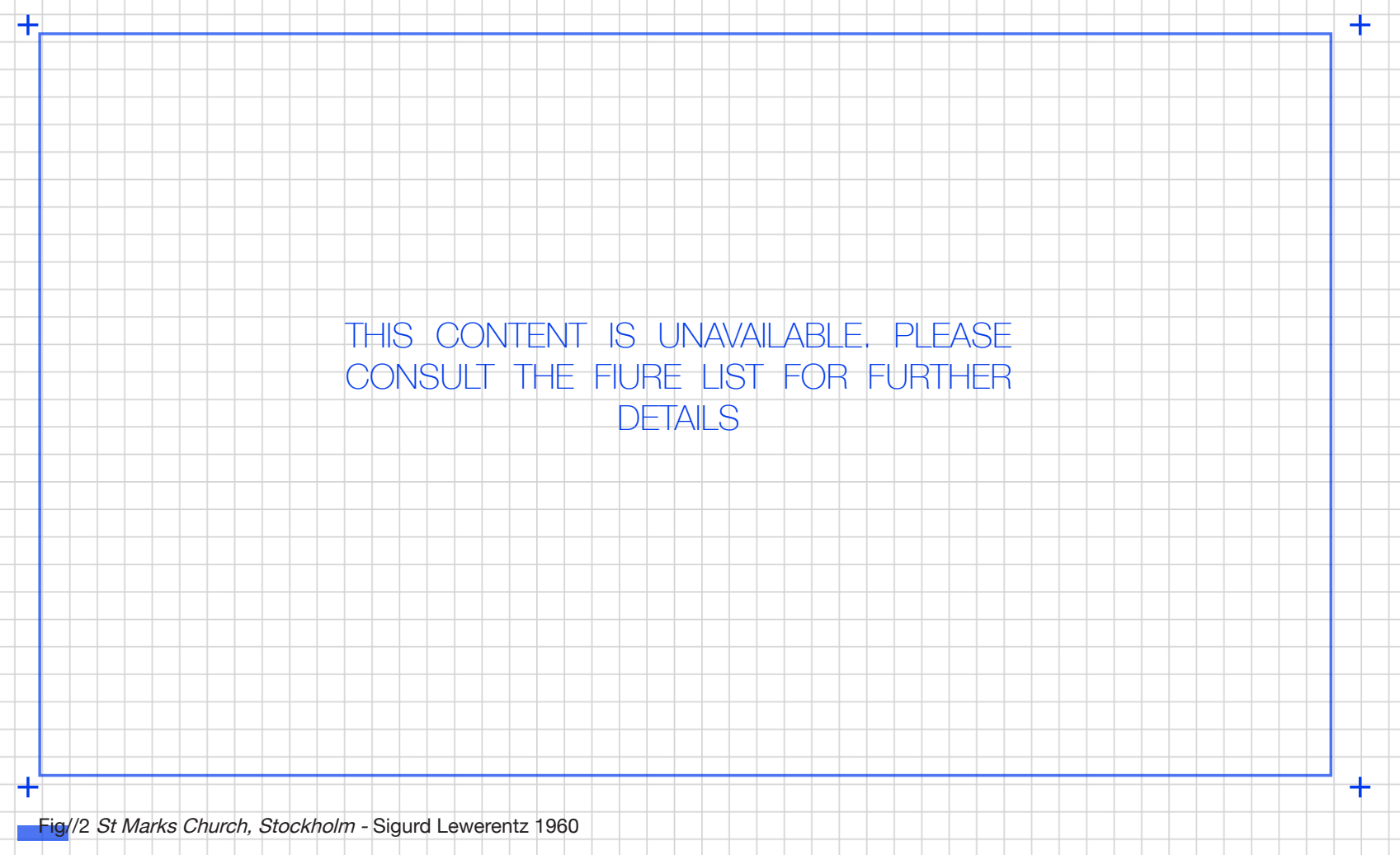


WHERE DO ARCHITECTS ACT OUT THEIR ROLES? CON-SITE) .e DEF-SITE.

HOW MUCH IMPORTANCE IS PLACED ON CRAFT IN ARCMITELTURE?

What is the role of the architect?

+ who's hands create architecture?
Shift of the role of the architect, from 'the Master Builder' to what could be argued today is 'the Assembler'. This shift is due to a multitude of factors such as population growth, industrial revolution, "MASTER-BOILDER"
(GREEK?) $\because \because \because]$ MDDLE economic change etc.

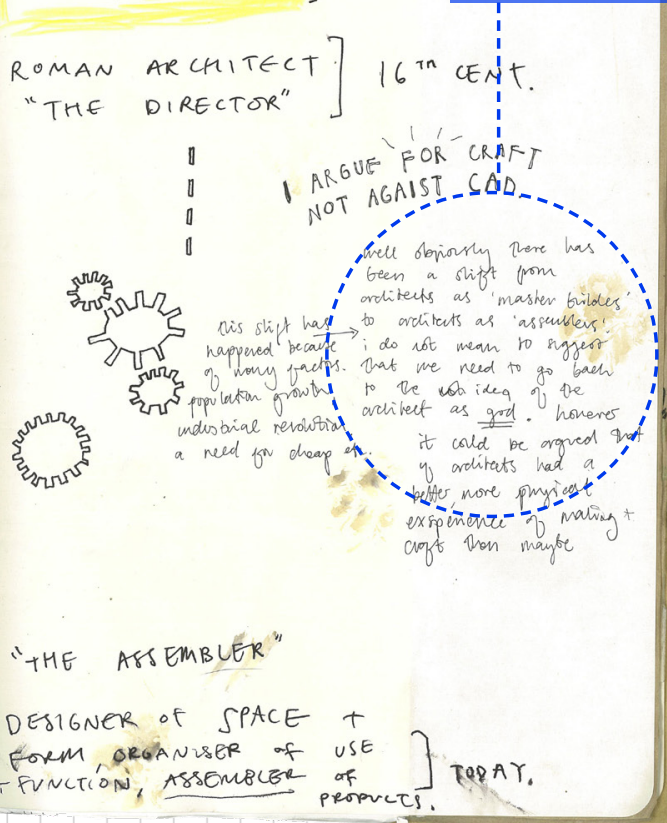


diminishing the feedback loop. This 'on-site' presence he adopted also allowed for a higher level of adaptability, or organic design decisions to be carried out.

Through the involved process of craft, an embodied character of material and detail is sought. The intelligence of the hand is revealed. I believe architectural process also needs an involved, craft-like quality in which the intelligent hand is observed. Drawing, being potentially one of the most overall and widely implemented physical acts of creating architecture today is the place where both brain and hand combine. (It should be noted that today the most used method of architectural production is in fact the computer however I do not categorise that as physical). The concept of the time craft involves is potentially a reasoning for architectures speculated separation from craft. Within practice, through the reduction of time taken to exercise physical drawing, and potential increase of virtual work, the sense of satisfaction that craft allows is not so prominent. Sennett suggests "the slowness of craft time serves as a source of satisfaction; practice beds in, making the skill one's own"24. It is the ownership and understanding of the hands capabilities that craft allows which enables an intelligent production/ability. The sense of ownership enabled through time heavy practice is seemingly the factor which reinforces the hands independent intelligence.

The hand is arguably the part of the human body most frequently used in symbolism ${ }^{25}$. It is used within language, gesture and motif. Sennett again introduces the decisive notion of the grip of the hand in comparison with the brain's somewhat unconscious movements allowing that, "Grips are voluntary actions; to grip is a decision, in contrast to involuntary motions like the blinking of the eyelids"26. Within these small acknowledgements of the importance of the hands ability to react and decide intelligently the separation of the hand and brain is suspended. This is also mimicked in language. We associate the hand with powerful and absolute sayings such as 'right hand man' or to 'come to grips with an issue ${ }^{27}$. Le Corbusier implemented the hand as a symbol throughout his works. His 26 meter tall 'Open Hand' sculpture in Chandigarh, India is hs largest and perhaps most direct application of the symbol. Being able to say one has built/made something with their 'own two hands' depicts a deliberate and considered human action. An intelligent hand is evidenced. Within this relation, it can be seen that although the hand and brain are perceived to be separate outside of craft, our subconscious appreciation and reliance on the hand as a source of knowledge is inherent. 


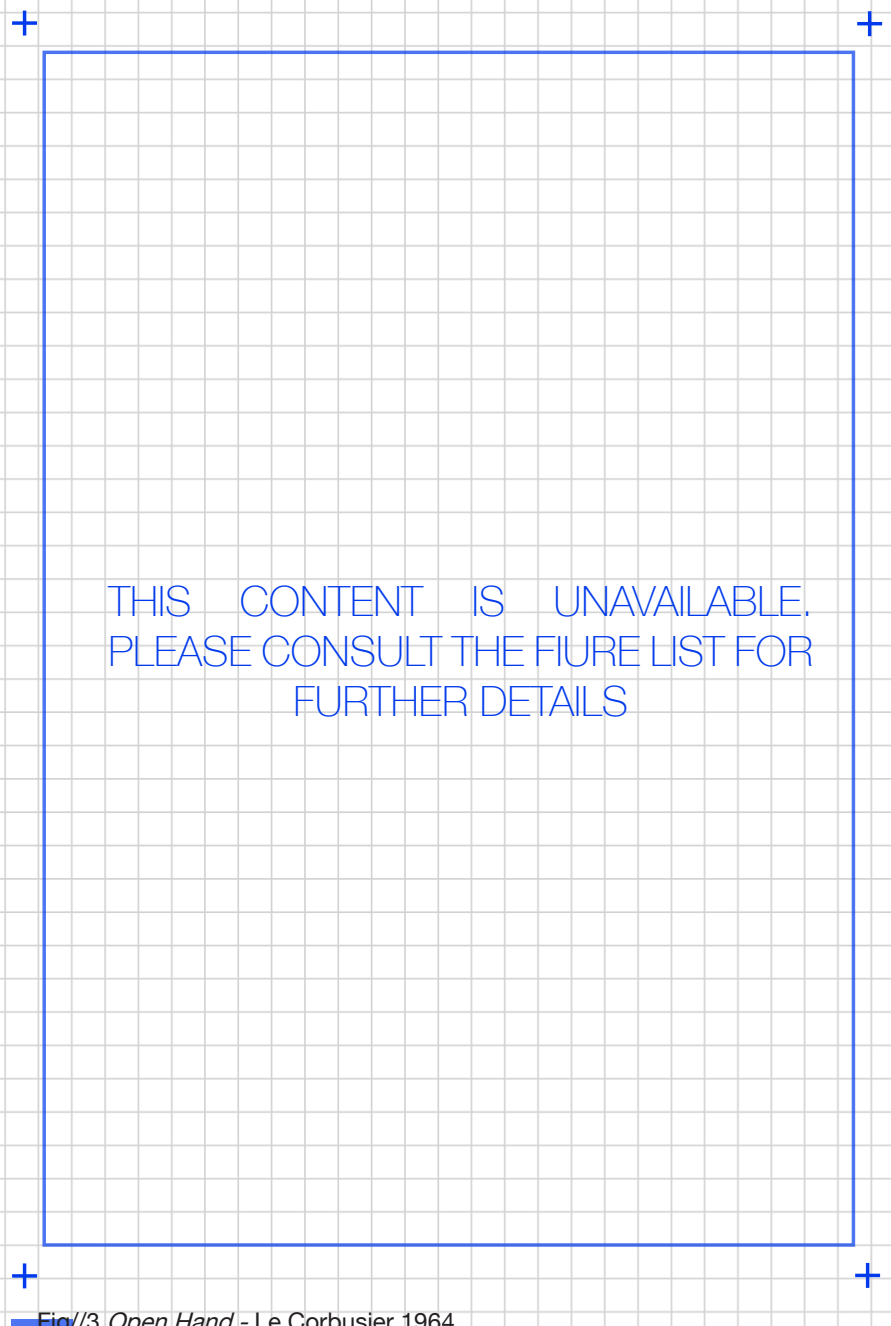


"But the craft of the hand is richer than we commonly imagine... The hand reaches and extends, receives and welcomes-and not just things: the hand extends itself, and receives its own welcome in the hands of other...But the hands gestures run everywhere through language, in their most perfect purity precisely when man speaks by being silent... Every motion of the hand in every one of its works carries itself through the element of thinking, every bearing of the hand bears itself in the element. All the work of the hand is rooted in thinking"28

-Martin Heidegger 
The separation of brain and hand has resulted in the diminished ability of the hand to assert its significant intelligent capabilities, or rather, its ability to be recognised within architecture. The traditional role of the architect today is somewhat distanced from not only the physical construction of architecture, but the consideration of physical elements of architecture. It is argued this separation from the manual labour of physical craft has been growing since the Renaissance ${ }^{29}$. Within 'Changing Ideals in Modern Architecture, 1750-1950, Peter Collins and Kenneth Frampton argue that preceding the Renaissance a conflict/crisis arose within society grappling for a 'new' architecture. They say the Renaissance "... brought man into closer contact with the inside and the outside of its buildings"30. This moral conflict of modern life was also proposed by the Arts and Crafts movement in which figures such as John Ruskin attributed manual labour with the social morality of life ${ }^{31}$. Shifting from the architect as the master craftsman to the architect as the assembler of parts ${ }^{32}$. However, Le Corbusier's assistant, Andre Wogensky, said of his mentor: "For him it was not enough to see it. He felt it with his fingers" ${ }^{33}$. Although he only physically constructed one of his own designs, Le Cabanon, Corbusier did in fact make architecture with his hands. For example, within his renowned later work Notre-Dame du Haut, Corbusier conducted exhaustive sketches and models to consider the chapels architecture. Within these physical interrogations of material, light, depth, form etc Corbusier was able to work through the elements of architecture at all levels at once, even considering (and placing great importance on) the route of the users, from approach to departure ${ }^{34}$.

Therefore, it could be said, there is a distinction between making and construction, both enable a character within the resulting architecture, and both create presence through craft. Yet, further, it could be argued that with the development of the architectural profession, the physical, even the detached physical hand is becoming predominantly absent. Pallasmaa observed, "the fact that being an apprentice at the construction site used to be a mandatory part of architectural education, and that architects often practised craft, drawing, painting or sculpture as a hobby or a means of acquiring manual skill and carrying out formal experiments, reinforced the connection between professional architectural practice and the realities of making - between idea and matter, form and its execution" ${ }^{35}$. 


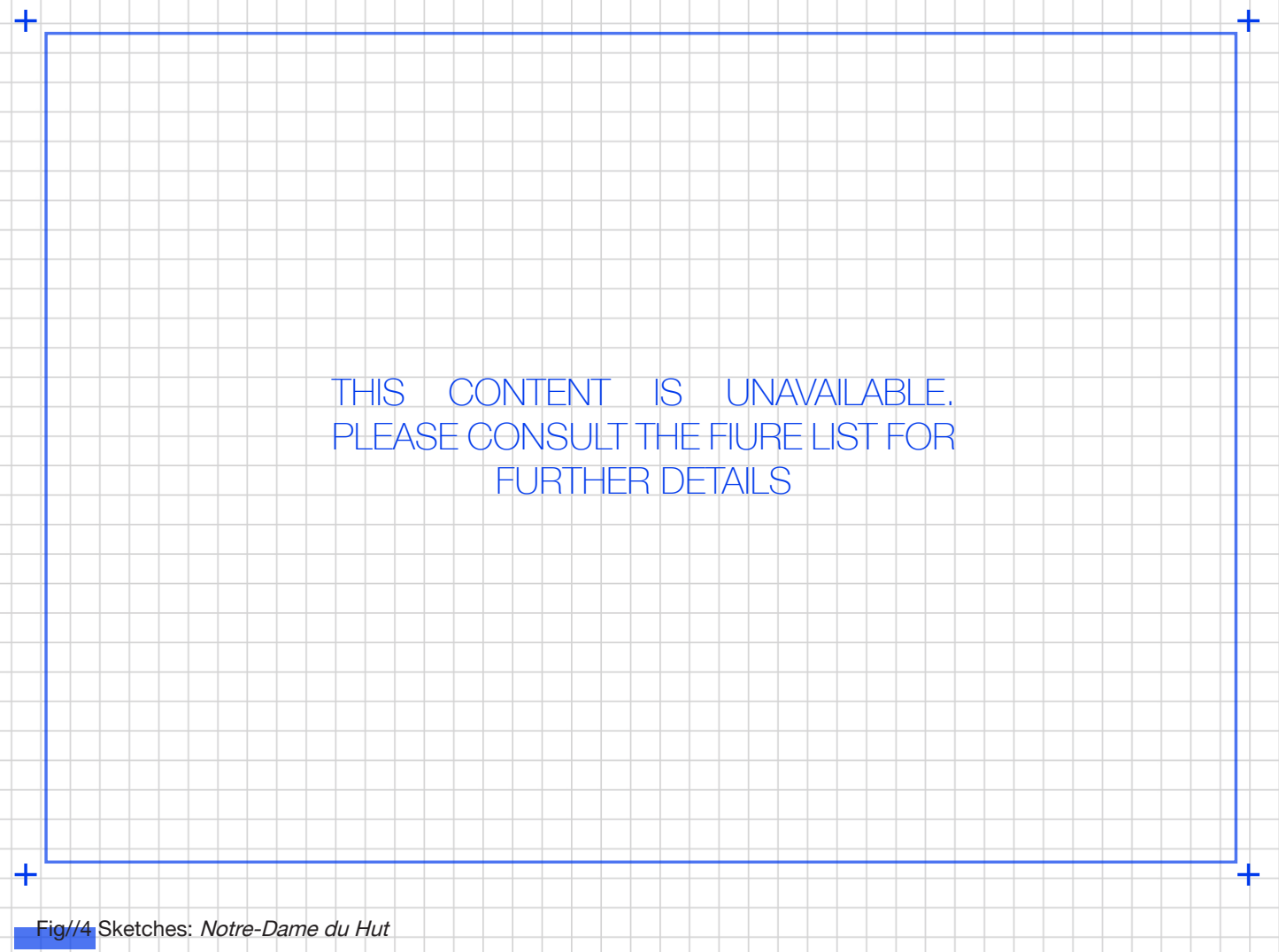


THIS CONTENT IS UNAVAILABLE. PLEASE CONSULTTHE FIURE LIST FOR FURTHER DETAILS 


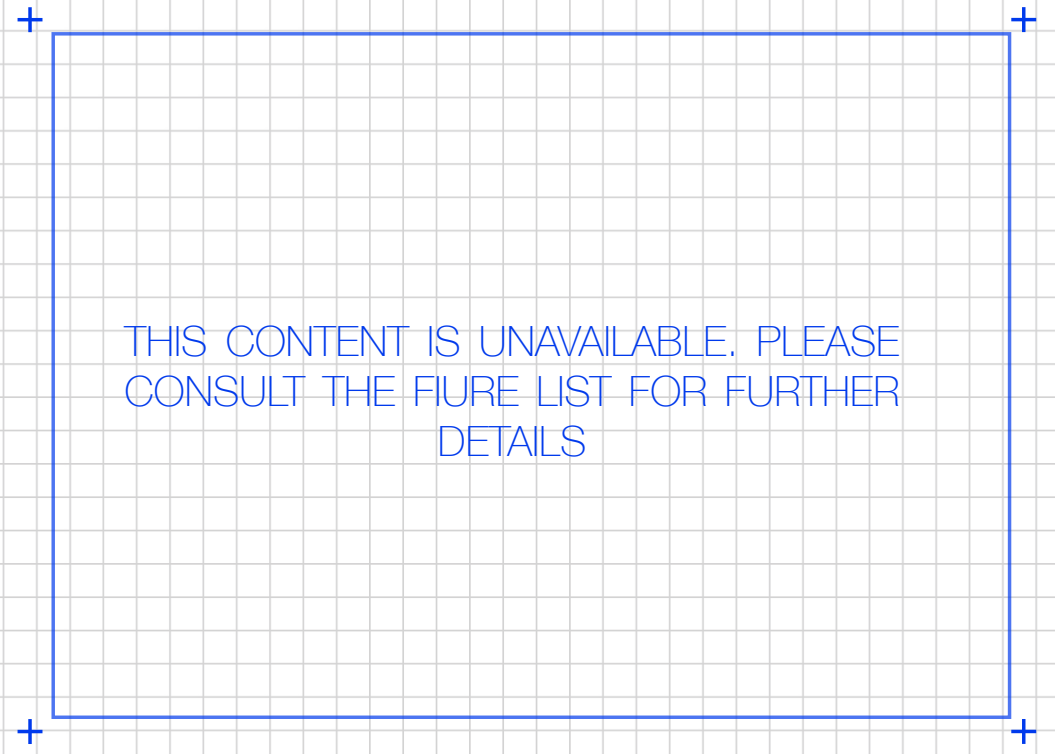

Fig//6 Sketch: Jinchokan Moriya Historical Museum - Terunobu Fujimori 
Regardless of subject matter, a trained and considered hand is developed through use; through the practice of the tactile movements of the hands, consequently recognised within the architectural object by the user. A trained hand in architecture leads to a visible, physical difference in what is built. Therefore, to consider the practical, real and making aspects of architecture, the architect's physical use of their hands becomes paramount. As Roy Decker insisted, the "hands are the most difficult to deceive, and eyes are the easiest" ${ }^{36}$. He then expands to consider the time difference between sight and touch, the former significantly quicker than the latter. Consequently, the craft of architecture is considered through time, thus resulting in an architectural process which utilises craft to manipulate moments of architecture. In doing so, the overall architecture develops its own character because of its perceived presence.

Terunobu Fujimori works, almost exclusively with elements on site, enabling the materials to reveal the craft. He humbly reveals that "The most fun thing about architecture for me is that I can build things with my own hands" ${ }^{37}$ Creating with the hands for Fujimori is an experience which allows not only exterior knowledge to be gained, but is in fact where the imagination, invention and consideration of architecture is explored. He expands to recognise his interest in working within the "basic unit for architecture" as allowing a more free and imaginative architectural exploration process ${ }^{38}$. Of his first work, 'Jinchokan Moriya Historical Museum', it was noted that 'This building is Fujimori himself. It is as if Fujimori has assumed the shape of a building. Here stands Fujimori, and there stands the building to which he has transformed himself" 39 . Through his process of making within architectural production Fujimori allows his own hands to be a direct self-actualisation of himself as an architect.

The consideration of architecture by its maker inevitably influences the result. Lazslo Moholy-Nagy explained that "the way in which something has been produced shows itself in the finished product. The way it shows itself is what we call fracture" 40 . The notion of fracture is inherent with architectural experience. With the shift away from architects as makers who experience a tactile relationship with the made comes a shift of the haptic relationship of user and the made. A change in the fracture. The story able to be told through architecture may not have changed as such, yet the process through which it is conceived has in a sense separated and diverged. 


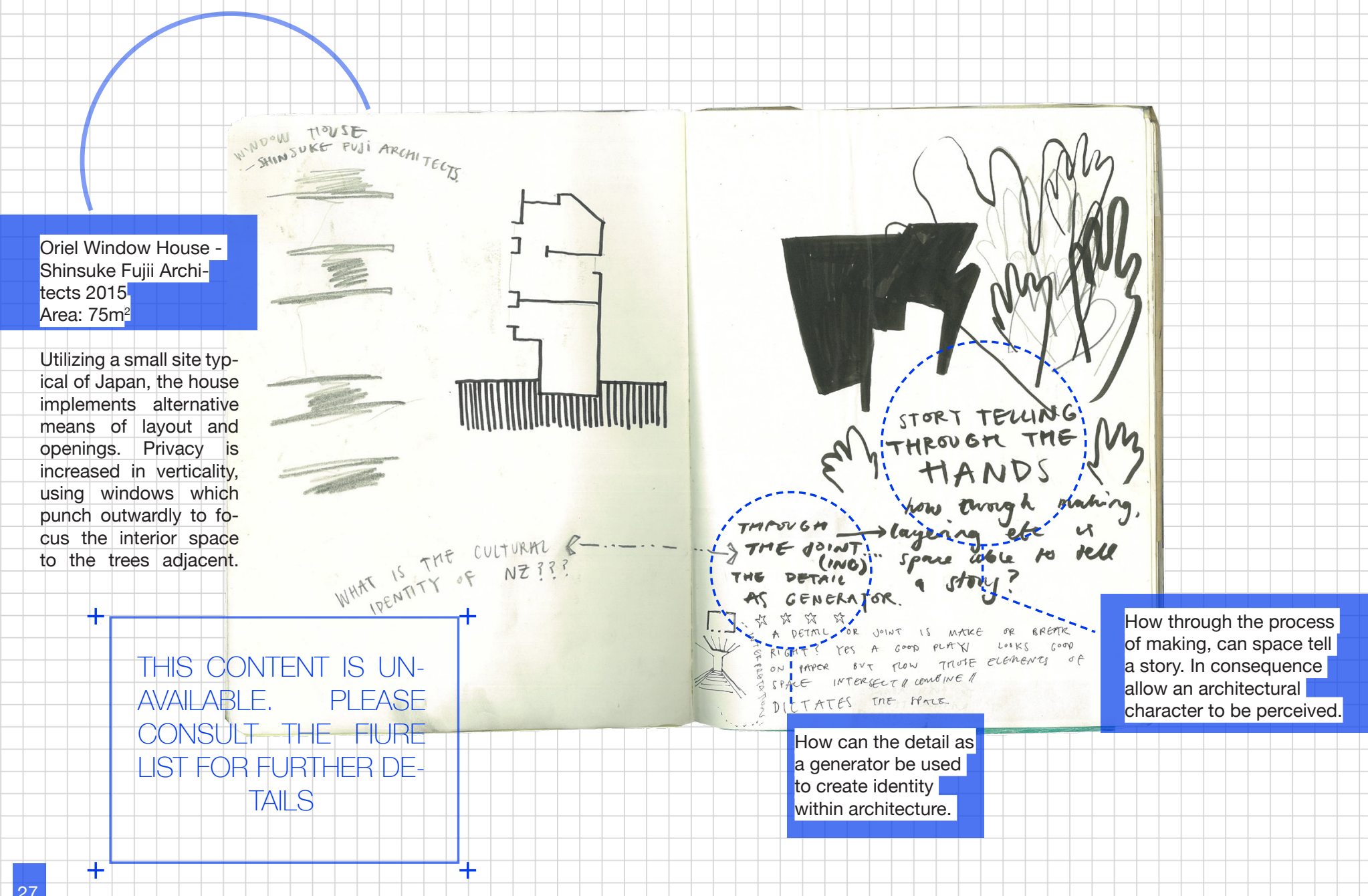
Fujii Archiects 2015

Utilizing a small site typical of Japan, the house implements alternative means of layout and openings. Privacy is creased in verticality, cus the interior space ees adjacent. i THE DETAIR tor

A DETALL

intaecect conbine

How can the detail as

a generator be used

to create identity

within architecture.
How through the process of making, can space tell a story. In consequence allow an architectural character to be perceived. 
Exploration of making. Detail and craft are built up through the making process to tell a story and create an architectural character.

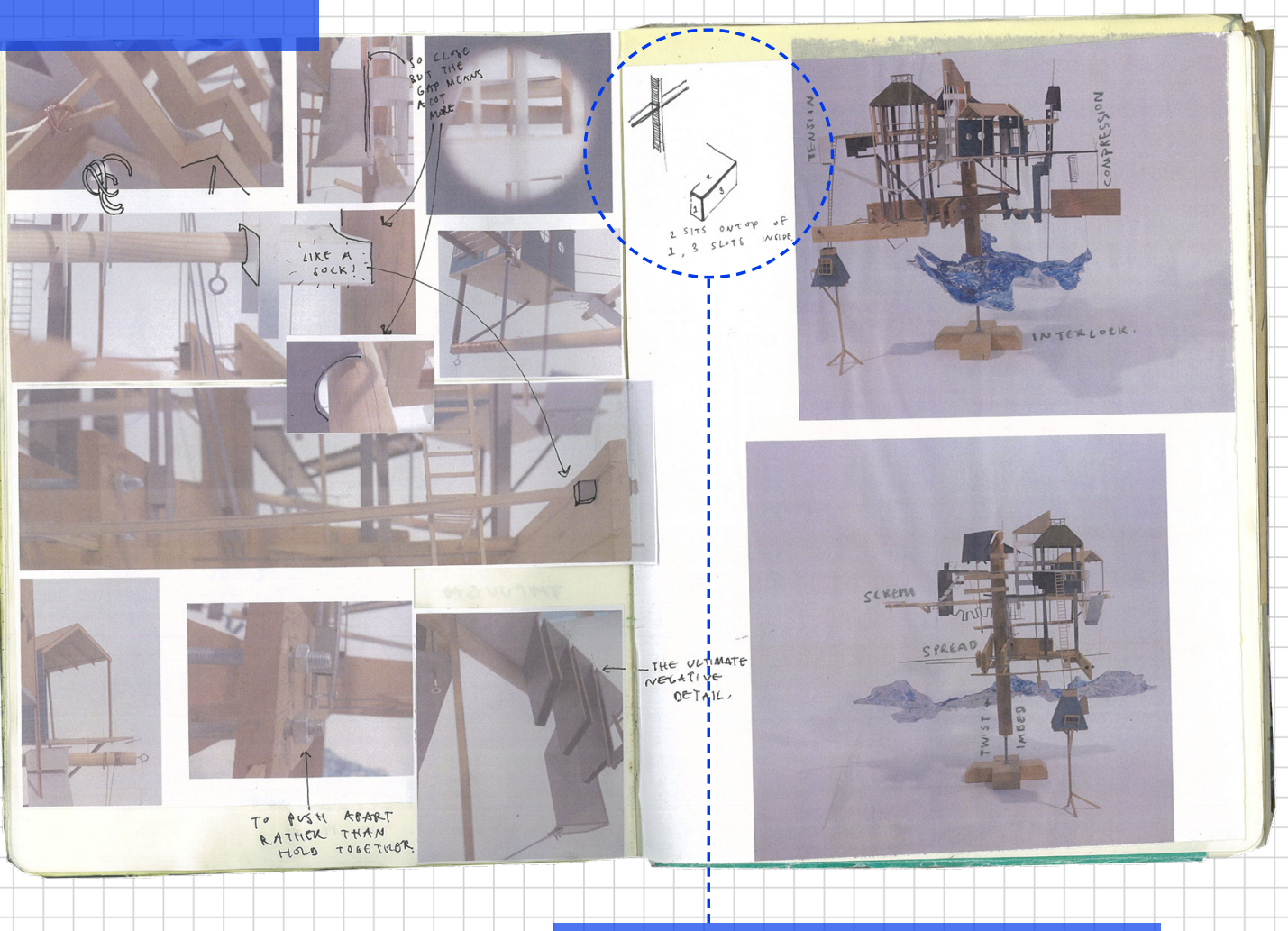

Construction process worked through modelling enabled consideration of reality of construction. Thickness and material are though over. 


\section{MARCO FRASCARI}
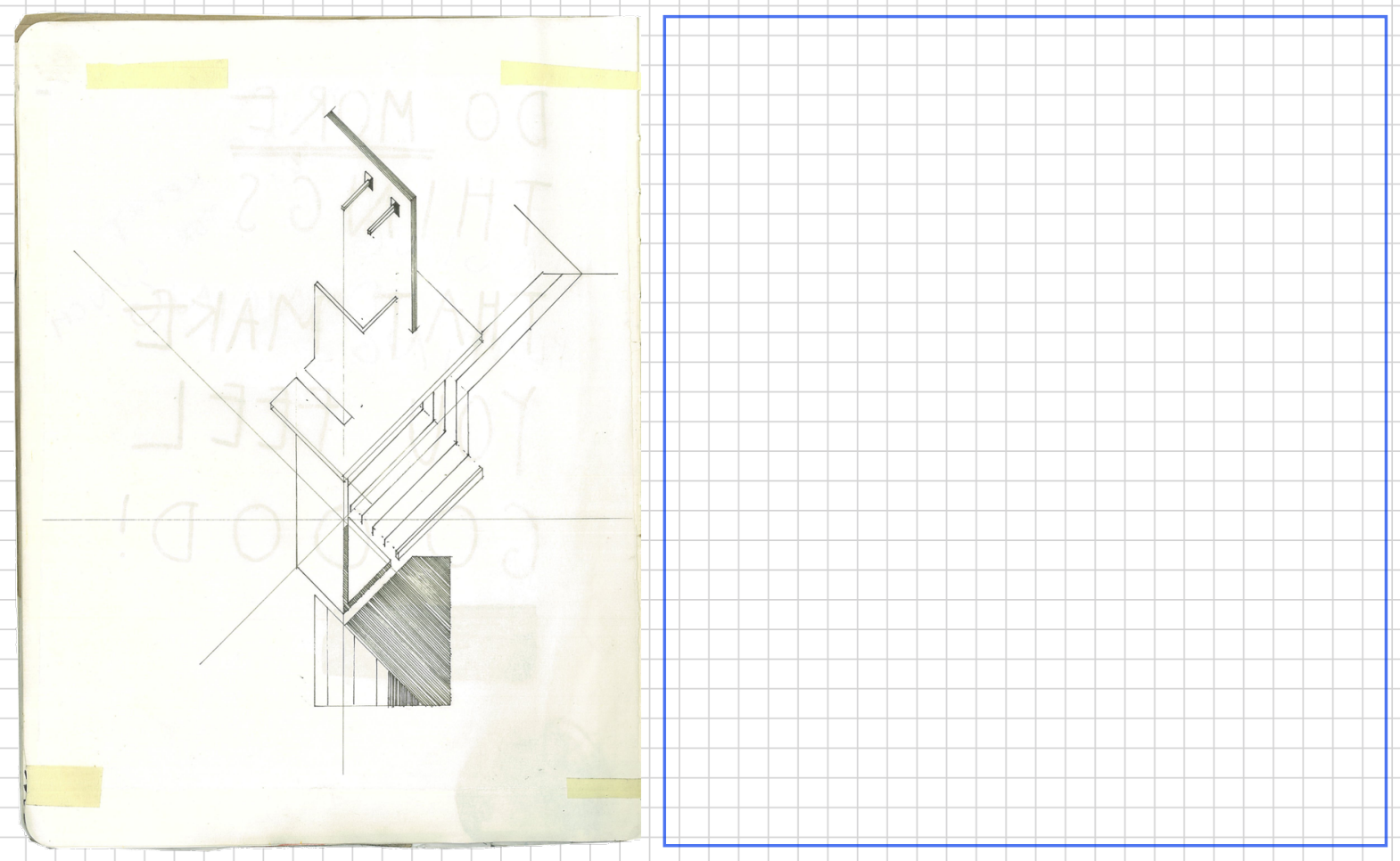
As a physical occupant of architecture, we are intrigued or rather able to react to forms, spaces, conceptions in which we can relate, or rather, correlate, our own body. Although arguably further toward writer than maker, Massimo Frascari suggested that "too much attention cannot be given to produce a distinct character in every building, not only in great features, but in minor detail likewise; even a moulding, however diminutive, contributes to increase or lessen the character of the assemblage of which it forms a part" ${ }^{41}$. It is from these details which constitute the whole that, inevitably, engagement with architecture is established. Consequently, the physical construction, of these details consummates the user's response.

For example, within my own home a set of floating stairs carries one from the ground floor up to a mezzanine. Effortless in their appearance, the stairs carry with them the inherent notion of intelligence. How is it possible to hover eight $150 \mathrm{~mm}$ thick slabs of solid timber in mid-air? The effect is one of intrigue which arguably heightens the experience of circulating upward. Similarly, the new Tate Modern extension houses a spiral staircase which, cast in situ, compels its user to consider its conception and thus actively engage with the architecture. Richard Sennett discusses the importance of presence within architecture, allowing that "Presence can be registered simply by leaving a maker's mark, such as a brickmakers stamp" ${ }^{42}$. Through the explanation of the making process the user is, if not consciously, inherently aware of the production of architecture. That awareness elevates the experience. Therefore, when discussing the notion of the haptic, it is rather a concept of acknowledgment of the tactile qualities the architecture possesses, or has been through which allows character to be determined. As Walter Benjamin said, "buildings are appropriated in a two-fold manner: by use and by perception or rather by touch and sight...Tactile appropriation is accomplished not so much by attention as by habit” ${ }^{43}$. The body's actions inherently and subconsciously act and react to the surrounding architecture. Lars Lerup suggests architecture must embrace building the unfinished. He argues, "human action...is a complicated matrix with unknown combinations, the result of which is considerable unpredictability, a marvellous unfinishedness and openness. When this fact is brushed, ignored or forgotten the importance of architecture becomes simply utilitarian, design becomes dull, repetitive and mechanical" ${ }^{4}$. Allowing the story of architectural production to be told enables a more involved user experience. 


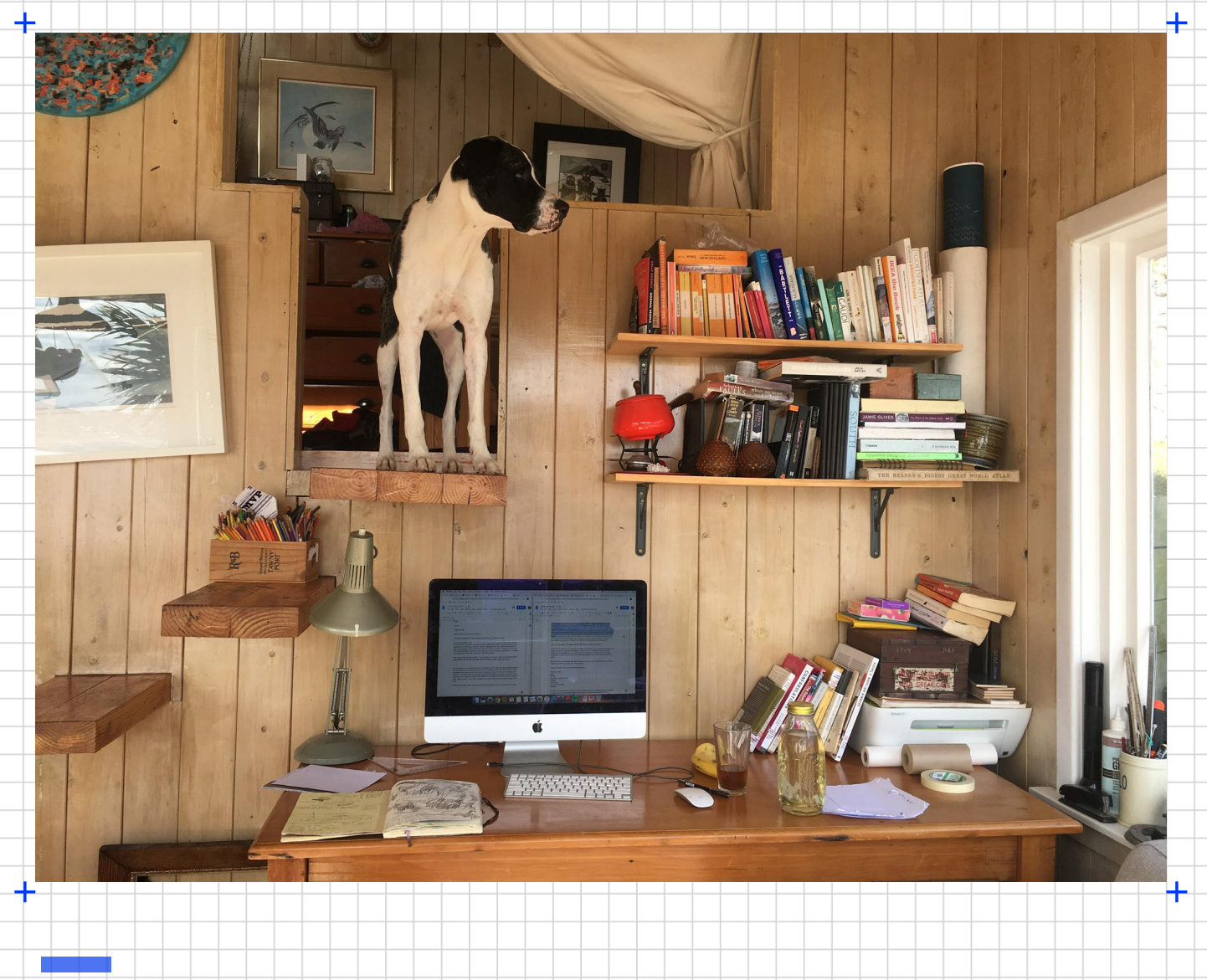

31 
THIS CONTENT IS UNAVAILABLE.

PLEASE CONSULT THE FIURE LIST FOR

FURTHER DETAILS 


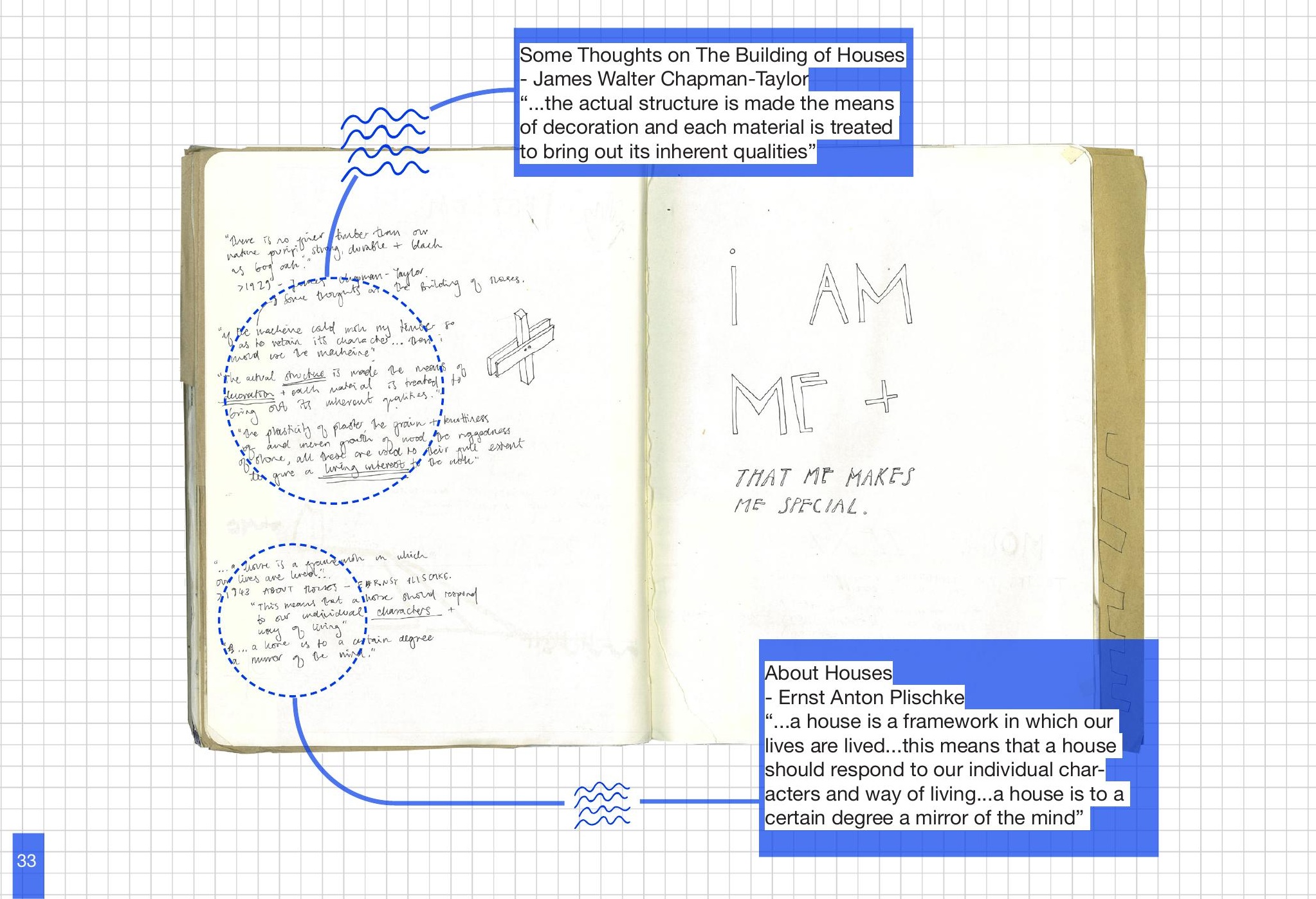


Firth Concrete of-

fices

Considered as an

influential and pivotal

piece of New Zea-

land architecture.

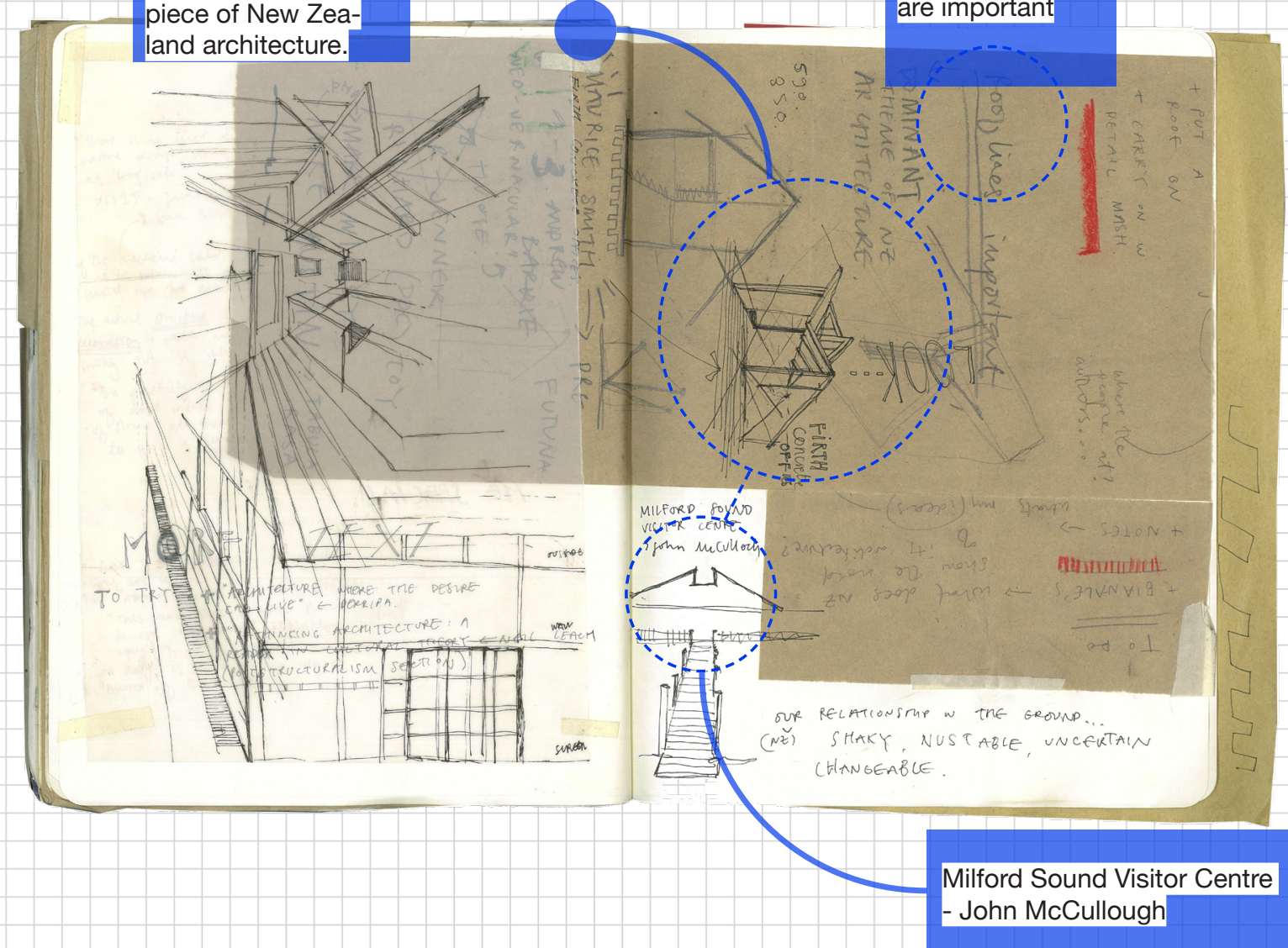

Roof lines

within New

Zealand context

are important 


\section{THEHAND}

chatt detail

Considering the notion of character and presence within architecture consequently announces the fundamental components of craft and detail. Frascari suggested that "It is possible to define architecture as a system in which there is a "total architecture", the plot, and the detailed architecture, the tale....architecture becomes the art of appropriate selection of details in the devising of the tale." 45 . Within this analogy, it could be understood that detail is the point at which the essence and consequential character of architecture is situated. How these details are thus crafted and constructed becomes the vindication of the tale. In essence, the craft of the detail, the imprint of the maker, allows for presence to be registered, which in turn amalgamates into an architectural character. For example, a bandsawn face of timber board recognises the act of the saw blade on the timber, and so offers insight into the material's conception. Prominent proponent of the Arts and Crafts Movement, John Ruskin famously stated that "Truth is craft. Craft is truth" 46 , in relation to the social wellbeing architecture allows. He believed craft was the utmost honest and moral treatment of material and structure, and thus architecture. Sennett considered this truthful unity of the head and hand as fundamentally shaping Ruskin's advocation of manual labour ${ }^{47}$. Through the dedication craft demands, the presence of its result is exhibited. This can be seen within master architect Carlo Scarpa's work. Scarpa was not involved in the construction of his works but he supervised them closely. He dedicated much of his time to the craft of drawing and conducted exhaustive discussions with manual workers, enabling a constructive craft basis for his work ${ }^{48}$. This is intelligently shown through his work on the Olivetti Showroom. A montage of materials, Scarpa utilised his knowledge of craft to exploit what was before a narrow, long and relatively dark space. Through a composition of heavy and delicate elements such as the marble staircase distinctly separated by small brass rods to allow a negative detail, the space is wholly crafted and considered. Considering even the floor in relation to the whole, he implemented an intentionally irregular tiled pattern using four different colours and sizes to create a water-like surface, consequently offsetting the heavier elements of the space. 
THIS CONTENT IS UNAVAILABLE. PLEASE CONSULT THE FIURE LIST FOR FURTHER DE-

TAllS

$+$

Fig//9 Olivetti Showroom - Carlo Scarpa 1957 


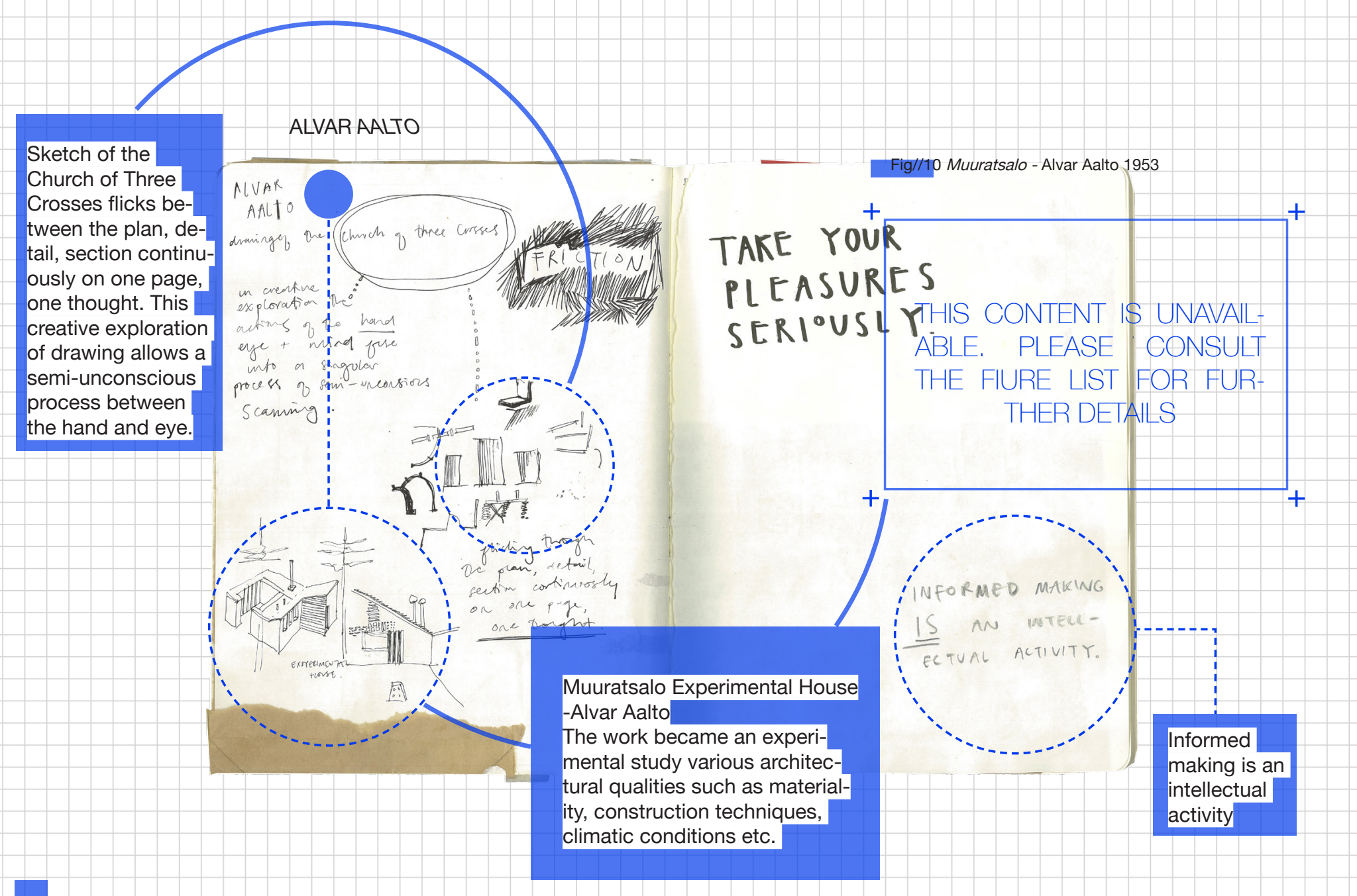


An admirer and student of Scarpa, Frascari ${ }^{49}$ commented that, "Details of Scarpa's architecture solve not only practical functions, but also historical, social, and individual functions" 50 . Through the craft of drawing, Scarpa was able to simultaneously consider all aspects of architecture in different scales. David Pye acknowledges the 'workmanship of risk', which is ultimately a fundamental aspect of craft. It simply allows that craft must have risk and contingency drive the work; it must not be preconceived ${ }^{51}$. Sennett suggests that "The good craftsman places positive value on contingency and constraint" 52 . In doing this the craftsman is able to utilise the potential that contingency and risk allows. However, in many instances and for many reasons, architecture has transitioned to a particularly low-risk practice, or rather works on minimising risk which arguably reduces the space for imagination. Till posed the question: "how could anything conceived in a vacuum cope with the conditions it has denied were there?" 53 suggesting that architecture which does not acknowledge exterior entities will inherently be unable to relate to the exterior society. He argues that architects must somewhat let go of control, explaining "But then we let time move in, disturbing the impossible purity of the plan...." ${ }^{4}$. These two seemingly distant concepts relate to one another in terms of consideration. Considered architecture embraces the external forces it is bound by. Interrogating the detail, Scarpa accommodated the unexpected. 


\section{THE HAND P}

The process of architectural production today is a lengthy one, and therefore maintains a large gap between thought and feedback, due to the insertion of other steps. This could be recognised as a long reward loop. The notion of reflection and revaluation is distanced through the gap between thought, action, result. Traditionally, architecture is realised through a process of representation. Firstly, an idea is conceived, then tested through drawing (predominantly virtually). This tested and documented idea is then passed on to someone to interpret it before building it. As previously discussed, both are distinct forms of making.

Although categorically art theory, the Process Art movement of the 1960's sought to embrace the limitation of craft as a process over art as visual object, thus shifting the focus from the image to the operation ${ }^{55}$. This could arguably sit parallel to the conversation seen within the architectural discipline today over the representation of architecture, its focus on imagery, of justification over making. Prolific artist Robert Morris said that "I believe that there are 'forms' to be found within the activity of making as much as within the end products" 56 . In this he suggests the rejection of form at the outset allows for a clearer, more logical approach to making which, rather than limiting contingency, simply excepts it. Challenging the traditional process of architectural production enables an exploration of the space between idea and result. Rather than potentially being a lengthy linear process, by speeding up the feedback loop, architectural production becomes a cycle of invention, reflection, adaption, reinvention. Jackson Pollock said his 'drip' paintings were "an extension of the body and as a process of discovery rather than an act of intention" 57 . He worked with the materials contingency to discover the unprescribed. 'Ant Farm', perhaps the most wellknown architectural group to practice within this movement, began in 1968 with the intention of exploring alternative styles and practices more in line with the revolutionary spirt of the time ${ }^{58}$. The group would stage large scale 'happenings' which critiqued the "virtual architecture of image, icon, and power"59. 
ROBERT MORRIS

EVA HESSE

\section{RICHARD SERRA}
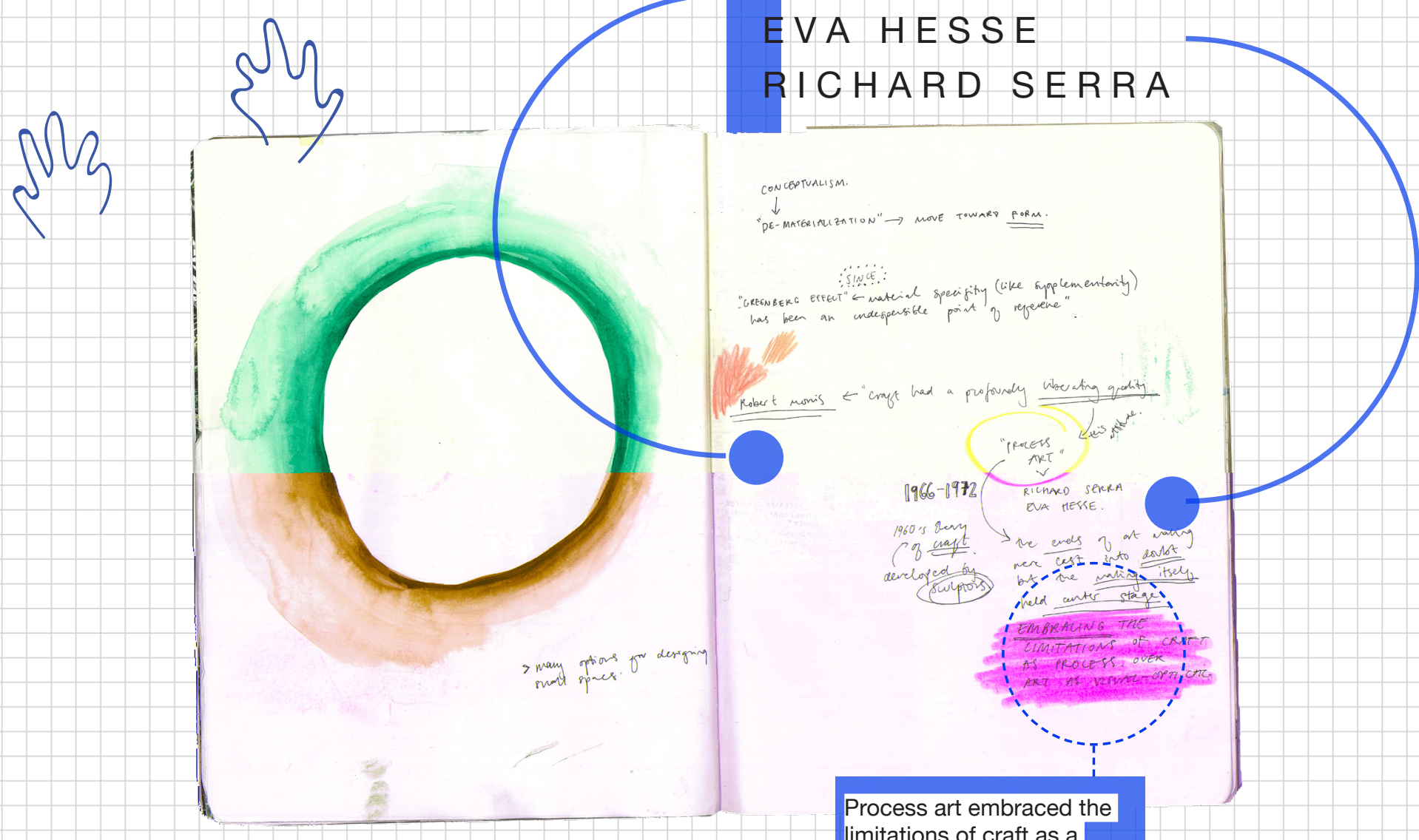

Process art embraced the limitations of craft as a process instead of art as an image or final product. In this act, the movement not only allowed for, but actively engaged with contingency. 


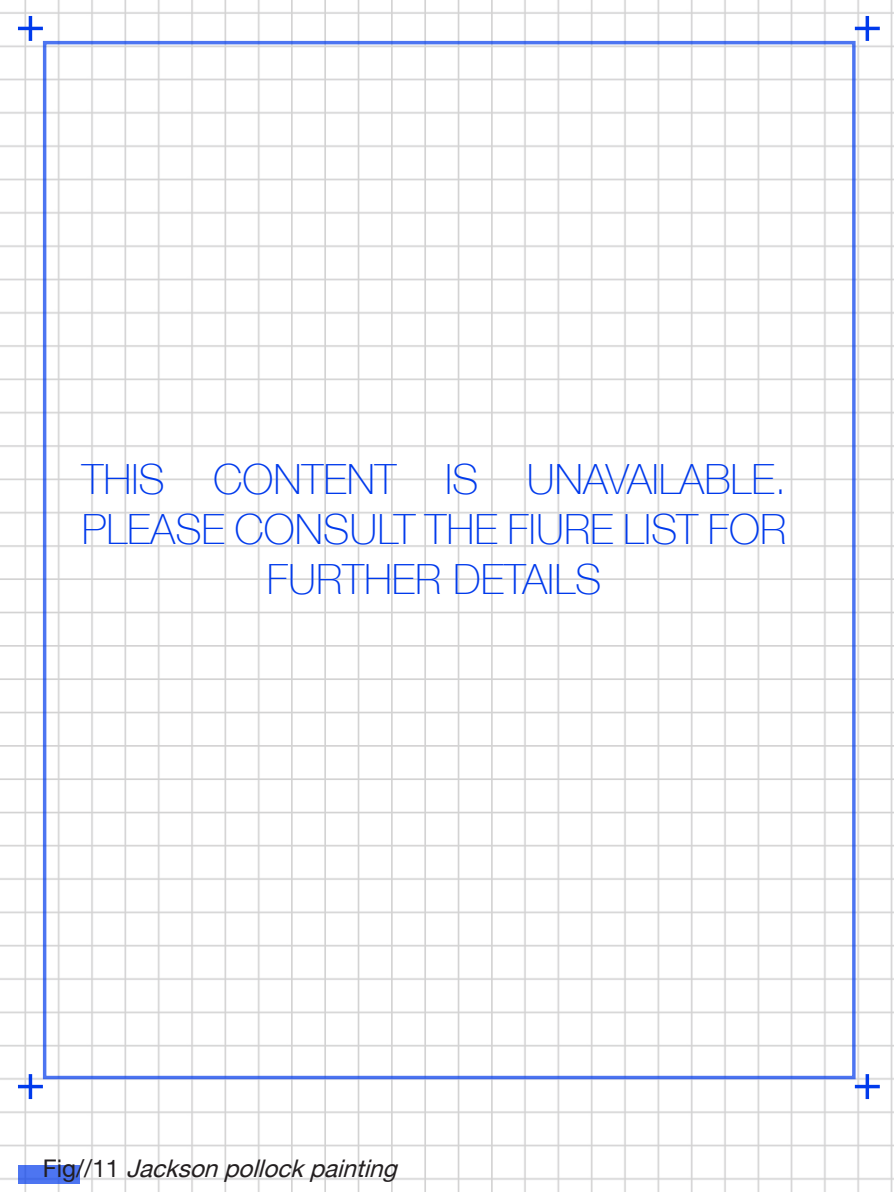




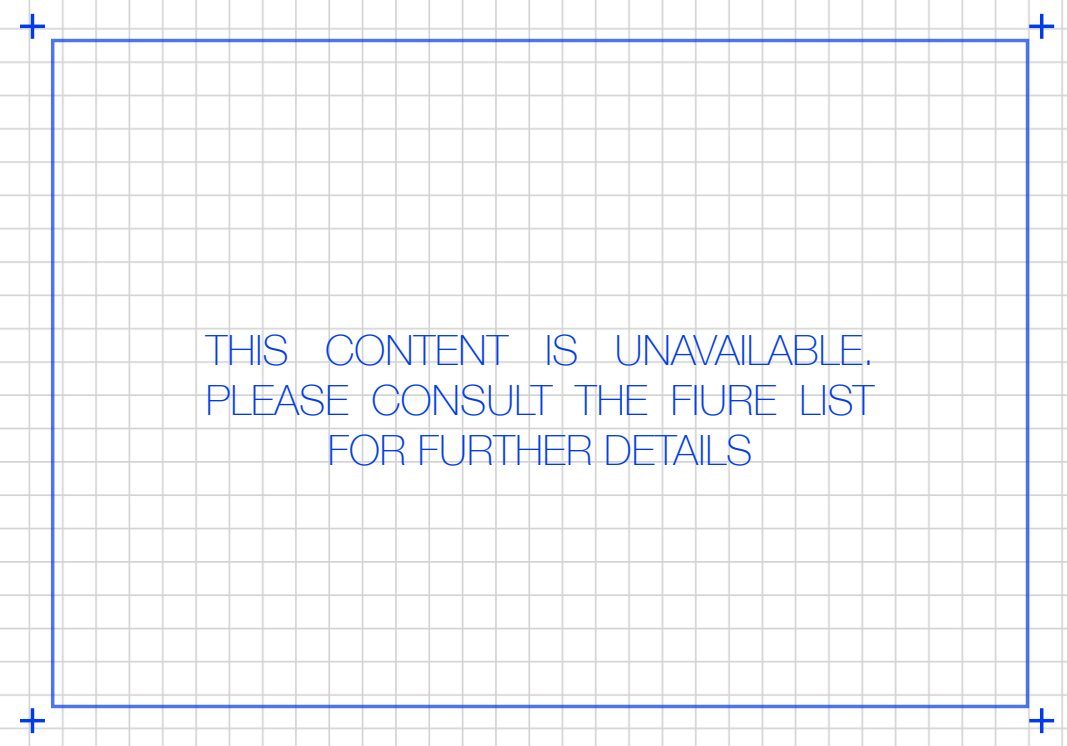

Fig//12 Ant Farm 'happening 


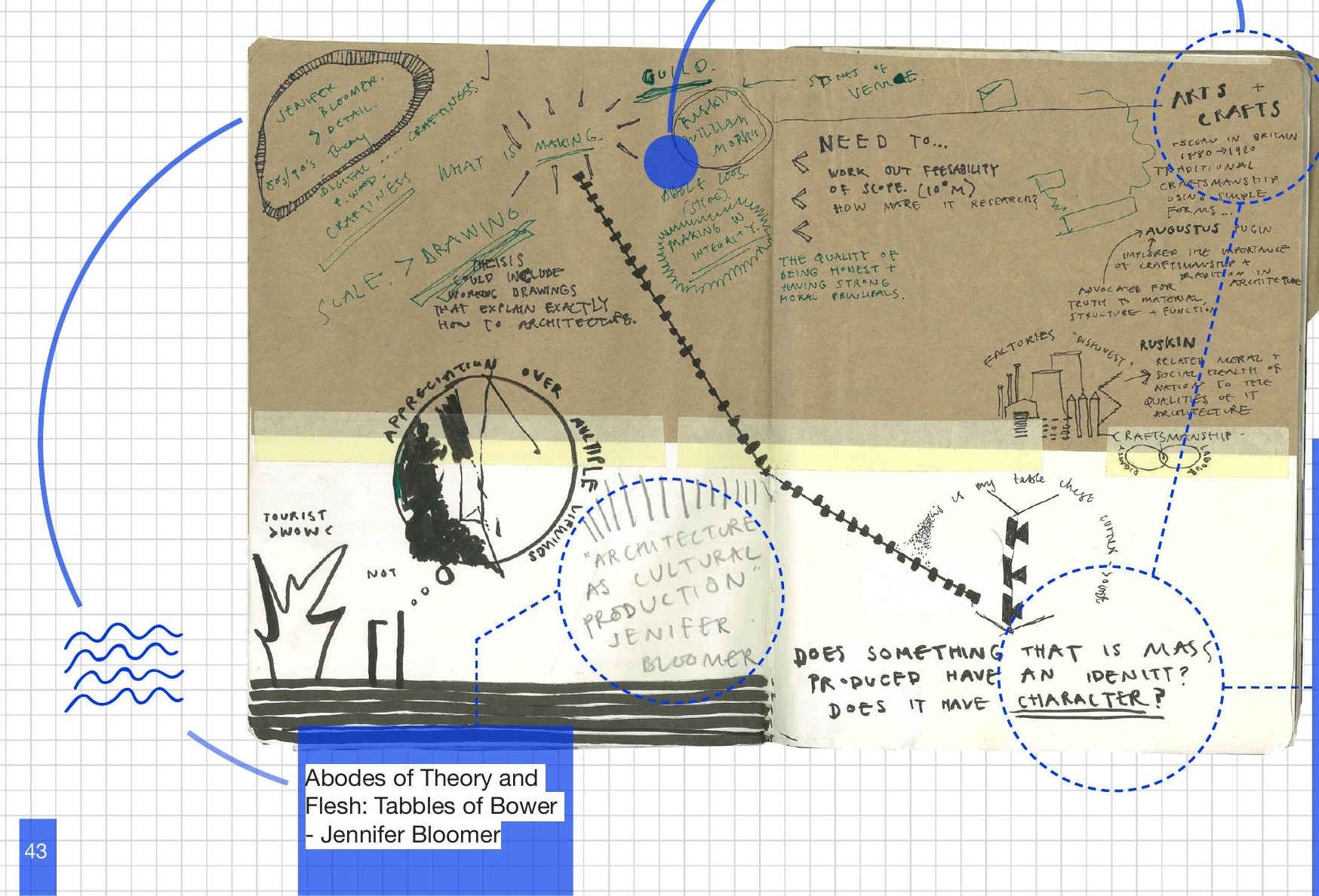

Arts and Crafts Movement sought to reintroduce manual labour within architecture, suggesting that factories of mass production were dishonest. To implement craftsmanship was to be honest and moral. 


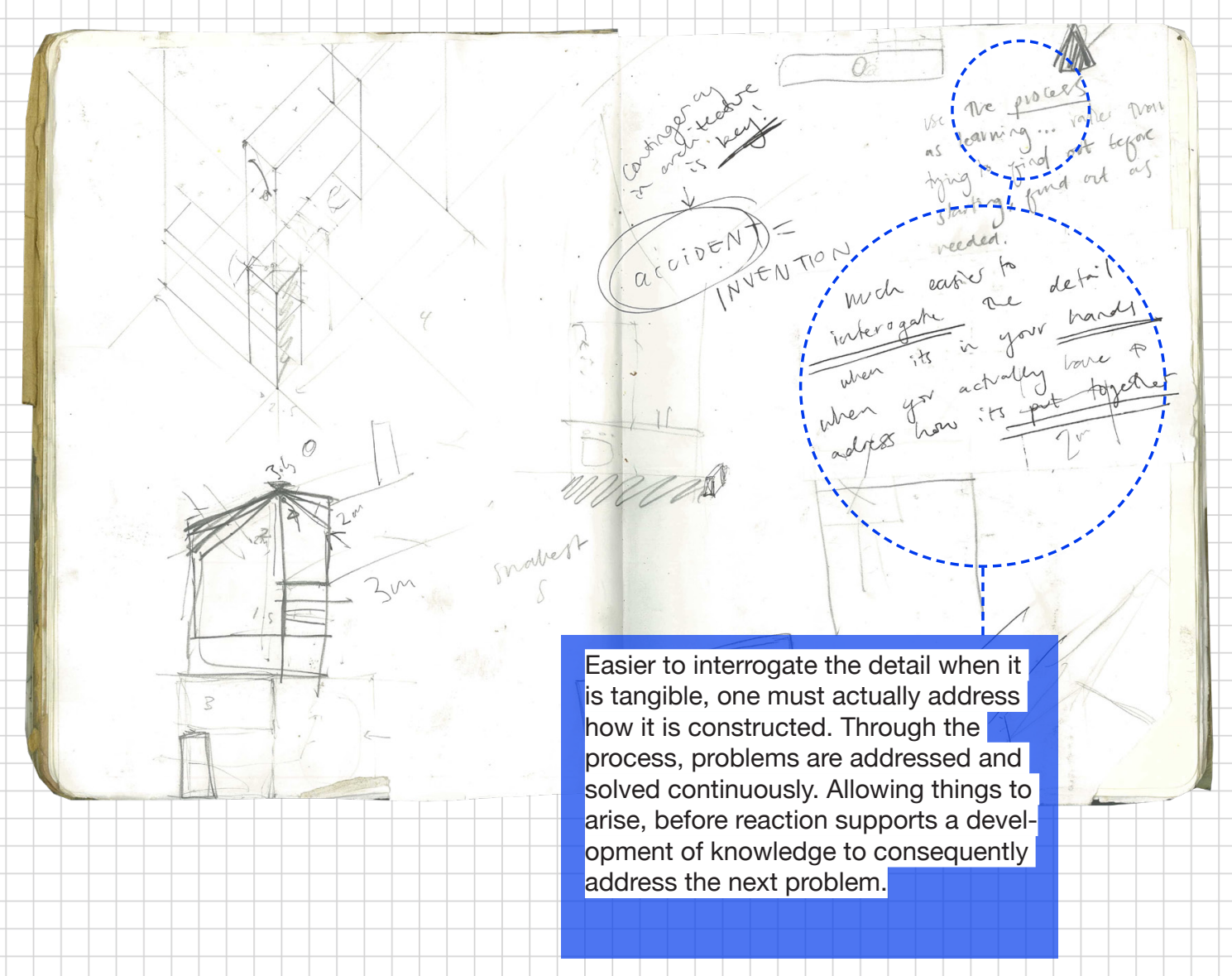




\section{THEHAND}

In suggesting that the traditional architectural process today is one of increasing specificity that leads to delayed feedback of architect and architecture, alternative methods which implement making challenge this perceived process. Through making, subconscious and conscious decisions are able to be made in real time, thereby embracing architectural contingency. Many of these alternative methods of architectural process were born out of a desire to experience and understand physically, the process of making architecture. For example, Wellington based firm 'Patchwork Architecture' essentially formed through an exploration of physically building. Founders Sally Ogle and Ben Mitchell-Anyon and their friends Tim Gittos and Caroline Robertson of 'Space Craft Architects' began with a simple ambition, "...to be practical" $" 60$. As a consequence, they decided to buy a piece of land in Whanganui and build something on it. The group bought four trusses and 45 pine poles and then set about designing how to make use of their purchases, ultimately allowing the material (along with site factors) to determine the design. Ogle writes, "The house is not attempting to 'speak' of anything -its not a symbol or metaphor for something else, and we haven't post-rationalised a conceptual starting point" 61 . Fundamentally the project was an exercise in experience, learning by doing, and an experience which has had a major impact on their retrospective careers and approach to architectural design ${ }^{62}$. Similarly, spaces such as Objectspace provide a platform to discuss alternative ways of making within the architectural context of New Zealand. In 2019, 'Making Ways: Alternative Architectural Practice in Aotearoa' asked how its possible to make architecture today? A reviewer wrote "...it left an impression of how much the work on show was eclipsed by ways of working"63, suggesting a tone of involved process; of architecture as a conversation rather than a statement.

Alternative forms of architectural education with the common focus of 'building' also implement making focused ideology, or rather learning by doing ${ }^{64}$, with some it being their primary focus ${ }^{65}$. One such program dubbed 'Ghost Lab' was the research laboratory of Mackay-Lyons Sweetapple Architects and began in reaction to North American architectural education ${ }^{66}$. The two-week summer design/build program consisting of a one-week design phase and one week build phase fundamentally aimed to provide construction experience. Perhaps the most concise treatise by its founder Brian Mackay-Lyons. In his introductory words of 'Ghost' he writes, "Pragmatism is the best teacher. Learning is accelerated by purpose. We learn best when we need to know. Technology is best understood by making. Teamwork is learned quickly when there is too much to do"67. This seemingly straightforward declaration provides an accurate description of the ideology of these design/build programs and perhaps the utopia of architectural practice. Perhaps the case here is not that architecture is stuck in a traditional, control focused modality but that the frequency of ability and space to challenge or test or explore alternative architectures is limited. 
THIS CONTENT IS UNAVAILABLE. PLEASE CONSULT THE FIURE LIST FOR FURTHER DEIAILS 
In her paper 'Building the Studio Environment', Louis Wallis conducted a comprehensive analysis of design/build studios around the world. She concluded the similarity between them was the importance placed on students experiencing the design and build process, in a hands-on way, as well as being involved in a real project ${ }^{68}$. She found learning by making provided students with a stronger link with material experimentation and construction, allowing them to develop a considered and understood architectural approach to program ${ }^{69}$. Rural Studio founder Sam Mockbee stated that "what's important is that the students understand the process... for young architects it takes it out of the theoretical and makes it real...students learn that drawing on paper and building models is not architecture"70. However, design and build schemes have been criticised because of their inability to be judged as architecture. In 2002 the Journal of Architectural Education said evidence of success was anecdotal, based on student learning and empowerment over 'architecture'

My research sits in the gap between the idea and the realized. The thought and the tactile. That is where true design comes from -the invention OR adaptation of an idea in the space between, rather than the beginning or end. 


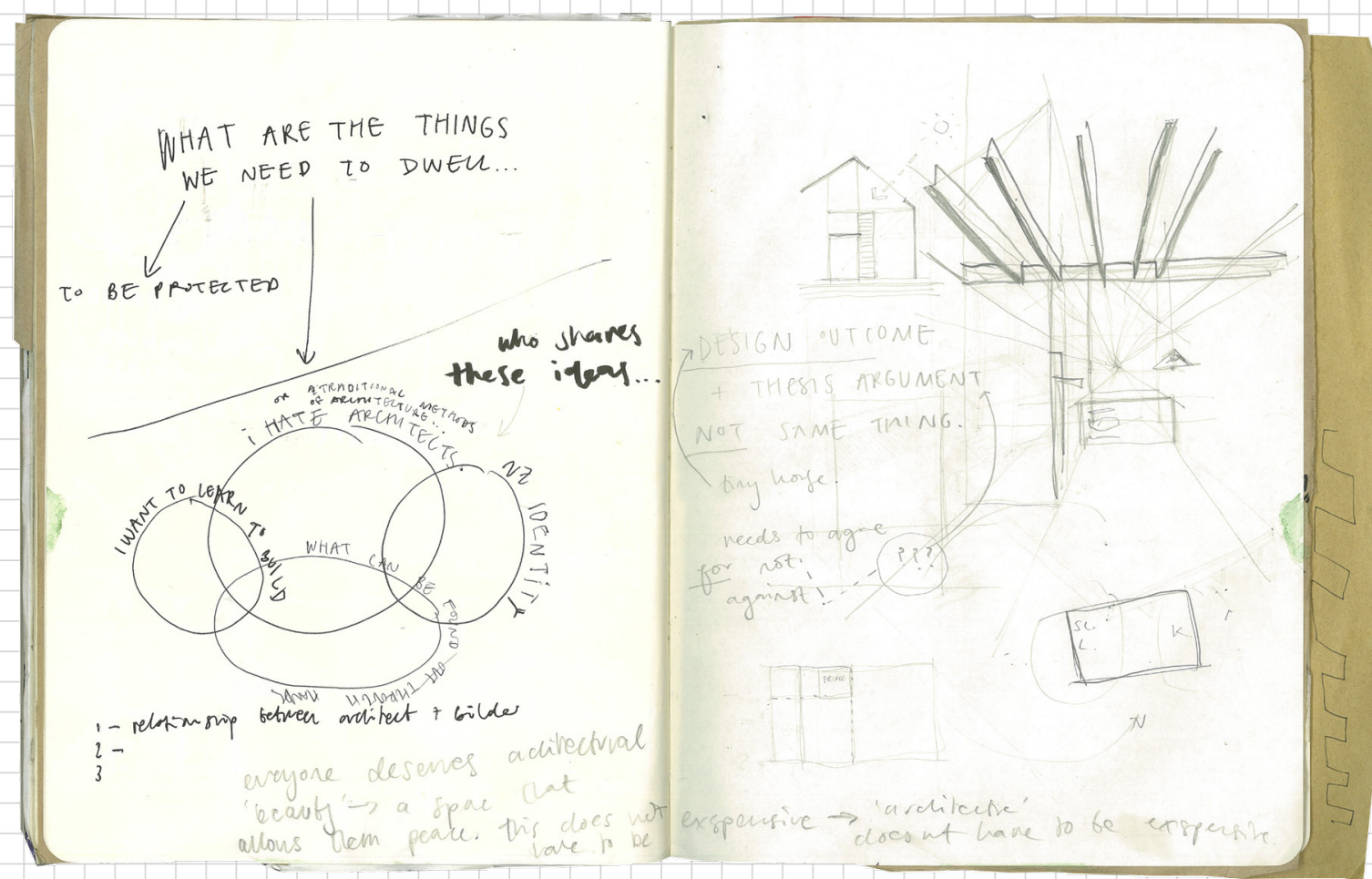


how to de monstrate

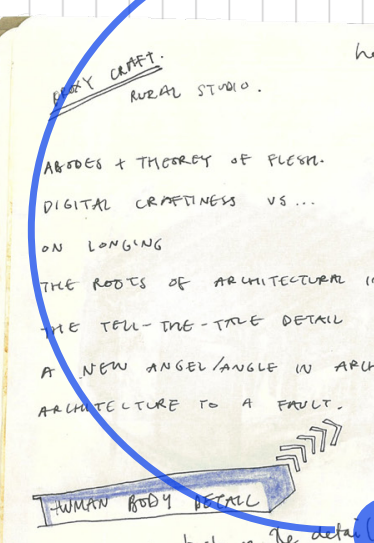

ungt, in ming

ŚMICROTELTURE.
is CRAFT HOUSE
is MUTZIC MADURN
VENACULAK MARMTEN

invintion Lamerián

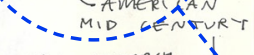

ctural rosemech

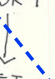

If i i maxe it

THeroutr This

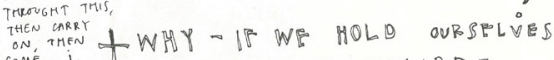

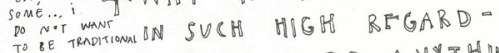

TO BE TRDDIIONA DO WE NOT DO ANYTHING?

arventicity of te dets
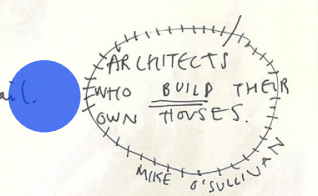

+ think about what i want to acheive

+ girish abodes

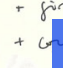

+ ma

Making allows for an almost immediate feedback loop not traditionally seen within architectural production. Decisions and reflections are able to be made in real time, allowing for the contingency of architecture to be embraced. Problem solving through the hands.

T( DWELL。

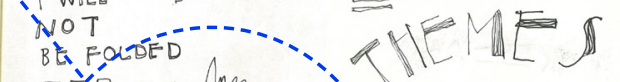

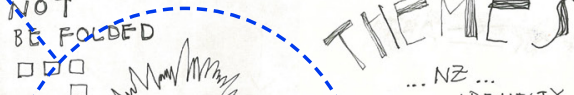

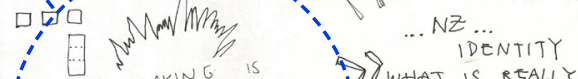

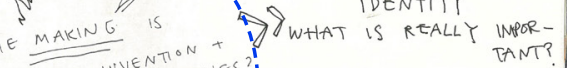
THE INUENTON UES?

iswitike 旁到 i

A BRÝPGE

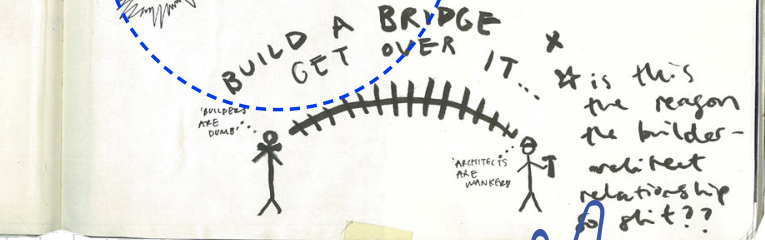




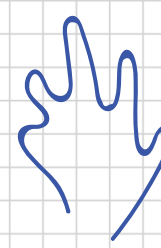

\section{MIKE O'SULLIVAN +PAOLO CARLESO}

THIS CONTENT IS UNAVAILABLE. PLEASE CONSULT THE FIURE LIST FOR FURTHER DETAlLS

Materially rich spaces softened through the consideration given. Craft and detail are interrogated through the relationship of maker and material.
Fig//14 Collection of scanned images in sketchbook
Details show sincerity of construction. Honest, simple materials are combined in a way which accepts their imperfections. 
SALLY OGLE +

TIM GITTOS +

BEN MITCHELL - ANYON

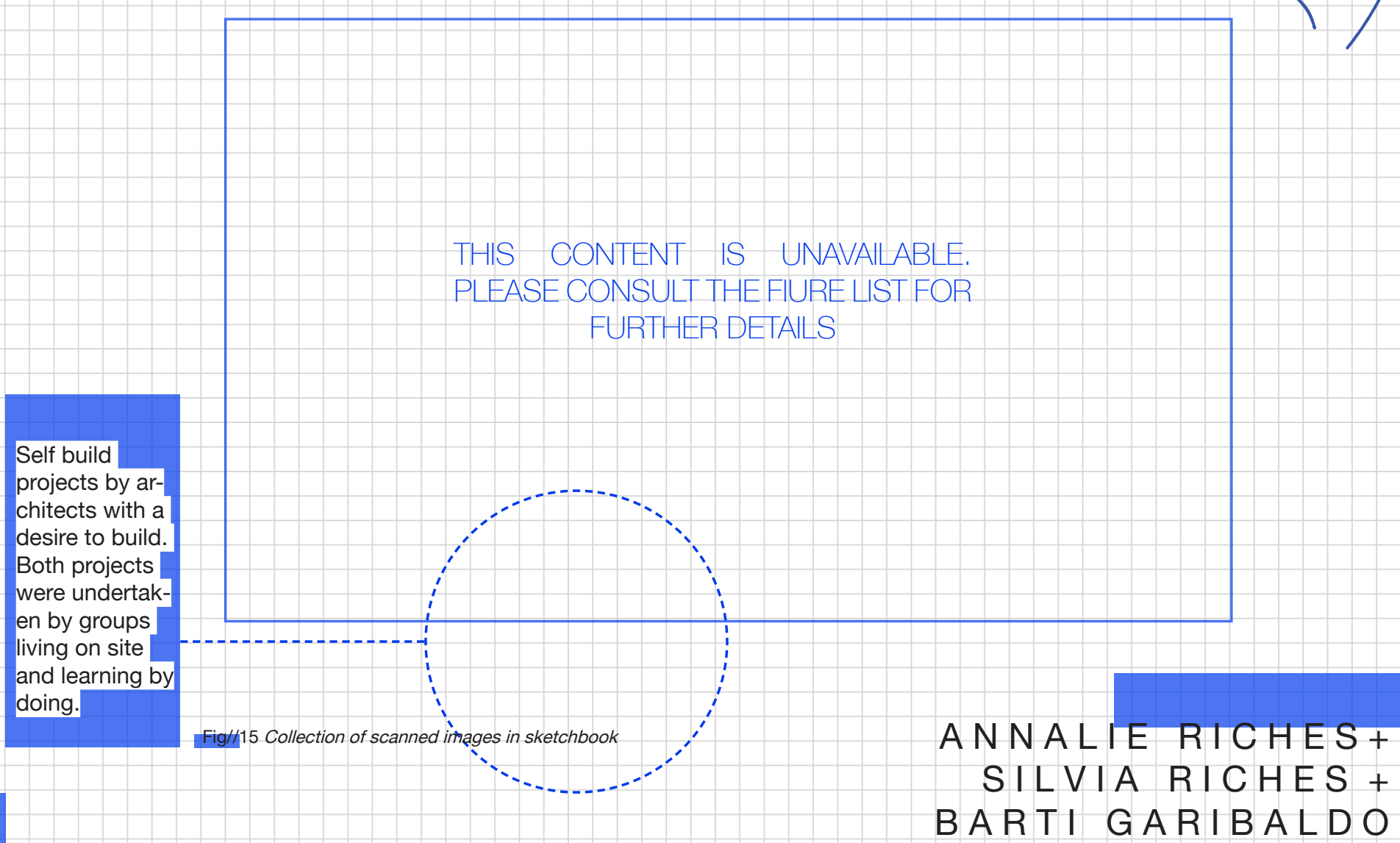



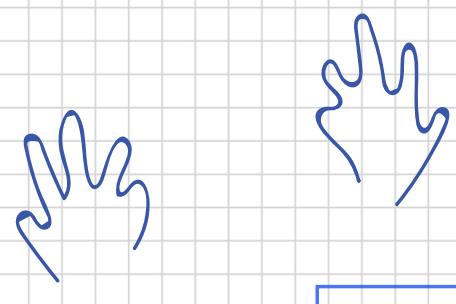

\title{
TONY WATKINS
}

\section{THIS CONTENT IS UNAVAILABLE. \\ PLEASE CONSULT THE FIURE LIST FOR \\ FURTHER DETAILS}

\begin{abstract}
Built completely himself, the space is materially rich, allowing the architecture to relate to the humah body. Boundaries are blurred as if the garden were an extension of the house enabling the user to continuously associate the surrounding outside.
\end{abstract}


THIS CONTENT IS UNAVAILABETE.-

PLEASE CONSULT THEFIURE ,'ŚT FOR FURTHER DETAILS

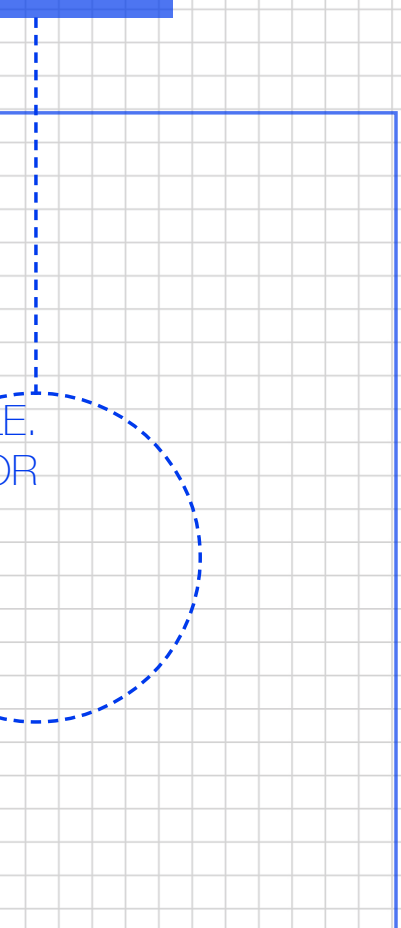



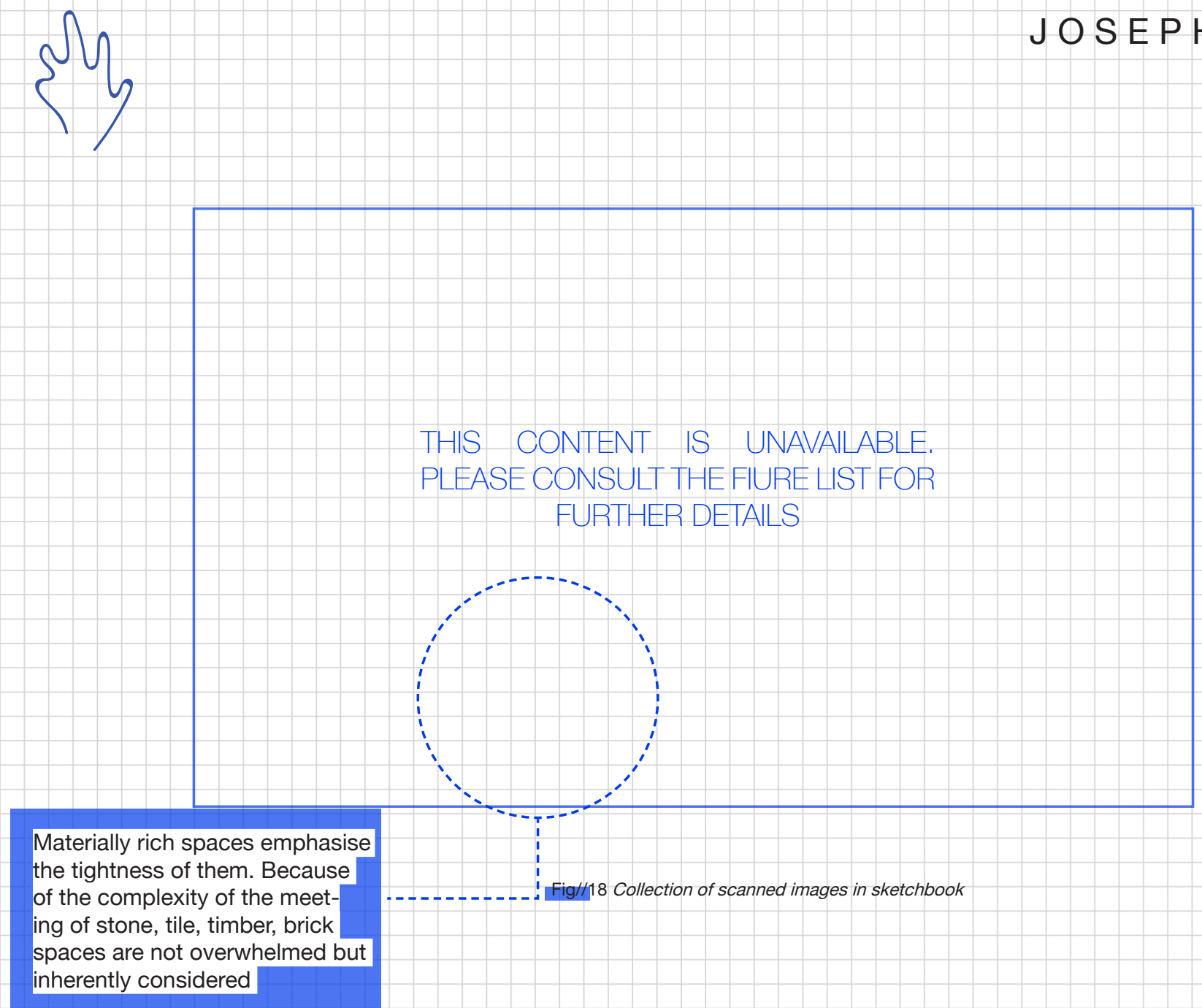


\section{AIMS:}

To aCQUIRE A PHYSICAL + EXPERIENCED

KNOWLEDGE OF BUILDING AND UNDERSTAND ITS INFLUENCE/IMPORTANCE WITMIN ARCHITELTUREL

PRACTICE.

METHODOLOGY:

THROUGA THE MEDIUM OF SMALL-SCALE ARCHITECTURE, I WILL PICK APART ARCHITECTURAL SPACES TO DESIGN SOMETHING WITH THE INTENTION OF BUILDING IT.

RESEARCH QUESTION:

WHAT CAN MY HIANDS ACHIEVE WHICH MY 


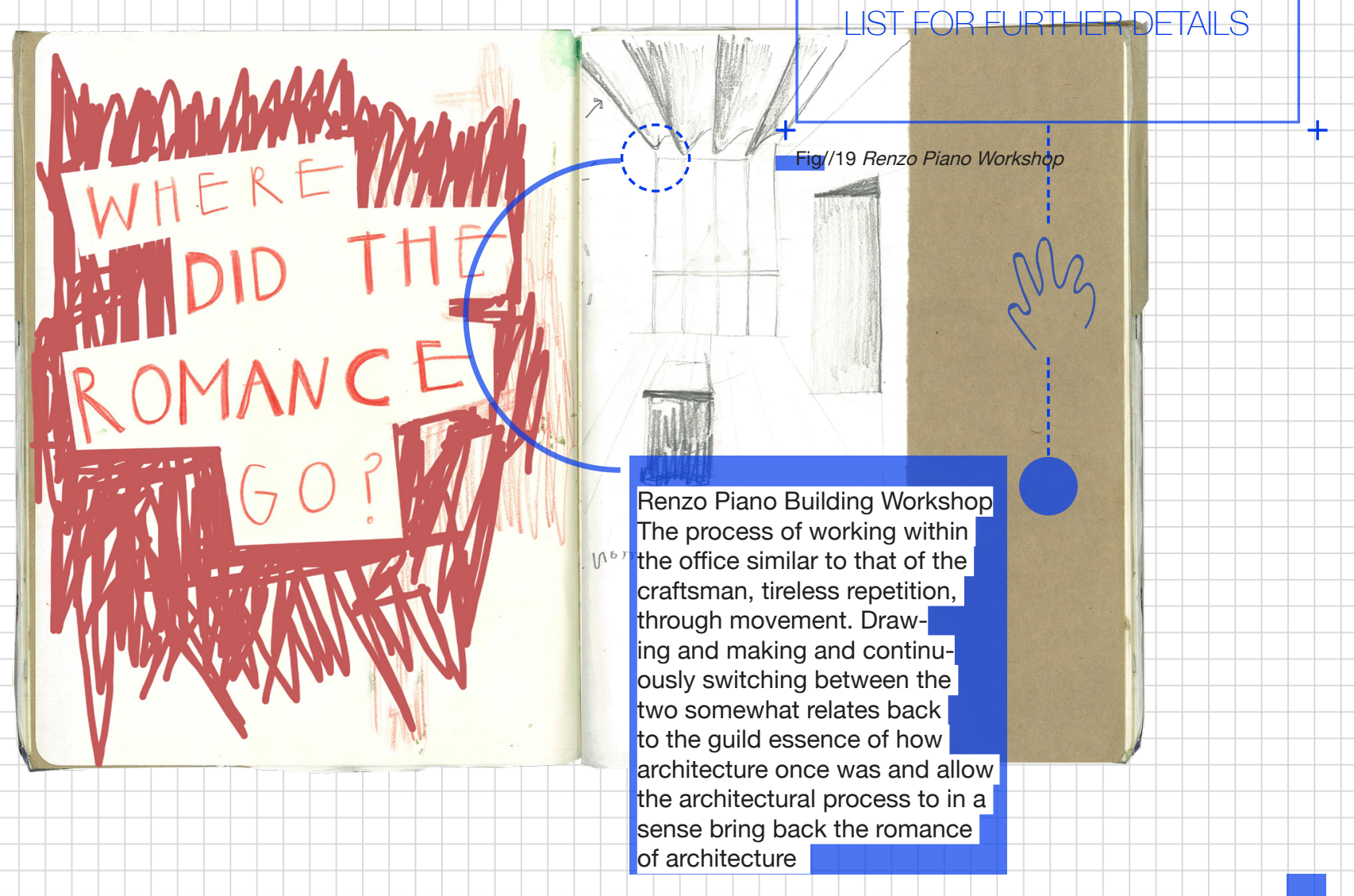




\section{GINNY PEDLOW + GARY HUNT}

M3

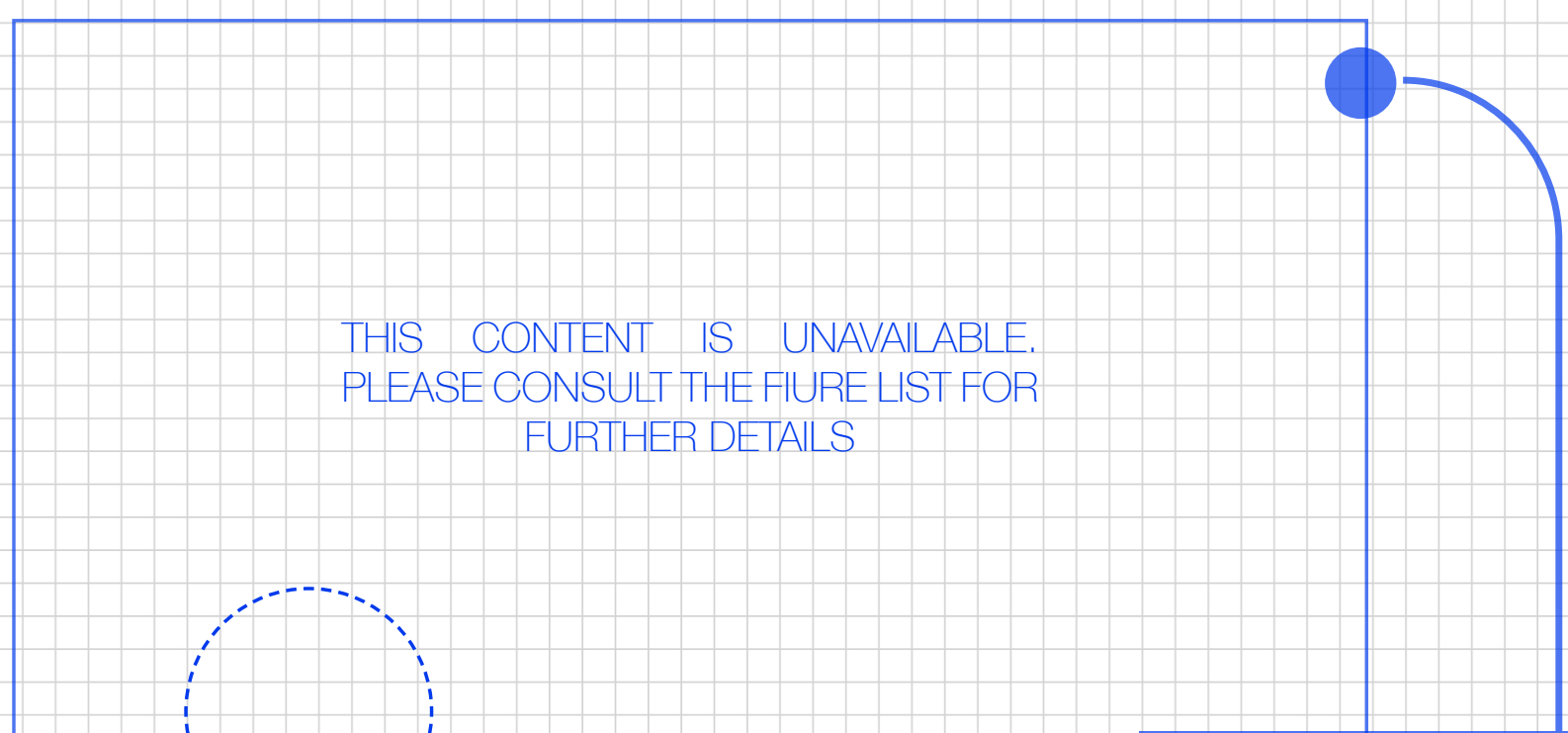

Design somewhat dictated by material objects. Makers sourced industrial window frames and consequently designed the house around them. This not only allowed for design decisions to be made, but also an opportunity to manipulate the treatment of the 


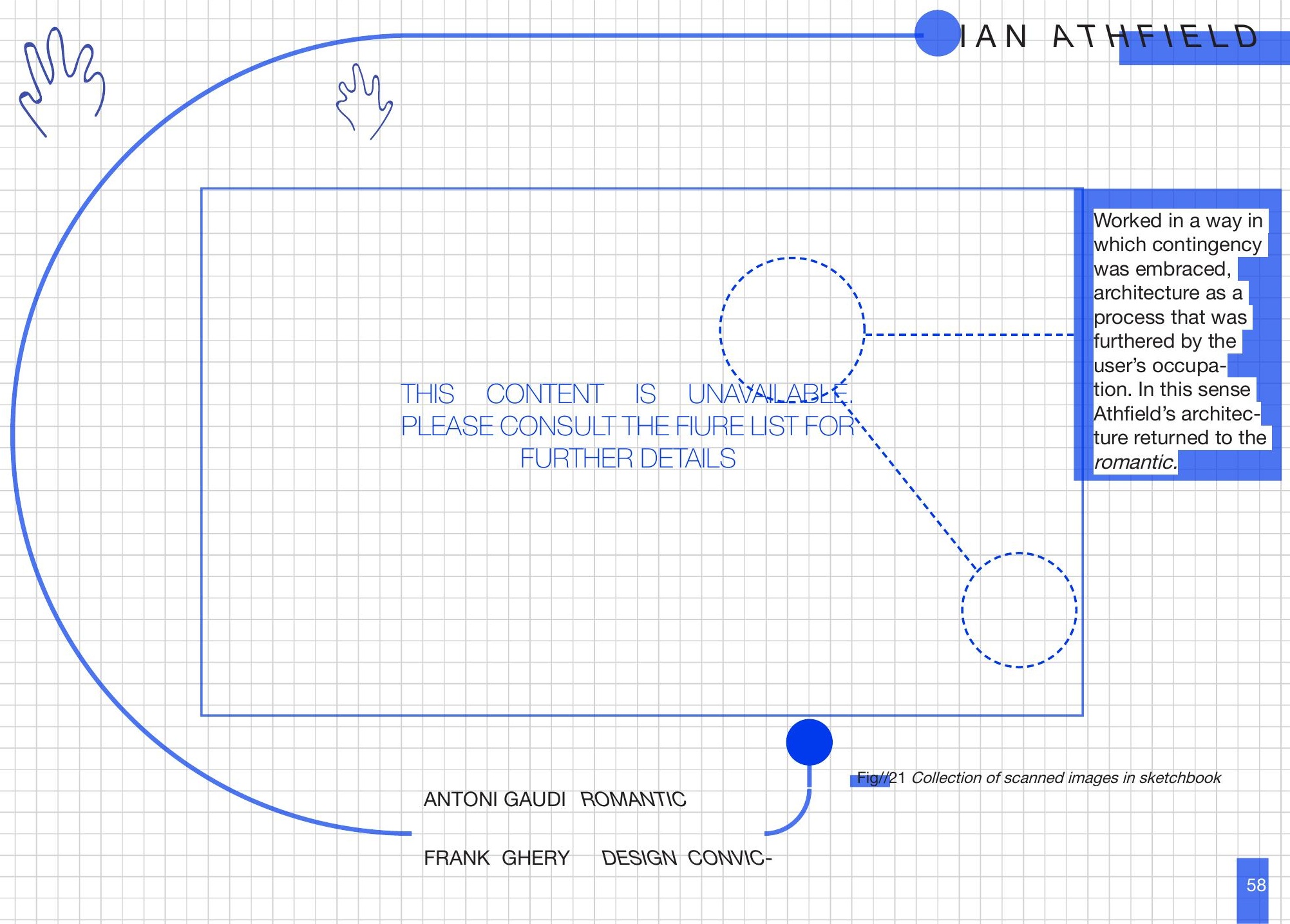




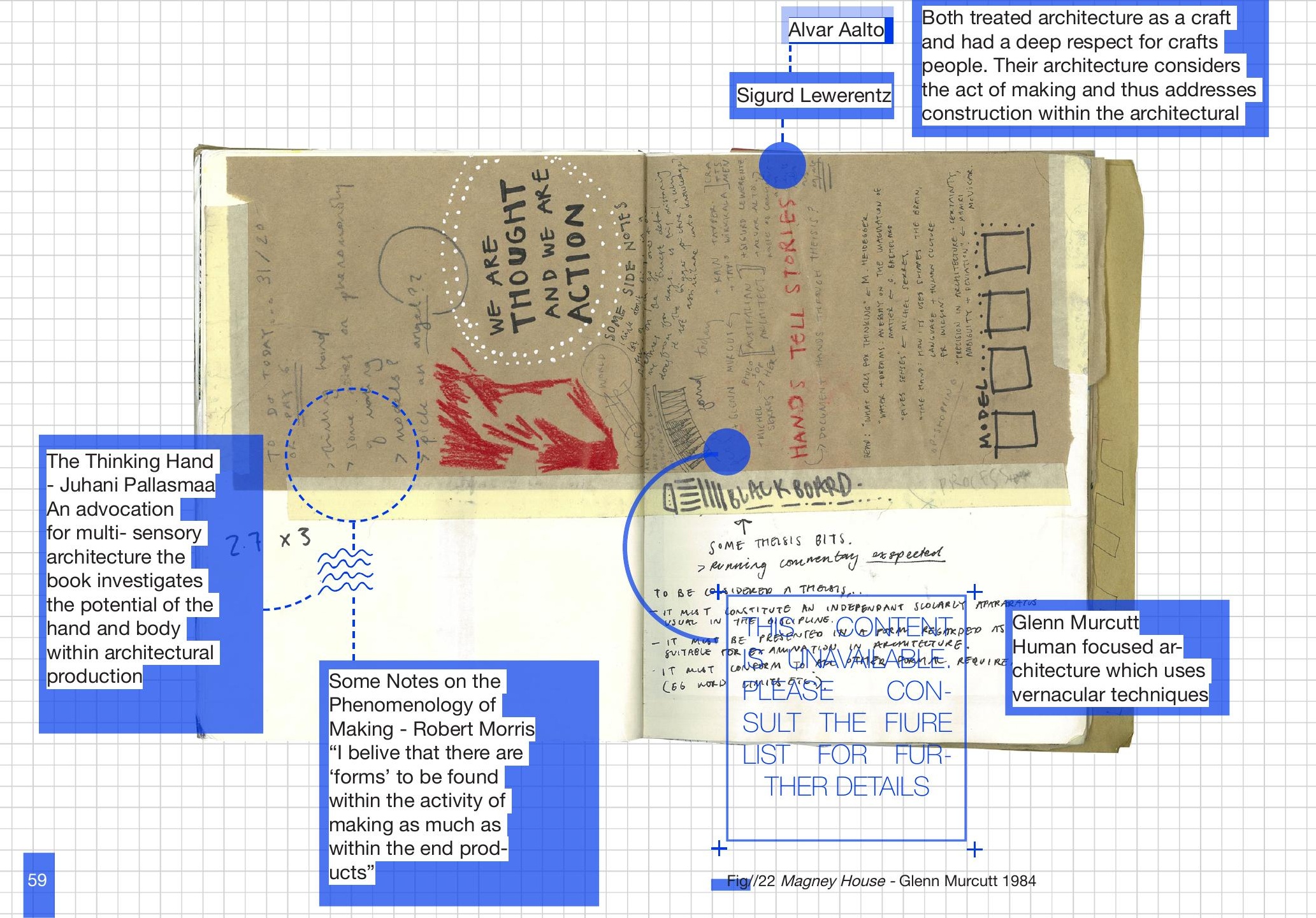


Studio 804

Part of the University of Kansas

Department of Architecture the nine

month course aims itself at those

who wish to be better architects by

gaining experience of completing the

whole process of construction.

\section{Ghost LAB}

Based on the apprentice model of professional education he two week course consists of one week design and one week build phases.

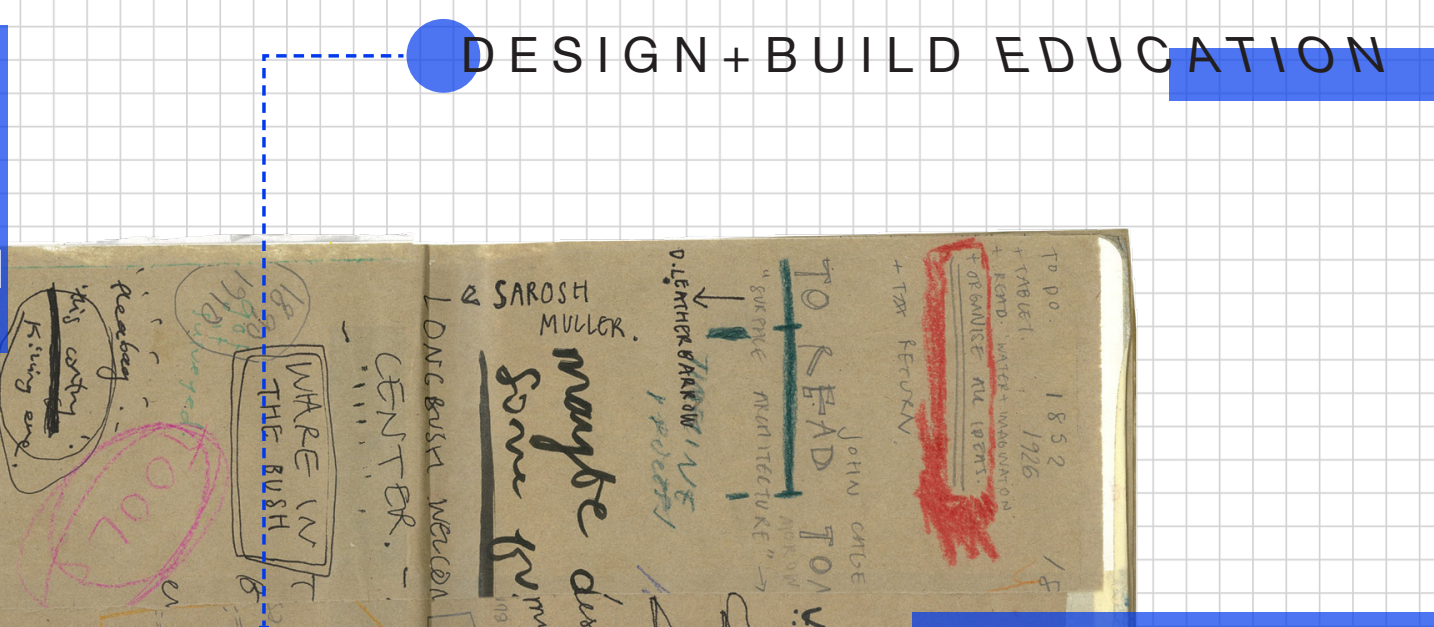

Rural Studio

Questioning what should be built rather than what can, the Designbuild program as part of Auburn University allows students to work within the community to gain hands-on educational experience.

BRIAN MACKAY-LYONS GHOST LAB

SAM MOCKBEE RURAL STUDIO

DAN ROCKHILL STUDIO 804 


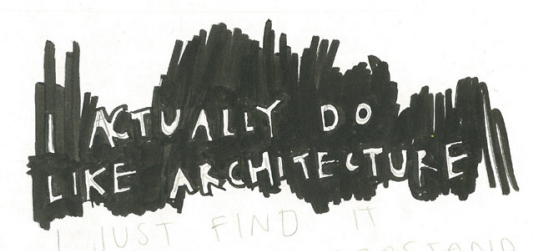

Object Space - Gallery Recognised a need for support within the field of craft applied art and design.

"At its heart Object Space has always been driven by the concerns of the discipline it serves". 
House on Sleds

- Crosson Architects

Moveable $40 \mathrm{~m}^{2}$ bach

designed to close up to the

elements when not in use.

Double height space in the

living area allows a greater

sense of space whereas and

defines kitchen from lounge.

Private spaces are then ac-

knowledged through vertical

and horizontal separation.

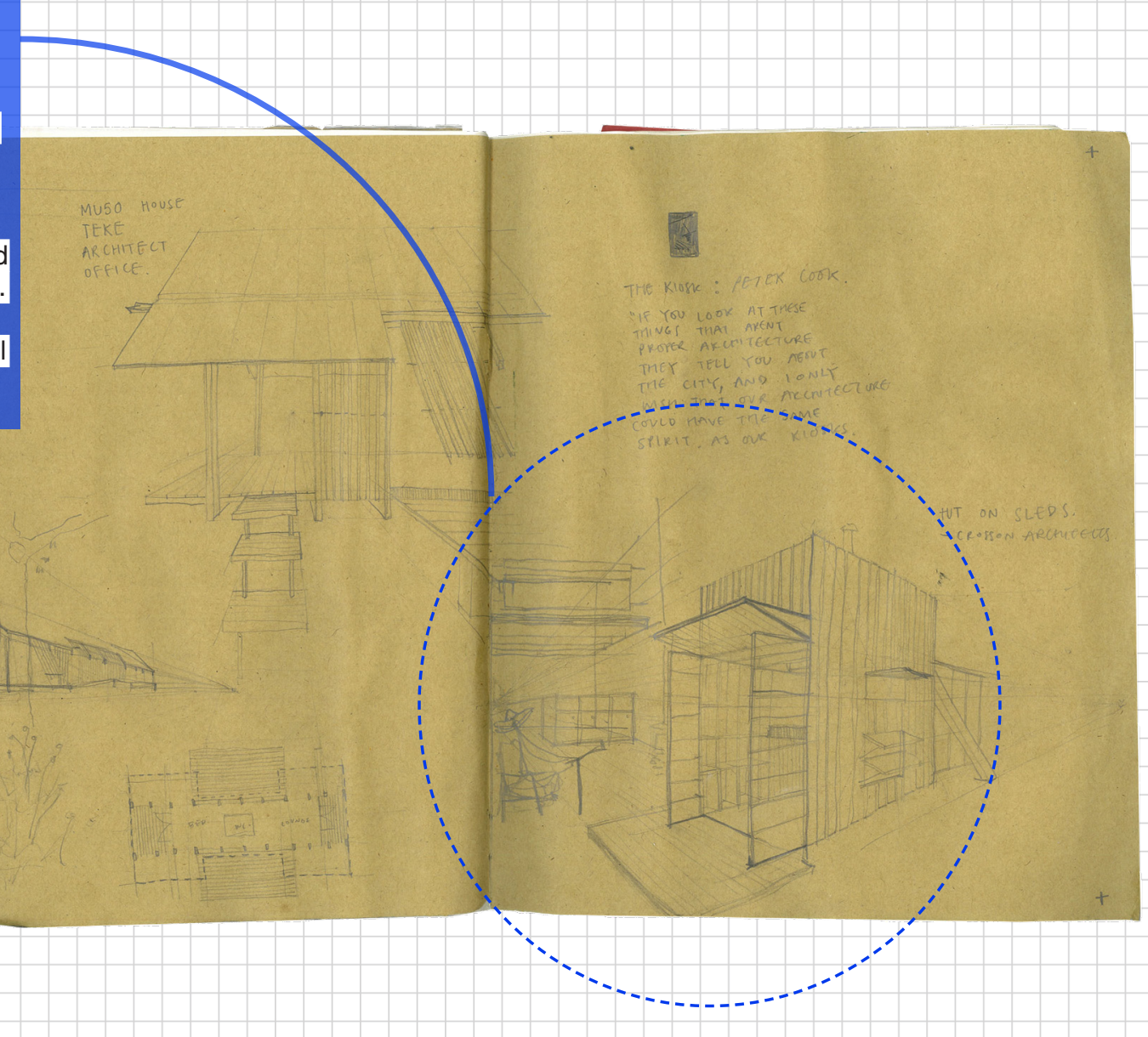


Process

Challenging the traditional process of architectural production enables an exploration of the gap between idea and result. Rather than potentially being a lengthy linear process, through quickening the feedback loop, architectural production becomes a cycle of invention, reflection, adaption, reinvention.

What though can my hands achieve that my brain cannot?
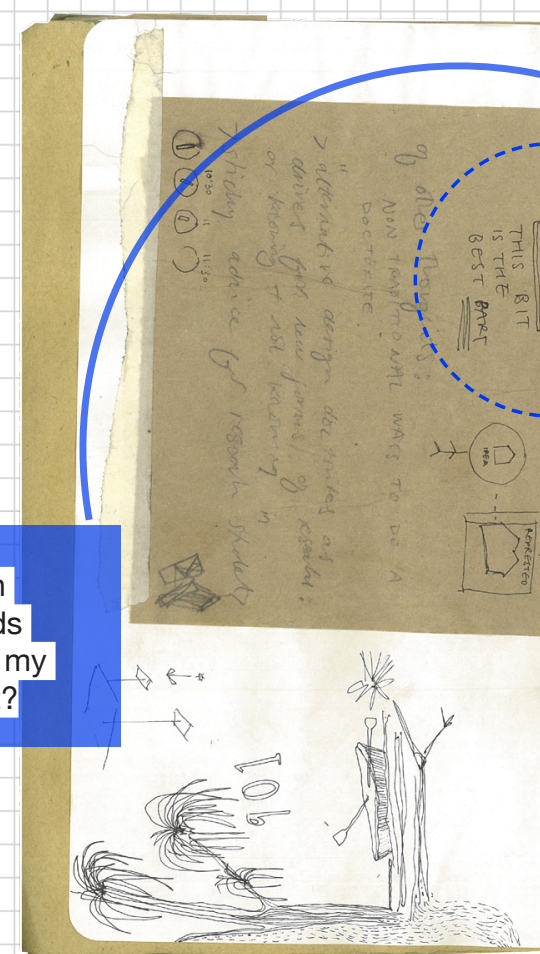


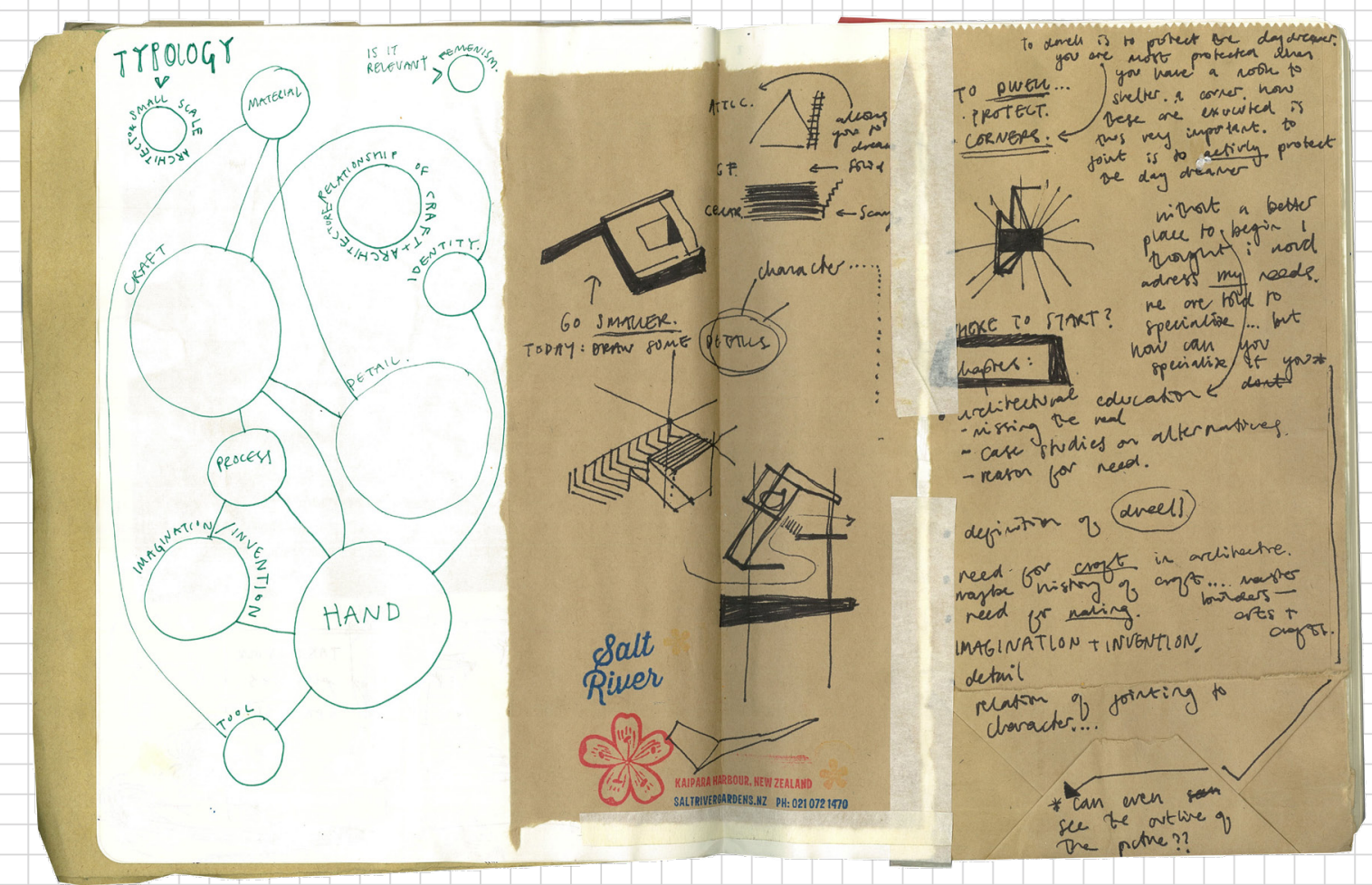




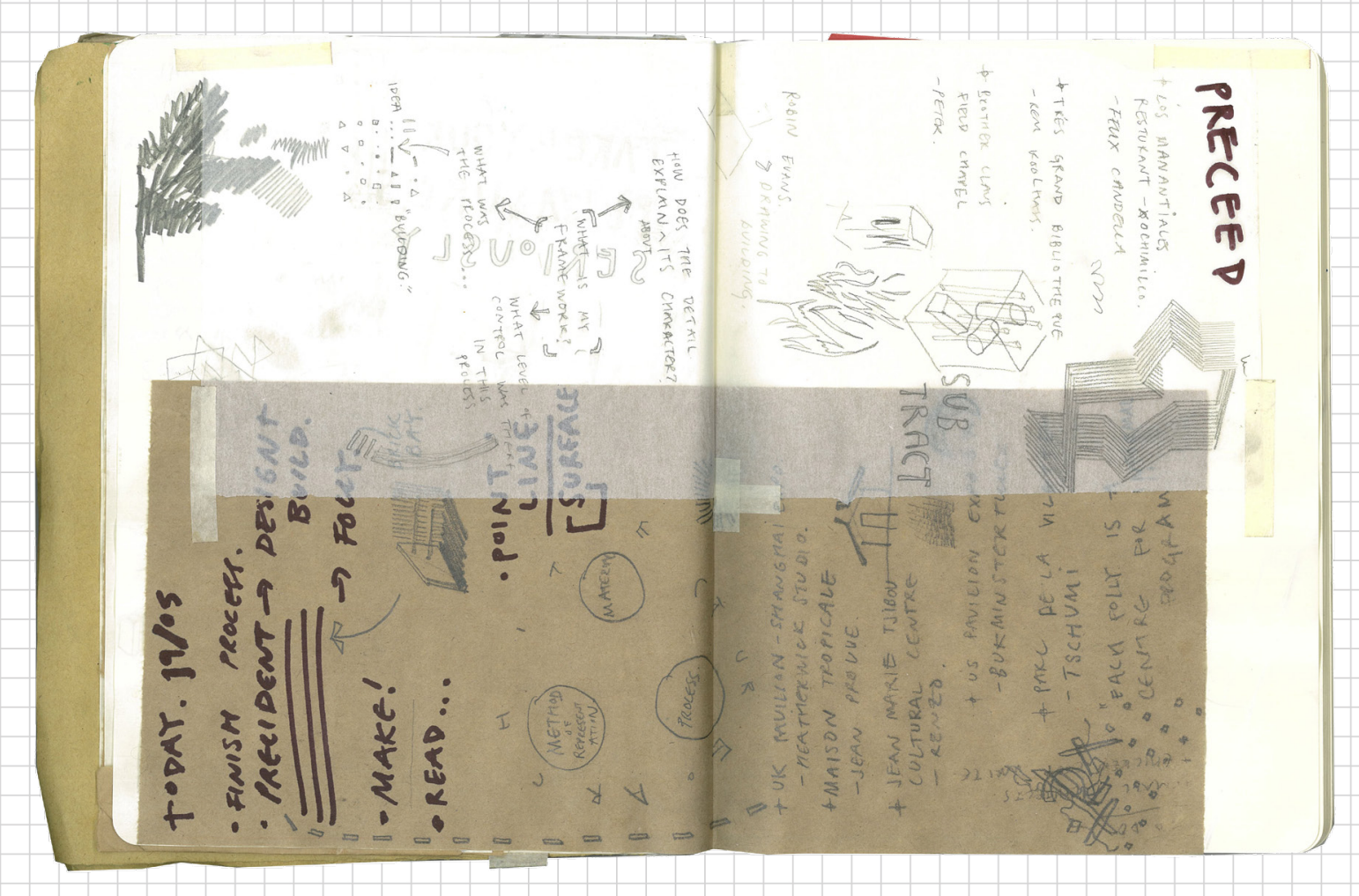


THIS CONTENT IS UNAVAILABLE. PLEASE CONSULT THE FURE LIST FOR FURTHER DETAILS

THIS CONTENT IS UNAVAILABLE. PLEASE CONSULT THE FIURE LIST FOR FURTHER DETAILS

THIS CONTENT IS UNAVAILABLE. PLEASE CONSULT THE FIURE LIST FOR FURTHER DETAILS 


\section{PART 1.0 ENDNOTES}

1 Rykwert, Joseph. On Adam's House in Paradise. New York, The Museum of Modern Art, 1972. p. 190

2 Rykwert, Joseph. On Adam's House in Paradise. New York, The Museum of Modern Art, 1972. p.192

3 Ogle, Sally. "Building the Dog Box". Patchwork Architecture. Patchwork Architecture. Par.5. www.patchworkarchitecture.co.nz/projects/dog-box Accessed: 03.05.2020

4 "Make." Dictionary.com. Houghton Mifflin Harcourt Publishing Company. 2002. www. dictionary.com/browse/make Accessed: 04.04.2020

5 Rossi, Aldo. A scientific Autobiography. Translated Lawrence Venuti, Cambridge Mass: MIT Press, 1981. P.55

6 Vesely, Dalibor. "Architecture and the Conflict of Representation." AA Files, no. 8, 1985, pp 21-38. JSTOR, www.jstor.org/stable/29543434. Accessed 1 May 2020.

7 Frascari, M. The Tell-The-Tale Detail. VIA7:The Building of Architecture, 1984

8 Pallasmaa, Juhani. The Thinking Hand: Existential and Embodied Wisdom in Architecture. United Kingdom, John Wiley \&Sons Ltd, 2009. p.65

9 Vesely, Dalibor. "Architecture and the Conflict of Representation." AA Files, no. 8, 1985, pp. 21-38. JSTOR, www.jstor.org/stable/29543434. Accessed 01.05.2020. p.22

10 Pallasmaa, Juhani. The Thinking Hand: Existential and Embodied Wisdom in Architecture. United Kingdom, John Wiley \&Sons Ltd, 2009

11 Bell, Charles. The Hand: Its Mechanism and Vital Endowments as Evincing Design.1833. Cambridge University Press, 2009

12 Pallasmaa, Juhani. The Thinking Hand: Existential and Embodied Wisdom in Architecture. United Kingdom, John Wiley \&Sons Ltd, 2009

13 Borden, Gail. Peter. Process: Material and Representation in Architecture. Routledge, 2014 ProQuest Ebook Central, https://doi.org/10.4324/9781315814827. p.21

14 Till, Jeremy. Architecture Depends. 2009. Cambridge, MIT Press, 2013. P.86

15 Bloomer, Jenifer. Abodes of Theory and Flesh. Assemblage, no.17, 1992, pp.7-29. JSTOR www.jstor.org/stable/3171221. Accessed: 03.20.2020

16 Pye, David. The Nature and Art of Workmanship. 1968. London, Herbert Press, 1995

17 Pallasmaa, Juhani. The Thinking Hand: Existential and Embodied Wisdom in Architecture. United Kingdom, John Wiley \&Sons Ltd, 2009

18 Sennett, Richard. The Craftsman. New Haven, Yale University Press, 2009

19 Pallasmaa, Juhani. The Thinking Hand: Existential and Embodied Wisdom in Architecture.
20 Both 'the craftsman' and 'the thinking hand' discuss at length

21 Pye, David. The Nature and Art of Workmanship. 1968. London, Herbert Press, 1995. P.17

22 Blundell Jones, Peter. "Sigurd Lewerentz: Church of St Peter Klippan, 1963-66", Arq: Architectura Research Quarterly, vol.6, no.2, 2002, pp. 159-173. ProQuest, https://search.proquest.com/scholarlyjournals/sigurd-lewerentz-church-st-peter-klippan-1963-66/docview/199346467/se-2?accountid=14782 . Accessed 05.09.2020

23 Pallasmaa, Juhani. The Thinking Hand: Existential and Embodied Wisdom in Architecture. Sussex (UK), John Wiley \&Sons Ltd, 2009

24 Sennett, Richard. The Craftsman. New Haven, Yale University Press, 2009. P.295

25 Biedermann, Hans. Dictionary of Symbolism. Facts on File, 1992.

26 Sennett, Richard. The Craftsman. New Haven, Yale University Press, 2009

27 Sennett, Richard. The Craftsman. New Haven, Yale University Press, 2009

28 Heidegger, Martin. 'What Calls for Thinking' in Basic Writings, New York, Harper and Row, 1977. P.357

29 Brothers, Cammy. Michelangelo, Drawing, and the Invention of Architecture. New Haven, Yale University Press, 2008

30 Collins, Peter, and Frampton, Kenneth. Changing Ideals in Modern Architecture 1750-1950. McGillQueen's University Press, 1998. ProQuest Ebook Central, https://ebookcentral-proquest-com.helicon. vuw.ac.nz/lib/vuw/detail.action?docID=3331090. Accessed: 05.07.2020. P.291

31 Ruskin, John. The Seven Lamps of Architecture. 1840. Electronic Book Company, 2000. ProQuest Ebook Central, www.ebookcentral-proquest-com.helicon.vuw.ac.nz/lib/vuw/detail. action?doclD=3008466. Accessed: 03.21.2020

32 Burr, Kevin L., et al. (2010) "The Role of the Architect: Changes of the Past, Practices of the Present, and Indications of the Future" International Journal of Construction Education and Research 6.2

2010, pp.122-138, Taylor \&Francis Online, DOI: 10.1080/15578771.2010.482878. Accessed: 03.12.2020

33 Wogenscky, André. Le Corbusier's Hands. 1987. Translated Martina Millà Bernad. London, MIT Press, 2006. P.7

34 Pauly, Danièle. Le Corbusier. The Chapel at Ronchamp. Walter de Gruyter GmbH

2008. ProQuest Ebook Central, www.ebookcentral-proquest-com.helicon.vuw.ac.nz/lib/vuw/detail. action?doclD=4338392. Accessed: 24.11 .2020

35 Pallasmaa, Juhani. The Thinking Hand: Existential and Embodied Wisdom in Architecture. Sussex (UK), John Wiley \&Sons Ltd, 2009 
36 Decker T, Roy. "Tactility and Imagination" (pp.203-219) in Philosophy and Architecture edited by Michael H. Mitias, Amsterdam, Rodopi, 1994. P.209

37 Fujimori, Terunobu. "Terunobu Fujimori Interview: A Feeling of Freedom." YouTube, uploaded Louisiana Channel, 01.12.2020. Accessed: 09.04.2020

38 Fujimori, Terunobu. "Terunobu Fujimori Interview: A Feeling of Freedom." YouTube, uploaded Louisiana Channel, 01.12.2020. Accessed: 09.04.2020

39 Fujimori, Terunobu. Fujimori Terunobu Architecture, TOTO Shuppan Japan 2007

40 Adamson, Glenn. Thinking Through Craft. London, Oxford International Publishers Ltd, 2007. P.59

41 Frascari, Marco. "The Tell-The-Tale Detail". VIA7:The Building of Architecture, 1984. P.24

42 Sennett, Richard. The Craftsman. New Haven, Yale University Press, 2009. P.137

43 Benjamin, Walter, and Hannah Arendt. Illuminations. New York: Schocken Books, 2007. P.18

44 Lerup, Lars. Building the Unfinished: Architecture and Human Action. Beverly Hills, Sage. 1997. P.21

45 Frascari, Marco. "The Tell-The-Tale Detail". VIA7: The Building of Architecture, 1984. P.26 46 Seven Lamps, ‘Truth' John Ruskin

47 Sennett, Richard. The Craftsman. New Haven, Yale University Press, 2009

48 Los, Sergio, and Klaus, Frahm. Carlo Scarpa. Benedikt Taschen. 1994

49 Ridgway, Sam. Architectural Projects of Marco Frascari: the Pleasure of a Demonstration Ashgate, 2015

50 Frascari, Marco. "The Tell-The-Tale Detail". VIA7: The Building of Architecture, 1984. P.30 51 Pye, David. The Nature and Art of Workmanship. 1968. London, Herbert Press, 1995 52 Sennett, Richard. The Craftsman. New Haven, Yale University Press, 2009. P.262 53 Till, Jeremy. Architecture Depends. 2009. Cambridge, MIT Press, 2013. P.19

54 Till, Jeremy. "Too Many Ideas". In Architectural Strategies and Design Method. News sheet 59 April 2001. 18th EAAE Conference Delft University of Technology, pp.20-24. http:/www. mom arq ufmg.br/mom/02_arq_interface/2a_aula/too_many_ideas.pdf Accessed: 09.10.2020. P.20

55 Grant, Kim. All About Process: The Theory of Modern Artistic Labour. Pennsylvania, Penn State University Press 2017. EBSCOhost, www.search.ebscohost.com/login.aspx?direct=true\&db=nlebk\& $\mathrm{AN}=1481812 \&$ site $=$ ehost-live Accessed: 25.11 .2020

56 Morris, Robert. "Sculptors on Sculpture: Some Notes on the Phenomenology of Making; the Search for the Motivated." Sculpture (Archive: 1987-2005), vol.13, no.2, 1994, pp. 22-29. ProQuest, https://search-proquest-com.helicon.vuw.ac.nz/docview/1431342520?accountid=14782.p29
57 Silverberg, Mark. "Working in the Gap Between Art and Life: Frank O'Hara's Process Poems" (pp. 37-47) in Neo-Avant-Garde, edited Hopkins, David, and Schaffner, Anna Katharina, Brill, 2006. ProQuest Ebook Central, https://ebookcentral-proquest-com.helicon. vuw.ac.nz/lib/vuw/detail.action?doclD=556888. Accessed: 30.10.2020. P.37

58 Lewallen, Constance M., et al. Ant Farm, 1968-1978 . University of California Press, 2004. 59 Lewallen, Constance M., et al. Ant Farm, 1968-1978 . University of California Press, 2004.

60 Ogle, Sally. "Building the Dog Box". Patchwork Architecture. Patchwork Architecture. www.patchworkarchitecture.co.nz/projects/dog-box Accessed: 03.05.2020. Par.6

61 Ogle, Sally. "Building the Dog Box". Patchwork Architecture. Patchwork Architecture. www.patchworkarchitecture.co.nz/projects/dog-box Accessed: 03.05.2020. Par.13

62 Ogle, Sally. Pers com

63 Flanagan, Sean. "Review: Making Ways." Architecture Now, 27 Jan, 2020 https:// architecturenow.co.nz/articles/review-making-ways/. Accessed: 13.04.2020

64 Rural Studio, Studio 804, DesignBuildBLUFF, design/buildLAB, Yale Building Project

65 Canizaro, Vincent B. "Design-build in architectural education: motivations, practices, challenges, successes and failures." ArchNet-IJAR: International Journal of Architectural Research, vol.6, iss.3, 2012, 20-36. ProQuest, https://search.proquest.com/scholarlyjournals/design-build-architectural-education-motivations/docview/1312295456/se2?accountid=14782 Accessed: 09.12.2020

66 MacKay-Lyons, Brian, and Peter Buchanan. Ghost : Building and Architectural Vision, Princeton Architectural Press, 2008. ProQuest Ebook Central, https://ebookcentralproquest-com.helicon.vuw.ac.nz/lib/vuw/detail.action?doclD=3387456 .P.10

67 MacKay-Lyons, Brian, and Peter Buchanan. Ghost : Building and Architectural Vision, Princeton Architectural Press, 2008. ProQuest Ebook Central, https://ebookcentralproquest-com.helicon.vuw.ac.nz/lib/vuw/detail.action?doclD=3387456 .P.5

68 Wallis, Louise. "Building the Studio Environment." (pp.201-218). In Design Studio Pedagogy: Horizons for the Future, ed. Ashraf M Salama and N. Wilkinson, Gateshead, UK Urban International Press

69 Wallis, Louise. "Building the Studio Environment." (pp.201-218). In Design Studio Pedagogy: Horizons for the Future, ed. Ashraf M Salama and N. Wilkinson, Gateshead, UK, Urban International Press

70 Mockbee, Sam. "Auburn University." (pp.) In Learning by Building: Design and Construction in Architectural Education ed. Carpenter, William J., and Hoffman, Dan. New York, Van Nostrand Reinhold, 1997

71 Erdman, Jori, et al. "Designing/Building/Learning." Journal of Architectural Education, vol. 55, no. 3, 2002, pp. 174-179. JSTOR, www.jstor.org/stable/1425537 Accessed 02.05.2020 


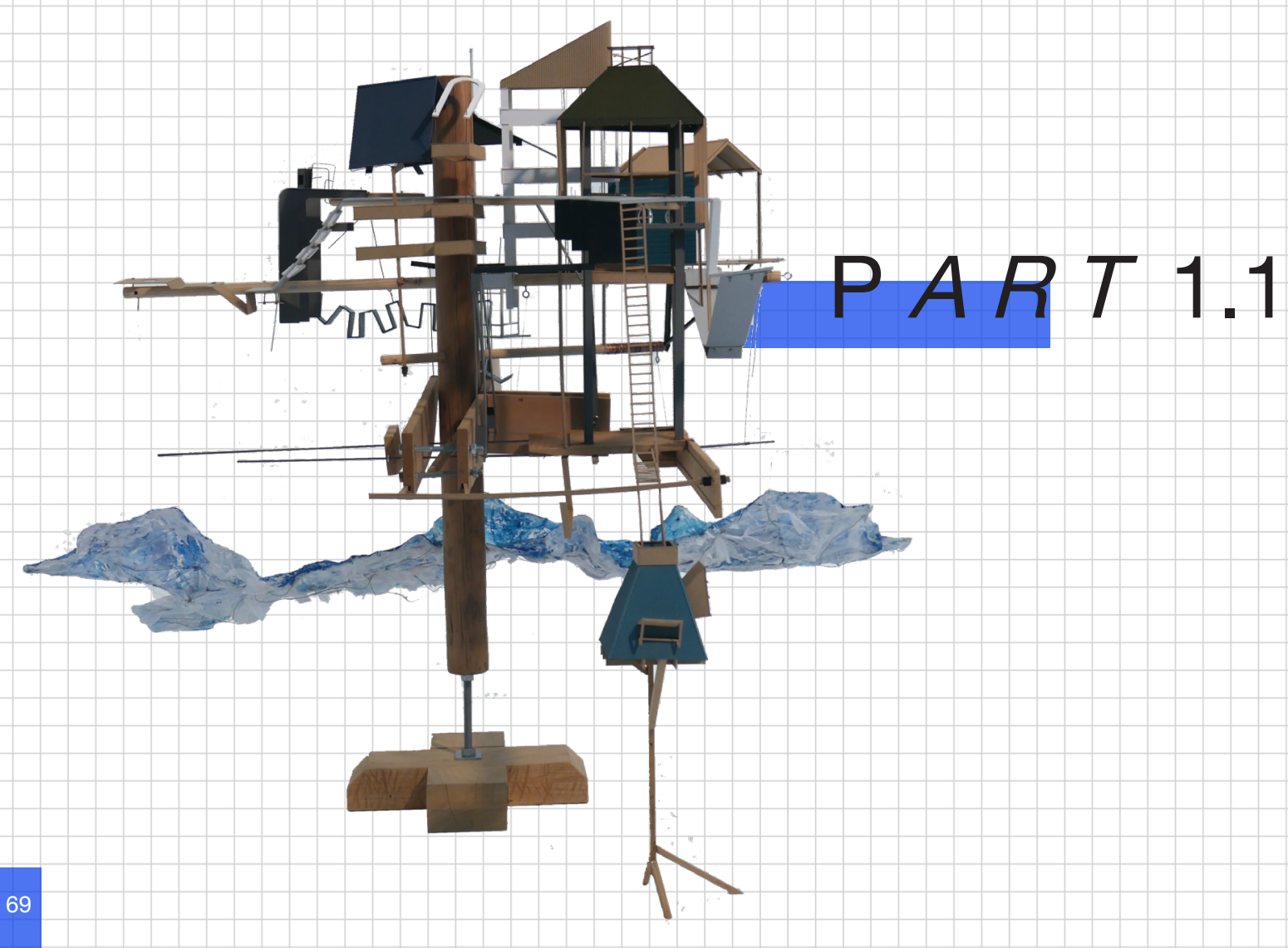



$+$

THIS CONTENT IS UNAVAILABLE. PLEASE CONSULT THE FIURE LIST FOR FURTHER DETAILS
THIS CONTENT IS UNAVAILABLE. PLEASE CONSULT THE FIURE LIST FOR FURTHER DETAILS

Fig/t27 The Plug-in City: Maximum Pressure Area - Peter Cook 1964 
The folly. The pavilion. The kiosk. The installation. The sculpture. All of these topologies of architecture have an innate cultural value, grappling with the concept of identity, technology, making and arguably most importantly, architectural experimentation.

Peter Cook suggested that, "....if you look at these things that aren't proper architecture they tell you about the city, and I only wish that our architecture could have the same spirit..."72. Small-scale architecture allows a quality relatively unseen within mainstream architectural discourse today, experimentation ${ }^{73}$. Due to a multitude of factors such as economic investment, political power and regulatory restrictions, traditional architectural objects must be defined and wholly specified. Often described as 'micro-architecture', small scale building is an avenue which deviates, or rather, reorientates itself from this restriction. Albeit varied from country to country, micro-architecture provides loopholes within the fabric that restrains architectural creativity. Thus, consequently creating space for experimentation. This includes elements of architecture such as material, detail, construction, regulation, timeframe and budget.

'Microarchitecture' is a somewhat ambiguous yet seemingly definitive term we use for some pieces of architecture. Works are described as 'microarchitecture', yet when asked what 'microarchitecture' is, it is almost impossible to receive a straight answer. Ruth Slavid suggests microarchitecture defines "...the construction of really tiny spaces, of buildings that are more like artefacts" ${ }^{\prime 4}$. Fuliginous in her wording, this description continues the notion that perhaps it is easier to explain what microarchitecture is not, than what it is. Within this also, Slavid alludes to the association the term micro-architecture has with the miniature and the act of miniaturization as imagery. The word 'artefact' denotes the object, and this object is often how 'micro-architecture' is depicted ${ }^{75}$. However, within this research the term 'microarchitecture' is implemented as an umbrella, with which to encompass architecture towards the smaller scale. From borderline product design spaces such as, Heatherwick Studios 'Paperhouse', to installation spaces such as, the Overtreders W 'The Roof That Goes Up in Smoke', micro-architecture denotes experimentation within architecture. 
THIS CONTENT IS UNAVAILABLE. PLEASE CONSULT THE FIURE LIST FOR FURTHER DETALS 
THIS CONTENT IS UNAVAILABLE. PLEASE CONSULT THE FIURE LIST FOR FURTHER

DETAILS

$+$

Fig//29 The Roof That Goes Up in Smoke -Overtreders W 2010 


\section{TINY}

Within the umbrella of micro-architecture, (along with many other topologies of architecture), sits the 'tiny house'. Many other topologies of architecture may have sufficed as appropriate avenues with which to conduct this research, but it has been determined that, in a New Zealand context, the 'tiny house' allows a degree of exploration relative to the scope of research. Its practicality also allows for a real client and budget to be established. The topology of the 'tiny house' provides the freedom of imagination, which Japanese architect Terunobu Fujimori likens to his work with tea houses as the 'basic unit for architecture'76. He explains that, for him, the most exciting thing about architecture is being able to build things with his own hands ${ }^{77}$. A language in which to express, without predisposition, what architecture through making can achieve. Similar to Fujimori's approach to architecture, through the lens of the 'tiny house' (small dwelling, micro-architecture) this research aims to both conceptually and practically question the idea of making, craft, and culture, and perhaps even provide an architectural 'spirit'.

Again, somewhat ambiguous, the term 'tiny house' can be interpreted in many ways and has somewhat recently been projected by social media, television shows and the like into the public domain, consequently widening its architectural field of vision. To attempt to address and thus provide a stance toward the 'tiny house' as both an idea and an architecture, this early section of research aims to investigate the term, the imagery, and the architecture before constructing a stance and consequential means.

Oxford defines 'tiny' as, 'very small'78. It is thought to have originated in the 16th century as an extension of the now obsolete 'tyne' which meant 'small, diminutive'. Its origins materialize from a word alluding to the unusual, the abnormal, the distinct. Yet there are two predominant and distinct aspects of the word 'tiny' as used today, one being the 'insignificant', the 'miniscule', the other being, the 'pocket-sized' or the 'cute'. The notion of the word 'tiny' insinuates something novel. Perhaps not your everyday. 


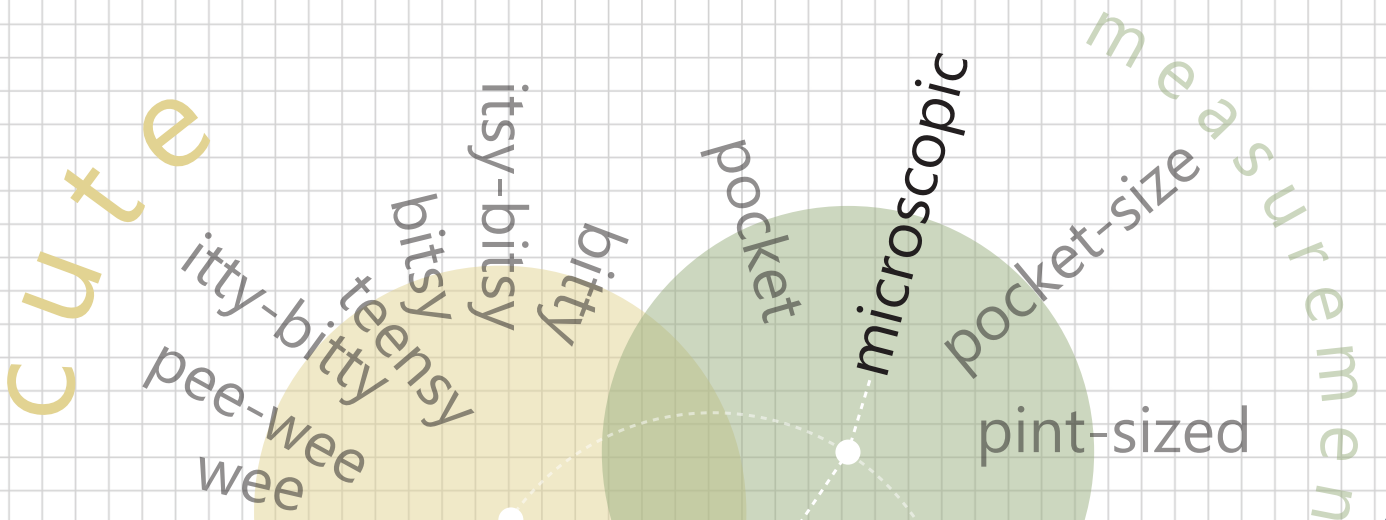

$$
\begin{aligned}
& \text { teensy-weensy } \\
& \text { dim }
\end{aligned}
$$

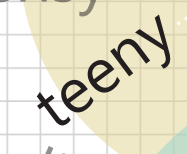


The word 'tiny' has had little investigation. In theoretical terms it is appropriate to investigate its synonym, the 'miniature'. Susan Steward analyses the idea of the miniature through lenses such as scale, nostalgia and value, recognising the miniature allows a certain freedom that 'real world' does not. She suggests "the miniature offers a world clearly limited in space but frozen and thereby both particularised and generalised in time - particularised in that the miniature concentrates upon the single instance and not upon the abstract rule, but generalized in that that instance comes to transcend, to stand for, the spectrum of other instances" ${ }^{\prime 79}$. In a similar way, a word can be confusing by itself in terms of the reader needed to decipher letters and meaning. However, if that word is then put in the context of a sentence, the meaning can jump out and instantly become clear and memorable.

This somewhat contradiction yet reliance seen within the relationship between the particular and the general, assists with the notion of juxtaposition the miniature faces. At one side the miniature is the object, inward facing and frozen, yet at the other, because of its particularisation, it is the avenue with which to explore. Oliver Herwig said "size loses itself when miniaturised" ${ }^{80}$, clarifying this idea that it is not so much the object, but the act of miniaturisation which challenges scale.

When relating this to architecture, although comparatively miniature, we are faced with a conflicting outside presence from the object; the user. In this sense the microarchitecture, the 'miniaturisation of architecture' must both adhere to its role as a miniature, while also maintaining some degree of function, form and structure ${ }^{81}$. This is an intelligence Fujimori carries throughout his work, but that is particularly evident and acute within his tea houses. Fujimori utilises the concept of miniaturisation (most occupying less than three square meters) as a form of condensation rather than small. For example, in his project Takasugi-an, which translates to 'a tea house built too high', rather than simply implementing large and frequent windows to allow the space to feel larger, he created an exaggerated, asymmetrical roof form which enabled golden light to filter through the space. This not only challenged the miniature internally but externally. The combination of small openings, assertive roof form, not to mention its separation from the ground plane, allow the tea house to become its own entity, accordingly, completely detached from the concept of traditional house and arguably somewhat abstract to micro-architecture. 


\section{MINIATURE}

Bachelard definitively stated that "the cleverer I am at miniaturizing the world the better I possess it" 22 . The act of making as discussed earlier also shares the quality of involvement that Bachelard is leaning toward here. Being able to consider something wholly allows one to further understand it wholly. Like Fujimori's tea houses this supports the notion of condensing and enrichment within the act of miniaturisation and in fact allows that miniaturisation is perhaps the stimulus needed to carry out these processes. Simply, it speaks to the idea that being able to consider something in its entirety, because of its reduction or simplification, allows a heightened understanding of its value. Practically Stewart allows that "minute description reduces the object to its signifying properties, and this reduction of physical dimensions results in a multiplication of ideological properties"83. He is suggesting that through the reduction of signification in a physical sense, the strength of ideological ability is multiplied. Therefore, it could be said that both the act of and resulting miniaturisation challenges traditional architecture. The act of, pertains to the aspect of detachment, which consequently allows architecture a freedom that is usually not available. It is within this gap that perhaps there is space for architectural imagination. Convention and tradition may be disregarded as the maker must think beyond the custom of architecture. Actual miniaturisation allows, at both a practical and ideological level, a pressurisation that in disregarding the unnecessary, allows the user/observer a greater understanding of the whole. 


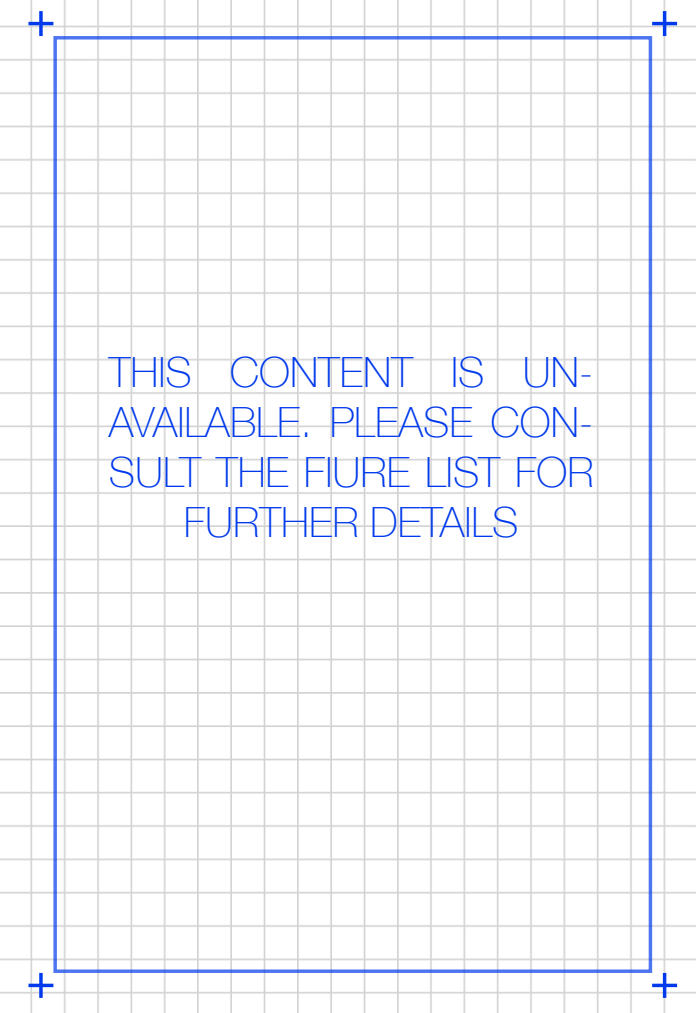

Fig//30 Takasugi-an - Terunobu Fujimori 2004 


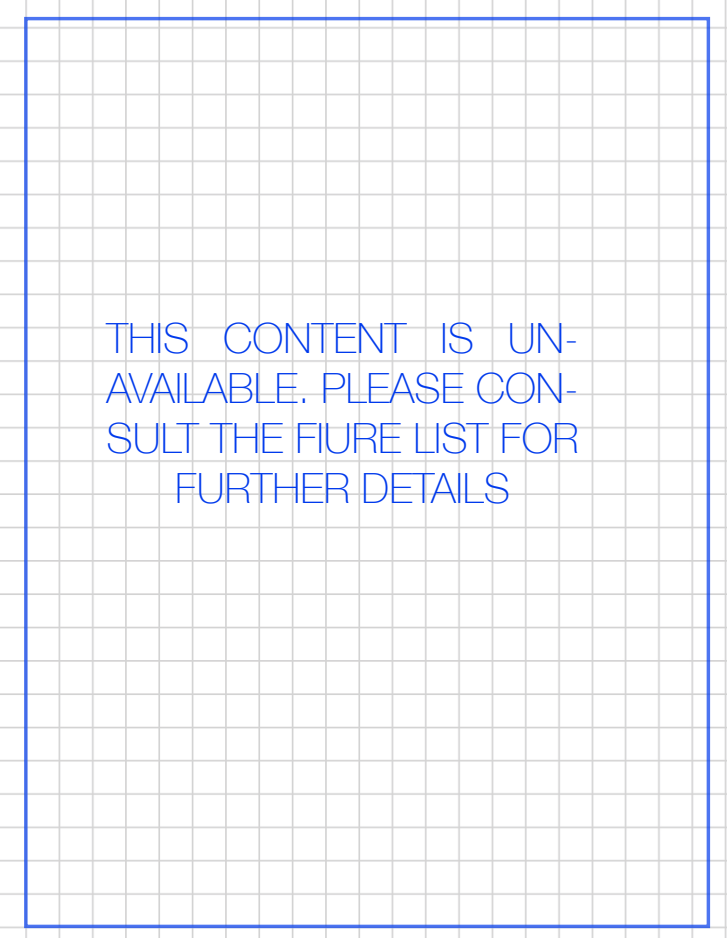




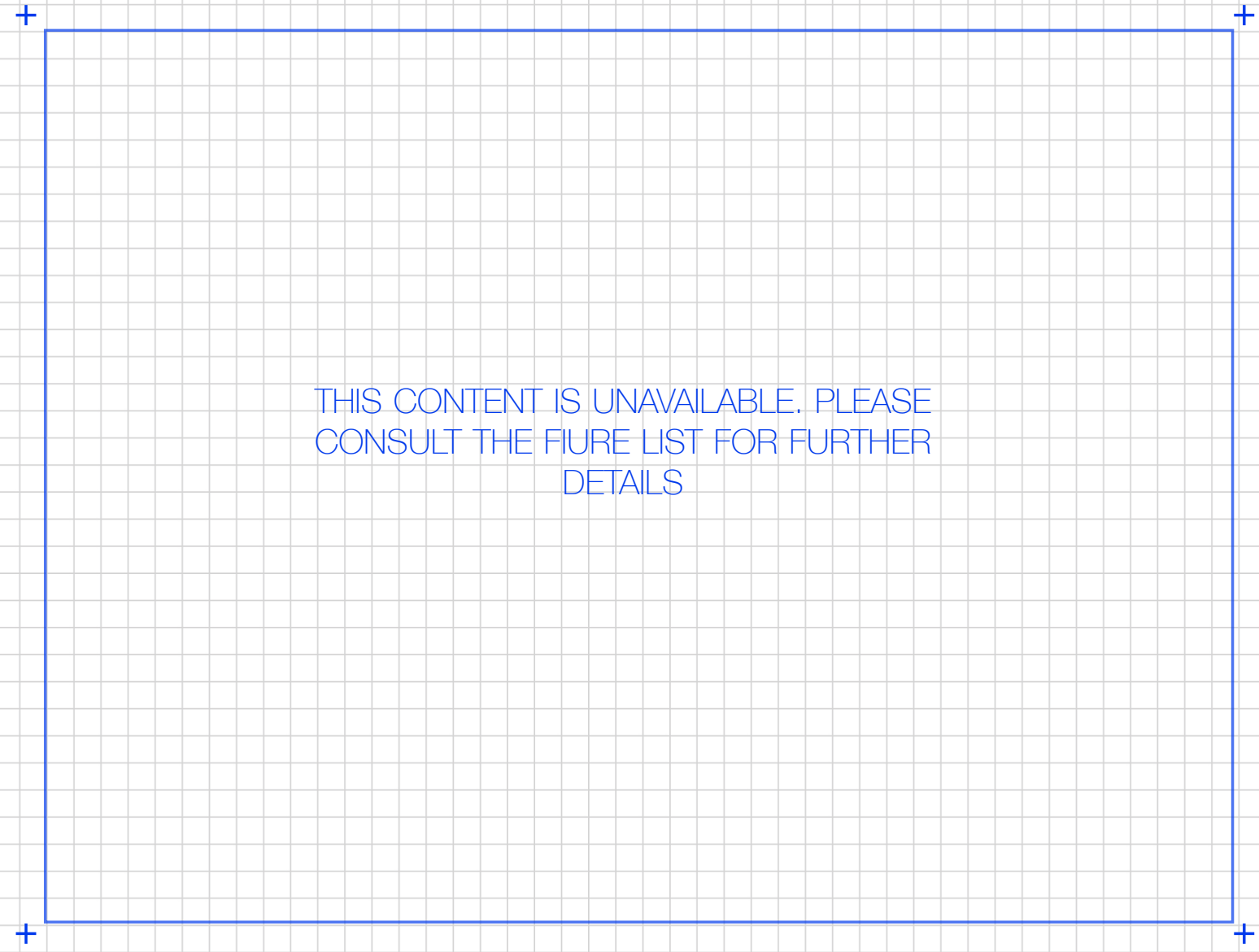

Fig//31 Walden - Tumbleweed Tiny House Company 
The term 'tiny house' is synonymic to such alternatives as cabin, hut, lean-to and shed. A 'tiny house' immediately alludes to a romanticised idea of 'getting away from it all' and 'the world as your backyard'. The media promulgates the notions that the 'tiny house' arguably has an aesthetic and challenges the traditional notion of liveable space through fold away tables and hidden storage. Therefore, this research aims to move away from the term 'tiny house' and move closer to that of architecture perhaps 'architeenie' or 'tiny-tecture'? By doing that, this research is not compared to the 'tiny house' aesthetic or ideology, it is simply tiny-tecture to suit a brief. However, to successfully move away from the 'tiny house', it is important to first conduct an interrogation of that.

It could be argued that living in small spaces has occurred since the primitive huts of our ancestors. Why then has the 'tiny house' movement gained so much attention in recent years both in New Zealand and elsewhere? An article in the New Yorker bluntly allows that "human beings have always lived in small houses - not to make a statement but because small houses were practical and cheap" 84 . Yet it has only been relatively recently that the 'tiny house' has been considered its own movement. However, there seems to be somewhat of a distinction between the 'tiny house' with respect to small living, and the 'tiny house' movement as such. Oliver Herwig insisted that "Mobile homes are a culture of their own, from the VW Bully with tent roof to transportable homes that can be stored up and secured with bricks. The idea of "here today gone tomorrow" is a romantic and pragmatic extension of nomad culture that exchanges the standardised suburban existence for taste of freedom" 85 . To begin to understand the distinction of culture and product it may be useful first to acknowledge the multitude of contributing factors. 
THIS CONTENT IS UNAVAILABLE. PLEASE CONSULT THE FIURE LIST FOR FURTHER DETAILS 
THIS CONTENT IS UNAVAILABLE. PLEASE CONSULT THE FIURE LIST FOR FURTHER DETAILS 


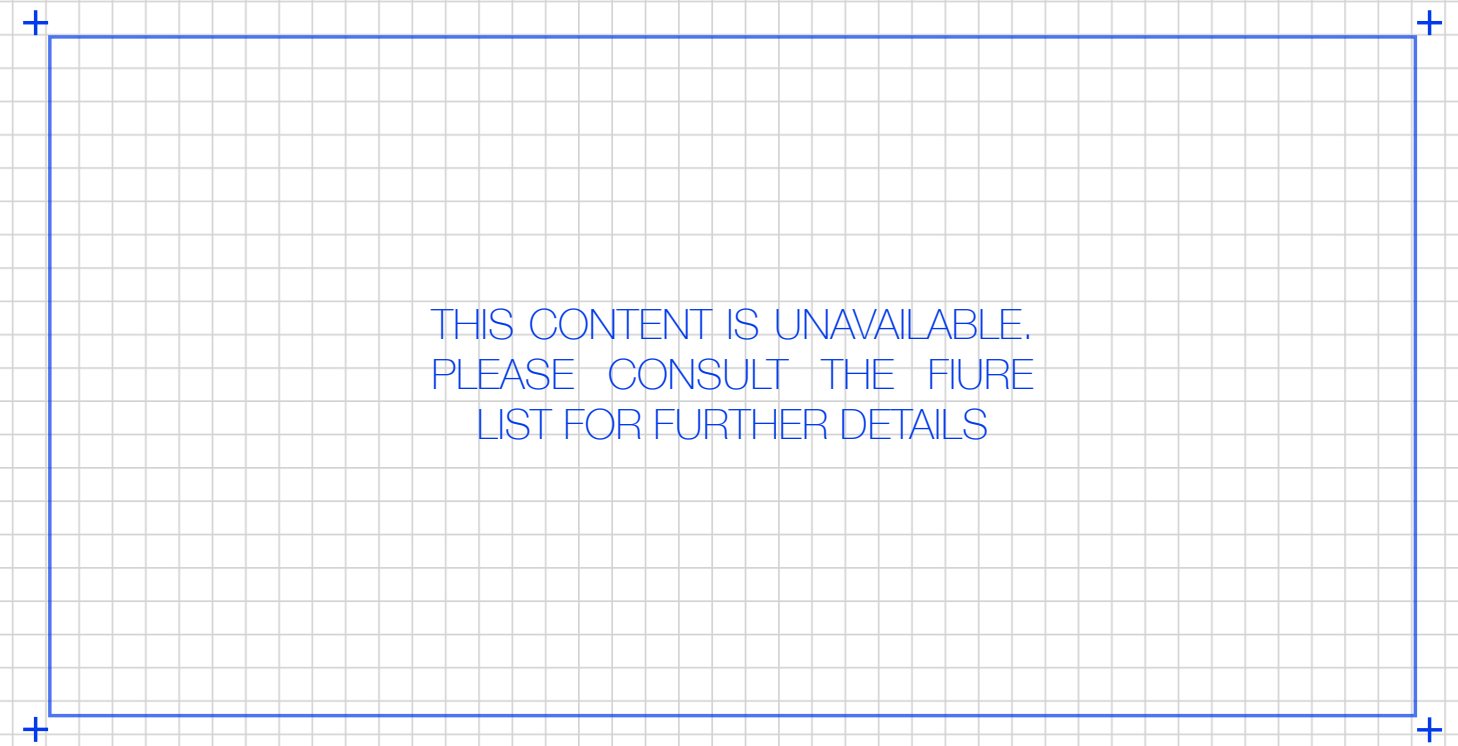

Fig//34 Nakgin Capsule Tower - Kisho Kurokawa 1977 
Japanese architecture conceptualised and promoted small-space living long before the concept of the 'tiny house' or the 'tiny house movement'. Post war Japan saw a push by the Government towards homeownership to boost the economy and this has since been cited as the predominant catalyst for smallscale living ${ }^{86}$. Legalities in terms of residential zoning requirements and land prices have further created a demand for innovative, non-conformist architecture. Today in Japan "most private lots are extremely small... and always more expensive than the buildings that stand on them"87. It is therefore understandable that domestic dwellings challenge traditionally preconceived ideas of space. Cathelijne Nuijsink cited as much as $70 \%$ of architectural firms work in Japan as coming from what is classified as micro-homes ${ }^{88}$. The alternative living models conceived by Japanese architects are arguably not so much a romanticised movement as they are simply a method of solving a problem. In a sense, through the restrictions of space seen within Japan, architecture is able to be redefined. Traditional needs are not so paramount. Arguably the largest scale small-living model arose out of the Metabolist era of Japanese architecture. Kisho Kurokawa's Nakagin Capsule Tower consisted of 144 theoretically interchangeable capsules the size of a shipping container which housed a residential unit ${ }^{89}$. However, preceding this definitive structure, detached/semi-detached residential dwellings have challenged preconceived notions of architectural tradition within the Modern Movement since the $50^{\prime} \mathrm{s}^{90}$. Curtains as walls, ladders, transparent or even completely open traditionally private space, the dwellings ultimately interrogate traditional residential architecture. It seems that Japanese small-scale architecture is simply a lifestyle, a societal difference from the western 'tiny house', established through many factors such as economy, land, regulation etc. 

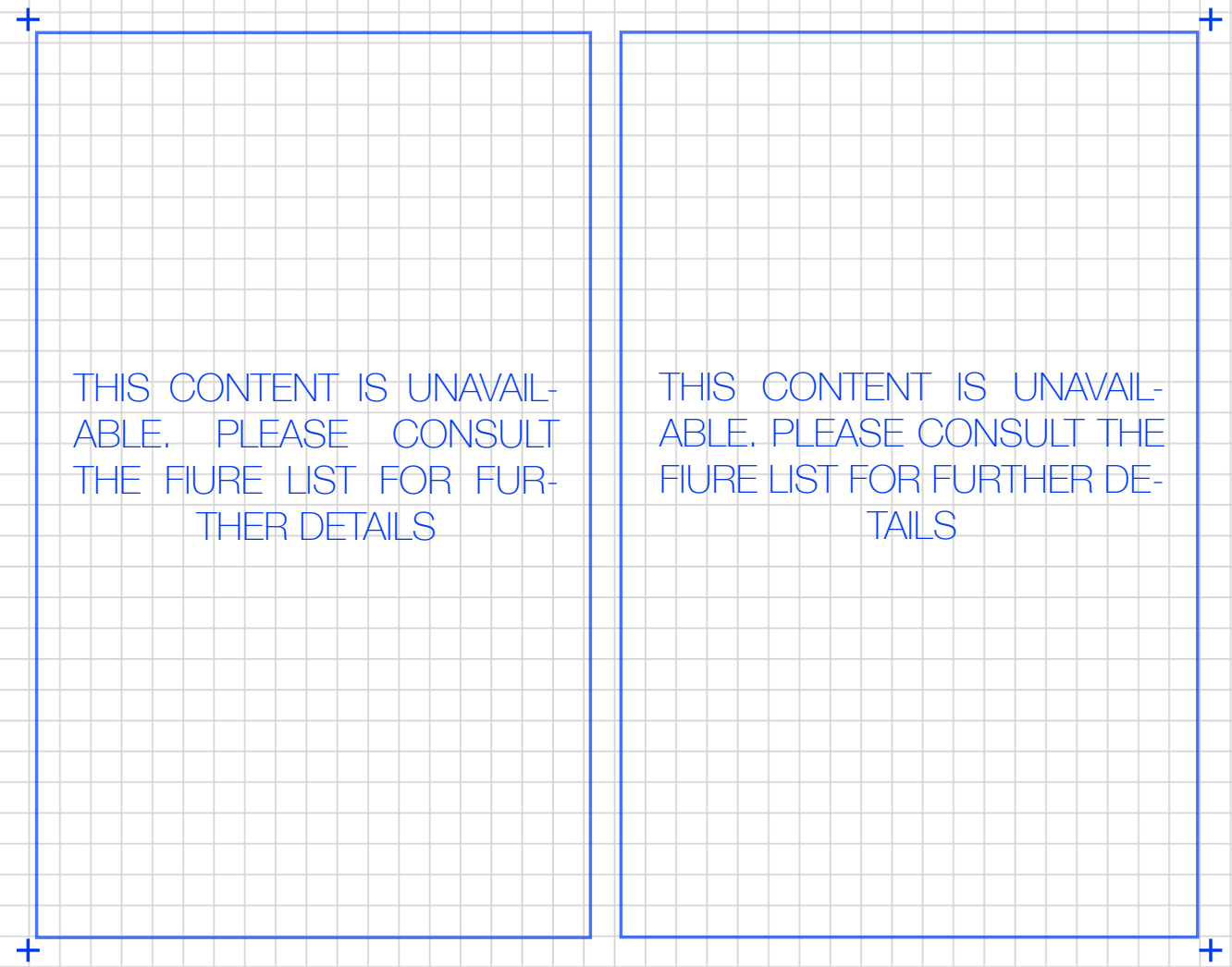

Fig//35 Steel Train - Kengo Kuma 2003

Fig//36 House NA - Sou Fujimoto Architects 2011 


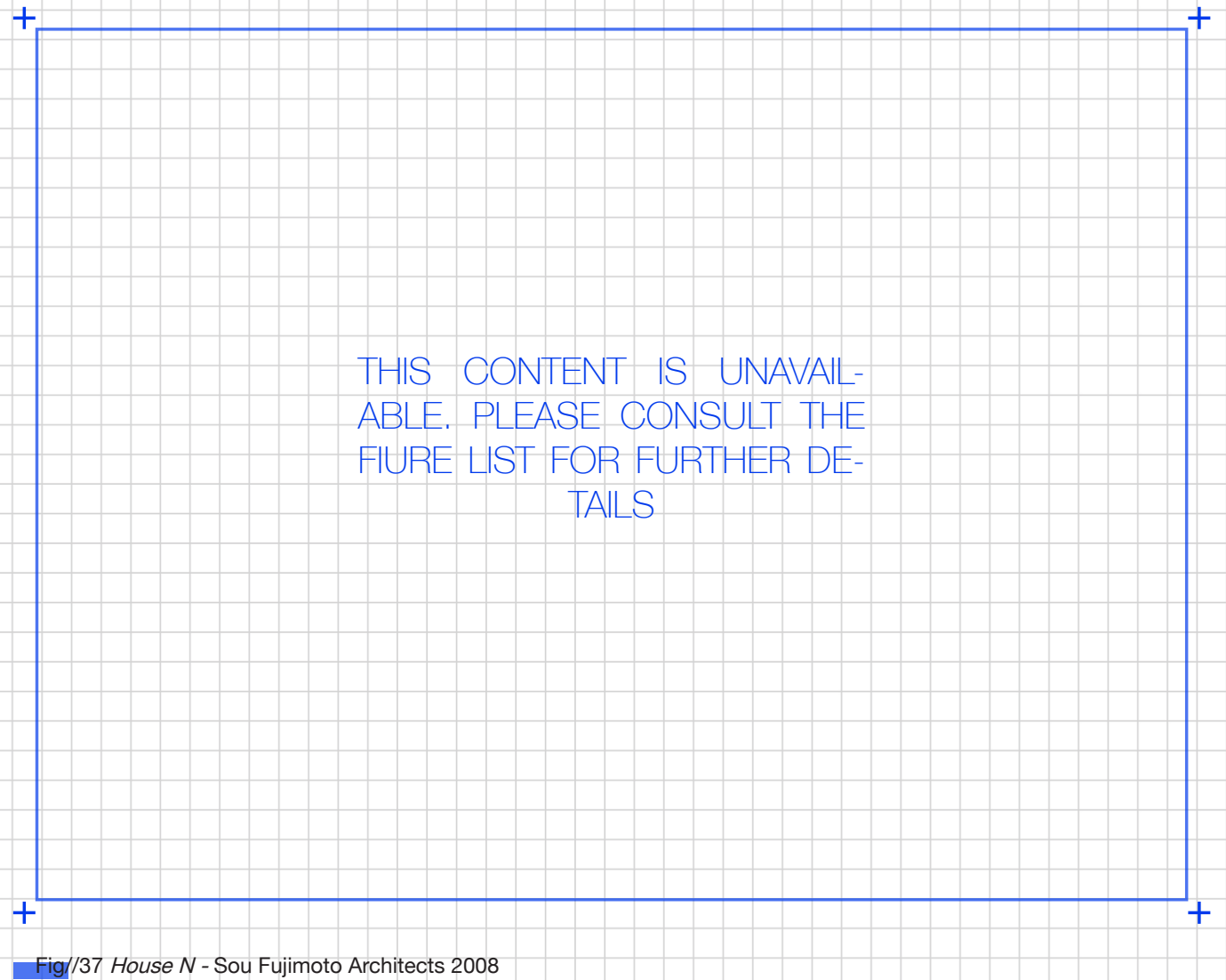




\section{TERUNOBUFUJMORI}

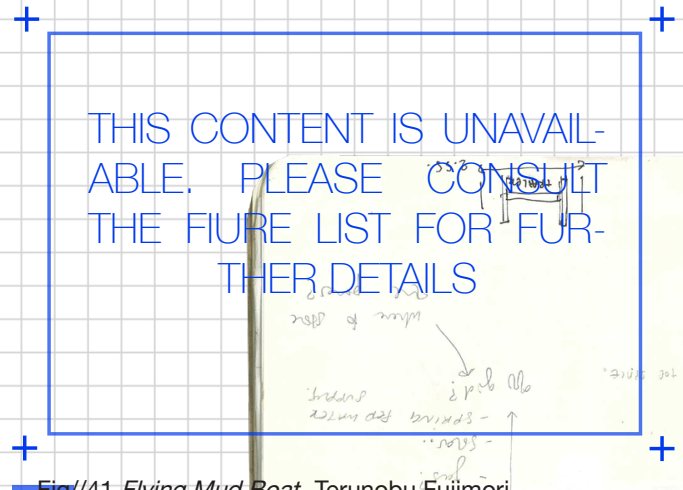

Fig//41 Flying Mud Boat -Terunobu Fujimori

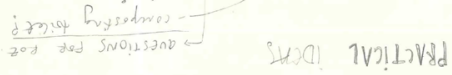

iisner 中uy

mare pros
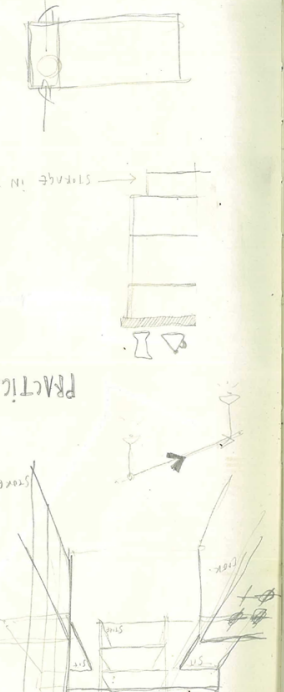

.

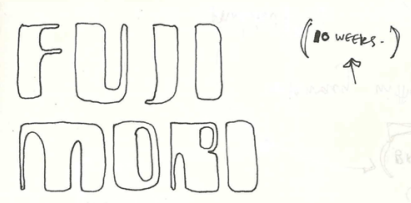

How Does the USE SLAL

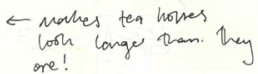

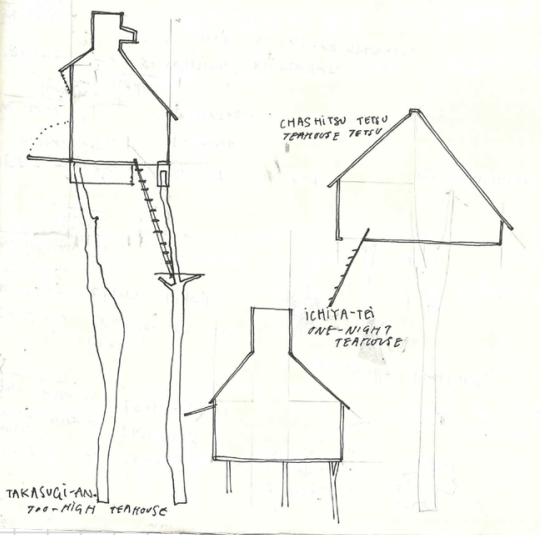

Exploration of the proportion between roof and body, and their relation to ground, within Fujimori's tea houses.

Play of scale allows teh small spaces to appear larger than they are, and become their own entity. 
'Tiny house' forums and media outlets suggest a multitude of reasons for the 'tiny house' movement's increase in popularity in America. These include, the 2008 financial crisis ${ }^{91}$, changes in housing legislation and ever increasing environmental concerns ${ }^{92}$. Particular texts such as 'Shelter' by Lloyd Khan and 'Tiny Houses' by Lester Walker are cited as being the inspiration for the movement, with particular emphasis and citation of transcendentalist Henry Thoreau's 1854 text 'Walden'. 'Walden' reflects upon living simply within the woods, which he did so for approximately two years. Poetic statements such as "With this more substantial shelter about me, I had made some progress toward settling in the world" ${ }^{93}$ are used as avocation for the 'tiny house' movement. Many 'tiny house' companies have even named their designs after 'Walden' motifs. Collectively these 'tiny house' texts are written with the resolve of simpler living, through a reduction in possessions and square meterage. The theme of Do-It-Yourself construction is also prominent, ultimately perpetuating the notion of the 'tiny house' as a device to positively enhance living. Walker states his intention for the book was "...to inspire those in need to dream and to build" 94 . In this relation of dreaming and building, Walker is thus, perpetuating the romantic, transcendentalists rhetoric that drives the movement's fundamental principles. This can be seen within both the terminology used within the movement and its aesthetic. Statements such as 'the world is your backyard', or 'getting away from it all' alongside pictures of wooden interiors and pot belly stoves induce the notion of the simple life connected with nature. Walker continues his declaration, explaining that, "one of the great thrills in life is to inhabit a building that one has built oneself" 95 . The sense of empowerment and, self-actualisation these perspectives embody perpetuate a dream the 'tiny house' movement in North America associates with. 
A woman named April Anderson who built her own 'tiny house' has critiqued the 'tiny house' movement (though not necessarily the 'tiny house'). Anderson suggests the romanticism surrounding the movement is more a marketing ploy aimed at creating a commodity than a bonafide philosophy. She maintains "... the rhetorical dependence on tropes of wilderness escapism and territorial appropriation threaten to undercut the 'tiny house' movement's more revolutionary aims" "96. Although smaller space living evidently can be implemented to solve societal problems ${ }^{97}$, the movement's rhetoric is to a greater extent image-centric romanticism. Anderson expands on this further, suggesting the 'tiny house movement' as more commodity based because of its temporality, allowing that many tiny homes are in fact stepping stones towards a realsized, larger house, or potentially even as a secondary income -an economic progression ${ }^{98}$. However, key figures within the movement such as Jay Shafer, cited as the 'pioneer', maintain the idealistic romanticism of simplification, Shafer states, "...I think it comes back to nature. In every area of nature, efficiency is the law of the land. Efficiency just makes sense. The only thing I know of that doesn't abide by efficiency is the human ego" 99 . However, Shafer too has commercialised the movement, setting up multiple companies which sell the dream.

Therefore, it seems perhaps the movement within North America advertises itself as a shift in ideology and lifestyle when in fact -respecting that in some instances this is the case -as a whole its concerns are more economically driven. 


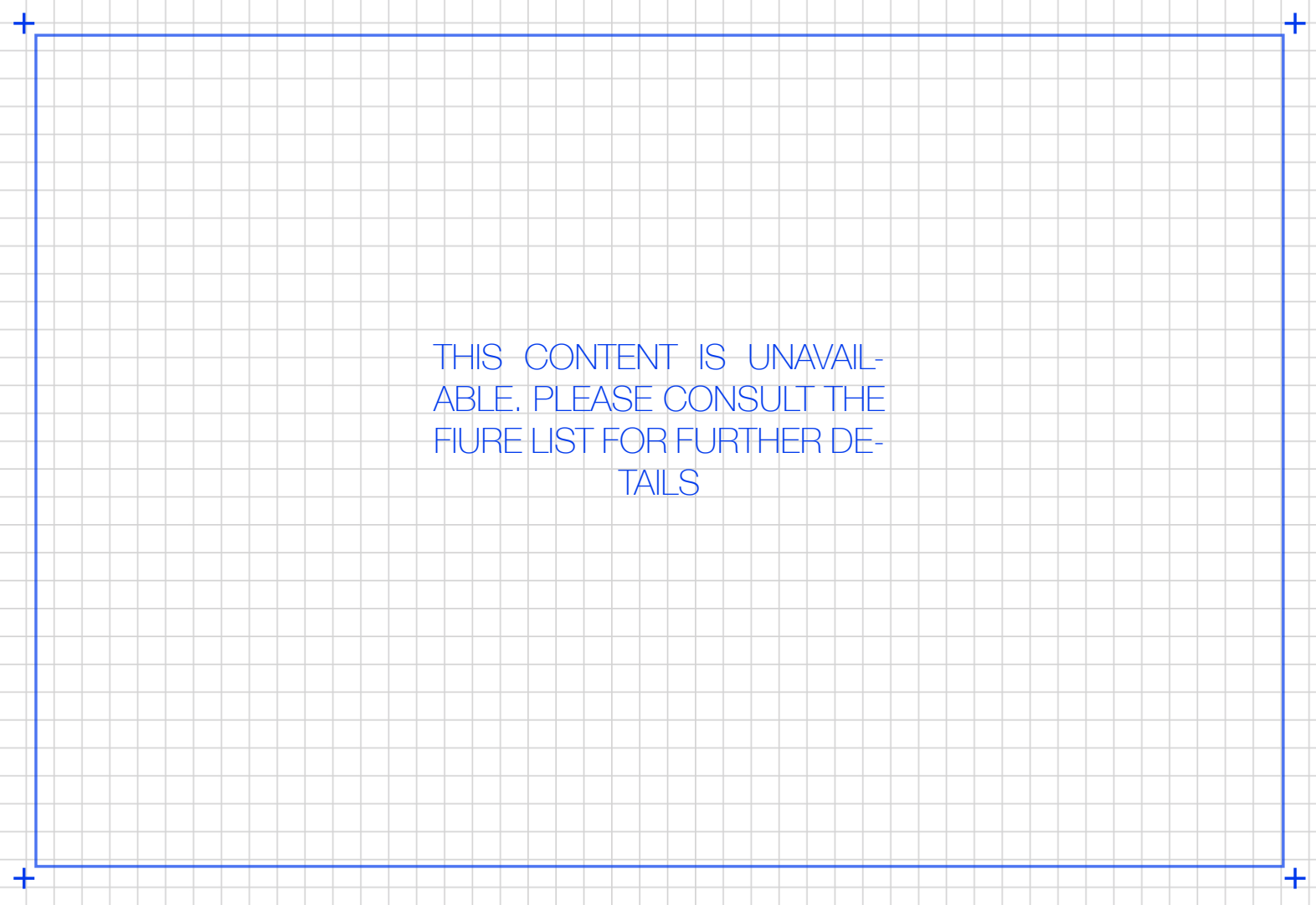

Fig//42 Tiny Hairloom Tiny House Company - North America 


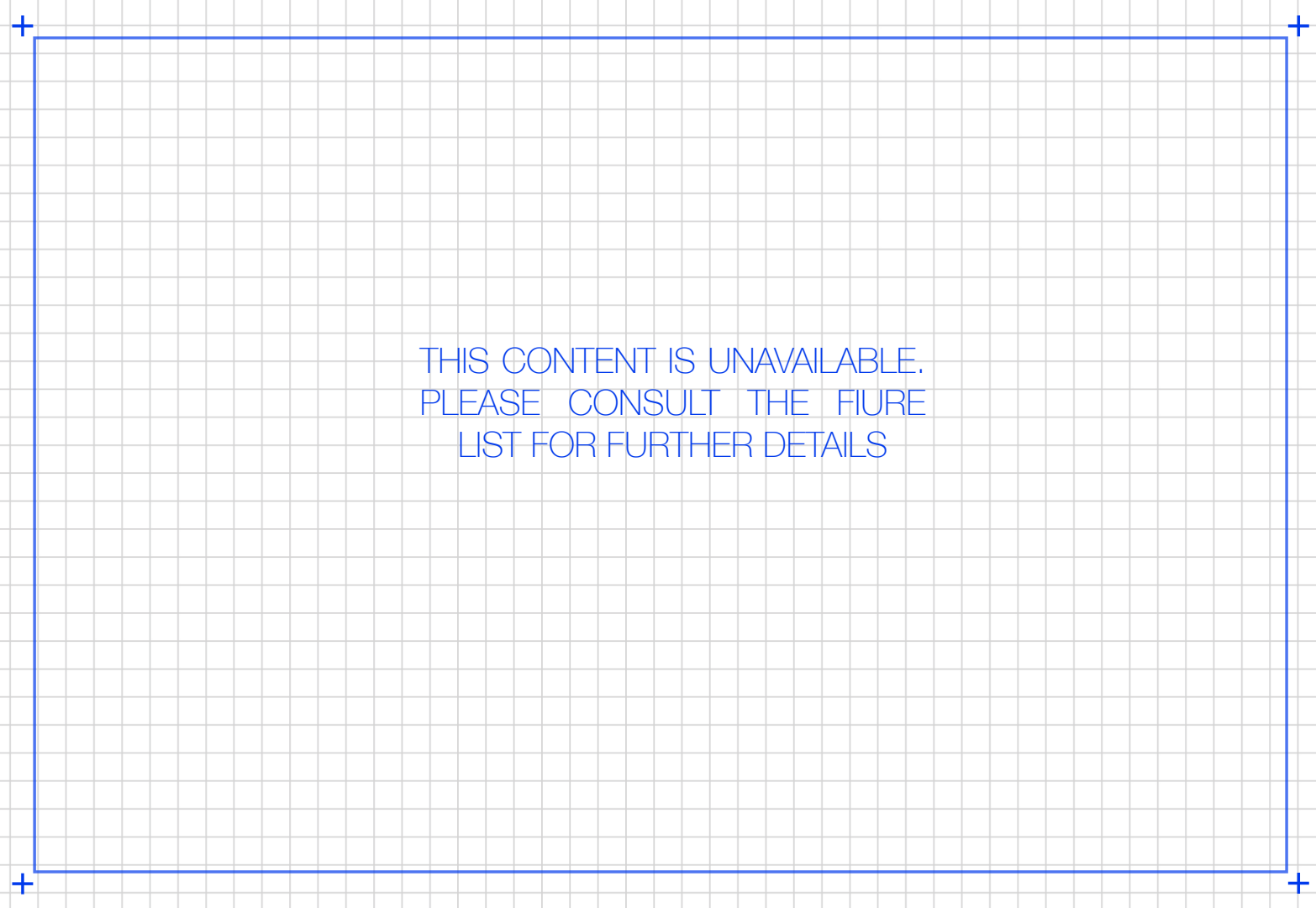

Fig//43 Conestoga Huts - Alliance for the Homeless 


\section{$Z$ e a l a $n$ d}

New Zealand's relationship with transient architecture is deep rooted within culture. Our relationship to the sea arguably recognises a fascination of movement. Mike Austin allowed, "...the oceanic connection between house and boat is acknowledged in numerous myths and stories"100.

Within the context of the New Zealand 'tiny house' movement, the notion of ideology distinct from actuality is also evident. However, it is arguably less romanticised than within the North American movement, adapting more so the D.I.Y aspect of the movement. When google searching "tiny house NZ" the majority of results are tiny home builders -companies offering their services to supply you with the dream house you can afford. When searching for "tiny house America" the results are populated by forums and "tiny house' blogs educating people on the benefits of 'going tiny'. In a podcast a New Zealand reporter allowed, "...there's something very Kiwi about tiny houses...it really fits with our desire to connect with nature, and it's really not that far from our rural heritage"101. This relation to rural nature may allude to a romantic rhetoric, however, not only do these things very much play an active role in our society today, but, as a comparatively young country, these aspects of lifestyle, the 'tiny house' movement, perpetuates are seemingly not so distant within our history. Mike Austin and Jeremy Treadwell acknowledge that "...houses in Oceania tend to be tied down rather than built up as with the compressive earth-based technologies of walls and arches"102, alluding to a more transient existence. Perhaps another rational for the "tiny house' movement gaining popularity within New Zealand is its natural progression from the house truck (a descendant of the Gypsy wagon) which arose within the 1970 's ${ }^{103}$. So far the main criticism and/or difficulty facing the 'tiny house movement' in New Zealand is the problem of obtaining land to park it ${ }^{104}$. The privilege that land associates arguably competes with the very principals the movement aims to address. Therefore, it should be acknowledged the 'tiny house' movement within New Zealand has its conflicts too.

To summarise, the 'tiny house movement' is arguably a separate concept from the 'tiny house'.

Furthermore, the term 'tiny house' alludes to a potentially preconceived notion of house model, a miniaturised house rather than architectural space. Beginning with the movement, a predominantly economically driven concept has the ability to detract from its fundamentally significant qualities. The object of the 'tiny house' provides an avenue within New Zealand -although potentially flawed in terms of land use and accessed within which to explore domestic living without restriction (comparatively). Separate to both movement and object, Japanese small-scale architecture provides a fundamentally confronting area of exploration within domestic architectural space. Therefore, this research aims to distinguish itself from the 'tiny house movement' aesthetic, ideology etc and through the 'tiny house' object, create architectural space which challenges domestic living. 


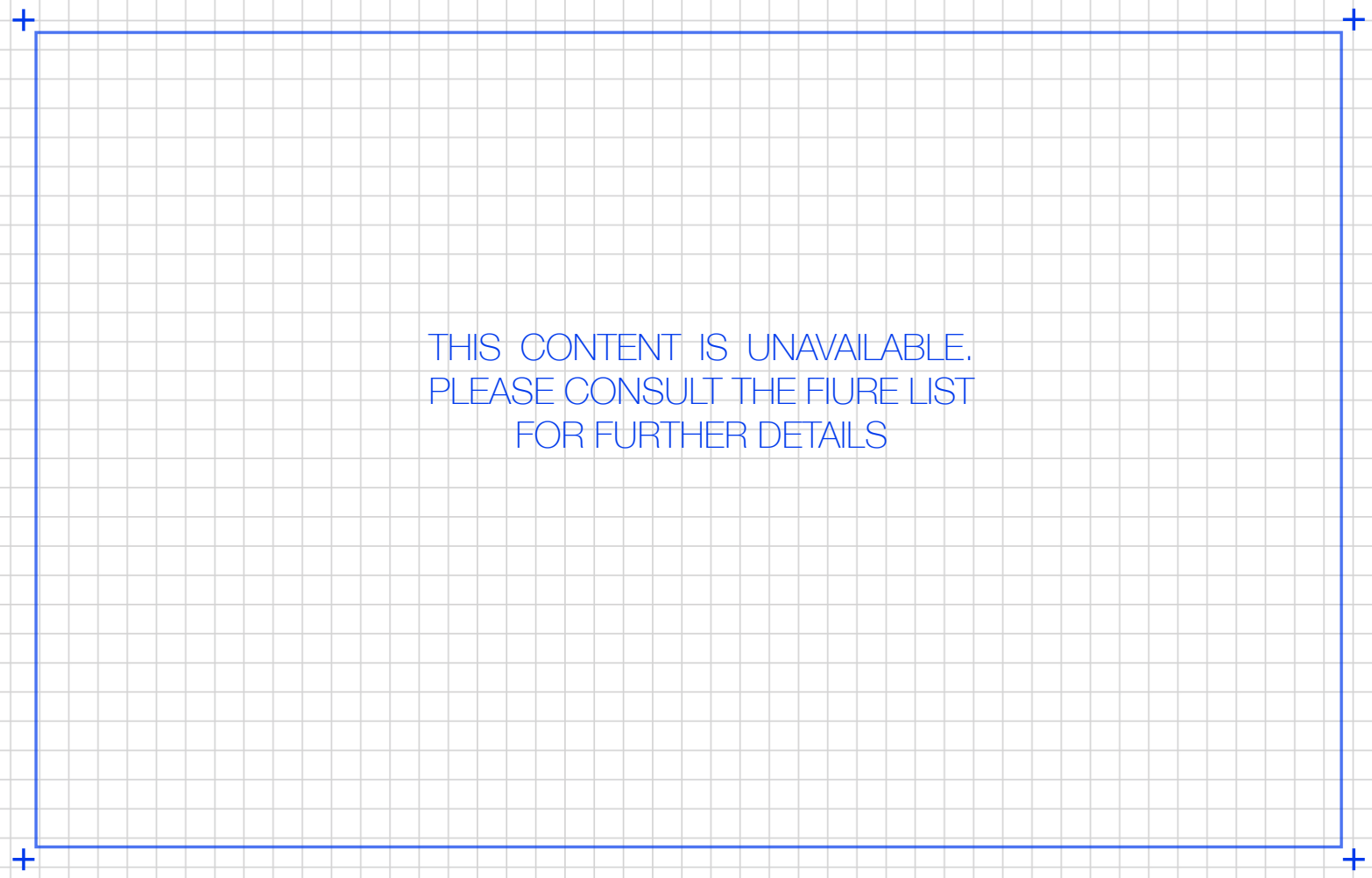

Fig//44 Hut on Sleds - Crosson Architects 2012 


\section{TINY TIMELINE}

\section{Gypsy Wagon}

Henry Thoreau:

+ inspiration for Tiny House movement, romantic text refered to by tiny house proponents

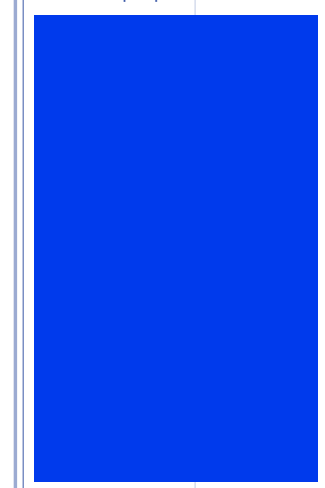

"Walden" house trucks popularised

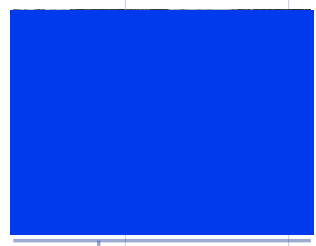

Charles Miller

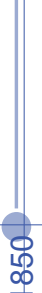



"Walden"

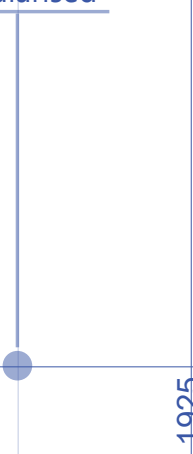

近

\section{Le Corbusier Cabanon}

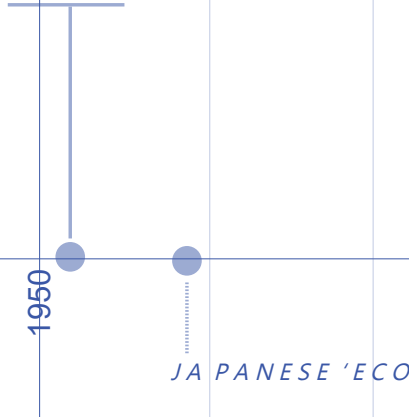


SCALELIVING O $0 \quad 0 \quad 0$

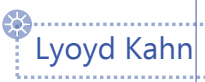

+ documents venacular

architecture, in depth

investigation of

indigenous

construction methods

and small dwellings

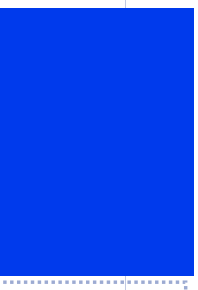

eph Rykwert

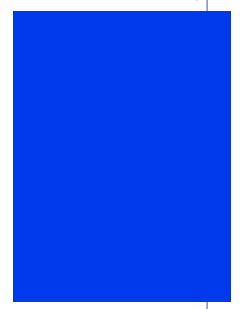

"Shelter"

Adam's House in Paradise"

点 $\bigcirc \quad 0 \quad$ Jay Shafer

FRA NCHISED

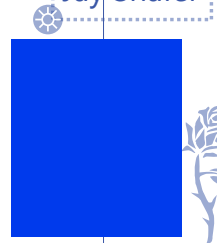

Shay Salomon

+ Nigel Valdez

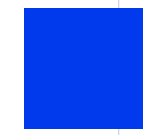

Sarah Susanka
+ ideas of 'as big as
you need'

"The Not So Big House"

Lester Walker

+ documents 40

small dwellings

from DIY

perspective

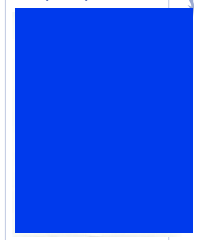

"Tiny Houses"

housetruck

living

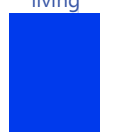

"Home Free"

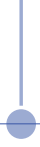

$\$$

Turtles Have

Nice Shells"

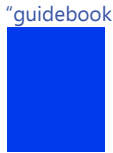

"Little House"

Rodger Beck

+ picture book

of hand built

housetrucks and

housebuses

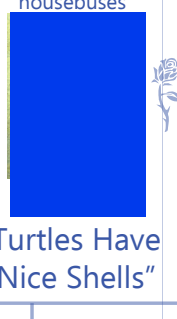

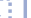
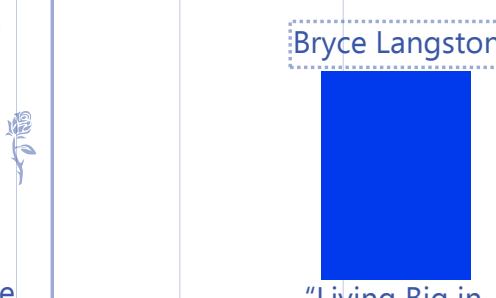

"Living Big in

a Tiny House" 
1 Cook, Peter "Architects, not Architecture" Home Edition 2020 . AnA Barcelona 01, Barcelona. September 27 2018. Talk. Accessed https://www.architectsnotarchitecture.com/en/cook

2 Schittich, Christian. "The Fascination of Small Structures" (pp. 8-10) in In Detail: Small structures. Ed. Schittich, Walter de Gruyter GmbH, 2010. ProQuest Ebook Central, https://ebookcentralproquest-com.helicon.vuw.ac.nz/lib/vuw/detail.action?docID=1075586 Accessed 19.03.2020

3 Slavid, Ruth. Micro: Very Small Buildings. London, Laurence King Publishing Ltd, 2007. P.9 4 Slavid, Ruth. Micro: Very Small Buildings. London, Laurence King Publishing Ltd, 2007

5 Fujimori, Terunobu. "Terunobu Fujimori Interview: A Feeling of Freedom." YouTube, uploaded Louisiana Channel, 01.12.2020. Accessed: 09.04.2020

6 Fujimori, Terunobu. "Terunobu Fujimori Interview: A Feeling of Freedom." YouTube, uploaded Louisiana Channel, 01.12.2020. Accessed: 09.04.2020

7 "Tiny." Dictionary.com. William Collins Sons \&Co Ltd. 2012. https://www.dictionary.com/browse/ tiny?s=t Accessed: 10.06 .2020

8 Stewart, Susan. On Longing: Narratives of the Miniature, the Gigantic, the Souvenir, the Collection. Duke University Press, 1993. P.48

9 Herwig, Oliver. "Big and Small - The Convergence of Architecture and Design". (pp.50-59) In Detail: Small structures. Ed. Schittich, Walter de Gruyter GmbH, 2010. ProQuest Ebook Central, https:// ebookcentral-proquest-com.helicon.vuw.ac.nz/lib/vuw/detail.action?doclD $=1075586$ Accessed 19.03.2020. p.59

10 Haack, Lydia, and Höpfner John "Microarchitecture - Experiments in Space Optimisation" (pp.11-23) In Detail: Small structures. Ed. Schittich, Walter de Gruyter GmbH, 2010. ProQuest Ebook Central, https://ebookcentral-proquest-com.helicon.vuw.ac.nz/lib/vuw/detail.action?doclD=1075586

\section{Accessed 19.03.202}

11 Bachelard, Gaston. The Poetics of Space. 1969. Beacon Press, 1994. P.150

12 Stewart, Susan. On Longing: Narratives of the Miniature, the Gigantic, the Souvenir, the Collection. Duke University Press, 1993. P.47

13 Wilkinson, Alec. "Let's Get Small". The New Yorker, 2011, https://www.newyorker.com/ magazine/2011/07/25/lets-get-small. Accessed: 06.06.2020

14 Herwig, Oliver. "Big and Small - The Convergence of Architecture and Design". (pp.50-59) In Detail: Small structures. Ed. Schittich, Walter de Gruyter GmbH, 2010. ProQuest Ebook Central, https://ebookcentral-proquest-com.helicon.vuw.ac.nz/lib/vuw/detail.action?doclD=1075586 Accessed 19.03.2020. P.55

15 Nuijsink, Cathelijne. How to Make a Japanese House. Rotterdam, NAi Publishers, 2012.

16 Hildner, Claudia. Small Houses: Contemporary Japanese Dwellings, Walter de Gruyter GmbH, 2011. ProQuest Ebook Central, https://ebookcentral-proquest-com.helicon.vuw.ac.nz/lib/vuw/detail. action?docID=1020491. P.11

17 Nuijsink, Cathelijne. How to Make a Japanese House. Rotterdam, NAi Publishers, 2012.

18 Zhongiie Lin "Nakagin Capsule Tower: Revisiting the Future of the Recent Past." In Journal of Architectural Education, 65:1, pp.13-32, DOI: 10.1111/j.1531-314X.2011.01158.x

19 Nuijsink, Cathelijne. How to Make a Japanese House. Rotterdam, NAi Publishers, 2012.

20 Nonko, Emily. "A Tiny House Movement Timeline". Curbed, 2017, https://www.curbed. com/2017/7/19/15974554/tiny-house-timeline. Accessed: 18.06.2020

21 Nonko, Emily. "A Tiny House Movement Timeline". Curbed, 2017, https://www.curbed. 


\section{PART 1.1 ENDNOTES}

com/2017/7/19/15974554/tiny-house-timeline. Accessed 18.06.2020

22 Thoreau, Henry. Walden. (1854). E-book, The Project Gutenberg, 2021.

23 Walker, Lester. Tiny Houses. New York, The Overlook Press, 1987. P.14

24 Walker, Lester. Tiny Houses. New York, The Overlook Press, 1987. P.14

25 Anson, April. "The world is my backyard": Romanticization, Thoreauvian Rhetoric, and

Constructive Confrontation in the Tiny House Movement. From Sustainable to Resilient Cities:

Global Concerns and Urban Efforts, vol.14, 2014, pp.289- 314. Emerald Group Publishing Limited

Global Concerns and Urban Efforts, vol.14, 2014, pp.289-314. Emerald
doi:10.1108/S1047-004220140000014013 Accessed: 10.06.2020. P.300

26 Community Supported Shelters. Conestoga Huts: Cost Effective and Durable Micro-Shelters, https://communitysupportedshelters.org/conestoga-huts. Accessed: 06.06.2020

27 Anson, April. "The world is my backyard": Romanticization, Thoreauvian Rhetoric, and

Constructive Confrontation in the Tiny House Movement. From Sustainable to Resilient Cities:

Global Concerns and Urban Efforts, vol.14, 2014, pp.289- 314. Emerald Group Publishing Limited,

doi:10.1108/S1047-004220140000014013 Accessed: 10.06.2020

28 Friedlander, David. "Talking to Jay Shafer About Making the Universal House." Life Edited, https:// lifeedited.com/jay-shafer-four-lights-future-of-tiny-houses. Accessed 10.06.2020. par.12

29 Austin, Mike. "From the Whare to Modernism." New Zealand Institute of Architects, Last

Loneliest, Loveliest: The New Zealand Pavilion at the 14th International Architecture Exhibition, La

Biennale Di Venezia, 2014.

30 Kenny, Katie, and Walters, Laura. "Tiny Houses".

Superfad Podcast. 2017. https://podcasts.google.com/feed/ 


$$
y^{17}
$$


$\mathrm{P} A R T 1.2$ 


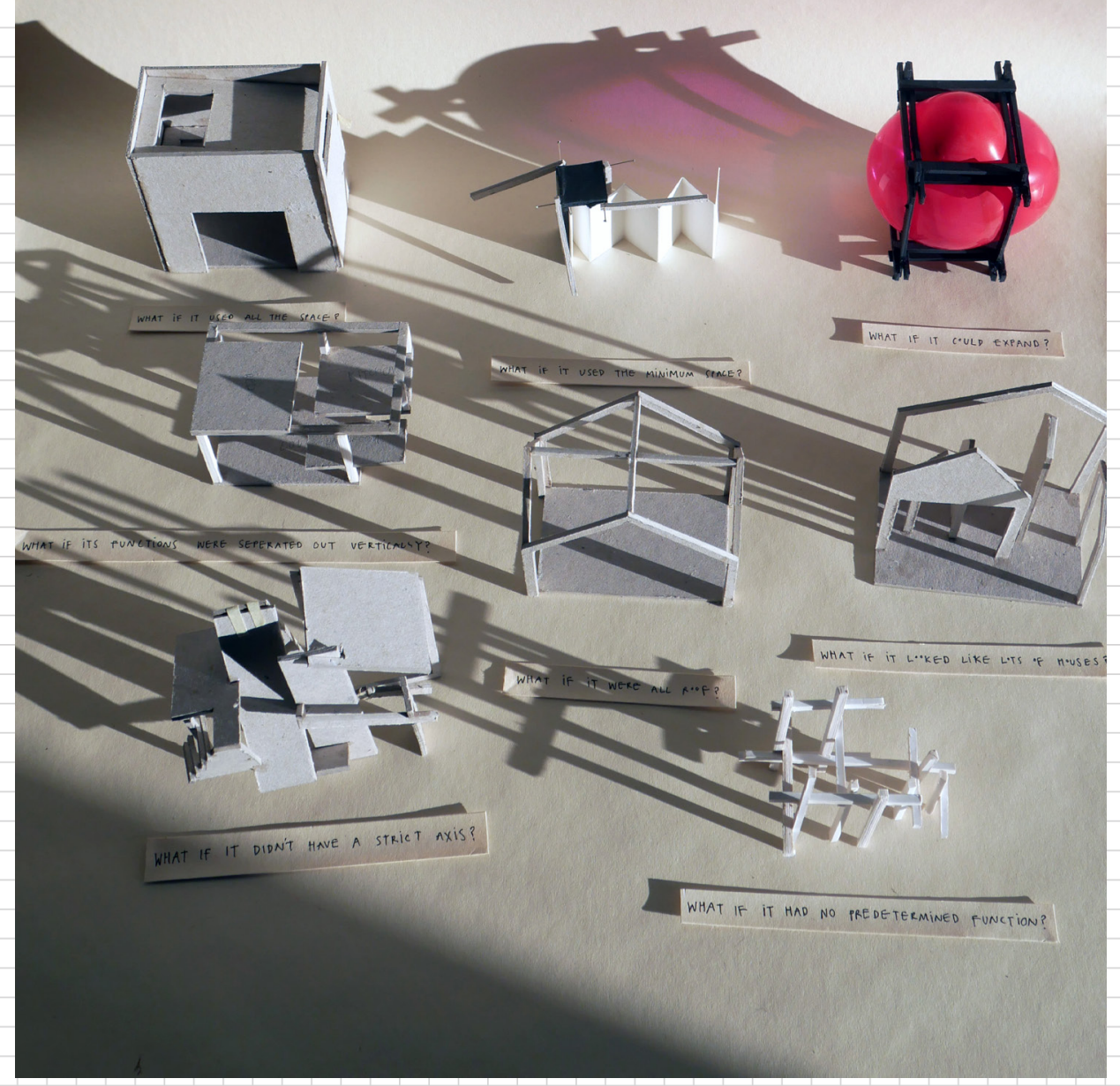




\title{
INVESTIGATION\# 1
}

\author{
$\begin{array}{lllllll} & h & a & t & i\end{array}$ \\ in order of appearance
}

The aim to move aesthetically away

from 'the tiny house' makes room to pose the question "what if?". This initial investigation aimed at challenging, or in some cases adhering to, both the idea of what a 'tiny house' is and what it looked like externally. Through the mode of making, this exploration developed organically, or rather, using the technical term, through prehension. I first came across this term in Richard Senette's book "The Craftsman" which explains movement in which the body anticipates and acts in advance of sense data ${ }^{105}$. Raymond Talis separates prehension into four categories; anticipation, contact, language cognition and reflection ${ }^{106}$. Essentially it is a process in which the hand acts before an awareness has been developed. In doing this, the investigation was enabled a freedom, or rather, expression, through the hand. This consequently allowed the preconceived 'tiny house' to be explored and challenged. 


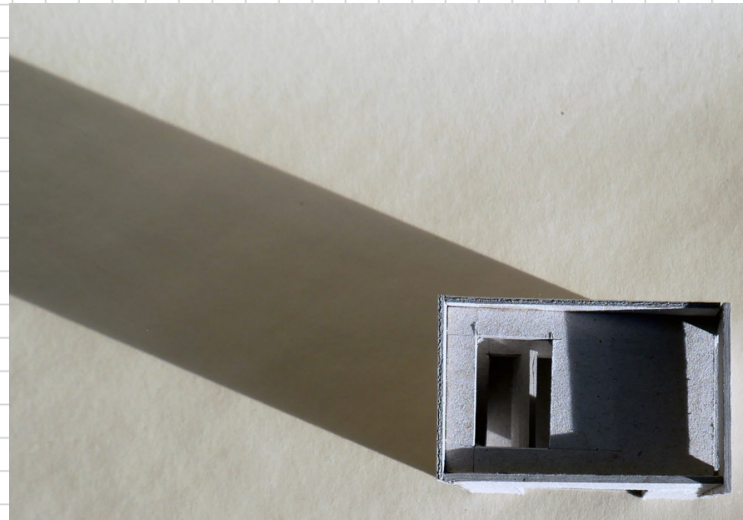

WHAT IF IT USEO ALL THE SFACE?
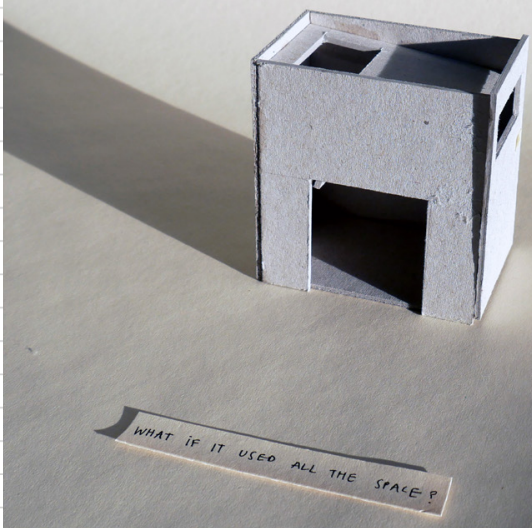

\section{wh a t if...}

..it used all the legal space allowed?

If the exterior is a box what then happens on the inside?

This is kind of what all tiny houses look like.. 


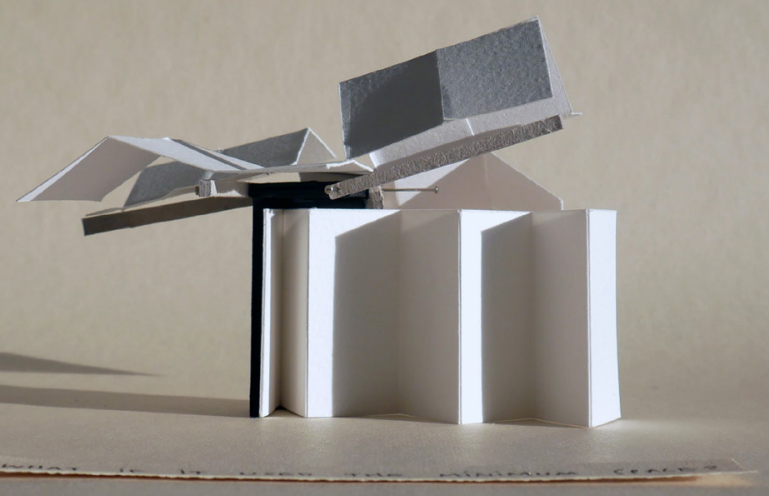

\section{what if...}

...it took up the bare minimum of space? What if it was all utility until it was in use? Fold.

Collapse. Up. Down. Out. In. What could it be

when not in use? What are its different functions

and at what time scale is this? If shelter is provided

how can the hearth be used to create walls?

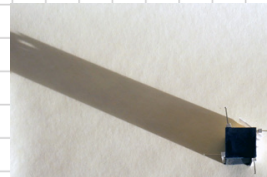

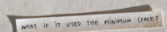
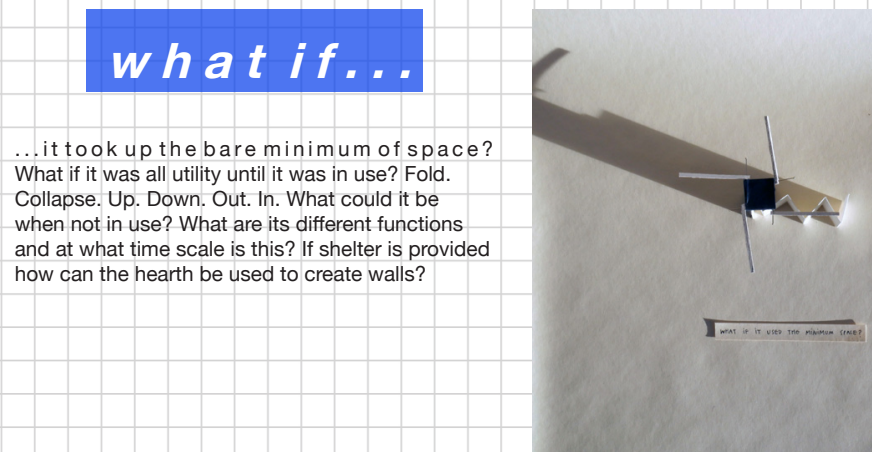

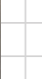

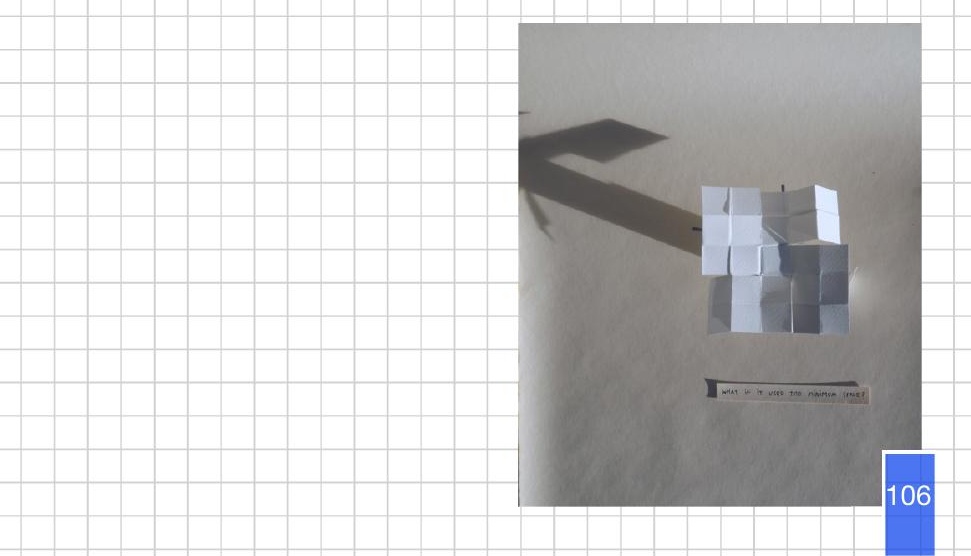




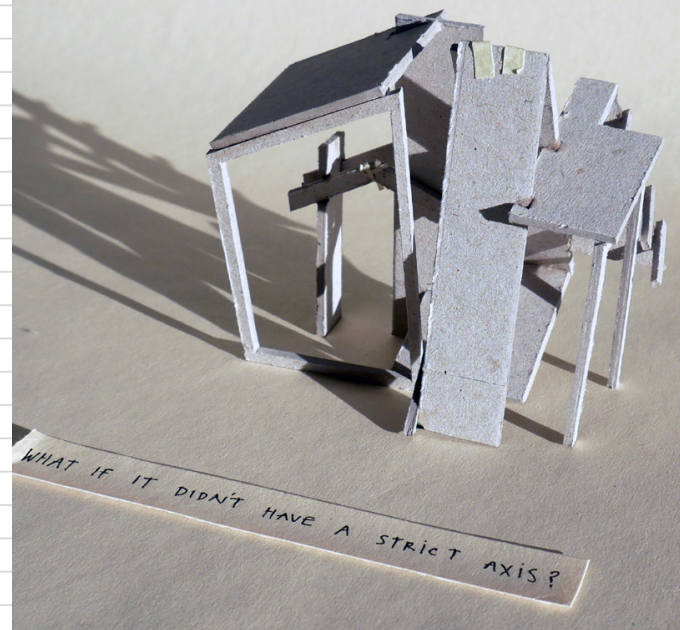

what if...

adid not have a strict/obvious axis?

Through this idea scale is also questioned. Determining one roof

form at a particular scale results in its relating parts to seem either

much larger or much smaller. Practically this exploration disregards

practicality. Further exploration into this could include challenging

parts which related to one another perpendicularity.
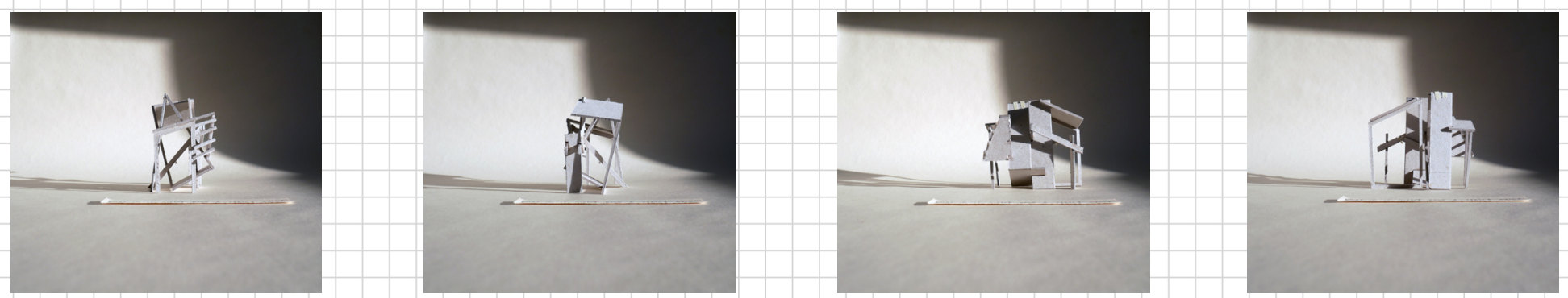

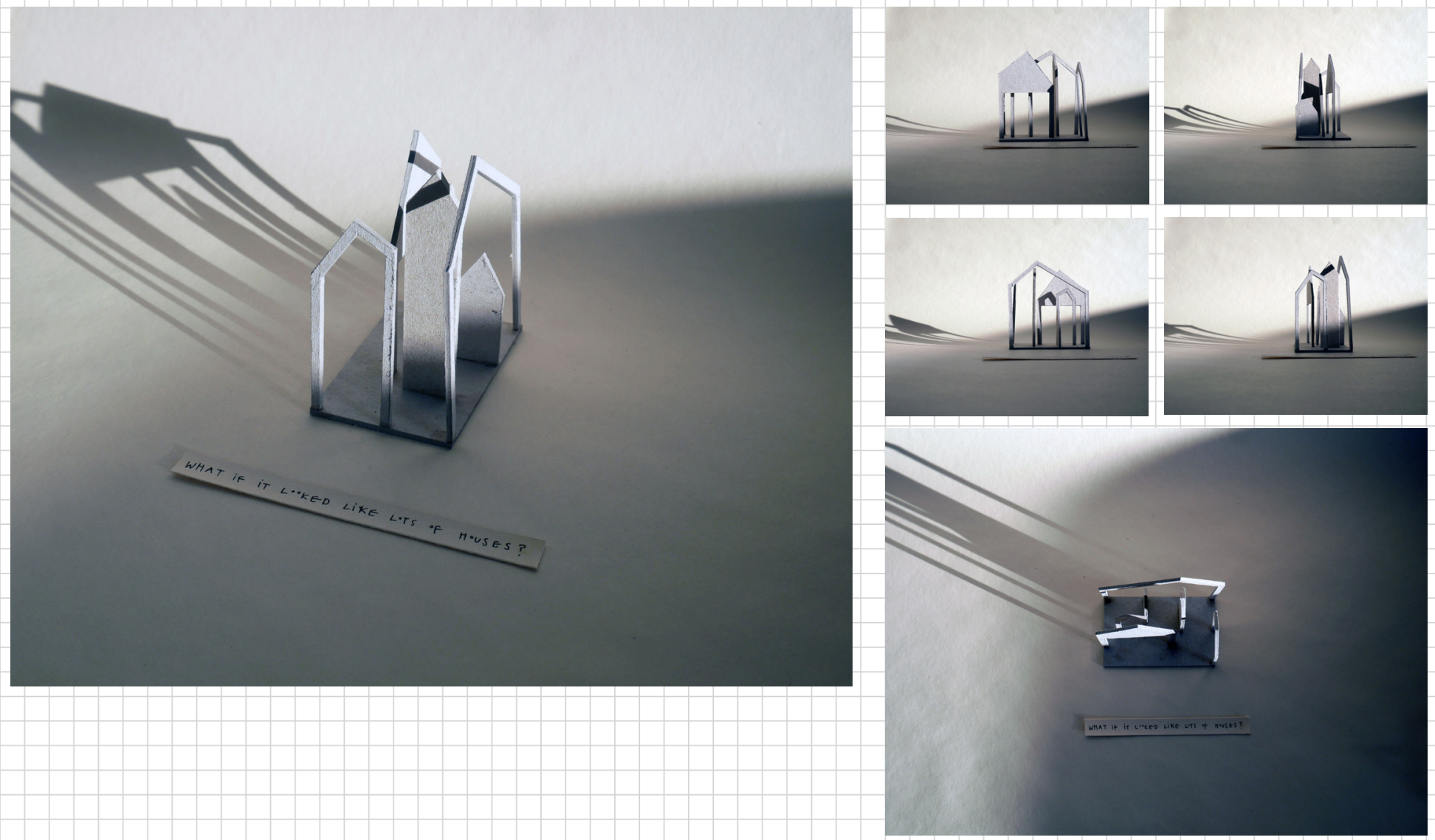

what if... 

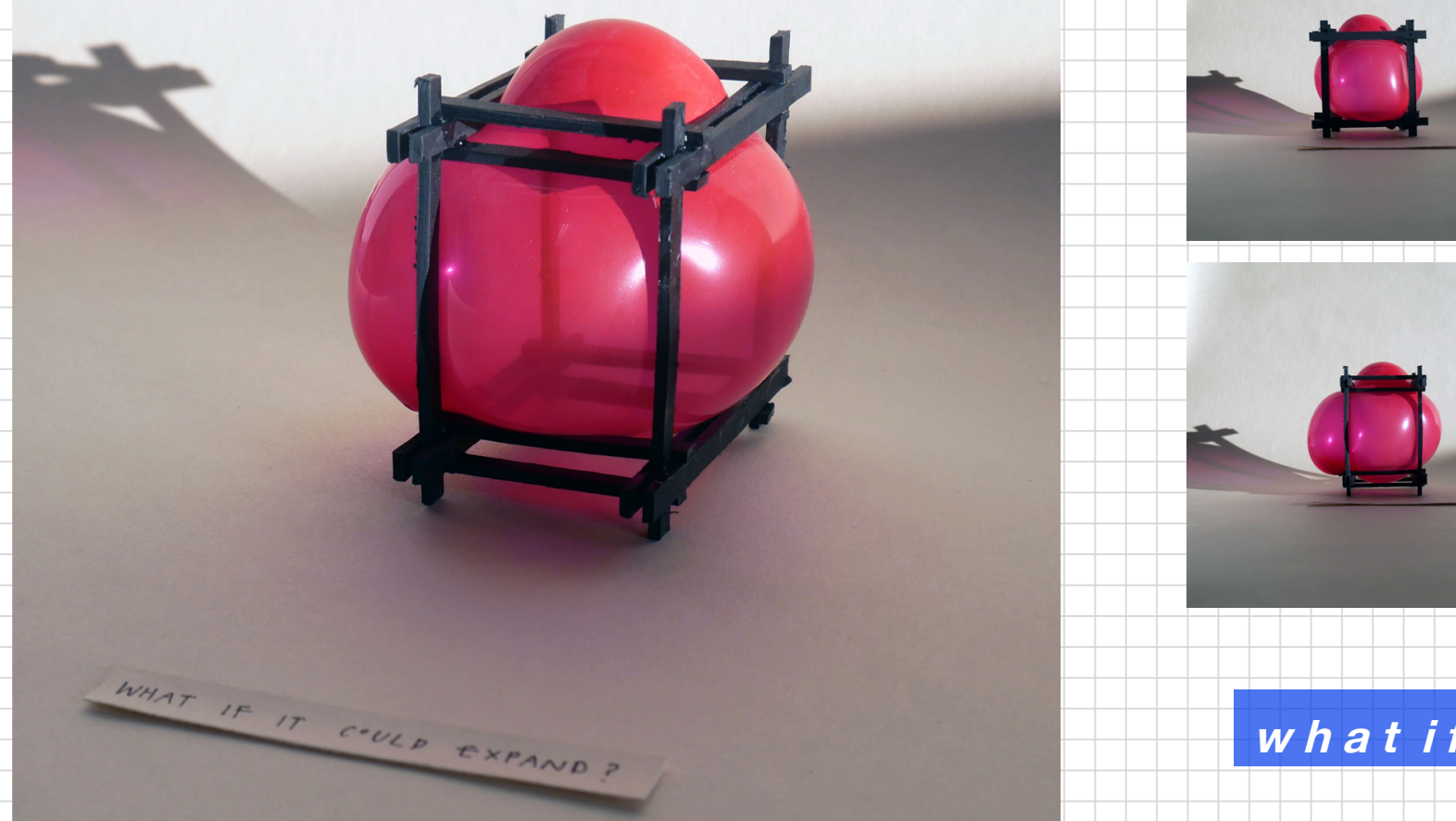

what if...

it could expand Questioning what aspect of the architecture must be stable. What is stability? What does 


\section{what if...}

What had no function? What if it were just frames?

What defines function? In not predetermining

a function, pure structure allows a freedom

that planes do not. Continuously changing

viewpoints.
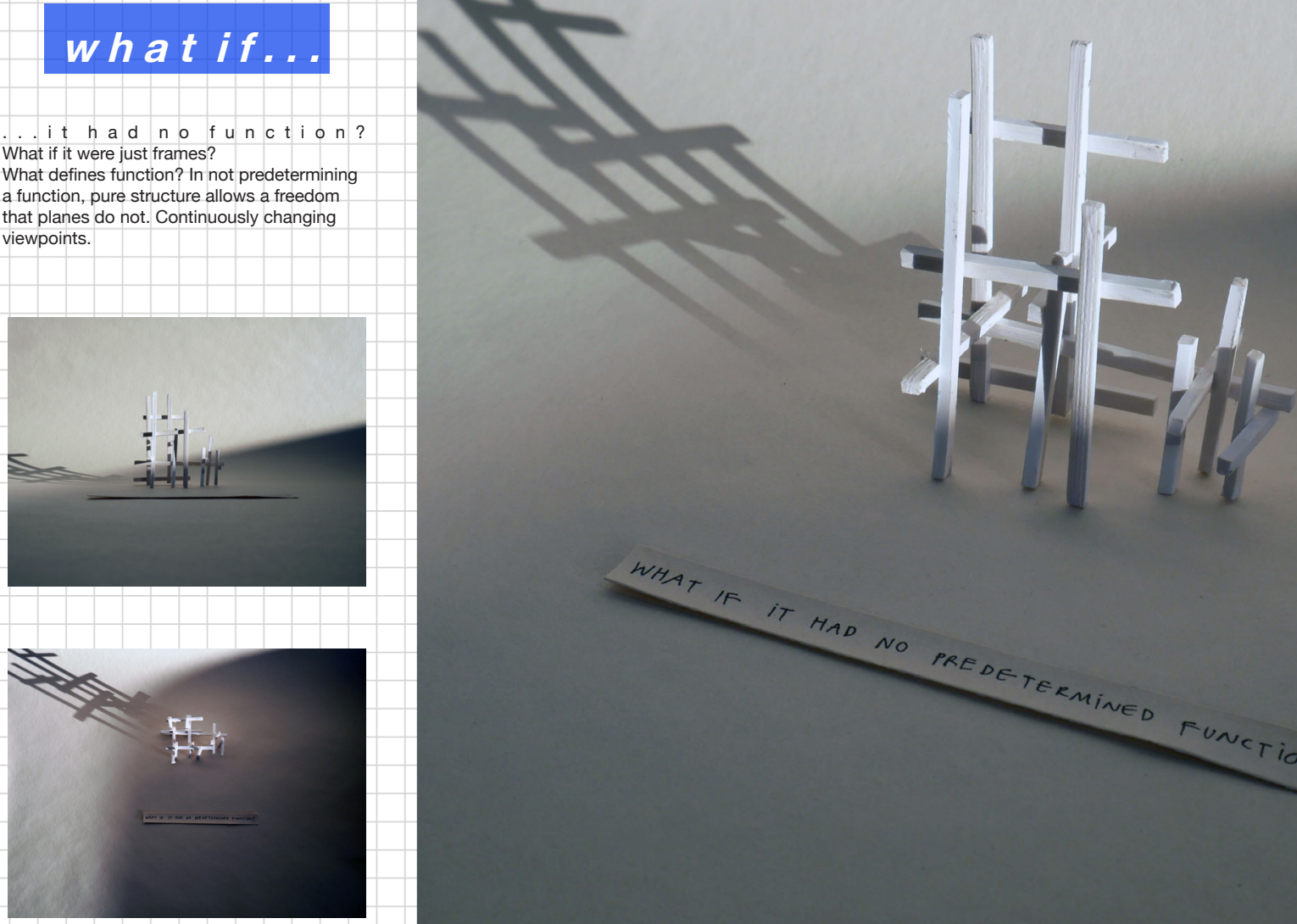

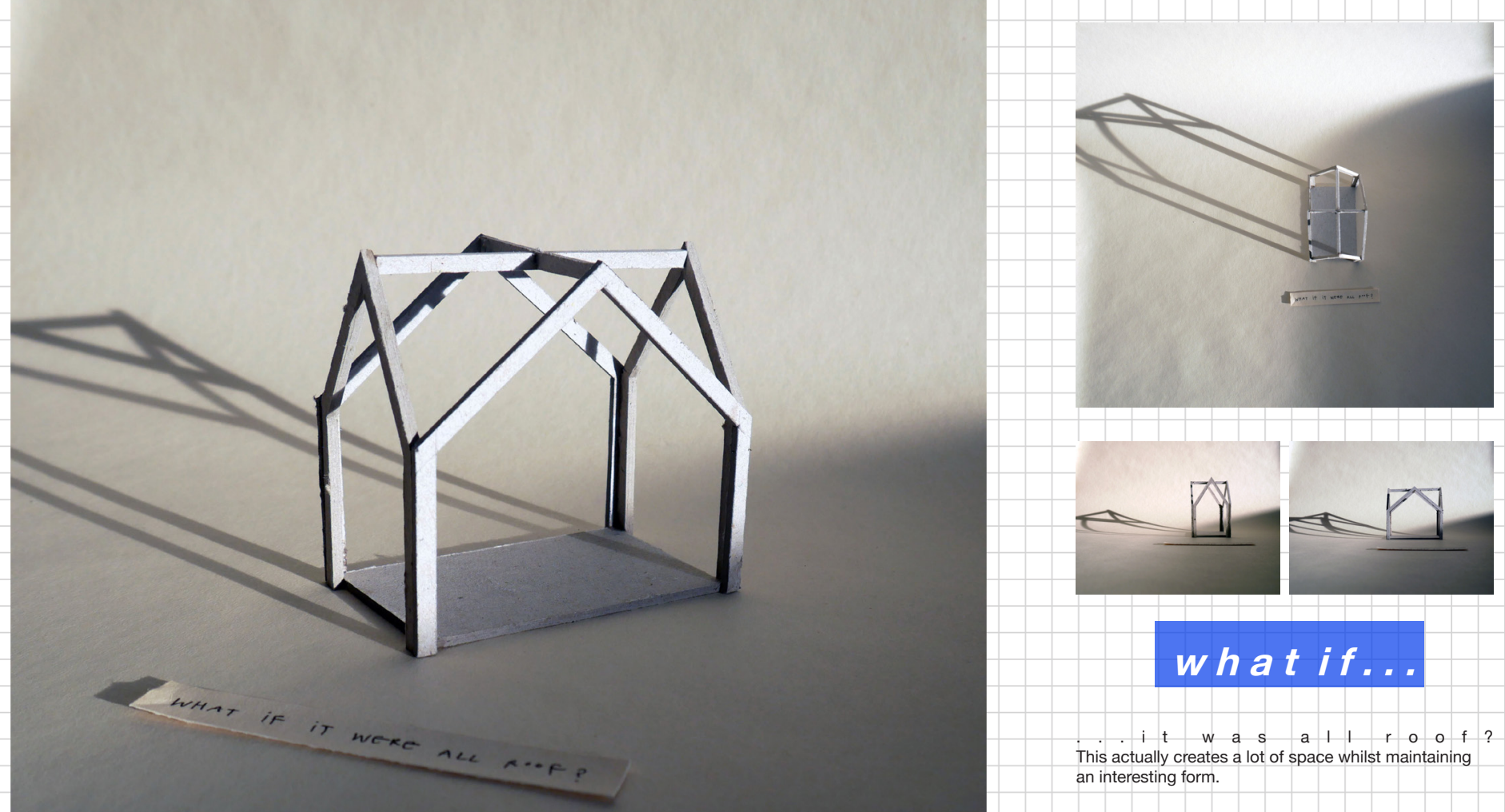

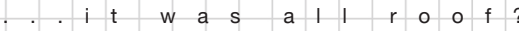
This actually creates a lot of space whilst maintaining an interesting form. 


\section{CONCLUSION}

An inherent and somewhat subconscious exploration of the 'tiny house' was enabled through the process of making with the hands. Pallasmaa explained that "the hand grasps the physicality and materiality of thought and turns it into a concrete image" 107 . Through the process of making physically, hand and mind, concept is developed. Design investigation \#1 employed a circular process in which multiple questions, concepts, preconceived notions etc. could be explored at once and subsequently perpetuate making and thought. Beginning with "what if it looked like all its allowed space?". Predominantly pragmatic, this naturally instigated, "what if it took up as a little as possible?", "what if it had no defined axis?" etc. To conclude, design investigation \#1 enabled a development of question. While design will inevitably become restricted, this process allowed thought to become concrete, which could consequently be again conceived. A development of the brief will enable a construction of Design Investigation \#2. 
I' lo looking for

a plot just like

this one. Please

build me o beautaful

archetini house on it is

Kery Pager 


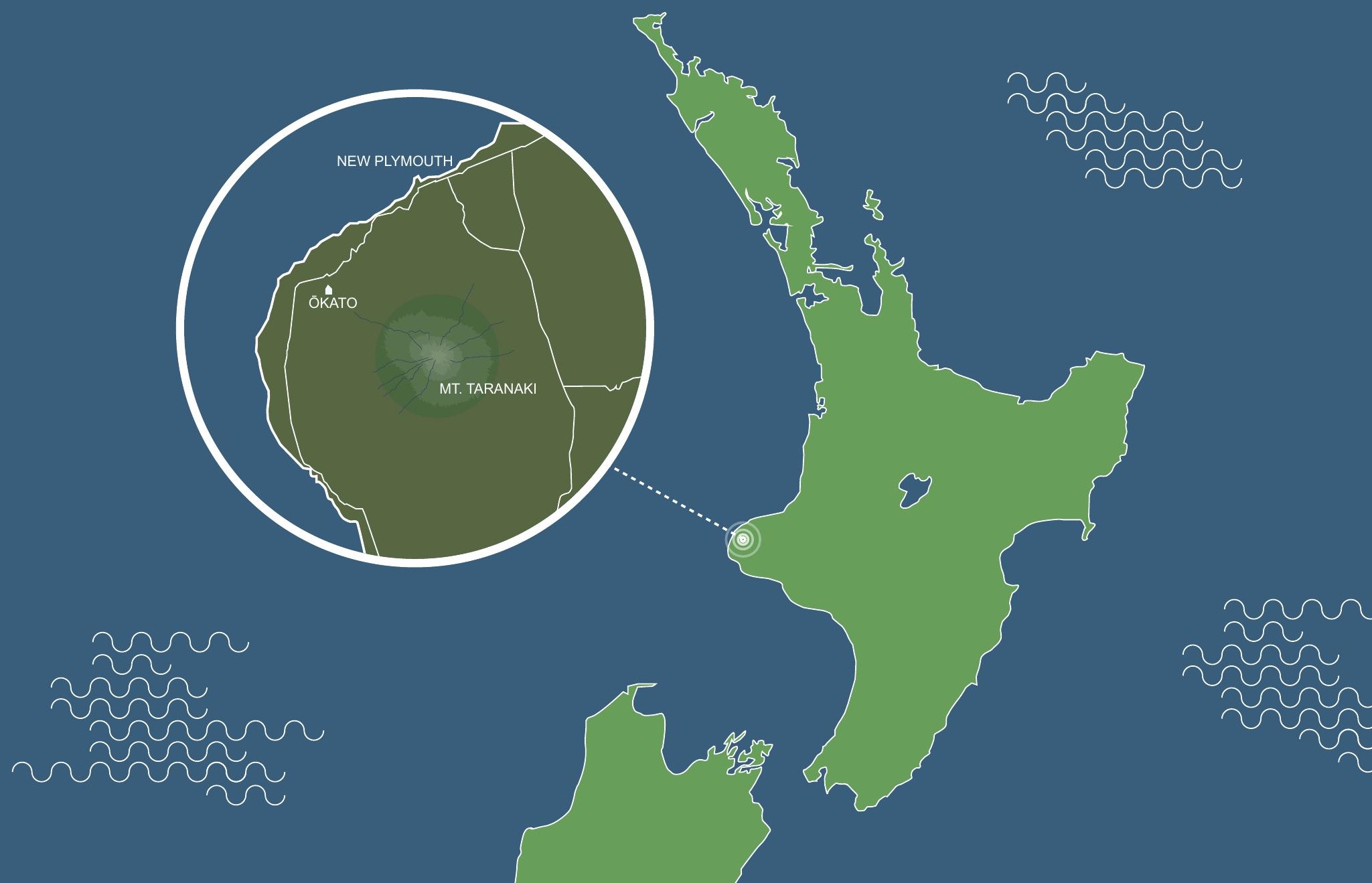




\section{ŌKATO}

+ $_{\text {Ōkato is a small rural town in Taranaki, approximately } 20 \text { minutes }}$ south of New Plymouth. Situated on the Surf Coast Highway// $\mathrm{SH} 45$, the surrounding area is populated by rough yet popular surf spots. The town itself has a school with a role of 280 , a Four Square, three Churches, a vet and a fire station. My sister's house is a quick six-minute drive south of the town itself with a surrounding acre of land which houses five sheep and four chickens. The house sits on the eastern border of the land with a garden planted on its western face. The site is relatively flat with a slight slope to the west. High winds and heavy rainfall frequent the area.
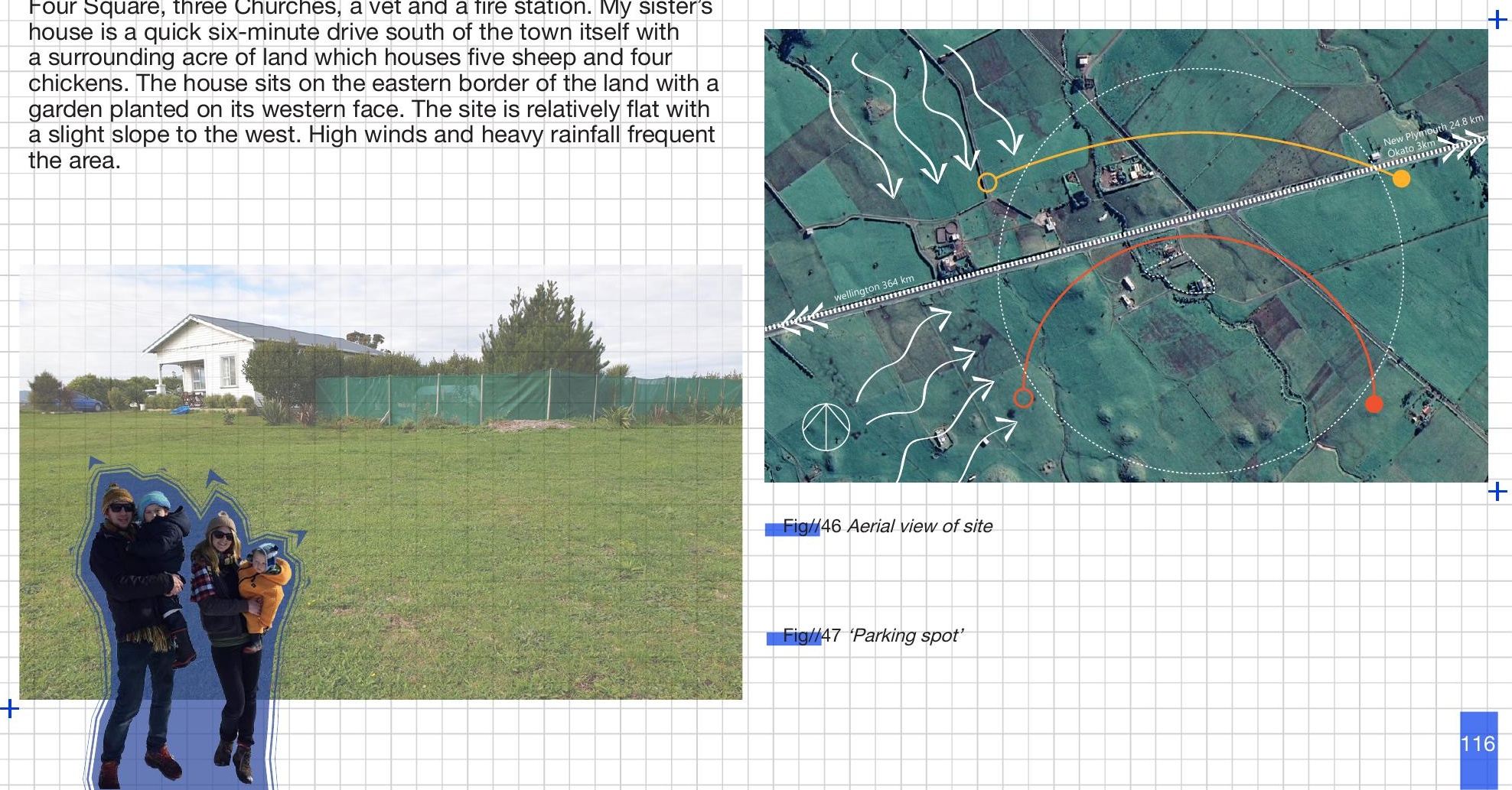

Fig//46 Aerial view of site

Fig//47 'Parking spot' 

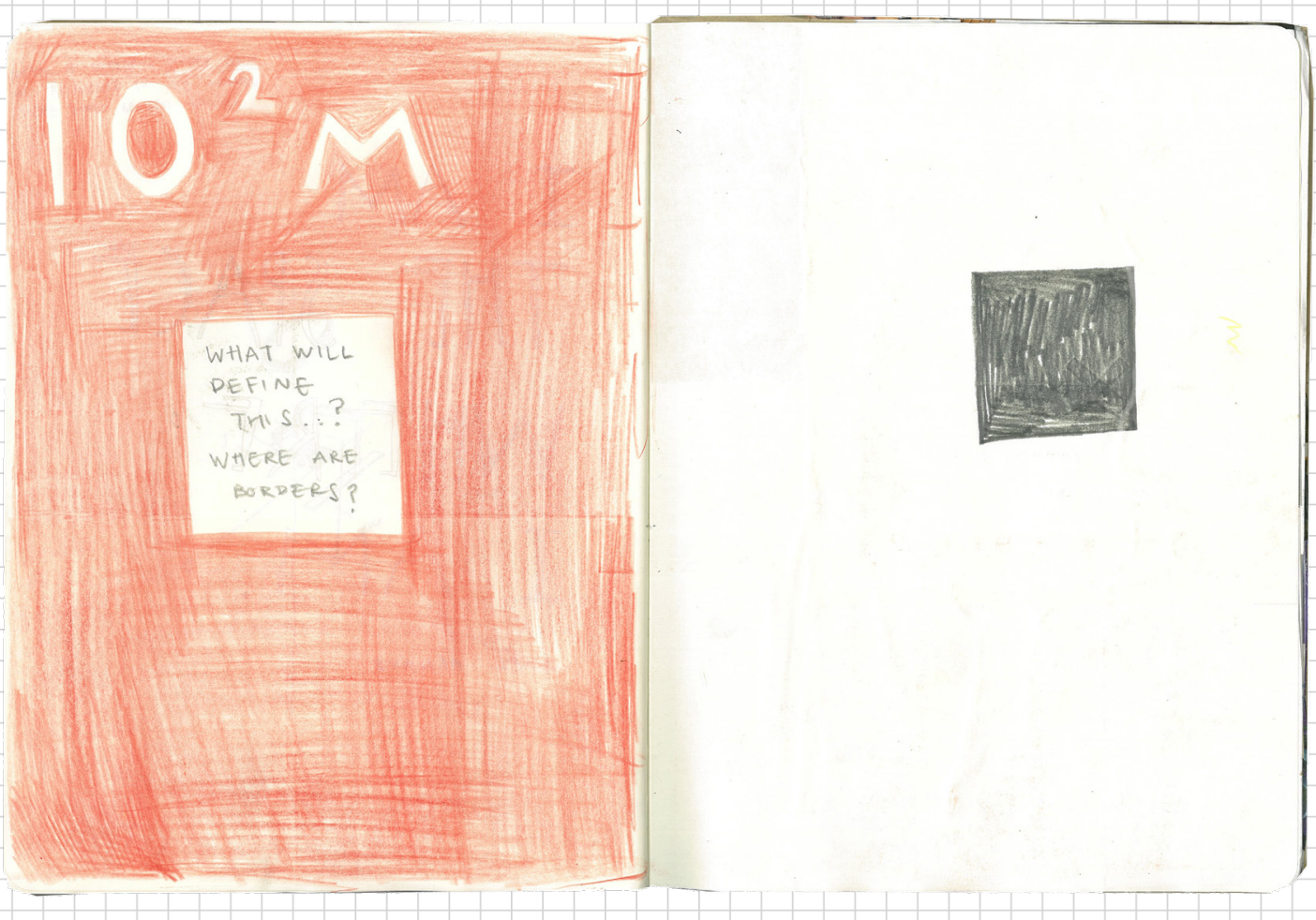

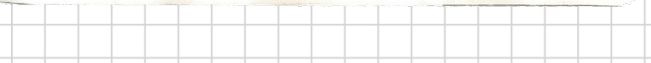




$$
\begin{aligned}
& \text { I WANT } \\
& \text { TO BE } \\
& \text { PROFOUND }
\end{aligned}
$$

\section{(0) PSUDE MY WINDOW}
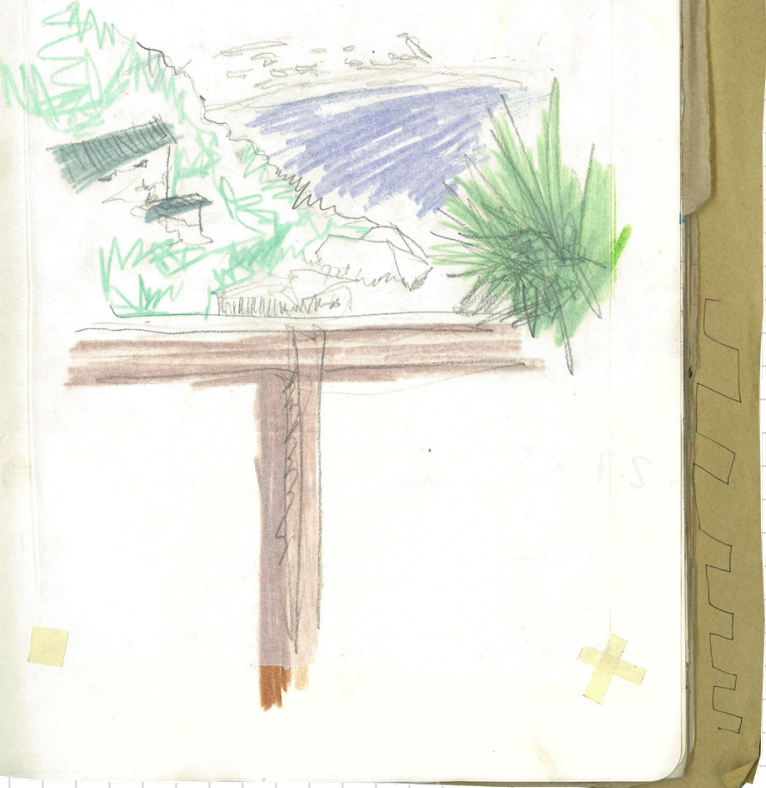


\section{BRIEFDEVELOPMENT}

\section{Everything must be comfortable}
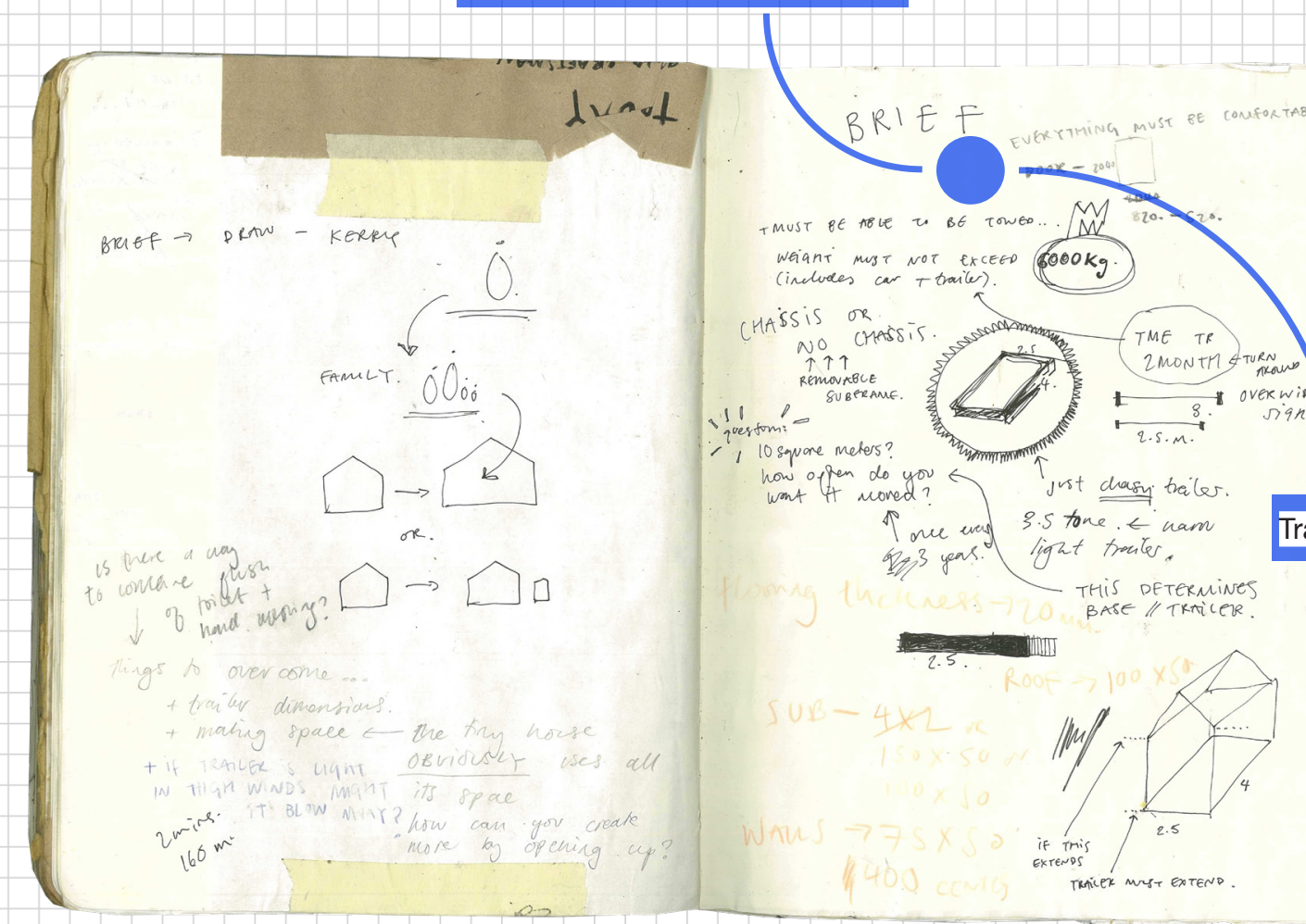

railer Tenure 


\section{PRAGMATICS + POETICS}

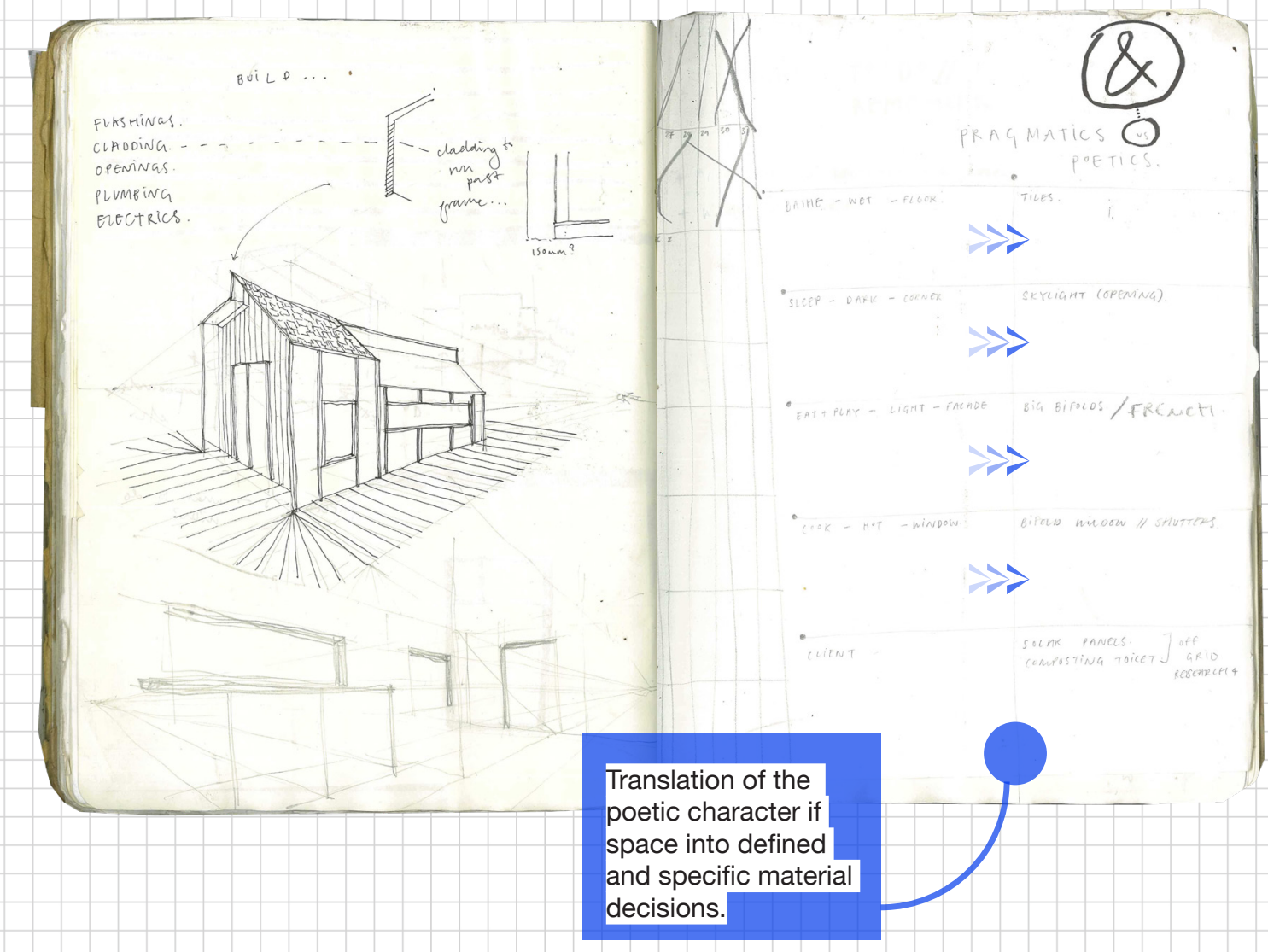




\section{Aakron Xpress Lto}

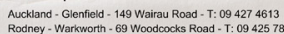

www.aakronxpress.co.nz / www.aakronboats.co.nz

sales@aakronxpress.co.nz

Customer
Solomon Rose

$\underset{\substack{\text { Solomon } \\ \text { solstsuiding@gmali.com } \\ \sharp}}{ }$

\section{Description}

Custom Trailer

As per specs in the comments section

REGO 12 month \& WOF 3 years. Please provide copy of DL and

copy of certificate of incorporation.

Commenta: Your $5 \mathrm{~m} \times 2.5 \mathrm{~m}$ trailer will be built from pre-galvanised box steel with welded areas cleaned and given two coats of 'cold-gall' zinc rich paint. The main frame

and draw-bar are from $65 \times 35 \times 2.5 \mathrm{~mm}$ steel with joits' t $600 \mathrm{~mm}$ centres, under which wrame

a supporting central 'spine' to stiffen up the floor. There will be two axles, the front.

one of which is fitted with Knott Break-away brakes allowing a GVM of $3500 \mathrm{~kg}$ on

a equalising suspension system. Lights are all LED's to NZTA requirements, a

gavivanised jockey wheel is fitted to the drawbar, tyres are 195R50-13" 8-ply

commercial rated to $900 \mathrm{~kg}$ each. Registration and WOF are included so you can

Knott Break-away brakes allowing a GVM of 3500kg:

Payment Terms:

\section{Remittance}

Direct Credit payments can be made to: ASB 12-3107-0019653-00

Please Include Reference: SO-00007050 and Solomon Rose

and Solomon Rose

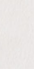

ASM Number

\section{Sales Invoice}

so-00007050

Due Date: 17/06/2020

Invoice: $17 / 06 / 2020$

Required Date 17/06/2020

Price Total

$143.48 \quad 143.48$

Sub Total $\quad 8,105.22$

$8,105.22$
$1,215.78$ $9,321.00$

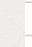

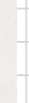

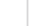

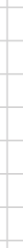

( 


\section{TRAILER TENURE}

The trailer is the first thing one must fork out for when constructing a 'tiny house'. It is the foundation and therefore, (I hope), one of the hardest things to decide on. The dimensions will determine the house, once that box steel frame has been welded together there really is no turning back. Then there is the issue of time, cost, Durogalv, dipped galv -all to be decided on when the ideas about what the end result could be are still being explored. It is a confusing juxtaposition and one I assume does not happen often in building practice. Even when all this confusion has been worked out you must then get the people making the trailers to answer the phone and give you what you believe to be a good price, based on your very limited knowledge. The real stress came when the first deal fell through. It was all arranged, good price, good turnaround time, dimensions given, quote received. I called the makers of the trailer to confirm. It was a Friday afternoon and I was excited to tick something off the 'to buy' list. I call Naweed, who informed me that unfortunately they had just received a deposit for five large trailers and therefore my trailer would not be done till the end of August. Not ideal.

Returning to the drawing board I then call, email, text, add to watchlist, leave messages for as many trailer companies as I can. Eventually coming to a second agreement with the help of Solomon, with a company named Aakron Xpress in Auckland. Four weeks, \$9321, 5X2.5m Done. 


\section{DOMESTIC SPACE brief development}

How can protection be emulated?

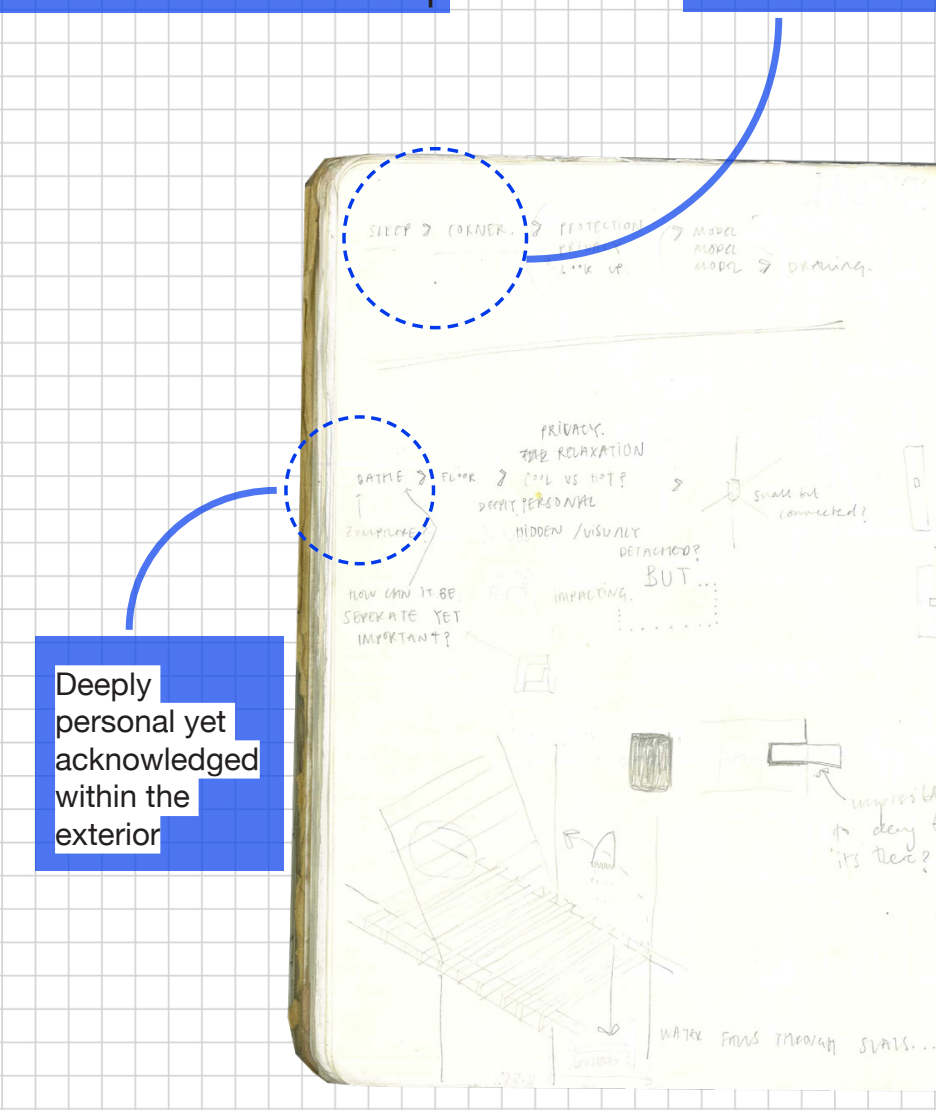

Beginning exploration of movement patterns of each space. Acknowledgment of restriction nof movement within small space. How can this inform/build upon the character of the

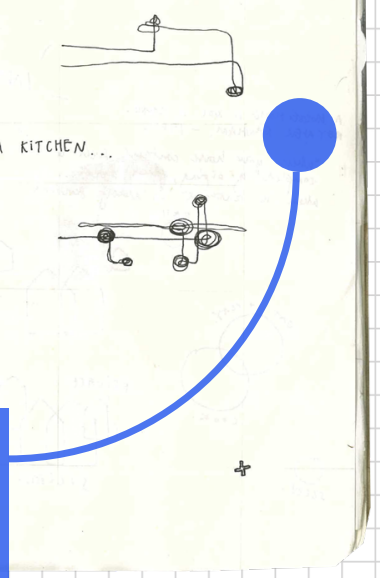

the character of the 


\section{INVESTIGATION\#2}

Following Design Investigation \#1 the need became evident for a theoretical framework to be developed to enable architectural space to be considered rather than the 'tiny house' as object. Within Design Investigation \#2 the aim was to establish both pragmatic and poetic principals of the space to be outlined. A question of need was explored in conjunction with character. Early on I stumbled upon two German terms, 'Erlebnis' and 'Erfahrung' which adequately describe this consideration. Both terms translate into experience, though Erlebnis describes the emotional impress of an event/relationship whereas Erfahrung depicts the pragmatic acknowledgement of an exterior event/relationship ${ }^{108}$. Beginning with analysis of the client's movement and pragmatic needs, the investigation would then reflect on literature and precedents before exploring questions established within these earlier phases through modelling. Essentially Design Investigation \#2 aimed to provide a framework, translating poetic character of space into defined specific material decisions. 


\section{DOMESTIC SPACE}

\section{brief development}

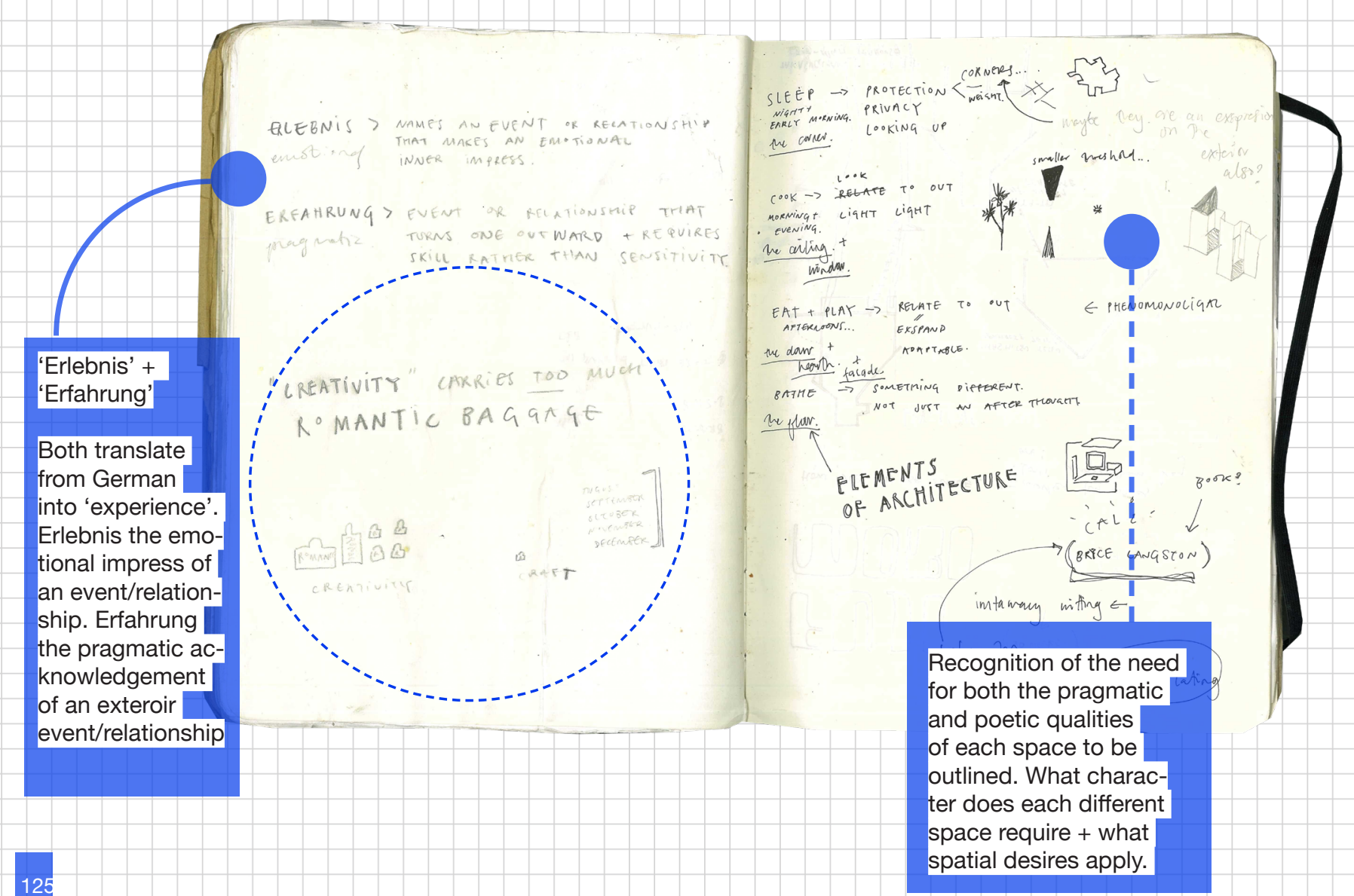




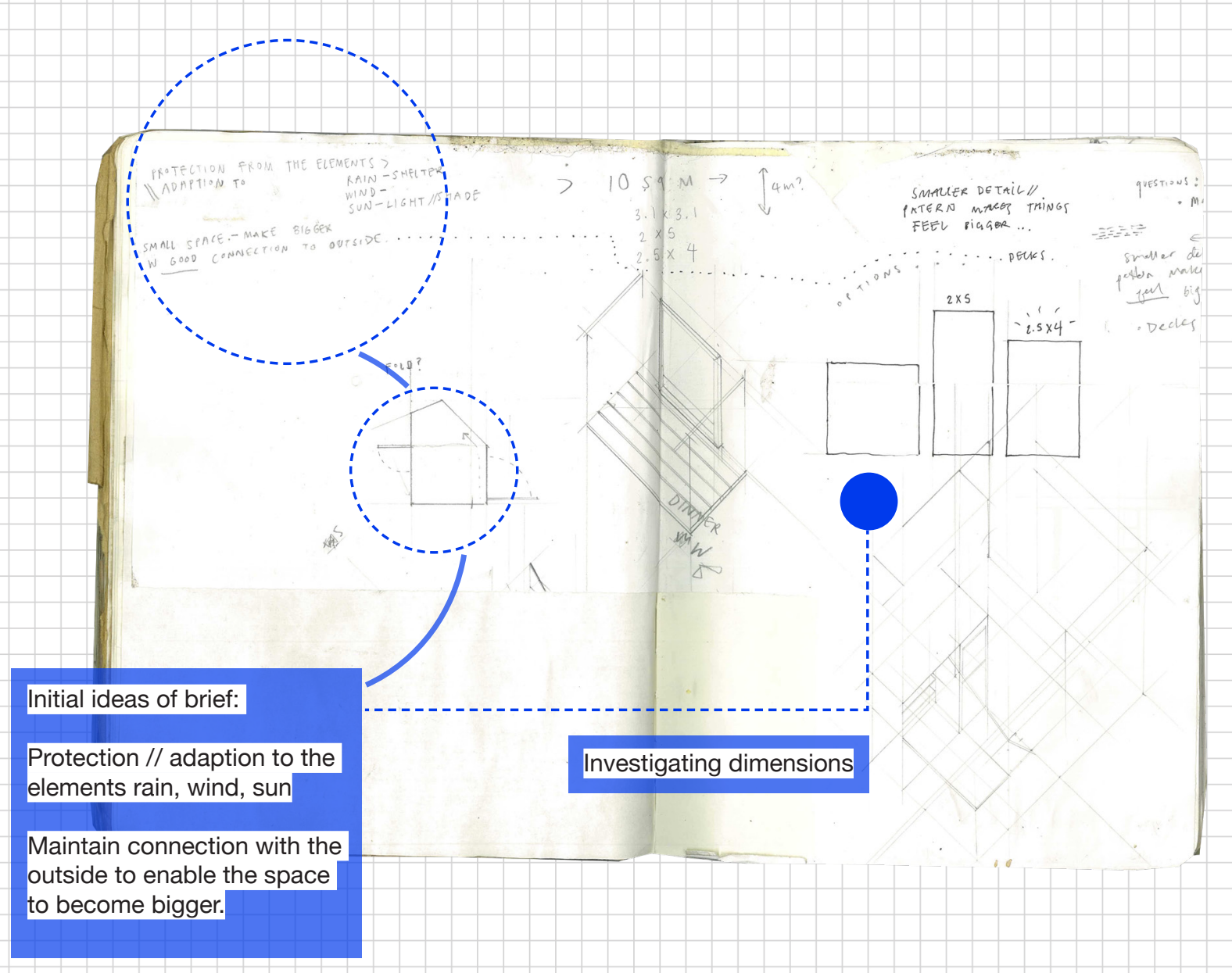




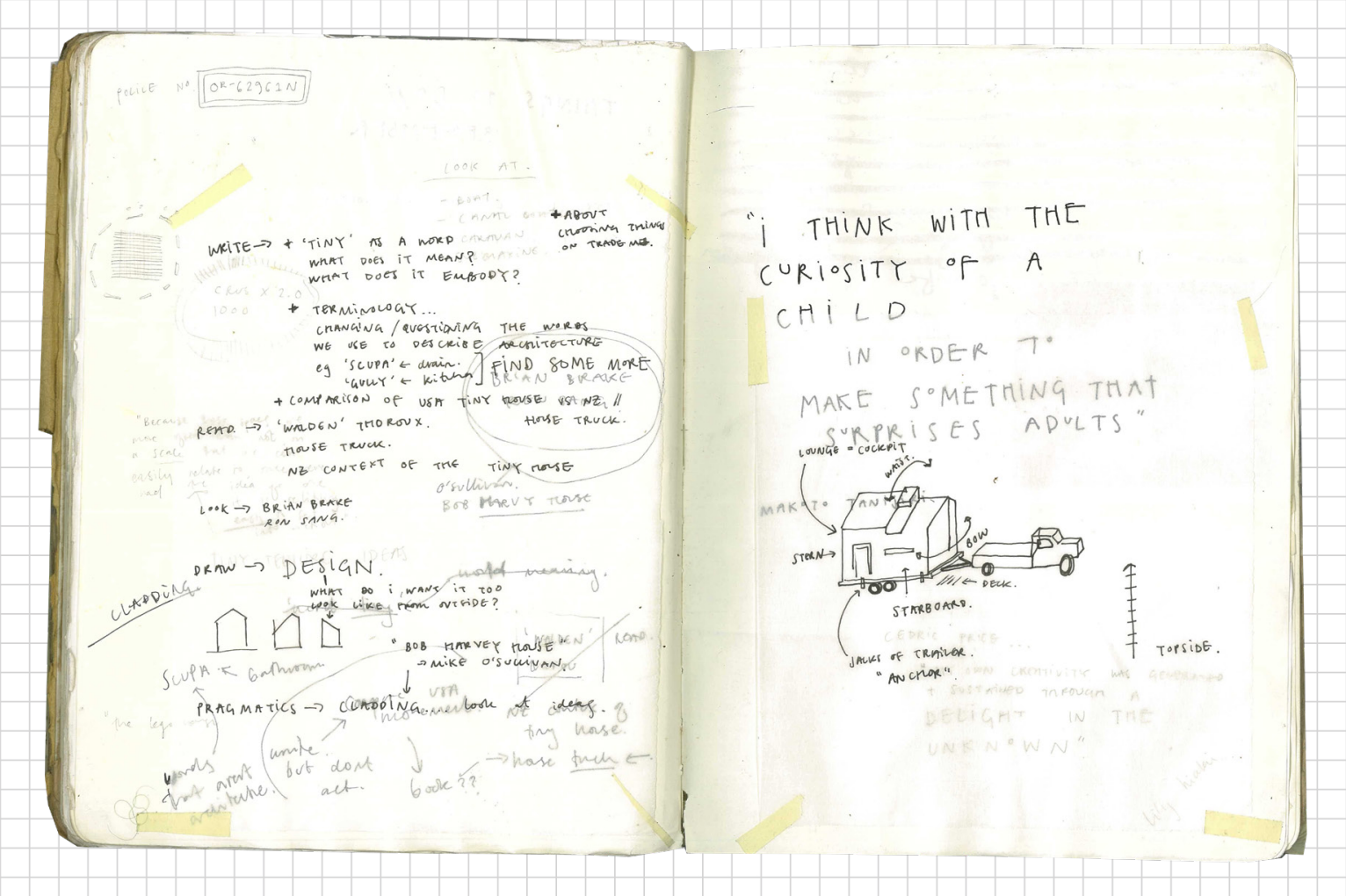




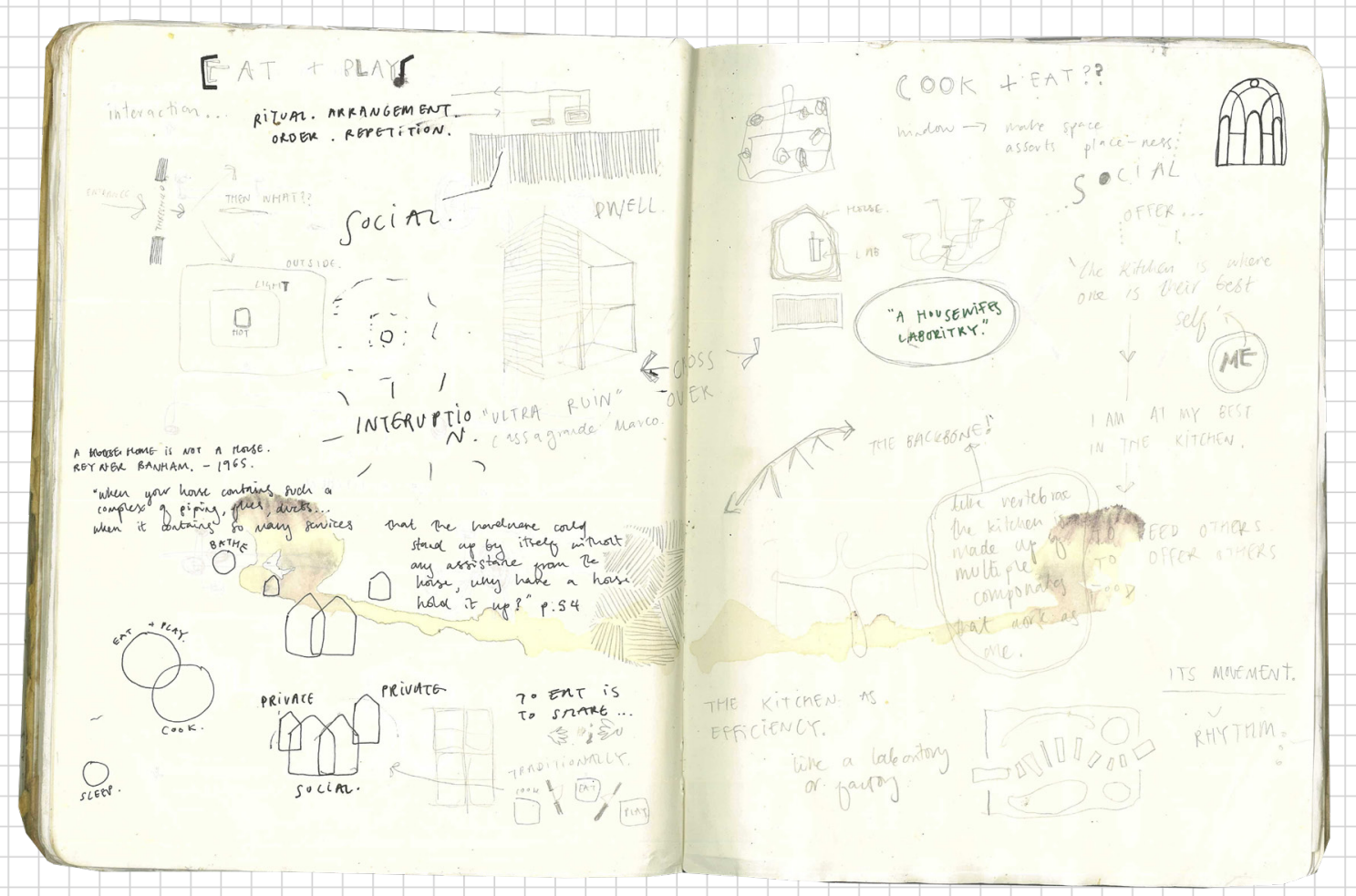


"What is secret never has total objectivity"

- Gaston Bachelard

"...I am the subject of what I am think-

ing."

- Gaston Ba-
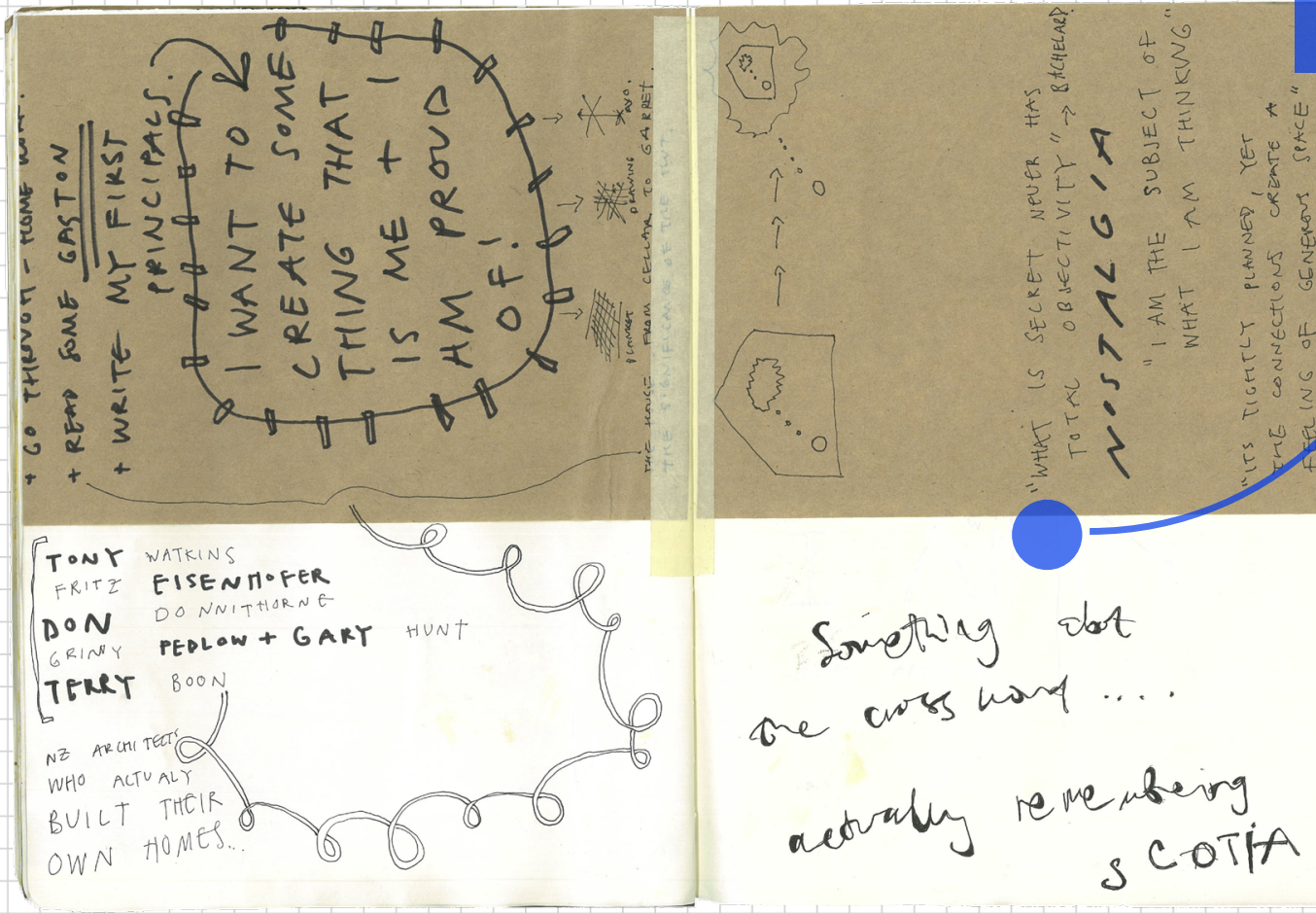


\begin{tabular}{|l|l|}
\hline 0 & I AM \\
0 & THE SPACE \\
\hline WHERE & I AM \\
\hline
\end{tabular}




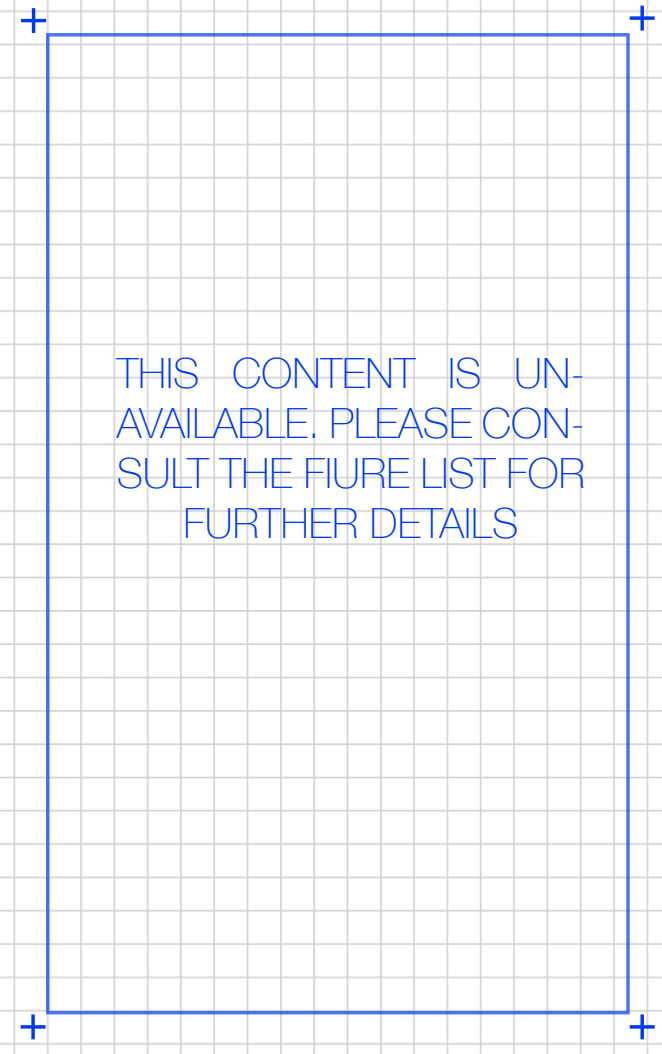

Fig/149 Walden - Henry Thoreau 1854 
The notion of inhabiting is arguably one of the primary functions of human behaviour ${ }^{109}$. Yet what is it to inhabit? A somewhat seminal text of the 'tiny house movement', 'Shelter', outlines what may be conceived as vernacular dwellings. It allows that shelter is much more than a roof overhead ${ }^{110}$. Both thinkers and practitioners -and all in between- grapple with the notion of inhabiting. From Heidegger to Bachelard, inhabiting has been discussed, theorised and examined -with some devoting their lifes work to explain this phenomenon. Therefore, this research does not aim to encapsulate the whole essence of inhabiting, but merely define a 'stance' of sorts to allow the development of a framework for design.

As Bachelard allows, "...it is not enough to consider the house as an 'object' on which we can make our judgments and daydreams react" 111 . We must go beyond pure description of facts or impressions to allow a closer understanding of what it is to inhabit. Micro-house user Christian Shallet said that in designing his 'Lego Apartment' in Barcelona "for me, the key approach was to ask one very simple question: what are the essentials of everyday living? The answers I came up with were somewhere to cook, wash, sit and sleep"112.

I have separated the qualities of the house into four spaces - 'Sleep', 'Bathe', 'Cook' and 'Eat + Play'. I acknowledge than in reality these spaces will almost definitely intersect and overlap. In short though, the aim of this exploration was to develop a character for each space from which to design.

I have attributed the four spaces a certain time or times of day which, along with other practical requirements, have been established through analysis of the client's regular sized home in Wellington. Similarly, each space has been assigned an architectural element(s) and local climate, again derived from analysis of the clients home yet further explored through theoretical concepts, precedents and model making. Through this codification the suggestion is that both the pragmatic and poetic will be clearly established within a defined framework. 



\section{DOMES}

In response, the space has been attributed the afternoon time of day. Within the occupational analysis, eat and play are seen to be ever flowing between one another, in a constant state of flux. It could be considered the heart of the house. By far the largest space, it pumps its blood to all other attached spaces. This analogy somewhat consolidates the notion of collectivity that eating and playing promote. Sharing a meal, or engaging in other activities with another is a collective action. In an investigation undertaken by Sarah Wigglesworth for the development of a residential space in London, movements of a dinner were mapped before being translated into the floorplan. Domestic life interrupts the conventional plan grid, resulting in unconventional yet collective spaces ${ }^{113}$. This notion of collectivity is a transformative process of individuating, disparate to the individual solely ${ }^{114}$. Thus, it could be argued the 'Eat + Play' space is conceptually interactive.

Because of this fact, I have attributed two architectural elements. The first is the façade because it facilitates the notion of collectiveness in relation to the whole, through both its exposure to the exterior and its direct relationship with the interior. The second, the hearth, is a more obvious, more primal explanation of collectiveness, a simple yet powerful gesture. Lastly to enable the openness that 'Eat + Play' maintains, its local climate has been assigned as light. The notion of the space as the heart was fundamentally adopted through the modelling phase. Consideration of how the hearth and façade work together to enable a sense of collectivity interrogated the notion of envelope and disruption. Through this, the essence of 'Eat + Play' was discovered to be fundamentally the heart. The surrounding spaces are influenced by and somewhat a product of 'Eat + Play'. 


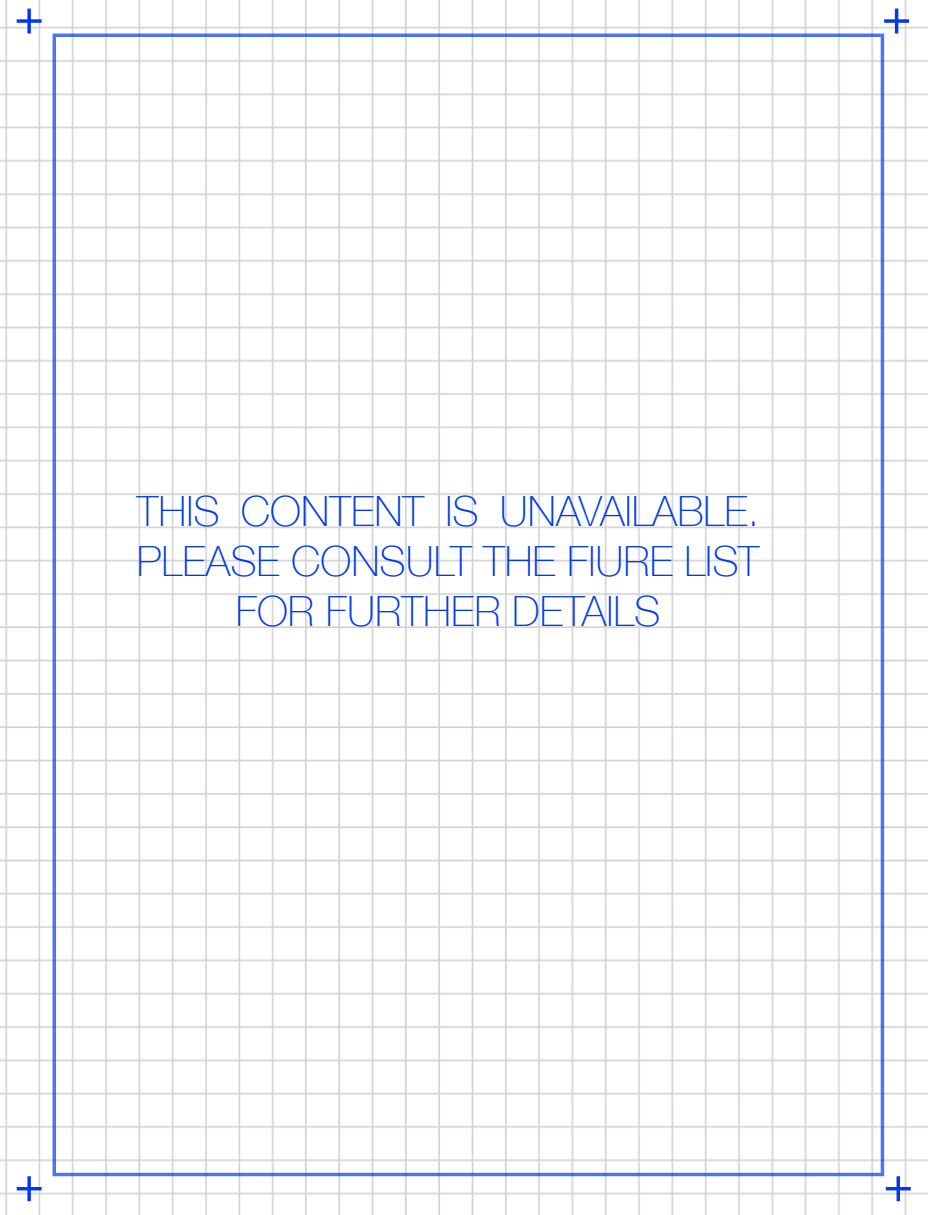

Fig//50 Sketch: Disorder in a Dining Table - Sarah Wigglesworth 
THIS CONTENT IS UNAVAILABLE. PLEASE CONSULT THE FIURE LIST FOR FURTHER

DETAILS

$+$

Fig//51 Dining Building with Window Chairs -Allan Wexler 1983 


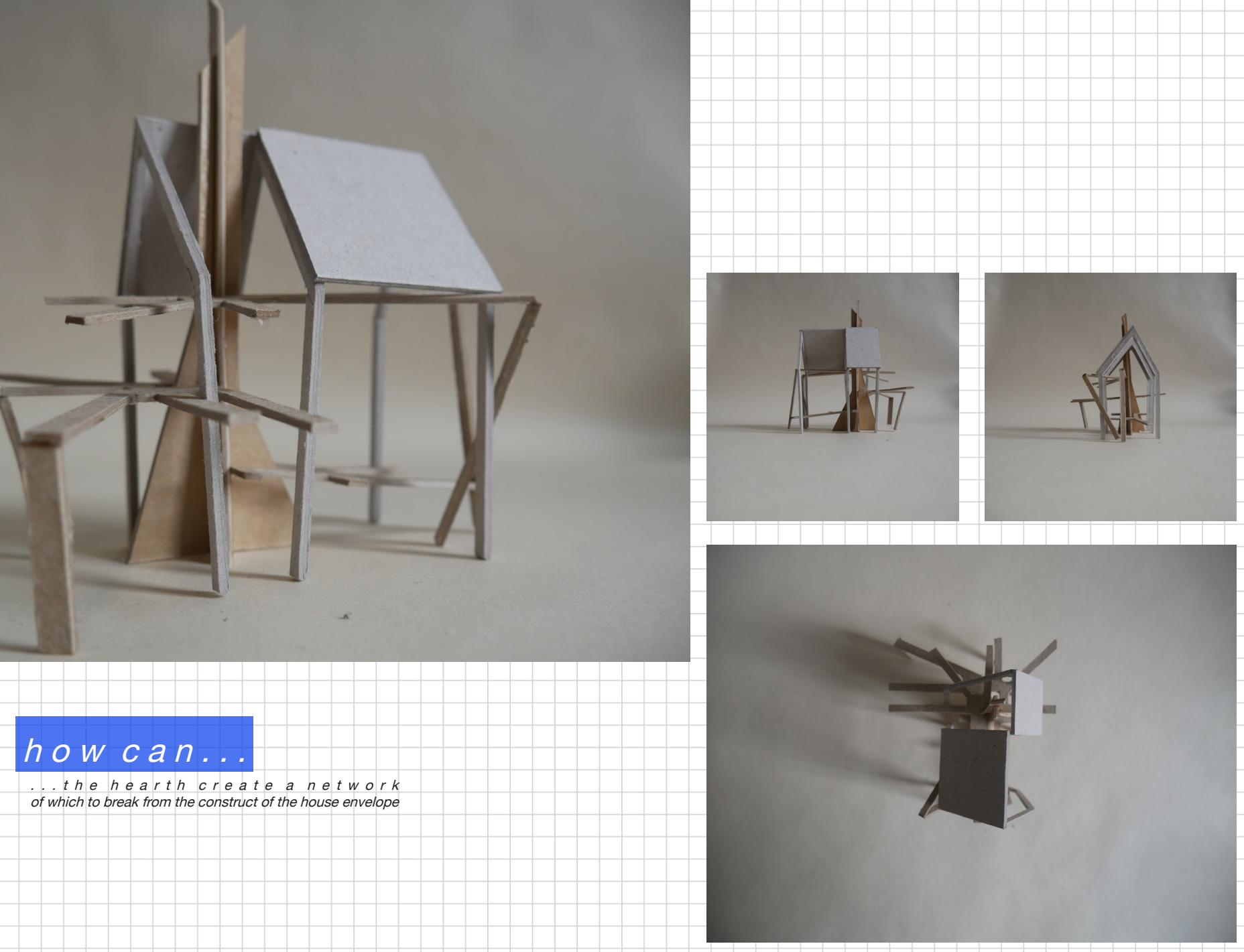




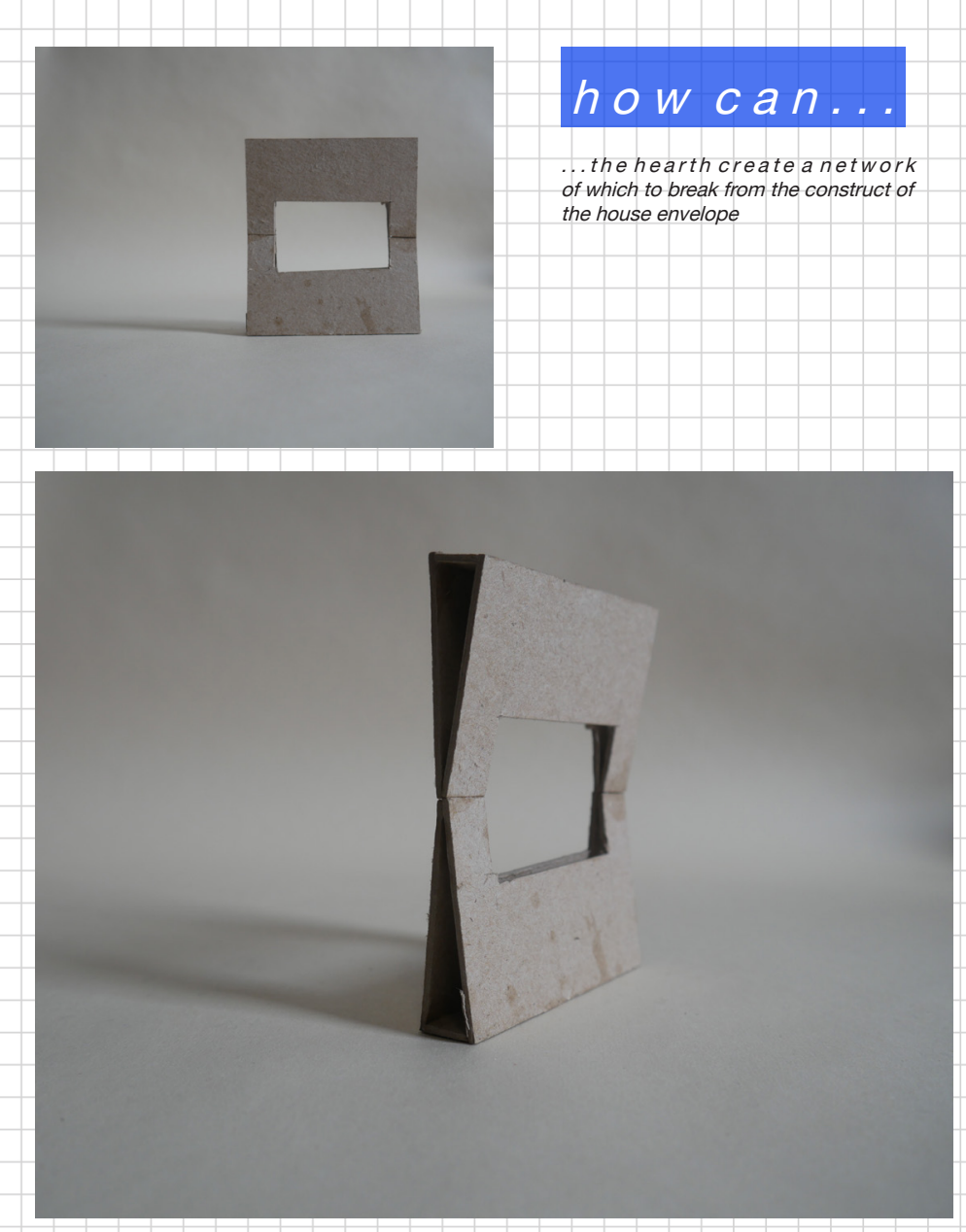




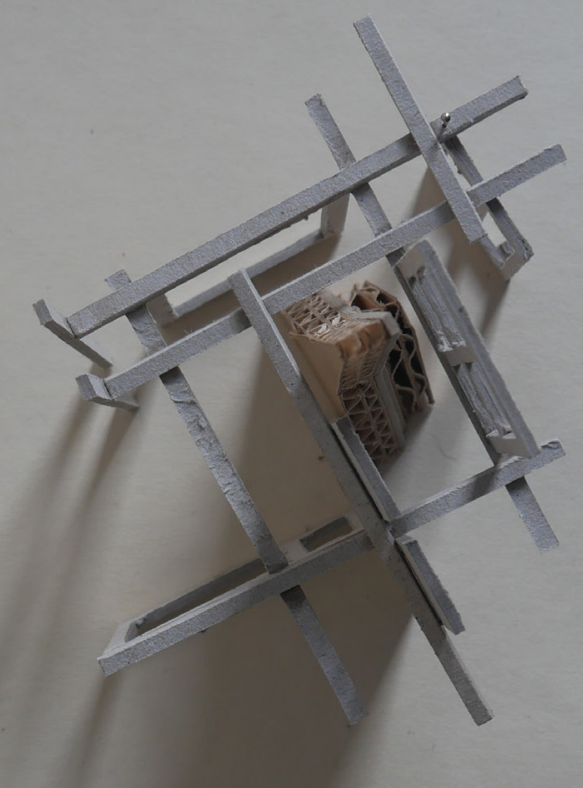



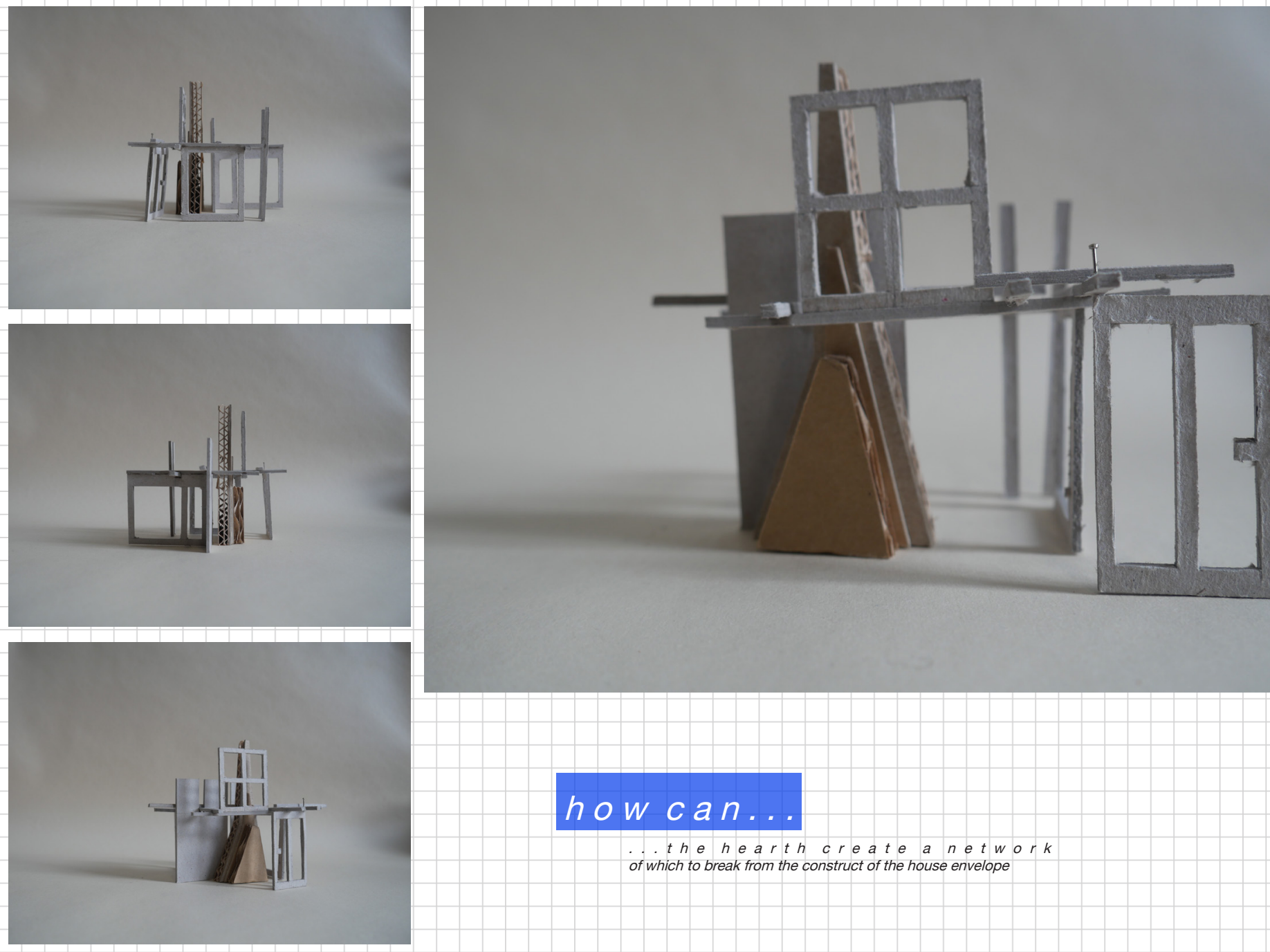

how can...

...the hearth create a network of which to break from the construct of the house envelope 


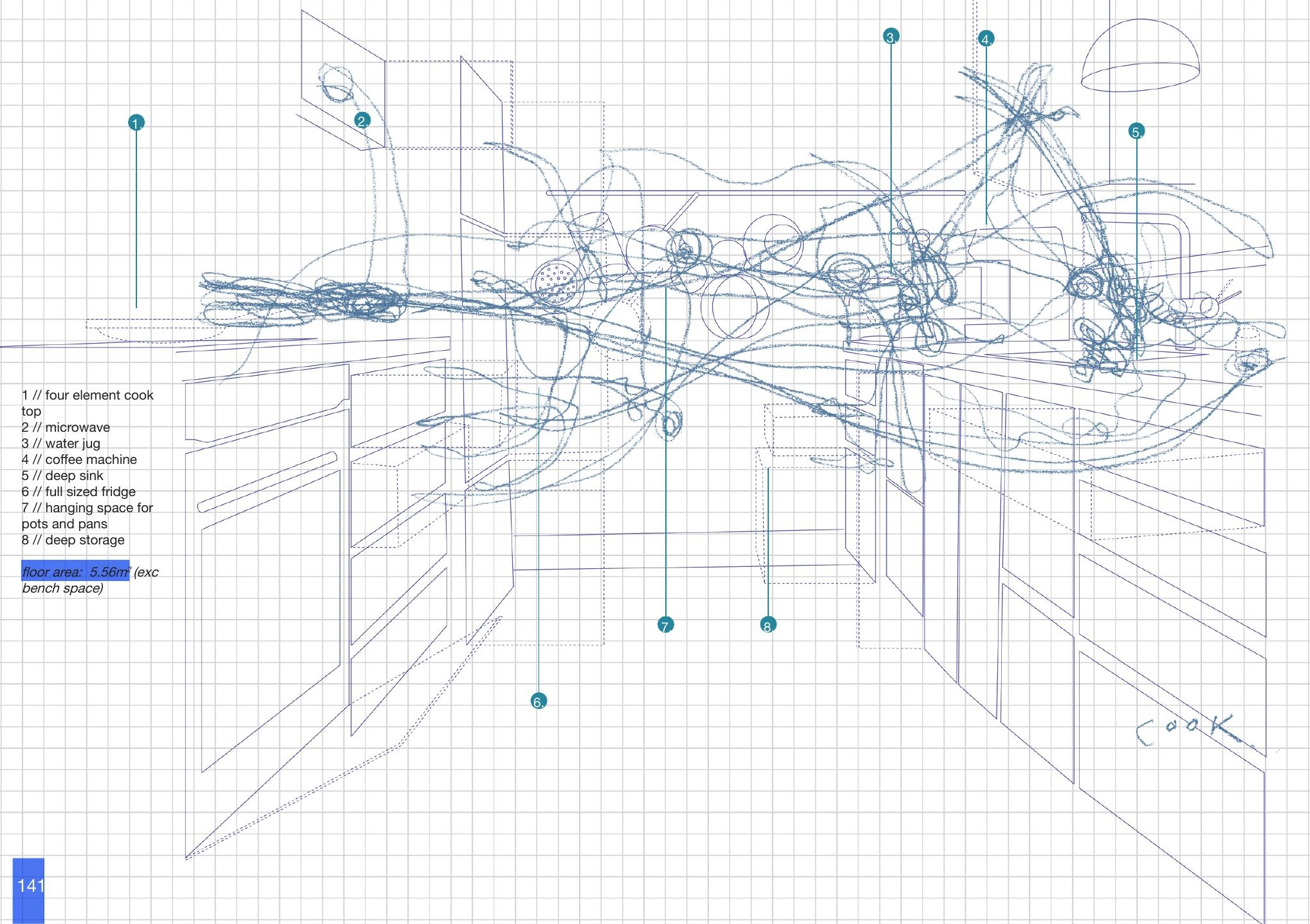


To cook is to dance. It is rhythm and science intertwined in creation. Its physical appearance is predominantly one of apparatus and function, yet its essence is arguably described by its occupation. The 'Cook' space my client currently occupies is her favourite room. The analysis of the space's occupation highlighted the very obvious trait of continuous movement, between tools of creation. However, because of the client's relation to the permanent house on the land, the space has been attributed only morning and afternoon times of day.

Conceptually, the 'Cook' space of the modern house may be considered an embodiment of humans' development of tools. An evolutionary demonstration of people's move from the open fire pit to the microwave, it is a space that houses the equipment needed/desired to carry out an essential task. It would be arrogant to overlook the role of 'The Frankfurt Kitchen' on modern 'Cook' spaces and their relation to the house. Designed by Grete Schutte Lihotzky in the 1920's, the design treats the kitchen as a laboratory. Unpretentious and socially orientated, Schutte Lihotzky believed the newly designed kitchen to be ".... one of the first steps toward building a better more egalitarian world..."115. Although the ideas projected in 'The Frankfurt Kitchen' profound at the time, what is taken from them today is somewhat aesthetic. It is therefore not the intention of this research to adopt nor take inspiration from The Frankfurt Kitchen, but simply to acknowledge its potentially unconscious yet distinct role within 'Cook' space. The advancement of tools within the 'Cook' space has changed its role in relation to the house. Tools are now showcased for others.

Once a separate space, the 'Cook' space is now an integrated and integral part of the home. It has therefore been attributed two architectural elements. Firstly, to draw attention to the notion of performance/ entertainment, the window. More subtly, the ceiling offers the symbolism of autonomy. Finally, to address its transient nature, a hot climate has bee attributed. The modelling phase predominantly investigated this transient quality of the 'Cook' space. It testing the juxtaposition between the tools and occupation of the space, and more conceptually, how the idea of the transient can be physically embodied through a blurred distinction of envelope and boundary.

To summarise, the 'Cook' space is both science and art. Its character aims to showcase a composition of occupant and tool. 


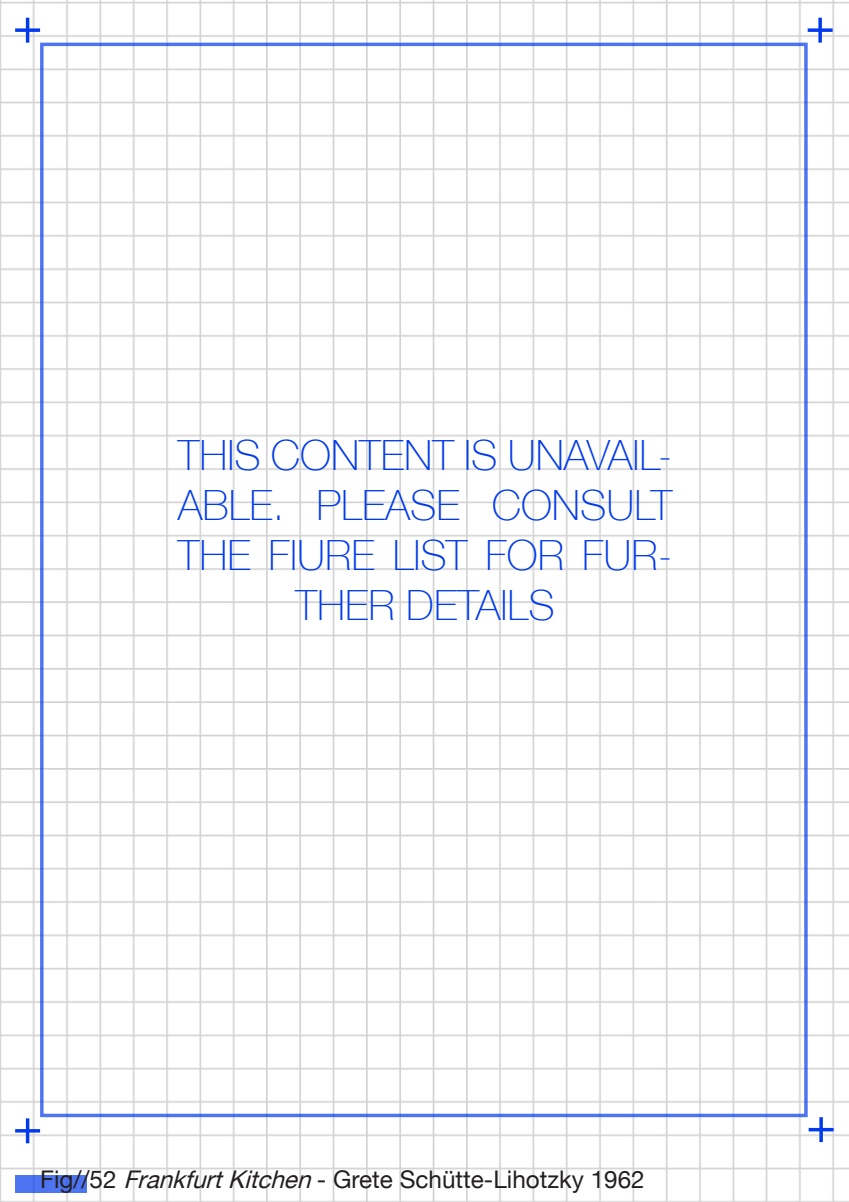



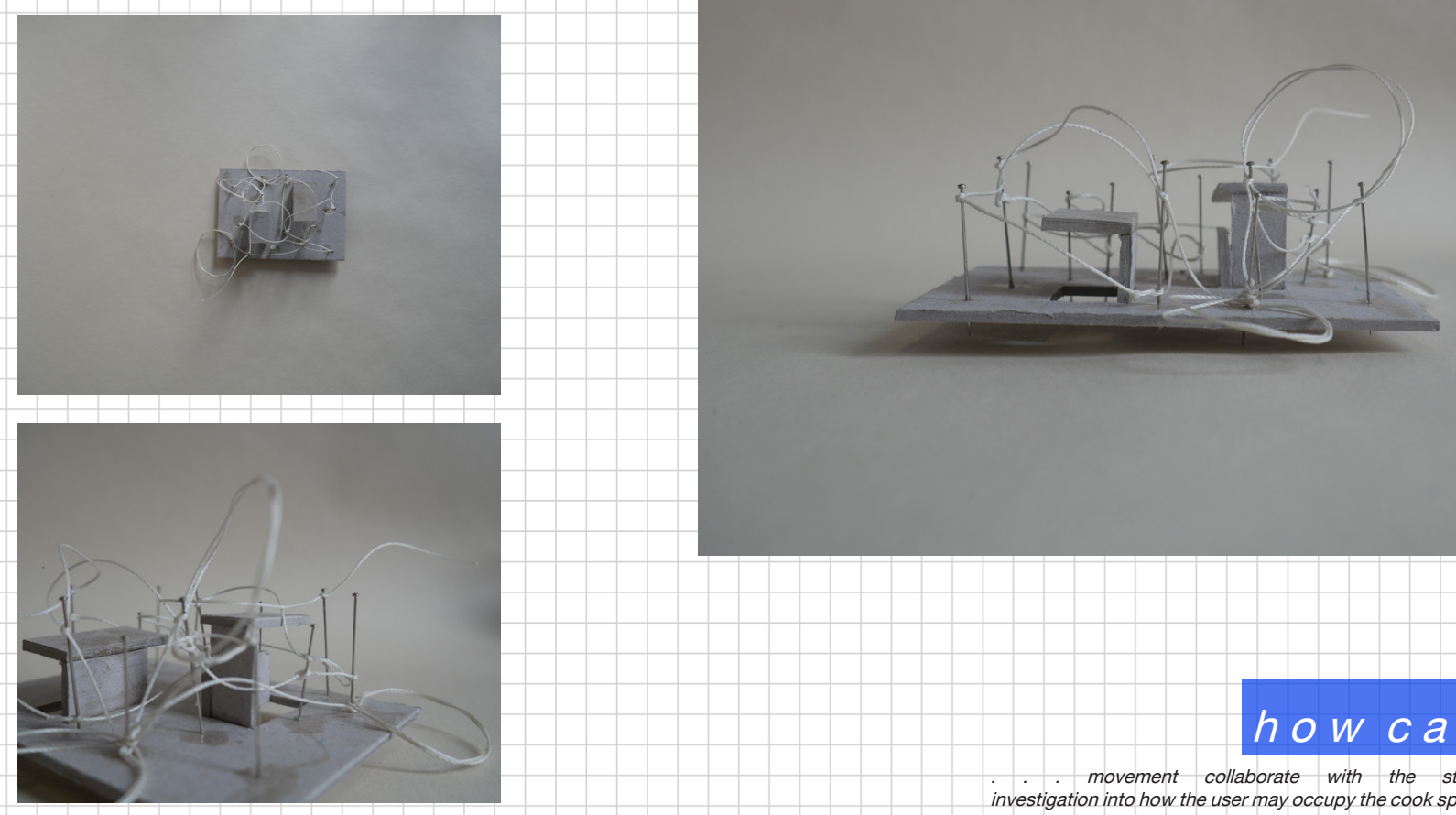

how can...

investigation into how collaborate with the static 


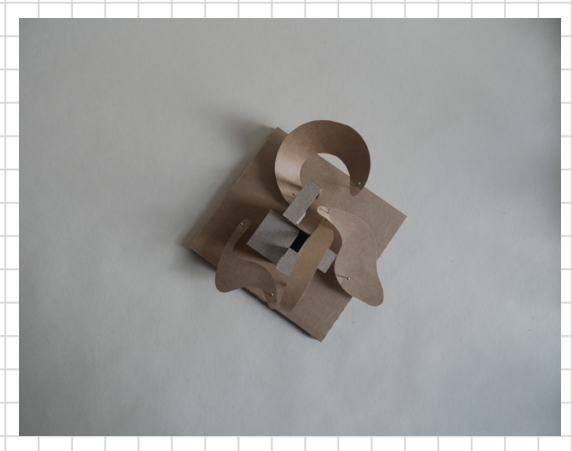

\section{how can...}

movement collaborate with the static
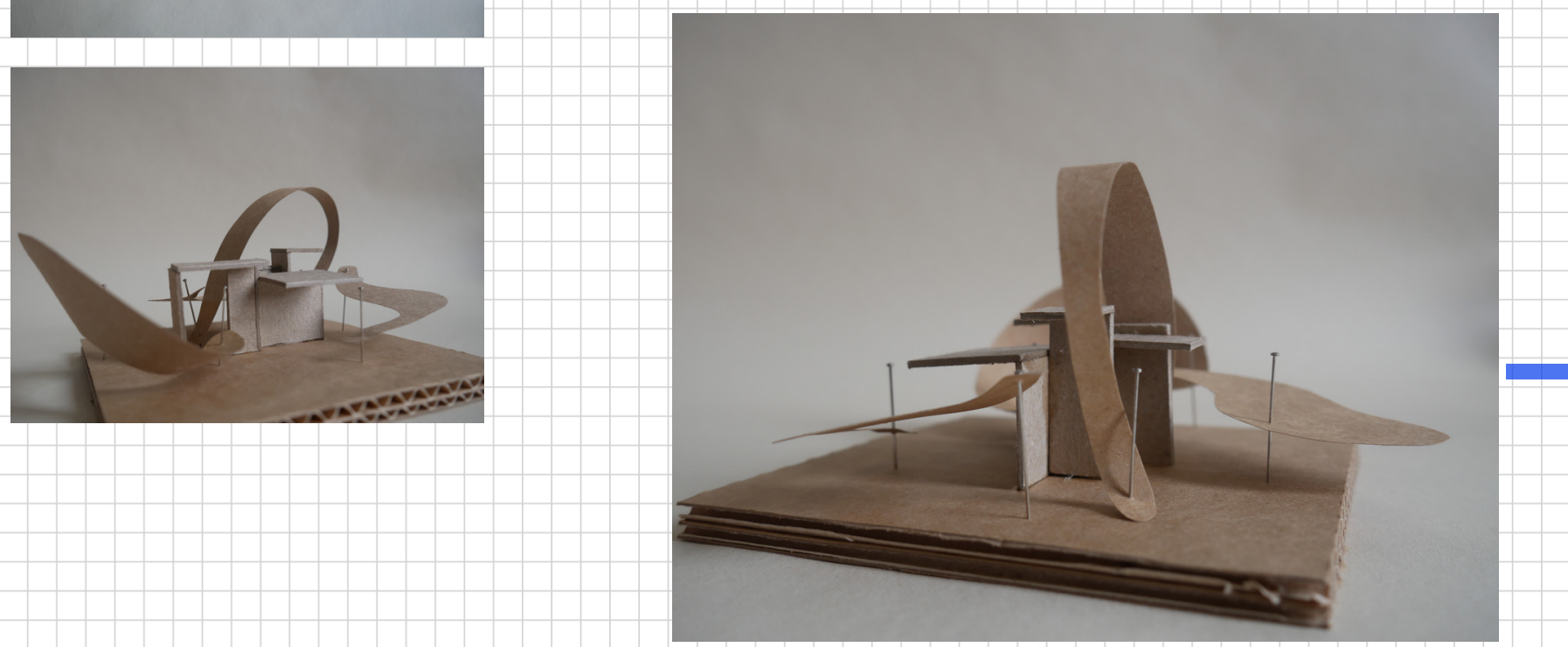

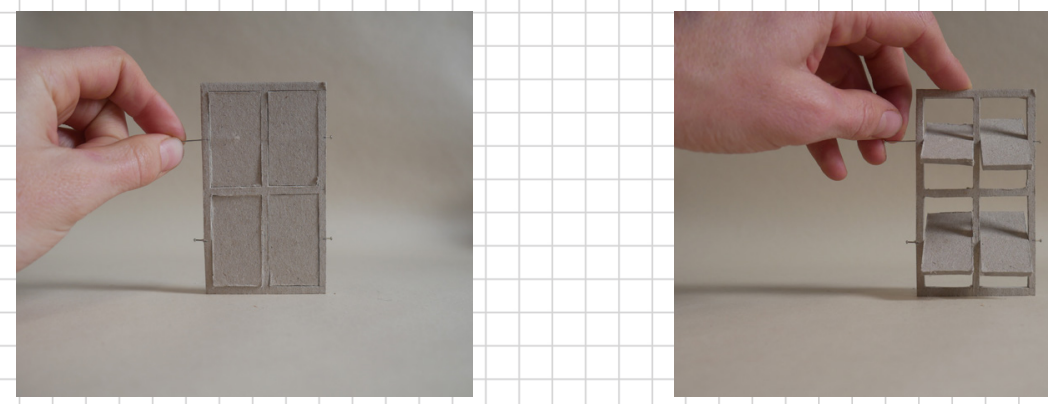

how can...

envelope allow a greater expanse of the space?
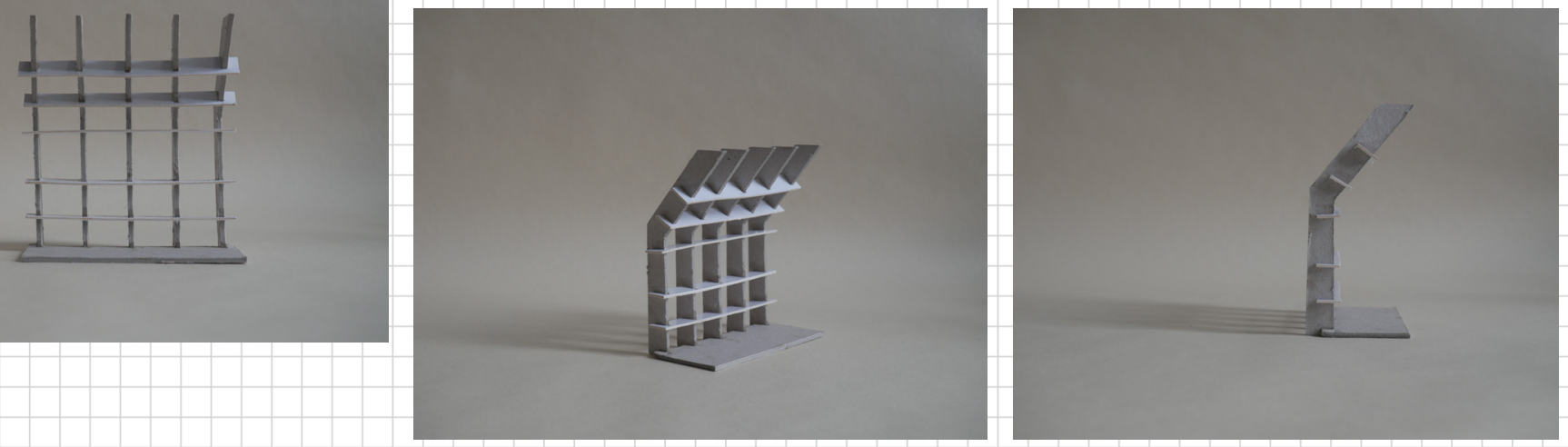

$14 \pi$ 

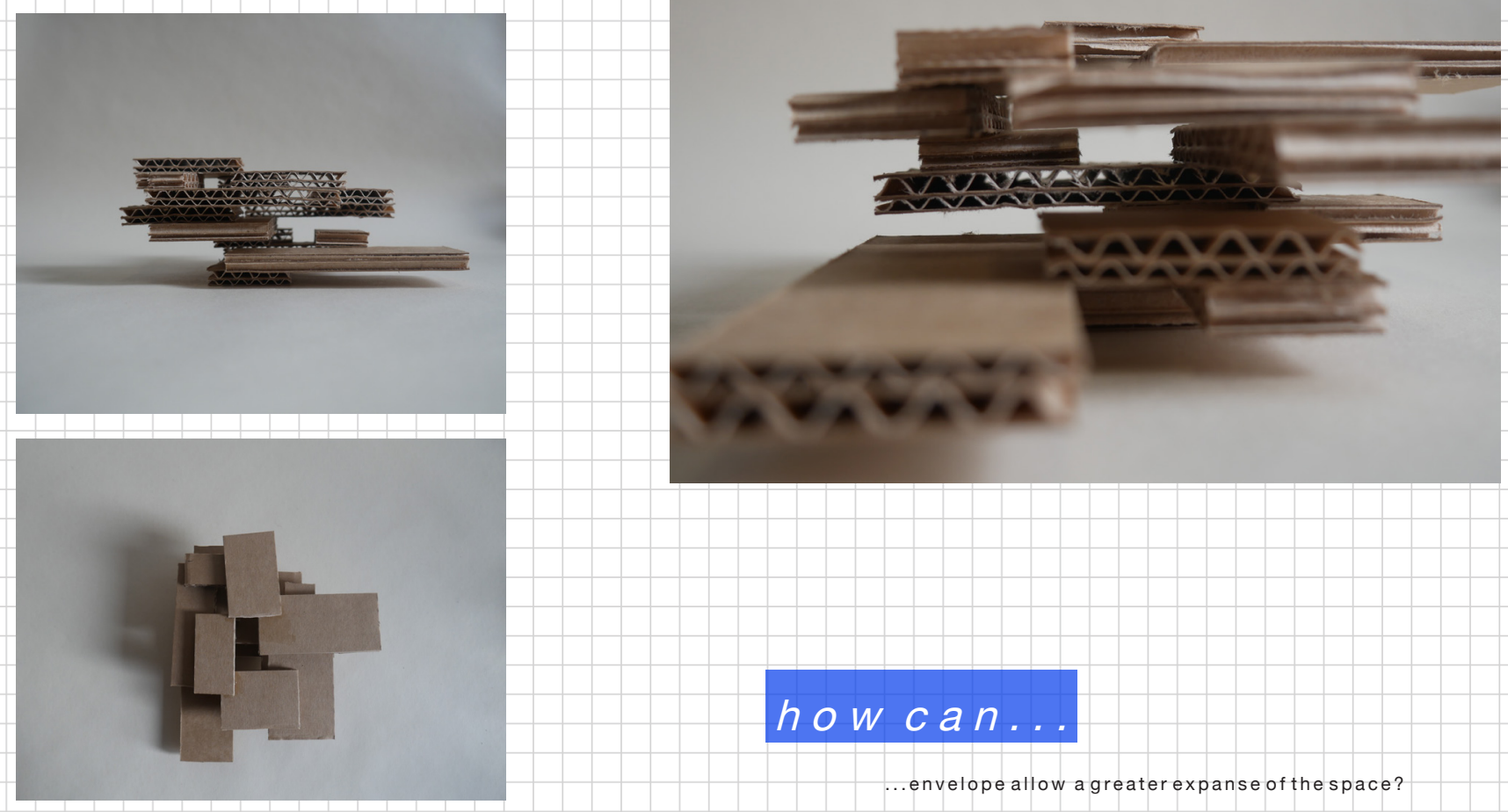

how can...

..envelope allow a greater expanse of the space? 


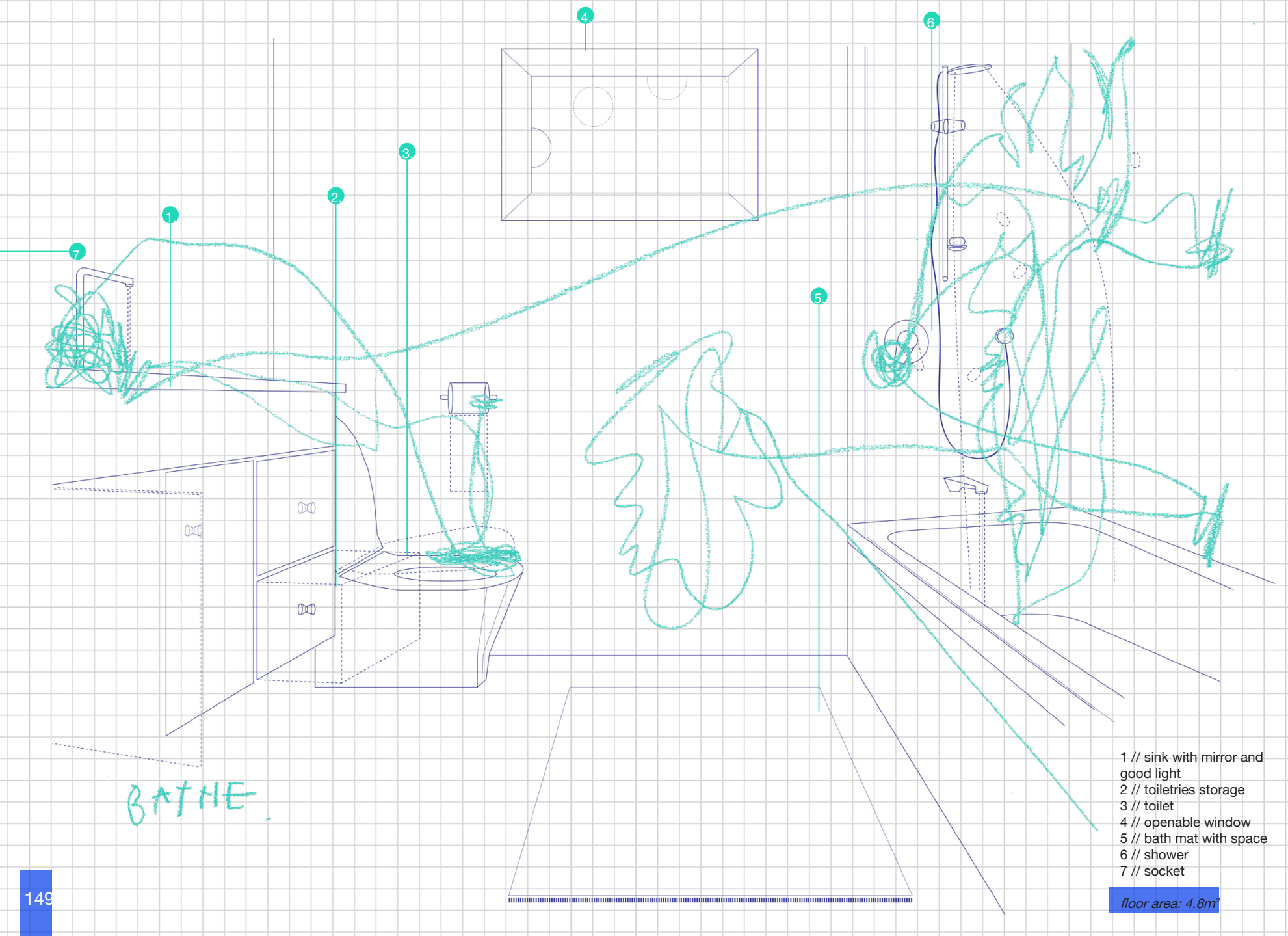


The bathroom is often a neglected aspect of architecture yet, is arguably the space where occupant and architect are most intimately bound. Occupational analysis of the client's bathroom resulted in what could be classified simply as efficiency. For obvious reasons the 'Bathe' space was attributed all times of day to address its role within occupant life. However, this research aims to delve further into the concept of the 'Bathe' space. To bathe is to reflect, to contemplate. It is privacy. Meanwhile its functionality is undeniable. An interesting and somewhat contrasting stance on the bathroom comes from an article written by Beatriz Colomina and Mark Wigley which suggest that, "...to enter the toilet is not to enter the smallest room in a building but to enter a space as big as a city whose smells, noises, flows, and chemical processes are deeply threatening"116.

Throughout history the bathroom has grappled to its relation with the rest of the house, largely staying away from the 'problem' (or addressing it at a superficial level). It has only really been since modern architects stopped denying and instead began to question the role of the bathroom within architecture, that true explorations of the bathroom have been conducted. Again, Colomina and Wigley explain that "to talk about architecture without talking about toilets is to operate in denial of a whole array of sexual, psychological, and moral economies"117. It could be argued this is not only because of its traditionally taboo subject matter but because of a functional need to collate activities which involve the exposure of wetness.

Because of this, the local climate assigned to the 'Bathe' space is wet. Due to its more personal and contemplative component it has been attributed the architectural element of the floor. Through these codification decisions the aim of the 'Bathe' space is enable both interaction and separation with the surrounding house, , yet adhere to its reflective, private needs and qualities. Continuing from this, within the modelling phase, explorations questioned how the space could physically interrupt the house without revealing itself wholly. Aspects of the 'Bathe' space were elongated, reduced etc to consider how this may conceptually be established. It should be noted here that this ideology was particularly influenced by the idea of the relationship of 'Bathe' space to 'Cook' space. For obvious reasons this cannot be achieved within a small space. It was therefore necessary to investigate conceptually, creating a separation which predominantly implemented verticality. In short, the character of the 'Bathe' space aimed to acknowledge and celebrate both the wholly private and contrastingly undeniably required aspects of the rituals involved within. 


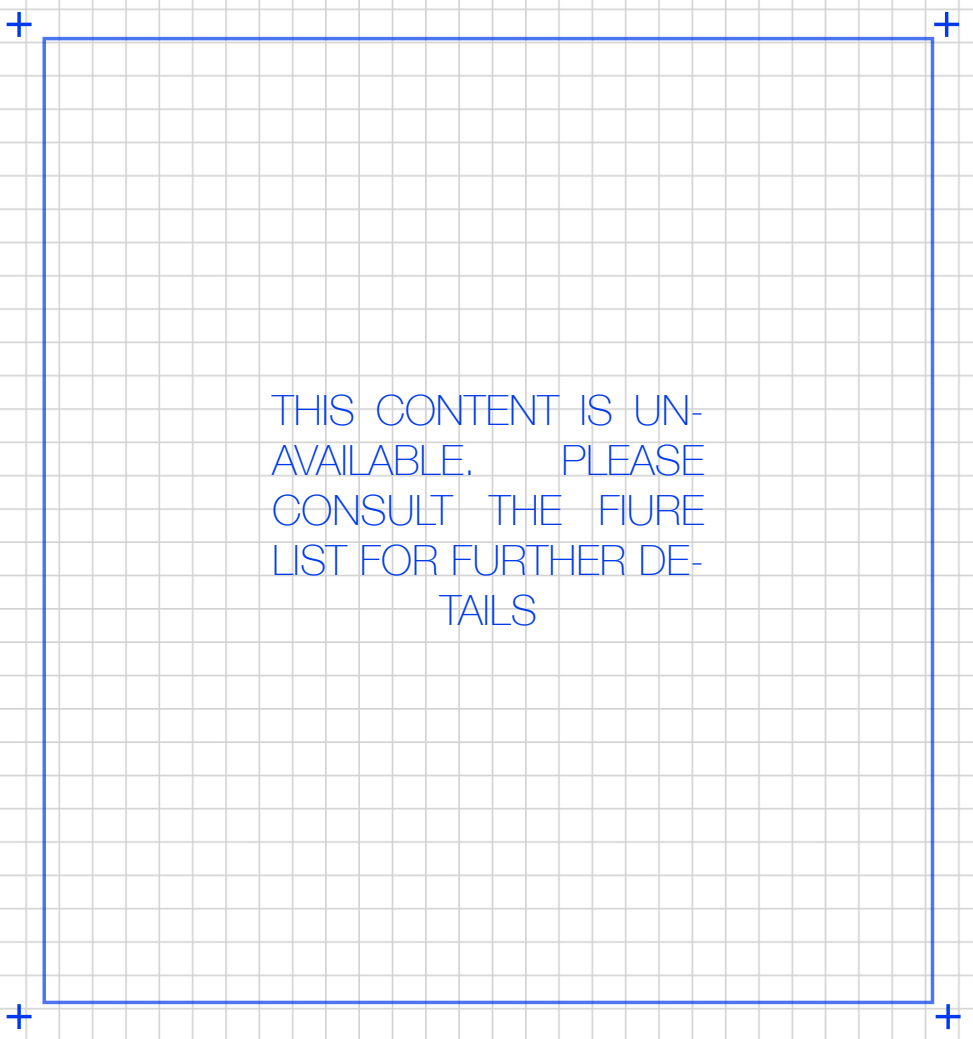

Fig//53 Bathroom Sweet-FAT 
$+$

THIS CONTENT IS UN-

AVAILABLE. PLEASE CON-

SULT THE FIURE LIST FOR

FURTHER DETAILS

Ideas taken from these examples investigate the privacy of the bathroom and its innate occupance within the household. How can the bathe space enable its users and nonusers to acknowledge it whilst maintaining privacy?

THIS CONTENT IS UNAVAILABLE. PLEASE CONSULT THE FIURE LIST FOR FURTHER DETAILS 
how can...

. the space asertitself

investigation of how levels and depth define oth-

er spaces whilst maintaining its own privacy
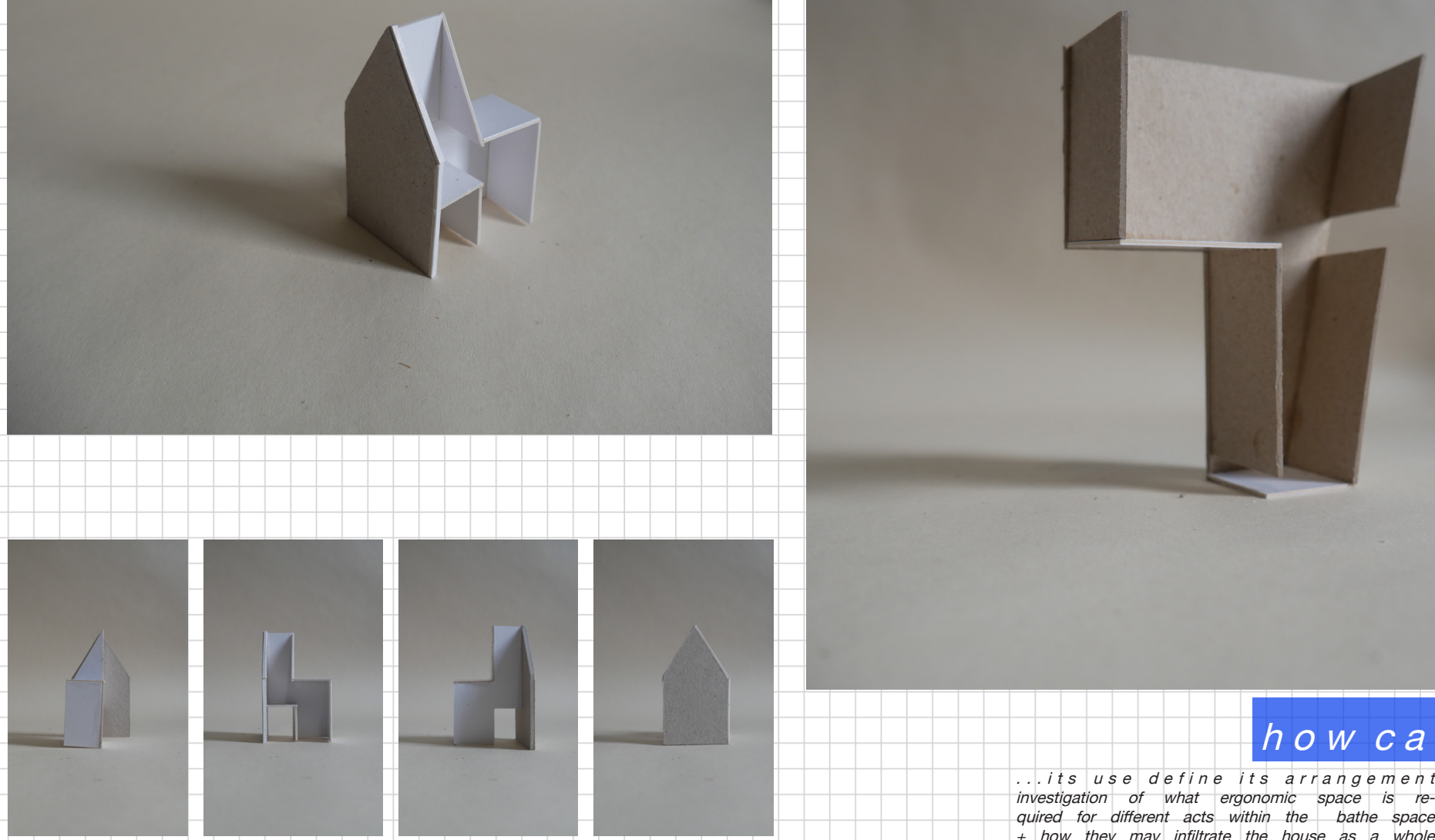

how can...

..its use define its arrangement investigation of what ergonomic space is required for different acts within the bathe space 


\section{DOMESTIC SPACE}

Occupational analysis of the client's 'Sleep' space indicated a need for adaptability, space for personal items and a relationship with the outside. The space was then attributed the times of day morning and night.

Conceptually, to sleep is to relax. It is to be protected within both the physical and mental realms. The philosophical intimacy of sleep and consequent, unconsciousness has arguably been taken for granted $^{118}$. Henry W Johnstone's rationale on the philosophy of sleep showns the inherent and explicit relationship between unconsciousness and consciousness. One must have their consciousness interrupted (being in a state of unconsciousness) to recognise their own consciousness ${ }^{119}$. Without one, the other cannot be recognised. Therefore, in his argument, Johnstone allows the notion that the 'Sleep' space allows an intimacy other space does not. Thus, it is conceivable that the 'Sleep' space is the most sacred of spaces for the user. The darkness (unconsciousness) must be acknowledged to allow the light (consciousness).

Through this avenue the sleep space has been attributed the local climate of darkness and the architectural element of the corner. These form the idea of protection. As Bachelard suggests, "... every corner in a house, every angle in a room, every inch of secluded space in which we like to hide, or withdraw into ourselves, is a symbol of solitude for the imagination; that is to say, it is the germ of a room, or of a house"120. To protect the dreamer is the most important duty of the house. For this reason, exploration through modelling considered the notion of protection as a concept with the physical. This included experimentation of how the idea of weight might produce ideas of protection. The modelling also considered how the ability to look up might allow a sense of both protection and freedom.

In conclusion the essence of the 'Sleep' space is one of inherent intimacy and protection. 

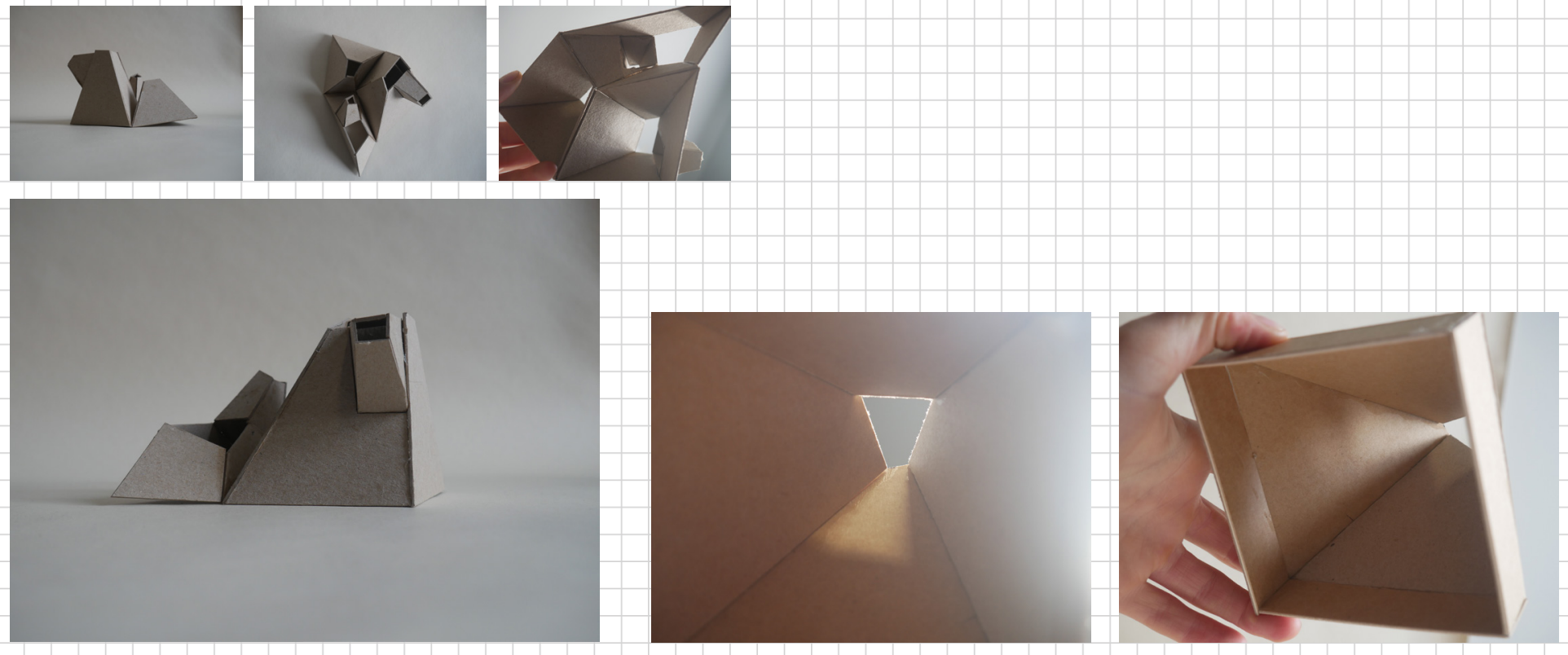

\section{how can...}

...the notion of protection be crafted investigation of what elements can create the idea of weight as oppose to the reality of weight 
DOMESTIO SPACE FRAMEWORK

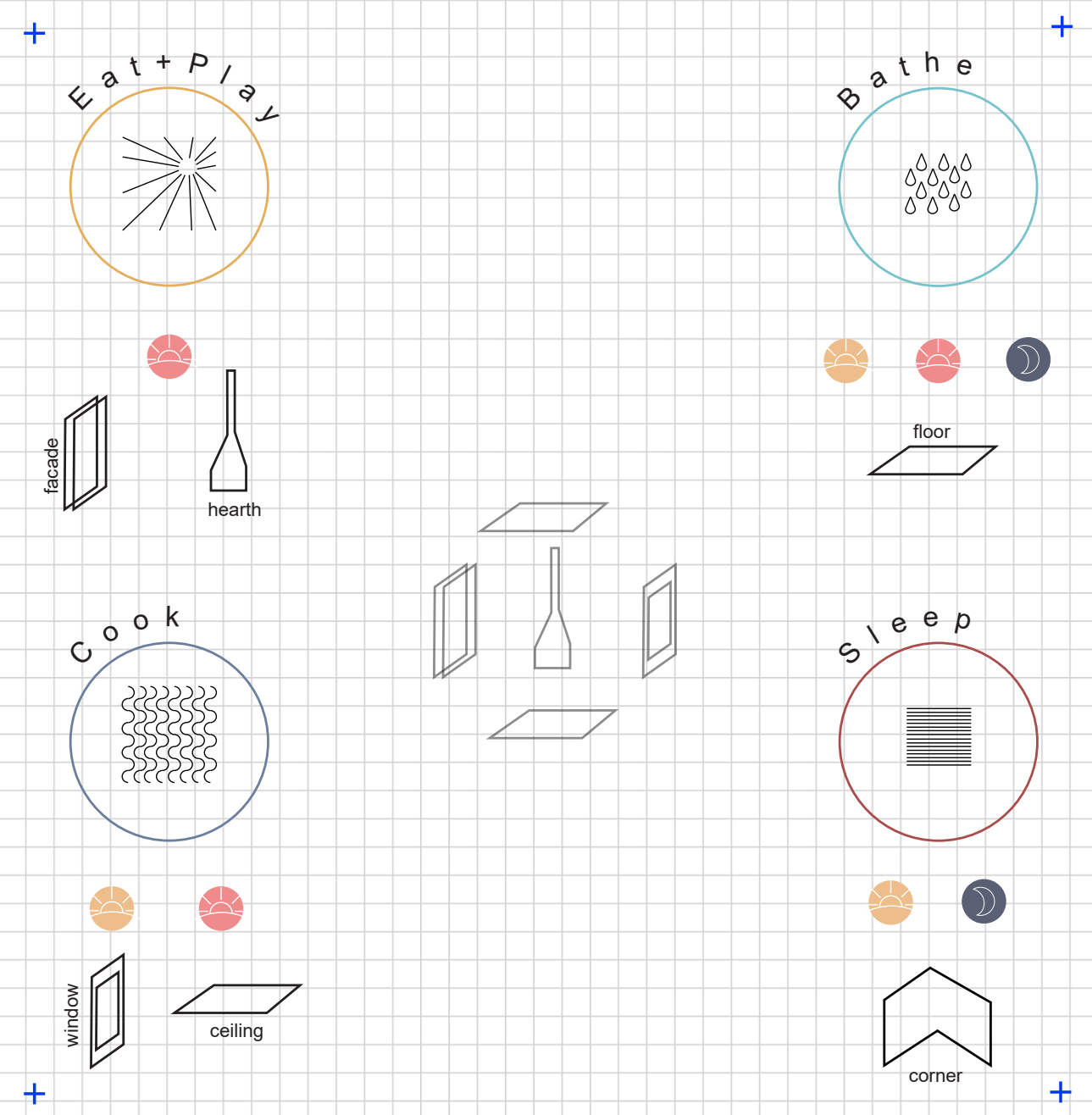




\section{CONCLUSION + DEVELOPMENT}

Design Investigation \#2 outlined the client's needs and consequential character of separate architectural spaces. As a result, the question 'how can' was explored through modelling. This enabled a reduction of reliance on the preconceived 'tiny house' as object, focusing rather on special qualities which depict an overall spatial character. Following Design Investigation \#2, development of design will be conducted.

Essentially, the development phase required all distinct aspects of exploration to converge. Pragmatic qualities such as client need, trailer dimensions and regulation restrictions had to meet poetic distinctions such as light, depth, adjacency and character. Initially drawings were conducted which consolidated the concept of each architectural space resulting in a conceptual focus. A clear requirement of roofline was established and explored here before a final concept was reached. 
DEVEL $O P M E N T$

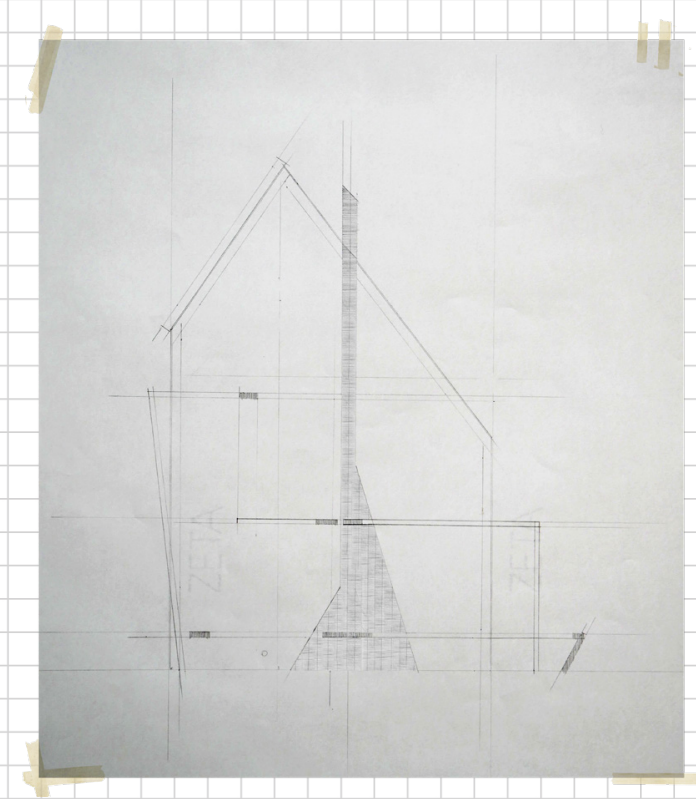

EAT + PLAY

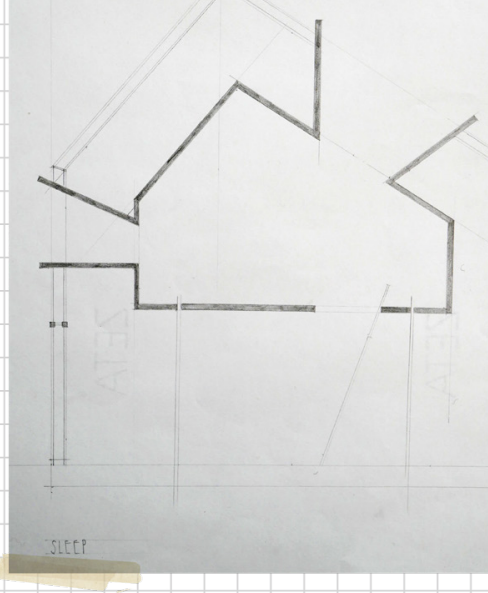

SLEEP 


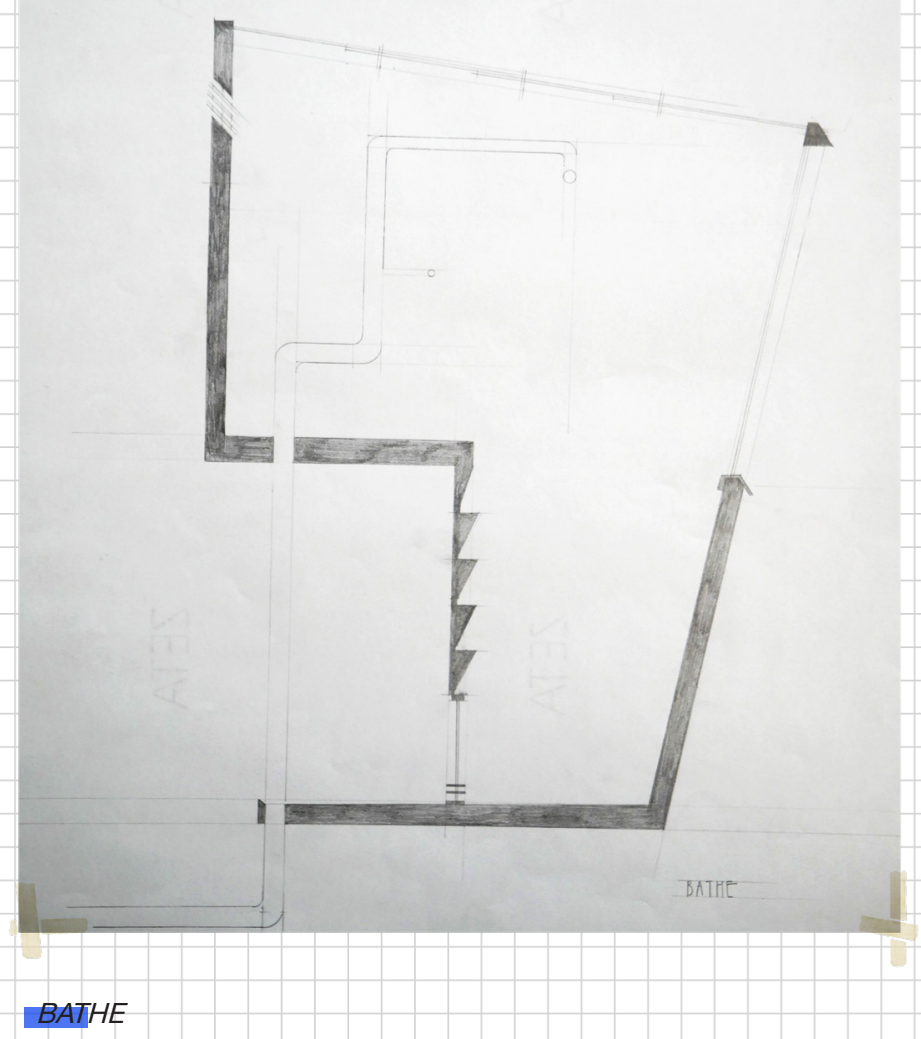




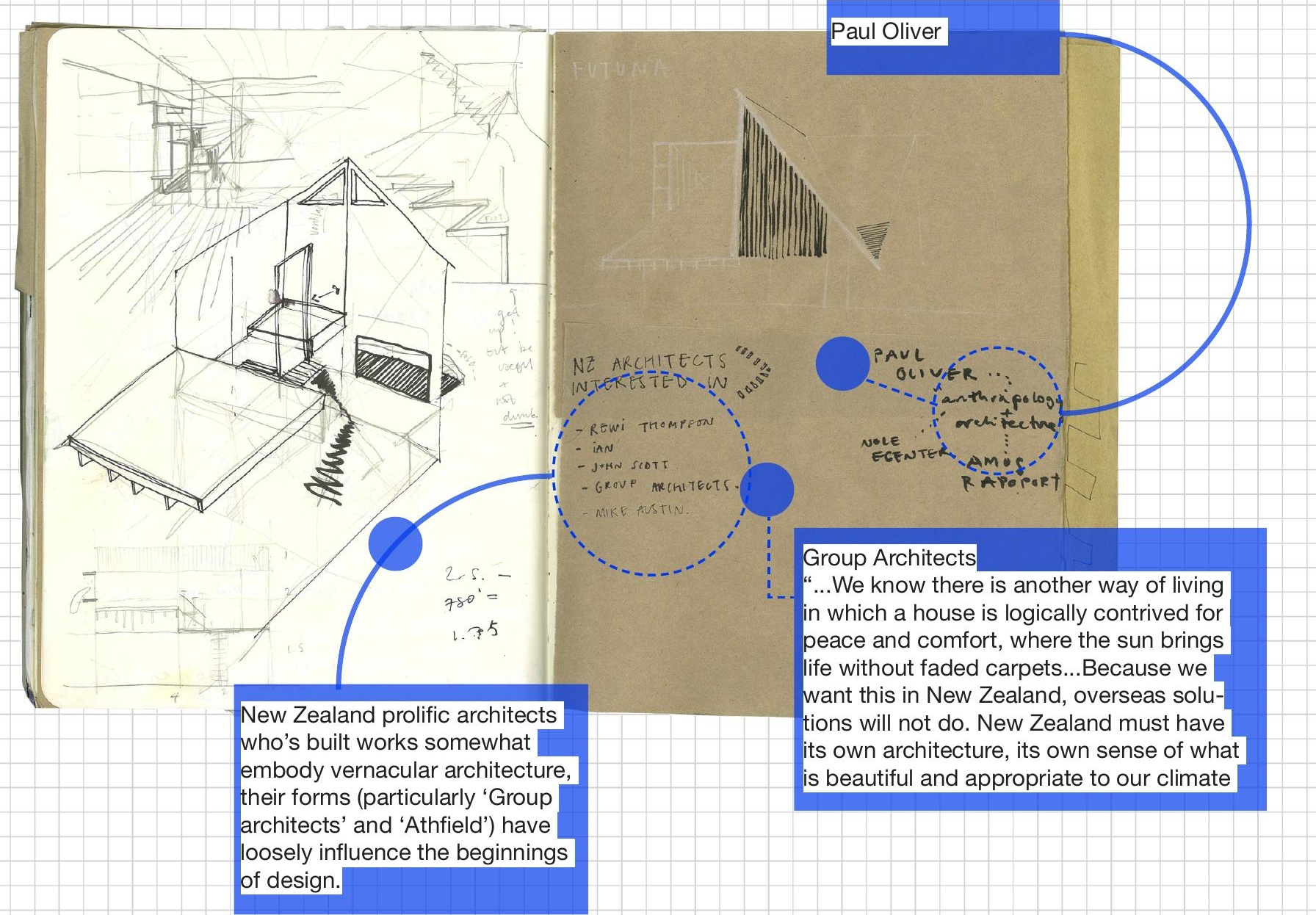




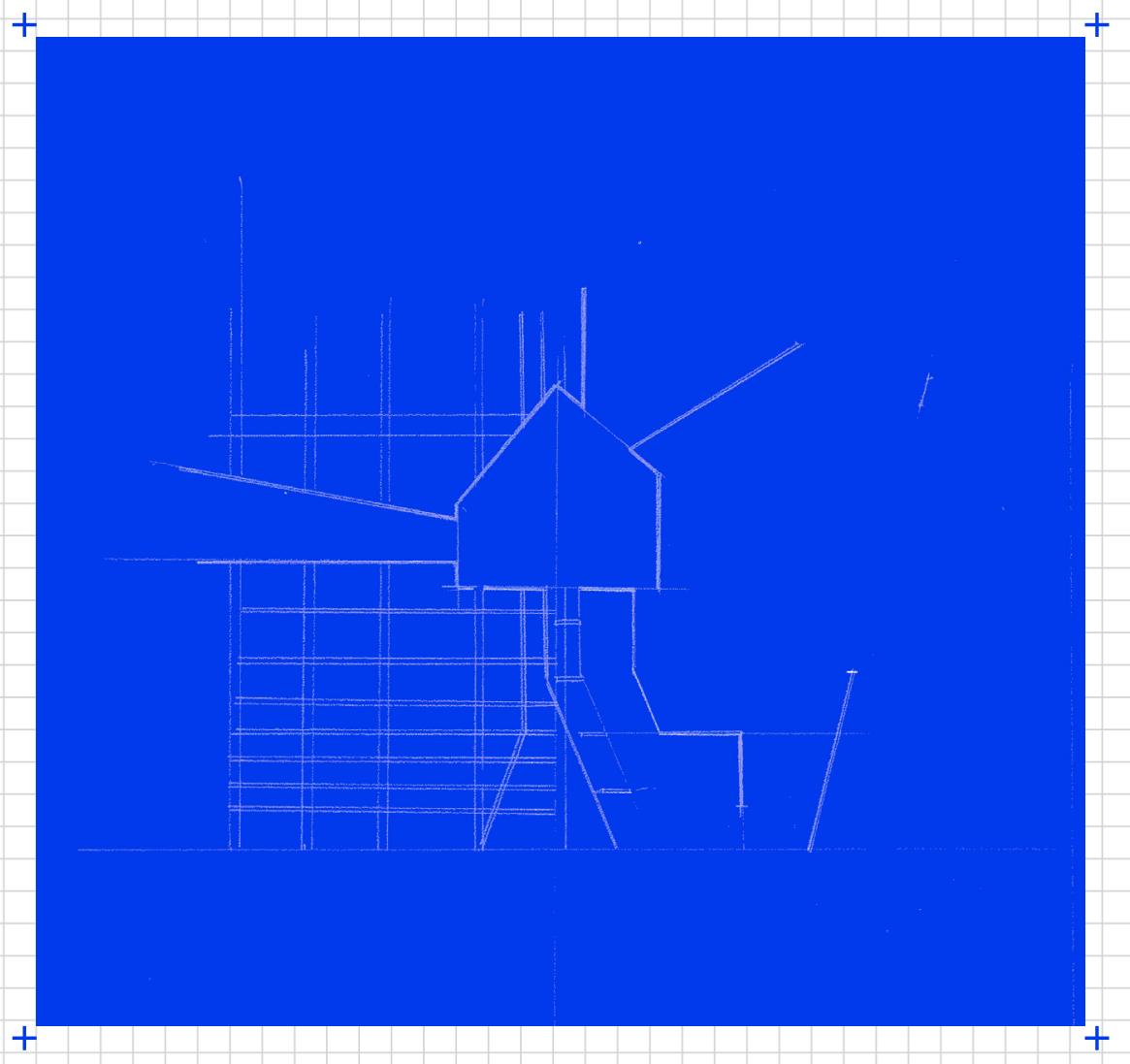

Fig//56 Conceptual drawings of spaces 

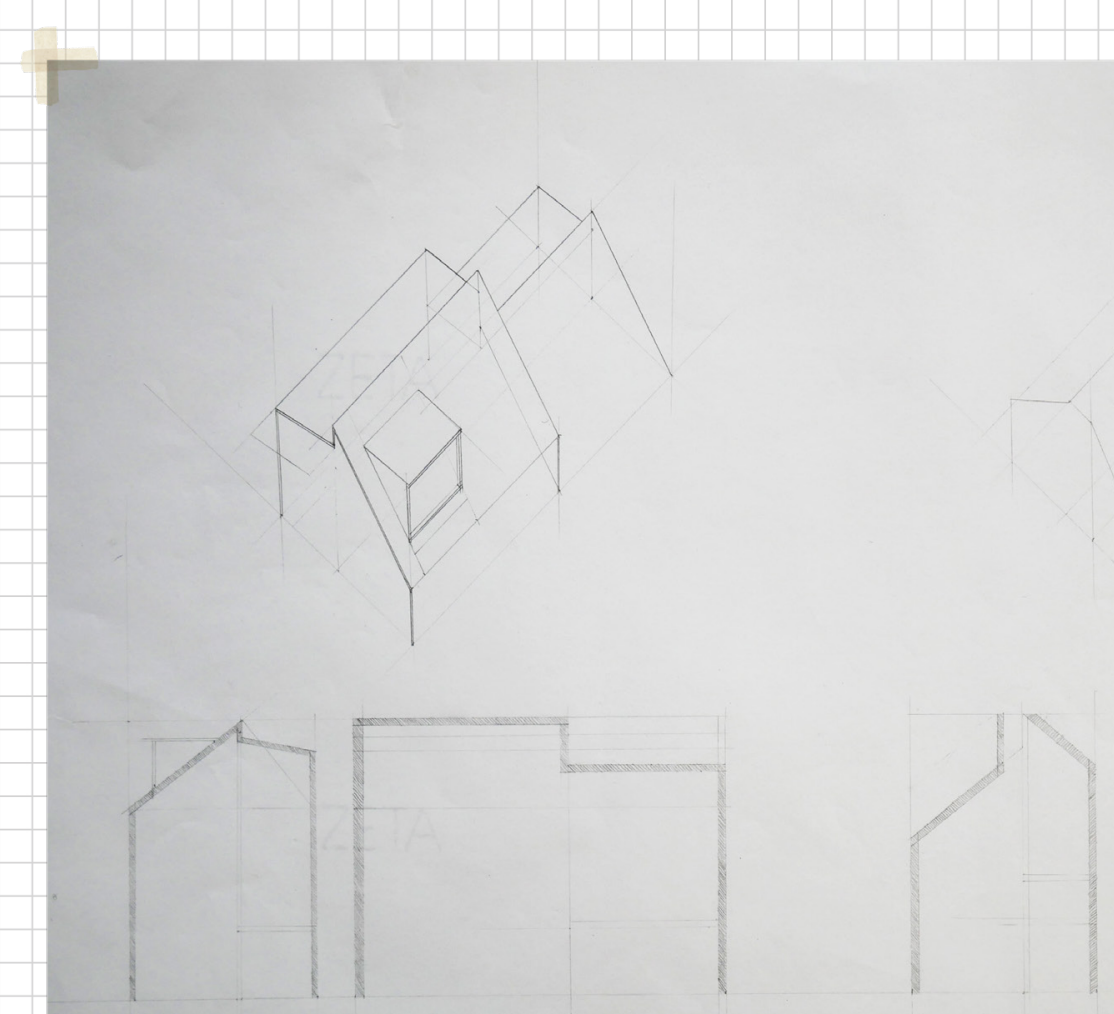

165 
DEVELOPMENT

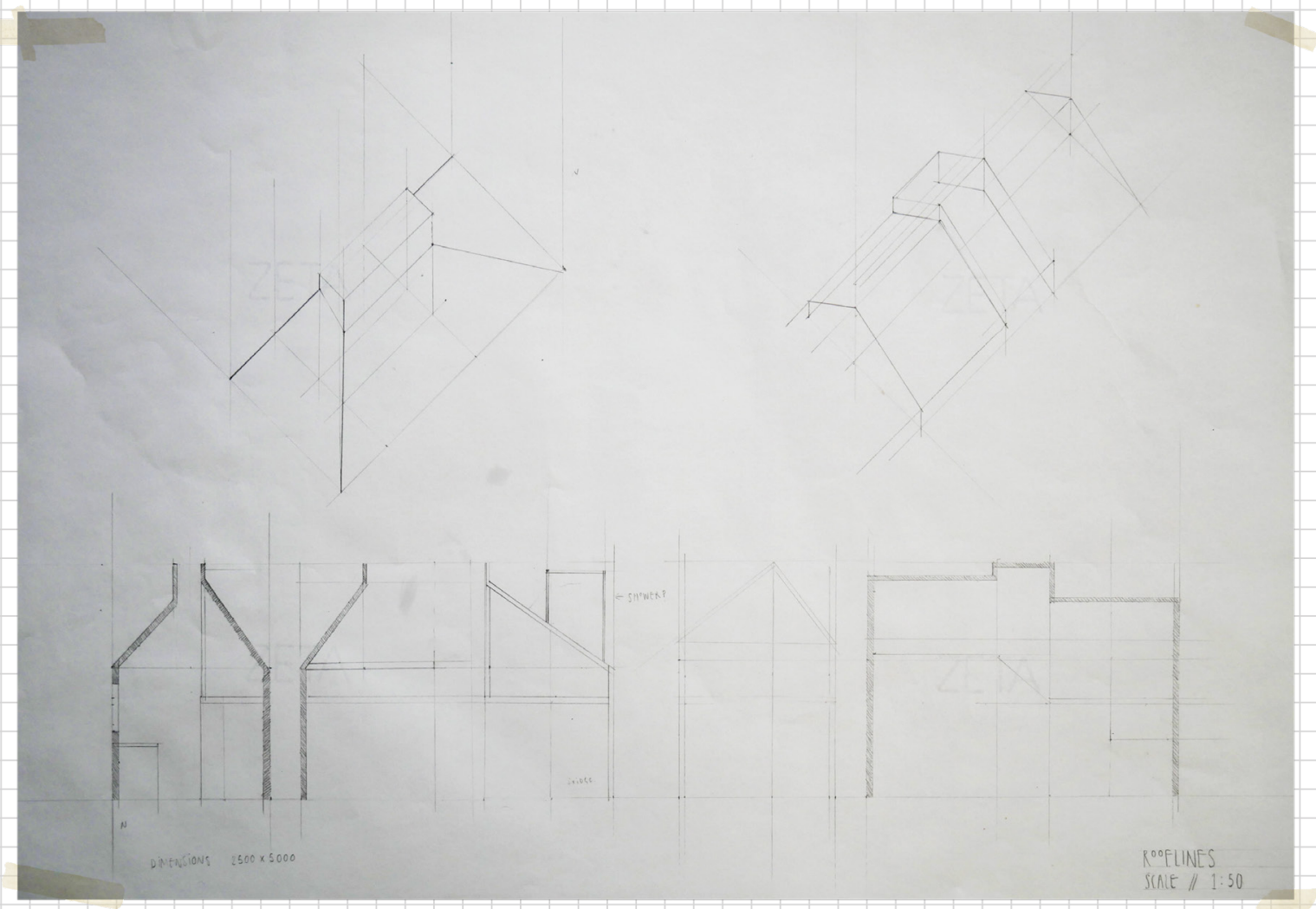



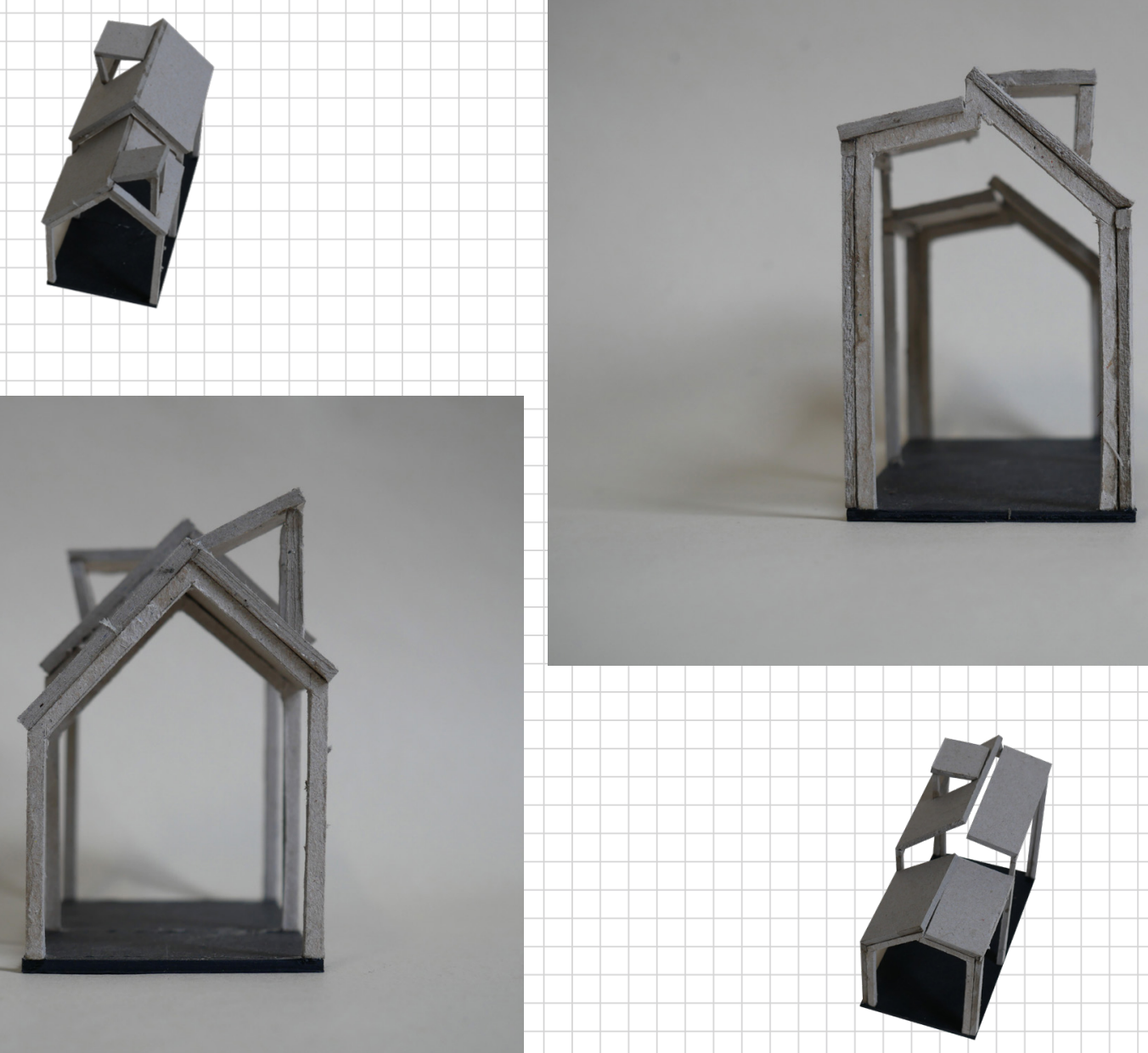


\section{b}
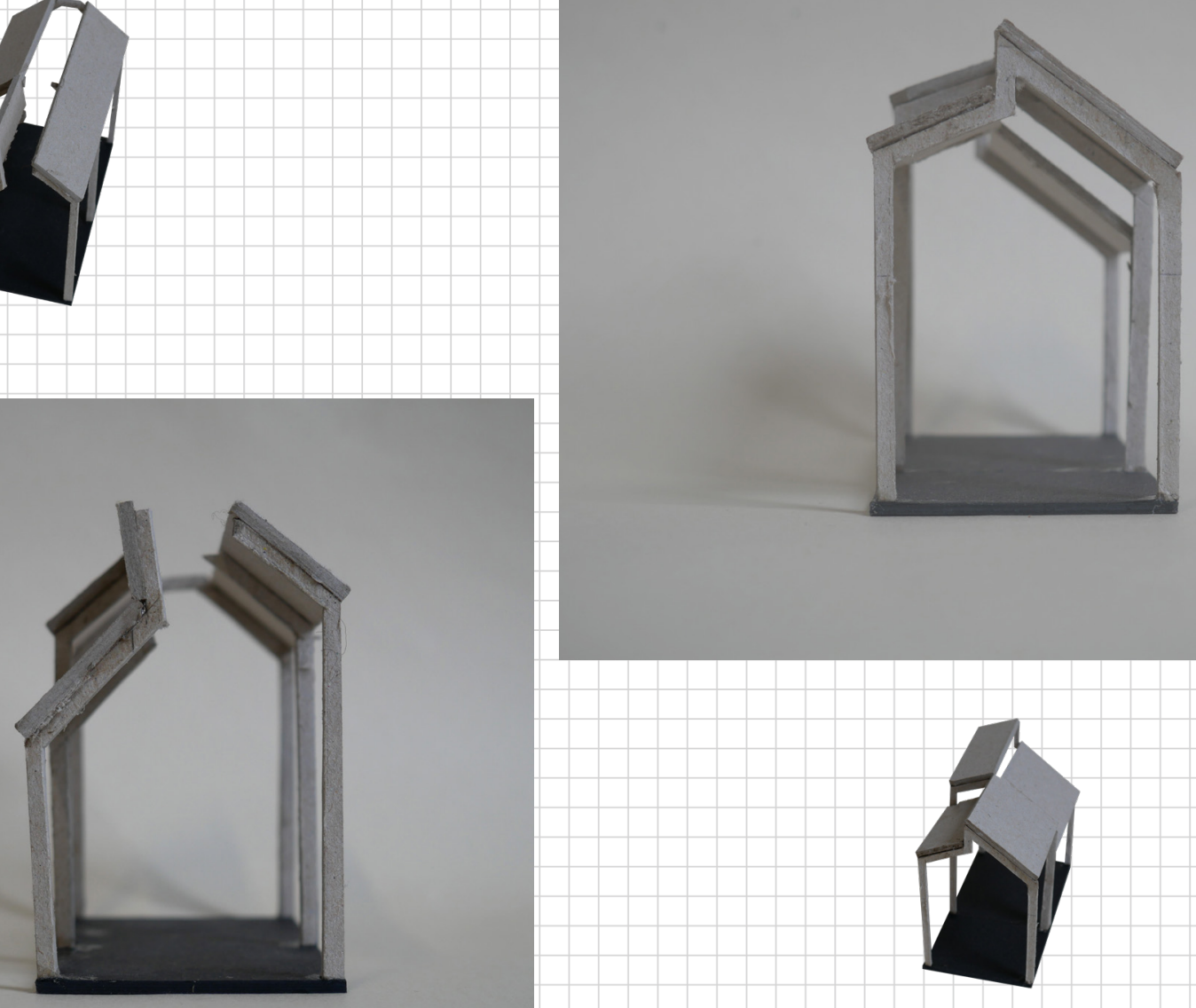


$$
11
$$




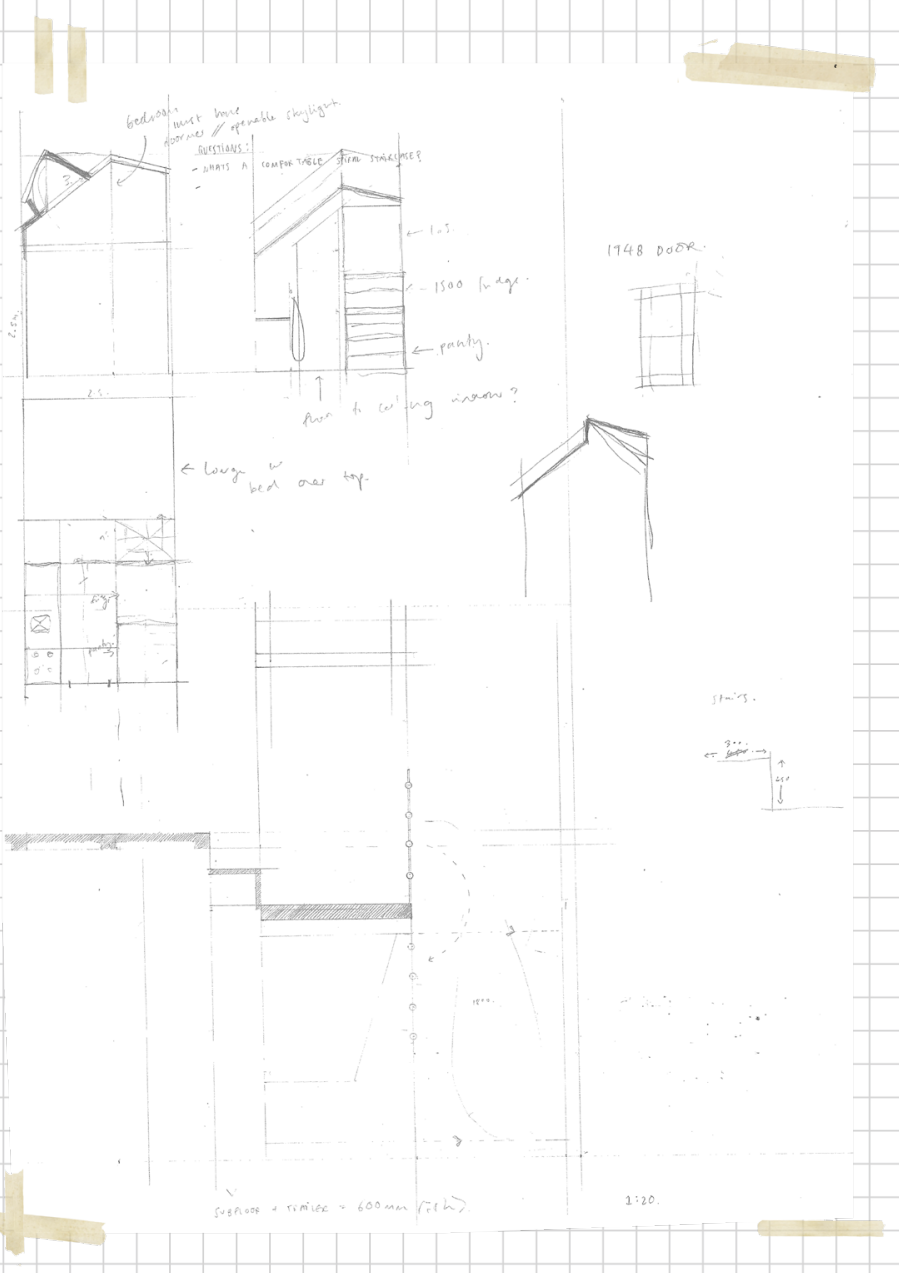



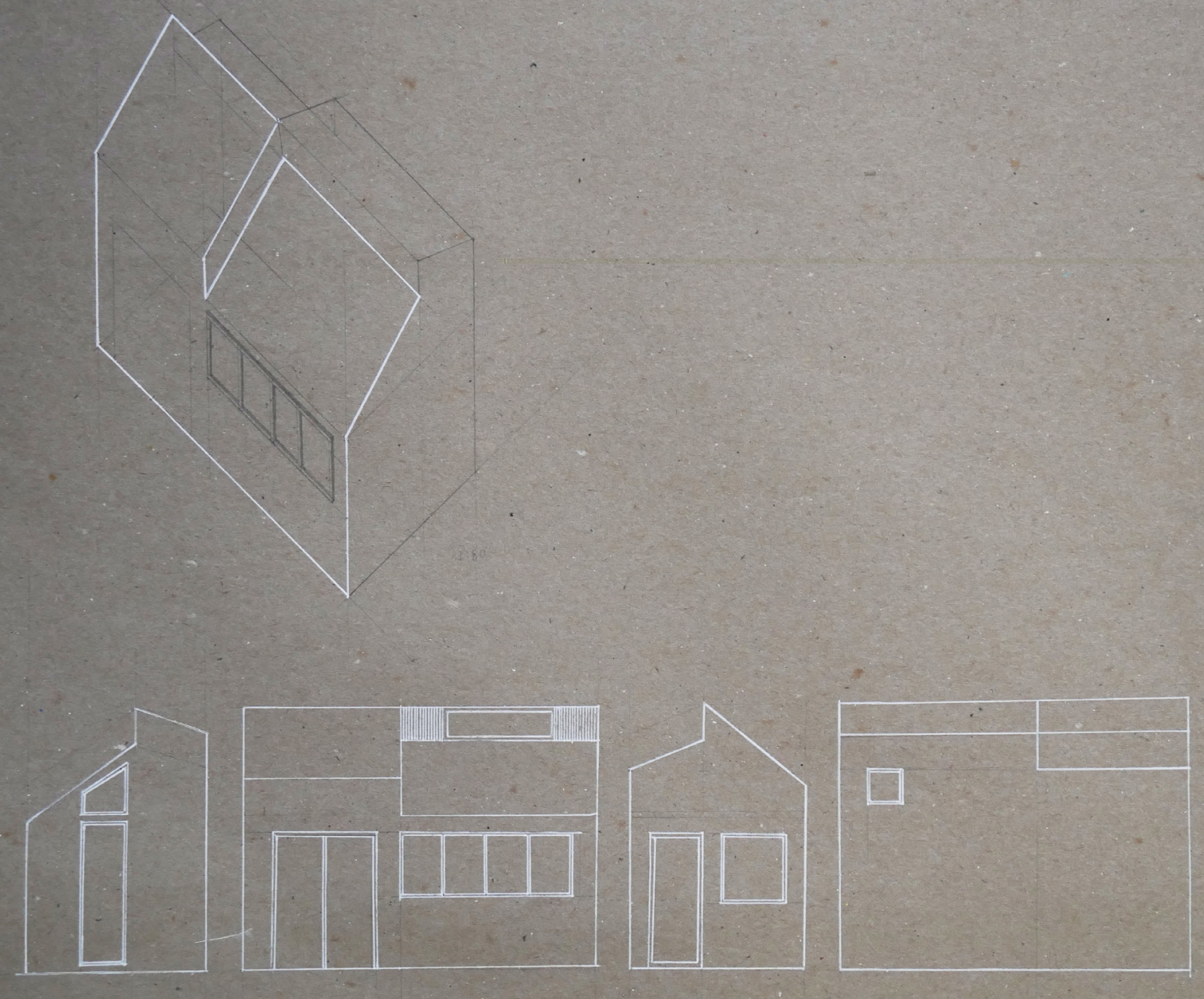


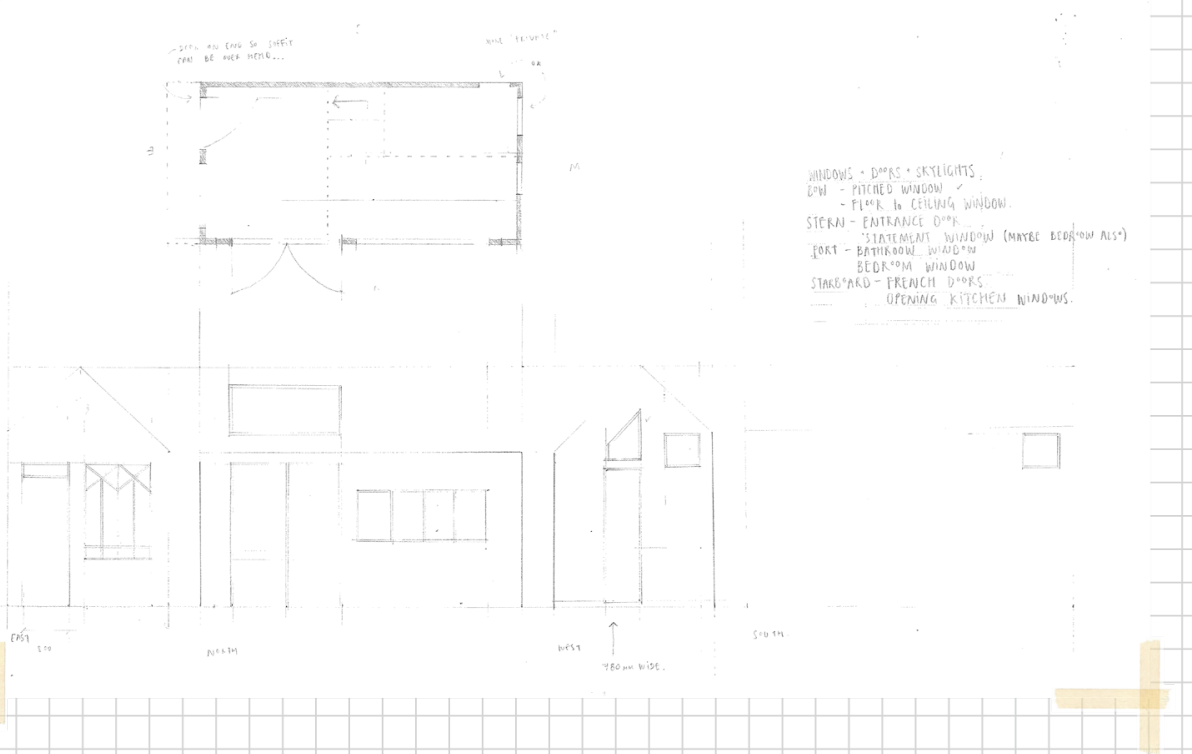





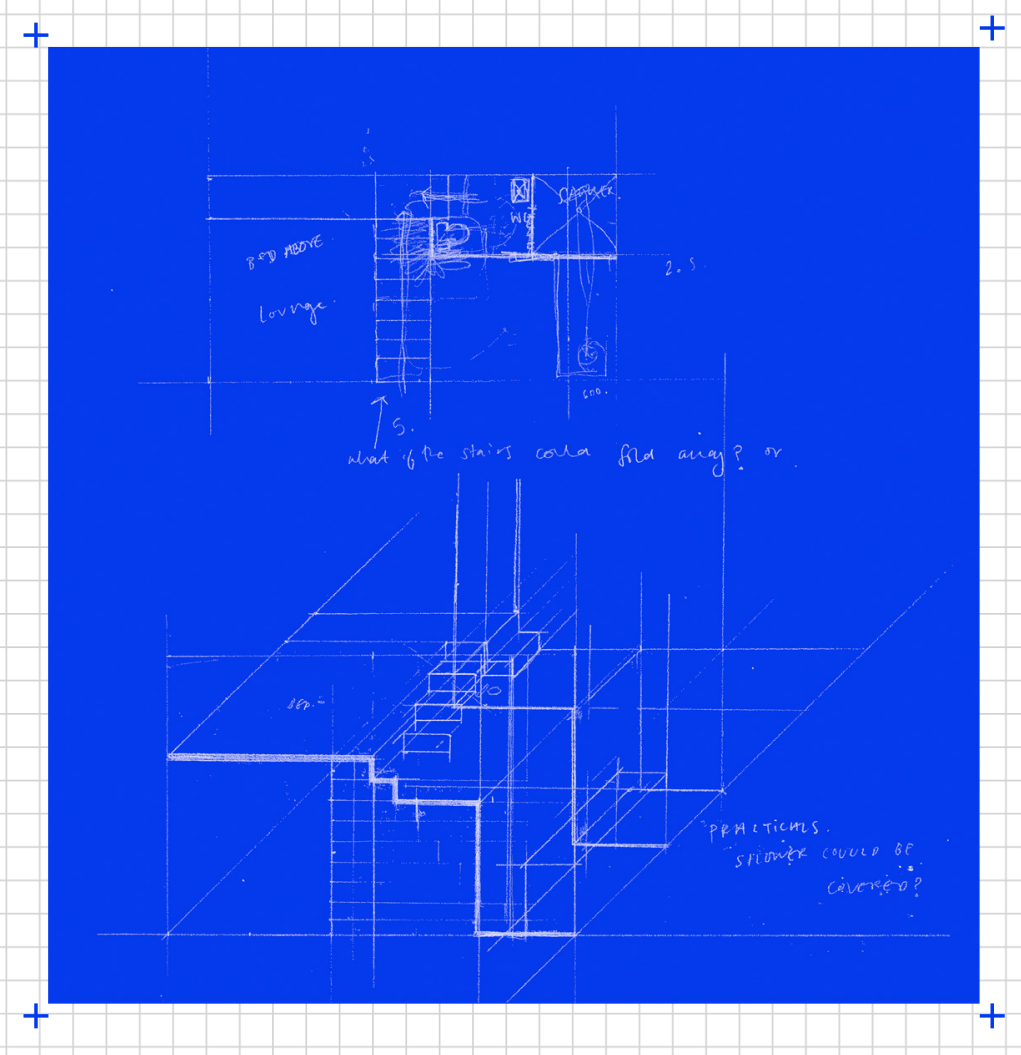




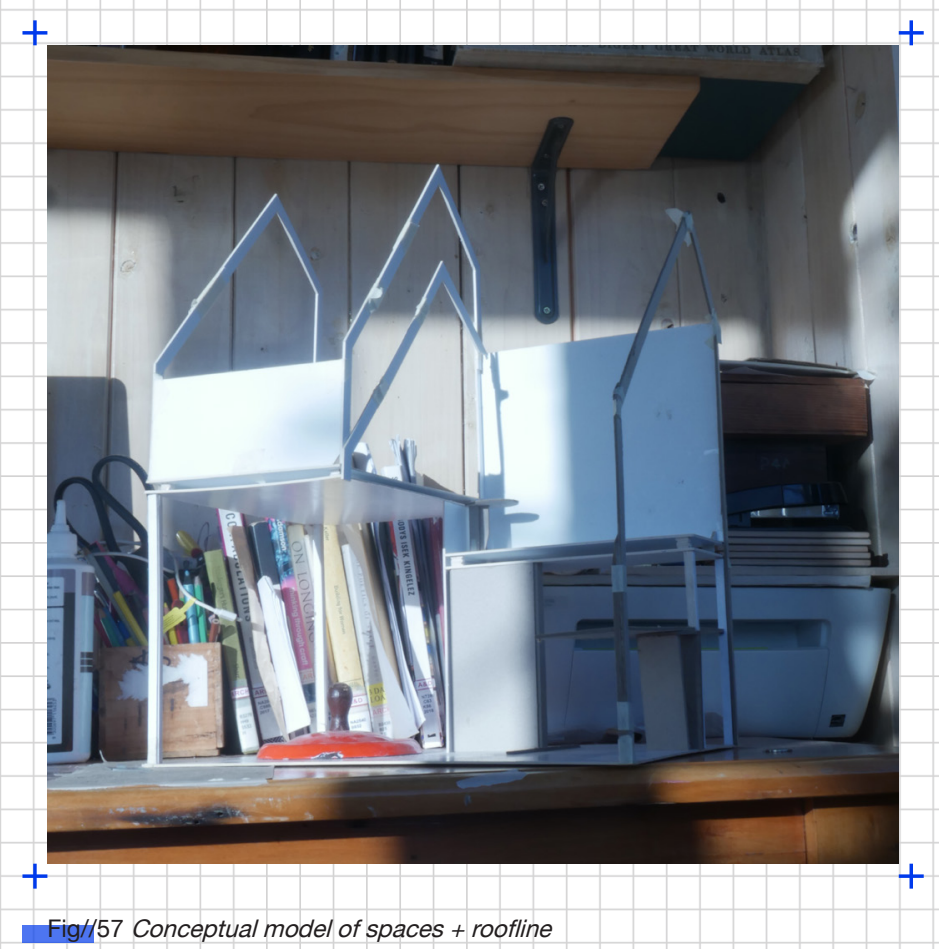




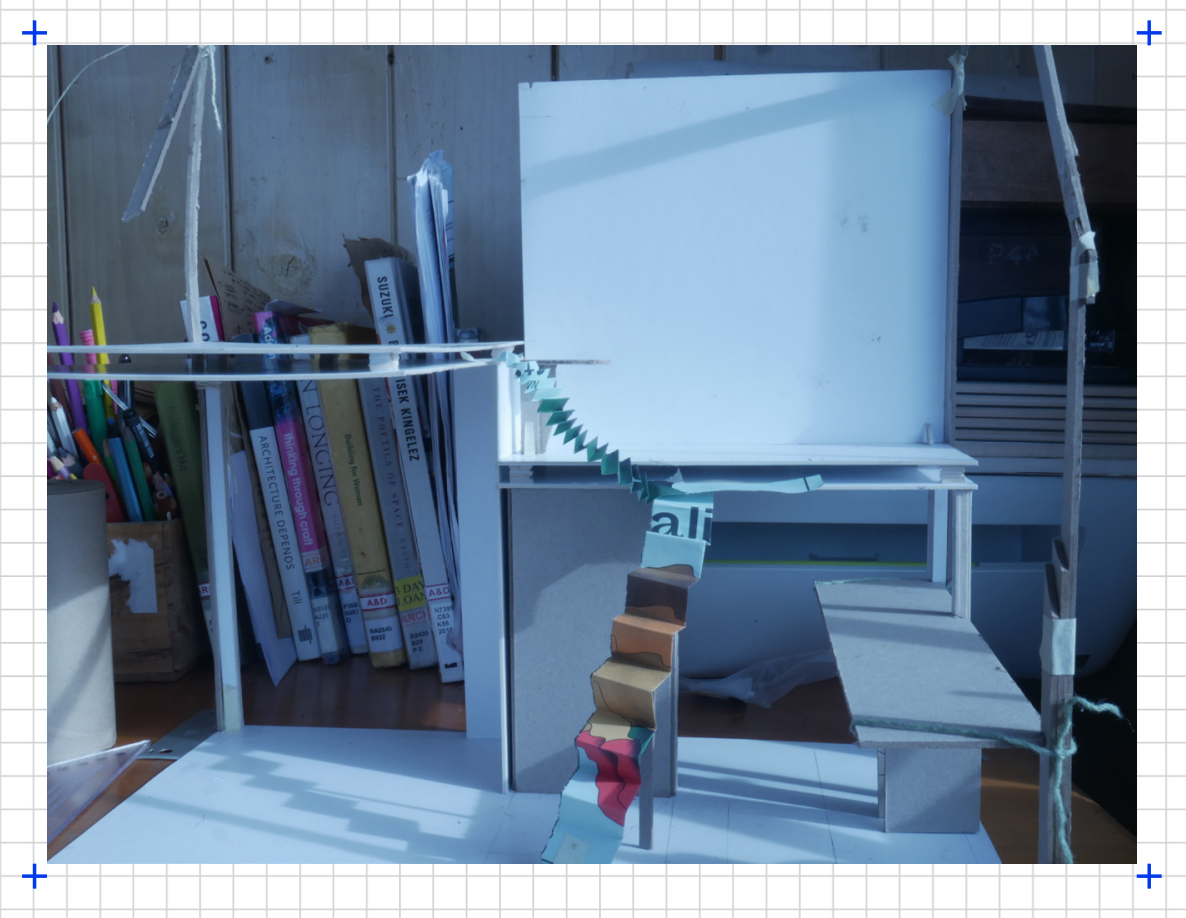




\section{CONCEPT}

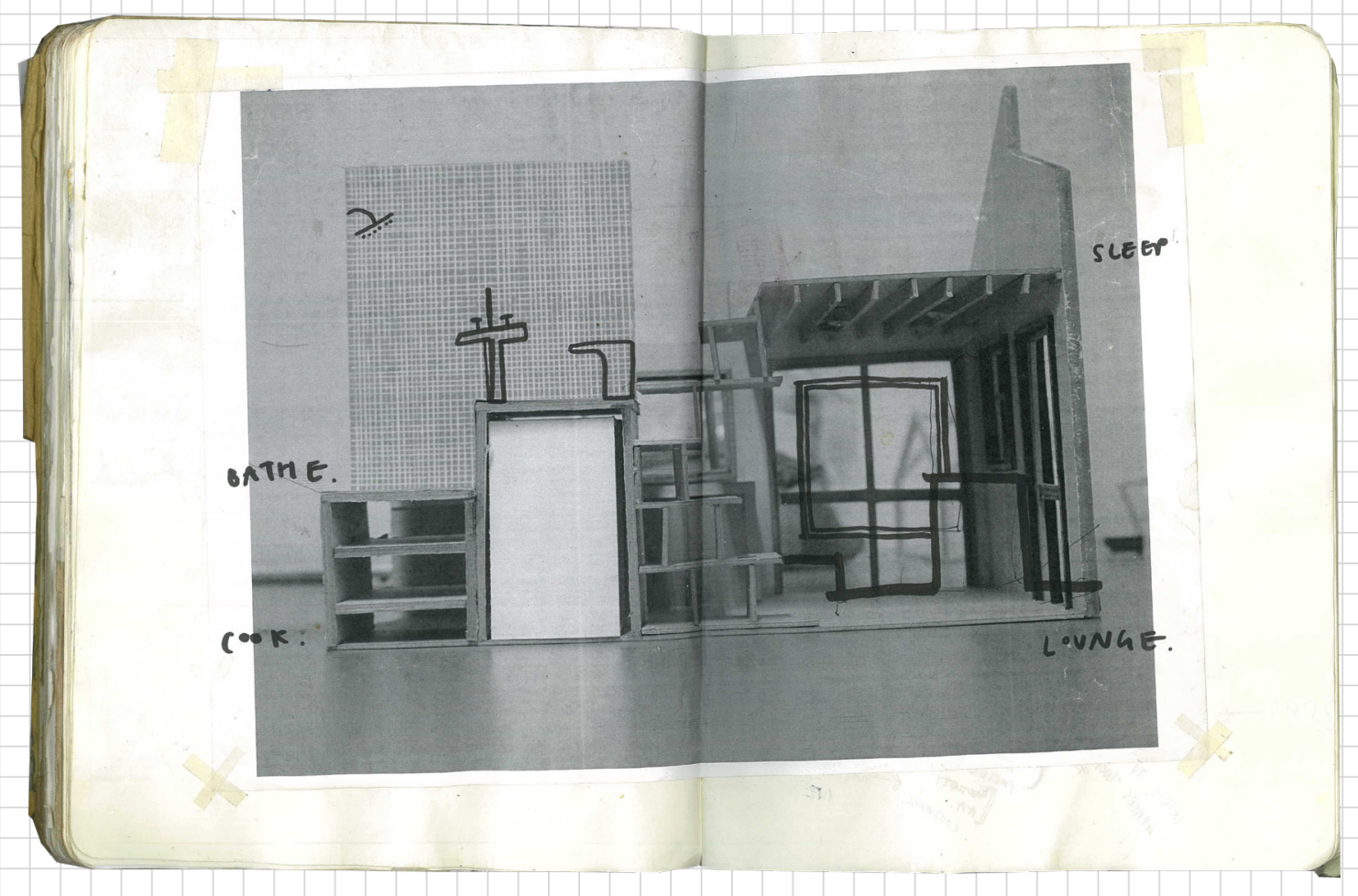


Exploration

of the use

of the plan

in design of

small space.

Upon reflec-

tion, some-

what reduc-

tive, further

investigation

must include

section and

detail.

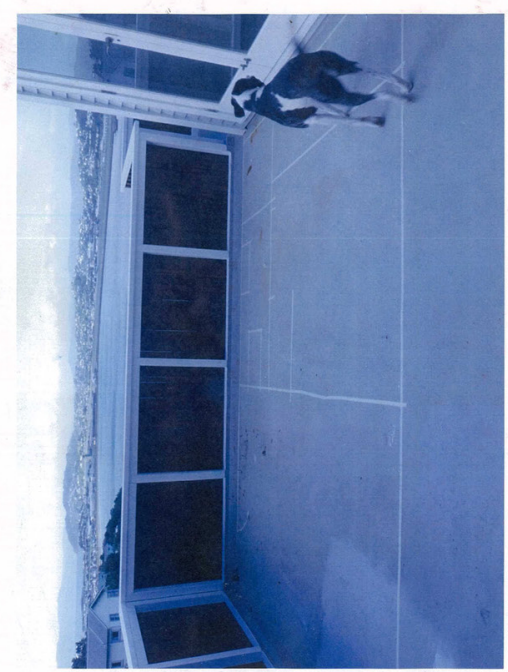

Who discusses the hand and craft within architecture?

Are the two separate? 

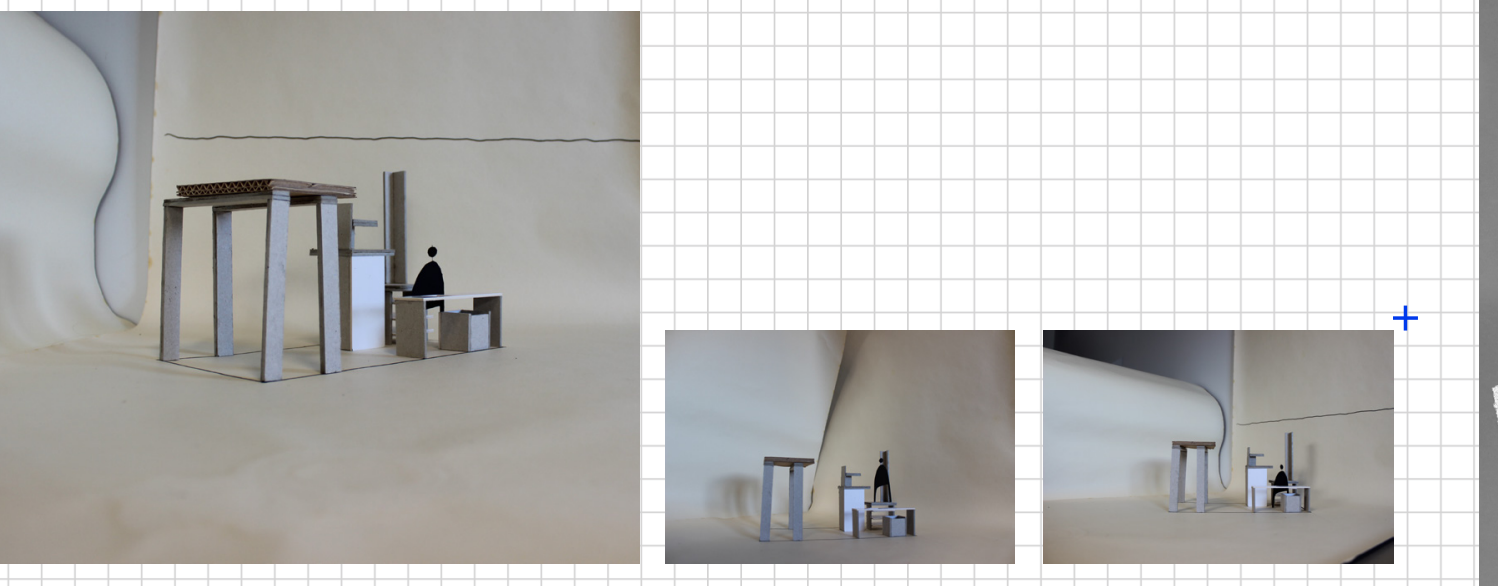

Full $=-2=$ Height.
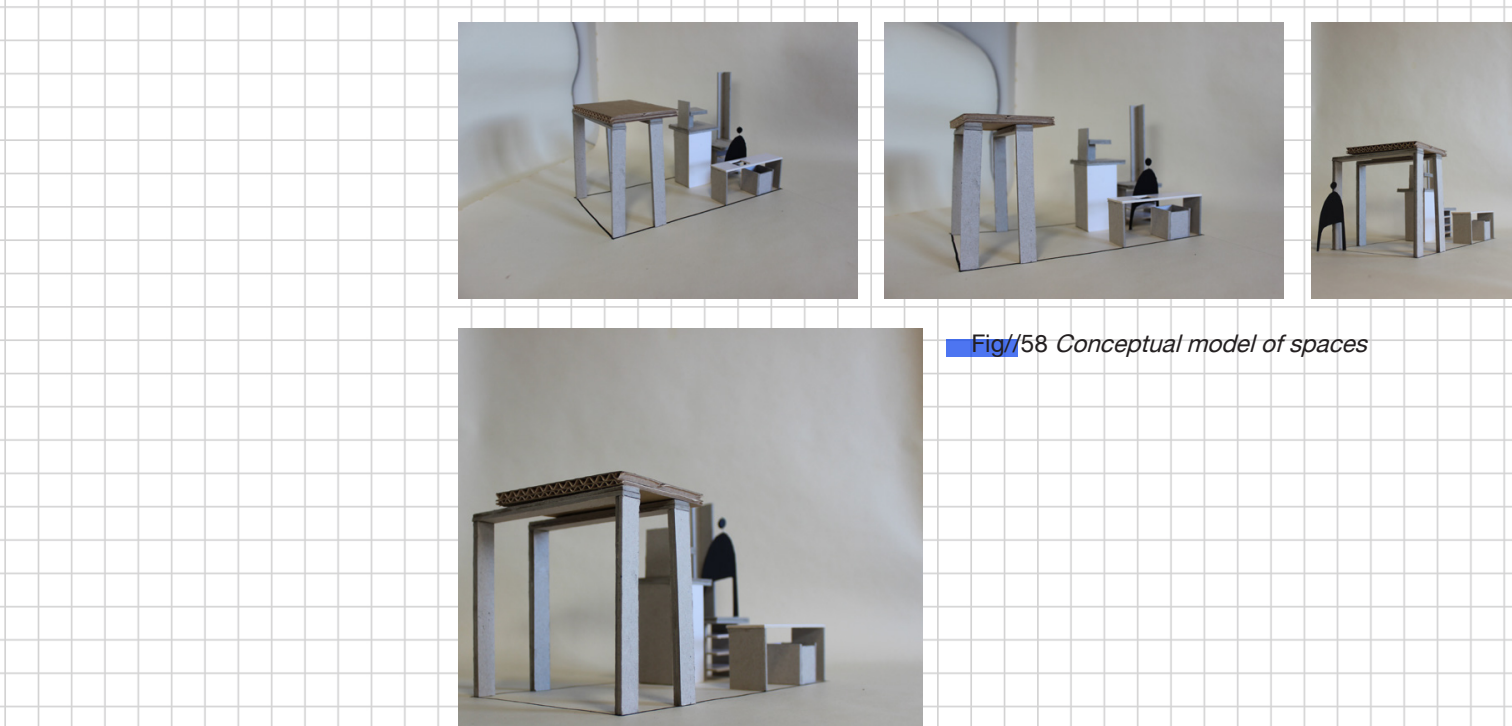

Fig//58 Conceptual model of spaces
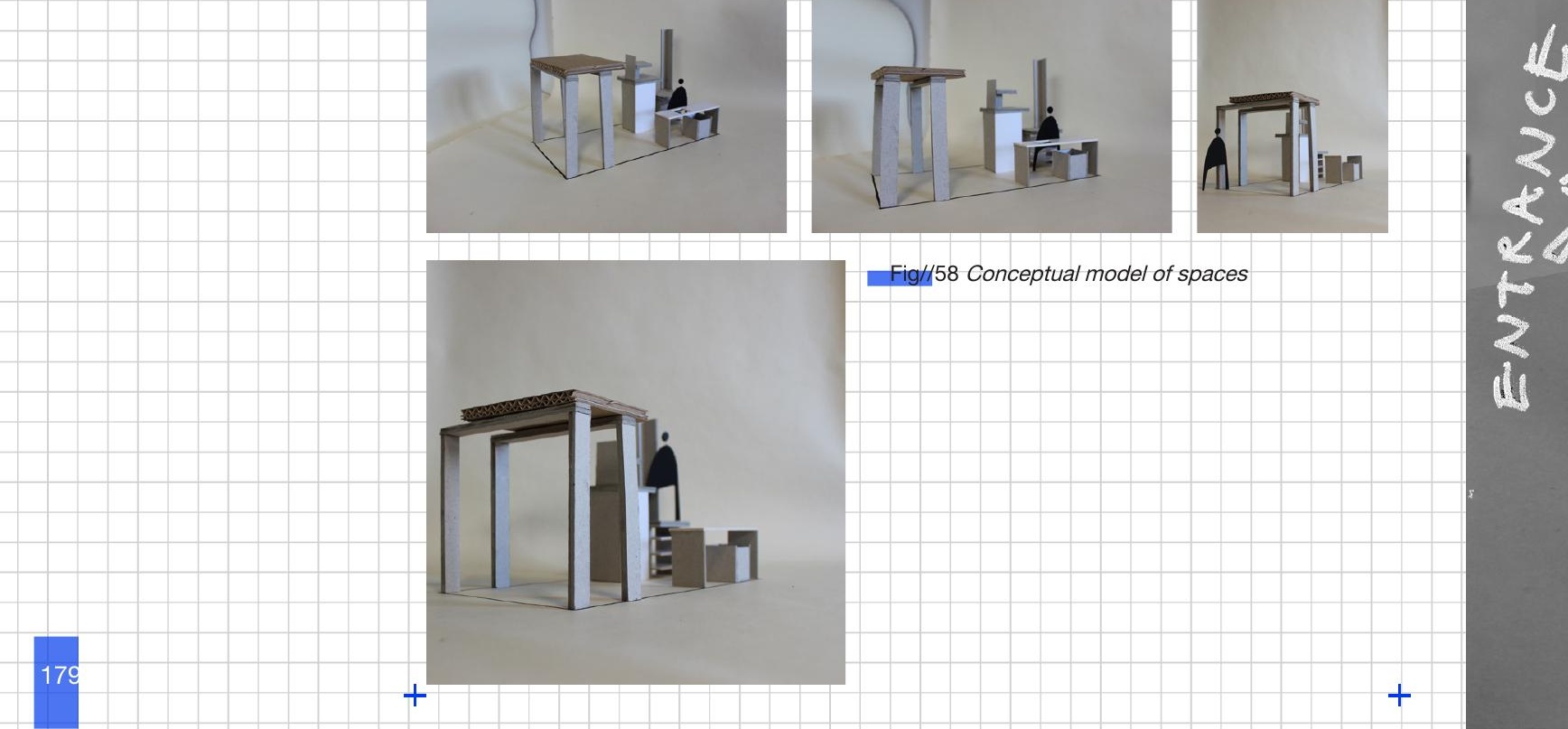


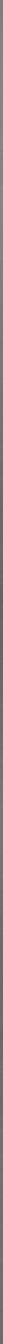




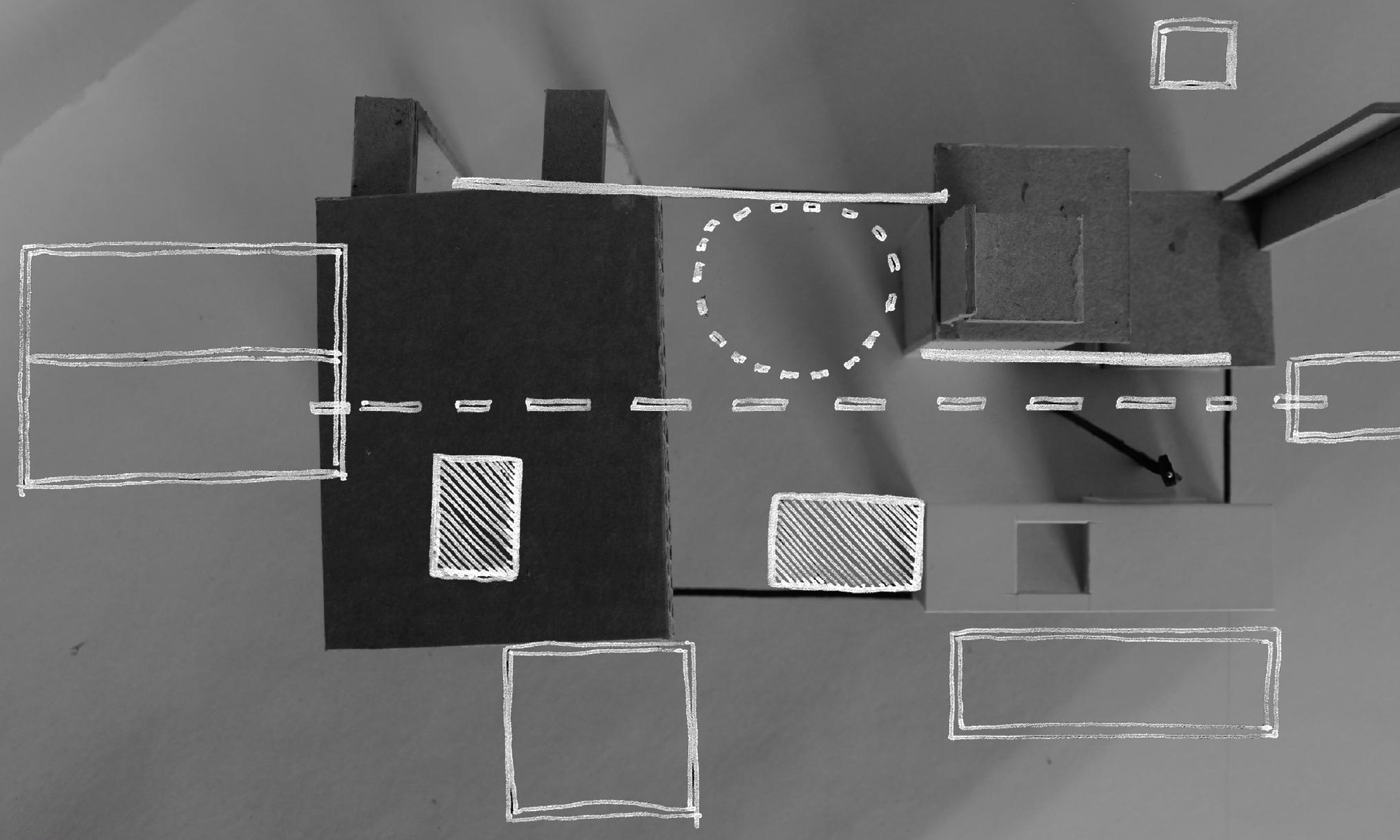


$+$

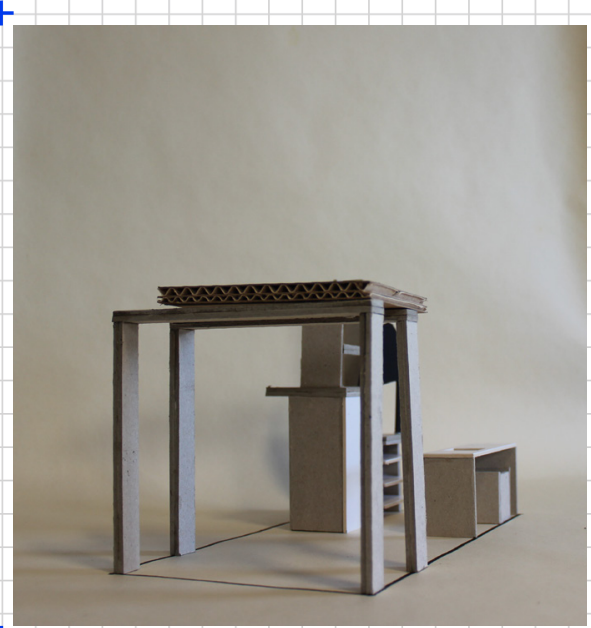

$+$

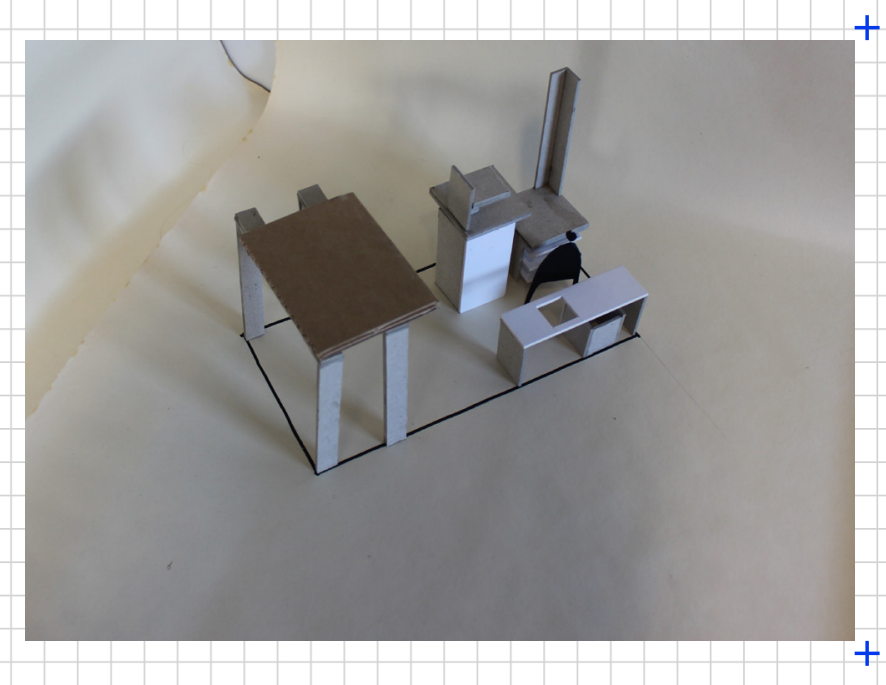




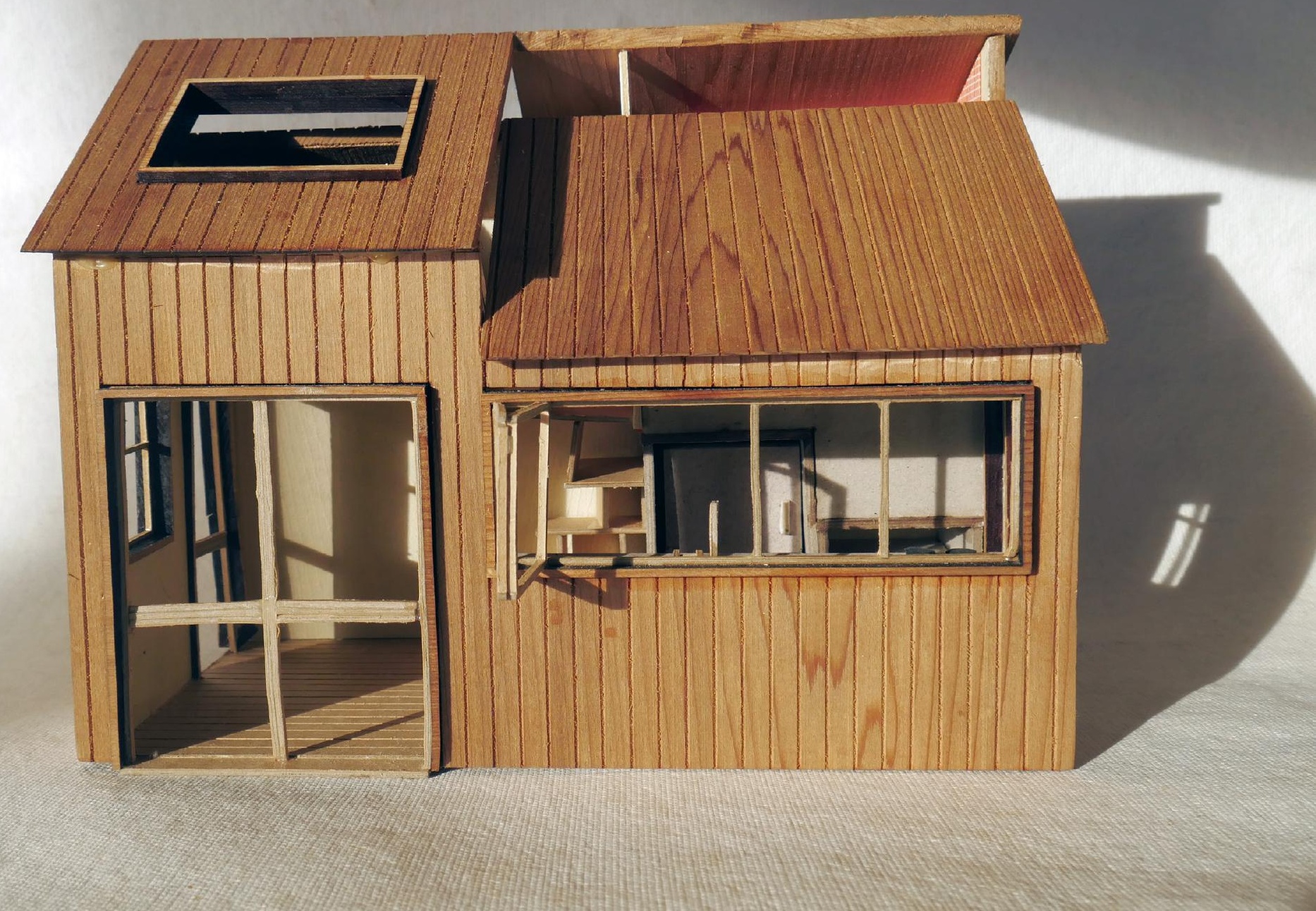




\section{FINAL MODEL}

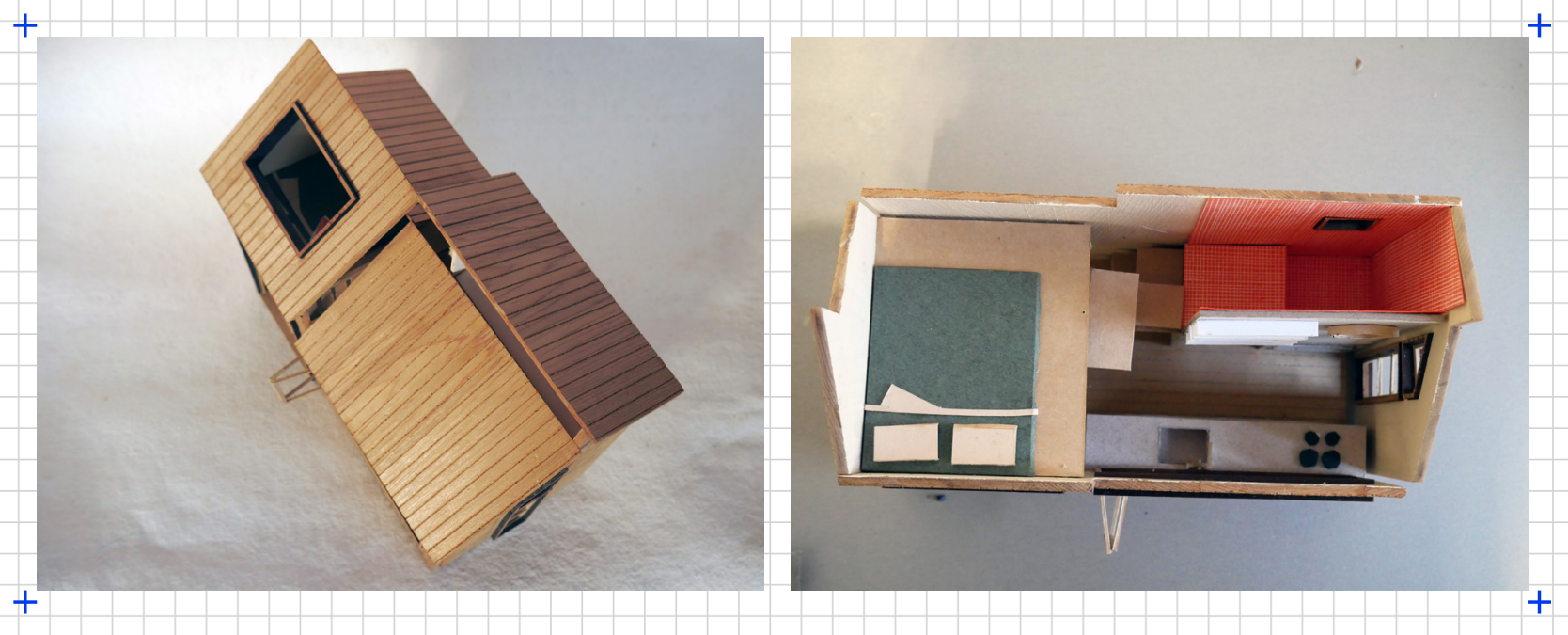




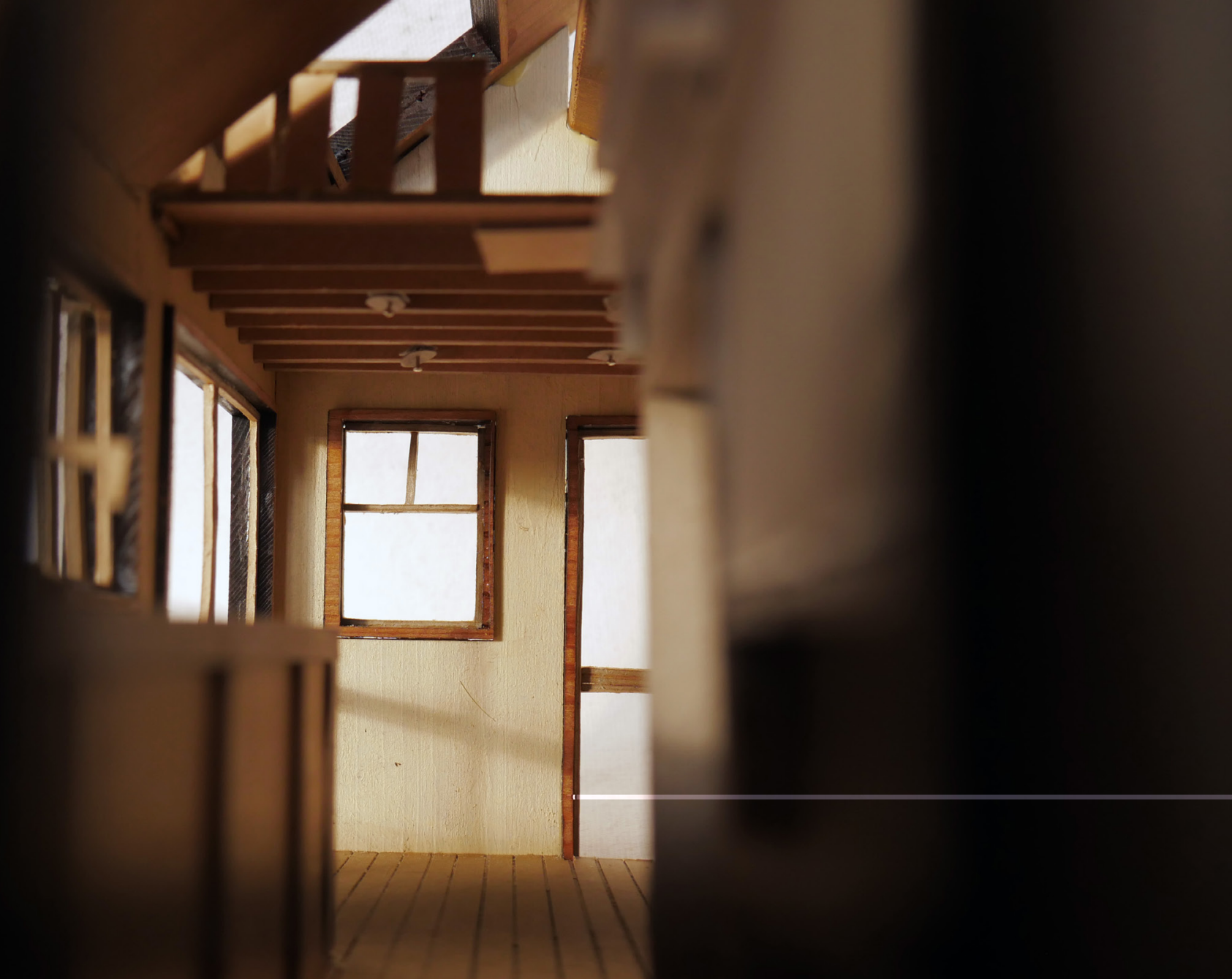



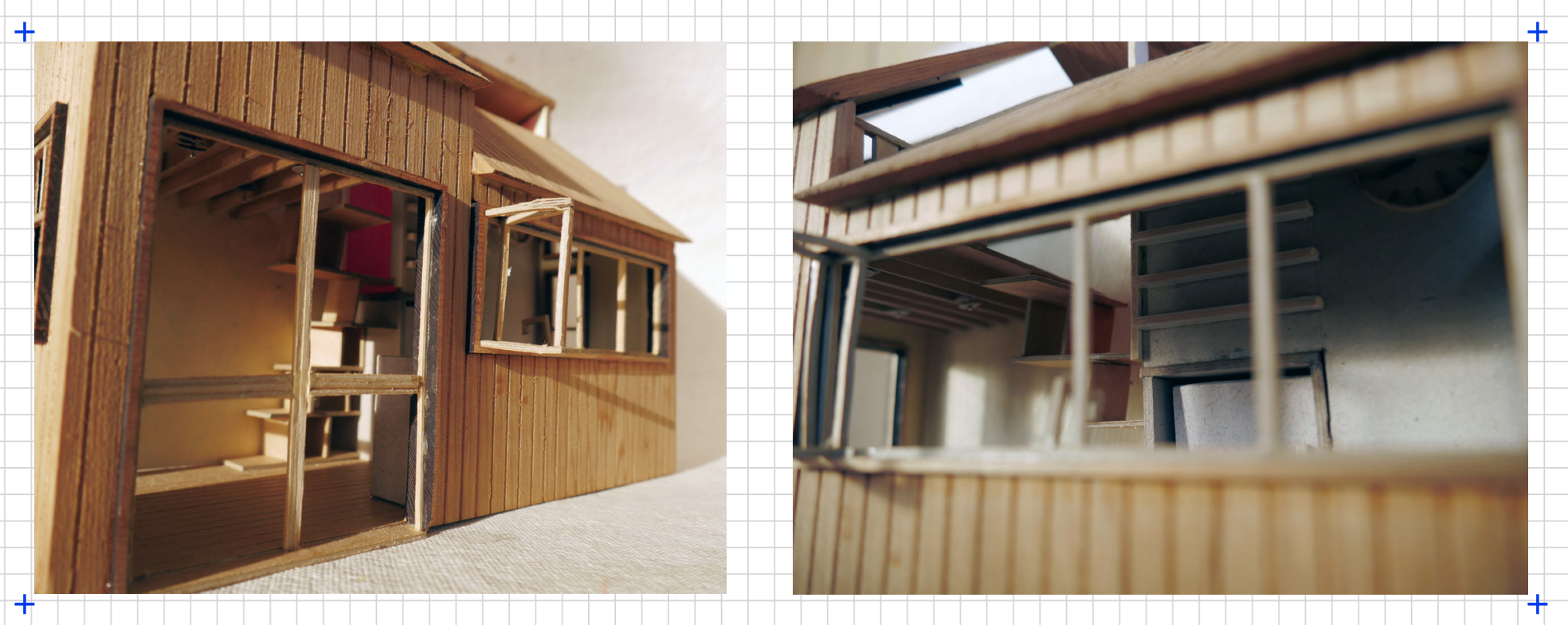

Fig//61 View into 'Eat \& Play’ space

Fig//62 View into 'Cook' space 


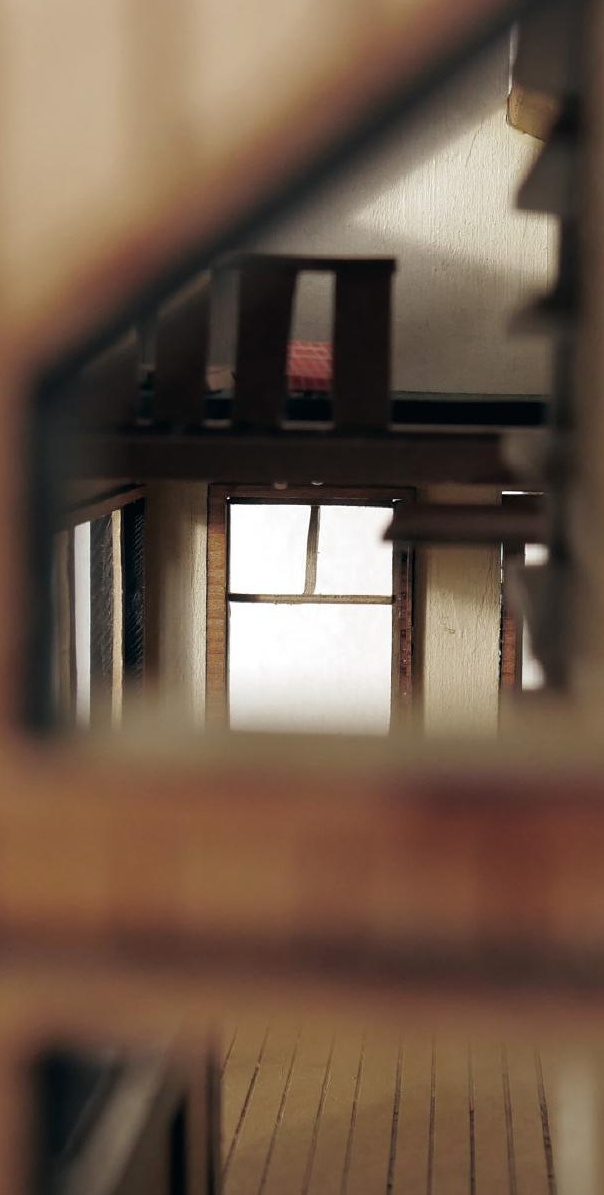




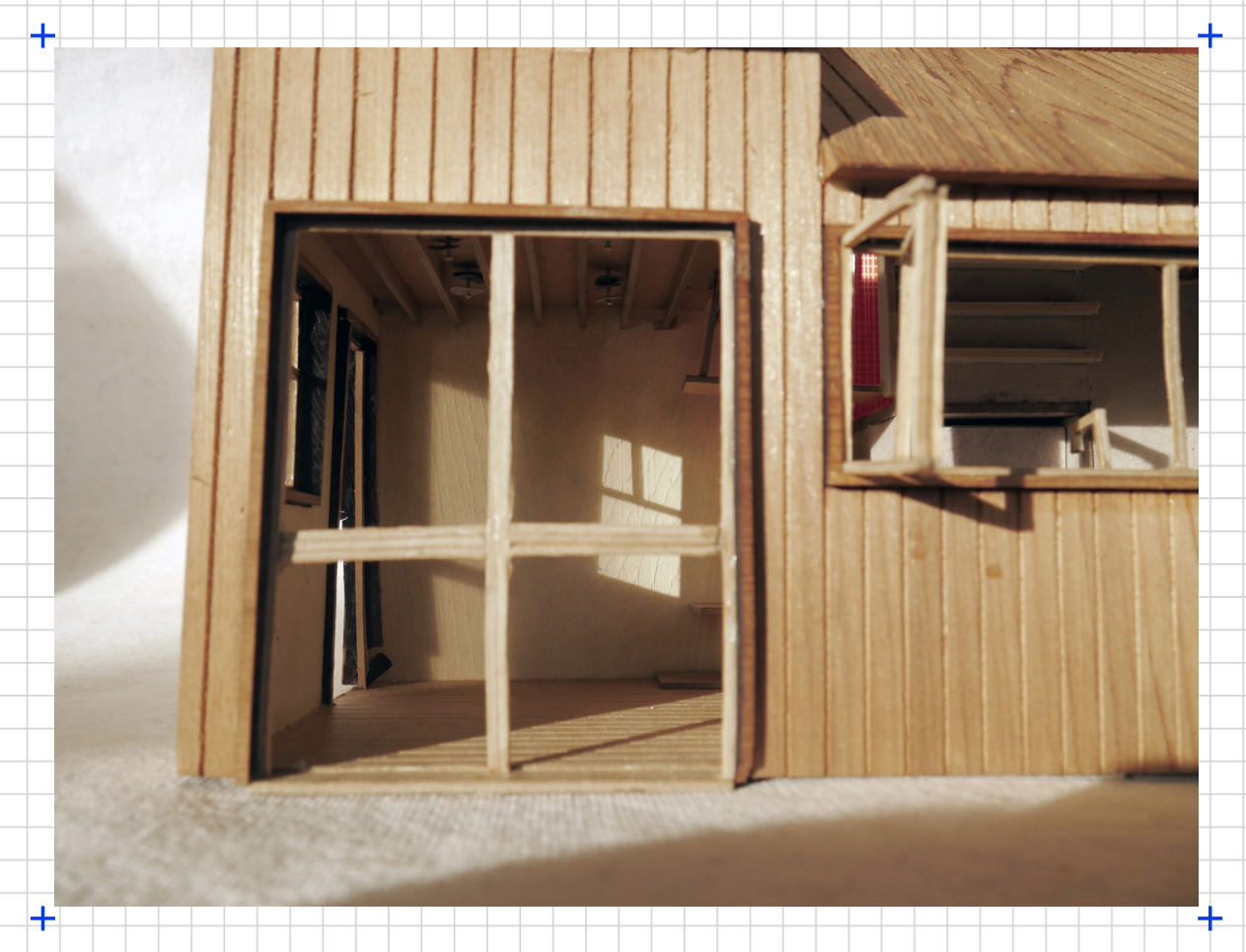




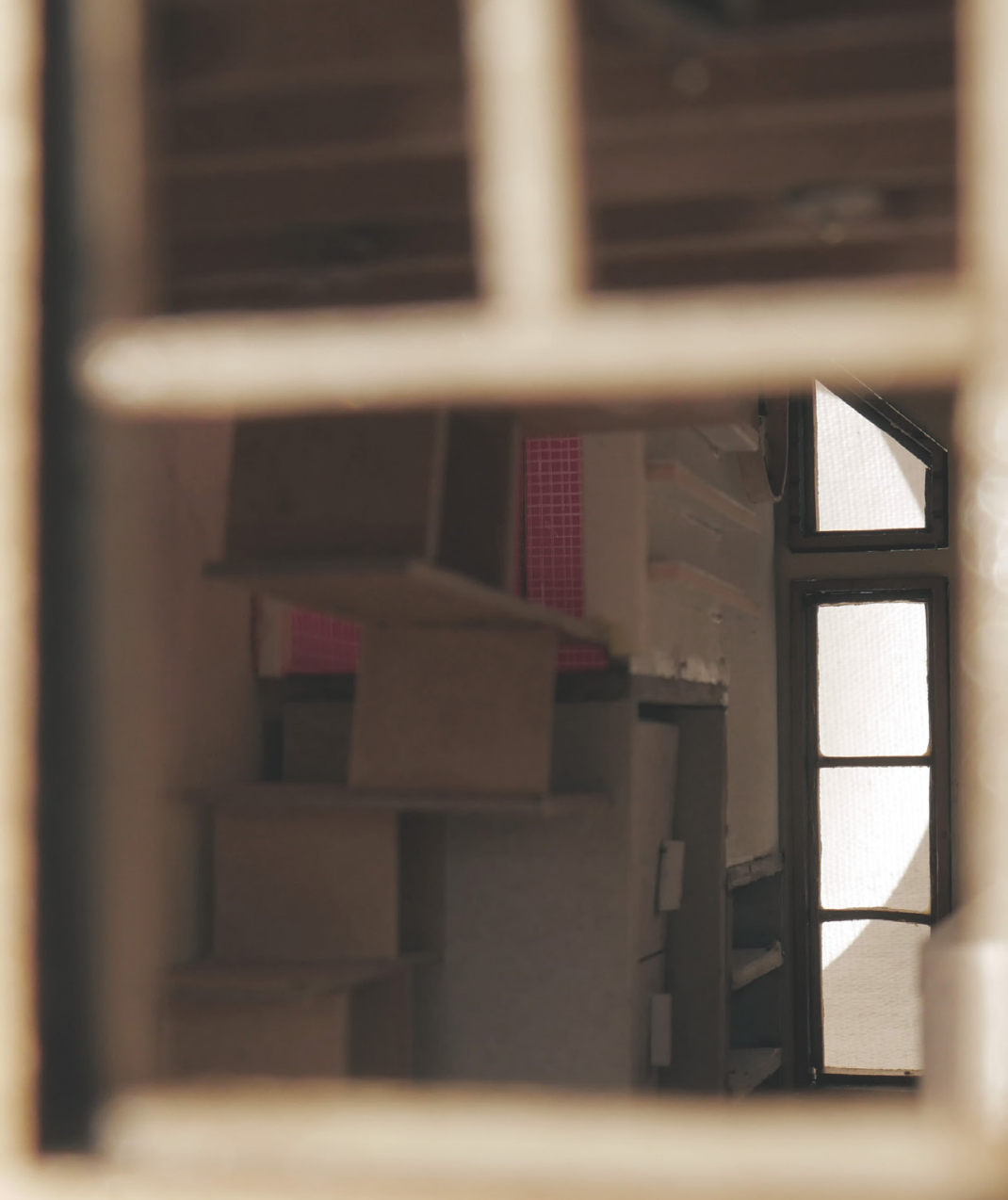



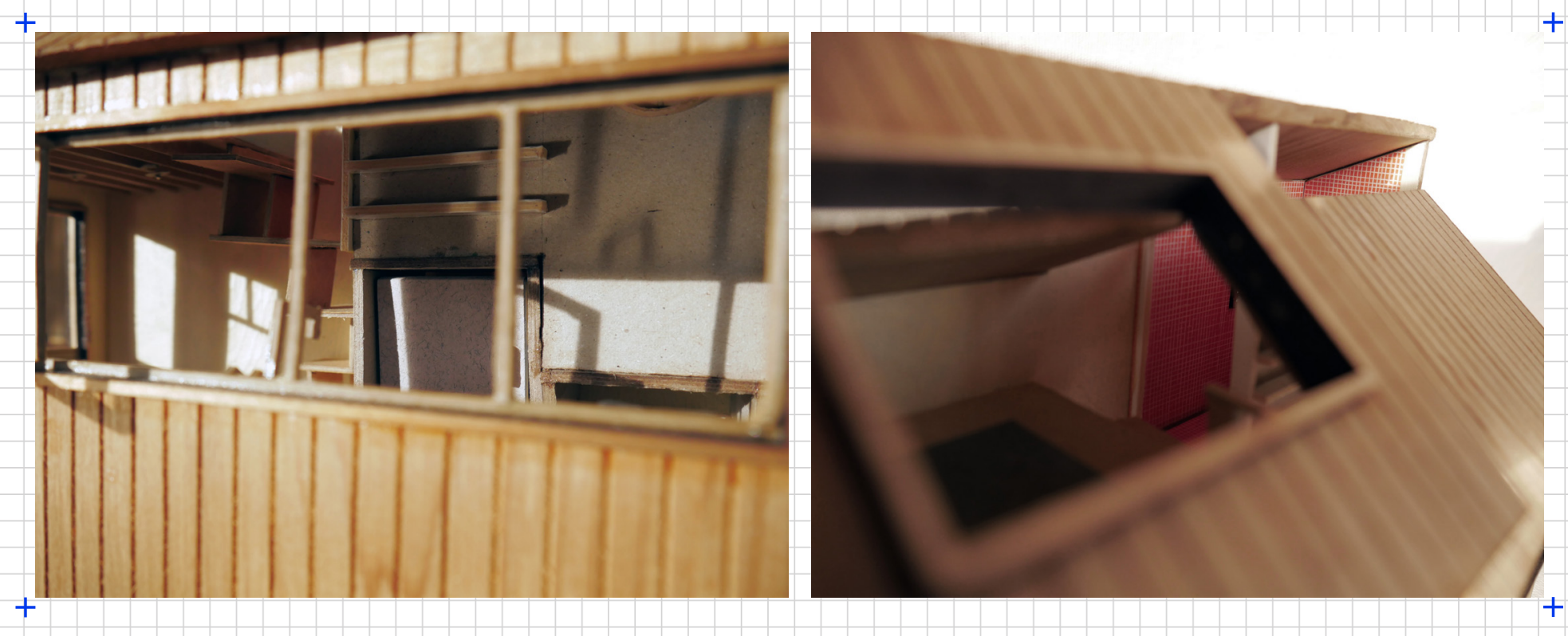


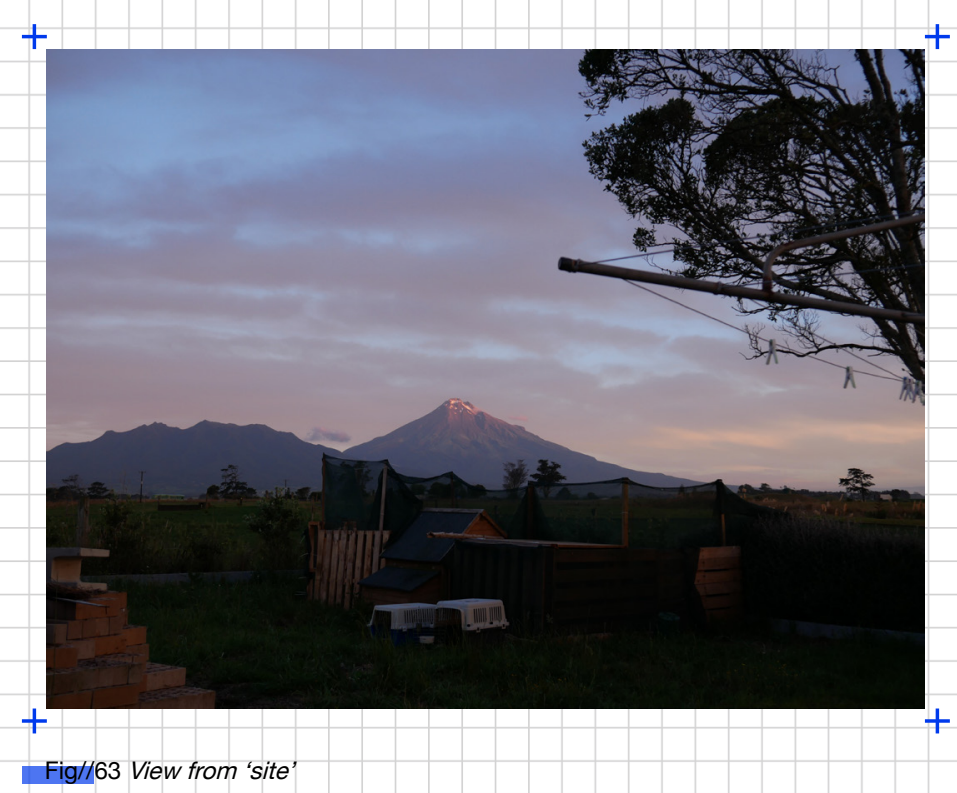

191 


\section{PART 1.2 ENDNOTES}

1 Sennett, Richard. The Craftsman. New Haven, Yale University Press, 2009

2 Tallis, Raymond. The Hand: A Philosophical Inquiry into Human Being. Edinburgh University Press, 2003. JSTOR, www.jstor.org/stable/10.3366/j.ctvxcrm97. Accessed: 24.05.2020.

3 Pallasmaa, Juhani. The Thinking Hand: Existential and Embodied Wisdom in Architecture. Sussex (UK), John Wiley \&Sons Ltd, 2009. P.12

4 Schulte, Joachim. Experience and Expression: Wittgenstein's Philosophy of Psychology. Clarendon Press, 1992

5 Rykwert, Joseph. On Adam's House in Paradise. New York, The Museum of Modern Art, 1972

6 Kahn, Lloyd. Shelter. New York, Shelter Publications. 1973

7 Bachelard, Gaston. The Poetics of Space. 1969. Beacon Press, 1994. P.3

8 Clarke, George, et al. George Clarke's Amazing Spaces . Quadrille Publishing, 2013. P.61

9 Horwitz, Jamie., and Paulette Singley. Eating Architecture. MIT Press, 2004.

10 Ednie-Brown, Pia. "Creaturely Collectives: Parametricism and Getting to the Afterparty". (pp. 1634). In, The Design Collective: An Approach to Practice, ed. Edquist, Harriet, and, Vaughan, Laurene. Cambridge, Cambridge Scholars Publishing 2012

11 Persse, Jason, and Stokes, Rebecca. "The Frankfurt Kitchen". Counter Space: Design \& the

Modern Kitchen. MoMA. 2011, https://www.moma.org/interactives/exhibitions/2010/counter_space/ the_frankfurt_kitchen/ Accessed: 18.04.2020

12 Colombina, Beatriz, and Wigley, Mark. "An Essay About Toilet Architecture." Pin-Up, iss. 23, 2017, pp. 235-236. https://pinupmagazine.org/articles/toilet-modern-architecture\#14 Accessed: 18.04 .2020

13 Colombina, Beatriz, and Wigley, Mark "An Essay About Toilet Architecture." Pin-Up, iss. 23 2017, pp. 235-236. https://pinupmagazine.org/articles/toilet-modern-architecture\#14 Accessed: 18.04.2020

14 Johnstone, Henry W. "Toward a Philosophy of Sleep." Philosophy and Phenomenological Research, vol. 34, no. 1, 1973, pp. 73-81. JSTOR, www.jstor.org/stable/2106781.

Accessed:04.04.2020

15 Johnstone, Henry W. "Toward a Philosophy of Sleep." Philosophy and Phenomenological Research, vol. 34, no. 1, 1973, pp. 73-81. JSTOR, www.jstor.org/stable/2106781. Accessed:04.04.2020

16 Bachelard, Gaston. The Poetics of Space. 1969. Beacon Press, 1994. P.136 

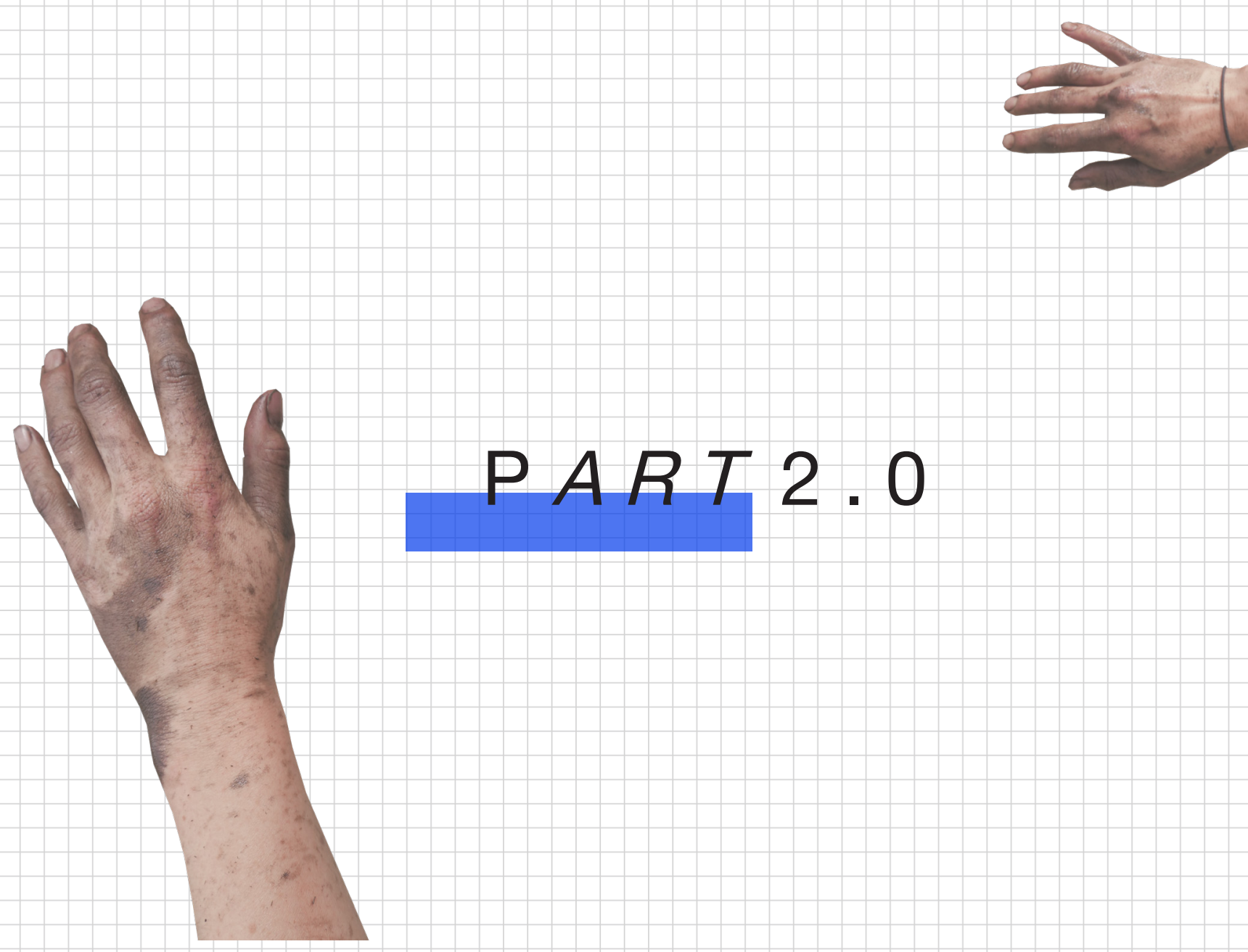


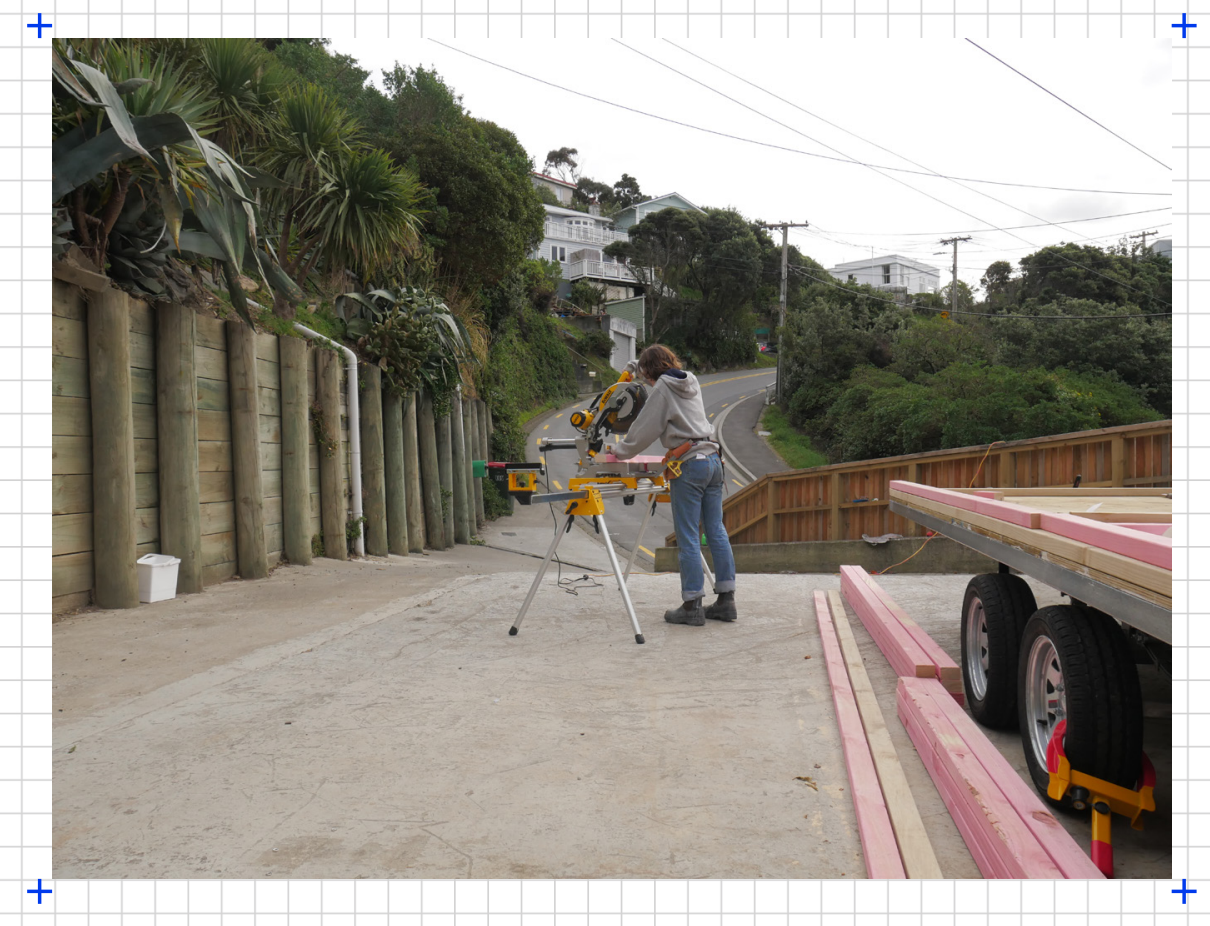




\section{INTRODUCTION}

It seems nothing, or very little would be achieved if not for daydreaming. It is a contradictory necessity to action.

Clearly visualising a specific scene -rather than simply imagining- and playing it over and over again. Taking the time to recognise the smells of that scene, the temperature of the air. How that scene makes one feel emotionally. The scene I began to constructed started with a coffee:

Listening to the pop of the percolator grow louder and louder before rolling over and getting up. Getting up inside something I had myself built. I then walk down the stairs I had conjured to fit within the tiny space I had decided it would be placed. I then glance out of the large window in the kitchen which I had myself flashed and fitted, over at my sister's humble white house before turning back to retrieve two mugs from the shelves I had attempted at welding together. Coffee in hand I place a drowsy hand on the cool handle -my first attempt at hardware installation-and pry open the front door, bare sunlight streaming in. I would take a few steps across the moist lawn before turning back to look at what I had created.

If it were not for this performance I had conceived and consequentially cultivated to become all-consuming, I highly doubt this somewhat mad idea would have left the ground. Introducing his notable text 'The Poetics of Space', Gaston Bachelard suggested that "...the reader of poems is asked to consider an image not as an object and even less as the substitute for an object, but to seize its specific reality"121. Only through an understanding and ownership of the specific reality of my dream was I able to progress. The next section of this thesis is the exploration of how I transcribed my poem. 
Transforming an idea into reality begins with a commitment. A irreversible, non-negotiable commitment. The kind David Pye touches on within his 'Workmanship of Risk' analysis ${ }^{122}$. A Professor of Furniture Design at the Royal College of Art, Pye was both a craftsman (wood-turner and carver) and academic, his notable works being 'The Nature of Design' and 'The Nature of Art and workmanship' -the latter introducing his most notable concept, the 'workmanship of risk'. A reaction to what he denotes as 'the workmanship of certainty', it is the notion of a commitment to something one is unsure the outcome of which consequently allows for its development as an idea ${ }^{123}$. It's the concept that "...at any moment...the workman is liable to ruin the job"124. It is the thrill of the unknown which drives the project.

My commitment was to buy a trailer. A trailer whose dimensions, I was committed $(5 \mathrm{mX} 2.5 \mathrm{~m})$. The first in a whole sting of concrete decisions I would be making. The ordeal of securing the right one has already been discussed, however to pick the trailer up was another adventure.

For many reasons, (particularly with respect to the pandemic which occupied our lives for most of the year 2020), the trailer I purchased was made in Silverdale, Auckland by a company called Aakron Xpress. Because of its length, Solomon and I had to drive a friend Matt's Ute to pick it up. Firstly, we had to navigate our way to Silverdale to meet Lloyd, the man I had been emailing. The drive there was winding and narrow, causing both me and Solomon to wonder about the difficulty of towing the trailer back to Solomon's parents house. After an hour or so of driving we finally arrived at number 124 Messenger Road, an iron gate on which looked like a sub-tropical orchard. I called Lloyd to let him know we had arrived and he promptly appeared from a nearby driveway and showed us to the trailer. He then proceeded to explain how the lock and tow ball worked and how to attach and unhitch the emergency brake. Barely inquiring into whether or not we had paid, he gave us the keys and we set off. Unfortunately, because of the trailers larger than usual width, getting back out of the iron gates proved difficult. I watched as Solomon manoeuvred the trailer out of the gate. Difficult. Allowing me to once again question the ideology of the tiny house movement. The notion of "here today gone tomorrow' it perpetuates seemingly idealist if not unrealistic. Nevertheless, somewhat anticlimactic, the trailer acquisition ran particularly smoothly on reflection.

The next day Solomon and I constructed the floor for the trailer. This was to enable us to pick up a few six-meter-tall palm trees in Tauranga on the way back to Wellington.

We began by taking a trip to one of the few hardware shops which stocked $2700 \mathrm{~mm} \times 1200 \mathrm{~mm}$ sheets of $19 \mathrm{~mm}$ plywood. A difficultly due to its non-standard size. Non-standard, as the standard size for sheets are $1200 \times 2400$ due to the New Zealand building code regulation of framing 'centres'125. A piece of knowledge I had never fully considered.

Typically, tiny homes are built at $2400 \mathrm{~mm}$ wide by multiples of $1200 \mathrm{~mm}$ to avoid the obvious wastage involved in cutting down $2700 \mathrm{~mm}$ sheets, however the maximum legal load width allowed in New Zealand is $2550 \mathrm{~mm}^{126}$. Although I knew about standard sizing, I did not quite realise its effect on the building process. This was the first of many realisations.

Shaking this off, we continued to pick up the things we needed to build the floor. Along with the ply we purchased three sheets of polycarbonate insulation, glue, drill bits, a chalk line, paint, self-tapping screws and a craft knife. Another

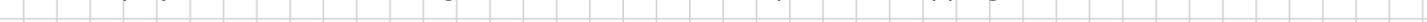


stark realisation at this point was the fact that building something real, outside of architecture school is expensive. Considering, representation is perhaps a less expensive from of realisation, I began to understand perhaps the need for representation. Before this, the maximum I had spent was approximately $\$ 300$ which consisted of materials and laser cutting time. This first shop, essentially to get the building 'out of the ground' cost $\$ 1380$. Luckily at this point the tools we needed, we had thanks to Solomon.

Taking our materials back to Solomon's parents' house north of Auckland we began. The next steps were seemingly straightforward, in the sense that each task happened sequentially and Solomon brought an understanding of everything we needed to do. We began by cutting the $2700 \mathrm{~mm}$ long plywood sheets down to $2500 \mathrm{~mm}$ (the trailer width) before painting the downward face with primer. Whilst the primer dried I cut the insulation with a craft knife to fit tightly between the trailer's joists. Lastly, and perhaps most challenging, was securing each piece of plywood to the trailer ensuring each tongue aligned and fit tightly with each groove of the plywood edge. Beginning at one end, we glued the section of the trailer's frame the ply would sit on. We then carefully placed the ply wood on top, and secured it with a self-tapping screw in each corner. Each subsequent sheet then followed, with the added intricacy of tapping the tongue edge of the sheet into the grove of the previously laid sheet. Although this sequence of tasks may sound relatively simple (I have before stuck wood to things) it became clear early on that had I not been clearly shown and directed, things would have become quite chaotic quite quickly.

This led me to acknowledge the amount of intelligence a builder acquires over their apprenticeship. An intelligence which enables them to see the bigger picture, to know when or where they must be exactly precise and when it doesn't matter so much. When I frustratedly asked how Solomon knows so much, or how he can do this or do that, I am always greeted with the same response; "Its because l've been doing it for eight years, you've never done this before". Disregarding the annoyance aimed at myself for never doing this before, I began to understand the importance of time in relation to skill, and the role of experience vs imagination/theory. Richard Sennett said "the slowness of craft time serves as a source of satisfaction; practice beds in, making the skill one's own"127. Time cannot be cheated. The experience of drilling thousands of $150 \mathrm{~mm}$ screws into steel is arguably the purest form of gaining the knowledge of how to carry out that particular task.

Having completed what was to one day become the floor of a home, there was an immediately a recognisable space to occupy. This was not 1:100 scale, or even $1: 10$, this was $1: 1$. Real life, I could relate my own body to it. We were able to walk around what would one day be the 'Cook' space, imagine a sink, in front of which stood Mt Taranaki framed by a window. At this stage one has not only inevitably reached a point of no return, but opened the project up for discussion. The possibility or impossibility of a concept may be considered. John Walsh said, "As soon as a design is done- lets -presume it's an admirable scheme- the battle to preserve its integrity begins" ${ }^{228}$. Once something is 'real', outside of one's head, the design may be prodded and questioned as a stable outcome, no longer protected by the dreamer. 


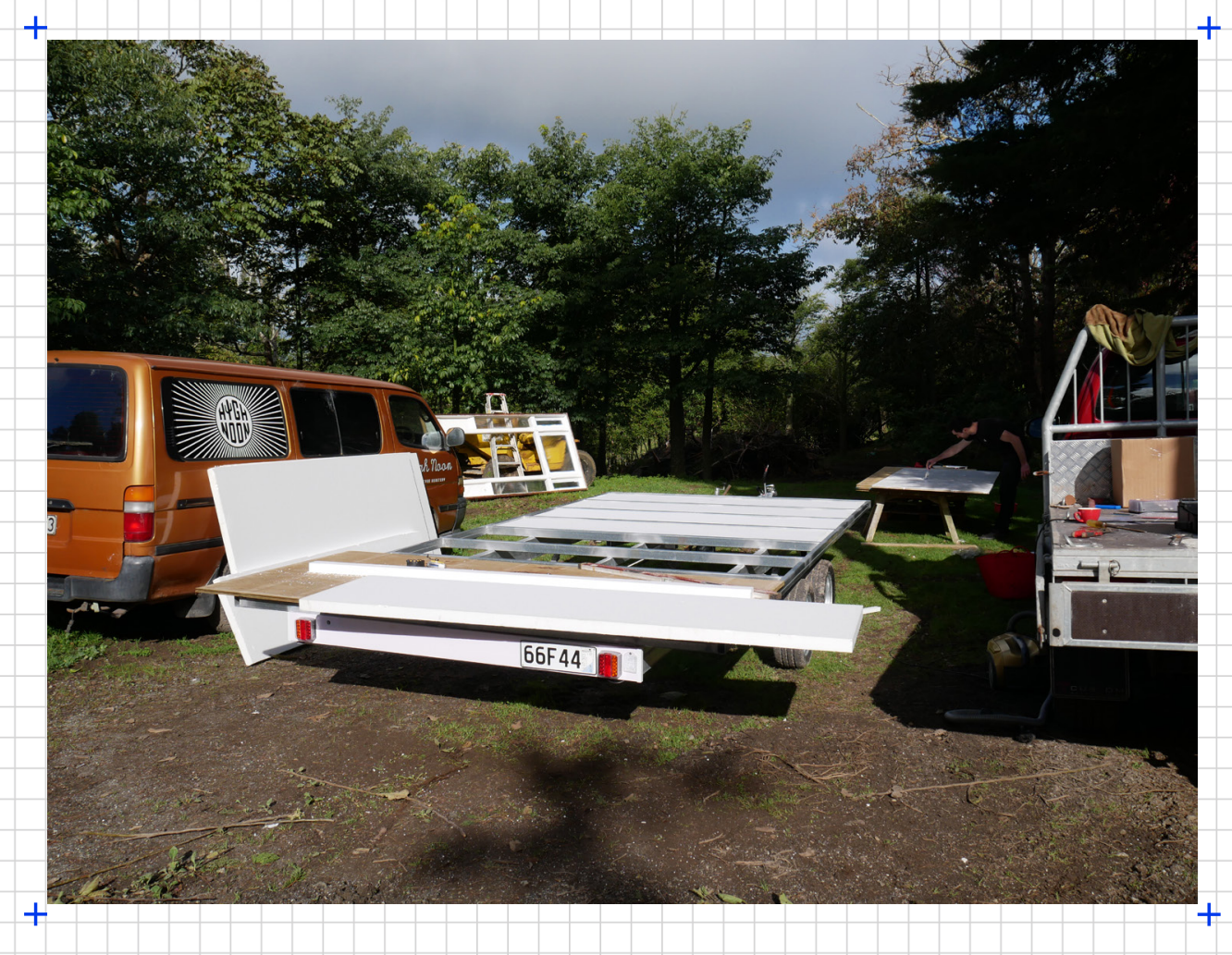

Fig//64 Progression of building floor 


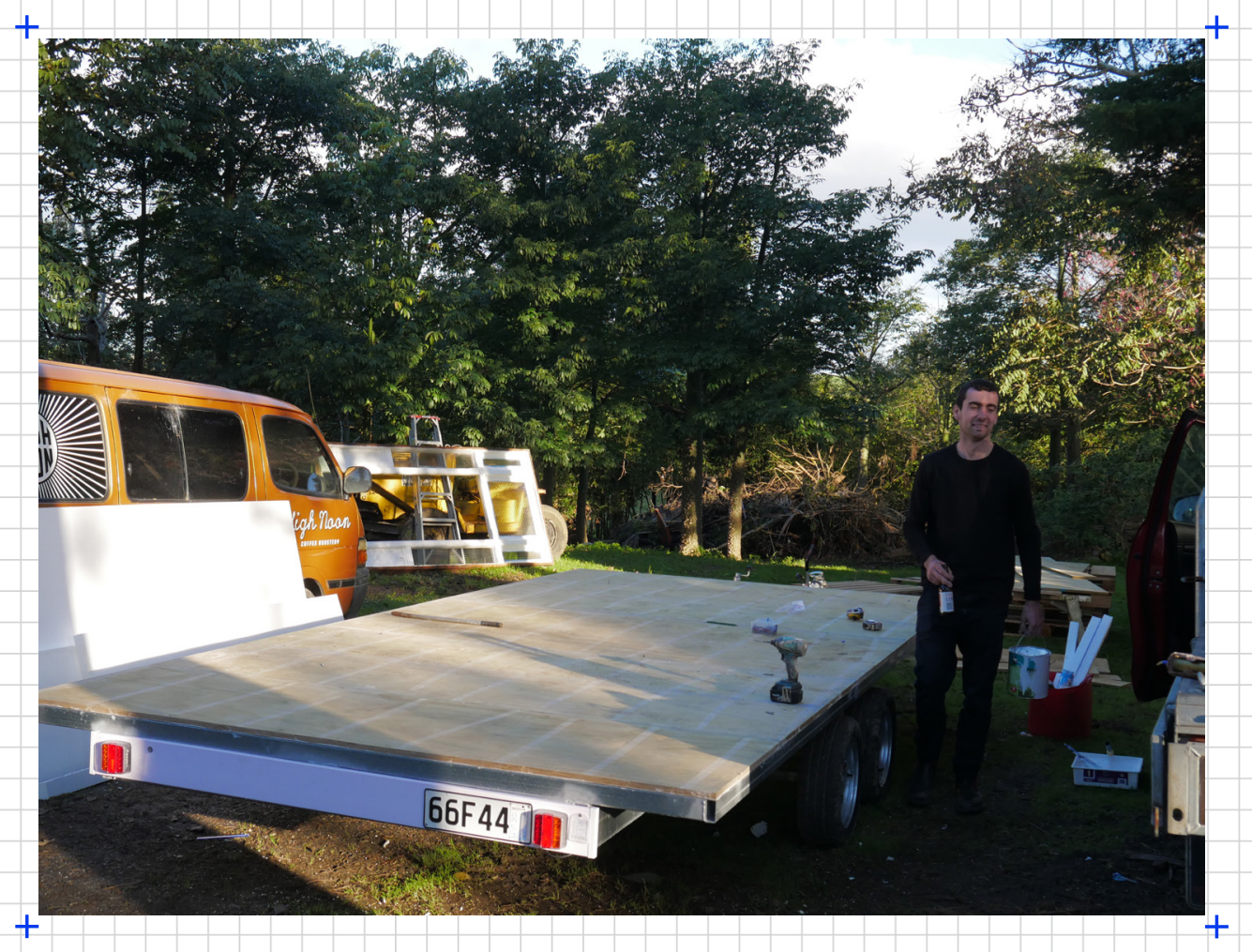




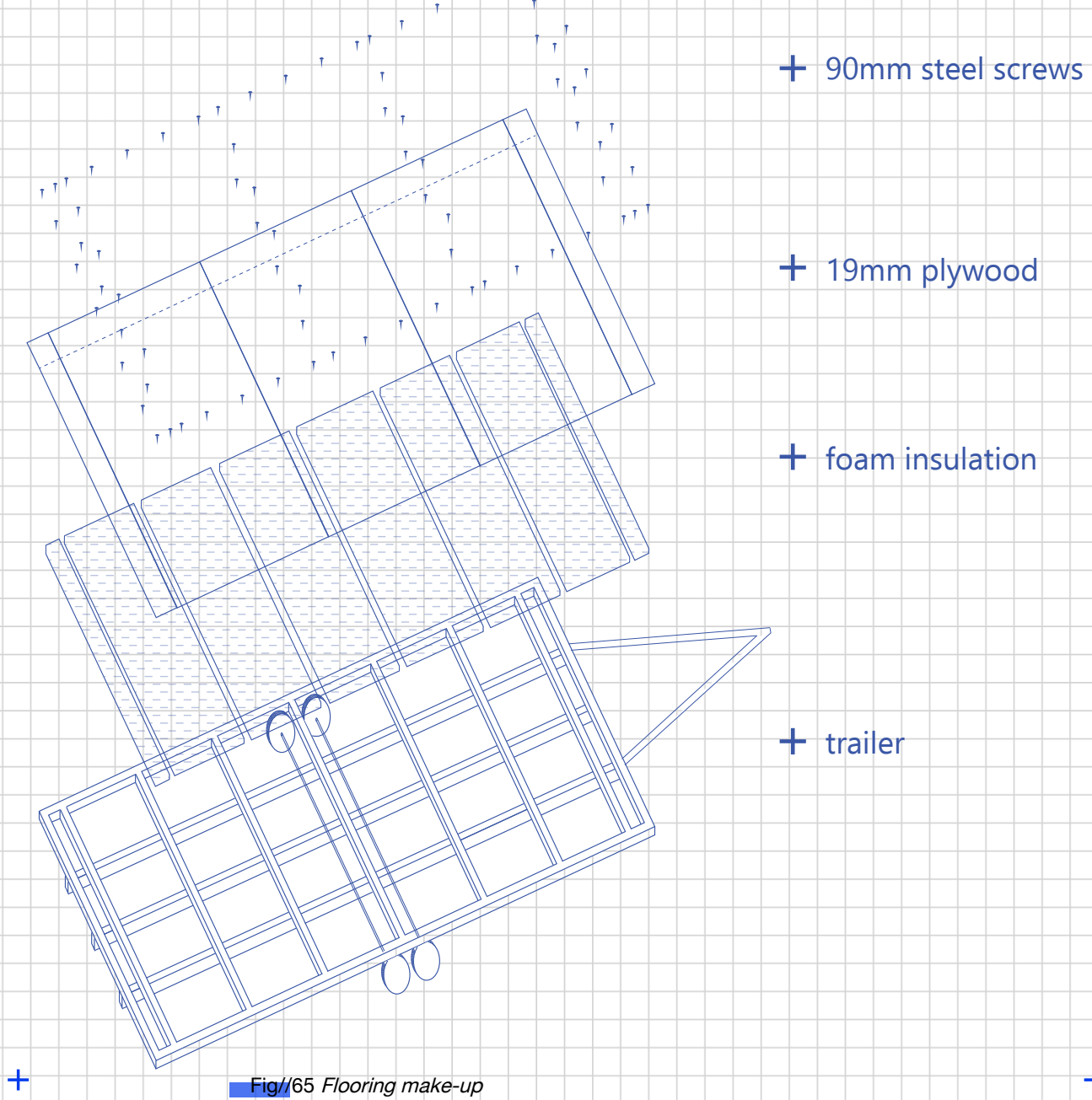




\section{JOURNEY}

With the floor complete we were ready for our journey back to Wellington. Attaching the trailer, we ensured the emergency brake was on and handbrake was off. We then loaded our things, ourselves and a dog into the cab. By $1 \mathrm{pm}$ we had reached Tauranga where we were to collect our final and largest load of the trip. Five palm trees. As I have often found, some of the most optimistic and can-do attitude people I have met are those with particularly difficult jobs. Hiab drivers are one of these people. Lifting 400-kilogram palms into the air and laying them flat on the back of a soon-tobe tiny house trailer may seem challenging, however for James, not only was it a smooth operation, it was done with a smile and a laugh. Once we stropped down our added two tonne weight we were on the road again. A long drive with a large load allowed me to again consider the possibility of frequently moving the tiny house around. Considering the palms to be a good test of the trailer I had just invested, it seemed the journey was not one to be doing every weekend. Reflecting on this somewhat strained journey back to Wellington forced me to think upon a tiny house I had seen on tiny house advocate Bryce Langston's YouTube show which documents "unique and interesting small homes", 'Living Big in a Tiny House'129.

Weighing only 500-kilograms, Tagami Haruhiko, a Japanese master-craftsman designed and built a tiny house with the purpose of being 'on the road' 130 . 'Baske-T', measuring just four meters by one and a half, is designed to be able to reshape itself, allowing it to be both office, sleep space, cook space, eat space etc. Yet I suppose one of the major components the designing of such a small space grapples with is its usability. Tatjana Schneider and Jeremy Till wrote that "inflexibility must be designed out" of residential architecture ${ }^{131}$. Specifically, that one may be able to move from one space to the next and carry out each individual task without the need to reconfigure the space. This conundrum seems to play a role in many of the tiny house's I have explored throughout this endeavour. The ability to move freely within a space whilst also allowing it to be adaptable and maximise its spatial potential. Tiny houses are in a sense, products. Because of their size the ability to definitively change it is predominantly impossible, therefore to counter this, the spaces are designed to fold out, slide in and stack. 


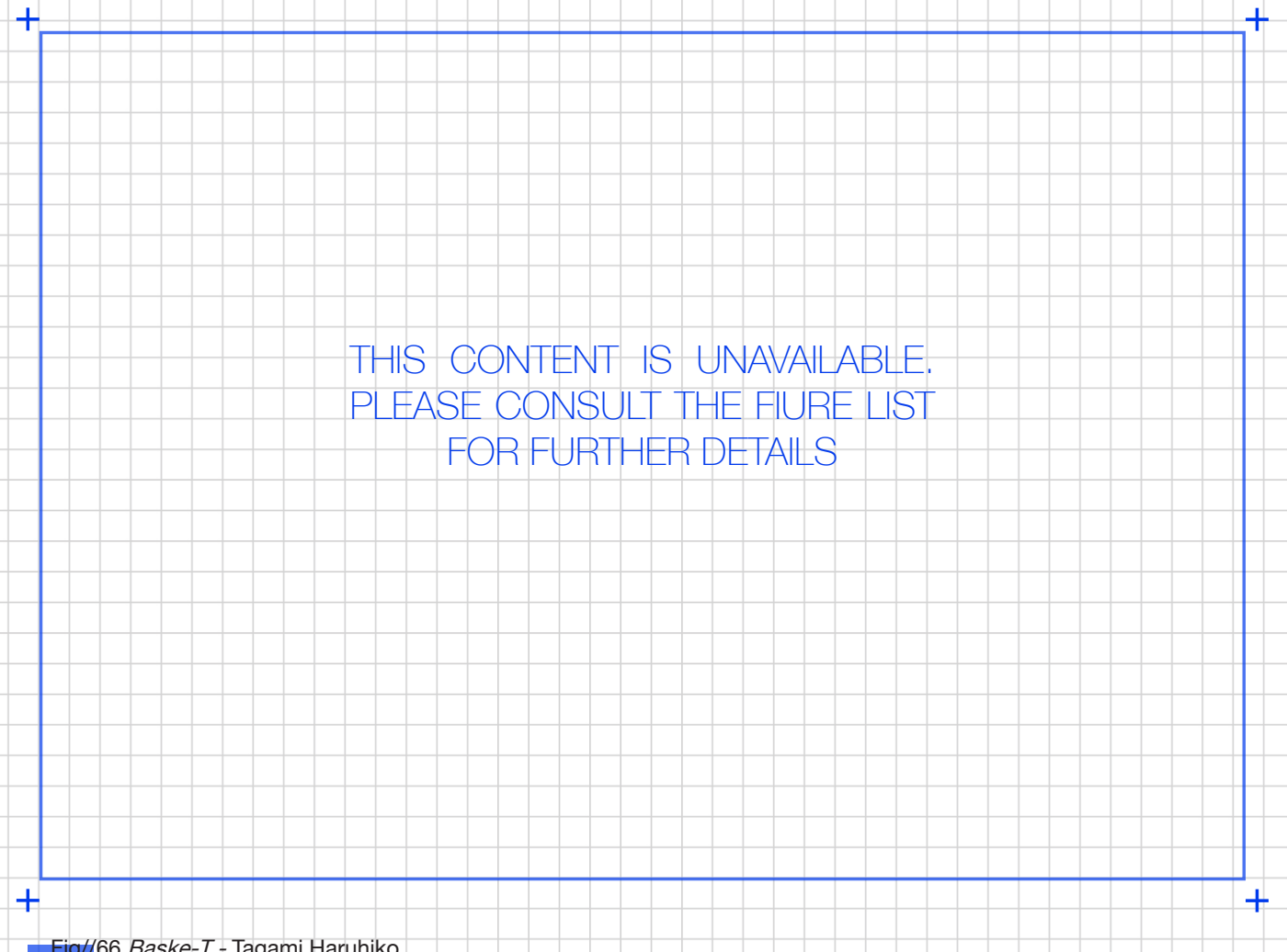




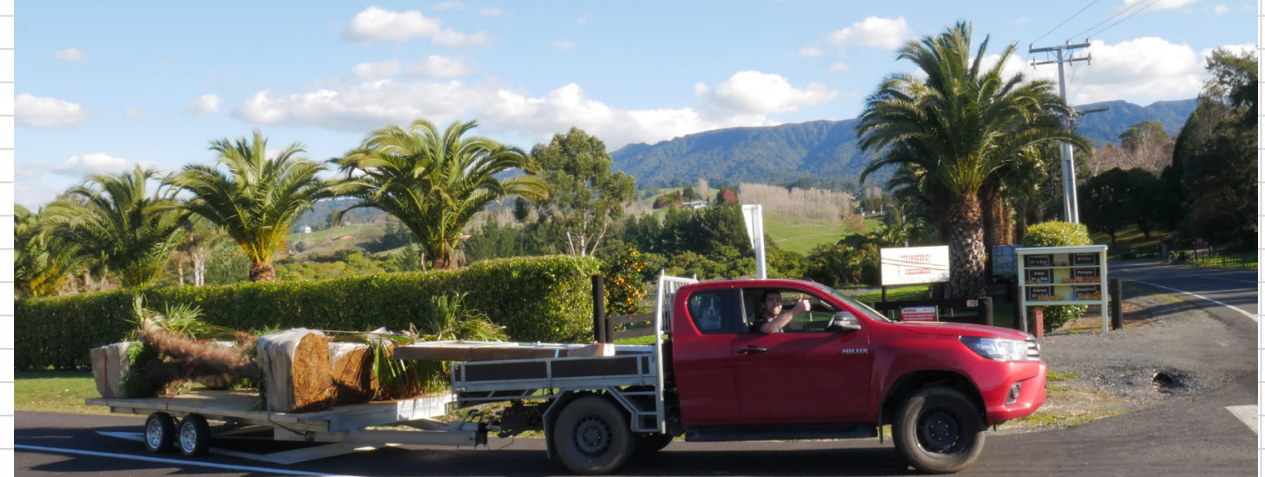

$+$

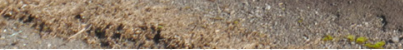

$+$

Fig//67 Palm trees on Ute 


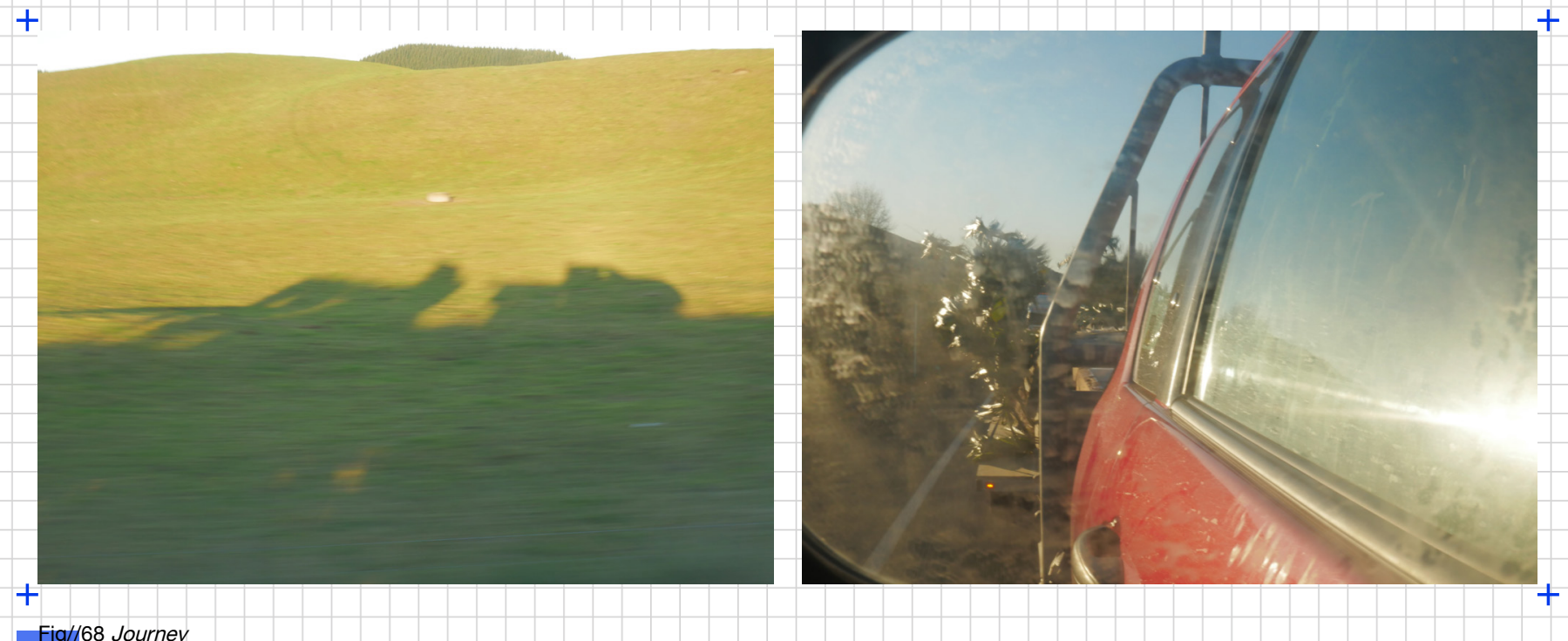

205 
The natural progression from purchasing and collecting the trailer was to overcome what many tiny house projects are confronted with. Site. The notion of site within architecture is well discussed and theorised, from site as self, to the meaning of context within architecture. Ruskin famously linked memory with site, he wrote, of architecture, "We may live without her, and worship without her, but we cannot remember without her"132. Architecture as site, an inherent character which allows one to bring forth memory. Japanese architect Jun Aoki suggest "making the site is not just a physical condition, but also a mental one" 133 . Within the same vain, Tadao Ando wrote "the presence of architecture -regardless of its self-contained character- inevitably creates a new landscape. It implies the necessity of discovering the architecture which the site itself is seeking"134. He explains his architecture is composed of a places inherent logic he seeks. Yet what happens when an architecture has no specific place, how can an architecture be created through transient characters of site?

However, currently, my site predicament was somewhat a more pragmatic need.

I needed a space which I could build. I decided it would be best to construct the dwelling outside my own home which had access to a garage with power. This imposed a slight issue when it came to the moving of the structure once it was built as the carport access led onto a steep corner of a relatively busy road. I accepted, this would be fronted at a later stage. 


\section{MATERIAL +}

TECHN CHICAL DECISIONS

Before framing were to commence, a consideration of the materials, and their consequential technical applications needed to begin. Consisting of a predominantly formal experiment thus far, I had naively neglected the very real problem of detail. Mike Austin and Jeremy Treadwell wrote that "Tectonic issues are often neglected, but the instability of architectural origins becomes immediately apparent to anyone trying to build even the most primitive of huts"135. I had deceived myself. Not considered the very real complex of how every material, every method would carry with it its own dimensions, own perceived quality, and most importantly its own ramifications. Further from these decisions was the need to order specific things in time, which, on reflection I was far out of my depth having predominantly only bought sheets of card off the shelf for 1:100 models. However this arose far later.

Material choice, particularly with respect to non-site-specific architectures, occupy a somewhat awkward space within architectural language. The notion of a relationship with surrounding is arguably left redundant as the relatable surrounding is ideologically transient. Therefore, the elements of consideration I was left with was, the client, her preference, obviously price and, unconventionally, weight (as the legal towing weight for the trailer was three tonnes ${ }^{136}$ ). Due to my clients favouring of technological over aesthetic decisions, material authority was assumed by me. For example, she often had extremely detailed queries as to where the steel for the trailer was sourced or the maximum capacity for her solar batteries but the big picture concept did not interest her. Her response to me asking her advice over this particular period was simply, "you're an architect, you know better than me!" of which I would be quite quick to respond with, "no l'm not I don't know anything!". Nevertheless, the task became of me to decide the structures externa material, technical and formal qualities.

Therefore, to acknowledge and test a variety of options that would fit my limited criteria upon the design's form, I began experimenting with relatively crude photomontage (photos) in conjunction with research into Fujimori's material use. Aiming to stray away from the previously discussed tiny house aesthetic, I investigated material combinations which could work within the context of New Zealand (as broad as that alludes to). 
$+$

THIS CONTENT IS UNAVAILABLE. PLEASE CONSULT THE FIURE LIST FOR FURTHER DETAILS

$+$

Fig//69 Lamune Onsen - Terunobu Fujimori 2004

Fig//70 Ichiya-Tei - Terunobu Fujimori 2003
$+$

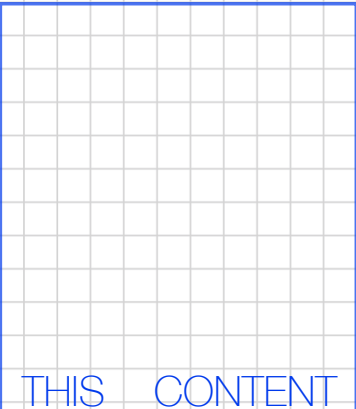

IS UNAVAILABLE. PLEASE CONSULT THE FIURE LST FOR FURTHER DETALS

THIS

CONTENT IS UNAVAILABLE. PLEASE CONSULT THE FIURE LIST FOR FURTHER DETAILS 
It would be an understatement to suggest this process was difficult. Where does one draw the line with exploration? Or decision making? Throughout my architectural education, arguably because of its representational quality, nothing has ever truly had to end. Nothing has been made concrete. Of course, there have been deadlines, but nothing to wholly commit to. It was at this point I compelled myself to return to a phrase Jeremy Till coined: "phony ethics of aesthetics" ${ }^{137}$. Within his work 'Architecture Depends', Till's critique on the traditional architect delves into the association architects have created between aesthetics and ethics, which they are stringently committed. This association, he implores, is fundamentally flawed. Allowing that through materialising ideas as objects, or rather, converting ethical qualities into aesthetic form, ethics is ultimately abstracted from its definition ${ }^{138}$. Ethical qualities arrive through architectural action/ reaction rather than aesthetic symbolism. Till advises, "By all means craft the building, compose the elevation, worry over the detail, but at the same time see these as just some tasks in service to another. The key ethical responsibility of the architect lies not in the refinement of the object as static visual product, but as a contributor to the creation of empowering spatial, and hence social, relationships in the name of others"139. That is, actual not imagined, relations. Within this, Till highlights the social aspect of architecture, the importance of the user and in doing so somewhat alleviated this decision process.

Concluding this exploration, a decision was made based on average prices, installation technique, weight and compatibility. Through investigation into Fujimori's work it became clear the ability to play with scale derived from not only his roof forms but also their application. Many of his works implement hand rolled copper sheets which allow the roof a variant quality, enabling their large surface areas to have a quality of unrefined movement. He specifically said of his 'Chashitsu Tetsa' tea house that "if I use hand-rolled copper sheet with bumpy surface, I has an interesting effect of being old and new at the same time" "140. It is this juxtaposition Fujimori continuously adopts which allows chaos to be controlled. Robert Venturi wrote in 'Complexity and Contradiction in Architecture', that "Complexity must be constraint in architecture. It must correspond in form and function"141. Complexity must be equated with simplicity. Because of the intention with which Fujimori's copper roof is crafted, the complexity of its form is balanced. I reasoned this could be emulated through cedar shingles as the varying widths create an irregular pattern similar to that of Fujimori's copper roofs, their application being both refined yet natural at once. This conveniently allowed me to fulfil another dream of mine which was to work with cedar shingles.

With respect to cladding, explorations acknowledged that verticality could be used to again play with the scale of the dwelling. Therefore, to somewhat relate back to the notion of the New Zealand bach, or rather simply traditional New Zealand construction technique, board and batten would make up the port and Starboard walls whilst vertical shiplap weatherboards would make up the Stern and Bow.

Comforted by resolution, by the reduction of elements in consideration, I was ready to begin framing up. 


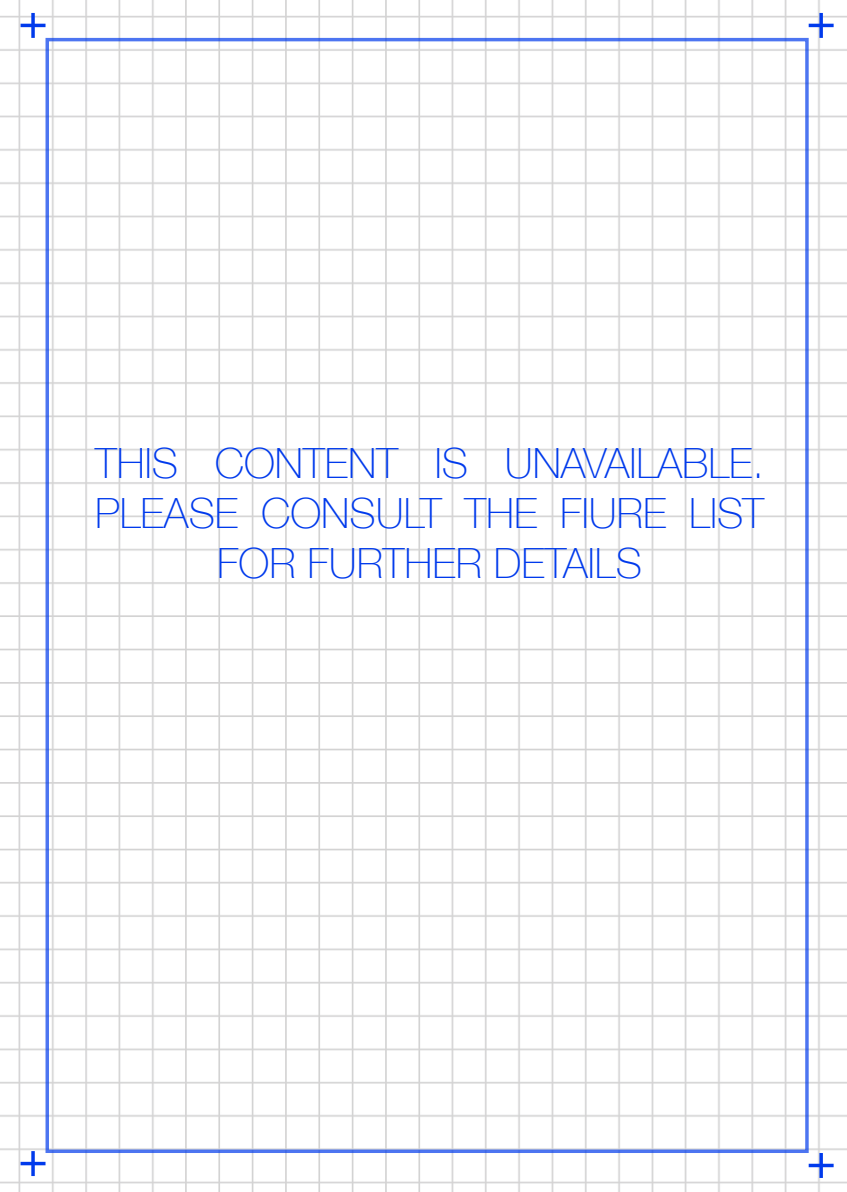

Fig//72 Chashitsu Tetsa- Terunobu Fujimori 2005 


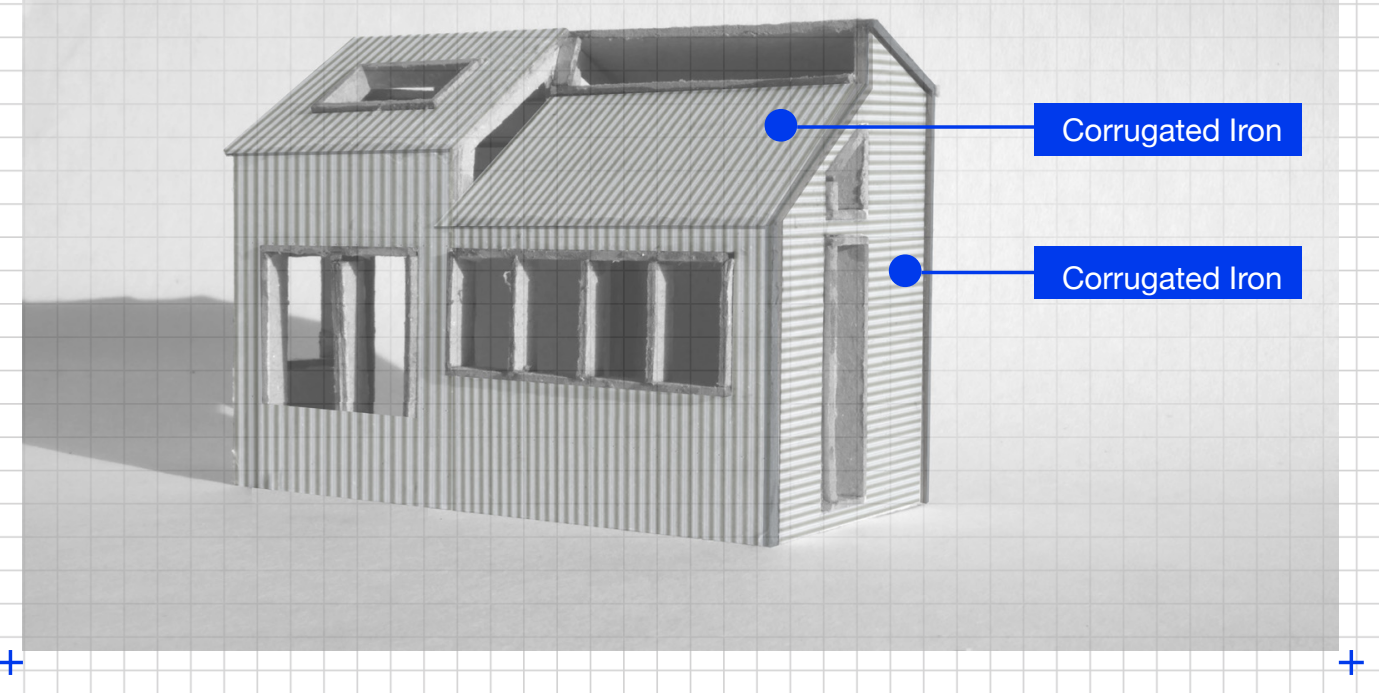

211 
MATERIAL EXPLORATION

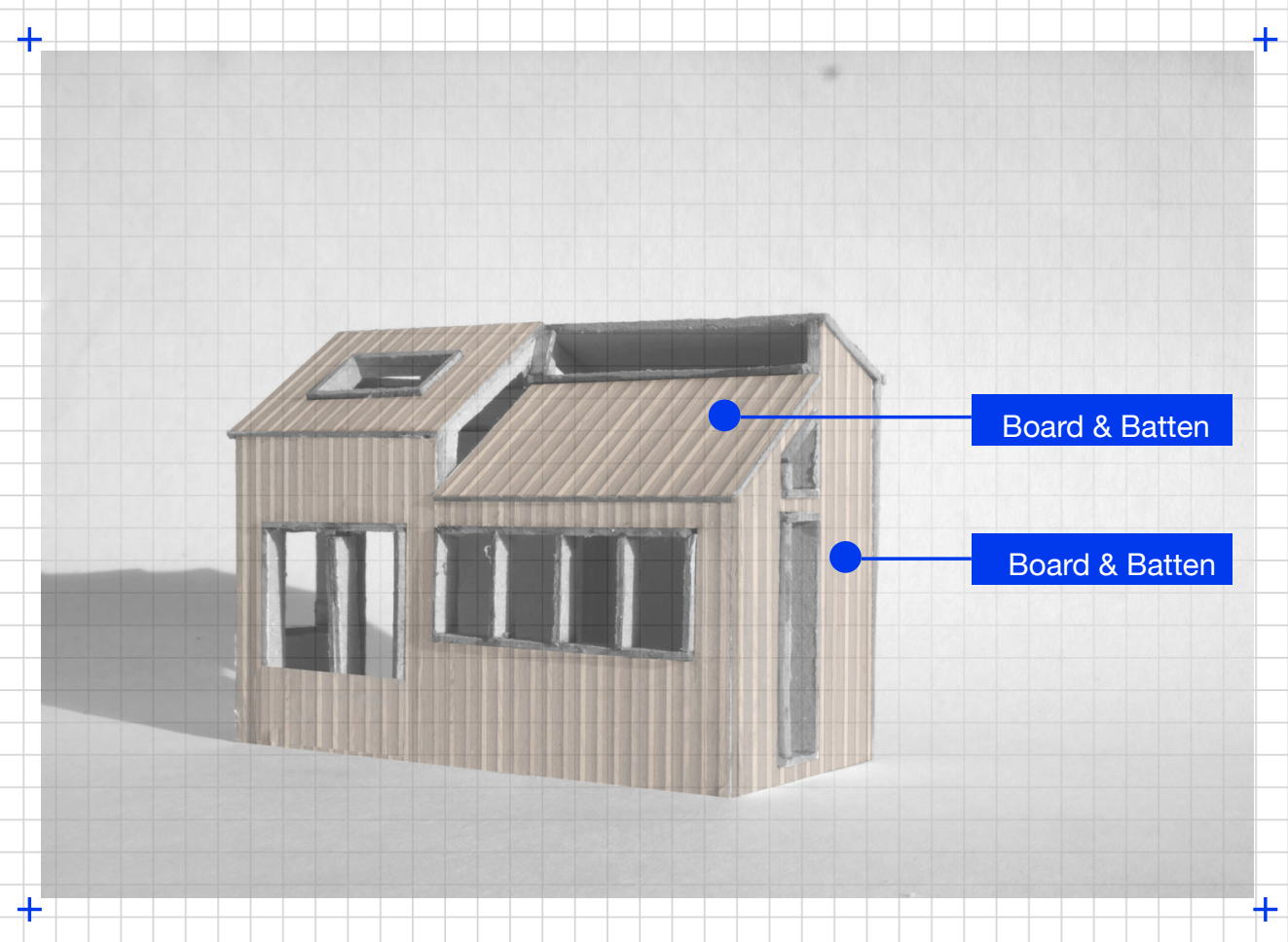




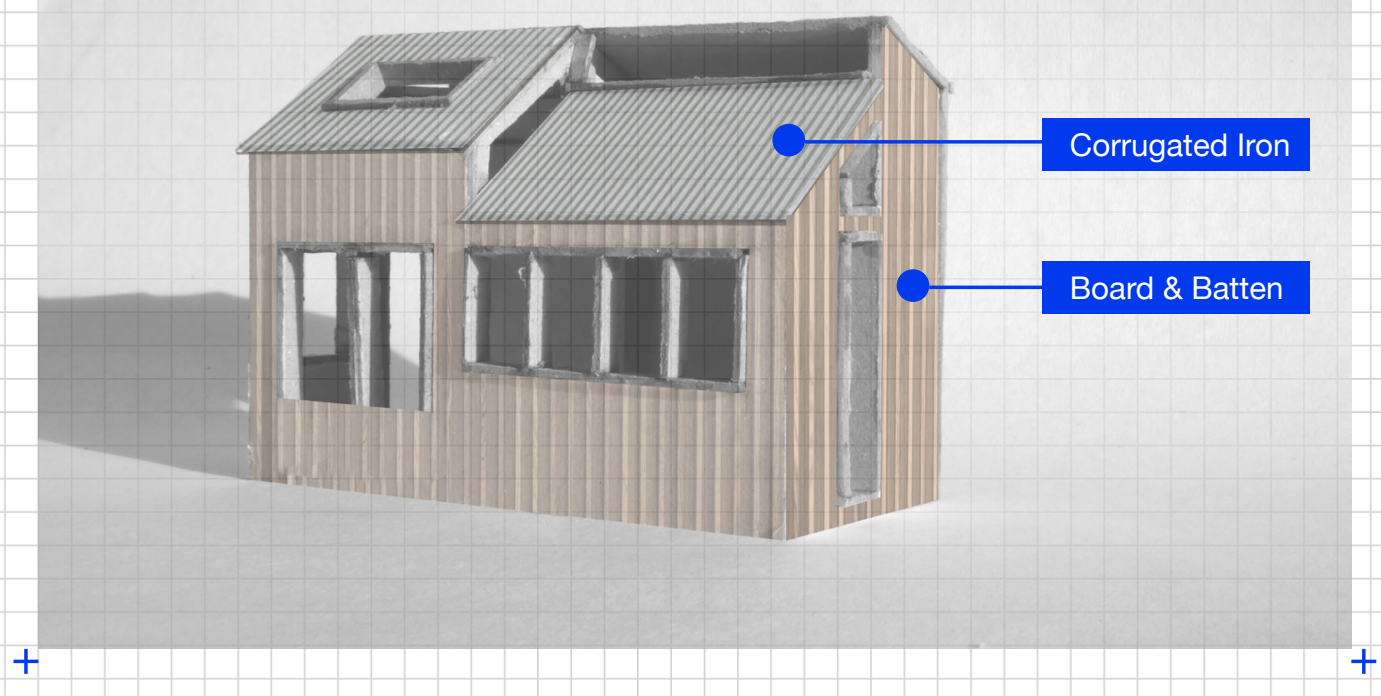

213 


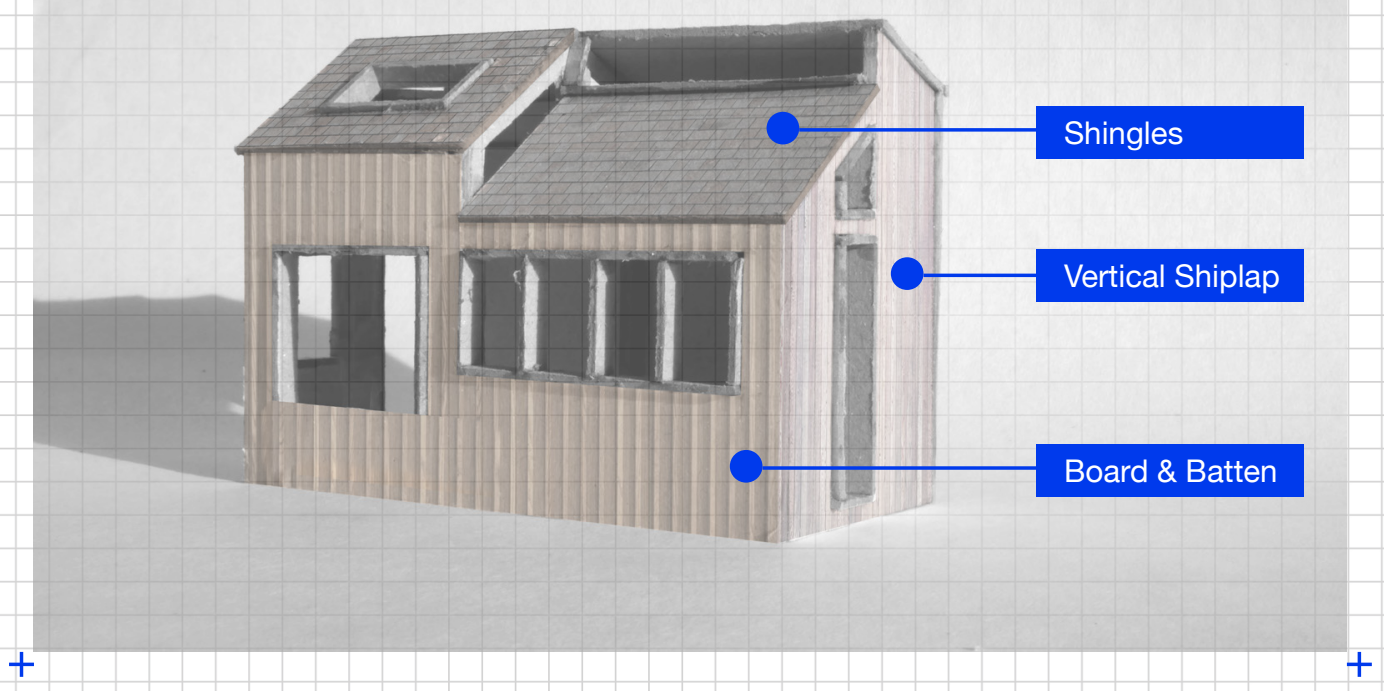




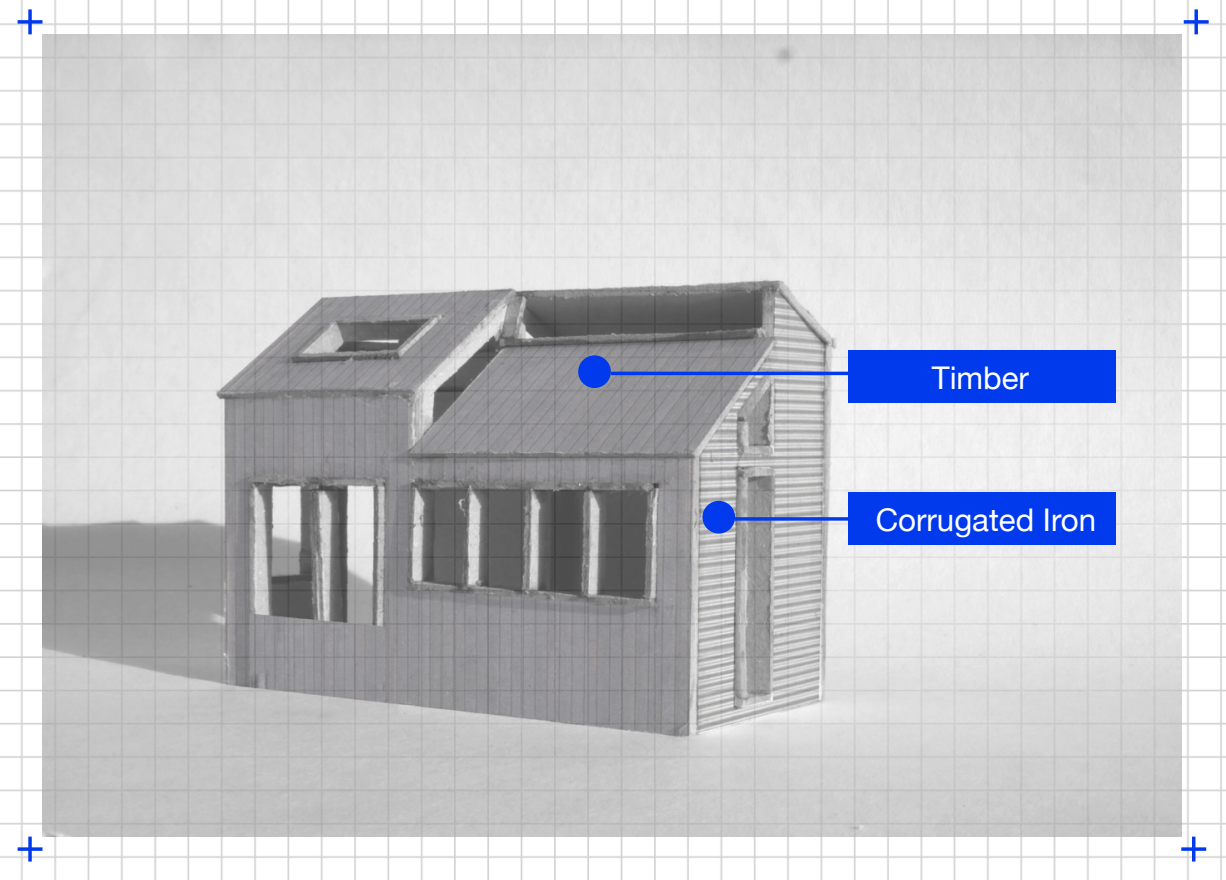

215 
$+$

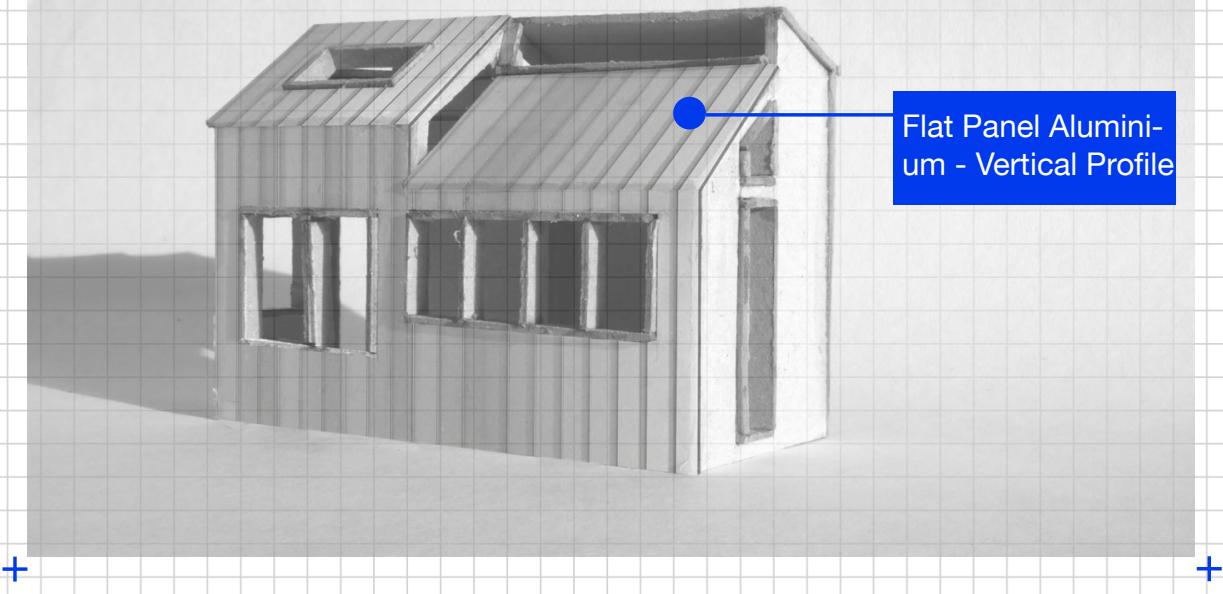

$+$

$+$ 


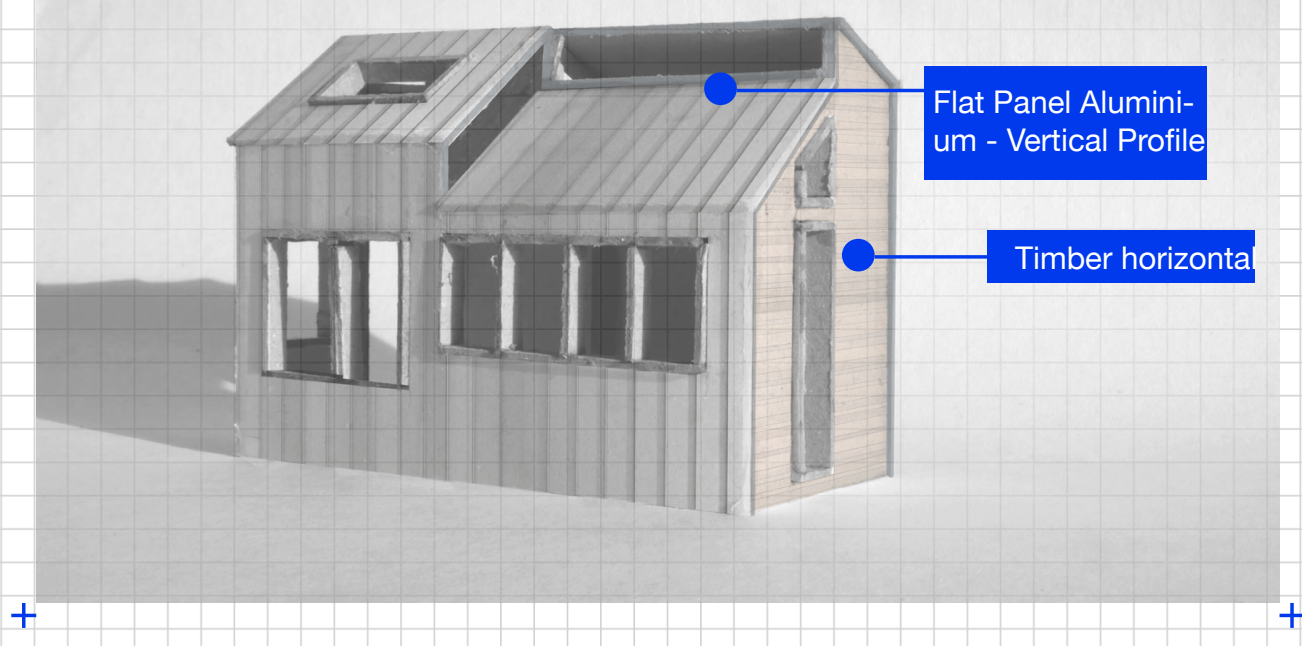




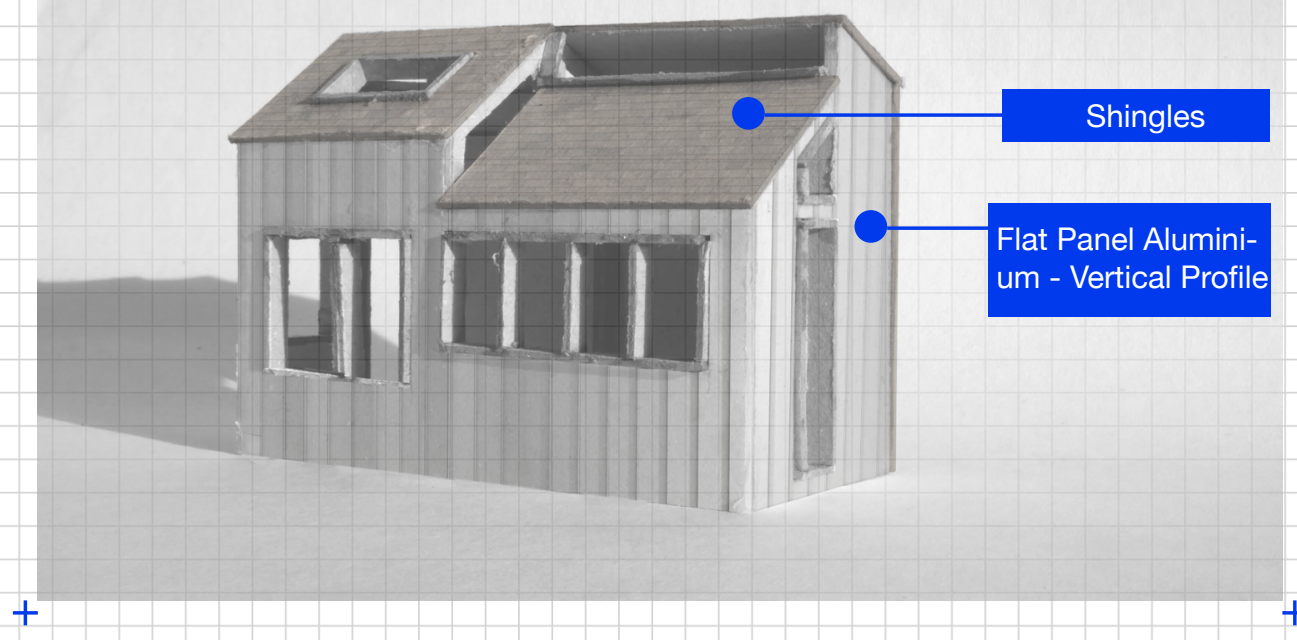




\section{$B E G I N N I N G$ BUILDING}

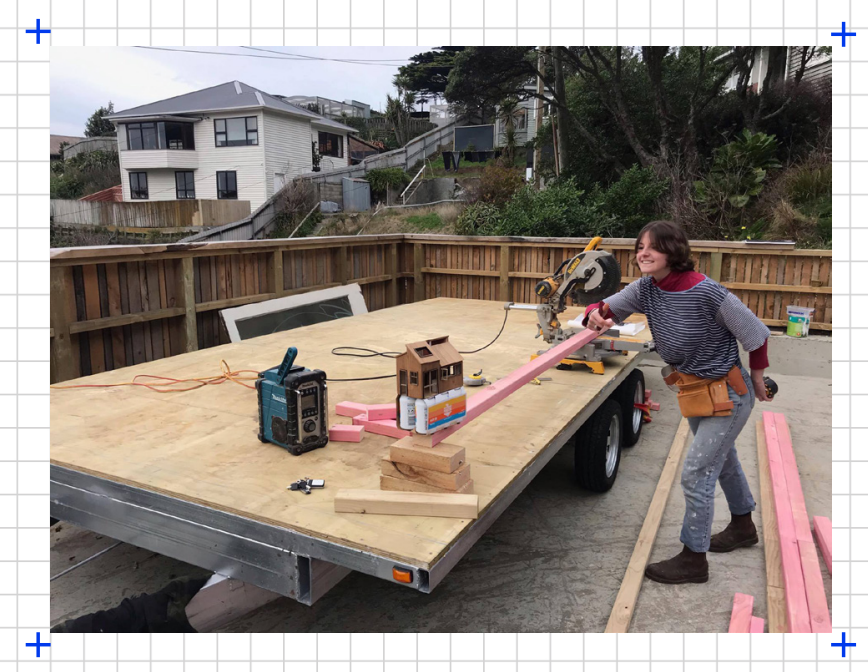

21 
Securely parked on the carport, handbrake and wheel lock on, we were ready to begin. We began by taking what was to be another, expensive trip the local hardware shop. Because of the grey area of regulation, the 'tiny house' occupies, the timber we could use for the framing did not need to fulfil the usual requirement outlined by NZ3604 ${ }^{142}$. Therefore, to reduce the overall weight and consequently allow for a slightly increased internal floor area, we purchased 20 lengths of $45 \times 75 \mathrm{~mm} \mathrm{H} 1.2$ timber. Along with the $\mathrm{H} 1.2$ we also purchased four lengths of H3.2 timber which would be used to construct the bottom plates and four lengths of LVL beams for the lintels.

In a somewhat hopeful leap into my building dream, the week previously I had purchased a drop-saw which I promptly set up on the carpark upon returning to site. Running leads to multi boxes, loading up my apron and, most importantly retrieving the radio -tasks I had been directed needed to be setup correctly to 'avoid chaos'- and we were ready to begin. Rather than producing a document set of drawings, specifying all details of construction and dimensions, I had drawn the basic elevations to establish each faces height and a section that would enable us to determine how they might meet. However, this research's aim was to quickly move away from the representational and into the physicality of building. As Louise Wallis -a senior Lecturer of Learning by Making at the University of Tasmania (UTas)- acknowledged, to "...extend students' design skills by making a stronger link with material experimentation and construction" ${ }^{143}$. Within her analysis of the Learning by Making curriculum at UTas, Wallis observed the value of implementing physical making as a way of working through design as opposed to the two terms separated ${ }^{144}$. 


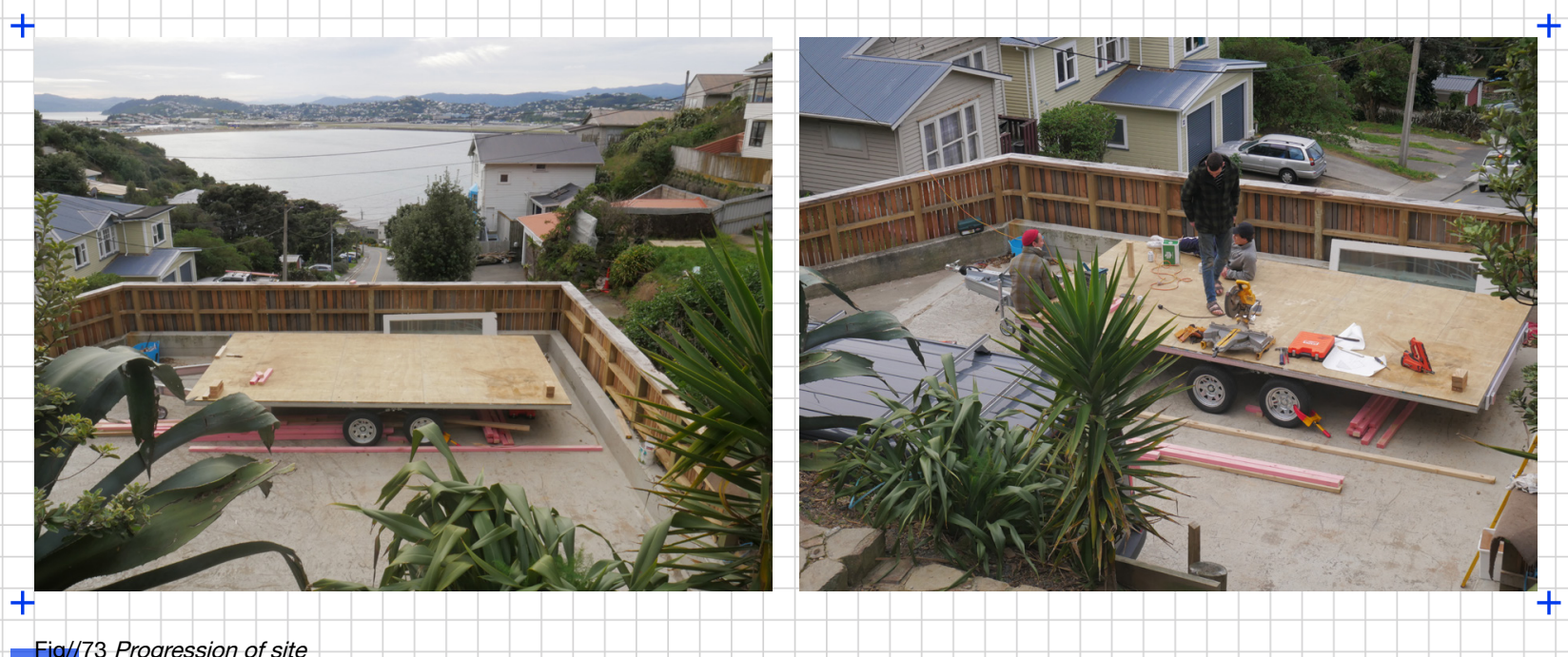

221 


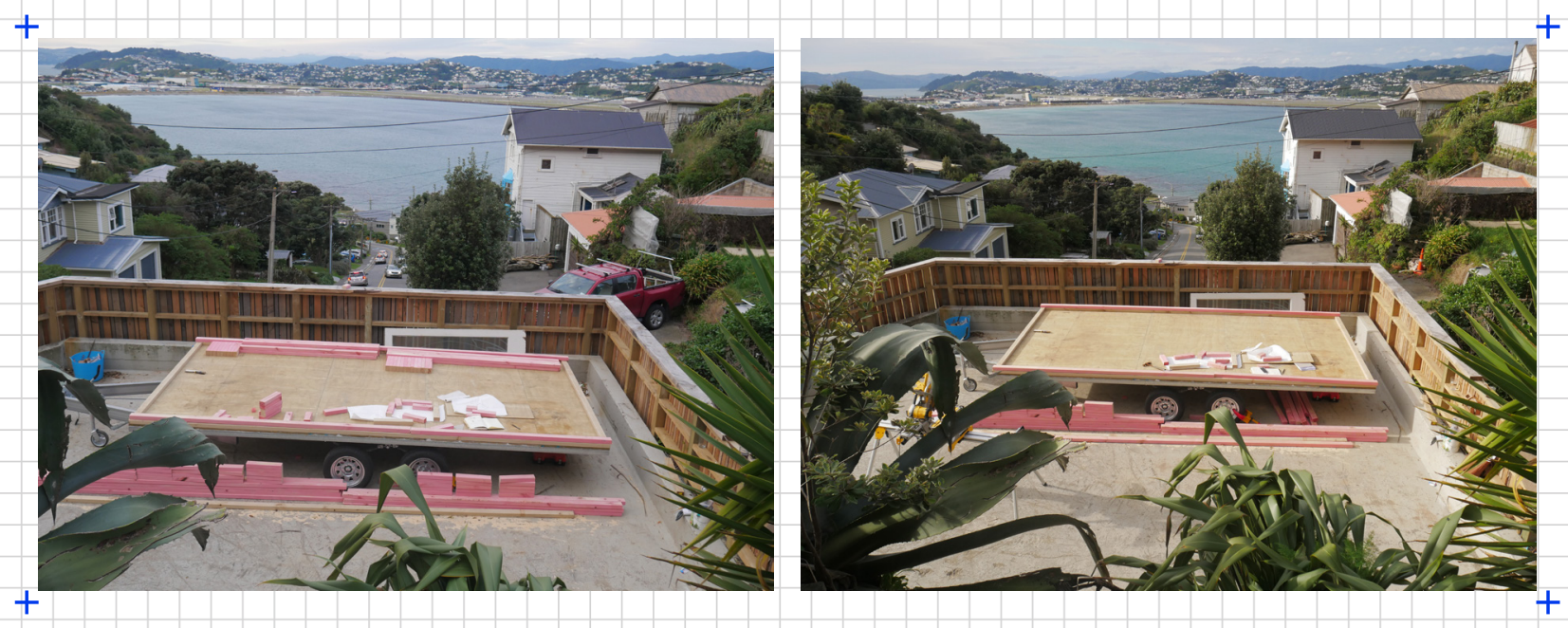




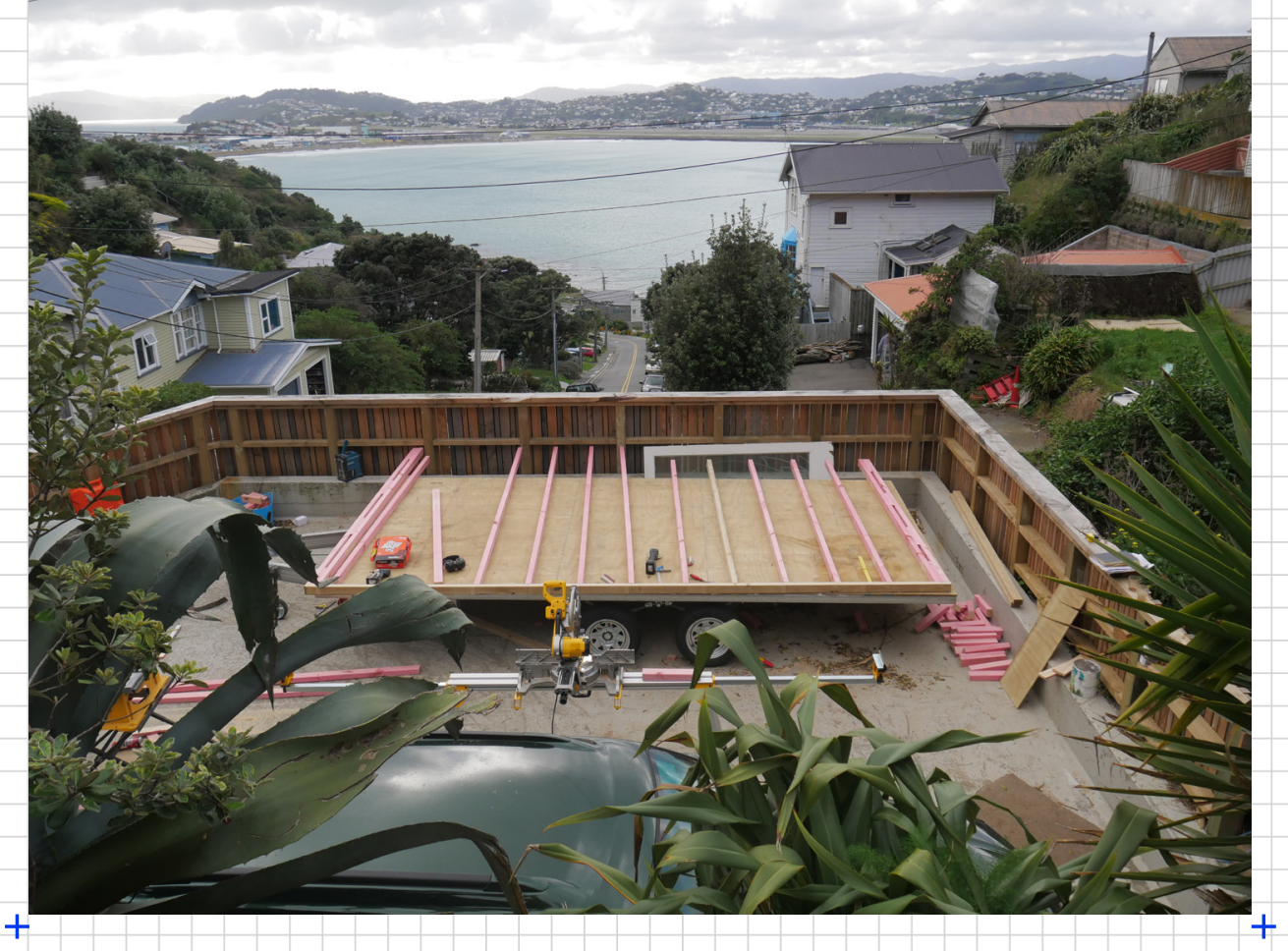




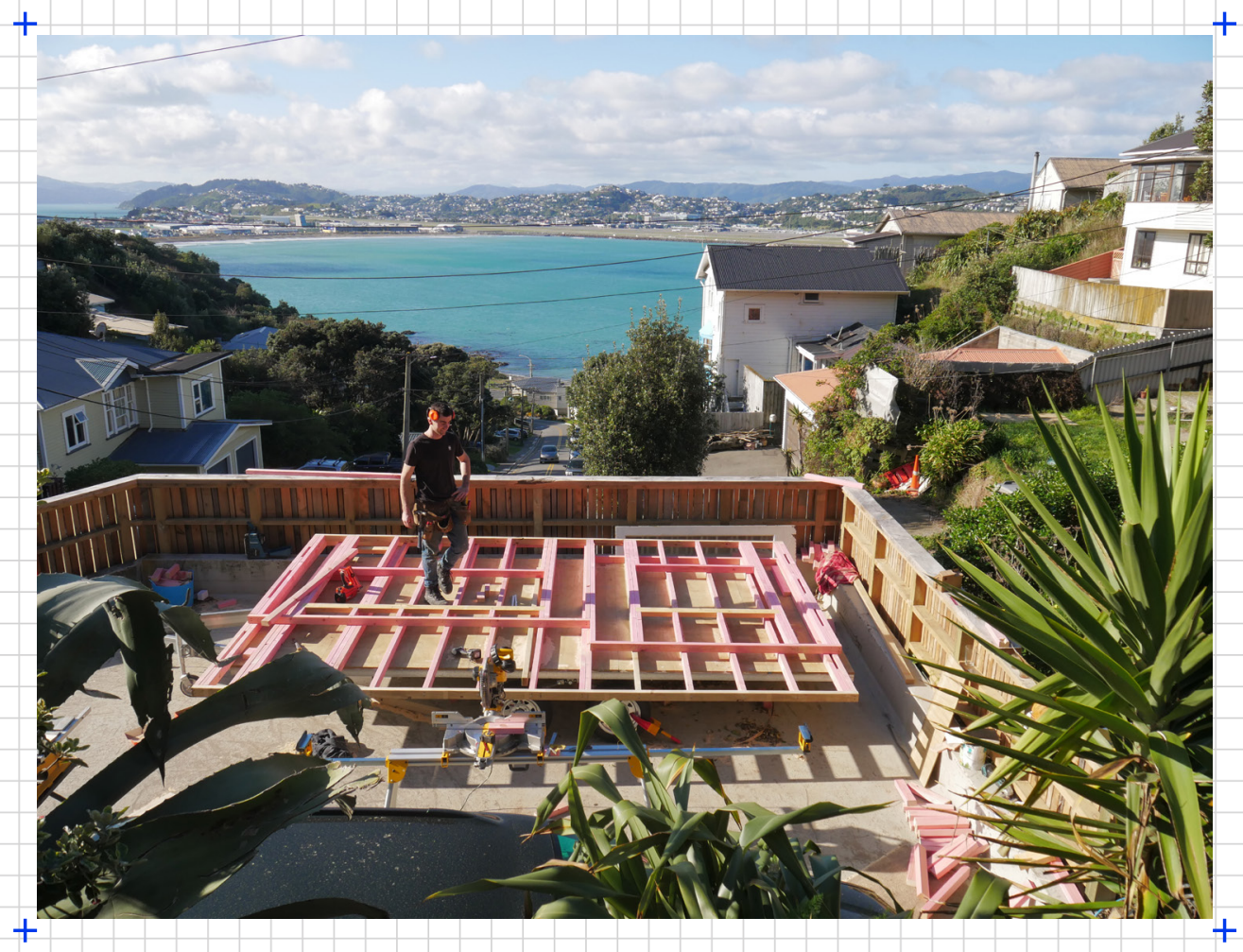


I began by cutting the timber we knew the lengths of. These were the top and bottom plates of the port and Starboard faces, along with their subsequent studs. However, after cutting the initial stud for what would make up the Starboard face, Solomon explained that because of various pieces of framing that would need to be inserted to hold the window and the windows architrave depth, the opening I had envisioned as sitting central to eye level would actually have to sit far lower. To refrain this from happening, the pitch of the roof would need to be lessened. This was the first major conflict I faced. Up until then the exchange between the poetics and the pragmatics had been predominantly worked through on paper. On paper, one is able to swap, cut, reduce enlarge etc in a far less destructive way than what I had felt that afternoon. Stuck in a conundrum, Solomon and I discussed the trade-off for both options. The window I had found on 'Trade Me' which ultimately dictated the pitch of the roof, would not be able to be used if we were to decrease the pitch. I had envisioned the view from the entrance door at the opposite end of the dwelling, stained sunlight drowning the cook space in a softened green hue. This one-of-a-kind heritage window would be left redundant if we were to change the roof pitch However, if we were to retain the window and thus roof pitch, what would be left would be a compensated space with an awkwardly placed window. Pragmatics and poetics in conflict. Solomon and I discussed options for some time. In the end there was no way around it, the window had to go. I couldn't compromise my client's livelihood for a window I simply though was beautiful. Decreasing the roof pitch we agreed would not stray from the formal roofline I had so conscientiously considered yet would significantly increase the internal spatial qualities of the dwelling.

Jeremy Till allowed that "The process of design cannot be subjected to method, the process of briefing cannot be fully rationalised (clients are hardly simple beings), the process of building is open to continual uncertainty, and the occupation of architecture is unpredictable." ${ }^{145}$. Within this Till argues, traditional architecture is solicited as rational and stable when in fact it is bound by contingency. Architecture is continuously acted upon by external forces, be it client, environment, policy or economy. Through an embrace of these contingent realities the design process was able to continue. On reflection, the ability to resolve in real-time, physically experience the internal special quality and discuss alternatives and additions, was a process I realised I had never experienced before. Although taxing at the time, the ability to embrace/accept contingency in fact allowed a new imagination and inventiveness not traditionally permitted within the architecture. 

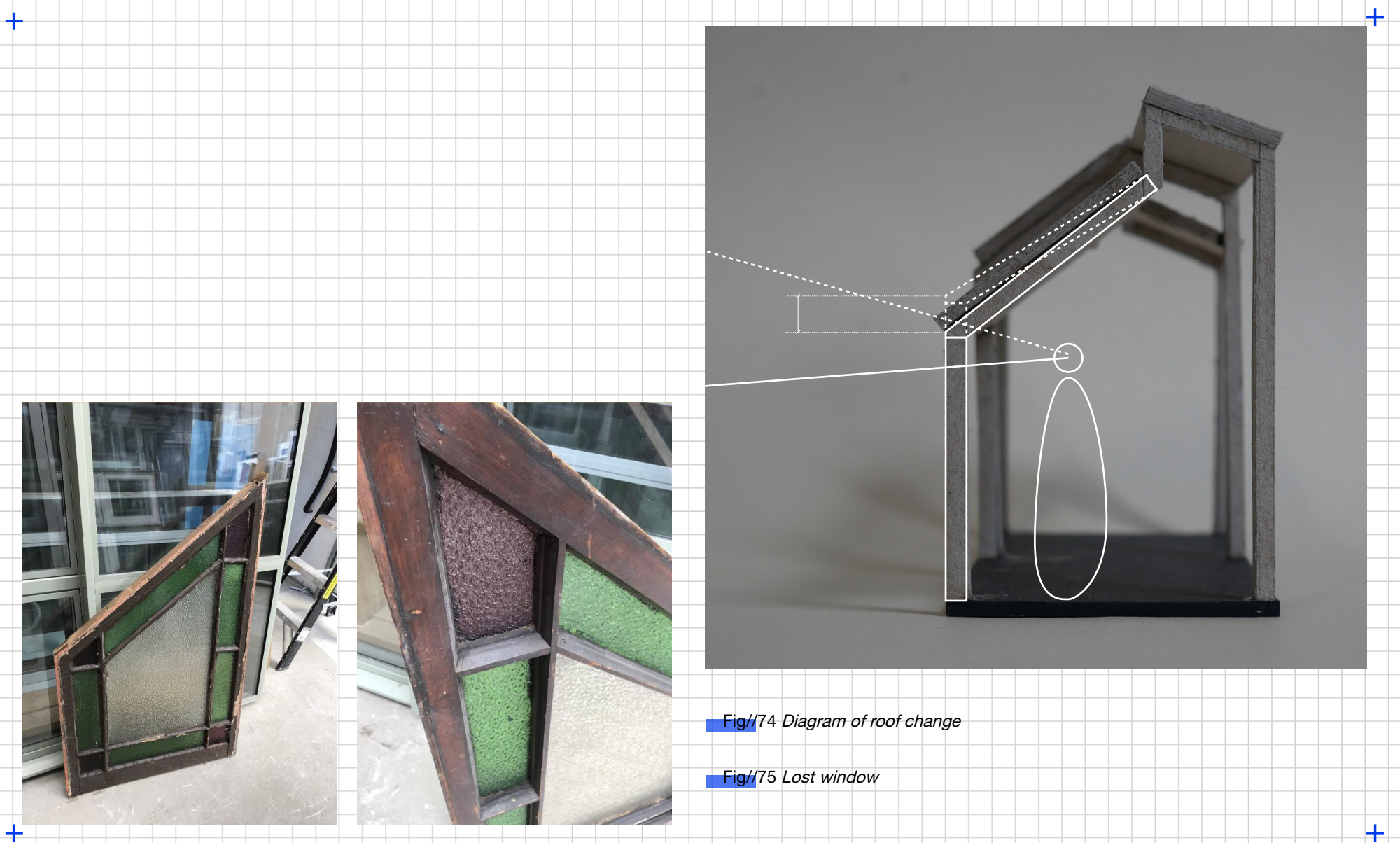

Fig//74 Diagram of roof change

Fig//75 Lost window 
Continuing on we then began framing out the new Starboard face. Again, by not specifying exact dimensions we had the ability to decide on-site. The Starboard face took the most time. Both windows proportionally had to work with both one another, its surrounding façade and its relation to the whole. Due to the distinct separation of 'Cook' and 'Eat + Play' spaces through the $400 \mathrm{~mm}$ high change, we decided that centring both windows within their separate domains would complement the overall façade, allowing a distinct character to each space. Considering architraves and purpose of the 'Cook' space window (to open outward) we then established the minimum distance from the exterior edge should be $300 \mathrm{~mm}$. The vertical placement of the window was ultimately dictated by bench height, maximising window area.

Once we had established the sliding window it became very clear the 'Cook + Play' window needed to be centred vertically as well as horizontally. These factors ultimately influenced the windows final dimensions.

Having arrived at a plan, we pressed on, placing suds at 400 centres from the end and introducing 'jack studs' and lintels where the windows were located. To further secure the Starboard face we then inserted purlin screws into each stud to tie the top and bottom plates. This process we then continued with the Port face. Comparative of the time we had spent making decisions, it seemed as though no time had passed before both frames had been constructed. Nothing is more fun than shooting $90 \mathrm{~mm}$ nails into timber framing.

Neatly stacked on top of one another on the trailer -being relatively pressed for space- we then encountered the logistically challenging task of standing each frame vertical and tying them together. Fortunately, I had some very willing neighbours who agreed to lend their hands. We began with the Starboard face, then the Port. We then promptly braced the outer faces before determining the Bow and Stern walls. We did this by first working through each space individually, ensuring each space allowed for the human body. It was the 'Bathe' space however, which ultimately dictated surrounding spaces. Much easier to acknowledge in real life than on paper or screen, we simply used the chalk line to draw a floorplan at 1:1. Acting out the movements one might carry out within the 'Bathe' space, washing hands, showering etc to visualise the minimum dimensions the space could occupy. We decided the width could be no less than $840 \mathrm{~mm}$ but concluded that the internal width would be $900 \mathrm{~mm}$. Minimum did not mean comfortable.

It is important to note here the distinction I discovered between building on land and building on a trailer, or boat, or truck, or anything movable. Whereas land-based building can be done using levels, a trailer moves, therefore levels are untrustworthy and everything must be measured exact. Observations such as these were somewhat pivotal within my approach to moveable architecture and allowed me to consider aspects of architecture I possibly would have never otherwise. Like Brian MacKay-Lyons said, "We learn best when we need to know"146. 

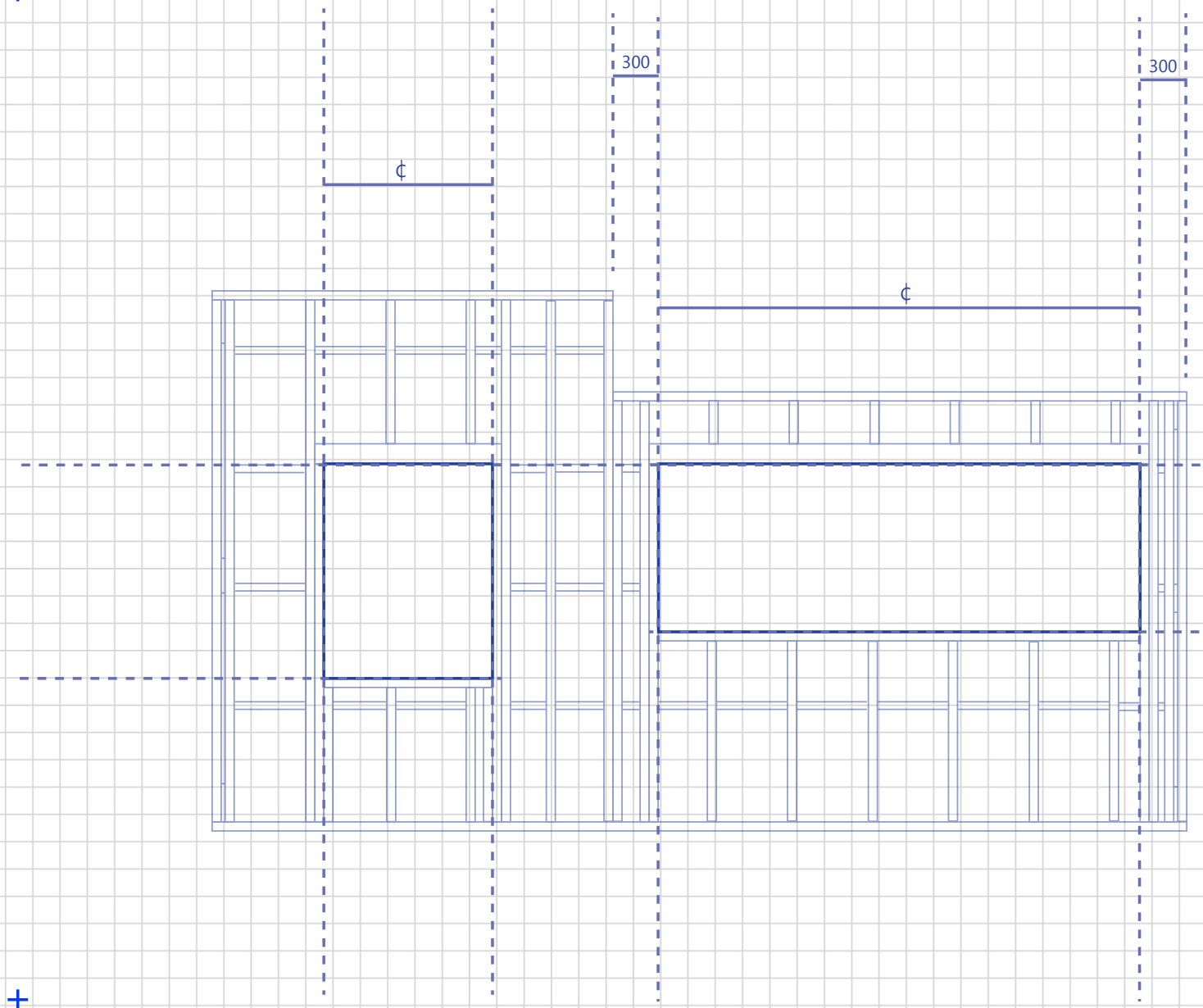

$+$ 


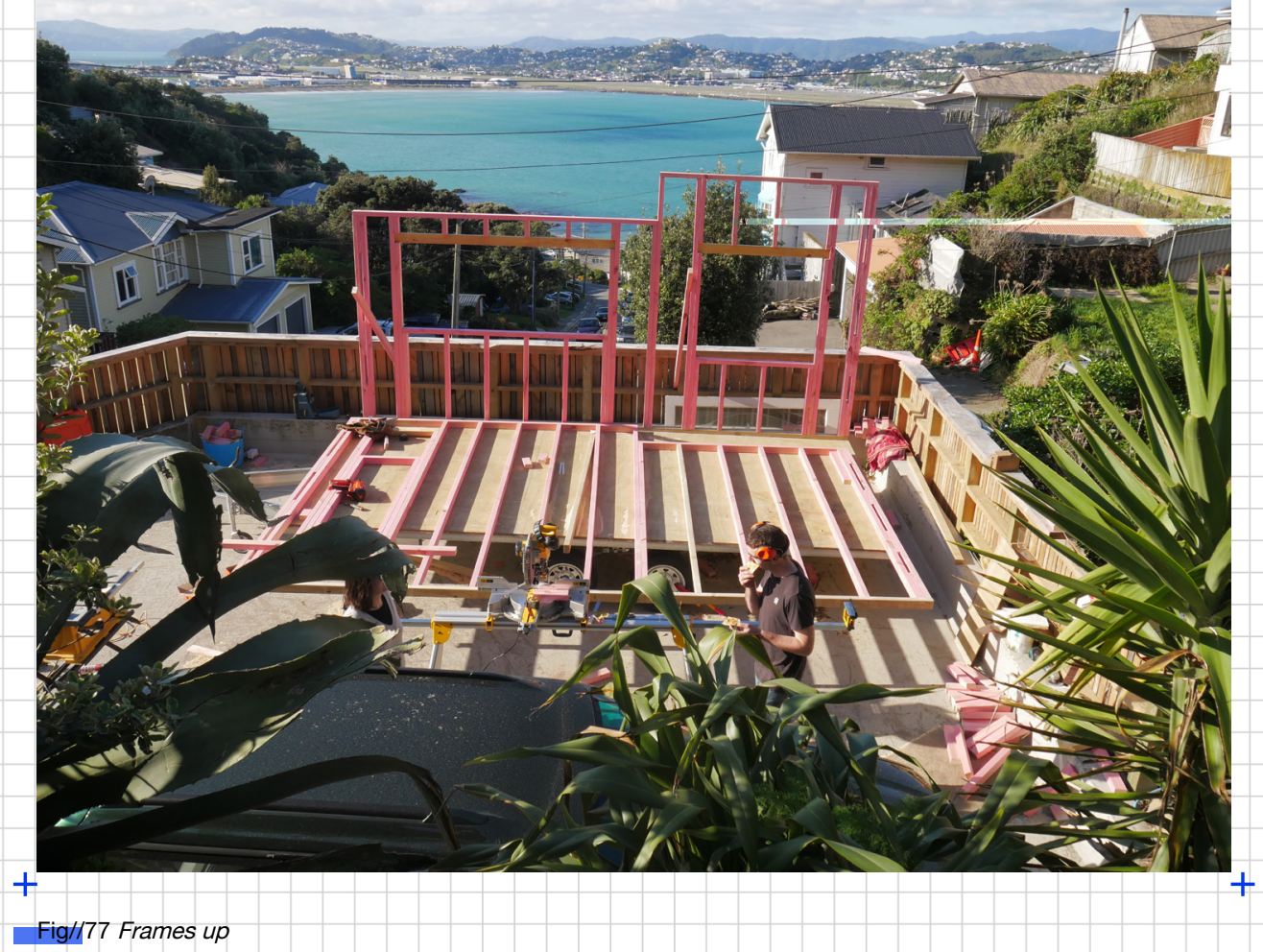




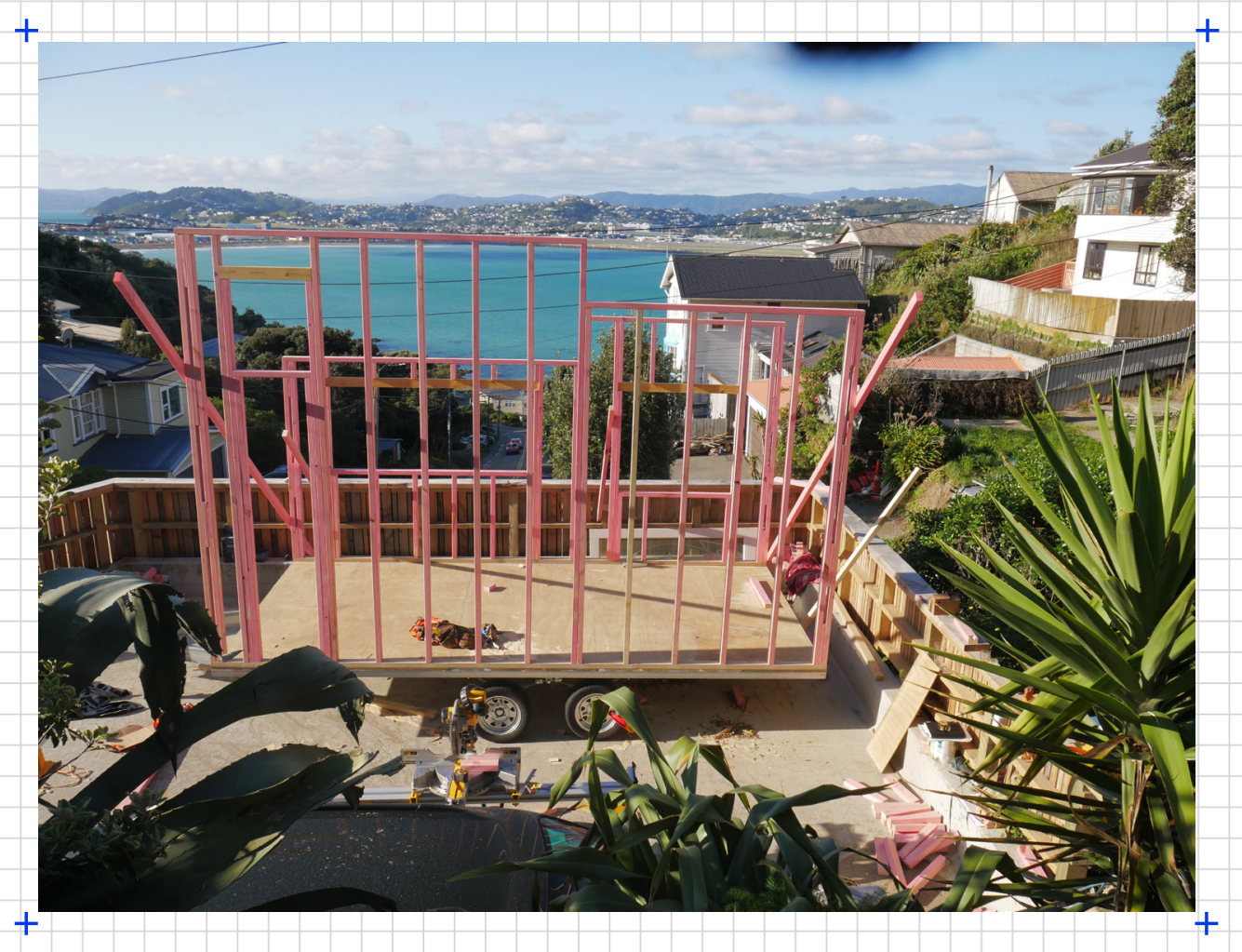


Fundamentally, the design was to visually 'break' at the point of the 'Bathe' space, splitting the roofline in two. Therefore, we began with the bathroom dimensions (Bow wall) and placed a stud that would act as the 'break' at 1050mm from the end stud. To work out the lesser angel we simply, or not so simply, held a piece of $2 X 3$ between the end stud and newly placed 'break' stud, and drew the angel. 9 degrees. Repeating this step on the steeper angel we found it was 33 degrees. Because these angles would be mimicked on the Stern wall, the rest became relatively quick work, and with them in place, the whole structure could hold itself up. With all walls now vertical it was really beginning to look like something. It almost looked like architecture perhaps. It looked like something I had dreamt up but it was real.

The subsequent days I spent strengthening the framing by inserting $d$ wangs.

Dwangs - I knew of and knew their purpose but somehow always confused with studs- are the horizontal framing elements that sit between the studs. Parallel to its construction definition, I have also recently found out another use of the term which is to describe a female who 'pretends to be stupid or dumb to get into a group or be accepted"147. Although I was certainly not explicitly trying to be ignorant and ill-informed, I was definitely attempting to be accepted within the tradie community. I pondered this as I mis-fired and occasionally split timber whilst inserting the dwangs. 

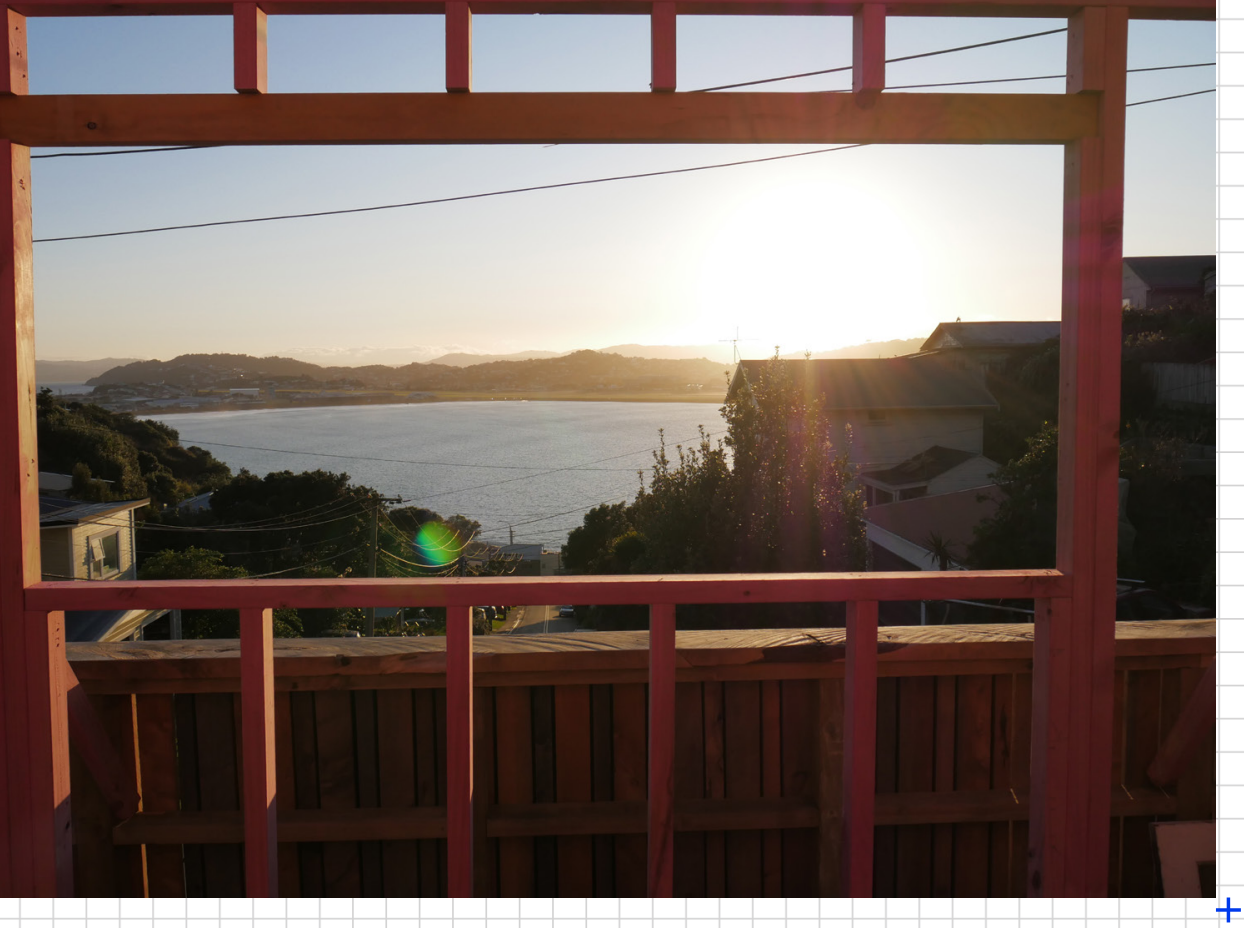

Fig//78 View out at 'sink' 

O SLEEP
bathe
Ocook
$\int E A T+P L A Y$
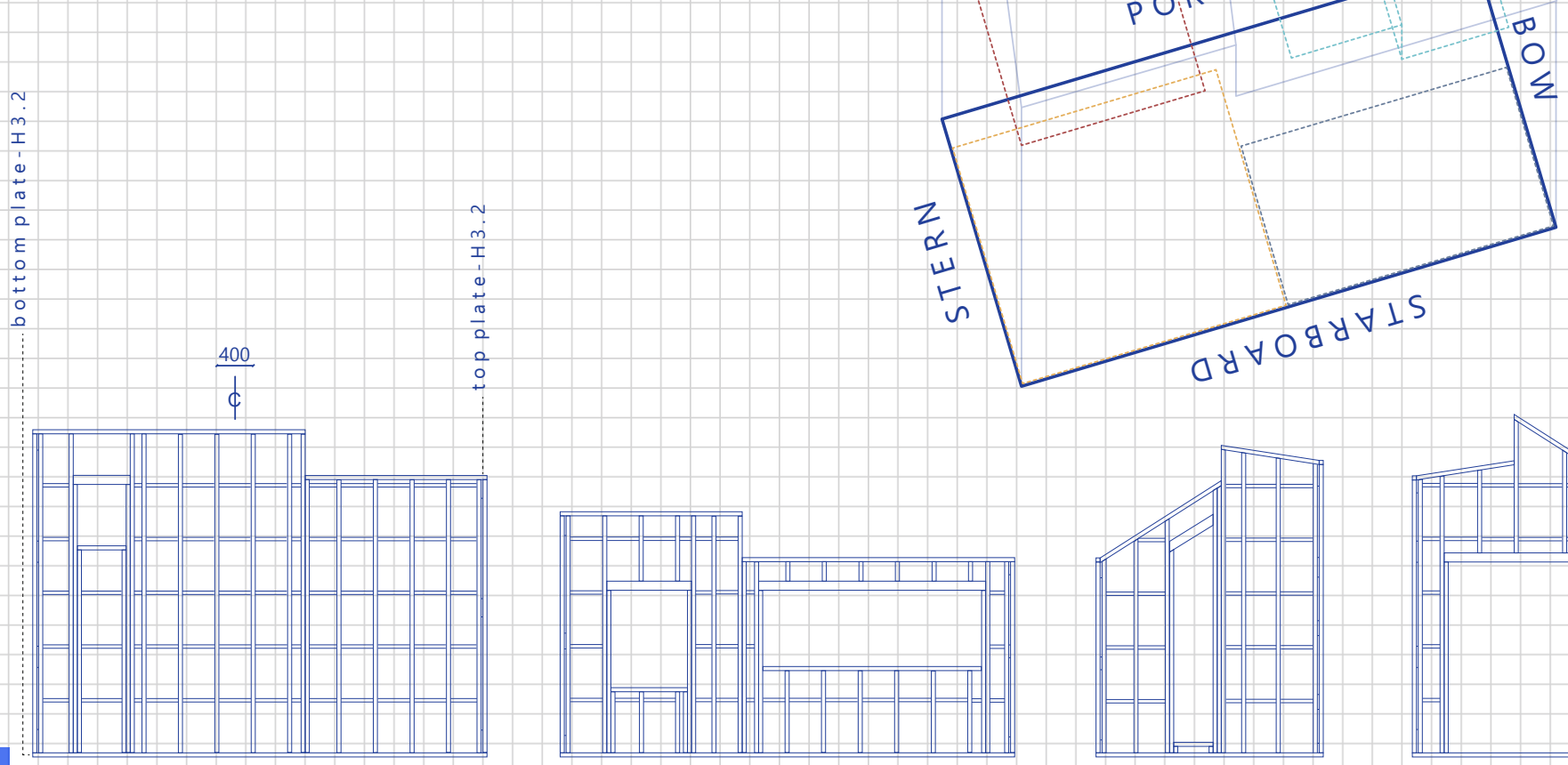

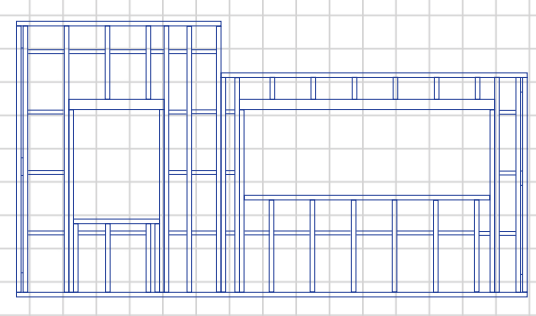

starboard

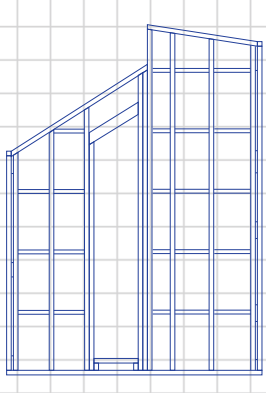

bow

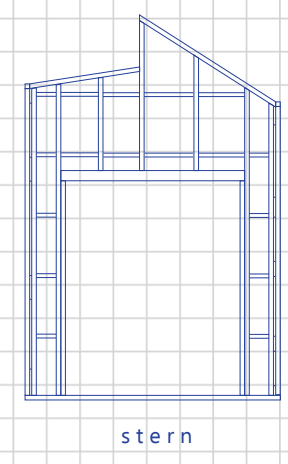




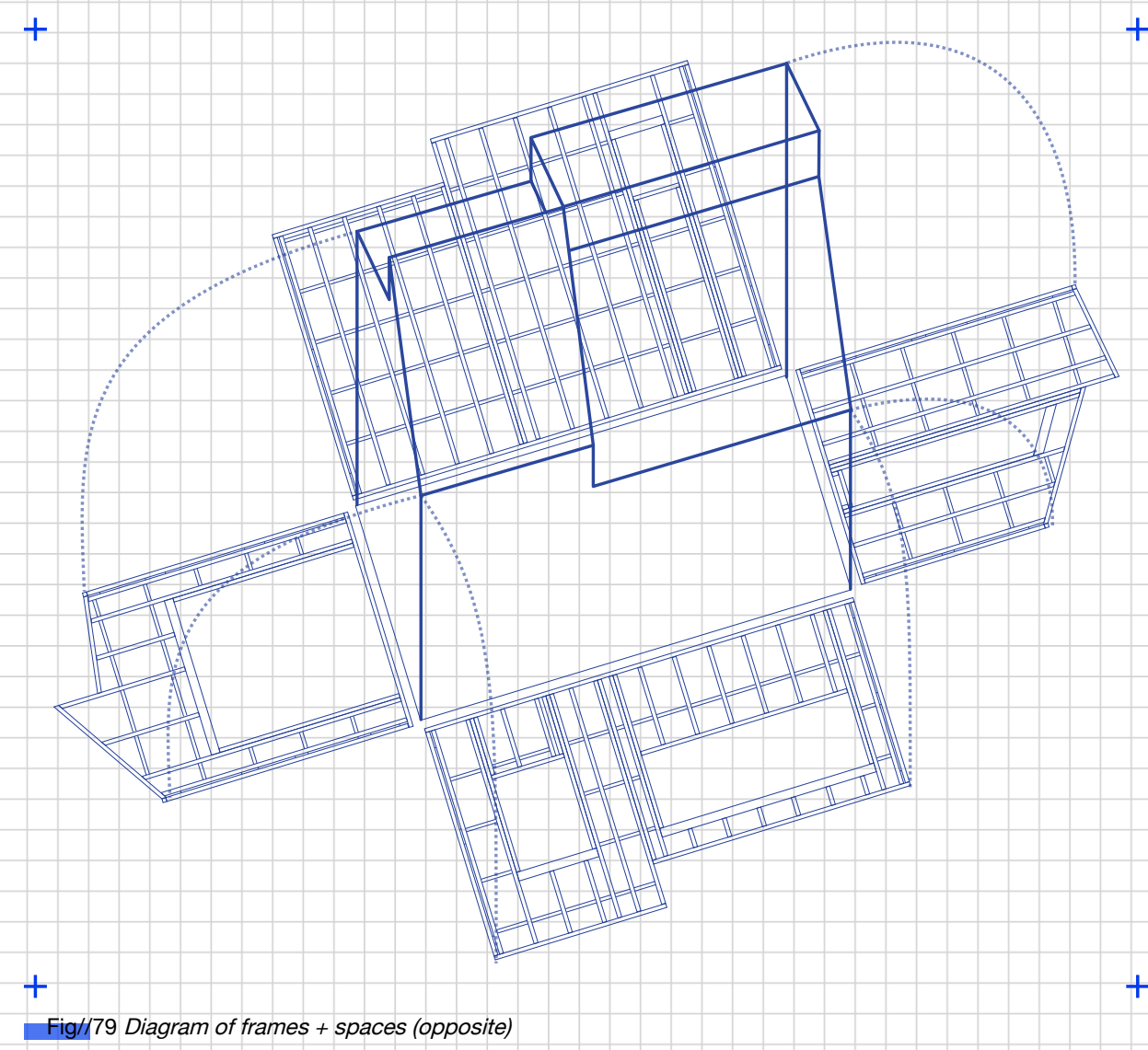




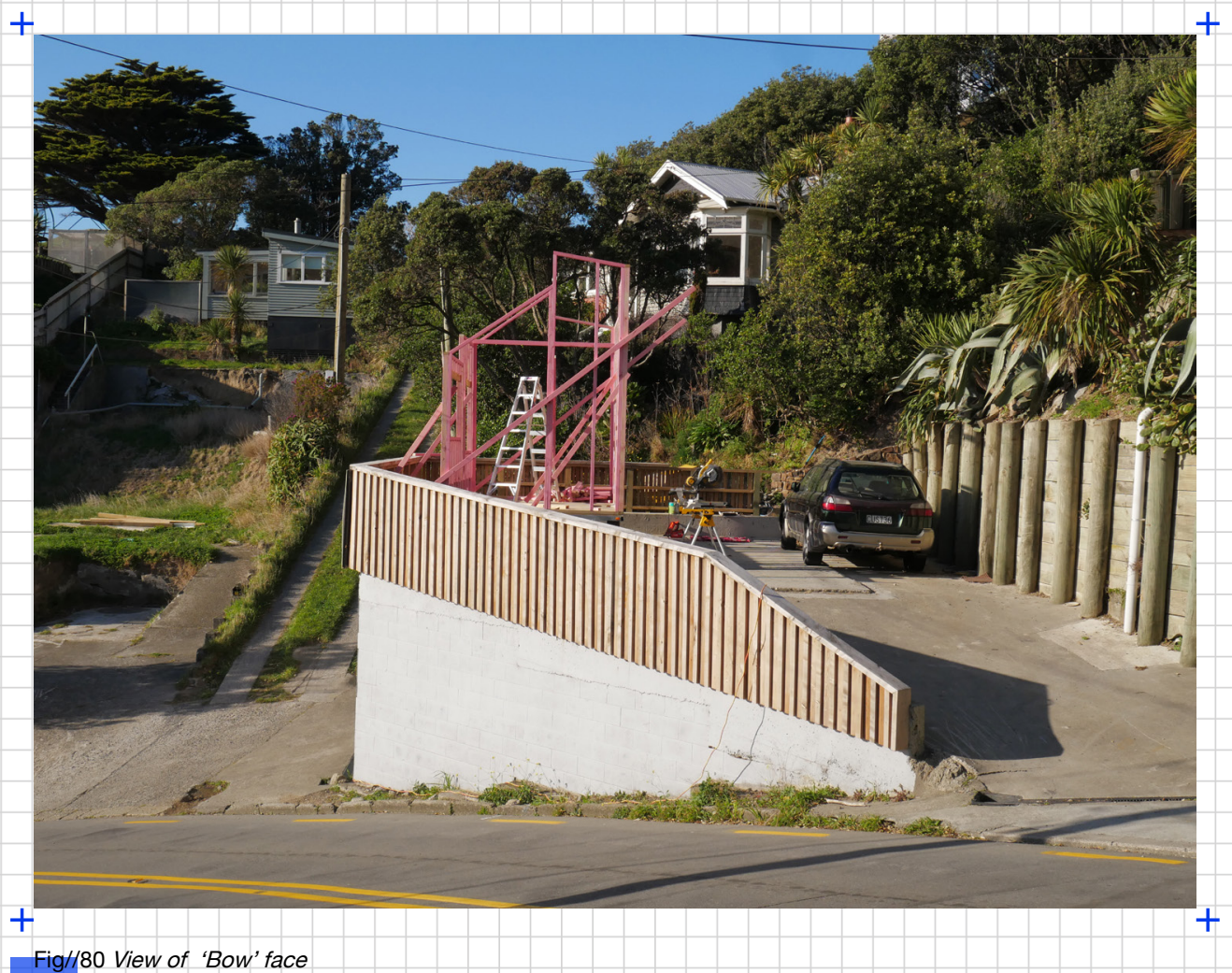


Because of the nature of trailer, or moveable based building, the roof, I found out would essentially allow the structure to work as one. It braces the walls to one another. Rather than being purely supported by the walls, the two work together to resist tension and compression from both vertical and horizontal forces. The day we assembled the roof was in some way an act of release. The structure could, in theory, be released into the world and hold itself together. We began, as always, with a trip to the hardware shop. We purchased more H1.2 framing, a more refined - 'clear, defect free pine'- and deeper $-45 \times 180 \mathrm{~mm}$ - piece of timber to use as the main ridge beam, and most importantly, a ladder. With every exercise such as this I became more aware of just how expensive building is, and began to acknowledge its inevitability.

We began by nailing the ridge beam to the Stern and Bow walls before securing it with three purlin screws at each vertical stud. This immediately allowed the strength of each opposing end to counter balance one another. Similar to the studs, we measured and placed the rafters at 400 centres from the internal wall at each end. However, because of the top plate-rafter intersection, to allow a seamless fall, each rafter needed to be skillion cut. This we did by again holding up a rafter and marking where the cut needed to be made, thus creating a template of which all the others could be cut. In the same manner as the windows, we framed out the skylight and once the upper rafters were placed and secured, the skeleton of the structure was well and truly one whole. It was completing this stage which truly held me. My two hands had executed one task after another, which, although not perfection, had resulted in a structure which made a shadow. With the exception of high school art projects and renders, this was the first time I had achieved this and it was extremely humbling. Similar to the feeling one gets when apricating their own shadow, a conscious, self-knowledge. Bachelard allowed that "...as soon as art becomes autonomous, it makes a fresh start"148. Although I was in no position to suggest that what I had created was art, I did gain a certain sense that this thing had become separate from me.

It was at this point I was able to order the joinery. Originally, I had hoped to source a portion of the windows and doors second hand. (I say portion as often second-hand windows can be very heavy, yet if they were special enough, the weight could be accommodated). In fact, the purchasing of a large heritage angled stain glass window was, in part the reason for the design's roofline. However, a week after I had paid for the window, given my address and had confirmation it had been sent, it had not arrived. I call the sender (a company in Christchurch specialising in second hand joinery) who sounded confused when I asked where it was. "I definitely sent it" followed by, "I'll have to follow it up". I recalled the decision Solomon and I had made previously to decrease the pitch of the roof to increase the kitchen height and thought "good job we didn't compromise the kitchen for a window that someone has lost...". Without hearing back from the sender, I sent him a message, inquiring into whether or not it had been found. A week later he responded, saying he could not find it and that he would refund me. Inquiring into how much it would cost to instead commission the joinery I found that all together 'Wilson Joinery' would do it for just over $\$ 9,000$, a sum which would only be slightly higher had I sourced them second hand. Knowing this would take some time, I sent him the dimensions and details before continuing with the build. 
$+$

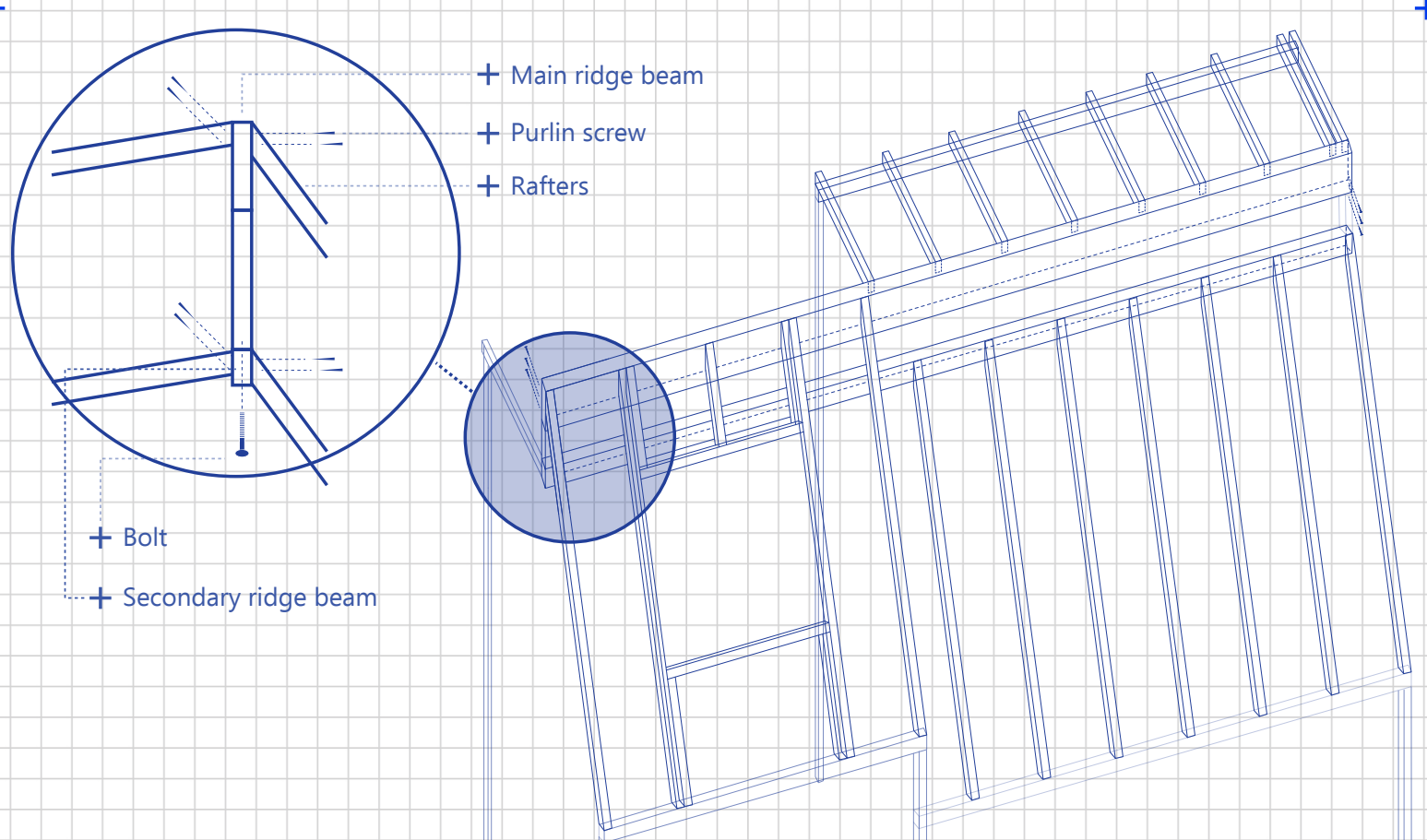

Fig//81 Diagram of roof framing

$23 \bar{t}+$ 
$+$

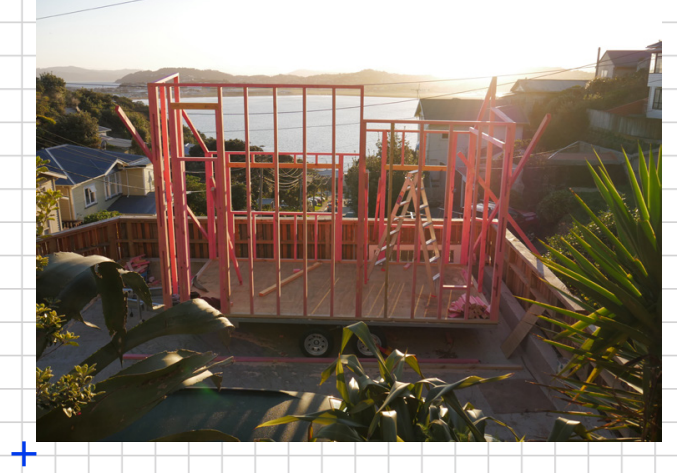

Fig//82 Progress - ridge beam and rafters
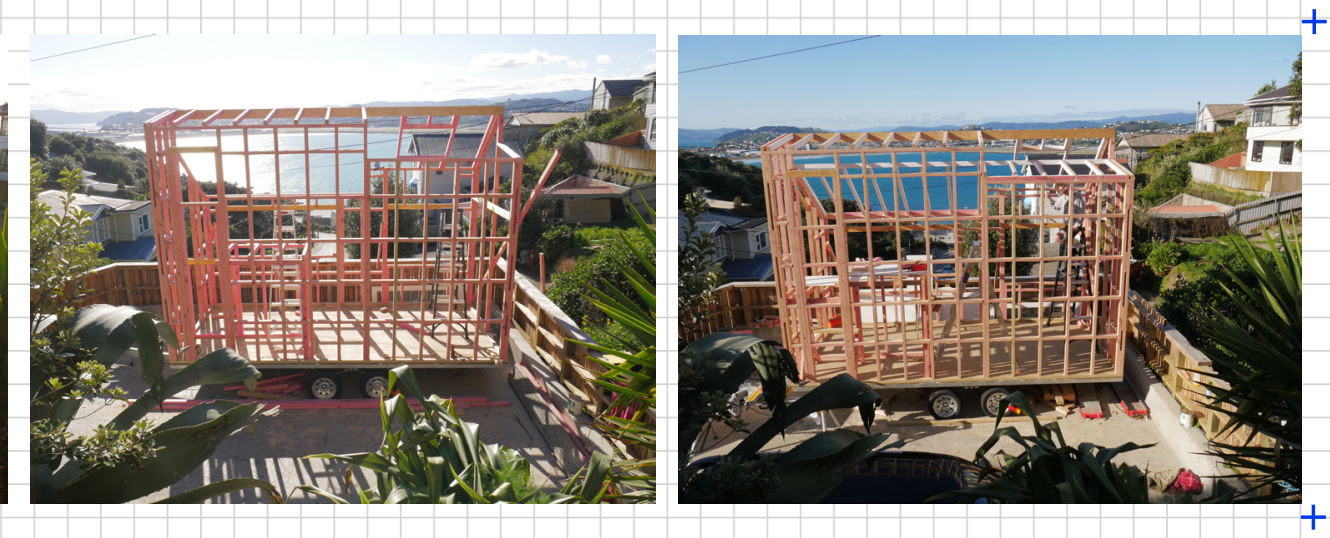


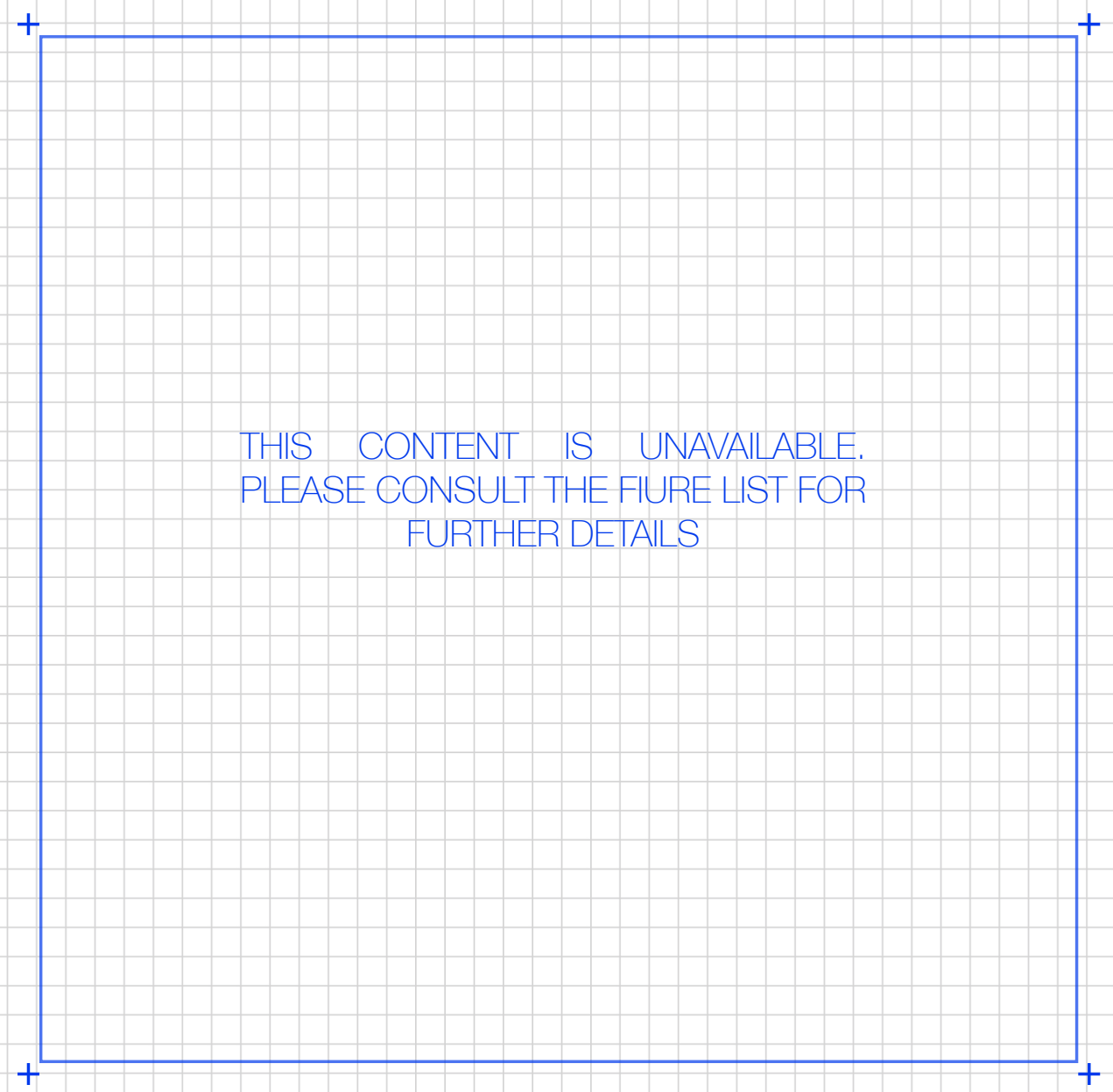

Fig//83 Caves, huts + tents - taken from 'Shelter' 
Perhaps the most primal elements of the structure of architecture, the roof is (usually) the first skin attached to the skeleton of structure. 'Shelter' explains that once man began to seek shelter, it was in the form of caves, huts and tents ${ }^{149}$. These early forms of shelter were arguably large, easy to construct roofs. The roof has since developed to become not only a form of pragmatics, but symbolic. Roofs can be used to make statements, conform or blend into the landscape. Frank Lloyd Wright wrote that "his roof was not only his shelter, it was his dignity, as well as his sense of home" 150 . With this in mind, I began the process of building a roof for shelter and for symbol.

The decision I had made earlier to cover the roof in cedar shingles meant plywood needed to be applied to the rafters before roofing. To allow a greater feeling of space internally, I wanted the rafters to be left exposed. This meant the exterior applied plywood needed to be a higher graded ply as it would be seen. Again, somewhat unaware of how much these things should cost and what the tell-tale signs of a bad sheet of ply were ( $\mathrm{am}$ actually quite partial to a knotty piece of timber), a friend Skip said he would help me obtain some CD grade $12 \mathrm{~mm}$ plywood. Although recognising the difference between a sheet of ply dotted with knots and one respectively less so, or simply devoid, the term 'clears' with respect to timber had no significance to me. The various letters attached to these timbers having even less significance. The grading of timber, I found out, is used in both a strength and aesthetic association. Both denote the percentage or tightness of the timber's knots and all have a specific purpose, as outlined in NZS $3602^{151}$ Therefore, in this instance, because the roof would be exposed but not high highly detailed, and the opposite face was not of concern, a CD grade was bought, one face 'C' the other, ' $\mathrm{D}$ '.

We began by driving to the closest hardware shop which we found had a small amount of DD grade sheets but no CD. We drove on to the second shop which although had plenty in stock -as Skip had informed me- the price was far too high. He suggested we would be much better off driving out of town to get some of the right grade at the right price. Thankfully at the third stop we were in luck. We stropped eight sheets down on the Ute, paid and left.

I firstly worked out that at 400 centres one sheet would cover four bays of rafters. I began by cutting down the sheets so that they comfortably overhung the framed walls -somewhat of an insurance policy- as they would be cut in place later. To enable the plywood to be flush with the vertical studs, I angled the circular saw to suit the various roof angles. Once done, I cut the plywood pieces that did not make up a whole sheet.

I found this straight-line skill particularly difficult. Once all the pieces had been cut, I then primed them and began attempting to screw them down. Another step I had neglected to fully comprehend the extensive physicality of. Attempting to lift a 1200X2200 sheet of ply alone was doable but uncomfortable. Trying to sit it on top of a steeply angled roof three meters up was next to impossible. In this came the realisation that not only did I not know very much, but that even knowing more than I did could not help me. I needed another pair of hands. It was one thing to know how to exercise a task I had read about, been advised on, or watched, but to appreciate the physicality of it is to come to the realisation that willing something does not make it so.

With another pair of hands, we securely fastened the ply to the rafters.

We did this the afternoon prior to the development of a large storm and with the ply attached, the structure was able to essentially act as a sail in high winds. Which, over the course of the evening progressed into $120 \mathrm{~km}$ NW gusts. Perfect. I do confess to getting up at 2 am to brace the whole thing to the 


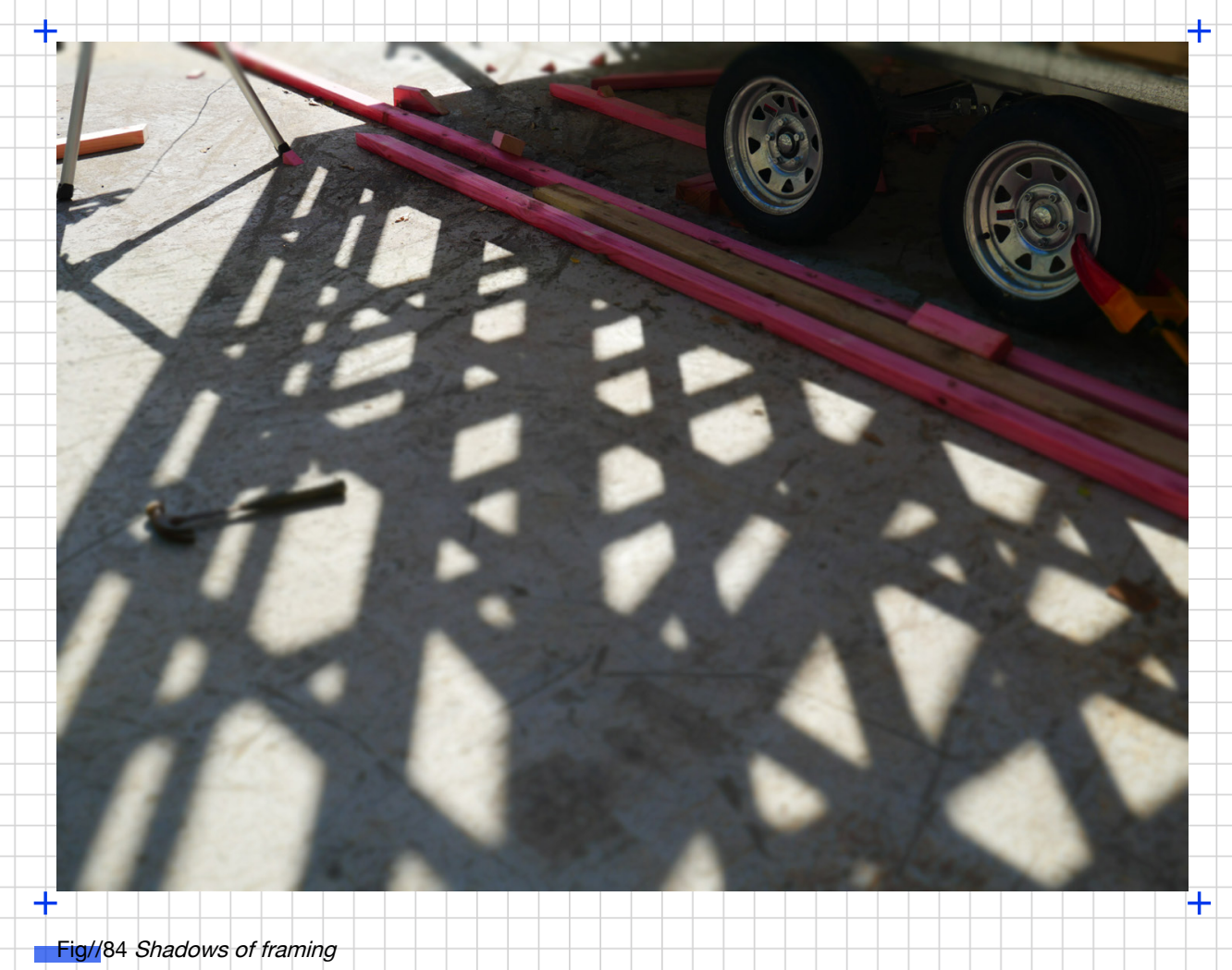

241 


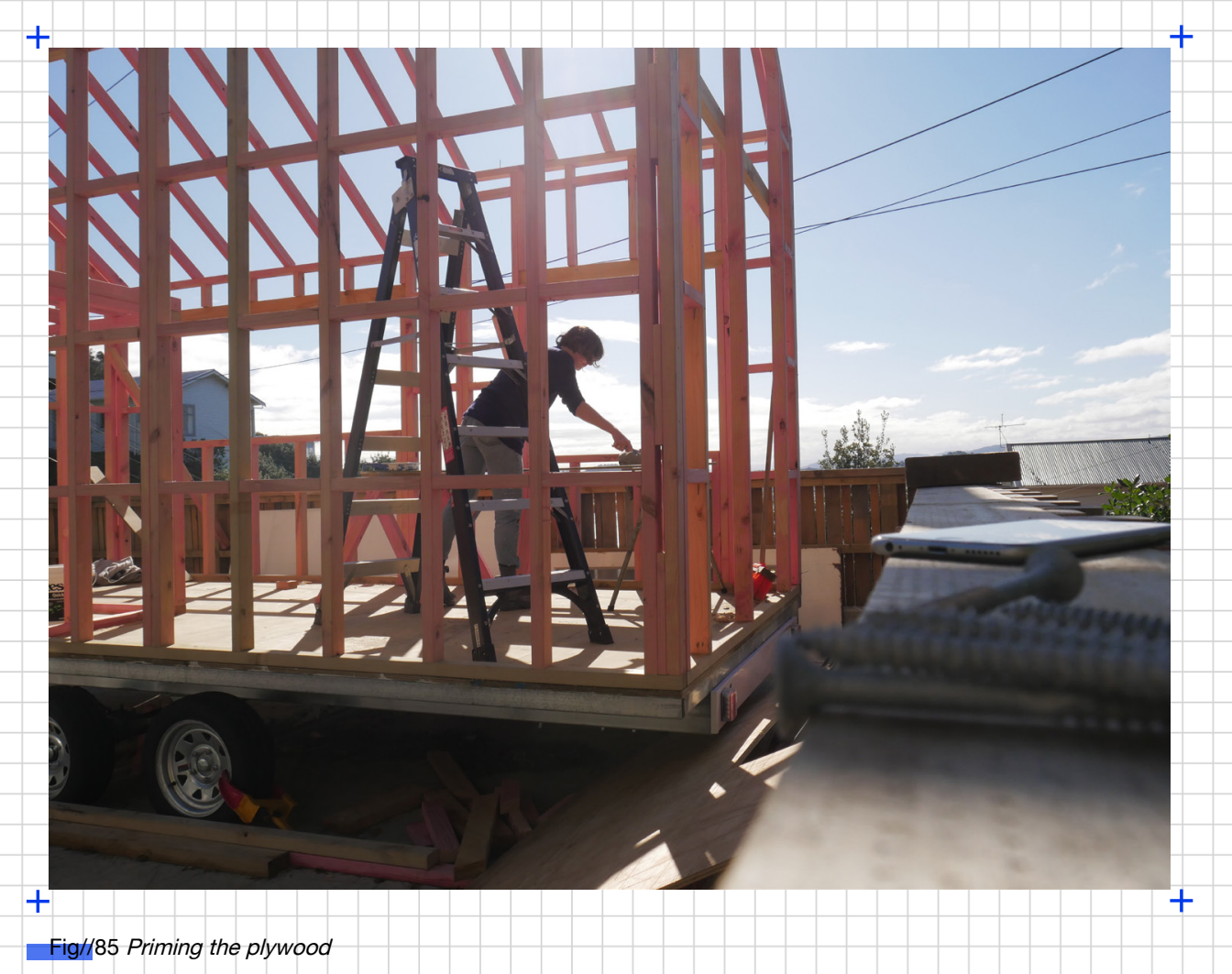




$$
+
$$

+ Cut in place

$+19 \mathrm{~mm}$ CD ply

$+400 \mathrm{~mm}$ stainless screws

+ Chalk-line 400 centres (rafters)

$$
+
$$

243

Fig//86 Diagram of roofing 


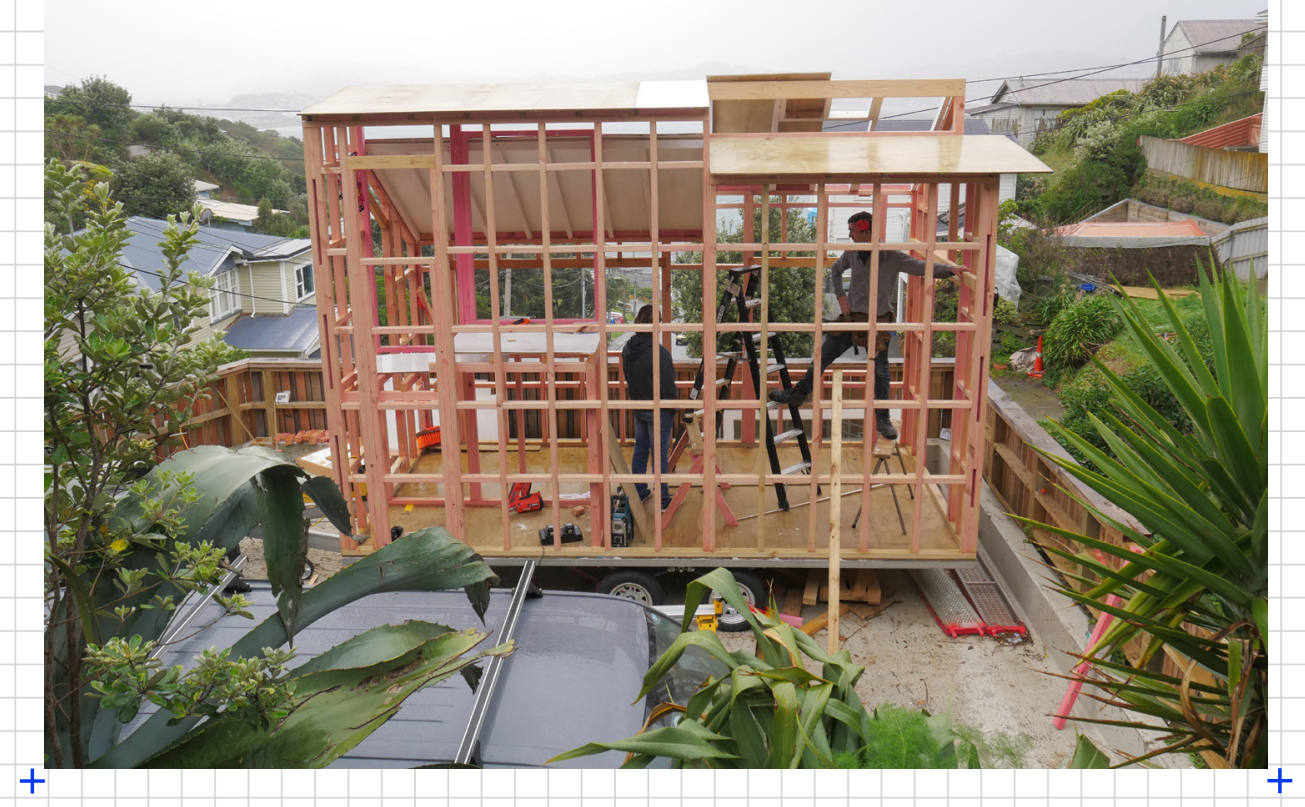

Fig//87 The first rain the roof held off (the afternoon before the storm) 


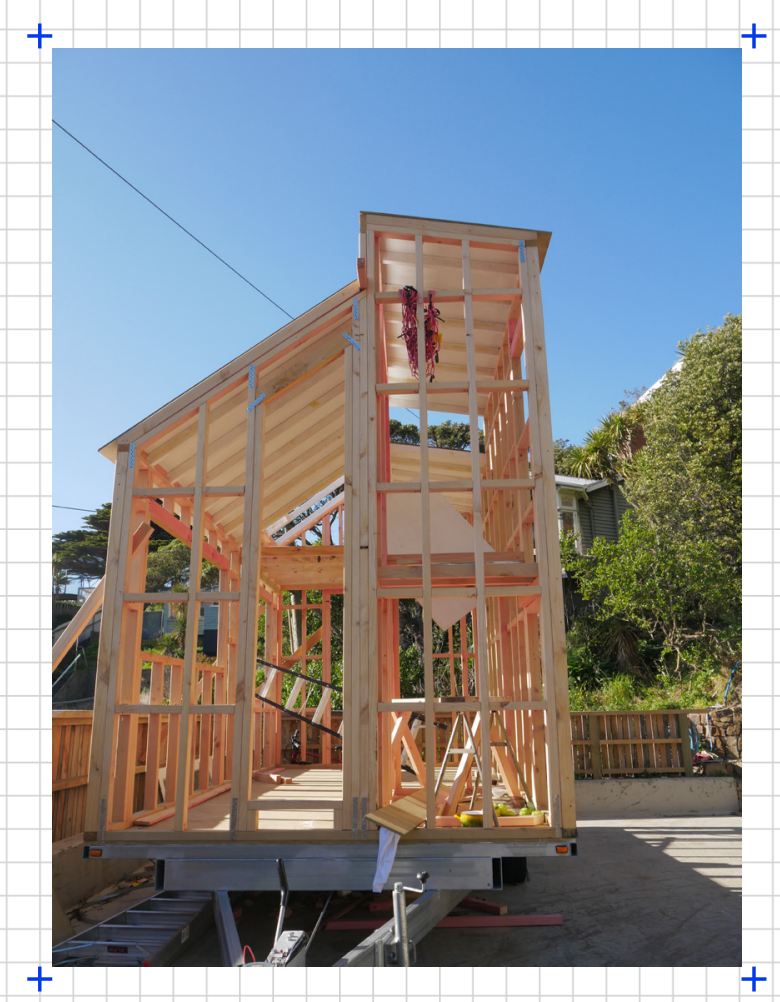

245 


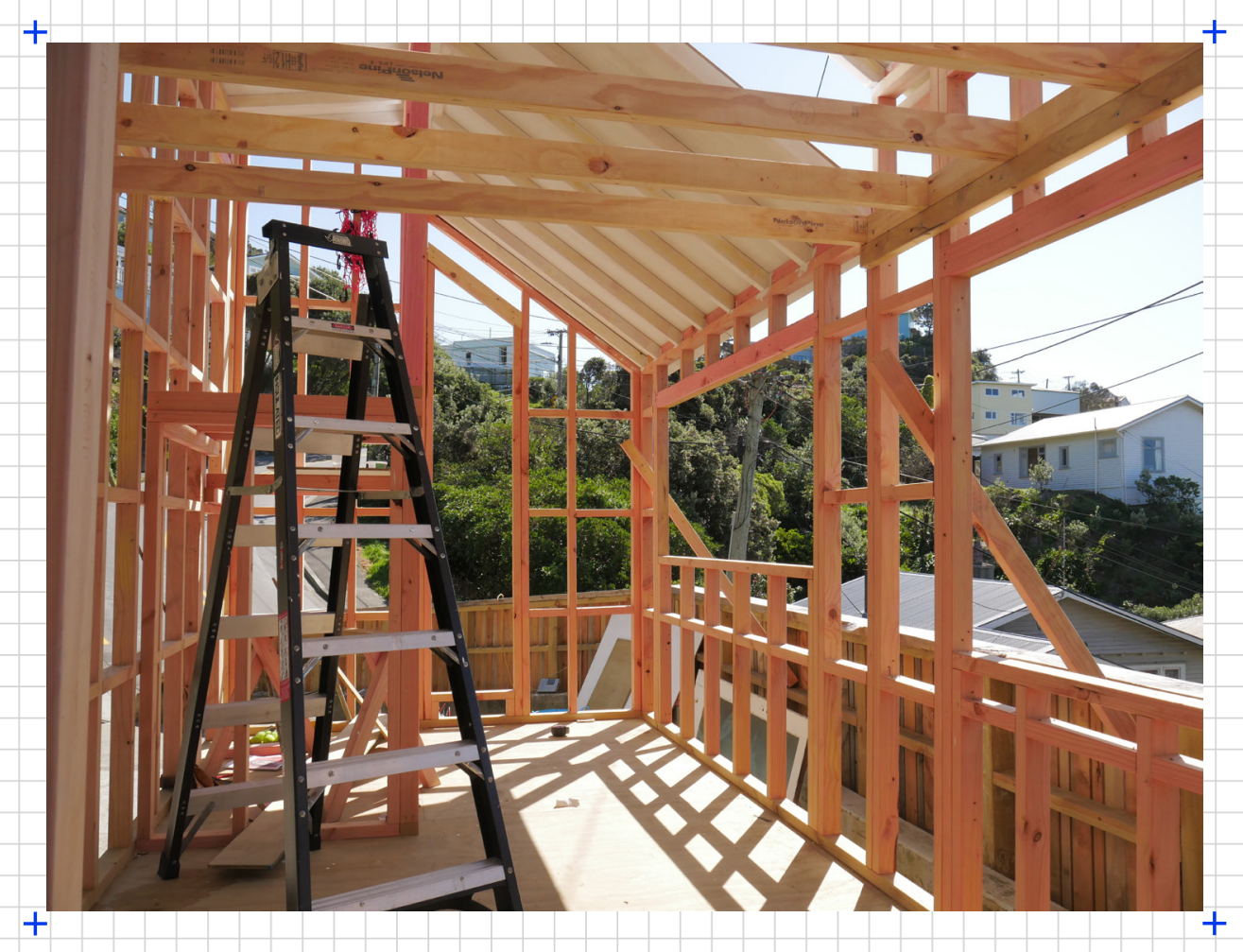




\section{MATERIAL CONCLUSIONS}

Having previously concluded that the cladding would be a combination of board \& batten, and vertical shiplap weatherboard, the next step was to order it. Front up and pay for something I had chosen, as, up until then I had only purchased items which were essentially non-negotiable.

This commitment gave a similar sensation as buying the trailer. However before committing a large amount of money (or lesser depending on the decision) I first had to research exactly what I needed. I began with figuring out the board \& batten, as predominantly the suppliers I was calling only had one option. Early on I decided I would need between a $45 \mathrm{~mm}-55 \mathrm{~mm}$ batten which was the only real decision I could make. Straightforward. The vertical shiplap proved slightly more laborious as certain profiles would take longer or induce an extra set up cost, not to mention the types of timber which could be used. I then found out, rather than timber costing a certain amount per meter, prices were given based on how many boards of each specific length I would need. Therefore, because of the desire to assemble continuous lengths, before I was able to receive any indication of prices I first had to work out how many of each length I would need. Subsequent to measuring this I began the search for a fair price and a good product that would be delivered on time.

This process required multiple days of back and forth communications with numerous suppliers until eventually Solomon suggested I call his 'rep' Lauren to obtain the material for me. I proceeded to provid her with the shiplap profile I wanted and the batten size and away she went. Within a few hours she had approximate prices, turnaround times and the ability to make it happen. Eager to get the ball rolling I promptly made some considerable decisions, such as changing the profile of shiplap for something that would be quicker and cheaper, and confirming that I would need $45 \mathrm{~mm}$ battens. Decisions such as these always left me consider whether I was trading my design for something. Was I compromising the architectural character I had formulated? Christian Norberg-Schulz wrote that "the character is determined by the material and formal constitution of place" 152 . The line between important and unimportant was difficult to grasp.

Nevertheless, the next day it was ordered. Having predominantly only purchased card and glue off the shelf to envision my architectural creations the notion of time I expected for materials to be obtained was relatively naïve. It allowed me a great appreciation and respect for project managers whom must continuously maintain a steady supply of material. I could not fully fathom the amount of multi-tasking and forward thinking needed. 



$$
2
$$




$$
\text { SERI USLY }
$$

Gutside

- LiNE.
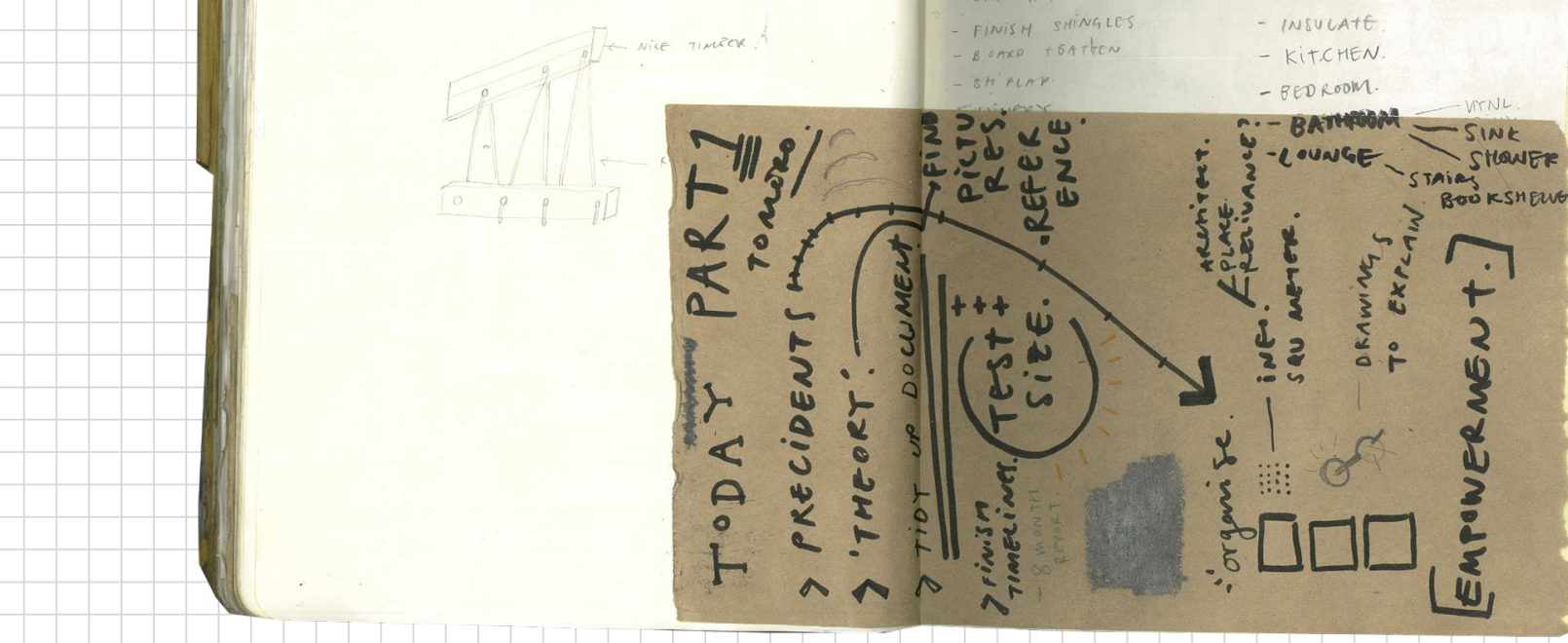


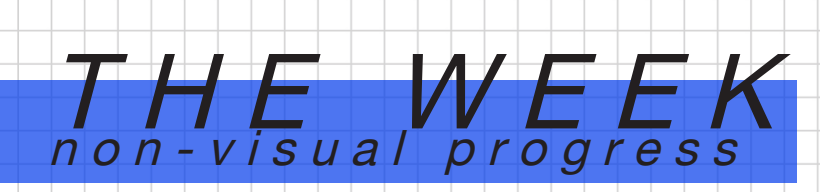

The inner working technologies of the 'tiny house' were not the first hurdles of this process to bring me to tears but they were certainly the most deplorable. It began with the obvious need to establish a clear plan for the electrics and plumbing. Plumbing was addressed through a process of elimination. Off-grid equals storage tank, rainwater collection and a composting toilet, I knew I would need a sink, and shower. In some ways the off-grid requirement in fact simplified plumbing issues. On the other hand, it did not simplify the electronic conundrum. It began with a discussion with a sparkie friend who said he thought it would be simpler and cheaper to run the whole dwelling on a 12-volt system, very similar to his boat. Many of the items needed he told me could be purchased from the local electronic or boat shop. Fitting. Consequently, I talked with my client about what I believed to be the two different options, 12-volt, or 240-volt. However, in hindsight I may have explained the plan for a 12-volt system without properly acknowledging the 240 -volt plan due to my own lack of knowledge. A simple regurgitation. The conversation ended vaguely, however, I followed up to confirm the decision of a 12-volt system via phone call a few days later. "Yes, that would be fine" she said. Great. My next step was to then enlist another sparkie friend to help out with the wiring, talk through lights, inverters (which would be needed to convert the 12-volt into 240-volt for plugs), plugs etc. before we applied the shingles to the roof. Because of the preconceived exposed rafters, to enable a ceiling light, all of the cable had either, to be run exposed along with the rafters, or on the topside of the attached roof ply and drilled through. For this reason, we decided to implement wall lights in the bedroom, bathroom and kitchen, and downlights under the mezzanine, resulting in only one hanging pendant in the kitchen. This would allow for less holes to be drilled through the roof, hopefully resulting in less confusion, less mess and more of a chance of being water tight.

This was the time within construction which seemed to be going smoothly. Decisions had been made, everyone happy. It was not until the phone call with my client a few days later that everything went downhill. I had actually called to ask if she wanted me to drop her some eggs later. However, after replying "yes we're down to two" she then proceeded to ask about the build and tell me things about 240 -volt systems she had found online; "did you know they sell 'tiny house' solar kits". I replied plainly that I had "literally just wired the house out for a 12-volt system like we discussed". Not terribly good at screening my frustration and desolation, I explained the situation before suggesting we discuss 'on site' later. Agreed. After an emotionally turbulent next few

hours I concluded that was all part of the process and things would be better for it.

The Monday that followed my client visited the site to go over what she actually wanted from the electrics.

Bachelard makes remarks upon the house as a form of stability within the contingency of the world ${ }^{153}$. I considered, this stability was reflected in the electrics of the dwelling. The home is meant to be stable, comfortable and reliable (wired for 240V) whereas the boat or the caravan are seen as transient or unpredictable (wired for 12V). Therefore, perhaps it was the right decision to bring an element of stability or status to this 'tiny house'. 


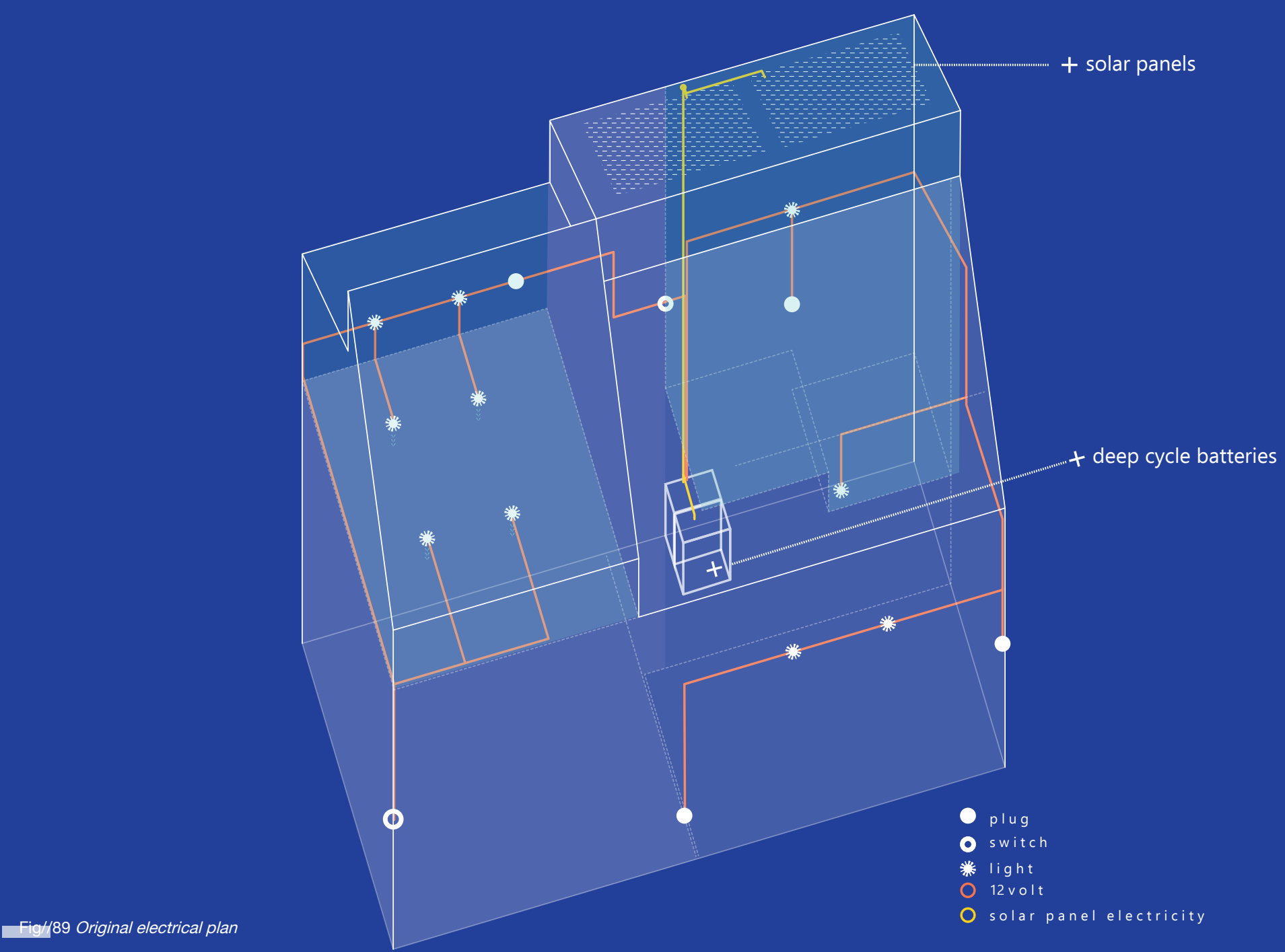


A week earlier I had ordered my cedar shingles from an importer in Auckland. To pick them up I had to borrow a friend's Ute. Before applying them, I first had to stain each one. Both faces and all the sides. Eight packs. Even more painstaking however, I needed to decide which stain to use. To move away from the cedar gingerbread house aesthetic, I wanted something darker. However, the decision became much harder after testing the various stains a nice salesman gave me. There was 'Midnight' (too heartless, 'clear' (too saturated) 'beech' (too yellow) 'elm' (too undecided) etc. Finally, I decided to 'Dark Oak' - dark enough to be obviously defiant, yet not too dark to hide the grain of the cedar. All of this was just the beginning of the laborious process to follow.

In total the process took approximately 18 hours, used almost exactly 20 litres of stain and caused one major hand cramp for a week. (However, this hand cramp was absolutely nothing compared to the repetitive strain injuries endured due to photoshop rendering before a big hand-in).

Once I completed the staining and with every inch of garage space lined with drying shingles it was time to prepare for their application. For this I enlisted the help of two extremely clever builder friends of mine, Solomon and Tom Wilson. We began the morning by borrowing a scaffold from another friend's job. This we set up on the Port face (or, largest fall). At this point in time, because there is such a thing as too many cooks in the kitchen (or people on top of a five-meter-high scaffold) Solomon and Tom set themselves up whilst I began cutting the battens that would go perpendicular to the rafters. As I cut, using a stapler, they applied the builders wrap to the first roof before applying the battens at $170 \mathrm{~mm}$ centres from the edge of the ply. Precariously balanced, I then began hoisting boxes of shingles on to the scaffold which Solomon and Tom began to lay. Once this was done again there was little I could do, I therefore proceeded with the task of tying down the framing to the trailer. This began badly.

After realising the drill-bit I needed $(8 \mathrm{~mm})$ would not go so deep as the trailer I went to buy one, only to discover on arrival back at site that it was in fact a masonry drill bit and would not drill through steel. Having learnt my lesson, I then confidently asked an employee to point me in the direction of the steel drill bits. Great. Third attempt back on site, the drill went in and came out the other side. However, the $140 \mathrm{~mm}$ long galvanised bolt I had bought the week before did not. I was sure I had asked for an $8 \mathrm{~mm}$ bolt but alas it was in fact $10 \mathrm{~mm}$. Trying not to give up I went back to the shop to find a $10 \mathrm{~mm}$ steel drill bit longer than $140 \mathrm{~mm}$. Again, I was out of luck. The did not stock one. However, I then remembered the shop where I had purchased these specialised bolts sold all kinds of things. I decided this would be my final attempt and if it failed I would have to surrender for the day. Thankfully then did indeed have a $10 \mathrm{~mm}$ steel drill bit longer than $140 \mathrm{~mm}$. Not getting my hopes up I raced home to try it out. Marking $22 \mathrm{~mm}$ from the edge of the bottom plate I carefully drilled down. Remarkably it fit perfectly. I then proceed to drill and fit bolts at precisely $1000 \mathrm{~mm}$ centres and at the corners.

Whilst this ordeal had been unfolding Sol and Tom had made far more progress with the shingles. With two roofs on the Port side complete that was the end of their day. 
$+$

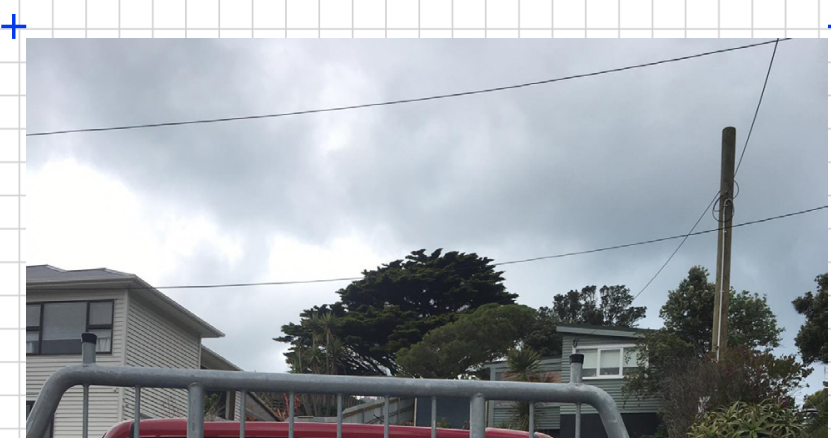

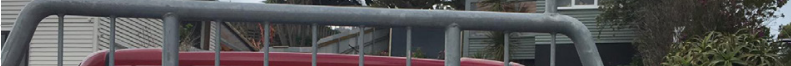

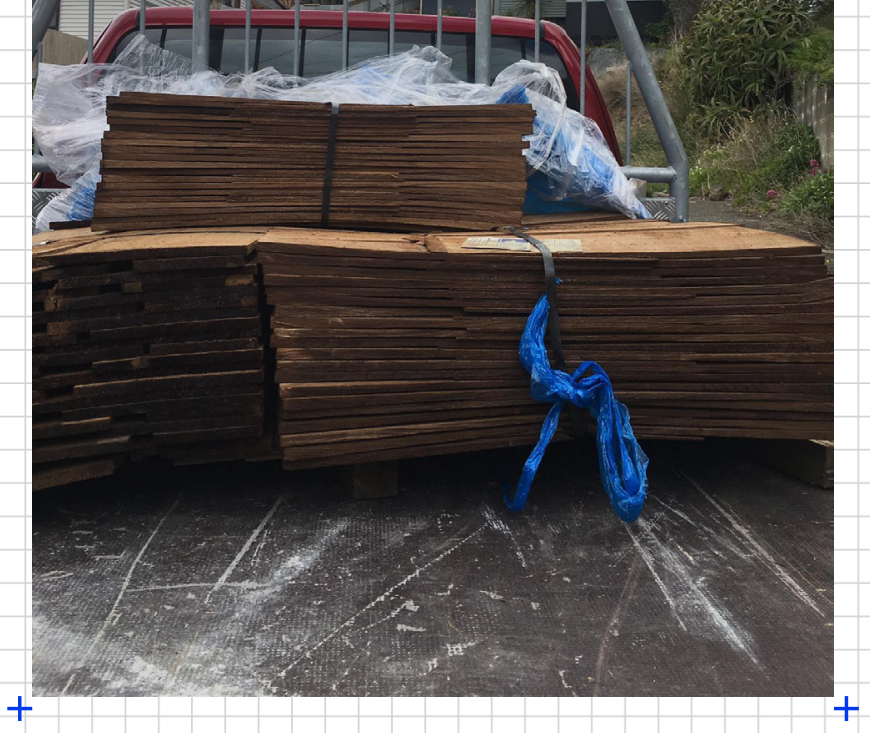

Fig//90 Picking up the shingles

$+$

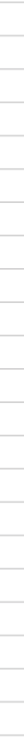




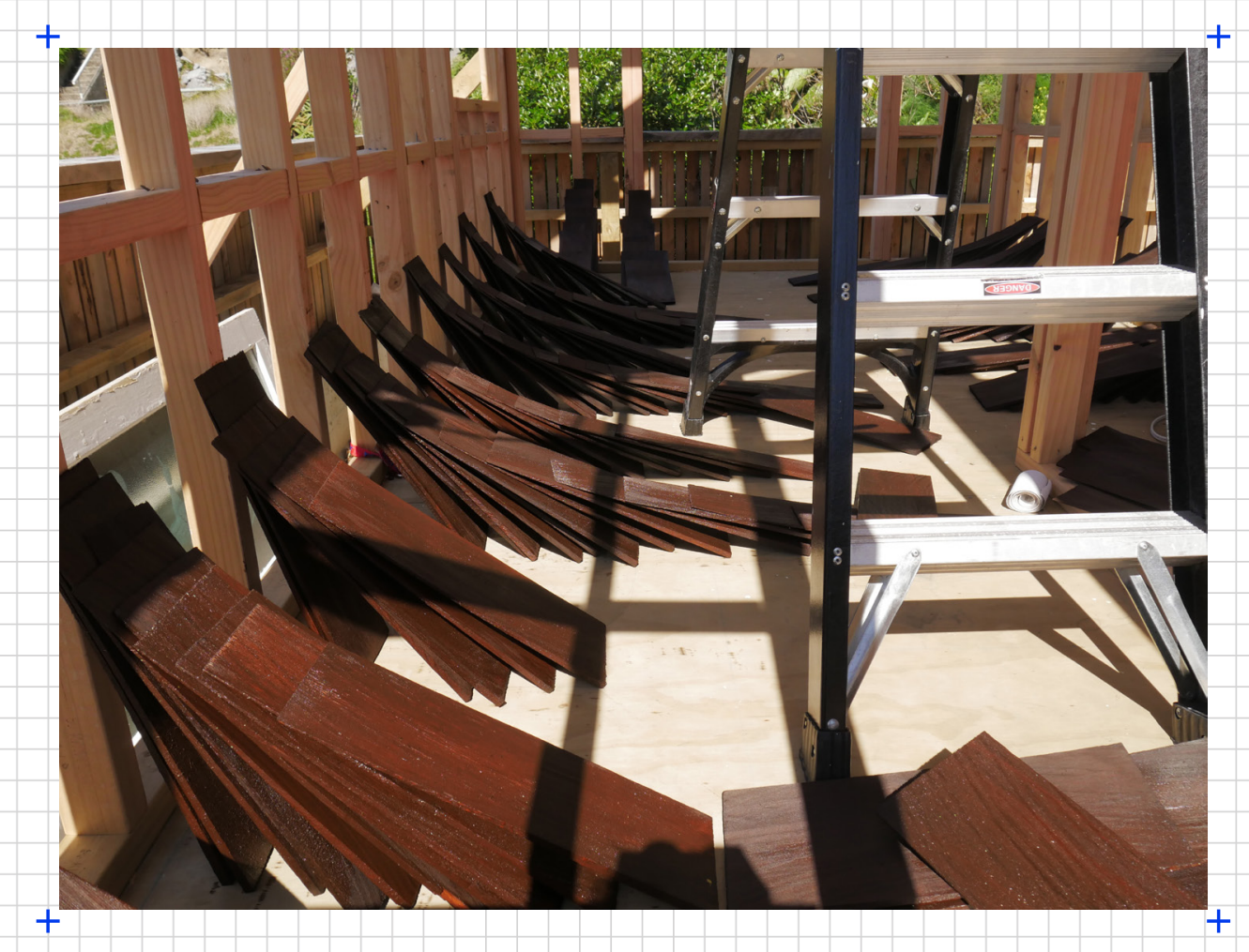

Fig//91 Stained shingles drying 


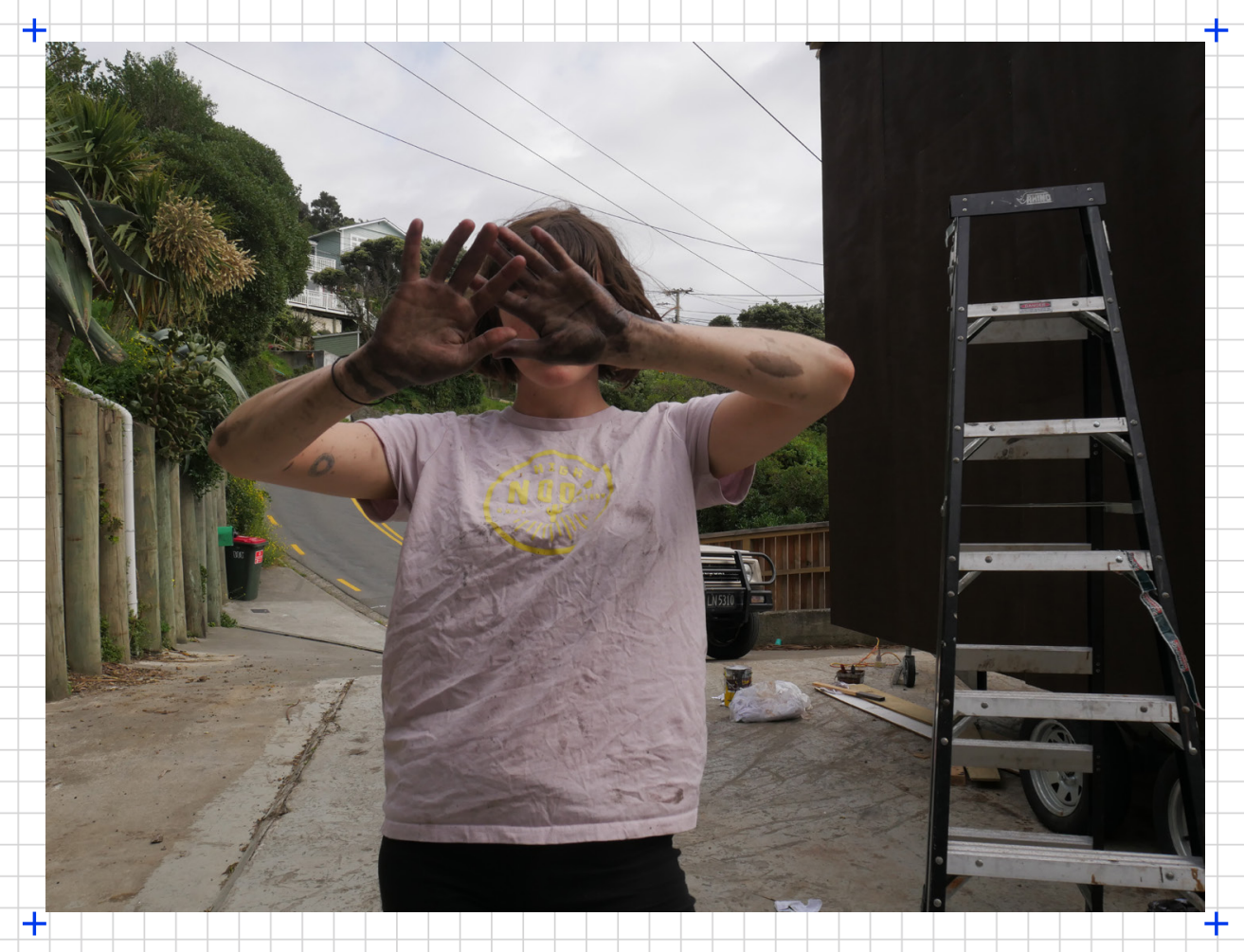




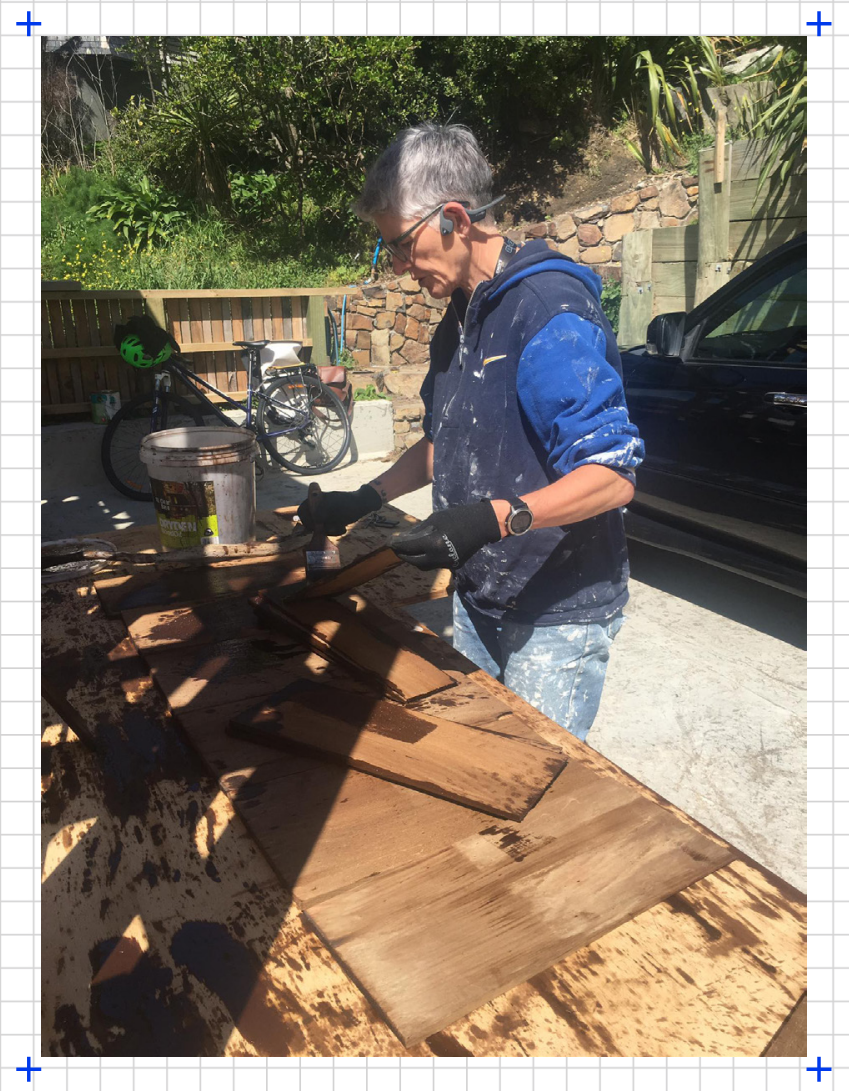

Fig//92 Kerry helping stain shingles 


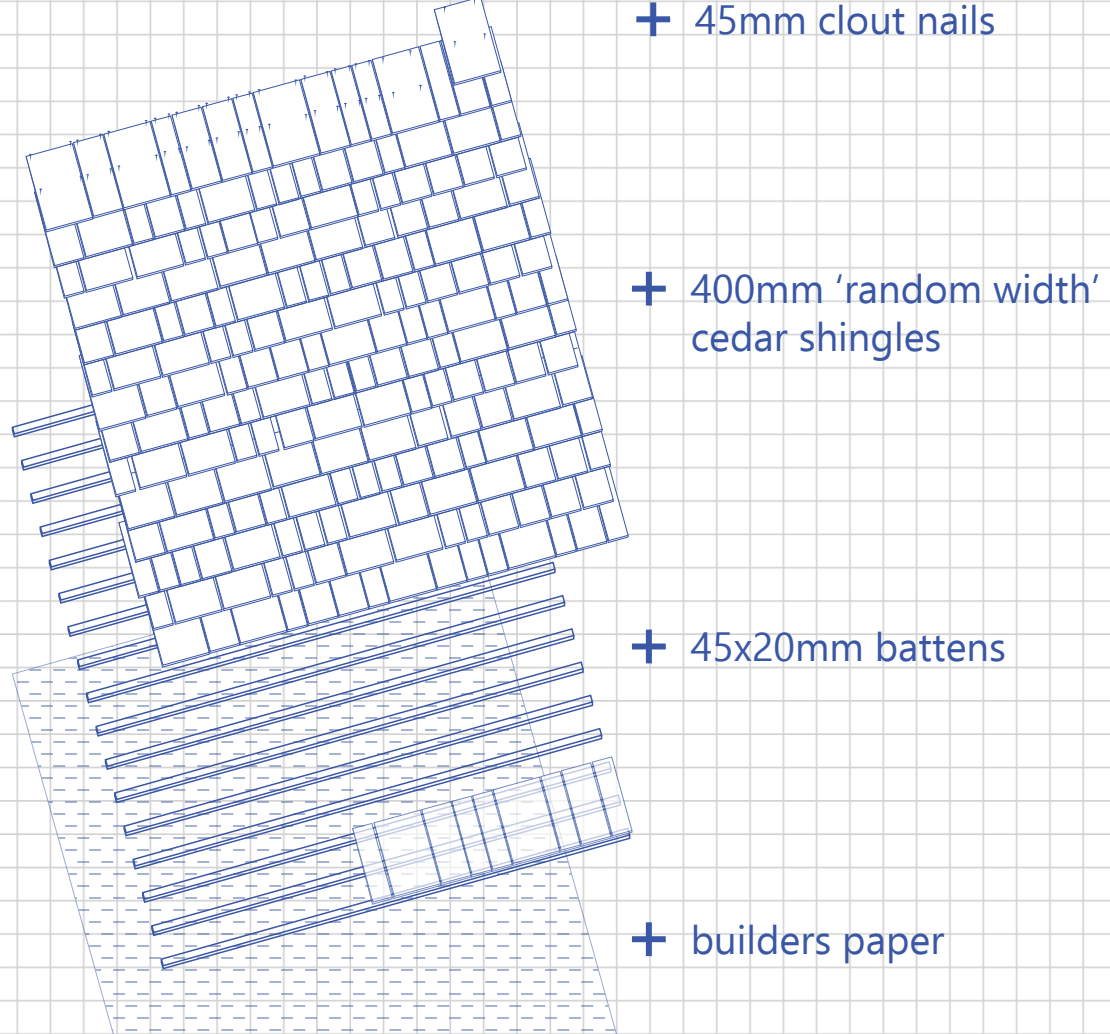




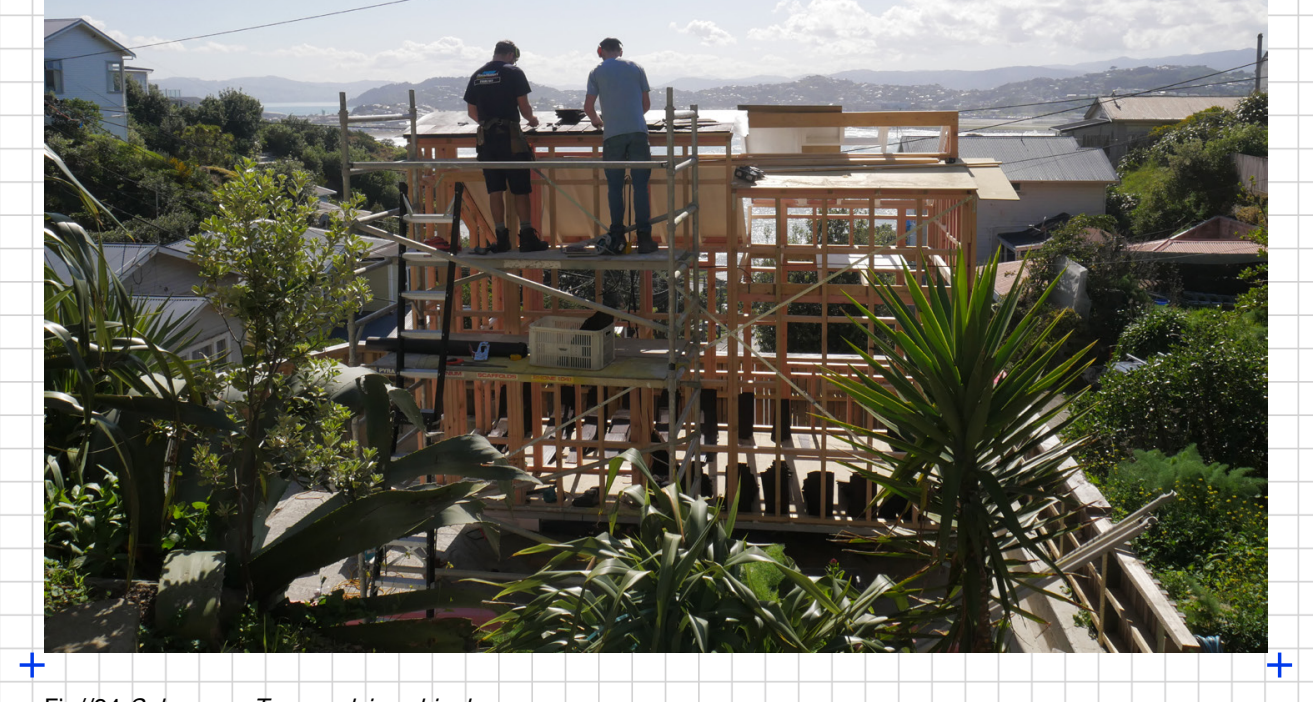

Fig//94 Solomon + Tom applying shingles 


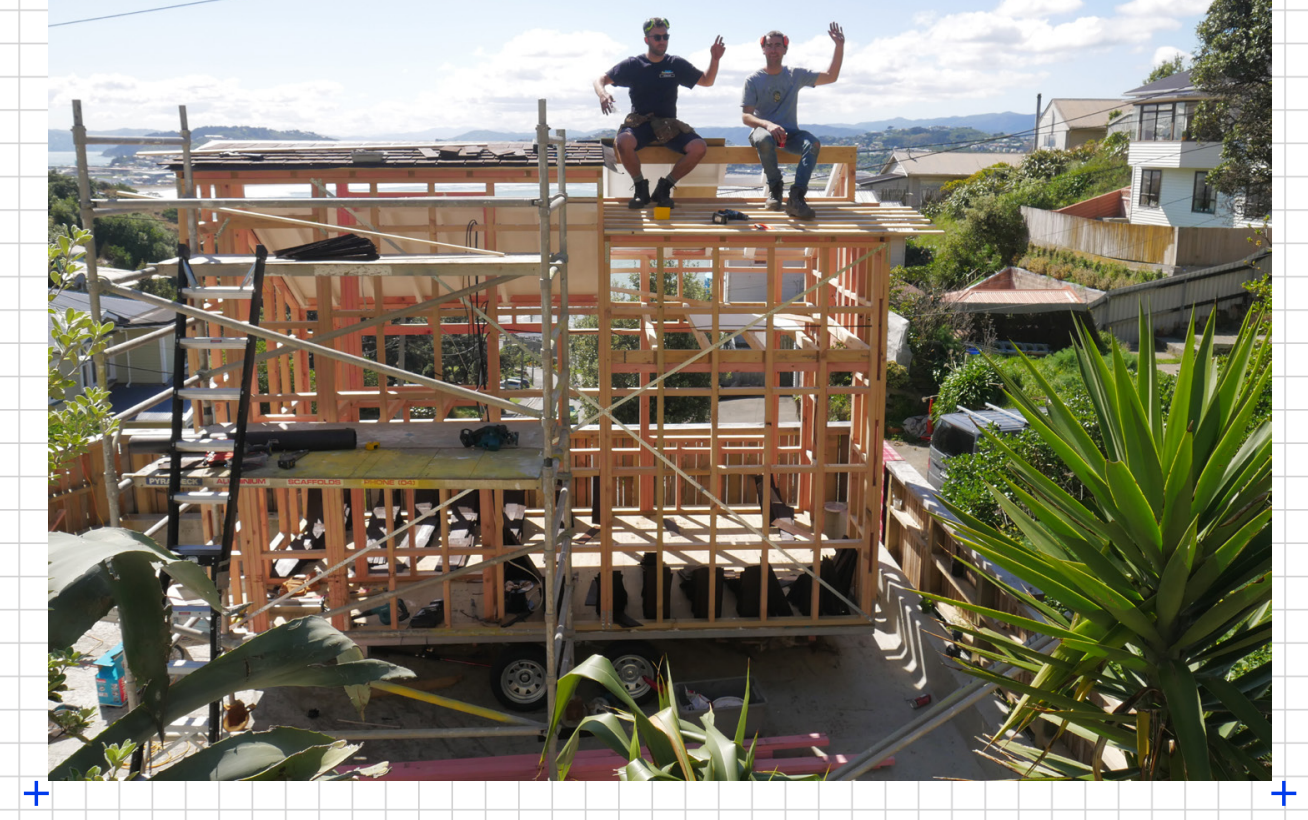


Since undertaking this project, I have come to recognise the importance of visual progress, rather, actual evidenced progress. A few occasions in which I would feel too beaten to stand up, Solomon would suggest "put all the dwangs in" or "prep the interior rafters". In essence, start the day by doing something 'easy', something you know how to do confidently and, once complete, are able to see a change visually.

At this particular stage I was continuously reminded of the fact that nothing dramatic had visually changed in quite some time and it was beginning to have a negative effect, not only with respect to my productivity, but also mentally, the whole project became blocked. The physicality of the build had become secondary, and for that I felt less involved. The separation between myself and my material task was causing me to, as Sennett analysed; overlook the material ${ }^{154}$. Therefore, once the cedar plywood and shiplap arrived I was more than ready to go. Because, I had already figured out plywood sheets are awkward to lift, Solomon allowed me to 'borrow' his worker Quinn for a few days to help me attach a skin onto my dormant skeleton.

On Monday morning we began by purchasing a roll of 'Thermakraft Watergate Plus' building wrap and a 'Rapid R23 Pro Steel' stapler with yellow trim. Another thing I found useful within this process was to begin a large new task on a Monday, not only setting the tone for the week but also being able to reflect on Friday about the week as a whole. Whilst I took care of ensuring all the faces of the structure were free from skewed nails and other irregularities which could warp the applied skin, Quinn placed additional dwangs where the plywood sheets would be screwed. Once completed, Quinn and I, carefully (beginning at the bottom) wrapped and secured with stables, the Port face of the structure.

Before leaving us to it in the morning, Solomon had suggested we place a block on the wall at the height the first sheet of ply would sit. This would make it easier to place the sheets. So, before we began, we worked out where the first sheet would sit (directly between the break of the structure) and attached a piece of 3X2. However, either Quinn or I had slightly mis-measured the length and where the sheet met the roof there was a $5 \mathrm{~mm}$ gap. (At times like I wished for the knowledge and experience of Solomon to decide whether or not this was an important mistake). Repositioning the block $5 \mathrm{~mm}$ higher, we found that now the sheet would not fit. After re-placing the block multiple times Quinn and I agreed to reject the block suggestion and proceeded to wing it. Or, implement a method of, Learning by Making ${ }^{155}$. Wallis acknowledges the importance of experimental learning, explaining that "...group work forces members to reassess their established frameworks of developing knowledge, problem solving and personal beliefs" ${ }^{\prime 156}$. 


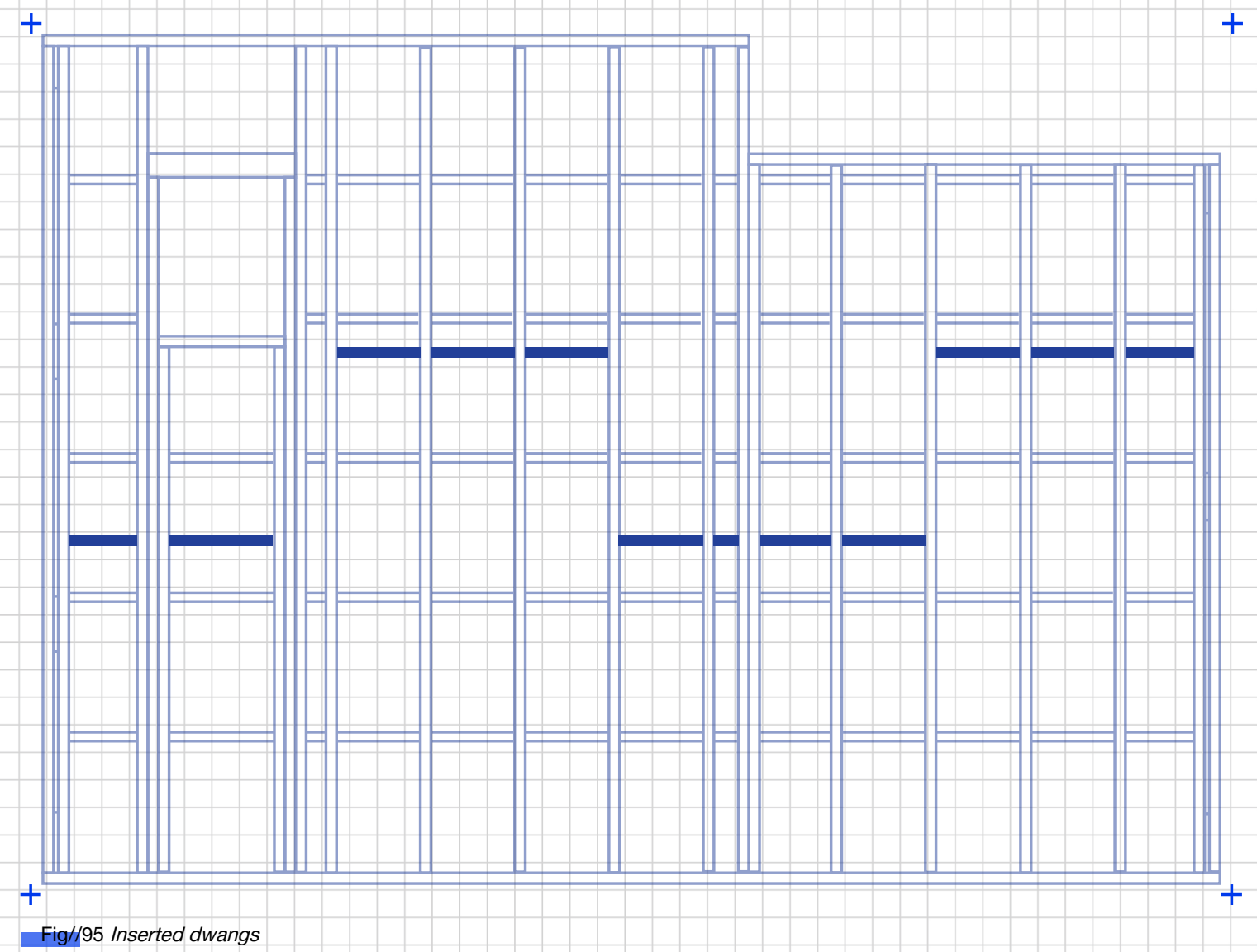


Rejecting the block method was much easier said than done. Solomon was right that the block made securing the sheets far easier as without it both Quinn and I had to lift it up into position before on of us held it up and the other used the pin gun to hold it in place. Awkward, time consuming and tiring.

Eventually we secured the first sheet to the structure, only to look back at our work and realise something was wrong. Either the cut made in the sheet was not straight, or the sheet was not straight, or, fundamentally worse, the studs were out. Frustrated and definitely not stimulated by visual progress, it was 5 o'clock Quinn packed up, leaving me to debate if it was better to start again, or compensate for whatever was not quite straight. After deciding that surely, I would have start again, Solomon came home and confirmed that "yeah it's a good idea. But lets just do it now!". The cut was slightly off but that it would not matter and could be compensated for. After working this out, we attached all of the sheets to the structure and it was confirmed; the block trick does work. Visual progress had been made. Things were happening and it allowed me, perhaps not to see the light at the end of the tunnel, but definitely begin visualising what that light might look like. Pallasmaa identifies that the true satisfaction of this, visually evident progression, realm of work is when the visual is balanced with the mental. Or rather when a challenging problem solving task is evidenced through the visual ${ }^{157}$.

Following on from the completion of the Port wall, I alone began to work on the Bow and Stern faces which would be clad in vertical shiplap. I was extremely impressed with the cedar when it first arrived not just for its aesthetic quality and incredible lightness, but also for the illusion it could create vertically. (The idea I have envisioned, it seemed, may work). 

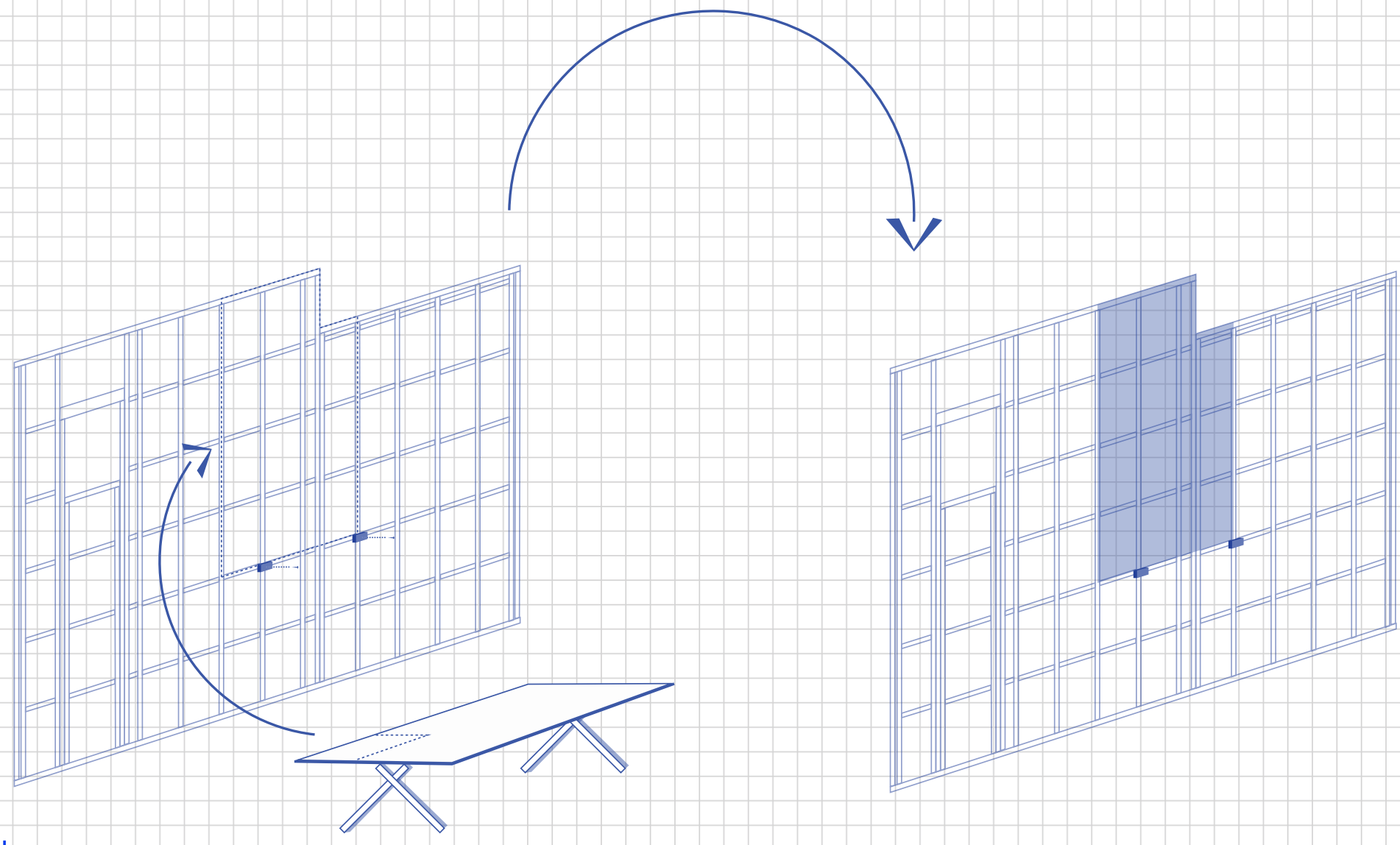

$+$

Fig//96 Diagram of 'block' trick 


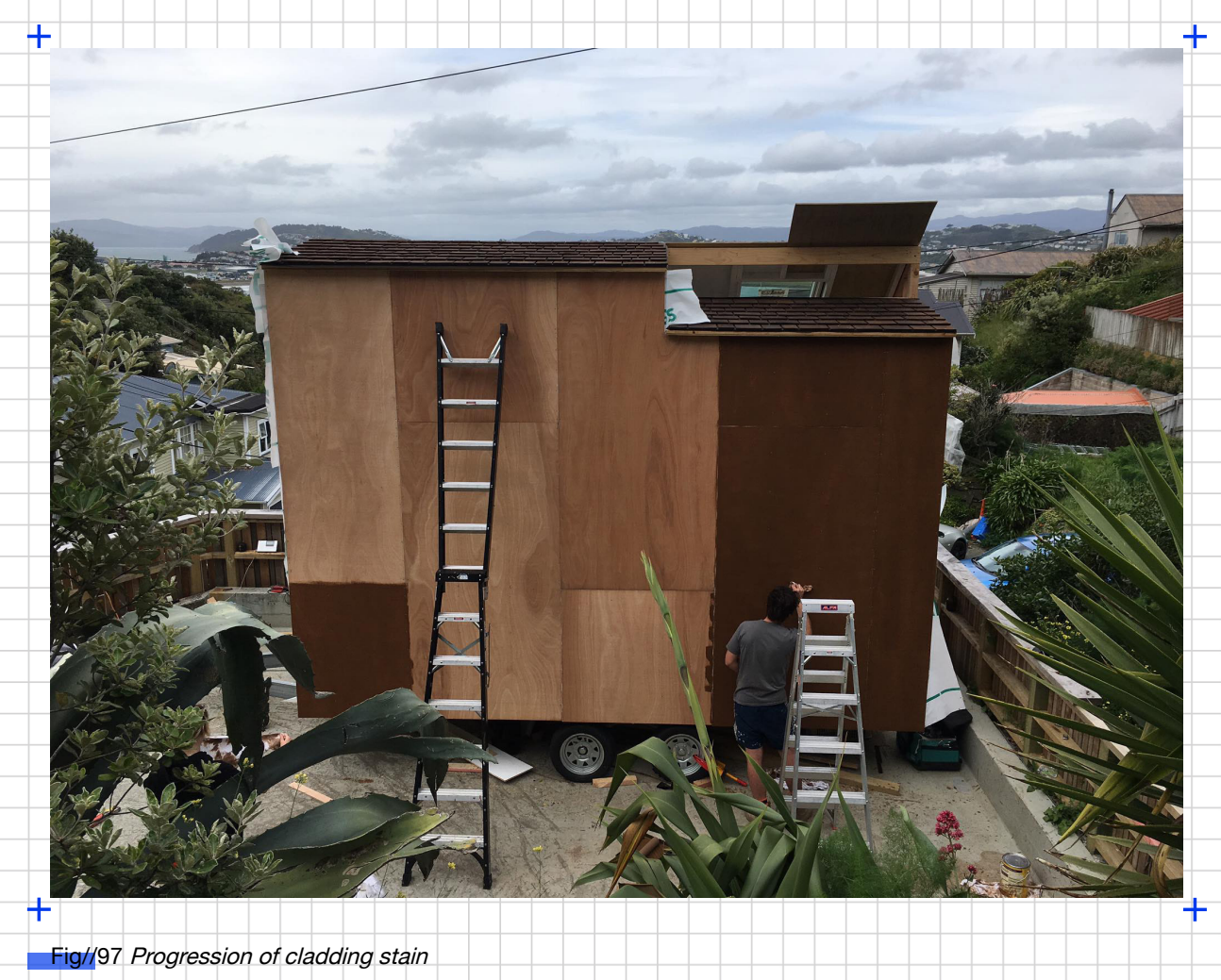




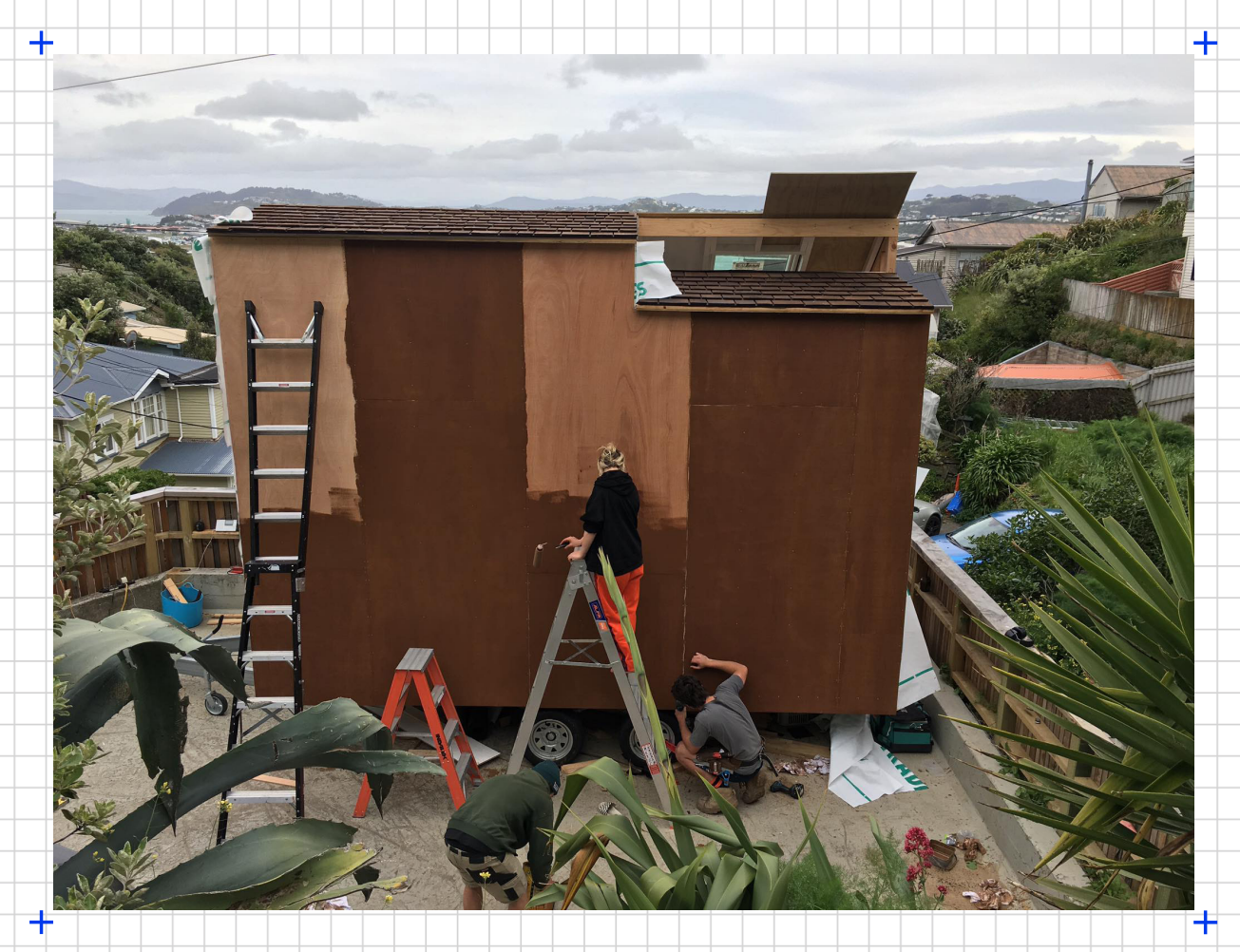


I began by staining the front and back of each board with a sandy colour by 'Cabot's'. Because of the cedar's original colour, I went with 'weathered cedar' which in all honesty did not transform the natural colour of the cedar, simply protected it. Once completing this and wrapping the Bow face I began methodically attaching the boards. For the first board I measured the length from the shortest point of the roof to $130 \mathrm{~mm}$ below the trailer before cutting on the angle of the roof that length. Then, using a pin gun, secured the board down the right-hand edge which would be hidden by the subsequent board. To ensure the board was vertical, I measured the bottom of the board to the end of the wall and measured the top of the board to the end of the wall. This definitely slowed the process down and if not on a trailer could have been done using a level, but it at least gave me peace of mind. Each board after the first I would measure from the longest point of the previous board and subtract $15 \mathrm{~mm}$ to account for the overlap, giving me the shortest length of the next board. Secure, check and repeat. This was by far my favourite task thus far, visually stimulating yet complex enough to be satisfied with the problem, it was rhythmic. Sennett said "....all skills, even the most abstract, begin as bodily practices" 158 . With every board, I was training my body. Gaining physical knowledge of the weight of the

brad gun, the rough and smooth faces of the board, each repetitive action becoming more efficient. Although it indeed took a whole day to complete something which maybe should have taken a few hours, by the time I reached the far-right edge I was (for once) very satisfied with what I had achieved. Two walls, up two to go but first I needed to stain the exposed plywood sheets already up on the Port face before the rain came in.

This decision proved slightly harder as I was very aware of the need to renounce from the 'gingerbread' romantic ideology and the cedar was tinged with a slight pink. Unsure of how to counter the pink tinge whilst maintaining the grain integrity and side skirting anything close to 'gingerbread' I bought ten litres of 'Auburn' which, with the help of some keen friends, covered the Port face with. 
Because of the way the shiplap was attached to the Bow face, I next had to properly secure the boards with nails. Before being left to my own devices I had been warned "don't miss the nail" as any 'half-moons' could not be sanded out because of the boards ban-sawn finish. This terrified me. I began by purchasing a box of 'silicon bronze rose head nails' before marking out and drilling where the nails would be hammered. I then began the nerve-racking task of hammering in these $90 \mathrm{~mm}$ nails without once hitting the perfect boards behind it. I was so aware of not 'half-mooning' I placed my hand in as sacrifice which resulted in an inflated thumb and a whole day spent nailing one wall. Definitely worth it when a passer-by shouted "love your work!".

Fuelled by the desire for more visual reinforcement, the next day I decided to skin the Stern wall. Starting on the right, I followed the same method I had executed for the Bow face. However, the further I progressed, the more apparent it became that I was running low on boards. By the time I was halfway above the door it became clear; I was going to run out of cedar before I reached the end. I had mis-ordered. I used up what I did have before calling Lauren, the woman I had ordered the boards of previously. I ordered only six more boards, along with the facia board I knew I needed and more battens for the Port and Starboard faces. I reasoned that if I was going to put another order in I may as well do it all at once. I explained my predicament and she assured me it would not be a problem and the boards would be at the depot within ten working days. (In the meantime, I still had to nail the boards I had already attached, finish the final face, stain...)

I waited for the cedar. I worked on nailing the boards I had already attached, finishing the final face, stain everything, prepping the rafters, framing the two break sections I decided to clad instead of window, and sawing the bottom plate of the entrance door. Ten days turned into a month, which then turned into two. Unable to contact Lauren all I could really

do was take an early Christmas holiday and wait Lauren out. 


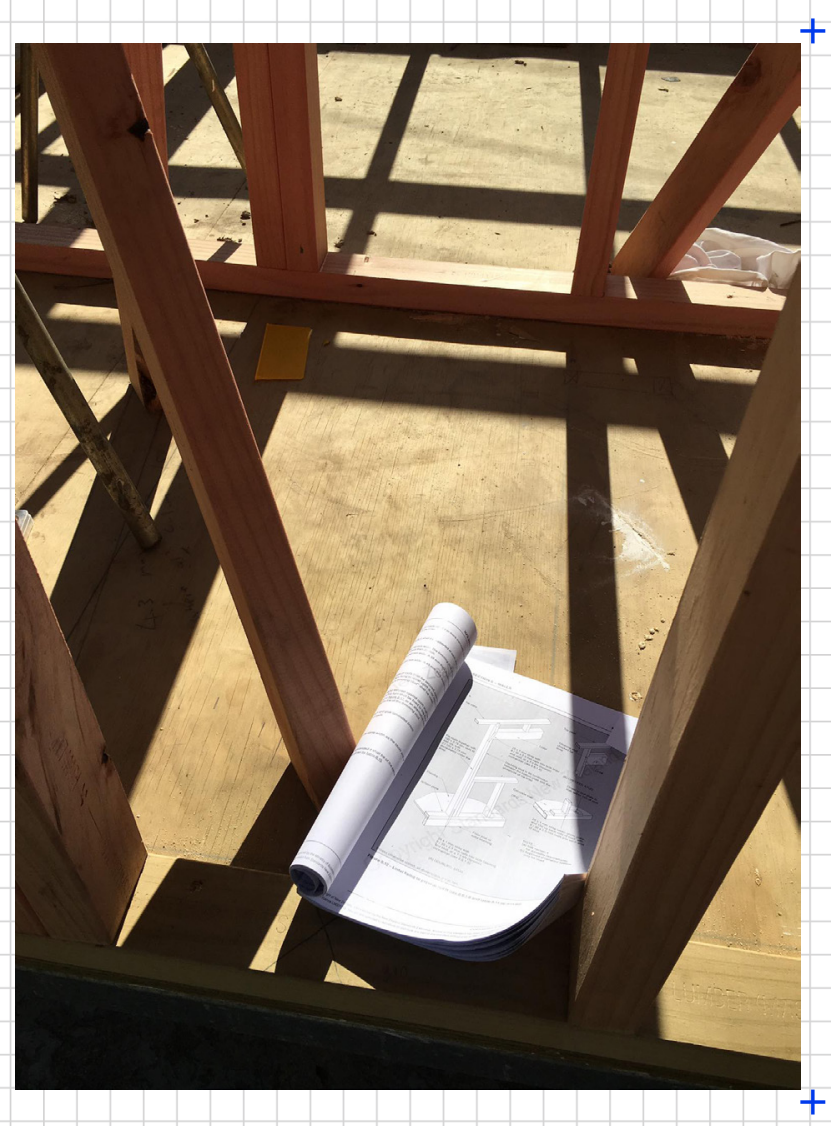

Fig//98 Various notation on 'site' 


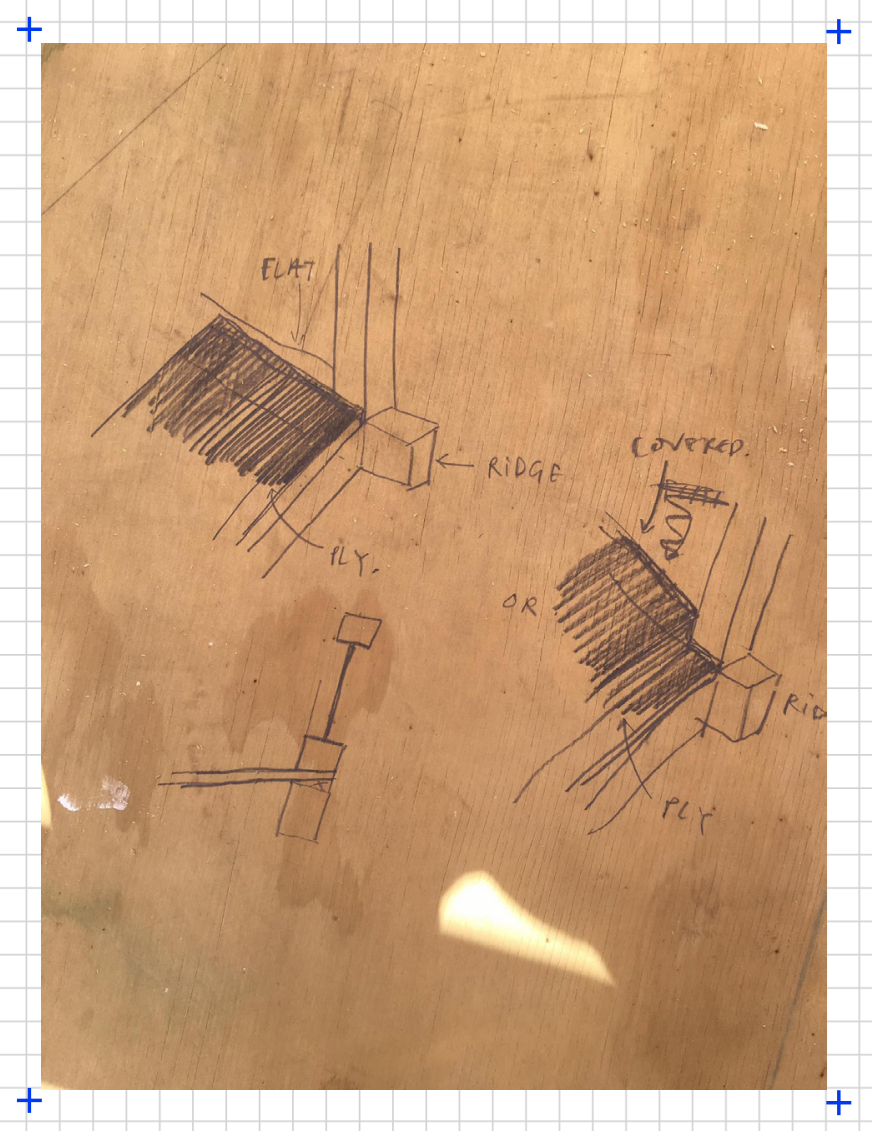




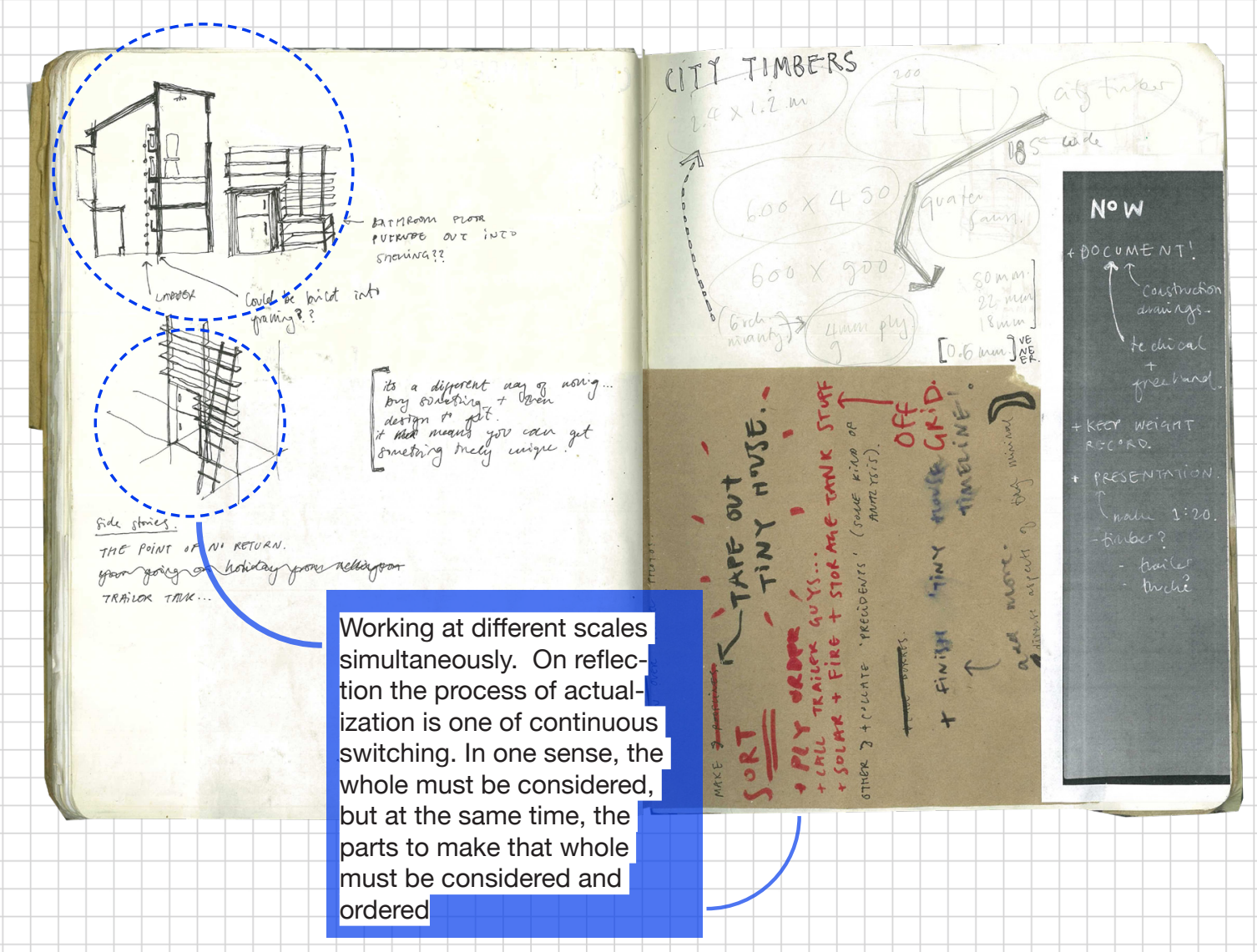




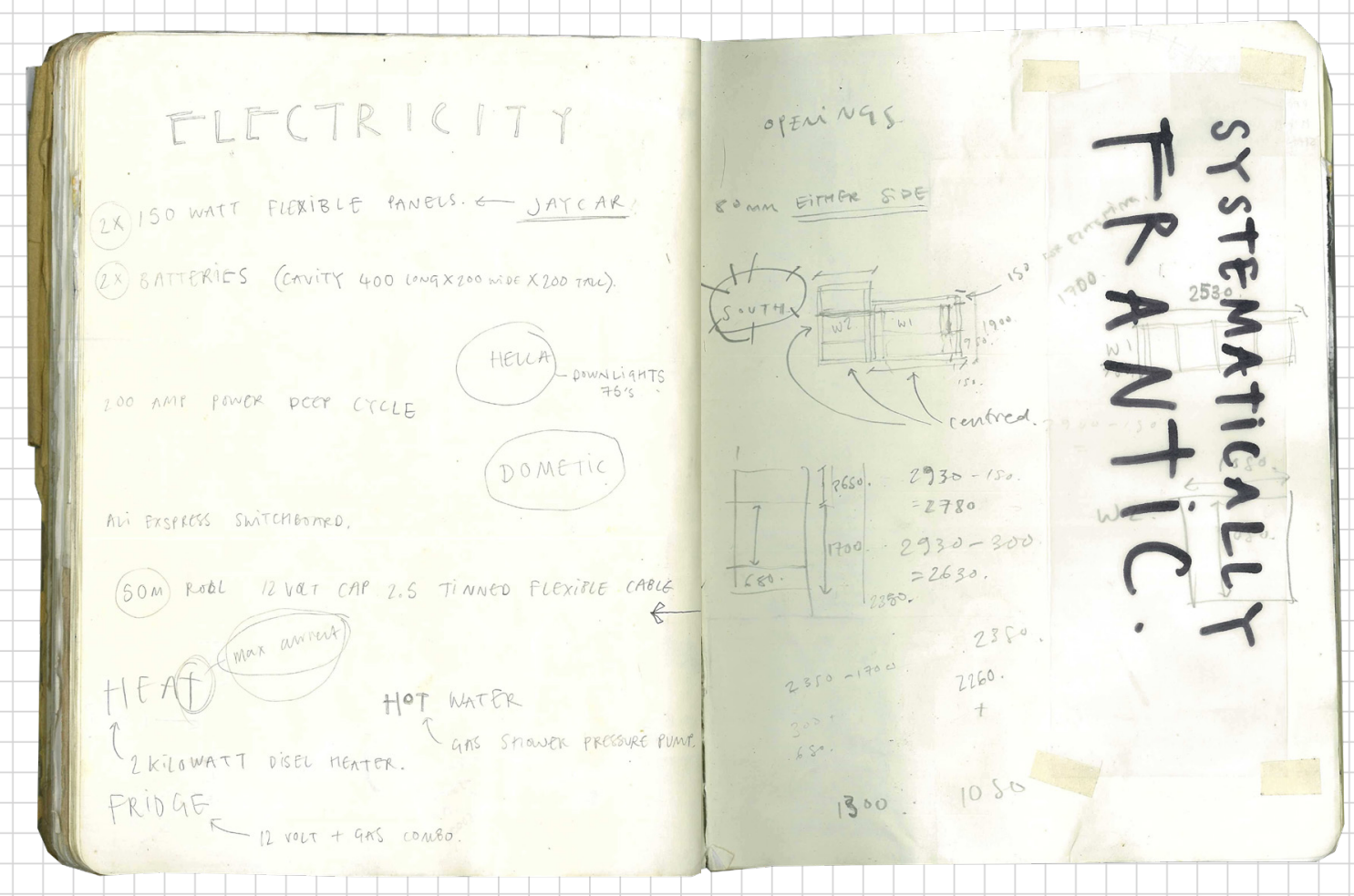


Being back on site after a break was both exciting and slightly demoralising. Although the cedar still hadn't arrived Solomon and his worker Julian were able to help me install the joinery and finish up the jobs I had only a vague, visual idea of how to carry out. There is something far more comforting when a few people are working together, it seems as though things move faster, or less time is wasted, plus there is the added bonus of being able to check whether or not something is correct. The time aspect of making is not reduced, but the ability to collectively make allows a fluid workflow.

To begin the week, we began by "having a big clean up" - a reset. Julian then set to work on finishing the ends of the already clad walls whilst Solomon and I fitted the joinery. We measured the large window opening before cutting the copper flashing to fit. We made a 45-degree cut to allow for the copper to bend over the opening before securing it with two clout nails at either end. Carrying the window to the external side of the opening which, because of the site is somewhat harder said than done, we carefully lifted it up into position. Snugly in its framed hole, Solomon secured it from the inside with purlin screws. However, not all the joinery was so simple, the doors for example needed quite a substantial amount of attention as not only were they were approximately $40 \mathrm{~mm}$ too short for the opening, the sill was too wide and deep. This complication was far beyond me; Julian however, had trained as a carpenter and therefore very accustomed to this kind of task.

By the end of the day all of the joinery was in except for the two 'break' windows I still hadn't quite ordered or decided upon. It was at times such as these in which I would wish I had specified the whole build before beginning. Till's discussion of contingency within architecture suggests that architects have become an interior focused profession, maintaining control, disregarding the unpredictable ${ }^{159}$. However, the projects general lack of specificity, was arguably not allowing me to better deal with contingency in so much as it was adding the contingent aspects to deal with. The opposite of architecture, as, Le Corbusier declared within 'Précisions' "to create architecture is to put into order"160. Where did this proclamation leave my project?

Once in, to seal the new windows and doors I prepped (sand, fill, sand, fill) and painted. A task which although fairly straightforward, requires a lot of time and attention to ensure its outcome. Whilst I worked on the outside, Solomon and Julian fixed the mezzanine, as to install the door, one of the LVL beams had to be ripped out, which subsequently prompted a constructional reshuffle. This comprised of us then ripping all of the joists out, which, as was usually the case, resulted in the timber splitting. Like dominos this eventually led to the whole mezzanine structure to be taken down. Purchasing more LVL lengths (and reusing the intact lengths we had) we proceeded to reconstruct the mezzanine. The reconstruction made apparent a $5 \mathrm{~mm}$ warp I had forced, so revising the mezzanine actually saved what would have otherwise been a mammoth task. 


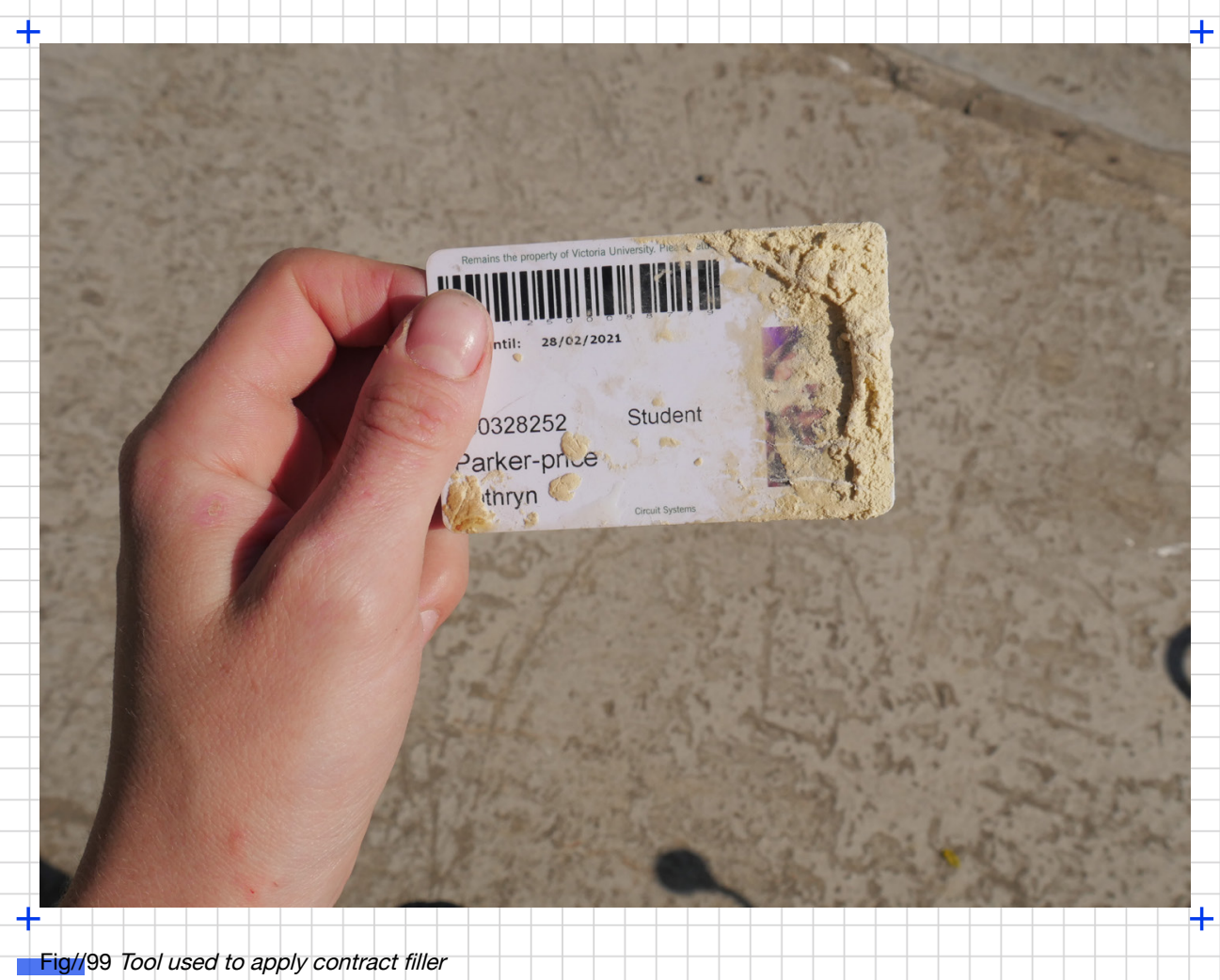




\section{COLOUR DILEMMA}

Once finished, I set about finishing the prep work. One final sand and they were ready to be top coated, the only issue was I needed to choose between 'YinYang' (a light green), 'half coriander' (a slightly darker, light green), 'Ecstasy' - (a red my client showed interest in) and 'Sweetcorn' (a pale yellow, just for a range). Buying a small test pot of each I painted a small section of each on the interior of the tall angular window in the cook space and made lunch to mull it over. Coming back to site I began to clear up, to subconsciously observe the colours as I walked around. However, aware of the fact that, one: the colour really did not matter in the grand scheme of the things, two: I could always change it, and three: I had so many other things to do than to waste time with this decision. I went to the paint shop and impulsively picked up a one litre container of 'waterborne enamel' in 'YinYang' for the sashes and 'Half Pearl Lustre' (an off white) for the frame. Somewhat impressed with my ability to make quick decisions I went back to site and began my clockwise painting exercise, first a round of 'Half Pearl Lustre' for the frames, then a first round of 'YinYang' for the sashes. I looked back on the 'YinYang' and thought, "yeah it works".

Because of the time it took me to do a full loop, and the heat, by the time I got back to my staring point I was ready to sand before painting a second coat. I stepped away from the wall to collect the sand paper before glancing at the windows I had just painted and thought, "Nope. Only a dated 70's batch could pull that colour off, I have to change it". Stalled for a moment I reasoned that I should at least see it through to check the second coat didn't 'wow' me. I sanded before repeating my previous loop. With such internal conflict occurring throughout this process, by the time I was done, the day way over and I could at last stop looking at my paint job. It was probably the light anyway. 


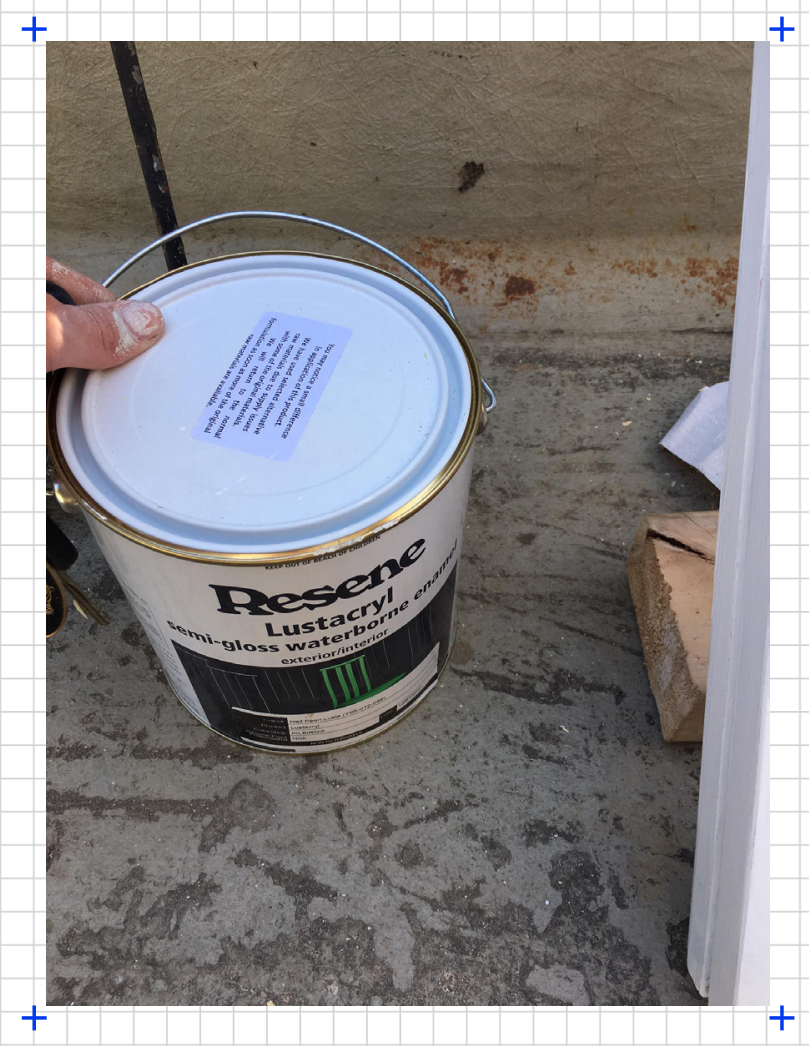




\section{$E L E C T R / C / \mathrm{ANS}$}

The following morning the electricians, Jamie and Josh arrived to do the pre-wire before I lined the interior. Before they began I showed Jamie where I wanted all the lights placed and where I wanted sockets and switches, marking on the framing with my pencil so I could remember. He then asked which switches controlled which spaces and which were separate circuit and which were combined. Although it should not have, this threw me. Thinking it through logically, I suggested the switch at the entrance should be able to control all the separate circuits besides the bedroom lights. There should definitely be a switch for the kitchen, at the opposite wall in the kitchen, and the pendant in the kitchen should be able to be on without the over bench light. This problem solving, I enjoyed as it allowed me to visualise a person, my mum even, living in the space. Moving past the design and into the reality was something I had never properly experienced, or truly envisioned experiencing. Kartsen Harries wrote "....architecture is on the one hand a product of human activity while on the other its helps to create the environment which gives shape to man's activities" 161 . However, this interaction was the first time I would be able to actually experience the latter.

The next question to do with batteries for the solar panels and switchboards were not so poetic and required me to consult my notes. Never the less the electricians got on with it whilst I, not able to carry out any of the small tasks I had to do in the same space, looked into the preparations my sister would need to begin to undertake to park the house. 
But first, I had to ensure she and my client had decided on a "parking spot"162. Her response was, "Well what do you think?". I proceeded to call my client who expanded, "somewhere next to the veggie patch but do you have any ideas? They have some ideas about moving the driveway and then building another shed by the sheep...". These back-andforth, non-committal conversations spanned the next few weeks. Till wrote "one might think that an abstract world can be ordered, beautified, and perfected, but in the end the real will come back to bite you"163. Leaving Wellington towing a 'tiny house' and having nowhere to park it was something I definitely did not want to be bitten by, so I ensured we did this with plenty of time to spare. It seemed one needed to be proficient not so much with predicting these sorts of user focused aspects of architecture, but accounting for, and embracing them. Although ideally this process would not have taken so long, the conversation of the driveway, the sheep and trees all allowed for a further potential for the space.

At some point though we had to make a concrete decision and prepare the ground for the dwelling's arrival. I received video walk thoughts, my client set up markers, we called, we sent photo and eventually we decided the dwelling would sit angled $-15^{\circ}$ of North, with its closest corner to the main house three meters from the tree line.

The next step was to arrange for the site to be prepared. To understand what would need to be done and advise both my client and sister I phoned a selection of 'tiny house manufacturers'. I received varying responses between very little preparation, and major earthworks, however overall it was suggested that the site would at least need to be levelled, scraping off the top soil, and placing down some kind of hardfill. The significance of the material world within the discussion of architecture, memory and place is decisive ${ }^{164}$. However, the material in respect to the transient architecture of the 'tiny house' is also transient, or at least suspect to change. The movable architecture cannot be dictated or influenced by site.

I suggested we hire a digger and driver locally to do the work, something she should perhaps enquire about. She responded with "well how much will it be?". I said I had no idea and that she should just call around to get an idea, a skill I had grown accustomed throughout the build. "Actually, do you think it would be cheaper to hire a digger and get a friend to do it?" she pursued.

At what point was the responsibility of this project given over? Where was the line? I reasoned that it was my sister's boundary line and that this coordination lay with her, or at least, not me. The following day I received a message; "in classic Ōkato fashion neither company answered their phone. I left messages" followed by, "managed to talk to someone who will have a look and do a quote". Do they not realise it is an actual thing now and cannot, not be 'parked'? 

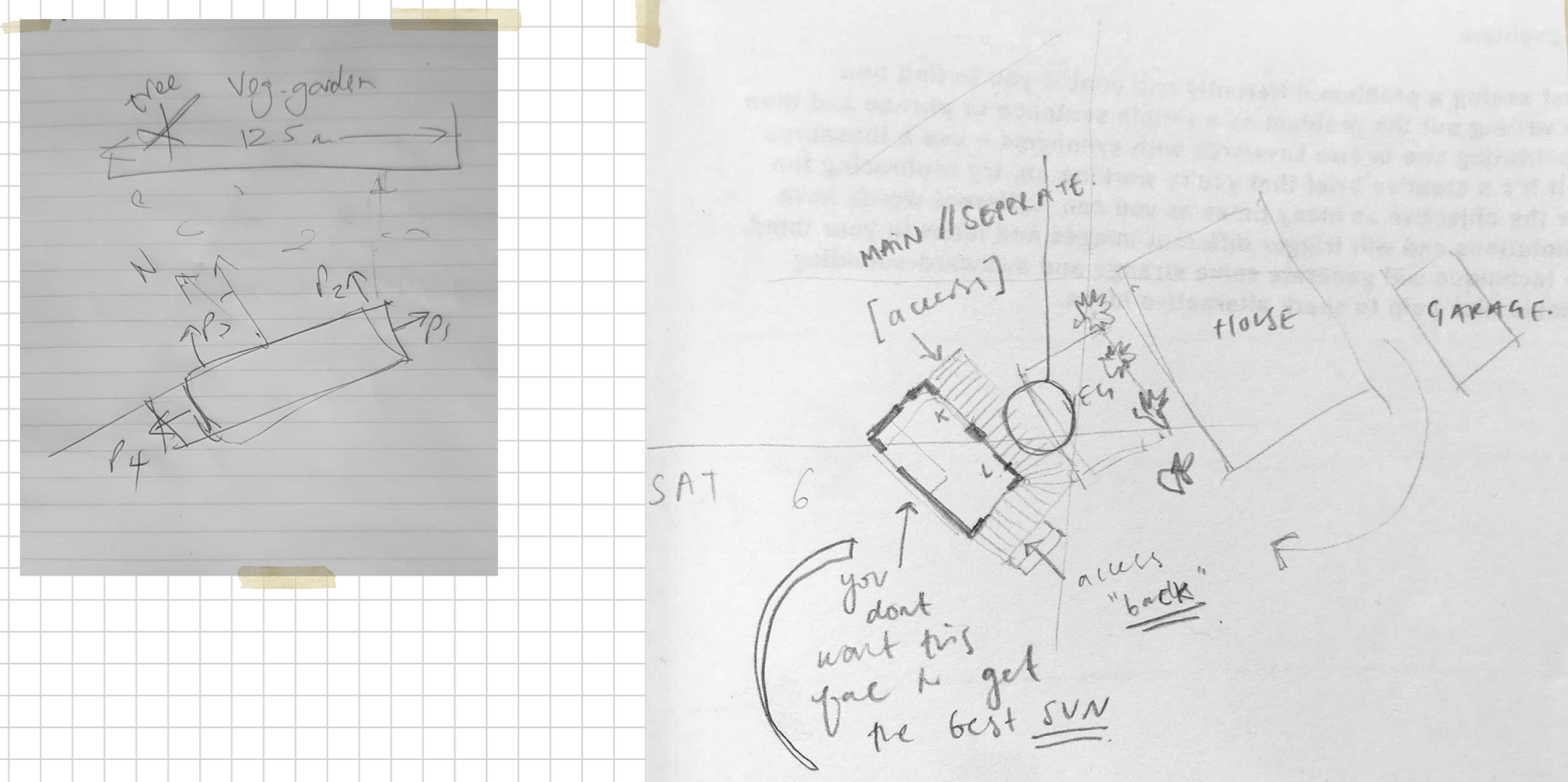


\section{MATERIAL ARRIVAL}

The following week I received a message affirming that the cedar had finally arrived at the depot. I made arrangements to pick it up promptly. This was the same day the plumbers Rodger and Tim, had agreed to fit out the bathroom and kitchen. I met them in the early morning, talked over what needed to be done. Adamant that no I would not need a toilet plumbed out "just in case" my client changed her mind about composting toilets. I instructed them on the placement for the vanity, shower and kitchen sink and where to place the pipes to the gas infinity, gave them my number and left them to it.

Because of its length, the cedar delivery would not fit on a standard Ute so I had to use a tipper truck, (otherwise known as the biggest truck you can legally drive on a standard car license). Arriving at the yard, I was met with confusion: small girl, big truck, something that for one reason or another is not often encountered. It felt monumental and slightly surreal to be collecting the materials I had waited almost three months for. Having given the collection details to a yard worker, (who looked slightly confused at to where it was and why the date was from so long ago). I waited as he trawled down isles of packets of timber before reappearing looking pleased. "Here it is!" he said, dropping off a much smaller packet than I would have guessed. Not intending to go home without everything I had ordered I questioned: "really? The 40X18 J101 battens, the bandsaw (BSF) faced shiplap, the 130X18 facia board and the 90X18 box corners boards? I ordered almost 300 lineal meters of material". "yes yes, see here, this is your order number, it says one packet so its all in here" he tried again pointing to the plastic wrapped packet. Conflicted by the inclination not to be pushy, and the desire to have materials to work with the following day, I asked if we could have a look to check. Cutting into the plastic it was obvious this packet was only the vertical shiplap. "Ah, sorry, yes, I will try and find the rest". Unsure of how long it would take I began researching composting toilets and vinyl for the bathroom. After approximately 35 minutes a much larger, much longer packet of timber came around the corner on a forklift. Success? We cut into it again to check, Facia, check. Box corner board, check. Battens, dressed rather than bandsawn. I decided the error, although annoying, would not distract me from leaving with it.

Stropping down the load, I thanked the men who had helped me and slowly drive home to drop it off. By this time, the day was almost over, and, although I had indeed had a huge win, I felt as though all I had done was prod, and question people and sit in a car. To counter this feeling, I examined what the plumbers had done. Whilst I was absent, they had fully plumbed everything extremely cleanly giving life to the frames of the walls. I returned to staining battens, which was a job I needed to do, but relatively less involved than other tasks. A new skill I had learnt the hard way, (never start a complicated or elongated job at five o'clock in the evening). 


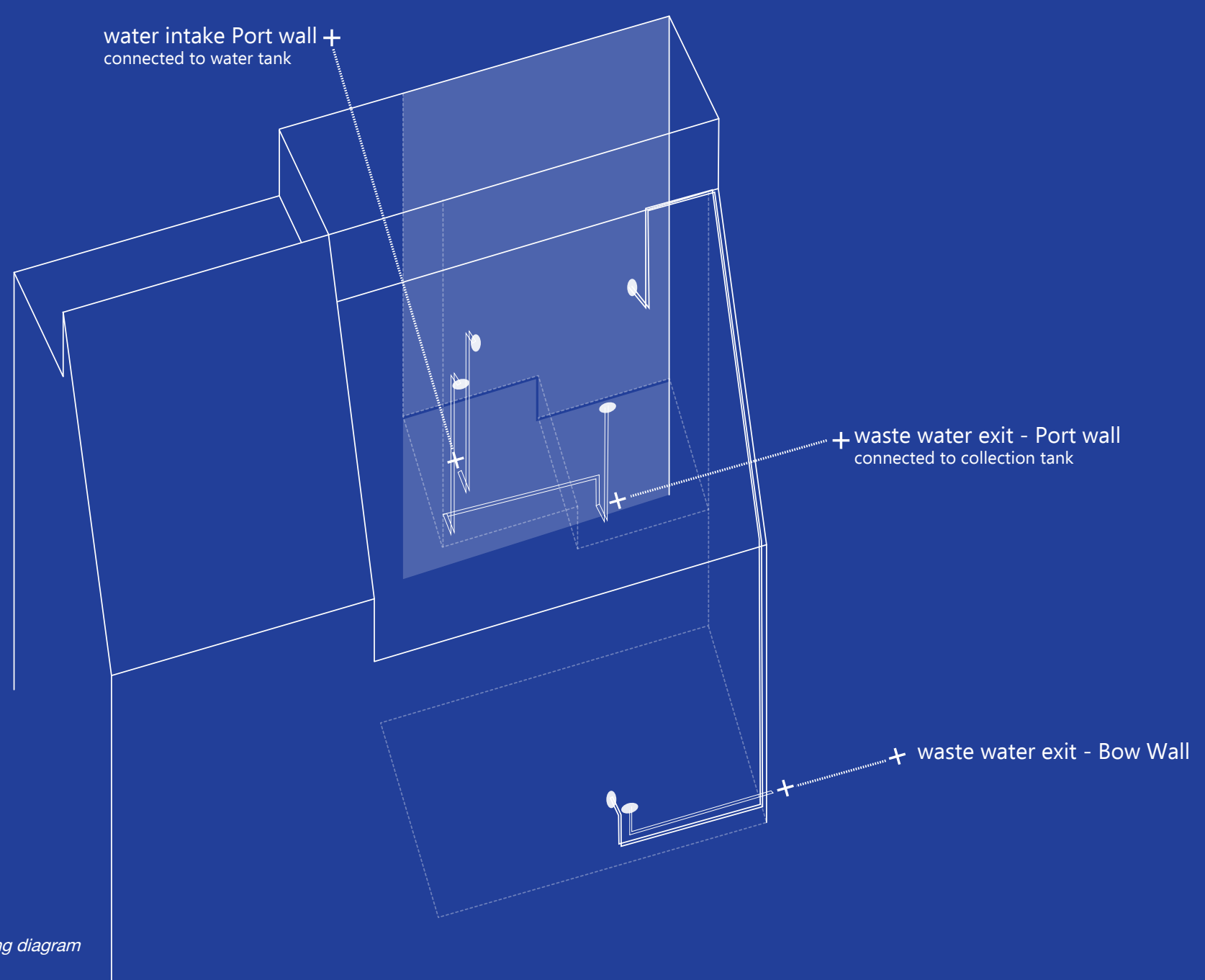




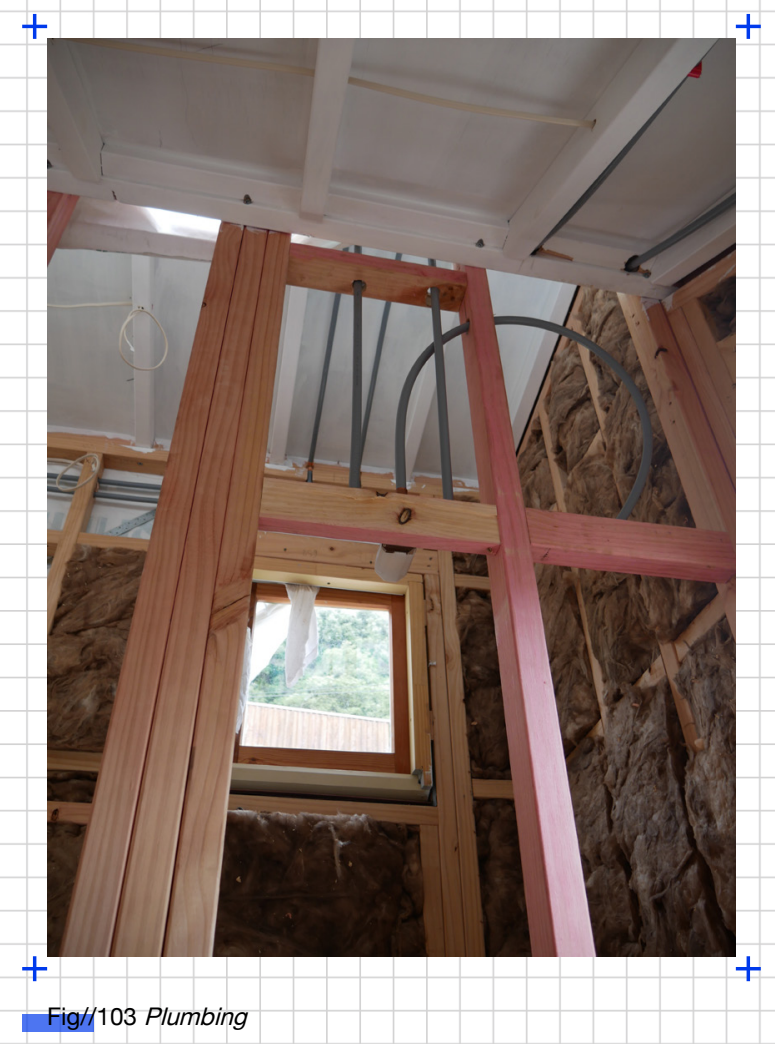

283 


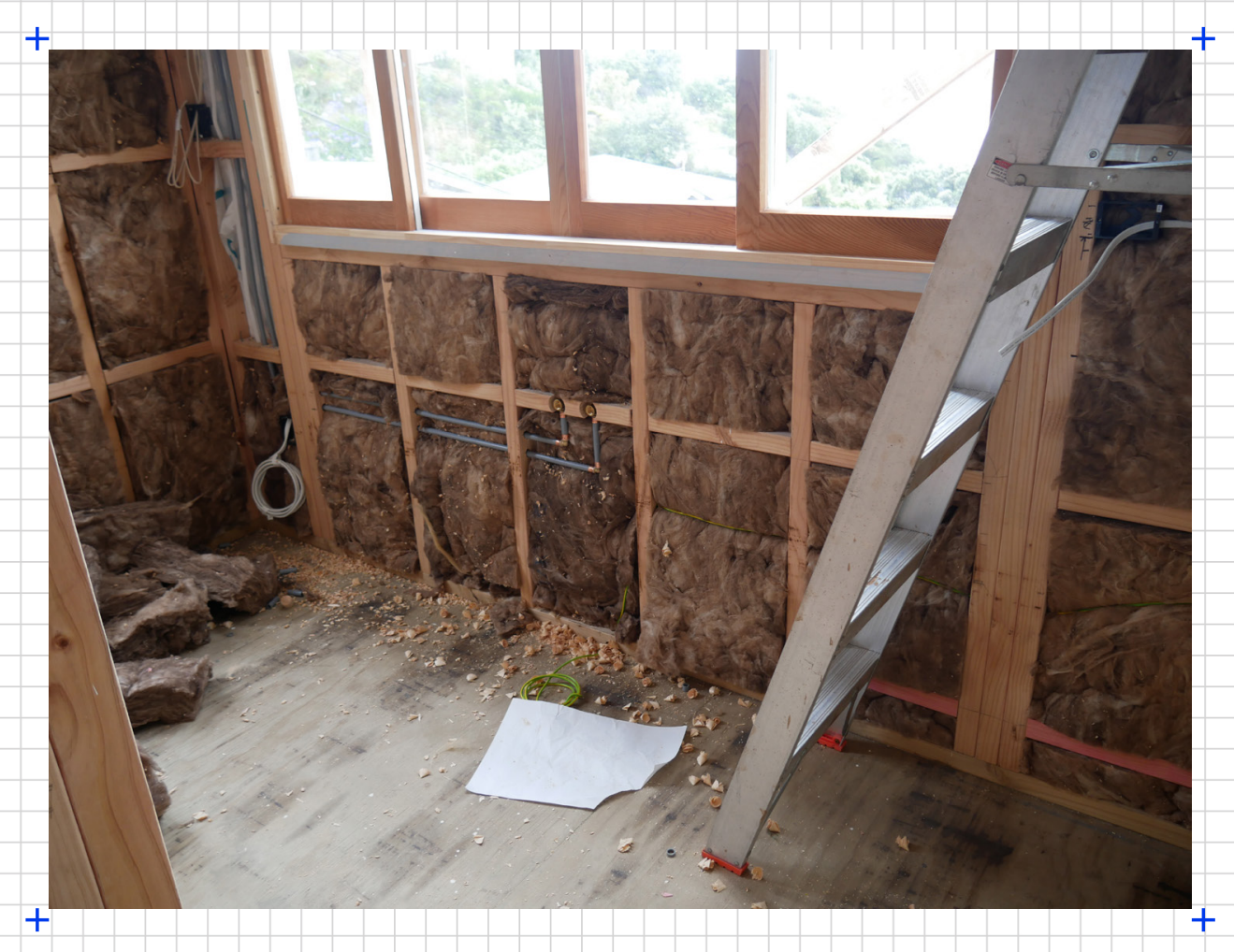




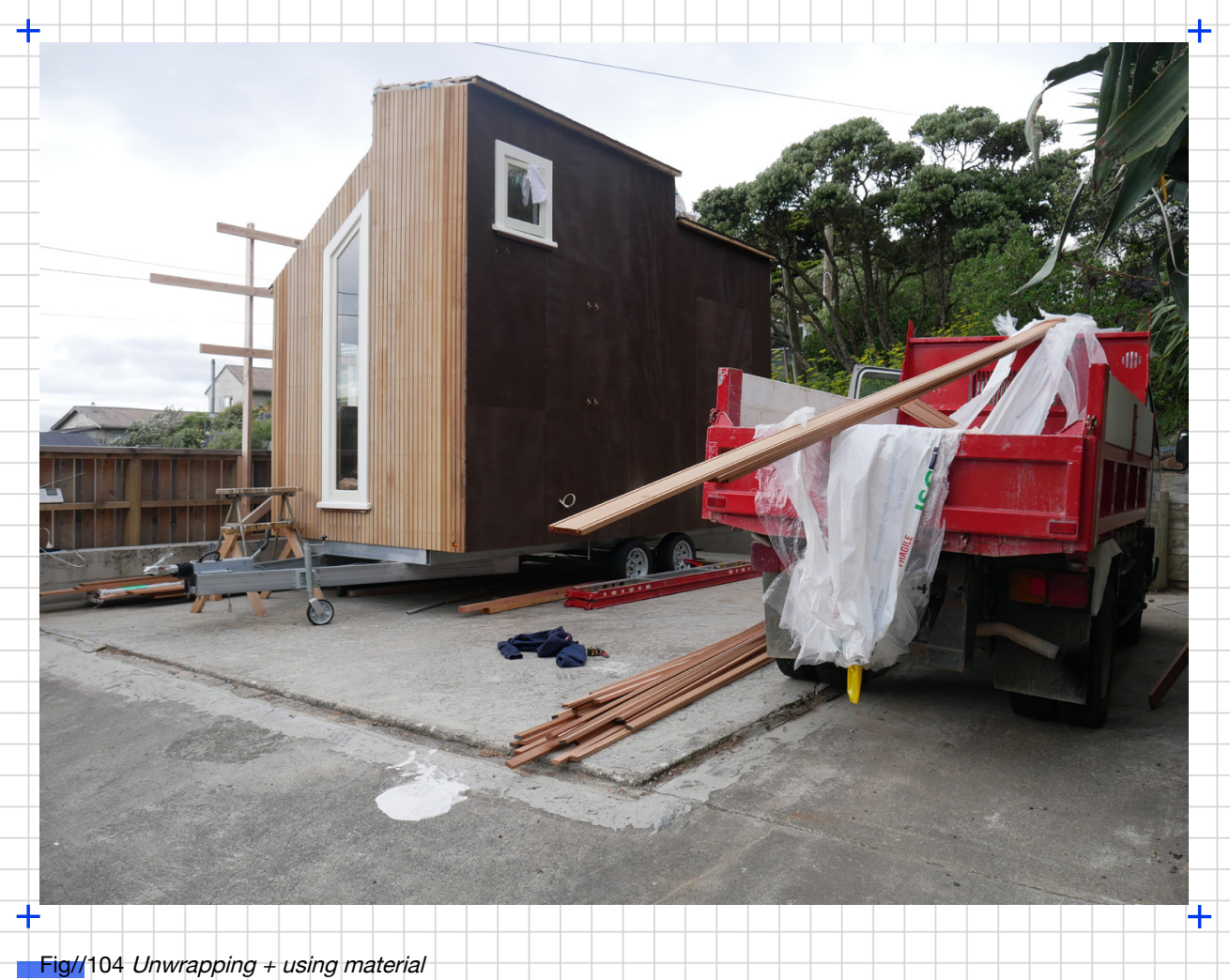




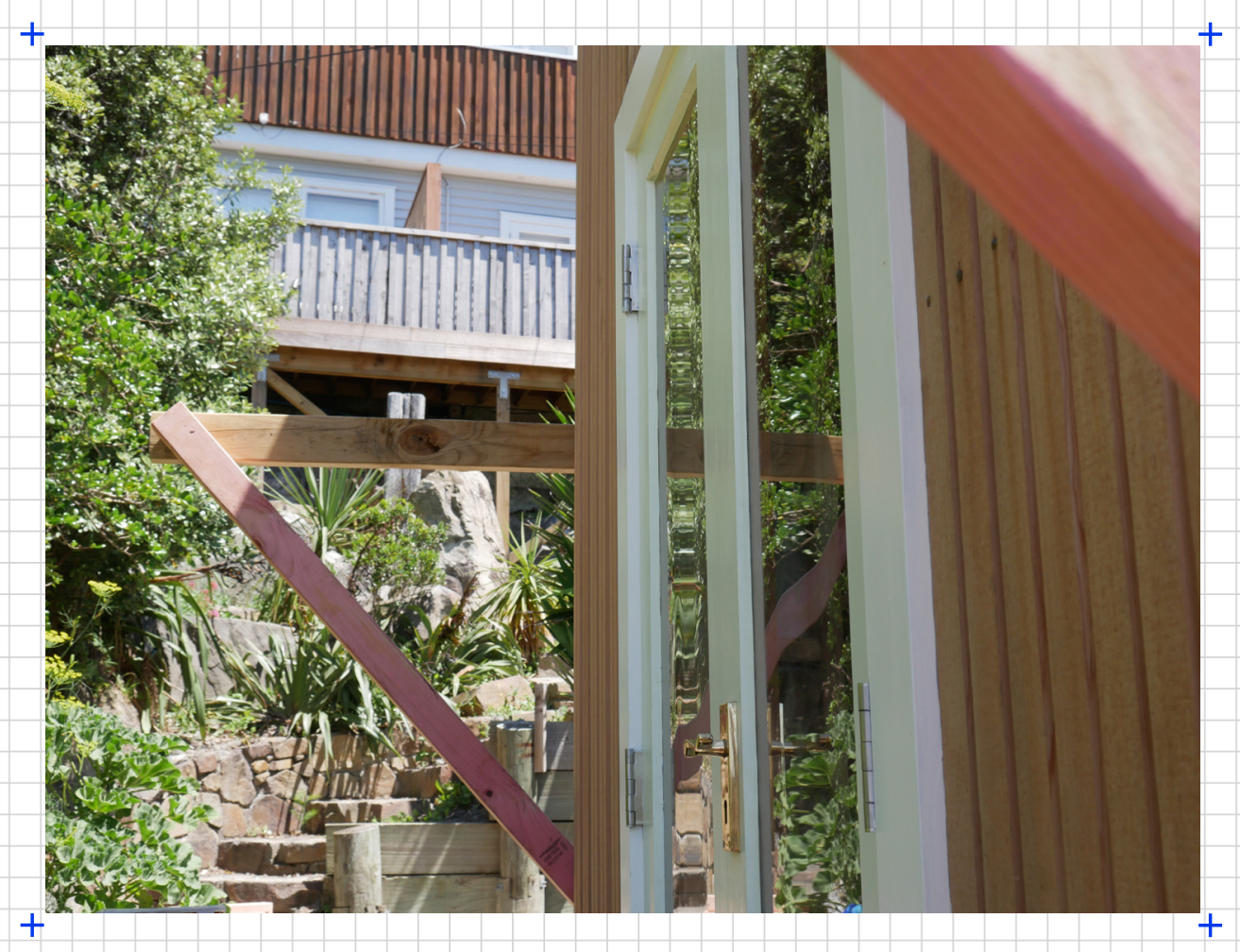




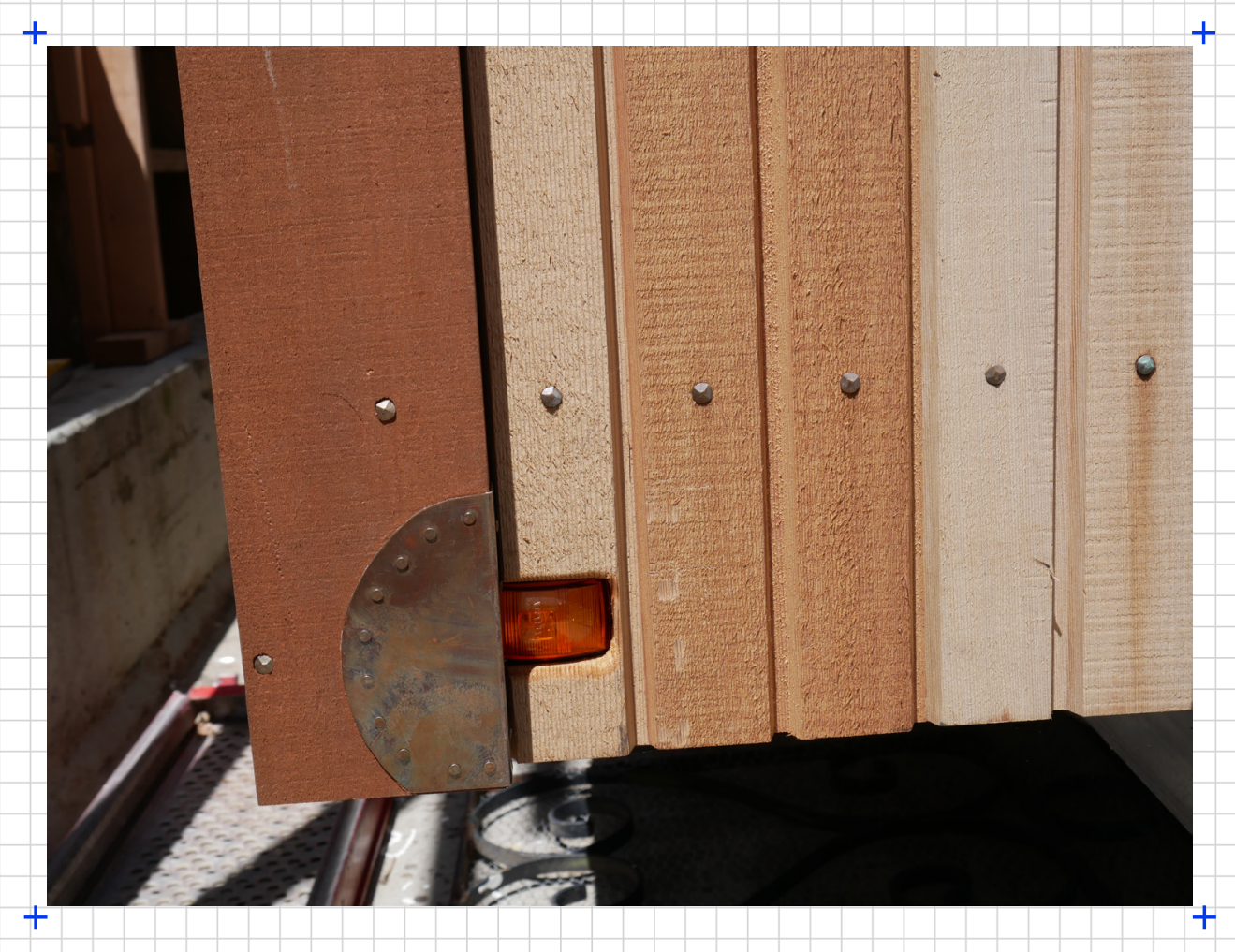

287 


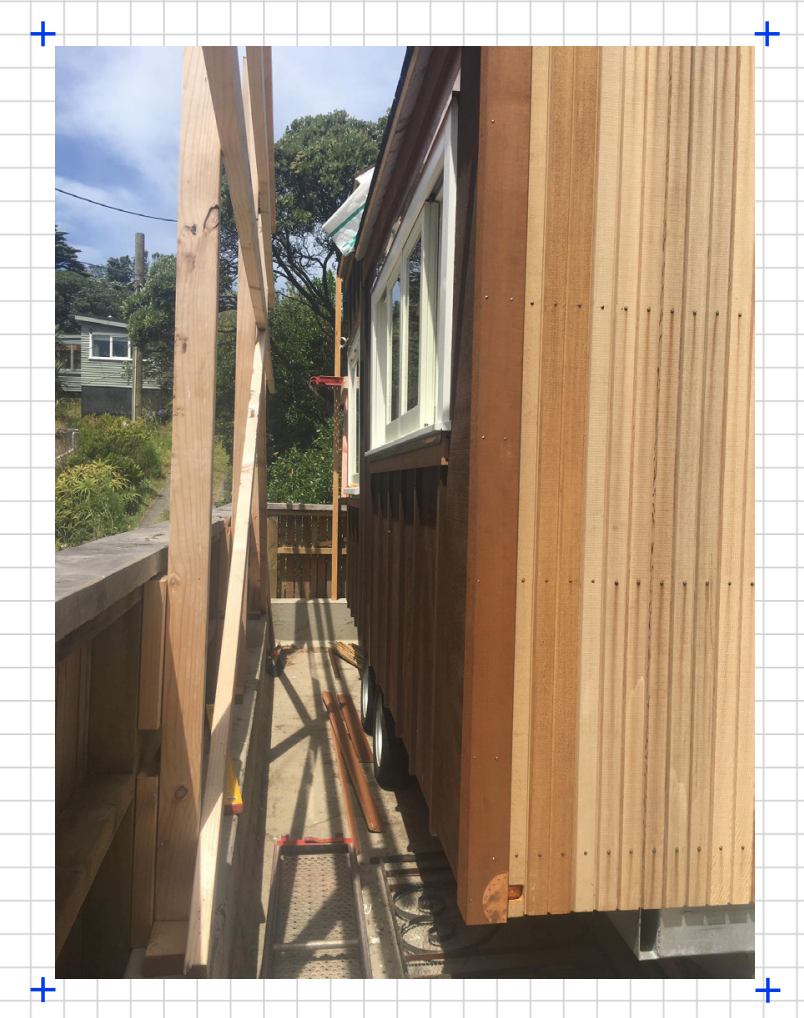




\section{FLASHINGS}

$+$

The week prior, Solomon and I had worked out the flashings we still needed to order. Apron flashings, barge capping and head flashings. I found this overwhelming as I worked through each detail whilst Solomon explained each rule and its corresponding angle, depth or width. However, once ordered, they arrived only a few days before the cedar. Picking them up I was instructed on how to carry the flashings without irreversibly warping them and was surprised at how heavy they were. Or rather, aware of the fact that I had never particularly considered the weight of a flashing. Using snips, we trimmed the flashings to suit each window and door and, similarly to the sill flashings, and secured with clout nails inside and outside.

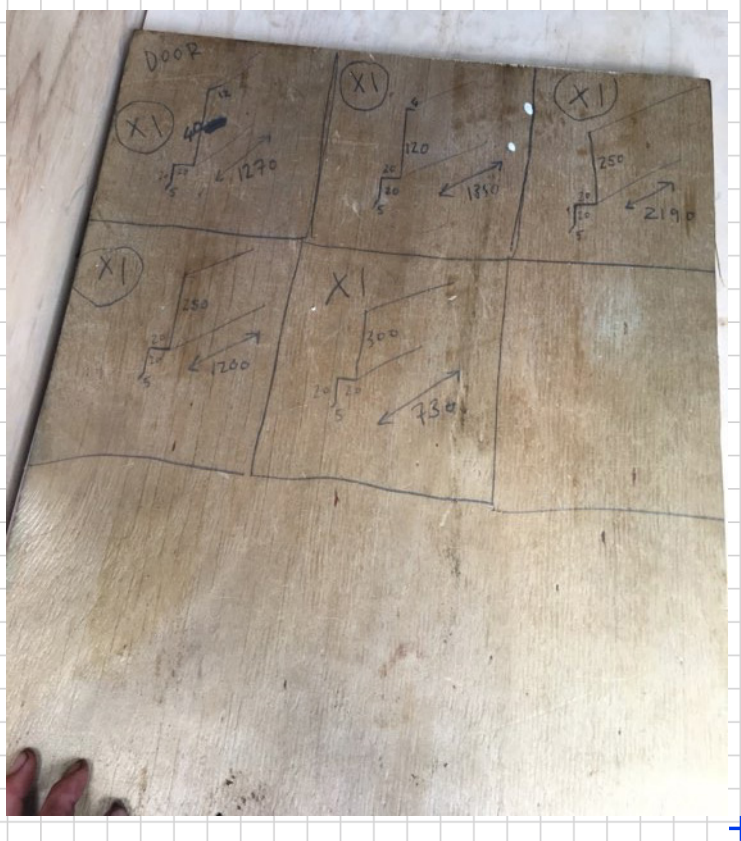




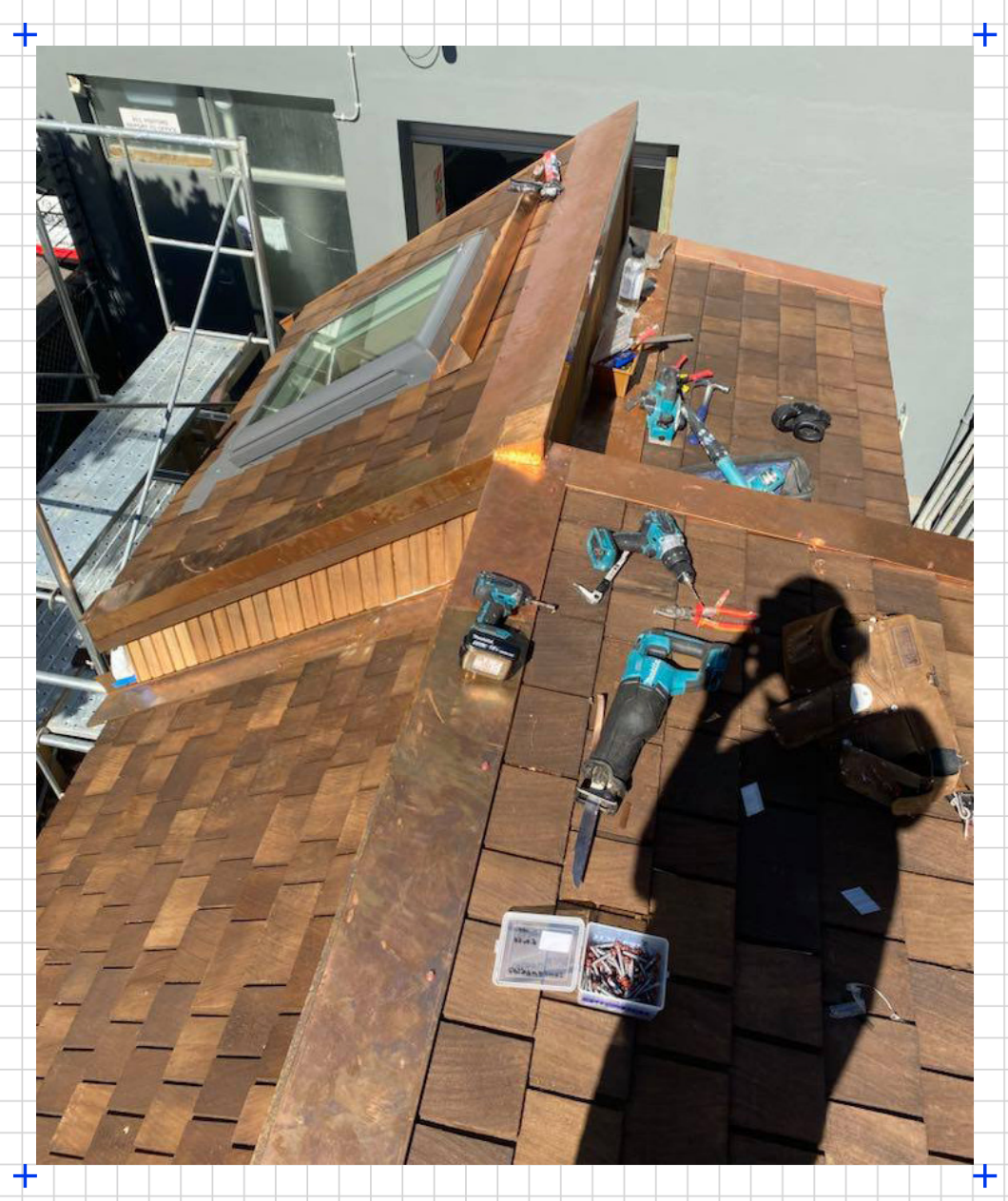




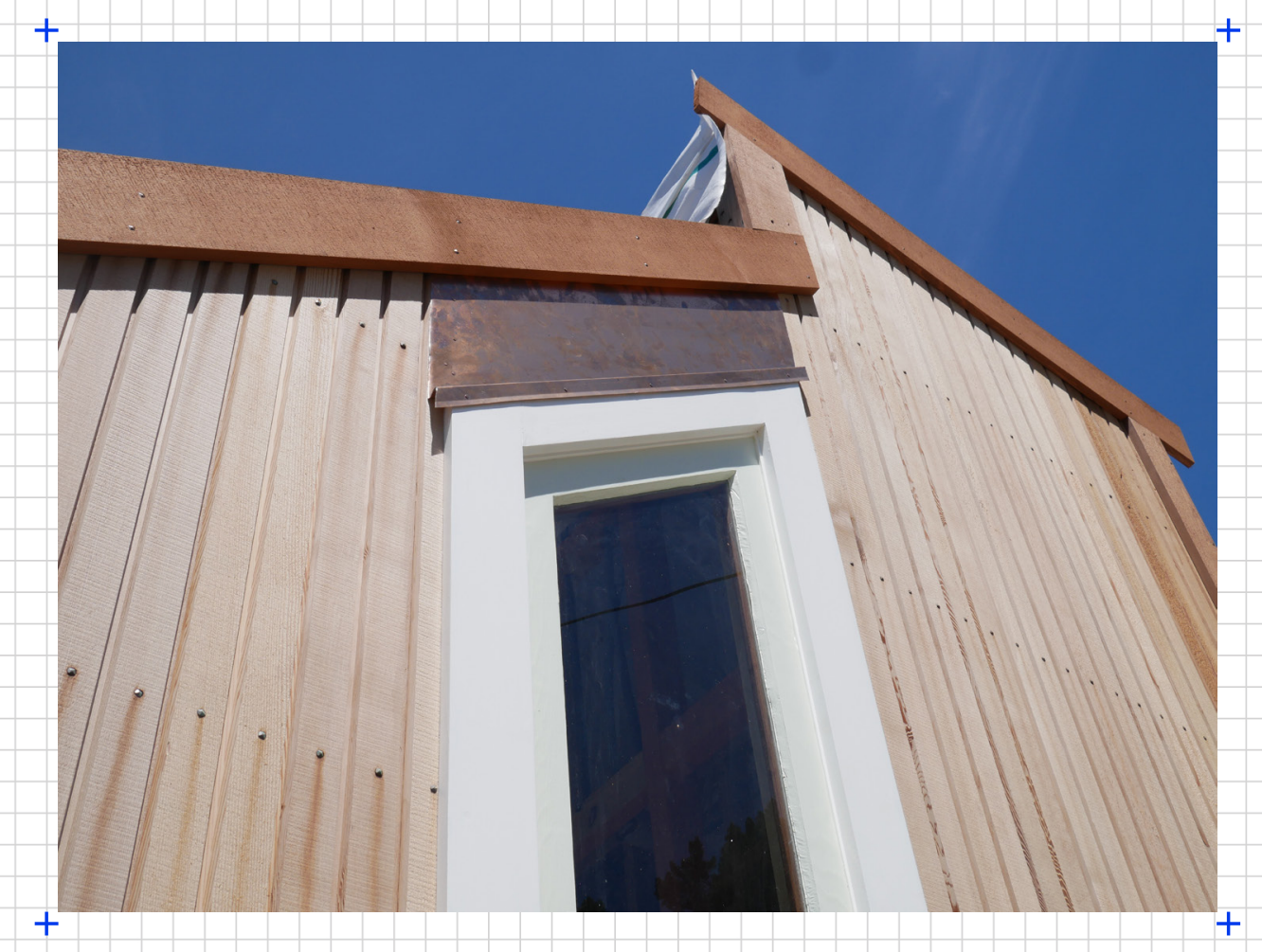

291 


\section{MATERIAL APPLICATION + INSULATION}

With the flashings and staining done, and the flatness of the ply faced Starboard and Port faces beginning to become overwhelmingly imposing, the application of facia and box corner boarding began. I secured the last of the vertical shiplap boards I had not been able to complete almost three months ago. Finally, no builders wrap was exposed and all faces had a relationship with one another. The diversity between the short and longer sides becoming immediately apparent. Lastly the battens were secured with brads before carefully nailing them off every $400 \mathrm{~mm}$ with bronze rose head nails. This allowed not only both faces a depth, but also a verticality similar to the shiplap clad faces.

With the envelope finally complete, the insulation could be installed. Originally, I had discussed using a foam insulation which is slightly lighter than traditional insulation. However, as one of the sparkie's warned, most foam insulation was not fire rated for the kind of wire they used. Therefore, after researching, and weighting up the cost, time and weight of 'fire rated foam board', I decided to browse the local hardware shop to see just how much heavier the insulation would be if I did not order it elsewhere. By chance, I spotted a 'special' board with ceiling and wall insulation rolls made of recycled glass which was only 7.5 kilograms per roll. I quickly approximated the area of insulation I would need and arrived at the conclusion that I would need a maximum of four rolls for the walls and ceiling. Although I had not yet calculated the weight of the structure I knew that the difference between 30 kilograms and 20 kilograms would not hinder the overall weight significantly enough not to buy this. Before leaving, I also bought more staples and a roll of strapping that I would use to secure the insulation in the ceiling.

Knife, measuring tape and metal ruler in hand I was ready to begin. The marble coloured roll felt soft to the touch but quickly became itchy and impossible to wipe off as I progressed. Although time consuming, ultimately the task was straightforward and visually rewarding. I roll out the insulation before slicing through its thickness with the satisfaction of wet sand, into rectangles and squares of varying sizes and slotting them into place. With the offcuts I would slice and squeeze them into awkward places so that every space was filled. 


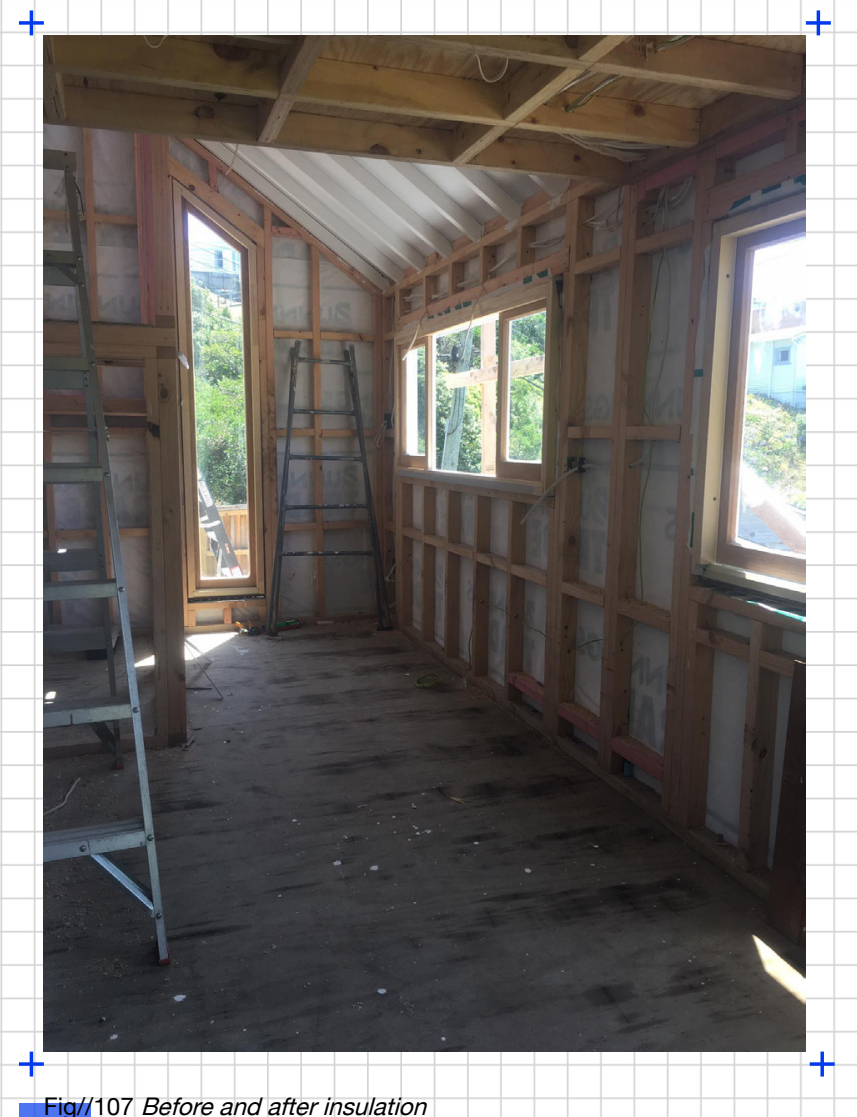

293 


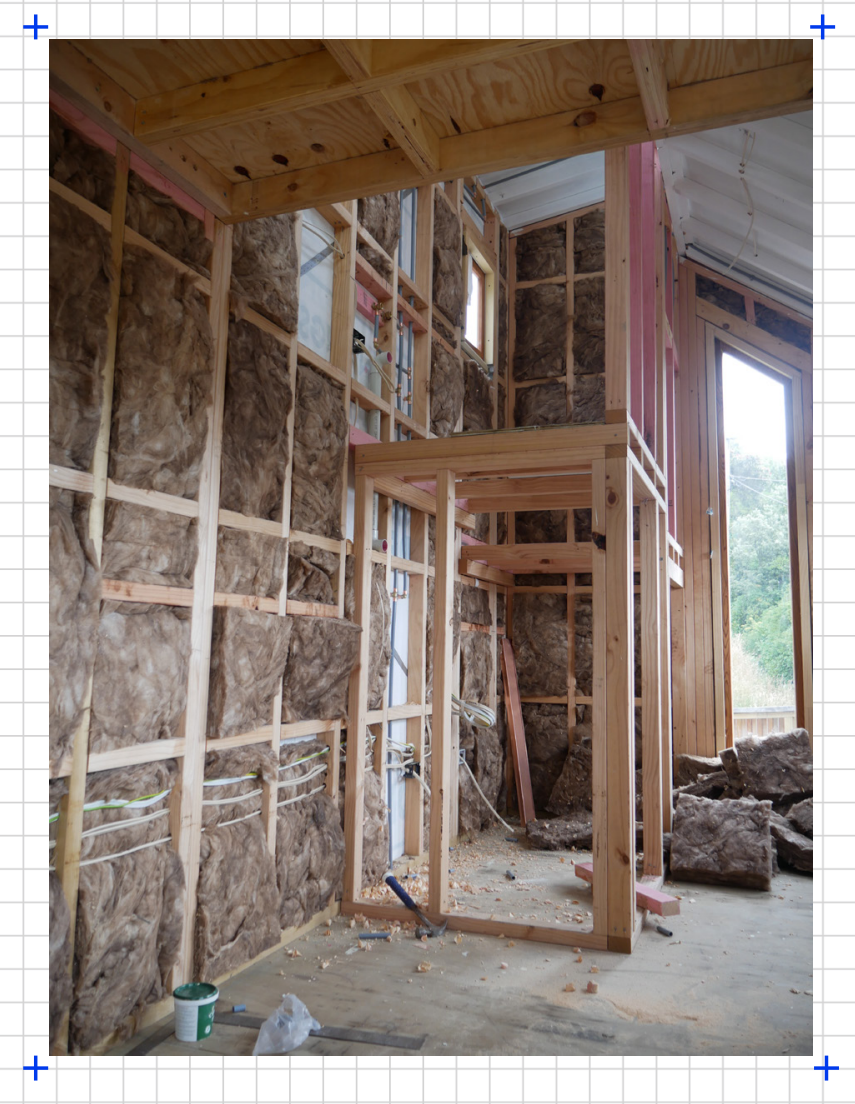




\section{FLESHING OUT}

WEIGHT

To complete (or not complete) the next phase of the build I needed to know how heavy the 'tiny house' was and formulate a method of determining the overall weight of the structure so far. A job I had been putting off. To ensure absolutely everything was calculated I diagrammed the structure and, beginning at the roof, worked my way through until I reached the trailer at the bottom.

I measured all of the various lengths of timber that made up the frame, all the $3 X 2$, LVL etc. I then calculated the areas of the plywood floor, plywood roof and exterior cladding (ensuring I distinguished between $12 \mathrm{~mm}$ plywood, $19 \mathrm{~mm}$ plywood, cedar faced plywood and the shiplap). Next, I measured the facia, box corners and battens as all have differing dimensions. Finally, I measured the flashings before weighing each material to work out its kilogram per meter $(\mathrm{kg} / \mathrm{m})$ or $\mathrm{kilogram}$ per square meter $(\mathrm{kg} / \mathrm{sqm})$. Other aspects of the structure such as the insulation, shingles, skylight, joinery and trailer I worked out previously. Once all the weights were noted, all I had to do was multiply each material's lineal or square meterage by its $\mathrm{kg} / \mathrm{m}$ or $\mathrm{kg} / \mathrm{sqm}$. Although this process indeed took the good part of a day, in short, the final calculation came to ap-

proximately 1791.56 kilograms. Which, although for many calculations I in fact rounded up, allows the structure to be well within the 3.5 tonne restriction. Calculating this not only helped me sleep that night, as I had been told by a few people that it would never be light enough using a timber frame, but also allowed me to progress with plans for lining and moving the dwelling. The added stress the weigh of a movable structure carries, bears no issue within traditional architecture. The ground is stable, the foundations carry that weight, however essentially the 'tiny house' structure is left to fend for itself and hold itself up. 


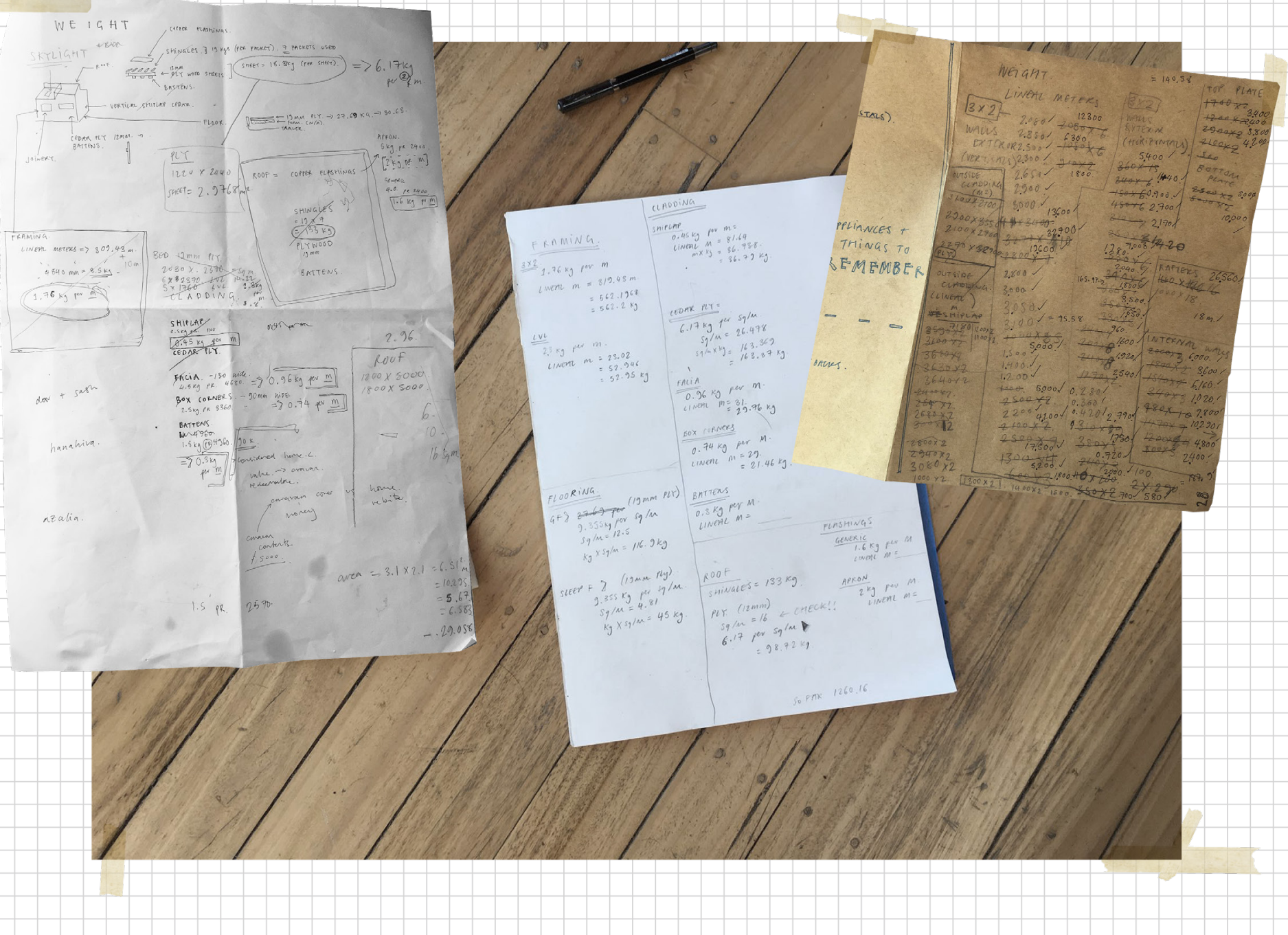




\section{MOVING DAY}

With small sections on the roof needing to be touched up and a few additions to make in places we could not reach, we decided to move the structure before its final completion. A generous friend Niall suggested we moved it to his workshop in town and suggested we use his Ute to do it. The following day we (Solomon, Niall and I) assembled on site and began working out a strategy for driving it off. Confident that the trailer would not break under the weight, because of my previous calculations, the main issue was the angle at which the structure would be at when driving onto the road.

Because of this we decided it would need some kind of ramp to level it, enabling a straighter drive up the hill and into town. Somewhat concerned with the whole structure tipping downhill and colliding with the road, I began to empty the structure of everything not screwed, nailed or bolted down, whilst Solomon and Niall bought framing and thick plywood. We then framed out a ramp which essentially substituted the severely steep angle of the car-port floor for a moderate angle that would decrease the angle at which the structure would be taken off at. The frame of the ramp was then bolted into the concrete of the road and carport to ensure it did not twist and fall away under the pressure of the weight.

After screwing down the sheets of plywood and feeling a confident as we could, we began to shift the trailer by hand into position (it was on the far-left hand side of the car-port whereas for a straight line it had to be on the right). Once in position we devised a plan, "okay so l'll stop traffic and then follow you guys to the workshop?" I suggested. "Can I drive!?" Niall piped up, which of course Solomon and I agreed to because not only was it his Ute, there was no way we wanted to be in charge of that. Without anything else to talk about it was time to attempt this terrifying undertaking. "If this works, dinners on me" I said, feeling as though this ten-month process could all be over in less than ten seconds. "If this works? You mean when this works" Niall said with the confidence I could not find. Till wrote that "... the metaphor of architecture as a stable authority is powerful, as to make one believe that it is also the reality of architecture" ${ }^{165}$. But at this moment, there was no chance of believing that metaphor.

In position, Niall in the driver's seat, Solomon behind the trailer, and I on the road, we proceeded, very slowly to move the trailer. From my vantage point I could quite clearly see the angle at which the structure was at and, although indeed it was not flat, I could have been worse. Slowly and with much effort and noise from the Ute, the structure began to be pulled off the car-port and up the road.

I couldn't believe it had worked. 


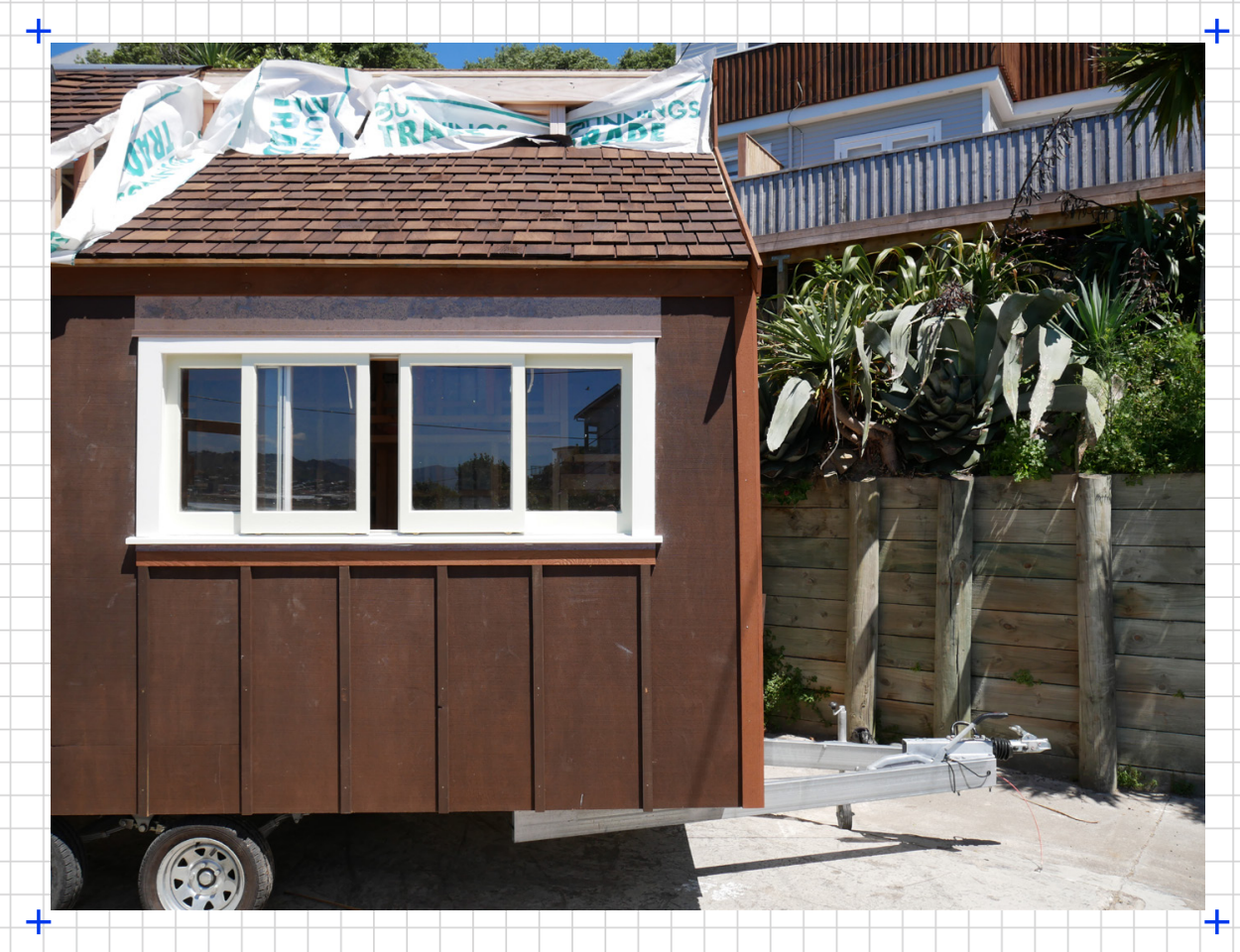



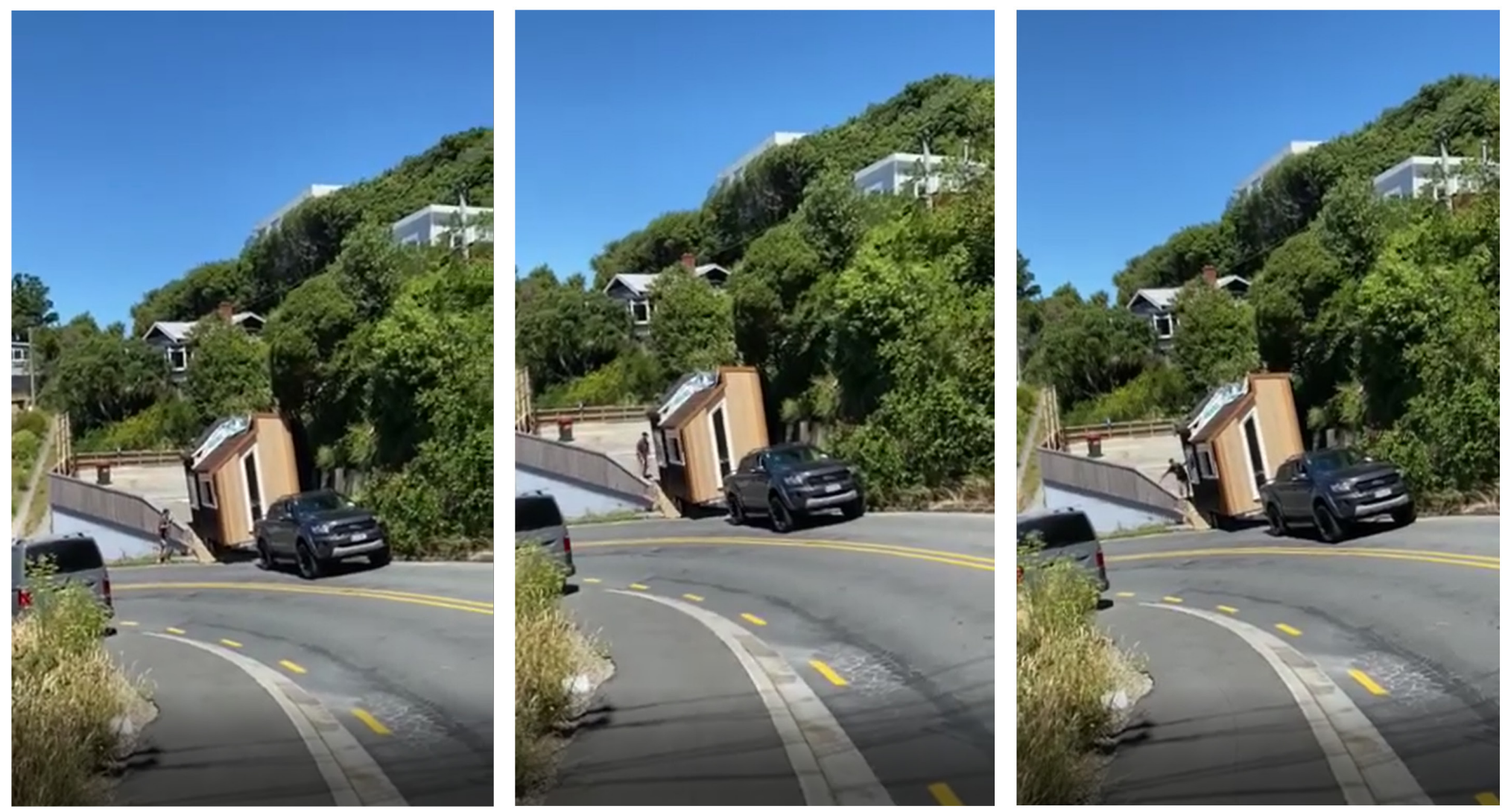

299 

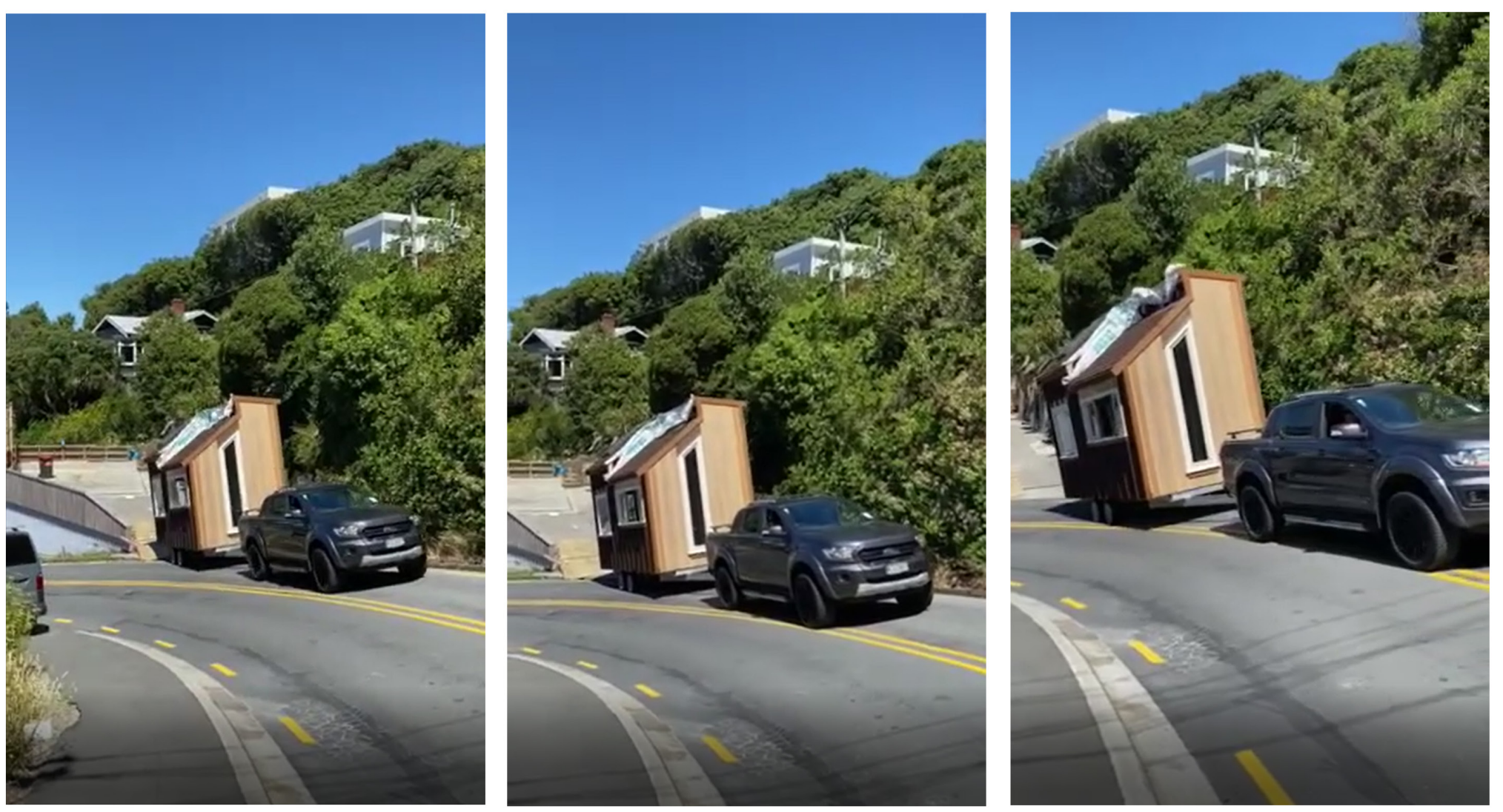


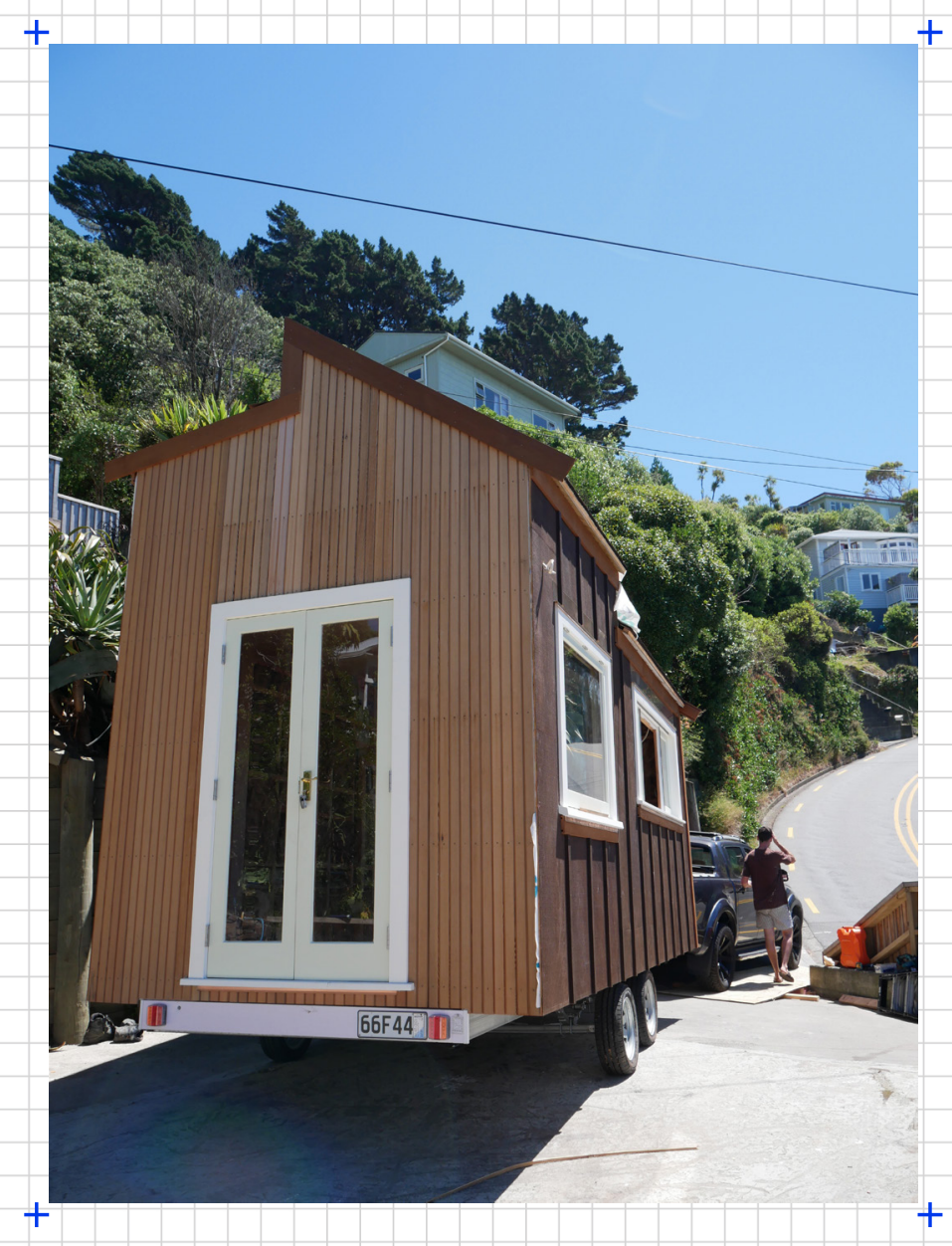




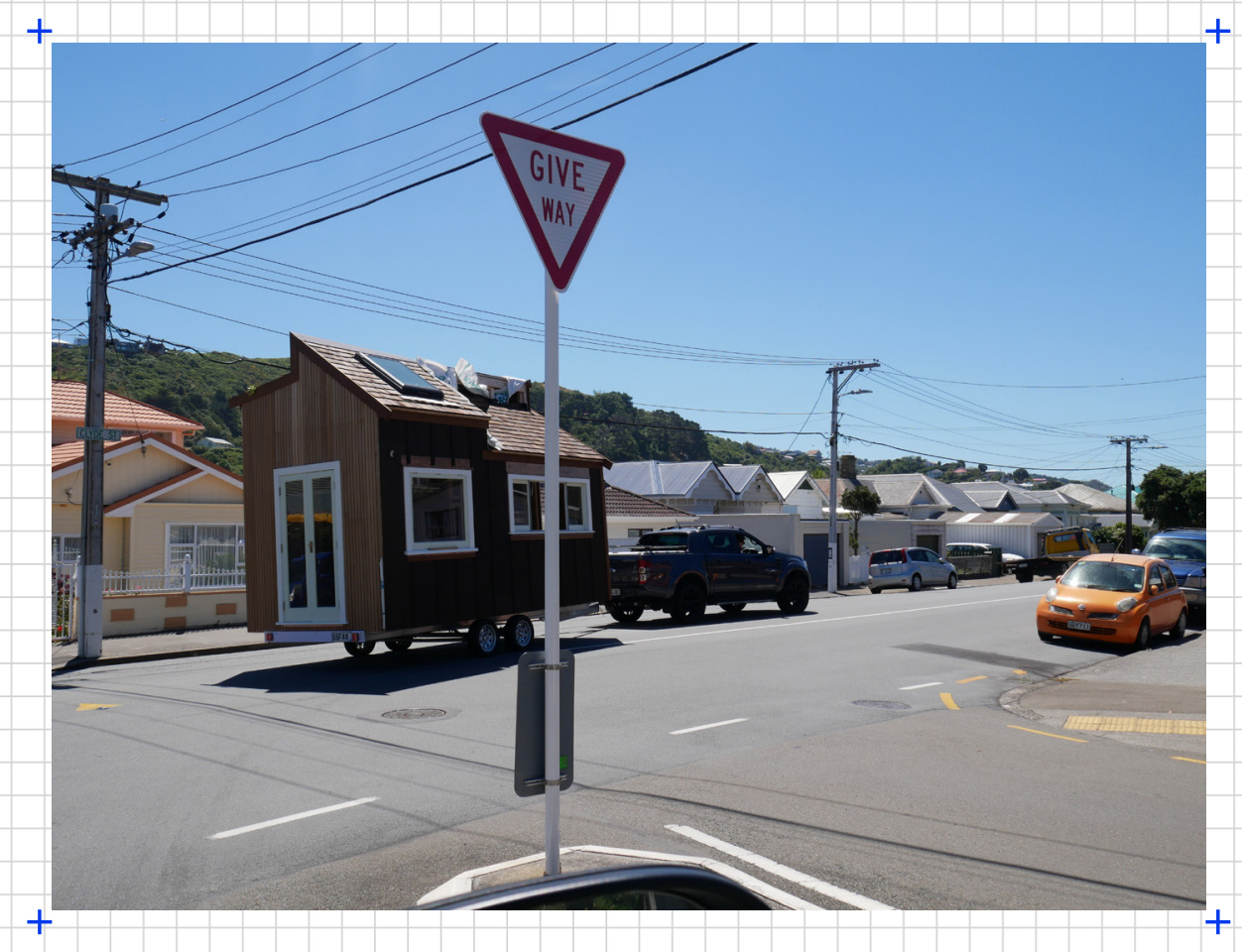




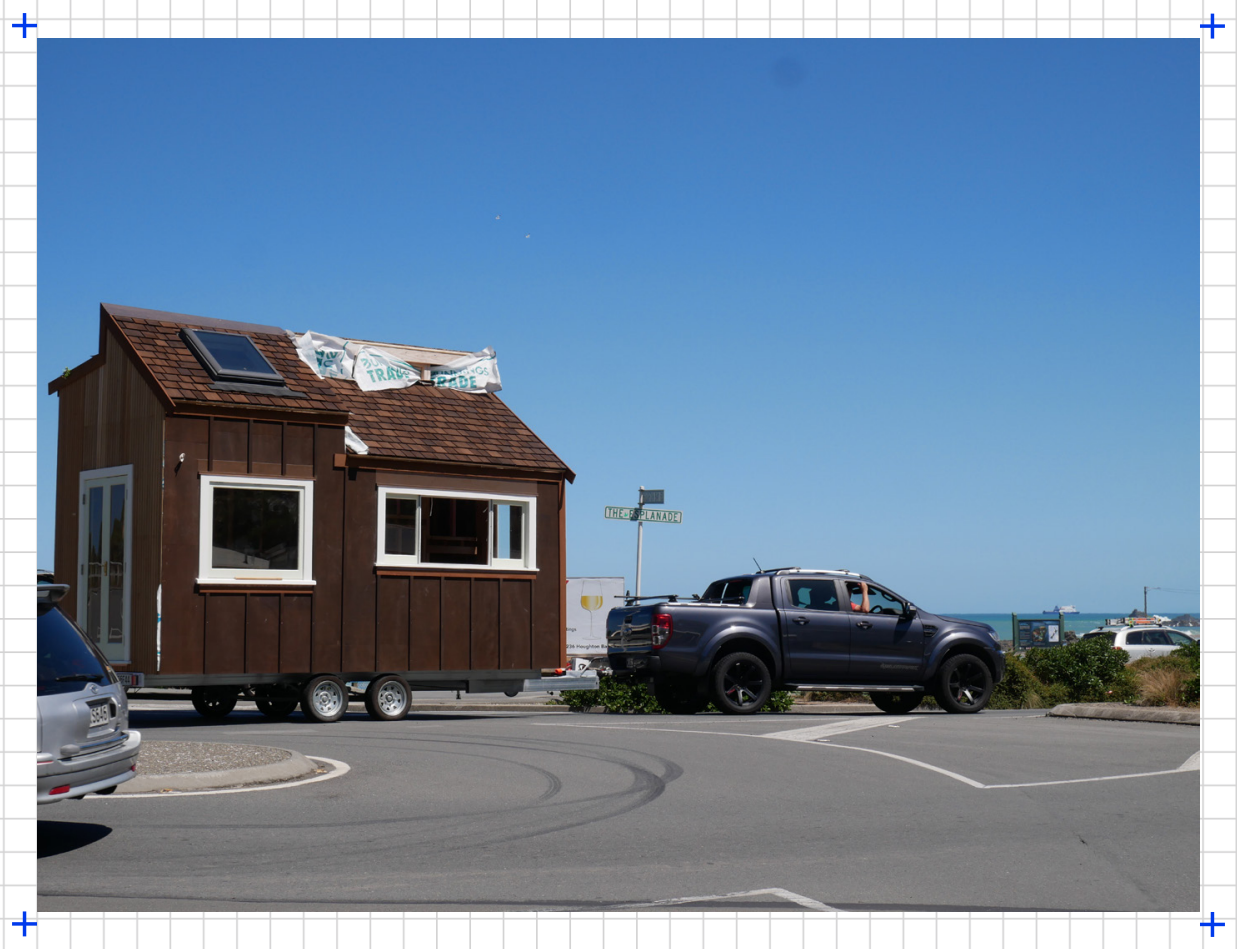

303 


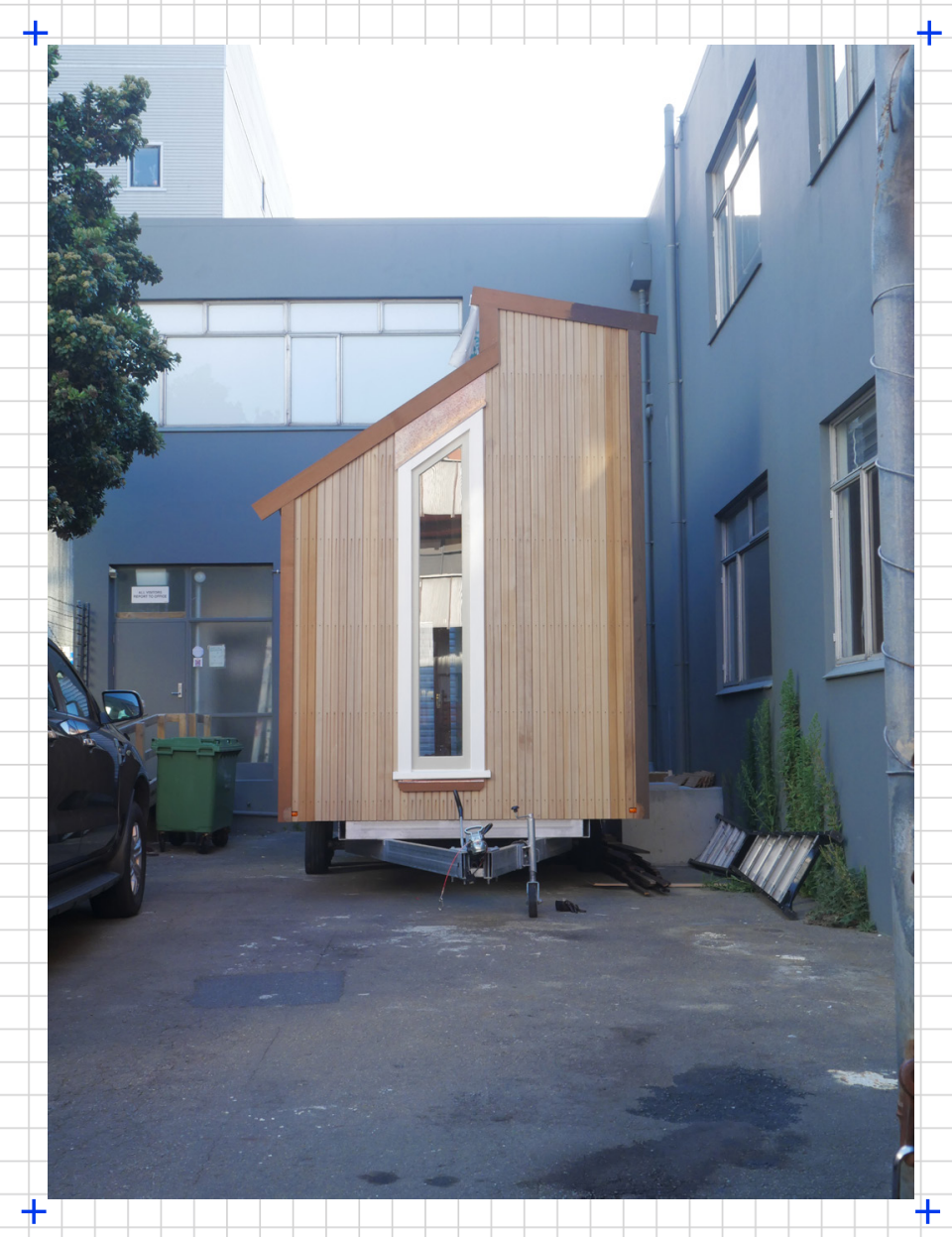




\section{CONCLUSION}

Concluding 'On Adams House in Paradise' Joseph Rykwert wrote:

"....in the present rethinking of why we build and what we build for, the primitive hut will, I suggest, retain its validity as a reminder of the original and therefore essential meaning of all building for people: that is, of architecture" 166 .

The primitive hut carries with its memory the fundamental notion of people. Built architecture is for people. Throughout this research my fundamental concern and thus experience has been attributed with the primal needs of people in all senses.

The 'tiny house' /small-scale architecture blurs the line between object and architecture. It could be argued these elements of architectural language occupy a different realm to that of architectural space, an 'anti-architecture', or that they disregard the role of the architect. However, the 'tiny house' addresses all the same issues as architecture. Although not physical, the 'tiny house' maintains the ability to ground the user and relate to site, it is simply a transient, or changeable relation. I believe the 'tiny house' offers an mode of considering architecture that

This thesis has aimed simply to explore what by own body can do and what knowledge (architectural or other) this develops. Although perhaps unconventional, the act of learning by making allowed real time decisions to be made and alternative routes of problem solving and finding to be sought. The ability to do this consequently allowed me to develop fundamentally unpredictable solutions. Although this process was not smooth (in all senses of the word), the encountered imperfections allowed me as a maker/designer to gain a direct experience and consequentially, knowledge of that particular task/decision/sequence. Similar to the concept of 'prehension' discussed earlier, the process, rather than

linear was circular and thus reflective ${ }^{167}$. The development of this process would enable the establishment a sequence 
Letting go of control is something which arguably architects do not do often. However, in conducting this research, I was in a constant state of uncontrollable control. Perhaps unintentionally conceived as organised chaos? The build itself once physically visible, was able to evolve and divulge from my preconceived notions of the project; simply framing up allowed a different perspective and consequential different opinion of the architecture to be posed. To look at something outside of one's head at a scale of 1:1 is something I found not only empowering, but also exceptionally conducive for further design work in the sense that both unknown problems and solutions could arise. For example, the ability to stand within the kitchen and consider the roof angle, before reducing it enabled an omittance of preconception. Problems could be solved impartially.

I found through the development of my own hands' movement, a greater knowledge and understanding of architecture was developed. Not simply how to build a building, but fundamentally I was able to consider the architecture.

Recognise the weight of material, the implication of $10 \mathrm{~mm}$ and $5 \mathrm{~mm}$, acknowledge the very real aspect of space, the list continues ${ }^{48}$. This experience I believe can be found not solely in building a building, but through an experiential understanding of craft. This could be through sculpture, painting, pottery etc. it is simply the ability to have a tactile relationship within making. In conclusion the ability that physical making allows in gaining tactile knowledge and understanding has a multitude of benefits within architectural practice. Rykwert said "... a "primitive" who's humble ways, whose daily contact with the soil, with animals, guaranteed him a more instinctive, a "truer" view of things" 49 . It is this acknowledgement which I believe architecture can embrace further. 
$B_{p} H_{11} I_{n \in w}{ }_{w} T$

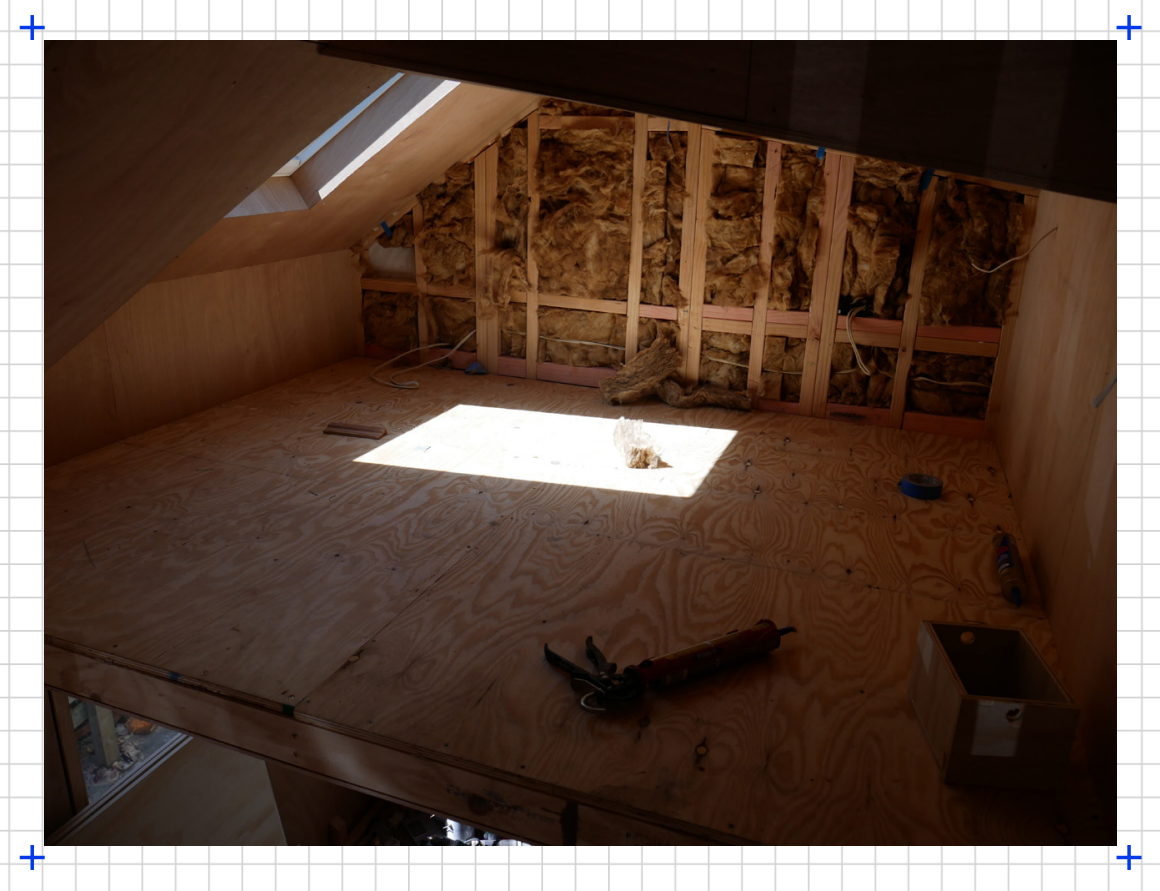

307 


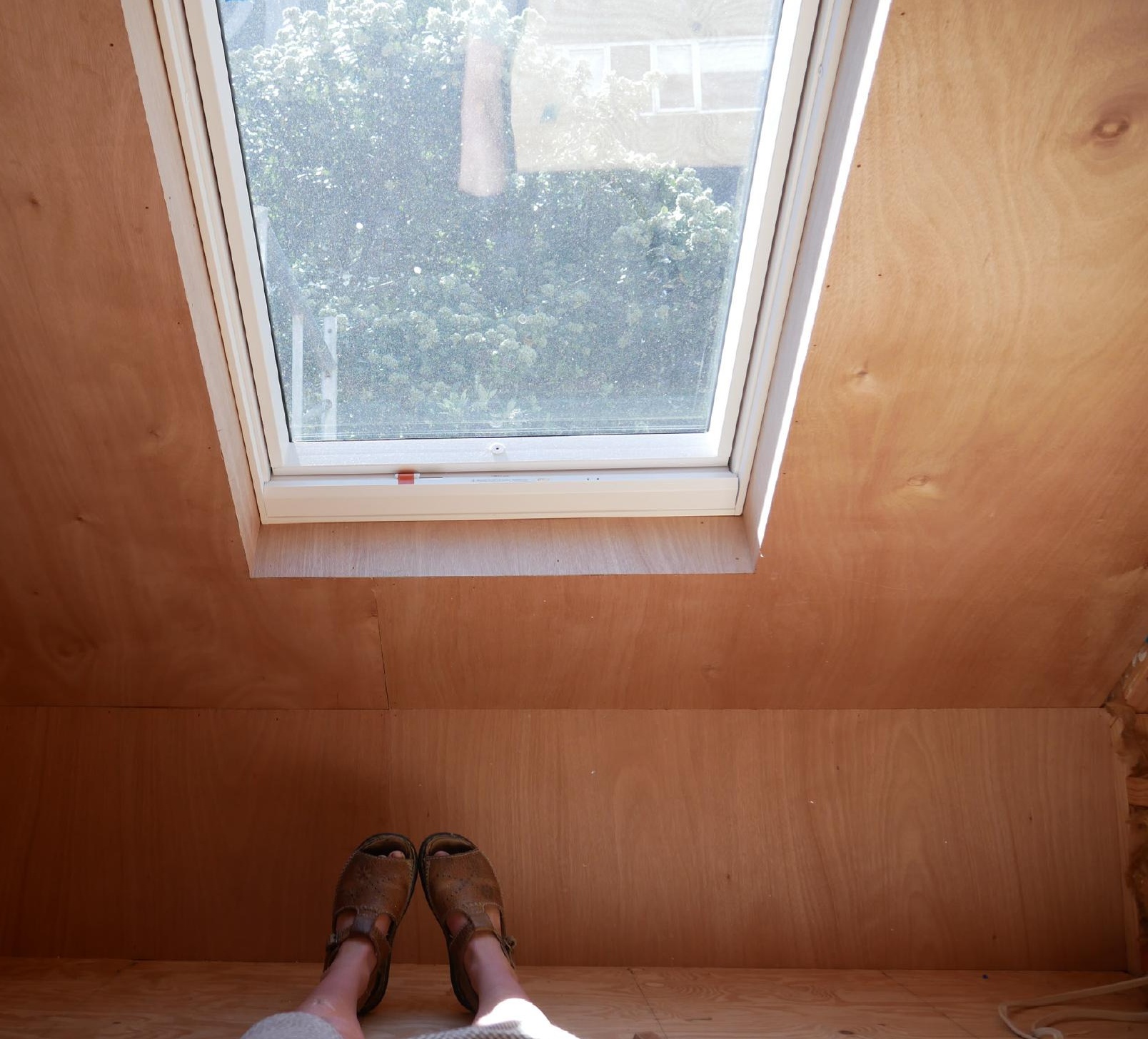




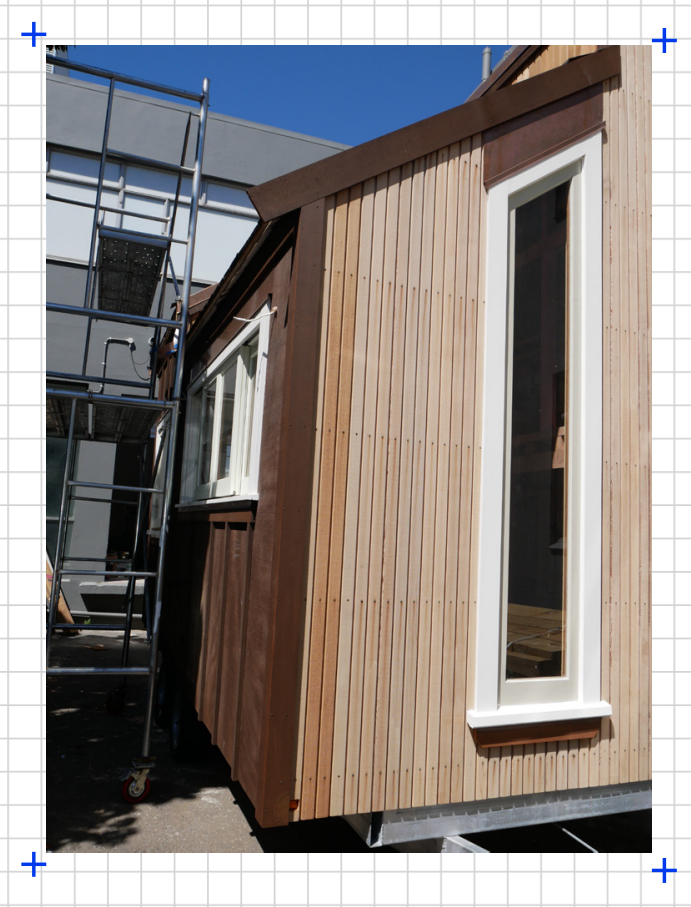




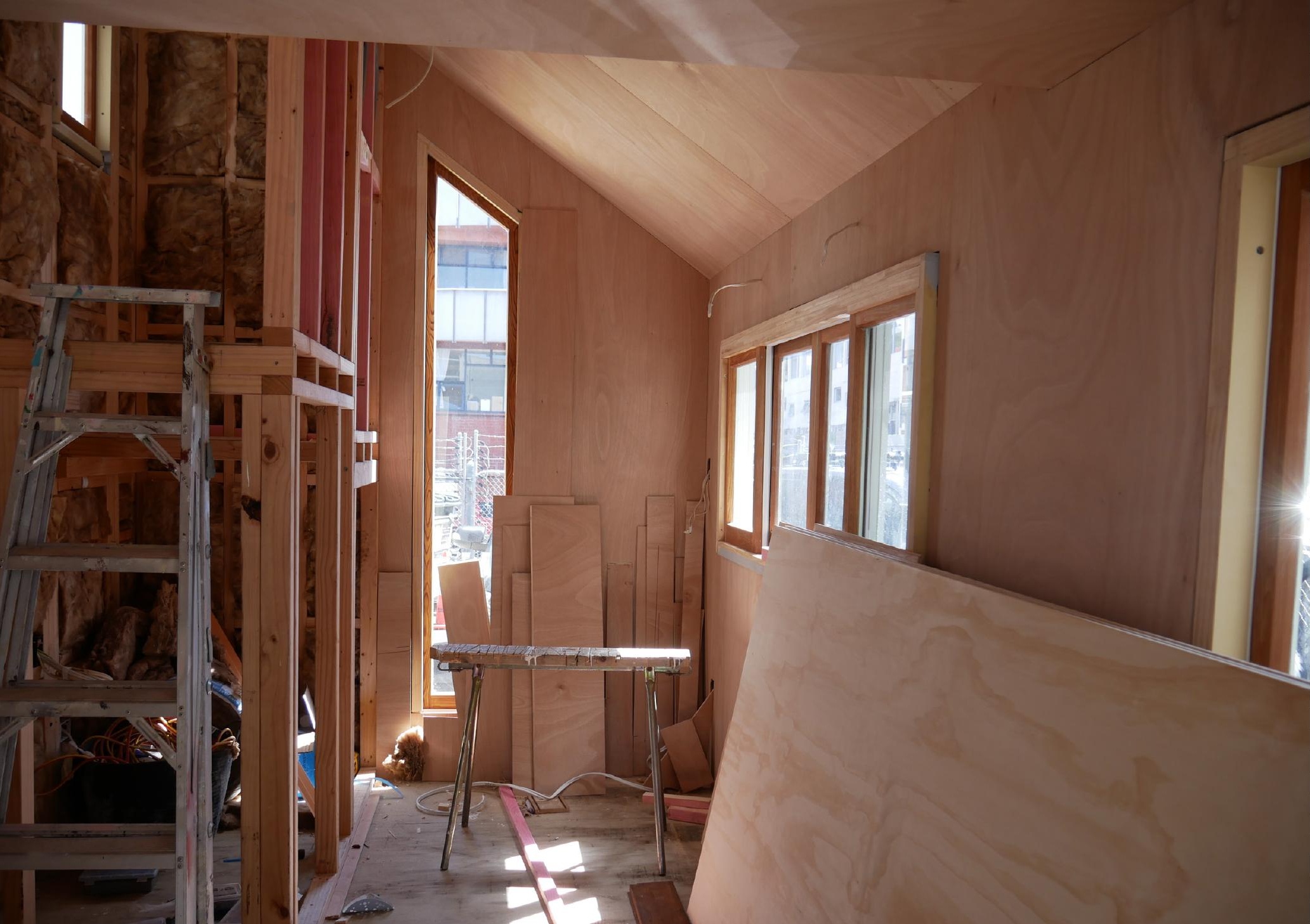




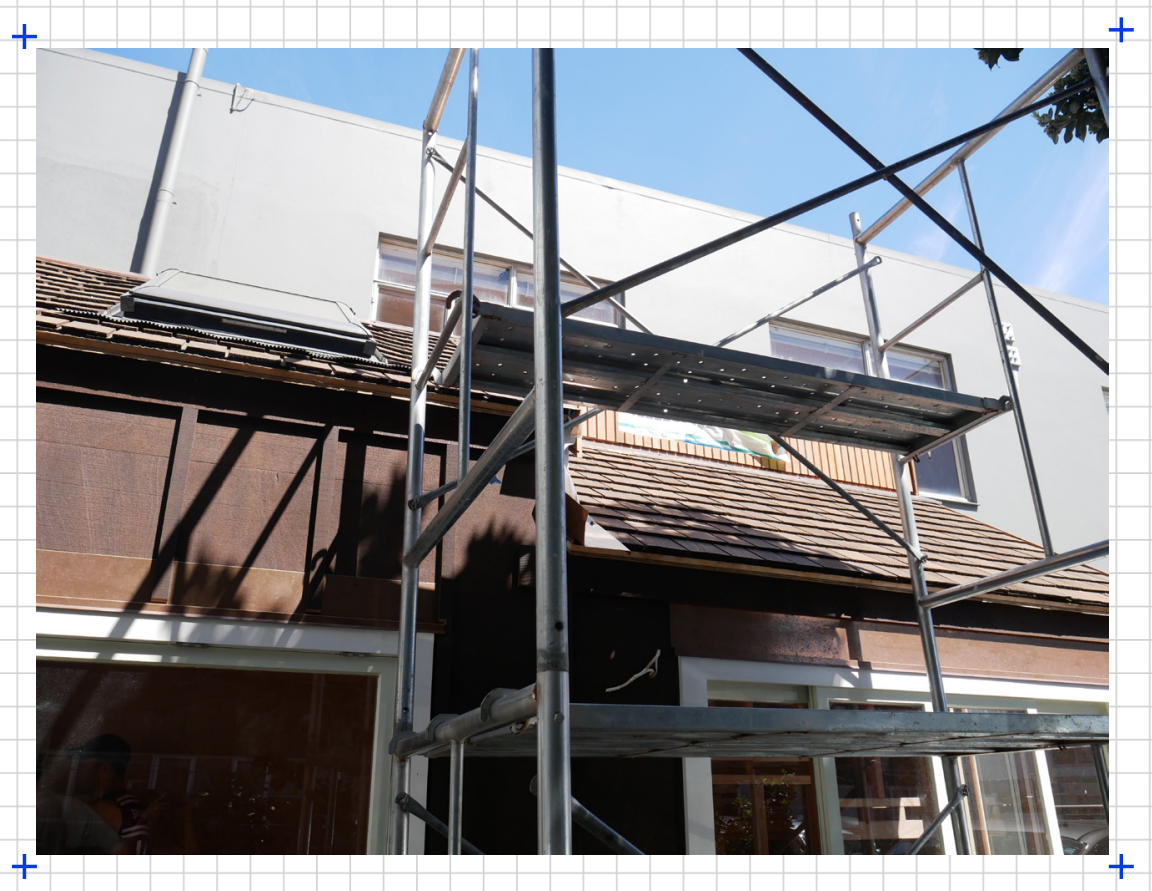




\section{THINGS I LEARNT}

bEING BODT TIRED BECAUSE of MANUAL LABOUR is REWARDING

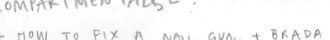

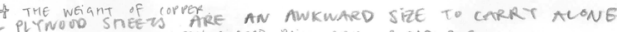

+ PLYNONO STEE TS ARE AN AWKWARD SizE TO CORE

+ AIM FOR THE NAIL! + GET A RHYTHM. - TIMEER (BY HAND OR

+SATISFYING DRIVING gOMM NAIL INTO TIMBER (BY MAND OR
A TIMBER GRADING.
NAIL GUN).

LABOUR TAKES TIME

- WMEN PUTAING IN DWANGS - SKEW \& NAILS INTO THE BOTTOM +

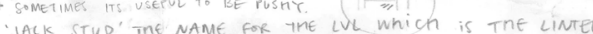

+ DRILL BITS

rov AKE PKIULING ThPOLEG

THE SAFE WAY TO RIP A PRICE OF $4 \times 2$ TO $3 \times 2$

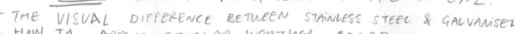

DO - IT WILL MAKE

TART WITh SOMETRING YOU KN OW MOW TO DO - IT WILL MAKE

HOW TO FLASH A OF THE OTHER GETS THMINGS DONE

MPLEX WHEN YOU TRY TO BUILO THEM

LWATS BE AWARE OF WHAT NEWLO GO GR. WRONG TO REOULE

SOME DEcisions TAKE TIME BUT SOME Sroved NOT.

+CUTtina straiaht is EASSER SAID TMAN DONE.

VISUM PROGRESS IS AN ELIXIR.

WEAR GLOUES WHILE HADDELLIN

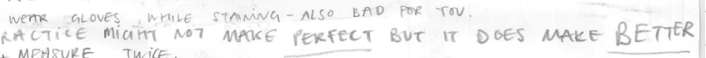

+ AWWATS LoAve LOTS of TIME.

+ Never measure tha multiple thinas at once on the same

PEICE OF TIMBER - THE PROY SAW ALWAYS STERLS GOME MM.

313 
+ BEING BODY TIRED BECAUSE of MANUAL LABOUR IS REWARDING + compartmentalse.

* HOW TO FIX A NAIL GVN + BRADA

t THE WGIGHT of coPPERE AN AWKWARD SIZE TO CARRT ALONE.

* PL TNU OD STEE

+ AIM FOR THE NAIL! + GET A RHTTHM.

+ SATISFTING DRIVING gOMM NAIL INTO TIMBER (BT MAND OR \# TIMBER GRADING. NAIL GUN)

t LABOUR TAKES TIME

+ WMEN PUTTING IN DWANGS-SKEW 3 NAILS INTO THE BOTTOM + * SOMETIMES ITS USETUL TO BE PUSHY \& $\mid \frac{1}{\mid}$

+ 'JACK STUD' TIE NAME FOR tME LUL which is tME LINTEL

+ PRILL BITS!! tMERE aRE PIFFERENT PRIUL bITS DEPENDING oN WMAT YOV ARE DRIULING TRPOUGA.

+ THE SAFE WAY TO RIP A PEICE OF $4 \times 2$ TO $3 \times 2$

+ THE VISUAL DIfFERENCE BETUEEN STAMUESS STEEL \& GALVAMISED.

+ HOW TO APPLY SMIPLAP WEATHER BOARD

+ START WITH SOMETHING YOU KNOW MOW TO DO - IT WILL MAKE + ONF FnOT ( 
25 Till, Jeremy. "Too Many Ideas". In Architectural Strategies and Design Method. News sheet 59 April 2001. 18th EAAE Conference Delft University of Technology, pp.20-24. http://www.mom.arq. ufmg.br/mom/02_arq_interface/2a_aula/too_many_ideas.pdf Accessed: 09.10.2020. P.22

26 MacKay-Lyons, Brian, and Peter Buchanan. Ghost: Building and Architectural Vision. Princeton

1 Bachelard, Gaston. The Poetics of Space. 1969. Beacon Press, 1994. P.xix

2 Pye, David. The Nature and Art of Workmanship. 1968. London, Herbert Press, 1995 3 Pye, David. The Nature and Art of Workmanship. 1968. London, Herbert Press, 1995 4 Kelsey, John. "Forward: Apostle of Workmanship in The Nature and Art of Workmanship". In, The Nature and Art of Workmanship by Pye, David. Cambridge University. P.9

5 Standards New Zealand. "Section 8 - Walls in Timber-Framed Buildings". In Timber Framed Buildings. New Zealand Standard, 2011

6 New Zealand Transport Agency, Trailers: Light Simple Trailers, New Zealand Government,

2017, https://www.nzta.govt.nz/assets/resources/factsheets/13d/docs/13d-trailers-light-simple. pdf Accessed: 10.04.2020

7 Sennett, Richard. The Craftsman. New Haven, Yale University Press, 2009. P.295

8 Walsh, John, and Reynolds, Patrick. Home Work: Leading New Zealand Architects' Own Houses. Godwit, 2010

9 Langston, Bryce. "About”. Living Big in a Tiny House, 2020, https://www.livingbiginatinyhouse. com/about/ Accessed: 25.03.2020

10 Langston, Bryce. https://www.livingbiginatinyhouse.com/japanese-tiny-house/ posted 21 February, 2017. Accessed: 07.05.2020

11 Till, Jeremy, and Schneider, Tatjana. "Flexible Housing: the Means to the End in Architectural". Research Quarterly, vol.9, iss.3-4, pp.287-296, 2005. Researchgate, DOI:

10.1017/S1359135505000345. P.287

12 Ruskin, John. "The Lamp of Memory". In The Seven Lamps of Architecture. 1840. Electronic Book Company, 2000. ProQuest Ebook Central, www.ebookcentral-proquest-com.helicon.vuw. ac.nz/lib/vuw/detail.action?doclD=3008466. Accessed: 03.21.2020

13 Aoki, Jun. "Suburban Toy House". (pp32-42). Interview by Cathelijne Nuijsink. How to Make a Japanese House. Rotterdam, NAi Publishers, 2012.

14 Ando, Tadao. "Toward New Horizons in Architecture." MoMA, no.9, 1991, pp.9-11. JSTOR, www.jstor.org/stable/4381165 Accessed: 26.11.2020. P.461

15 Austin, Mike, and Treadwell, Jeremy. "Constructing the Pacific Hut". Interstices: Journa of Architecture and Related Arts, vol.10, pp. 32-41. https://doi.org/10.24135/ijara.v0i0.360 Accessed: 09.03.2020. P.32

16 New Zealand Transport Agency, Trailers: Light Simple Trailers, New Zealand Government,

2017, https://www.nzta.govt.nz/assets/resources/factsheets/13d/docs/13d-trailers-light-simple. pdf Accessed: 10.04.2020

17 Till, Jeremy. Architecture Depends. 2009. Cambridge, MIT Press, 2013

18 Till, Jeremy. Architecture Depends. 2009. Cambridge, MIT Press, 2013

19 Till, Jeremy. Architecture Depends. 2009. Cambridge, MIT Press, 2013. P.178

20 Fujimori, Terunobu. Fujimori Terunobu Architecture, TOTO Shuppan Japan 2007

21 Venturi, Robert. "Complexity and Contradiction in Architecture: Selections from

a Forthcoming Book." Perspecta, vol.9/10, 1965, pp. 17-56. JSTOR, www.jstor.org/ stable/1566911. Accessed: 23.11.2020. p.19

22 Standards New Zealand. Timber Framed Buildings. New Zealand Standard, 2011

23 Wallis, Louise. "Building the Studio Environment." (pp.201-218). In Design Studio Pedagogy:

Horizons for the Future, ed. Ashraf M Salama and N. Wilkinson, Gateshead, UK, Urban

International Press. P.202

24 Wallis, Louise. "Building the Studio Environment." (pp.201-218). In Design Studio Pedagogy:

Horizons for the Future, ed. Ashraf M Salama and N. Wilkinson, Gateshead, UK, Urban

international Press
Architectural Press, 2008. ProQuest Ebook Central, https://ebookcentral-proquest-com.helicon.vuw. ac.nz/lib/vuw/detail.action?doclD=3387456. P.5

27 "Dwang". Urban Dictionary, https://www.urbandictionary.com/define.php?term=Dwang Accessed: 19.10 .2020

28 Bachelard, Gaston. The Poetics of Space. 1969. Beacon Press, 1994. Pxxxii

29 Kahn, Lloyd. Shelter. New York, Shelter Publications. 1973

30 Lloyd-Wright, Frank. "Architecture and Modern Life". 1937. (pp.276-291). in The Essential Frank

Lloyd-Wright: Critical Writing on Architecture. Princeton University Press, 2008.

31 New Zealand Standard, Timber and Wood-based Products used in Buildings, 2003. https://www. standards.govt.nz/assets/Publication-files/BSP/NZS3602-2003.pdf Accessed: 12.01.2021

32 Norberg-Schulz, Christian. The Phenomenon of Place (pp.414-428) in Theorizing a New Agenda for Architecture edited Kate Nisbitt p.420

33 Bachelard, Gaston. The Poetics of Space. 1969. Beacon Press, 1994

34 Sennett, Richard. The Craftsman. New Haven, Yale University Press, 2009

35 Wallis, Louise. "Building the Studio Environment." (pp.201-218). In Design Studio Pedagogy:

Horizons for the Future, ed. Ashraf M Salama and N. Wilkinson, Gateshead, UK, Urban International Press

36 Wallis, Louise. "Building the Studio Environment." (pp.201-218). In Design Studio Pedagogy: Horizons for the Future, ed. Ashraf M Salama and N. Wilkinson, Gateshead, UK, Urban International Press. P.211

37 Pallasmaa, Juhani. The Thinking Hand: Existential and Embodied Wisdom in Architecture. Sussex (UK), John Wiley \&Sons Ltd, 2009

38 Sennett, Richard. The Craftsman. New Haven, Yale University Press, 2009. P.35

39 Till, Jeremy. Architecture Depends. 2009. Cambridge, MIT Press, 2013

40 Le Corbusier. Précisions. trans. Schreivber Aujame, Edith, Cambridge MA: MIT Press, 1991. P.68

41 Harries, Karsten. The Ethical Function of Architecture. MIT Press, 1997. P.395

42 Bryce Langston, Living Big in a Tiny House - Often/always refer to the tiny house site as a parking spot.

43 Till, Jeremy. Architecture Depends. 2009. Cambridge, MIT Press, 2013.P.25

44 Hornstein, Shelly. Losing Site: Architecture, Memory and Place. Routledge, 2016, https://doi. org/10.4324/9781315592992

45 Till, Jeremy. "Architecture and Contingency". In, Field: A Free Journal for Architecture, vol.1 pp.120-135, 2008, Ual University of the Arts London. http://www.field-journal.org/uploads/file/2007 Volume_1/j\%20till.pdf Accessed: 20.11.2020. P.135

46 Rykwert, Joseph. On Adam's House in Paradise. New York, The Museum of Modern Art, 1972.

P.192

47 Tallis, Raymond. The Hand: A Philosophical Inquiry into Human Being. Edinburgh University Press, 2003. JSTOR, www.jstor.org/stable/10.3366/j.ctvxcrm97. Accessed: 24.05.2020.

48 See list in appendix.

49 Rykwert, Joseph. On Adam's House in Paradise. New York, The Museum of Modern Art, 1972. P.22 


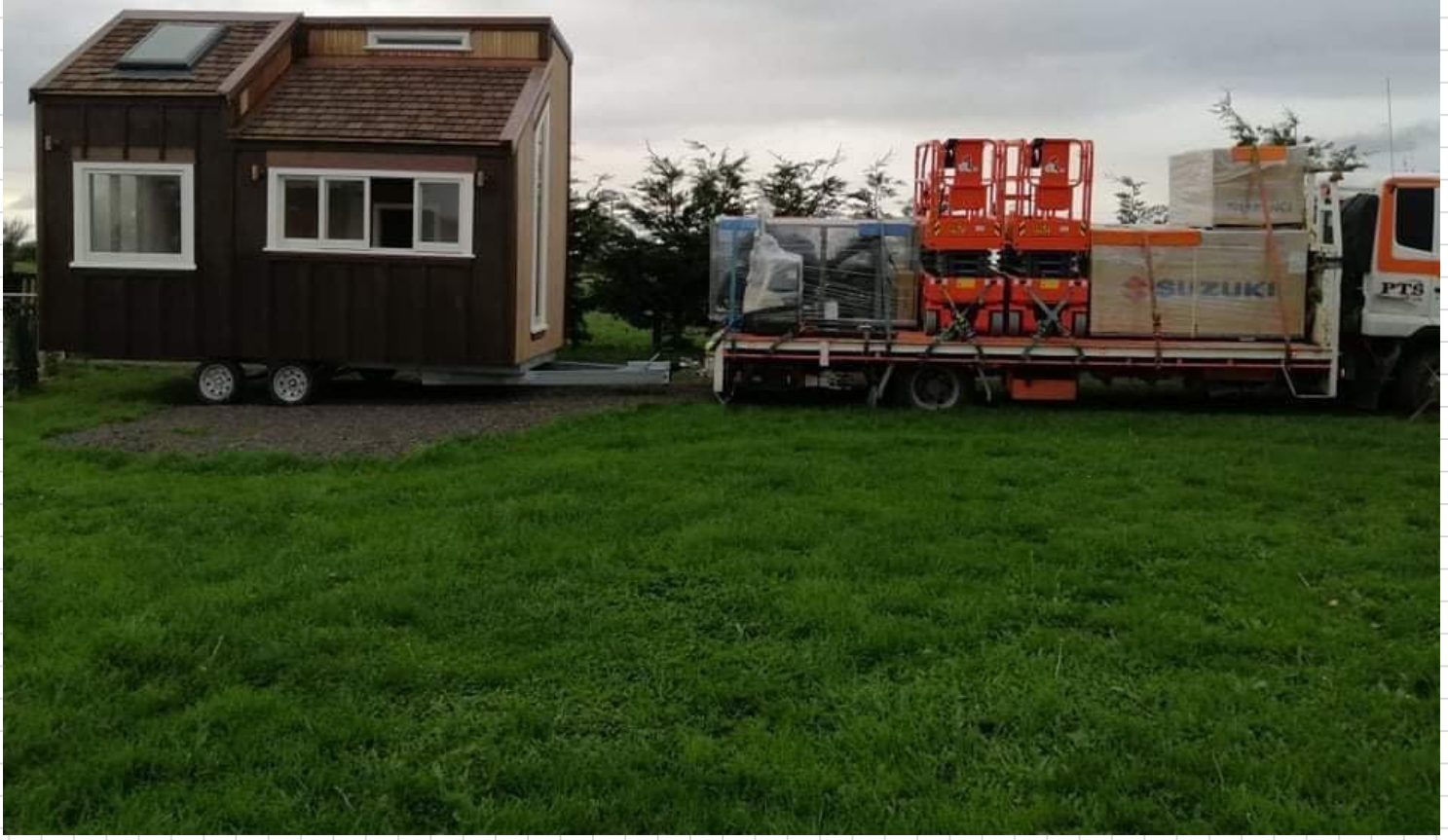




\section{F/GURES}

\section{Unless referenced, photos are owned by the author}

1. personal work process axonometric (own)

2. St Marks Church, Stockholm - Sigurd Lewerentz 1960

+ Ellgaard, Holger. AD Classics: St. Mark's Church in Bjorkhagen / Sigurd Lewerentz. unknown. ArchDaily, Online, https://www.archdaily.com/157478/ ad-classics-st-marks-church-in-bjorkhagen-sigurd-lewerentz Accessed: 03.12 .2020

+ Sigurd Lewerentz. St Mark's Church, Bjorkhagen. 1960. 2014. Tumblr Online, https://onsomething.tumblr.com/post/47821772372 Accessed: 03.12.2020

3. Open Hand - Le Corbusier 1964

+ Van Damme, Sebastian. Open Hand: Le Corbusier. unknown. 13 (blog). Online, https://www.sebastianvandamme.nl/open-your-hand-for-le-corbusier Accessed: 09.01.2020

\section{Sketches: Notre-Dame du Hut}

Le Corbusier. Le Corbusier, conceptual sketches for the Notre Dame du Haut chapel. 1950. Fondation Le Corbusier. Online, https://www.inexhibit. $\mathrm{com} / \mathrm{mymuseum} /$ notre-dame-du-haut-le-corbusier-ronchamp-chapel/ Accessed: 02.10.2020

\section{Notre-Dame du Hut - Le Corbusier 1955}

+ Flickr user Marydoll. Le Corbusier's Ronchamp chapel is one of the 20th century's most important buildings. Dezeen, Online, https://www.dezeen. com/2016/07/24/le-corbusier-notre-dame-du-haut-ronchamp-chapelfrance-unesco-world-heritage-list/ Accessed: 20.01.2020

+ Dalbéra, Jean-Pierre. Interior view of the chapel toward the main altar. Online, https://www.inexhibit.com/mymuseum/notre-dame-du-haut-lecorbusier-ronchamp-chapel/ Accessed: 12.02.2020
6. Sketch: Jinchokan Moriya Historical Museum - Terunobu Fujimori

Fujimori, Terunobu. Jinchokan Moriya Historical Museum: First Sketch. 1984. Terunobu Fujimori Architecture. TOTO Shuppan. P.37

\section{Own home staircase}

8. Tate Modern Staircase

Mawdsley, Lee. Tate Modern Staircase. unknown. Tate, online, https:// www.tate.org.uk/about-us/location-filming-and-photography Accessed: 03.06.2020

9. Olivetti Showroom - Carlo Scarpa 1957

+ English Architects, Mark. The Stair. The Architects' Take. Online, https:// thearchitectstake.com/ Accessed: 29.11.2020

+ Flickr: d.teil. Olivetti Showroom. Architects Architecture Architectuul. Online, http://architectuul.com/architecture/olivetti-showroom Accessed:

10. Muuratsalo - Alvar Aalto 1953

Saieh, Nico. AD Classics: Muuratsalo Experimental House / Alvar Aalto. ArchDaily, online, https://www.archdaily.com/214209/ad-classics-muuratsalo-experimental-house-alvar-aalto Accessed: 03.04.2020

11. Jackson pollock painting

Namuth, Hans. Jackson Pollock, 1950. Artcurial. Online, https://www.artcurial.com/en/lot-hans-namuth-1915-1990-jackson-pollock-1950-tirage-argentique-de-lepoque-1119-172 Accessed: 10.01.2021

\section{Ant Farm 'happening'}

Maniaque, Caroline. Clean Air Pod, 1970, performance at lower Sproul Plaza, University of California. Ant Farm. University of California Press. P.16

12. The Dog Box in progress

reference from email

14. Collection of scanned images in sketchbook

+Bull O'Sullivan Architecture. O'Sullivan Family Home. BOS Architecture. On- 
line, http://www.bosarchitecture.co.nz/projects/osullivan-family-home/ Accessed: 03.04.2020

+Bossi, Simone. Casa CM. ArchDaily. Online, https://www.archdaily. com/597221/casa-cm-paolo-carlesso Accessed: 03.04.2020

\section{Collection of scanned images in sketchbook}

+Ogle, Sally. Building the Dog Box. Patchwork. Online, https://patchworkarchitecture.co.nz/writing/building-the-dogbox/Accessed: 03.04.2020

+Mikhail Riches. Whatcott's Yard, North London. Mikhail Riches. Online, http://www.mikhailriches.com/project/whatcotts-yard/\#slide-4 Accessed: 03.04.2020

\section{Collection of scanned images in sketchbook}

Reynolds, Partick. Tony Watkins. Home Work : Leading New Zealand Architects' Own Houses . Godwit, 2010.

17. Collection of scanned images in sketchbook

ofhouses.com. Le Corbusier's Cabanon seaside cabin is his smallest building on the World Heritage List. Dezeen. Online, https://www.dezeen. com/2016/07/20/le-corbusier-french-holiday-home-cabanon-17-buildingsunesco-world-heritage-list/ Accessed: 03.04.2020

\section{Collection of scanned images in sketchbook} get reference for the book!!

\section{18. Collection of scanned images in sketchbook}

Reynolds, Partick. Ginny Pedlow + Gary Hunt. Home Work : Leading New Zealand Architects' Own Houses . Godwit, 2010.

20. Collection of scanned images in sketchbook

Reynolds, Partick. Ian Athfield. Home Work : Leading New Zealand Architects' Own Houses. Godwit, 2010.
20. Collection of scanned images in sketchbook

21. Magney House - Glenn Murcutt 1984

Browell, Anthony. The Magney House. Thought Co. Online, https://www. thoughtco.com/magney-house-by-glenn-murcutt-178002 Accessed: 03.04.2020

\section{Renzo Piano Workshop}

Fregoso \& Basal. Renzo Piano Workshop. Architects Architecture Architectuul. Online, http://architectuul.com/architecture/view_image/renzo-pianobuilding-workshop/6823 Accessed: 05.04.2020

23. Parc de la Villette - Bernard Tschumi 1998

Penarroyo, Cyrus. AD Classics: Parc de la Villette/Bernard Tschumi Architects. Online, https://www.archdaily.com/92321/ad-classics-parc-de-lavillette-bernard-tschumi Accessed: Accessed: 10.05.2020

\section{UK Pavilion Shanghai - Heatherwick Studio 2010}

Jordana, Sebastian. UK Pavilion for Shanghai World Expo 2010 / Heatherwick Studio. ArchDaily. Online, https://www.archdaily.com/58591/ukpavilion-for-shanghai-world-expo-2010-heatherwick-studio Accessed: 10.05.2020

25. Très Grande Bibliothèque - OMA 1989

OMA. Très Grande Bibliothèque. OMA. Online, https://oma.eu/projects/tresgrande-bibliotheque Accessed: 10.05.2020

26. Kunsthaus Graz - Peter Cook + Colin Fournier 2003

Schiffer, Harry. Spotlight: Peter Cook. ArchDaily. Online, https://www.archdaily. com/440979/happy-birthday-sir-peter-cook Accessed: 10.05.2020

27. The Plug-in City: Maximum Pressure Area - Peter Cook 1964

Archigram Archives. AD Classics: The Plug-In City / Peter Cook, Archigram. Online, 
https://www.archdaily.com/399329/ad-classics-the-plug-in-city-peter-cook-archigram Accessed: 10.05.2020

\section{Paperhouse - Heatherwick Studio 2002}

Heatherwick Studio. Paperhouse. Heatherwick Studio. Online, http://www. heatherwick.com/project/paperhouse/ Accessed: 10.05.2020

29. The Roof That Goes Up in Smoke -Overtreders W 2010

Warmann, Catherine. The Roof That Goes Up in Smoke by Overtreders. Dezeen. Online, https://www.dezeen.com/2010/12/27/the-roof-that-goes-up-in-smoke-byovertreders-w/ Accessed: 10.05.2020

30. Takasugi-an - Terunobu Fujimori 2004

Fujimori, Terunobu. Takasugi-an. 2004. Terunobu Fujimori Architecture. TOTO Shuppan.

\section{Walden - Tumbleweed Tiny House Company}

Walden. Inhabit. Online, https://inhabitat.com/7-teensy-tiny-tumbleweedhomes-we-love/walden-vineyard/ Accessed: 05.04.2020

32. Google search 12.06 .2020

33. Pintrest search 12.06 .2020

34. Nakgin Capsule Tower - Kisho Kurokawa 1977

Arcspace. AD Classics: Nakagin Capsule Tower / Kisho Kurokawa. ArchDaily. Online, https://www. archdaily.com/110745/ad-classics-nakagin-capsule-tower-kisho-kurokawa Accessed:11.09.2020

\section{Nakgin Capsule Tower - Kisho Kurokawa 1977}

35.Steel Train - Kengo Kuma 2008

Nuijsink, Cathelijne. Steel Train. How to Make a Japanese House. NAi Publishers. 2012

36. House NA - Sou Fujimoto Architects 2011
Nuijsink, Cathelijne. House NA. How to Make a Japanese House. NAi Publishers. 2012

\section{House N - Sou Fujimoto Architects 2008}

Nuijsink, Cathelijne. House N. How to Make a Japanese House. NAi Publishers. 2012

\section{Shimogamo Jinja Hojo-An-Kengo Kuma}

Shimogamo Jinja Hojo-An by Kengo Kuma and Associates. Dezeen. Online, https:// www.dezeen.com/2013/01/11/shimogamo-jinja-hojoan-by-kengo-kumaand-associates/ Accessed: 20.05.2020

39. Beetle's House - Terunobu Fujimori 2010

Pasi, Aalto. Terunobu Fujimori: Beetle's House. Designboom. Online, https://www. designboom.com/architecture/terunobu-fujimori-beetles-house/ Accessed: 20.05.2020

\section{A-Z Wagon - Andrea Zittel 2000}

Brewer, Lance. Tiny camping pods by Andrea Zittel serve as a creative refuge in the California desert. Dezeen. Online, https://www.dezeen. com/2016/08/19/wagon-station-encampment-andrea-zittel-tiny-campingpods-creative-refuge-california-desert/ Accessed: 20.05.2020

41 Flying Mud Boat -Terunobu Fujimor

Onishi, Kazumasa. High-Hanging Tea House Offers Suspended Getaway. Dornob. Online, https://dornob.com/high-hanging-tea-house-offers-suspended-getaway/ Accessed: 20.05.2020

42. Tiny Hairloom Tiny House Company - North America

Tiny Hairloom. Full Customizable Tiny Living. Tiny Hairloom. Online, https:// www.tinyheirloom.com/what-we-offer/ Accessed: 10.01.2020

\section{Conestoga Huts - Alliance for the Homeless}

Conestoga Huts Cost-Effective and Durable Micro-Shelters. Community Supported Shelters. Online, https://communitysupportedshelters.org/conestoga-huts Accessed: 11.05.2020

44. Hut on Sleds - Crosson Architects 2012

Crosson Architects. Hut on Sleds. Crosson Architects. Online, https://crosson.co.nz/ hut-on-sleds-whangapoua/ Accessed: 12.03.2020 


\section{Aerial view of site}

Google. Ōkato. Accessed: 05.04.2020

46. Parking spot'

authors own

\section{Authors own}

48. Trailer invoice -authors own

49. Walden - Henry Thoreau 1854

Walden. Wikipedia. Online, https://en.wikipedia.org/wiki/Walden Accessed: 18.06.2020

50. Sketch: Disorder in a Dining Table - Sarah Wigglesworth

Wigglesworth, Sarah. Sarah Wigglesworth's Dining Tables. The Architectural Review. On line https://www.architectural-review.com/essays/folio/folio-sarahwigglesworths-dining-tables Accessed: 14.04.2020

\section{Dining Building with Window Chairs -Alex Wexler 1983}

Wexler, Allen. Dining Building with Window Chairs. Allan Wexler. Online, http://www.allanwexlerstudio.com/projects/dining-building-window-chairs Accessed: 14.04.2020

52. Frankfurt Kitchen - Grete Schütte-Lihotzky 1962

MoMA. The Frankfurt Kitchen:View Toward the Window. MoMA. Online, https:// www.moma.org/interactives/exhibitions/2010/counter_space/the_frankfurt kitchen/ Accessed: 14.04.2020

\section{Villa Savoya Bathroom - Le Corbusier 1929}

Alter, Lloyd. Bathroom in Villa Savoye. Treehugger. Online, https://www.treehugger.com/ touring-toilets-le-corbusier-4857593 Accessed:

54. House for Essex - FAT 2014

Grayson Perry and FAT Reveal the Elaborate Interiors of their House. Dezeen. Online, https://www.dezeen.com/2015/05/15/house-for-essex-fat-grayson-perry-charles-hollandliving-architecture-alain-de-botton/ Accessed:
57. Conceptual model of spaces + roofline

58 Conceptual model of spaces

59. View points, circulation + stationary areas

60 View through 'cook' space window

61. View into 'Eat \& Play' space

62. View into 'Cook' space

63. View from 'site'

\section{Progression of building floor}

65 Flooring make-up

66 Baske- $T$ - Tagami Haruhiko

\section{Palm trees on Ute}

68 Journey

69 Lamune Onsen - Terunobu Fujimori 2004

Fujimori, Terunobu. Lamune Onsen 1984. Terunobu Fujimori Architecture. TOTO Shuppan. P.37

70 Ichiya-Tei - Terunobu Fujimori 2003

Fujimori, Terunobu. Ichiya-Tei First Sketch. 1984. Terunobu Fujimori Architecture. TOTO Shuppan. P.37

\section{Student Dormitory (Kumamoto Agricultural College) - Terunobu Fujimori} 2000

Fujimori, Terunobu. JStudent Dormitory. 1984. Terunobu Fujimori Architecture. TOTO Shuppan. P.37

\section{Chashitsu Tetsa- Terunobu Fujimori 2005}

Fujimori, Terunobu. Chashitsu Tetsa 1984. Terunobu Fujimori Architecture. TOTO Shuppan. P.37

73 Progression of site 


\section{Diagram of roof change}

75 Lost window

76 Proportions of Starboard face diagram

77 Frames up

\section{View out at 'sink'}

79 Diagram of frames + spaces (opposite)

80 View of 'Bow' face

\section{Diagram of roof framing}

82 Progress - ridge beam and rafters

83 Caves, huts + tents - taken from 'Shelter'

84 Shadows of framing

85 Priming the plywood

86 Diagram of roofing

87 The first rain the roof held off (the afternoon before the storm)

88. Calculating material quantities

89 Original electrical plan

90 Picking up the shingles

91 Stained shingles drying

92 Kerry helping stain shingles

93 Diagram of roof sequence

94 Solomon + Tom applying shingles

95 Inserted dwangs

\section{Diagram of 'block' trick}

97 Progression of cladding stain

98. Various notation on 'site

99 Tool used to apply contract filler

\section{New electrical plan}

101 Drawings discussing placement

102 Plumbing diagram

103 Plumbing

104 Unwrapping + using material

105 Working out flashings

106 Flashing roof intersects

107. Before and after insulation 


\section{WORKS CITED}

Adamson, Glenn. Thinking Through Craft. London, Oxford International Publishers Ltd, 2007

Anson, April. "The world is my backyard": Romanticization, Thoreauvian Rhetoric, and Constructive Confrontation in the Tiny House Movement. From Sustainable to Resilient Cities: Global Concerns and Urban Efforts, vol.14, 2014, pp.289-314.

Emerald Group Publishing Limited, doi:10.1108/S1047-004220140000014013 Accessed: 10.06 .2020

Aoki, Jun. "Suburban Toy House". (pp32-42). Interview by Cathelijne Nuijsink. How to Make a Japanese House. Rotterdam, NAi Publishers, 2012.

Ando, Tadao. "Toward New Horizons in Architecture." MoMA, no.9, 1991, pp.911. JSTOR, www.jstor.org/stable/4381165 Accessed: 26.11.2020

Austin, Mike. "From the Whare to Modernism." New Zealand Institute of Architects, Last, Loneliest, Loveliest: The New Zealand Pavilion at the 14th International Architecture Exhibition, La Biennale Di Venezia, 2014.

Austin, Mike, and Treadwell, Jeremy. "Constructing the Pacific Hut". Interstices: Journal of Architecture and Related Arts, vol.10, pp. 32-41. https://doi. org/10.24135/ijara.v0i0.360 Accessed: 09.03.2020

Bachelard, Gaston. The Poetics of Space. 1969. Beacon Press, 1994

Benjamin, Walter, and Hannah Arendt. Illuminations. New York, Schocken Books, 2007

Borden, Gail. Peter. Process: Material and Representation in Architecture. Routledge, 2014. ProQuest Ebook Central, https://doi. org/10.4324/9781315814827. Accessed: 03.20.2020

Bloomer, Jenifer. Abodes of Theory and Flesh. Assemblage, no.17, 1992, pp.729. JSTOR. www.jstor.org/stable/3171221. Accessed: 03.20 .2020

Blundell Jones, Peter. "Sigurd Lewerentz: Church of St Peter Klippan, 1963-66", Arq: Architectural Research Quarterly, vol.6, no.2, 2002, pp. 159-173. ProQuest, https://search.proquest.com/scholarly-journals/sigurd-lewerentz-church-stpeter-klippan-1963-66/docview/199346467/se-2?accountid=14782. Accessed 05.09.2020
Biedermann, Hans. Dictionary of Symbolism. Facts on File, 1992.

Bell, Charles. The Hand: Its Mechanism and Vital Endowments as Evincing Design.1833. Cambridge University Press, 2009

Brothers, Cammy. Michelangelo, Drawing, and the Invention of Architecture. New Haven, Yale University Press, 2008

Burr, Kevin L., et al. (2010) "The Role of the Architect: Changes of the Past, Practices of the Present, and Indications of the Future". International Journal of Construction Education and Research, 6:2, 2010, pp.122138, Taylor \&Francis Online, DOI: $10.1080 / 15578771.2010 .482878$. Accessed: 03.12.2020

Clarke, George, et al. George Clarke's Amazing Spaces. Quadrille Publishing, 2013

Collins, Peter, and Frampton, Kenneth. Changing Ideals in Modern Architecture, 1750-1950. McGill-Queen's University Press, 1998. ProQuest Ebook Central, https://ebookcentral-proquest-com.helicon.vuw.ac.nz/lib/ vuw/detail.action?doclD $=3331090$. Accessed: 05.07.2020.

Colombina, Beatriz, and Wigley, Mark. "An Essay About Toilet Architecture." Pin-Up, iss. 23, 2017, pp. 235-236. https://pinupmagazine. org/articles/toilet-modern-architecture\#14 Accessed: 18.04.2020

Community Supported Shelters. Conestoga Huts: Cost Effective and Durable Micro-Shelters, https://communitysupportedshelters.org/ conestoga-huts. Accessed: 06.06.2020

Cook, Peter. "Architects, not Architecture." Home Edition 2020. AnA Barcelona 01, Barcelona. September 27 2018. Talk. Accessed https://www. architectsnotarchitecture.com/en/cook

Canizaro, Vincent B. "Design-build in architectural education: motivations, practices, challenges, successes and failures." ArchNet-IJAR: International Journal of Architectural Research, vol.6, iss.3, 2012, 20-36. ProQuest,

https://search.proquest.com/scholarly-journals/design-build-architectural- 
education-motivations/docview/1312295456/se-2?accountid=14782 Accessed: 09.12.2020

Decker T, Roy. "Tactility and Imagination" (pp.203-219) in Philosophy and Architecture ed. by Michael H. Mitias, Amsterdam, Rodopi, 1994

"Dwang". Urban Dictionary, https://www.urbandictionary.com/define. php?term=Dwang Accessed: 19.10 .2020

Ednie-Brown, Pia. "Creaturely Collectives: Parametricism and Getting to the Afterparty". (pp. 16-34). In The Design Collective: An Approach to Practice, ed. Edquist, Harriet, and, Vaughan, Laurene. Cambridge, Cambridge Scholars Publishing 2012

Erdman, Jori, et al. "Designing/Building/Learning." Journal of Architectura Education,vol. 55, no. 3, 2002, pp. 174-179. JSTOR, www.jstor.org/ stable/1425537 Accessed 02.05.2020

Foucault, Michel. "The Subject and Power." Critical Inquiry, vol. 8, no. 4, 1982, pp. 777-795. JSTOR, www.jstor.org/stable/1343197. Accessed: 10.01.2021.

Frascari, Marco. "The Tell-The-Tale Detail". VIA7:The Building of Architecture, 1984

Friedlander, David. "Talking to Jay Shafer About Making the Universal House." Life Edited, https://lifeedited.com/jay-shafer-four-lights-future-oftiny-houses. Accessed 10.06.2020

Fujimori, Terunobu. Fujimori Terunobu Architecture, TOTO Shuppan Japan 2007

Fujimori, Terunobu. "Terunobu Fujimori Interview: A Feeling of Freedom." YouTube, uploaded Louisiana Channel, 01.12.2020. Accessed: 09.04.2020

Flanagan, Sean. "Review: Making Ways." Architecture Now, 27 Jan, 2020 https://architecturenow.co.nz/articles/review-making-ways/. Accessed: 13.04.2020

Lerup, Lars. Building the Unfinished: Architecture and Human Action. Beverly Hills, Sage. 1997.
Grant, Kim. All About Process: The Theory of Modern Artistic Labour. Pennsylvania, Penn State University Press 2017. EBSCOhost, www.search. ebscohost.com/login.asp ? direct $=$ true $\& \mathrm{db}=$ nlebk\&AN $=1481812 \&$ site $=$ eho st-live Accessed: 25.11 .2020

Haack, Lydia, and Höpfner John. "Microarchitecture - Experiments in Space Optimisation" (pp.11-23) In Detail: Small structures. Ed. Schittich, Walter de Gruyter GmbH, 2010. ProQuest Ebook Central, https://ebookcentral-proquest-com.helicon.vuw.ac.nz/lib/vuw/detail. action?doclD=1075586 Accessed 19.03.2020

Harries, Karsten. The Ethical Function of Architecture. MIT Press, 1997.

Heidegger, Martin. 'What Calls for Thinking' in Basic Writings, New York Harper and Row, 1977

Heidegger, Martin. "Building, Dwelling, Thinking". In Housing and Dwelling ed. Barbara Miller Lane published 2007, Routledge.

Herwig, Oliver. "Big and Small - The Convergence of Architecture and Design". (pp.50-59) In Detail: Small structures. Ed. Schittich, Walter de Gruyter GmbH, 2010. ProQuest Ebook Central, https://ebookcentralproquest-com.helicon.vuw.ac.nz/lib/vuw/detail.action?doclD=1075586 Accessed 19.03.2020

Hildner, Claudia. Small Houses: Contemporary Japanese Dwellings, Walter de Gruyter GmbH, 2011. ProQuest Ebook Central, https://ebookcentralproquest-com.helicon.vuw.ac.nz/lib/vuw/detail.action?doclD=1020491.

Hornstein, Shelly. Losing Site: Architecture, Memory and Place. Routledge, 2016, https://doi.org/10.4324/9781315592992

Johnstone, Henry W. "Toward a Philosophy of Sleep." Philosophy and Phenomenological Research, vol. 34, no. 1, 1973, pp. 73-81. JSTOR, www. jstor.org/stable/2106781. Accessed:04.04.2020

Kahn, Lloyd. Shelter. New York, Shelter Publications. 1973

Kenny, Katie, and Walters, Laura. "Tiny Houses". Superfad Podcast. 2017. https://podcasts.google.com/feed/ 
aHR0cHM6Ly9yc3Mud2hvb3Noa2FhLmNvbS9yc3MvcG9kY2FzdC9pZC8yNzEX Accessed: 11.06 .2020

Kelsey, John. "Forward: Apostle of Workmanship in The Nature and Art of Workmanship". In, The Nature and Art of Workmanship by Pye, David. Cambridge University

Langston, Bryce. "About". Living Big in a Tiny House, 2020, https://www. livingbiginatinyhouse.com/about/ Accessed: 25.03.2020

Langston, Bryce. https://www.livingbiginatinyhouse.com/japanese-tiny-house/ posted 21 February, 2017. Accessed: 07.05.2020

Le Corbusier. Précisions. trans. Schreivber Aujame, Edith, Cambridge MA: MIT Press, 1991.

Los, Sergio, and Klaus, Frahm. Carlo Scarpa. Benedikt Taschen. 1994

Lloyd-Wright, Frank. "Architecture and Modern Life". 1937. (pp.276-291). in The Essential Frank Lloyd-Wright: Critical Writing on Architecture. Princeton University Press, 2008.

MacKay-Lyons, Brian, and Peter Buchanan. Ghost: Building and Architectural Vision. Princeton Architectural Press, 2008. ProQuest Ebook Central, https://ebookcentral-proquest-com.helicon.vuw.ac.nz/lib/vuw/detail. action?docID $=3387456$

Mockbee, Sam. "Auburn University." (pp.) In Learning by Building: Design and Construction in Architectural Education ed. Carpenter, William J., and Hoffman, Dan. New York, Van Nostrand Reinhold, 1997.

“Make." Dictionary.com. Houghton Mifflin Harcourt Publishing Company. 2002. www.dictionary.com/browse/make Accessed: 04.04.2020

Morris, Robert. "Sculptors on Sculpture: Some Notes on the Phenomenology of Making; the Search for the Motivated." Sculpture (Archive: 1987-2005), vol.13, no.2, 1994, pp. 22-29. ProQuest, https://search-proquest-com.helicon.vuw.ac.nz/ docview/1431342520?accountid $=14782$

New Zealand Standard, Timber and Wood-based Products used in Buildings, 2003. https://www.standards.govt.nz/assets/Publication-files/BSP/NZS36022003.pdf Accessed: 12.01.2021
New Zealand Transport Agency, Trailers: Light Simple Trailers, New Zealand Government, February 2017, https://www.nzta.govt.nz/ assets/resources/factsheets/13d/docs/13d-trailers-light-simple.pdf

Nonko, Emily. "A Tiny House Movement Timeline". Curbed, 2017, https://www.curbed.com/2017/7/19/15974554/tiny-house-timeline. Accessed: 18.06 .2020

Norberg-Schulz, Christian. "The Phenomenon of Place" (pp.414428) in Theorizing a New Agenda for Architecture: An Anthology of Architectural Theory 1965-1995 ed. Kate Nisbitt, New York, Princeton Architectural Press, 1996.

Nuijsink, Cathelijne. How to Make a Japanese House. Rotterdam, NAi Publishers, 2012.

Ogle, Sally. "Building the Dog Box". Patchwork Architecture. Patchwork Architecture. www.patchworkarchitecture.co.nz/projects/ dog-box Accessed: 03.05.2020

Pallasmaa, Juhani. The Thinking Hand: Existential and Embodied Wisdom in Architecture. Sussex (UK), John Wiley \&Sons Ltd, 2009

Pauly, Danièle. Le Corbusier. The Chapel at Ronchamp. Walter de Gruyter GmbH, 2008. ProQuest Ebook Central, www. ebookcentral-proquest-com.helicon.vuw.ac.nz/lib/vuw/detail. action?docID=4338392. Accessed: 24.11 .2020

Persse, Jason, and Stokes, Rebecca. "The Frankfurt Kitchen". Counter Space: Design \& the Modern Kitchen. MoMA. 2011, https://www. moma.org/interactives/exhibitions/2010/counter space/the frankfurt kitchen/ Accessed: 18.04.2020

Pye, David. The Nature and Art of Workmanship. 1968. London, Herbert Press, 1995

Ridgway, Sam. Architectural Projects of Marco Frascari : the Pleasure of a Demonstration . Ashgate, 2015.

Rykwert, Joseph. On Adam's House in Paradise. New York, The Museum of Modern Art, 1972

Rossi, Aldo. A scientific Autobiography. Translated Lawrence Venuti Cambridge Mass: MIT Press, 1981 
Ruskin, John. The Seven Lamps of Architecture. 1840. Electronic Book Company, 2000. ProQuest Ebook Central, www.ebookcentral-proquestcom.helicon.vuw.ac.nz/lib/vuw/detail.action?doclD $=3008466$. Accessed: 03.21 .2020

Ruskin, John. "The Lamp of Memory". In The Seven Lamps of Architecture. 1840. Electronic Book Company, 2000. ProQuest Ebook Central, www.ebookcentral-proquest-com.helicon.vuw.ac.nz/lib/vuw/detail. action?doclD $=3008466$. Accessed: 03.21.2020

Sennett, Richard. The Craftsman. New Haven, Yale University Press, 2009

Silverberg, Mark. "Working in the Gap Between Art and Life: Frank O'Hara's Process Poems" (pp. 37-47) in Neo-Avant-Garde, ed. Hopkins, David, and Schaffner, Anna Katharina, Brill, 2006. ProQuest Ebook Central, https://ebookcentral-proquest-com.helicon.vuw.ac.nz/lib/vuw/detail. action?doclD $=556888$. Accessed: 30.10 .2020

Schittich, Christian. "The Fascination of Small Structures" (pp. 8-10) In Detail: Small structures. Ed. Schittich, Walter de Gruyter GmbH, 2010. ProQuest Ebook Central, https://ebookcentral-proquest-com.helicon. vuw.ac.nz/lib/vuw/detail.action?docID=1075586 Accessed 19.03.2020

Schulte, Joachim. Experience and Expression: Wittgenstein's Philosophy of Psychology. Clarendon Press, 1992

Slavid, Ruth. Micro: Very Small Buildings. London, Laurence King Publishing Ltd, 2007.

Friedlander, David. "Talking to Jay Shafer About Making the Universal House." Life Edited, https://lifeedited.com/iay-shafer-four-lights-future-oftiny-houses. Accessed 10.06.2020

Stewart, Susan. On Longing: Narratives of the Miniature, the Gigantic, the Souvenir, the Collection. Duke University Press, 1993

Standards New Zealand. "Section 8 - Walls in Timber-Framed Buildings". In Timber Framed Buildings. New Zealand Standard, 2011

Standards New Zealand. Timber Framed Buildings. New Zealand Standard, 2011

Tallis, Raymond. The Hand: A Philosophical Inquiry into Human Being. Edinburgh University Press, 2003. JSTOR, www.jstor.org/stable/10.3366/j. ctvxcrm97. Accessed: 24.05.2020.

Till, Jeremy. Architecture Depends. 2009. Cambridge, MIT Press, 2013

Till, Jeremy. "Too Many Ideas". In Architectural Strategies and Design Method. News sheet 59 April 2001. 18 ${ }^{\text {th }}$ EAAE Conference Delft University of Technology, pp.20-24. http://www.mom.arq.ufmg.br/mom/02 arq interface/2a_aula/too many ideas.pdf Accessed: 09.10.2020

Till, Jeremy, and Schneider, Tatjana. "Flexible Housing: the Means to the End in Architectural". Research Quarterly, vol.9, iss.3-4, pp.287-296, 2005. Researchgate, DOI: 10.1017/S1359135505000345.

Till, Jeremy. "Architecture and Contingency". In, Field: A Free Journal for Architecture, vol.1, pp.120-135, 2008, Ual University of the Arts London. http://www.field-journal.org/uploads/file/2007 Volume 1/j\%20till.pdf Accessed: 20.11.2020

"Tiny." Dictionary.com. William CollinsSons \&CO Ltd. 2012. https://www. dictionary.com/browse/tiny?s=t Accessed: 10.06 .2020

Thoreau, Henry. Walden. (1854). E-book, The Project Gutenberg, 2021.

Walker, Lester. Tiny Houses. New York, The Overlook Press, 1987

Wilkinson, Alec. "Let's Get Small". The New Yorker, 2011, https://

www.newyorker.com/magazine/2011/07/25/lets-get-small. Accessed: 06.06.2020

Wright, Andy. "When You Live In A Housetruck, Everywhere Is Home". Atlas Obscura, 2015, https://www.atlasobscura.com/articles/look-at-theseadorable-tiny-homes-on-wheels-called-housetrucks. Accessed 09.07.2020

Wallis, Louise. "Building the Studio Environment." (pp.201-218). In Design Studio Pedagogy: Horizons for the Future, ed. Ashraf M Salama and N. Wilkinson, Gateshead, UK, Urban International Press

Walsh, John, and Reynolds, Patrick. Home Work: Leading New Zealand Architects' Own Houses. Godwit, 2010 
Wogenscky, André. Le Corbusier's Hands. 1987. Translated Martina Millà Bernad. London, MIT Press, 2006.

Vesely, Dalibor. "Architecture and the Conflict of Representation." AA Files, no. 8, 1985, pp. 21-38. JSTOR, www.jstor.org/stable/29543434. Accessed 01.05 .2020

Venturi, Robert. "Complexity and Contradiction in Architecture: Selections from a Forthcoming Book." Perspecta, vol.9/10, 1965, pp. 17-56. JSTOR, www. istor.org/stable/1566911. Accessed: 23.11.2020

Zhongjie Lin. "Nakagin Capsule Tower: Revisiting the Future of the Recent Past." In Journal of Architectural Education, 65:1, pp.1332, DOI: 10.1111/j.1531-314X.2011.01158.x 


\section{Endnotes}

1 Rykwert, Joseph. On Adam's House in Paradise. New York, The Museum of Modern Art, 1972. p.190

2 Rykwert, Joseph. On Adam's House in Paradise. New York, The Museum of Modern Art, 1972. p.192

3 Ogle, Sally. "Building the Dog Box". Patchwork Architecture. Patchwork Architecture. Par.5. www.patchworkarchitecture.co.nz/projects/dog-box Accessed: 03.05.2020

4 "Make." Dictionary.com. Houghton Mifflin Harcourt Publishing Company. 2002. www.dictionary.com/browse/make Accessed: 04.04.2020

5 Rossi, Aldo. A scientific Autobiography. Translated Lawrence Venuti, Cambridge Mass: MIT Press, 1981. P.55

6 Vesely, Dalibor. "Architecture and the Conflict of Representation." AA Files, no. 8, 1985, pp. 21-38. JSTOR, www.jstor.org/stable/29543434. Accessed 1 May 2020.

7 Frascari, M. The Tell-The-Tale Detail. VIA7:The Building of Architecture, 1984

8 Pallasmaa, Juhani. The Thinking Hand: Existential and Embodied Wisdom in Architecture. United Kingdom, John Wiley \&Sons Ltd, 2009. p.65

9 Vesely, Dalibor. "Architecture and the Conflict of Representation." AA Files, no. 8, 1985, pp. 21-38. JSTOR, www.jstor.org/stable/29543434. Accessed 01.05.2020. p.22

10 Pallasmaa, Juhani. The Thinking Hand: Existential and Embodied Wisdom in Architecture. United Kingdom, John Wiley \&Sons Ltd, 2009

11 Bell, Charles. The Hand: Its Mechanism and Vital Endowments as Evincing Design.1833. Cambridge University Press, 2009

12 Pallasmaa, Juhani. The Thinking Hand: Existential and Embodied Wisdom in Architecture. United Kingdom, John Wiley \&Sons Ltd, 2009

13 Borden, Gail. Peter. Process: Material and Representation in Architecture. Routledge, 2014. ProQuest Ebook Central, https://doi.org/10.4324/9781315814827. p.21

14 Till, Jeremy. Architecture Depends. 2009. Cambridge, MIT Press, 2013. P.86

15 Bloomer, Jenifer. Abodes of Theory and Flesh. Assemblage, no.17, 1992, pp.7-29. JSTOR. www.jstor.org/stable/3171221. Accessed: 03.20.2020

16 Pye, David. The Nature and Art of Workmanship. 1968. London, Herbert Press, 1995

17

18 Sennett, Richard. The Craftsman. New Haven, Yale University Press, 2009

19 Pallasmaa, Juhani. The Thinking Hand: Existential and Embodied Wisdom in Architecture. Sussex (UK), John Wiley \&Sons Ltd, 2009

20 Both 'the craftsman' and 'the thinking hand' discuss at length

21 Pye, David. The Nature and Art of Workmanship. 1968. London, Herbert Press, 1995. P.17

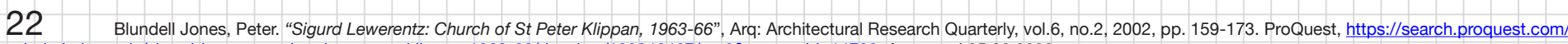
scholarly-journals/sigurd-lewerentz-church-st-peter-klippan-1963-66/docview/199346467/se-2?accountid=14782. Accessed 05.09.2020

Pallasmaa, Juhani. The Thinking Hand: Existential and Embodied Wisdom in Architecture. Sussex (UK), John Wiley \&Sons Ltd, 2009

Sennett, Richard. The Craftsman. New Haven, Yale University Press, 2009. P.295

Biedermann, Hans. Dictionary of Symbolism. Facts on File, 1992. 